LA DESERCIÓN ESCOLAR COMO PRETEXTO PARA CONVERSAR SOBRE IDENTIDAD, FAMILIA Y ESCUELA

\title{
LA DESERCIÓN ESCOLAR COMO PRETEXTO PARA CONVERSAR SOBRE \\ IDENTIDAD, FAMILIA Y ESCUELA
}

Esmeralda Ramos Gutiérrez

Trabajo de grado para optar el título en Magister en Psicología Clínica y de la Familia

\author{
Directora \\ Mariana Andrea Pinillos Guzmán \\ Psicóloga
}

Universidad Santo Tomás

División de Ciencias de la Salud

Facultad de Psicología Maestría en Psicología Clínica y de la Familia

Bogotá, D.C.

Junio 28 de 2018 


\section{LA DESERCIÓN ESCOLAR COMO PRETEXTO PARA CONVERSAR SOBRE IDENTIDAD, FAMILIA Y ESCUELA

\section{Agradecimientos}

Agradezco a Dios por la fortaleza, la persistencia y el coraje que me dio para no rendirme cuando todo parecía perdido.

Dedico de manera especial este trabajo a cada uno de mis familiares y amigos por hacer parte de este proceso, donde las palabras de aliento nunca faltaron, y sobre todo hacerme comprender que todo esto valía la pena, aquellos que vieron el esfuerzo y el coraje que se debe tener para lograr aquello que parecía imposible.

A mis amados padres quienes a pesar de que hoy no estén a mi lado, sé que desde el cielo están orgullosos de ver en lo que me he convertido y a quienes debo todo lo que soy.

A mi esposo Guillermo, mi agradecimiento por su sacrificio, esfuerzo y su apoyo incondicional en todo momento de mi vida, sin el nada hubiese sido posible.

A mis hijos Guillermo y Nataly por ser mi fuente de motivación personal superando cada obstáculo de mi vida y para quienes espero llegar a ser un digno ejemplo que seguir en cada momento de sus vidas. También a mi nieta Mariana quien es la luz de mis ojos y la alegría de mi hogar.

Especialmente a Lolita, quien siempre ha estado acompañándome con sus oraciones y palabras de aliento, a través de ella a ese ángel que creyó en mí, y en la posibilidad de continuar y terminar esta Maestría.

De manera especial a mi asesora. Doctora Mariana Pinillos Guzmán, por su respeto, dedicación, comprensión y entrega con el trabajo realizado.

Gracias. 


\section{LA DESERCIÓN ESCOLAR COMO PRETEXTO PARA CONVERSAR SOBRE IDENTIDAD, FAMILIA Y ESCUELA

Tabla de Contenido

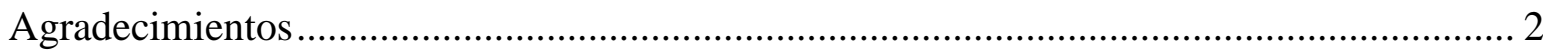

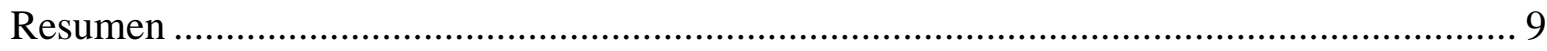

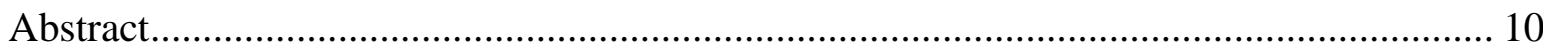

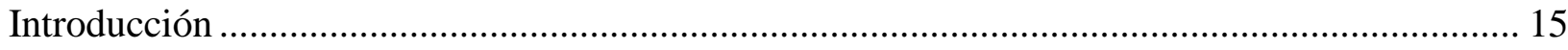

Pregunta que orienta la investigación/ intervención............................................................... 18

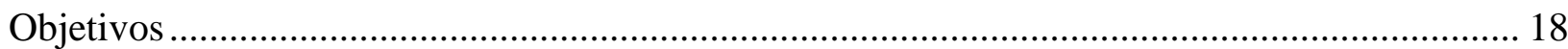

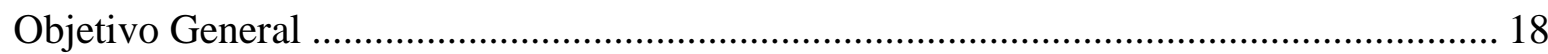

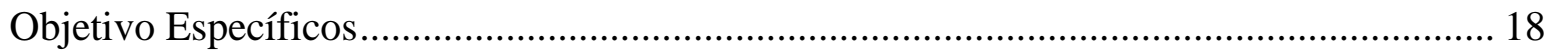

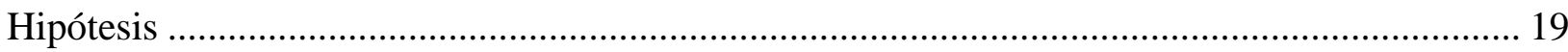

Comprensiones sobre la etapa de la Adolescencia ............................................................. 20

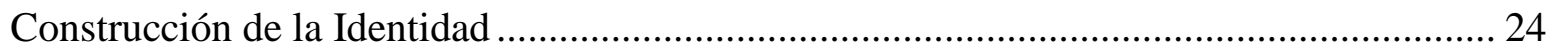

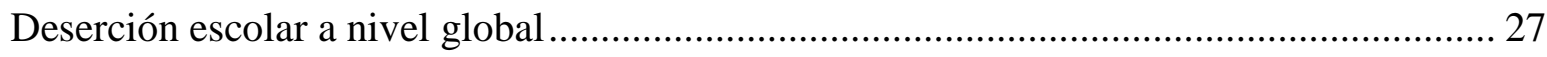

Deserción escolar en Colombia ........................................................................................... 30

Relación joven, familia e institución educativa en torno a la deserción escolar .................... 40

Tendencias y comprensiones de la deserción escolar............................................................... 44

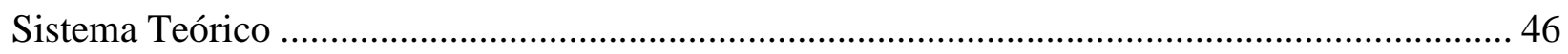

Comprensiones sobre la construcción de identidad............................................................ 46

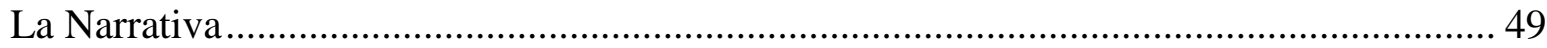

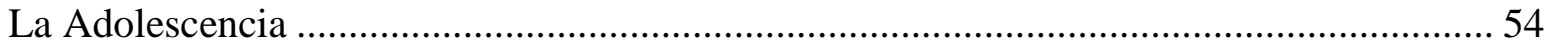




\section{LA DESERCIÓN ESCOLAR COMO PRETEXTO PARA CONVERSAR SOBRE IDENTIDAD, FAMILIA Y ESCUELA

Deserción escolar. 57

Metodología 60

Modelización 61

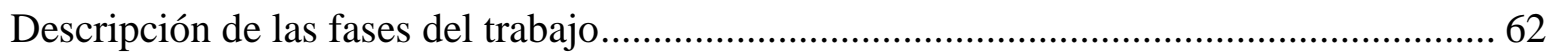

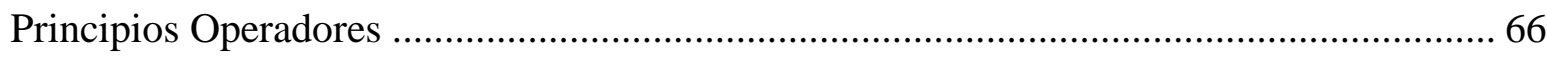

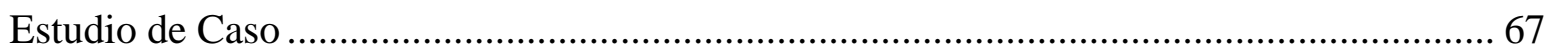

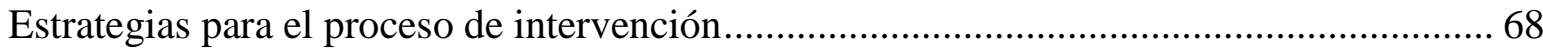

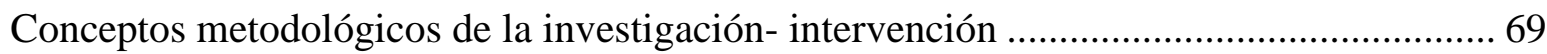

Descripción de los Conceptos Metodológicos ………………………………………........ 70

Las historias dominantes y su incidencia en la construcción narrativa de la identidad......... 70

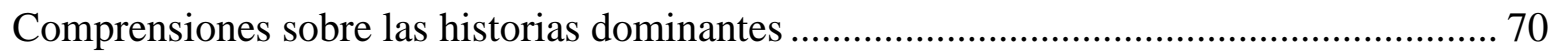

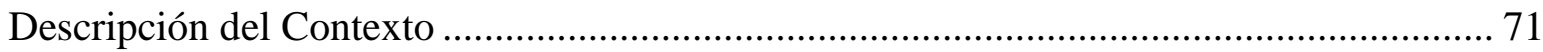

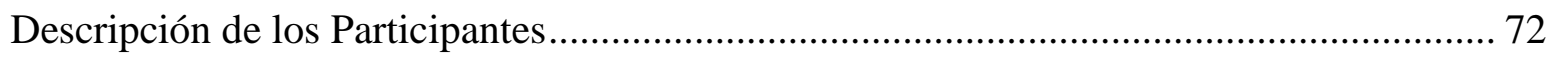

Diseños y neo- diseños de Investigación........................................................................... 73

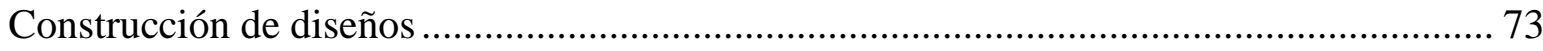

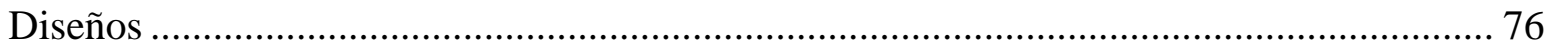

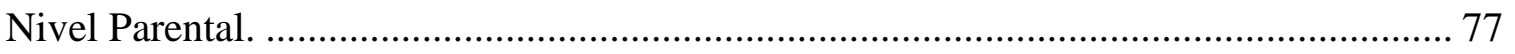

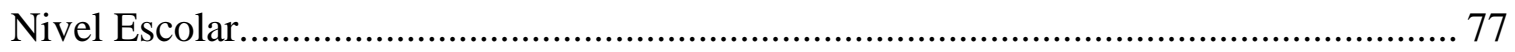

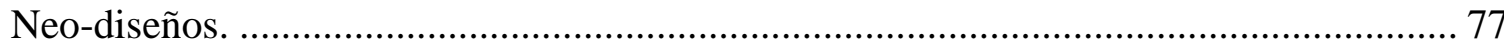

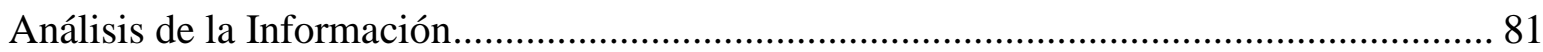




\section{LA DESERCIÓN ESCOLAR COMO PRETEXTO PARA CONVERSAR SOBRE IDENTIDAD, FAMILIA Y ESCUELA

Resultados 84

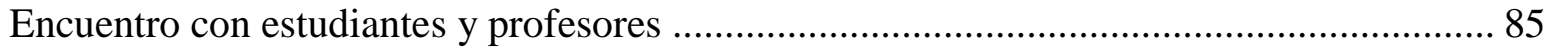

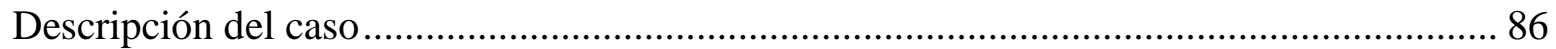

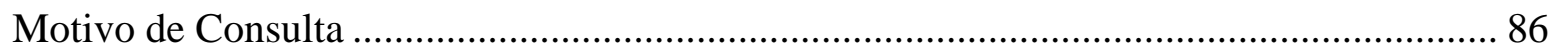

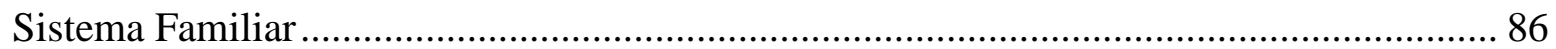

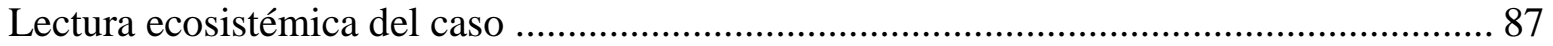

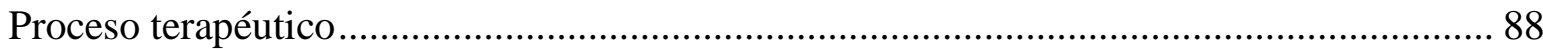

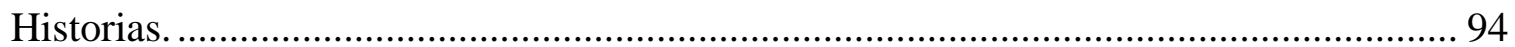

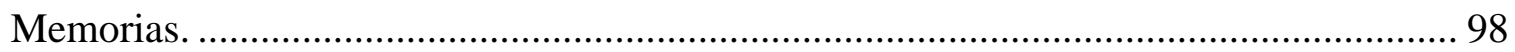

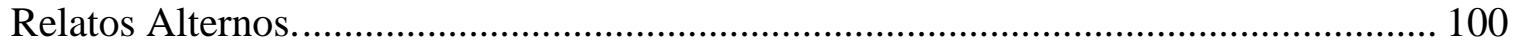

Nuevas comprensiones de la deserción escolar................................................................... 101

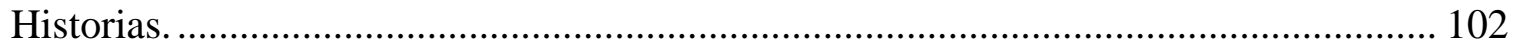

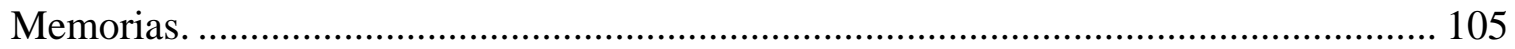

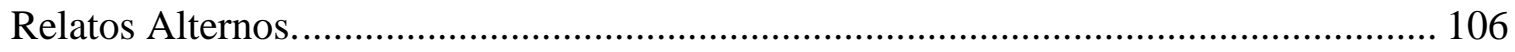

Relación Joven, Familia e Institución Educativa en Torno a la Deserción Escolar ............ 108

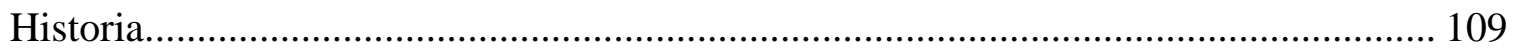

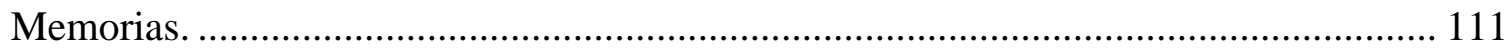

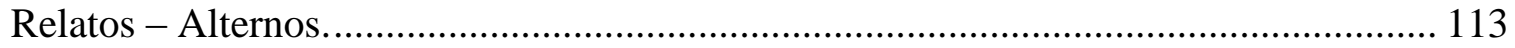

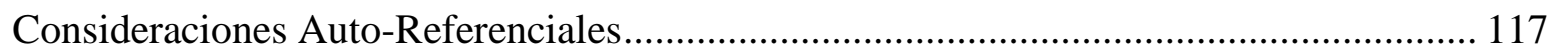

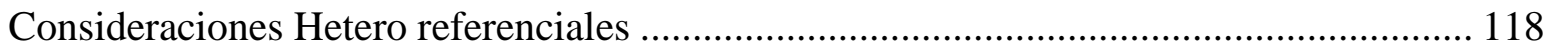

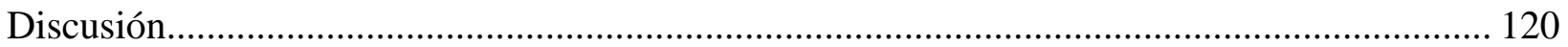




\section{LA DESERCIÓN ESCOLAR COMO PRETEXTO PARA CONVERSAR SOBRE IDENTIDAD, FAMILIA Y ESCUELA

Alcances de la investigación- intervención....................................................................... 132

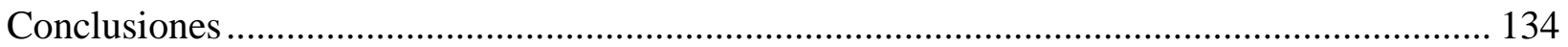

Comprensiones sobre el estado del arte......................................................................... 134

Comprensiones Teóricas .......................................................................................... 136

Comprensiones sobre la Metodología .................................................................. 137

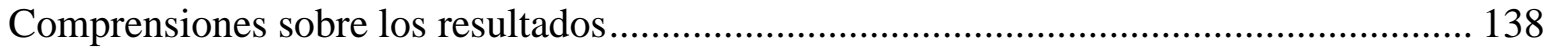

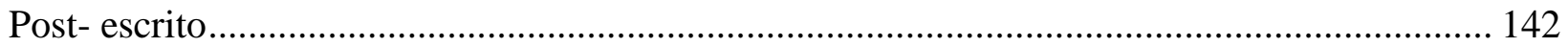

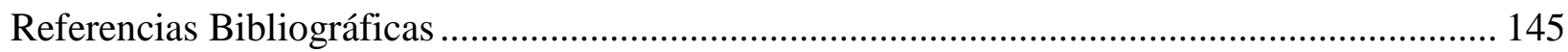

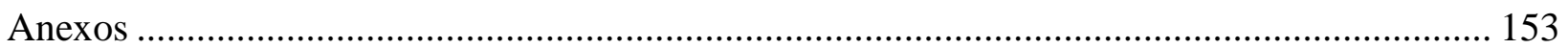




\section{LA DESERCIÓN ESCOLAR COMO PRETEXTO PARA CONVERSAR SOBRE IDENTIDAD, FAMILIA Y ESCUELA

\section{Lista de Tablas}

Tabla 1. Modelización de los procesos de la Investigación- Intervención. ................................. 62

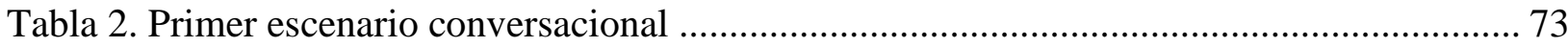

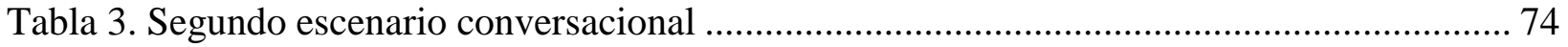

Tabla 4. Tercer escenario conversacional ......................................................................... 74

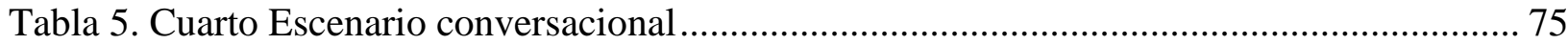

Tabla 6. Quinto escenario conversacional ..................................................................... 75

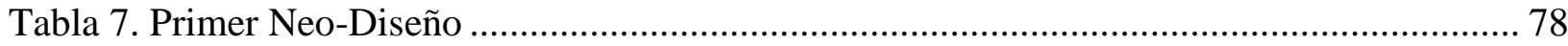

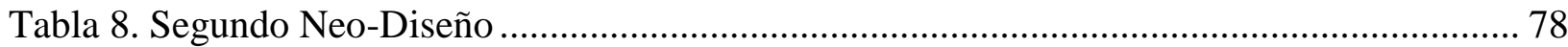

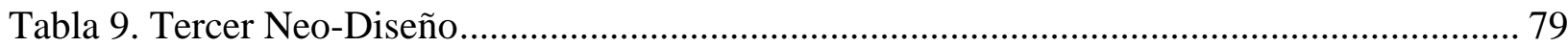

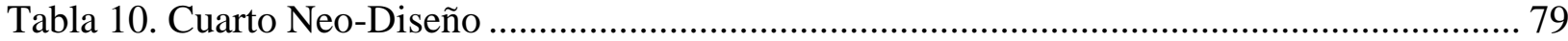

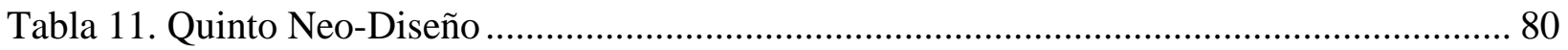

Tabla 12. Formato para el análisis de Resultados .............................................................. 83

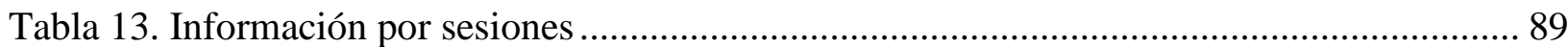




\section{LA DESERCIÓN ESCOLAR COMO PRETEXTO PARA CONVERSAR SOBRE IDENTIDAD, FAMILIA Y ESCUELA

\section{Lista de Figuras}

Figura 1. La deserción es un fenómeno complejo. No obedece a una sola causa. ...................... 36

Figura 2. Construcción narrativa de la identidad en adolescentes. ....................................... 52

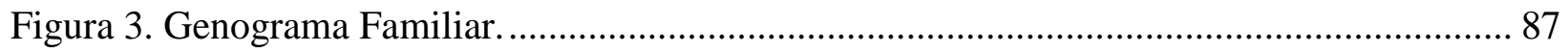




\section{LA DESERCIÓN ESCOLAR COMO PRETEXTO PARA CONVERSAR SOBRE IDENTIDAD, FAMILIA Y ESCUELA

\section{Resumen}

El presente trabajo de grado hace parte del macroproyecto "historias y narrativas familiares en diversidad de contextos" de la Maestría en Psicología Clínica y de Familia, que se encuentra vinculado a la línea de investigación Psicología, Sistemas Humanos y Salud Mental, la cual está adscrita al grupo de investigación Psicología, Familia y Redes de la Facultad de Psicología de la Universidad Santo Tomas. El objetivo de la presente investigaciónintervención fue comprender cómo se construye y co-construye narrativamente la identidad de una adolescente en situación de deserción escolar, y las relaciones que se entretejen en el contexto familiar y el escolar para dar respuesta al fenómeno de la deserción escolar. La metodología implementada fue un estudio de caso, en el que se desarrollaron 5 escenarios conversacionales en el diseño y 5 en el neo-diseño, con un sistema familiar, que fue identificado en uno de los escenarios conversacionales realizados en el Colegio San Jerónimo Emiliani de la ciudad de Tunja.

Los hallazgos de este estudio se lograron visibilizar a partir de la movilización del sistema familiar, lo cual se relaciona con el hecho de que en el proceso investigativo-interventivo la madre logro construir narrativas emergentes alrededor de la deserción escolar, junto con la reconstrucción del vínculo parental a partir de la generación de comprensiones alternativas entorno al rol y el significado de cada uno de los miembros del sistema y la relación de los mismos, lo cual genero relatos emergentes que se han mantenido en el tiempo. Finalmente, se plantea que el término "deserción" puede no ser es el más acorde para dar cuenta del proceso dentro del cual un joven se retira de una institución educativa, puesto que este no siempre se desvincula de la institución, sino que puede aplazar temporalmente sus estudios, ya que en este proceso el o la joven pueden contemplar nuevas opciones que den respuesta a otras expectativas y retomar sus estudios; en vista de lo anterior cabe resaltar que solo en un bajo porcentaje los jóvenes no ingresan de nuevo a las instituciones educativas para finalizar su proceso de educación básica y media, ya que puede que estos se capaciten en un oficio específico que les permita desempeñarse laboralmente.

Palabras Clave: Deserción, adolescencia, intervención, relación, construcción 


\title{
LA DESERCIÓN ESCOLAR COMO PRETEXTO PARA CONVERSAR SOBRE IDENTIDAD, FAMILIA Y ESCUELA

\begin{abstract}
The present work of master is part of the macro-project "Histories and familiar narrations in diversity of contexts" in Clinical Psychology and of Family program, is linked to the line of investigation Psychology, Human Systems and Mental Health which is assigned to the group of research Psychology, Family and Networks of the School of Psychology of Universidad Santo Tomás. The objective of the present investigation is the understanding of how the identity of an adolescent is constructed and co-constructed narratively in the situation of school desertion and the relationships that are given in family contexts and to respond to the phenomenon of school desertion. The methodology implemented was a case study in which 5 conversational scenarios were developed in the design and 5 in the neo-design, with the family system, which was identified in one of the conversational settings in San Jerónimo Emiliani School in Tunja.

The results of this study were made visible through the mobilization of the family system, which is related to the fact that the investigative-intervention process the mother was able to construct emerging narratives about school desertion, along with the reconstruction of the bond between a mother and her daughter from the generation of alternative understandings to the environment and the meaning of each of the members of the system and their relationship, emerging stories that have been kept over time. Finally, it was found that the term "desertion" is not the most appropriate to refer to a young person who withdraws from an educational institution, which is in most cases a temporary postponement occurs, in this search the young man contemplates new options that respond to new expectations and back to school, just a low percentage of young people do not come back to schools in order to get their studies over, however, they dedicate themselves to learning an occupation that allows them to perform work.
\end{abstract}

Key Words: Desertion, adolescence, intervention, relationship, construction 


\section{LA DESERCIÓN ESCOLAR COMO PRETEXTO PARA CONVERSAR SOBRE IDENTIDAD, FAMILIA Y ESCUELA

\section{Presentación}

El trabajo se inscribe en el proyecto "Historias y narrativas familiares en diversidad de contextos, pertenecientes al plan institucional de investigación de la familia (PLANFA) de la Maestría en Psicología Clínica y de Familia de la Universidad Santo Tomas que se encuentra vinculado a la línea de investigación Psicología, Sistemas Humanos y Salud Mental la cual está adscrita al grupo de investigación Psicología, Familia y Redes de la Facultad de Psicología de la USTA.

En relación con lo anterior, la educación es acompañada de procesos de socialización que inician en el sistema familiar, con los primeros aprendizajes y posteriormente se profundizan al ingresar a la escuela, en la medida en que se avanza en los diferentes niveles educativos.

Ahora bien, el papel que cumple la escuela en la vida de los jóvenes es significativo por ser el escenario en el cual se adquieren conocimientos, también el lugar en donde se exponen las diferentes normas sociales, se adquieren reglas y se interactúa con las costumbres de la comunidad. Por su parte la UNESCO (2018) manifiesta que la escuela desempeña un papel clave en la vida de los estudiantes al establecer políticas y generar entornos de protección frente a los diferentes factores que están influyendo en la vida de los adolescentes llevándolos a abandonar sus estudios, el papel de la escuela a nivel pedagógico es sensibilizar a la población estudiantil sobre estos temas, estimular ambientes de vida sana, impartir charlas preventivas, con miras a fortalecer sus conocimientos y las capacidades para tomar decisiones en el momento en que lo necesiten.

Por su parte Díaz, (2006) manifiesta que la escuela y la familia se han concebido como referentes de formación de educación del ser humano, conformando alianzas interconectadas en el tiempo, por periodos largos o cortos dependiendo del ciclo vital del sistema familiar y 


\section{LA DESERCIÓN ESCOLAR COMO PRETEXTO PARA CONVERSAR SOBRE IDENTIDAD, FAMILIA Y ESCUELA

con pautas de relación que se mantienen a lo largo de la vida, convirtiendo estas dos instituciones en las instancias con mayores recursos para producir transformaciones. Sin embargo, en esta relación surgen diversos aspectos que dificultan la formación de los adolescentes esto sucede cuando cada uno de los contextos empieza a inculpar al otro como artífice de las dificultades en la formación.

Además en algunos contextos no se presentan las condiciones para que la permanencia de los estudiantes se dé, presentándose procesos de deserción identificados con diferentes etiologías, como son las características estructurales del sistema educativo, la interacción de factores individuales y del desarrollo, factores económicos, socioculturales y familiares. En relación con estos factores se ha encontrado que la movilidad de las familias es recurrente en diferentes zonas del país, en este sentido las familias pierden el interés por matricular a sus hijos en el nuevo sitio de residencia, tienen dificultades para encontrar un nuevo establecimiento educativo o simplemente no hay cupo para recibir al nuevo estudiante (Colombia digital 2013). Otro factor que incide en la deserción escolar es la distancia que hay entre el lugar de residencia y la escuela y la violencia que se presenta entre pandillas juveniles, grupos armados al margen de la ley y los conflictos que se presentan entre docentes y estudiantes (Colombia digital 2013).

Además de los factores psicosociales y familiares mencionados anteriormente, existen factores propios del contexto social y motivacional de los jóvenes asociados al fenómeno de la deserción, dentro de estos se encuentran: la presión del grupo de pares, la relación de los docentes con los estudiantes, el rendimiento académico, entre otros; los cuales contribuyen a que los adolescentes manifiesten este tipo de problemas. En este sentido se comprende la deserción escolar como un proceso de abandono, voluntario o forzoso por circunstancias 


\section{LA DESERCIÓN ESCOLAR COMO PRETEXTO PARA CONVERSAR SOBRE IDENTIDAD, FAMILIA Y ESCUELA

internas o externas, el cual puede estar relacionado con la falta de motivación provocada por

el fracaso escolar, al igual que por la falta de contención familiar, la falta de proyección y construcción de roles claros en el sistema familiar y social.

Ahora bien, el capítulo del estado del arte ofrece los referentes teóricos e investigativos, alrededor de la construcción narrativa de la identidad, la deserción escolar y la relación entre adolescente, familia e institución educativa, para la convergencia compleja de dichos factores, dentro de las comprensiones del fenómeno de estudio.

El sistema teórico tuvo como propósito indagar y comprender el fenómeno de la deserción escolar desde la perspectiva epistemológica y paradigmática que brinda el enfoque sistémico construccionista- constructivista complejo, la construcción de la identidad desde la narrativa y la adolescencia como parte del ciclo vital.

En el sistema metodológico define la forma como se va a operar la investigaciónintervención, para ello se retoma la modelización como forma de operar en la investigación los principios operadores, la reflexividad, la recursividad, la autorreferencia y los procesos conversacionales, a través de ellos se puede comprender el fenómeno de estudio, las experiencias vividas por cada miembro del sistema familiar. Los conceptos metodológicos que orientan el proyecto de investigación-intervención son las historias, las memorias y los relatos. La narrativa, se integra al proceso de investigación- intervención a partir de los escenarios conversacionales.

Los resultados se organizan desde los tres conceptos metodológicos: a. Las historias dominantes y su incidencia en la construcción narrativa de la identidad; b. las memorias como recurso para comprender como intervenir narrativamente en la relación joven, la familia y la institución educativa entorno a la deserción escolar y los significados que adquieren los 


\section{LA DESERCIÓN ESCOLAR COMO PRETEXTO PARA CONVERSAR SOBRE IDENTIDAD, FAMILIA Y ESCUELA

relatos en estos contextos; c. los relatos emergentes, los cuales surgen de las reflexiones y

movimientos que se presentan durante los encuentros conversacionales con el sistema familiar, emergiendo comprensiones que permite el restablecimiento del vínculo parental, y nuevas opciones para que la adolescente se reintegre al sistema educativo. También se presentan los aspectos autorreferenciales y hetero referenciales emergentes en la intervención, de la investigadora- interventora y de la familia.

En el capítulo de discusión se presentan las reflexiones y hallazgos de los resultados, en conversación con el estado del arte y los referentes teóricos frente al fenómeno de construcción y co-construcción narrativa de la identidad en la relación entre la joven, la familia y la institución educativa, en una situación de deserción escolar.

Finalmente, en el apartado de conclusiones se realizan las comprensiones de cada uno de los capítulos y los aportes realizados a la Psicología Clínica para pensar en la posibilidad de cambio en el contexto educativo y familiar; generando nuevas posibilidades para los sujetos en relación con las formas tradicionales de aprender y transmitir el conocimiento. 


\section{LA DESERCIÓN ESCOLAR COMO PRETEXTO PARA CONVERSAR SOBRE IDENTIDAD, FAMILIA Y ESCUELA

\section{Introducción}

El proceso de investigación- intervención desarrollado en este trabajo se encuentra en el grupo Psicología, familia y redes, en la línea de Psicología, sistemas humanos y salud mental, adscrito al macroproyecto "Historias y Narrativas Familiares en diversidad de contextos". Se desarrolló bajo la metodología de caso único, desde los planteamientos del enfoque sistémico, constructivista, construccionista complejo, a través de un proceso de investigaciónintervención.

El fenómeno de investigación-intervención, gira en torno a la deserción escolar y la relación de esta en los procesos de construcción de identidad.

Los procesos identitarios son construidos por las interacciones sociales entre grupos y personas que comparten opiniones, el "self" social se construye en las interacciones con los otros, de esta manera se concibe la construcción social como el producto de las relaciones entre seres mediados por la comunicación de sus participantes (Renau, Oberst \& Carbonell, 2013). Ahora bien, la deserción escolar genera una narrativa que inicia en la infancia y trasciende hasta la edad adulta (García \& Sánchez, 2014), en la que se reflejan los procesos relacionales del sistema familiar, la escuela y los acontecimientos más importantes que han marcado sus vidas.

Actualmente el desempeño académico está marcado por lineamientos institucionales que deben ser tenidos en cuenta en el momento de realizar la evaluación a un estudiante, y se da cuenta de éste por medio de la calificación asignada por el profesor o el promedio obtenido por el estudiante.

Por otra parte, el fracaso escolar y la deserción académica son elementos que están asociados a la perdida de potencial, considerada un riesgo, debido a las implicaciones que 


\section{LA DESERCIÓN ESCOLAR COMO PRETEXTO PARA CONVERSAR SOBRE IDENTIDAD, FAMILIA Y ESCUELA

puede tener en el desarrollo, especialmente en el área de salud física y mental, al igual que otros aspectos tenidos en cuenta en la sociedad actual, como lo son el embarazo, el consumo de SPA, la delincuencia y el desempleo. Por consiguiente, se comprende que la deserción escolar refleja factores extraescolares, como violencia en el ámbito educativo, reflejada en la relación estudiante-profesor, como lo mencionan Peña, Soto \& Calderón (2016), quienes plantean que esto puede producir en los jóvenes daños emocionales, estrés, desmotivación, ausentismo, llegando a incidir en el rendimiento y permanencia en los establecimientos educativos. De igual forma se entienden que existen otros factores asociados a la deserción escolar que tienen gran influencia en el fenómeno de estudio, como lo son el factor económico, los problemas socioculturales y políticos que obligan a las familias a desplazarse y buscar nuevos sitios para establecerse, los problemas de violencia intrafamiliar, produciendo la desintegración en la familia nuclear, lo anterior teniendo en cuenta que la deserción es una problemática que surge debido a las condiciones del contexto y los procesos dados en el mismo.

En este sentido, vale la pena pensar en que existen factores escolares y sociales que están incidiendo directamente en el fenómeno de estudio, por lo tanto, la deserción escolar se enmarca en las historias dominantes del sistema familiar y social, las cuales pasan por los castigos físicos, el maltrato psicológico y las agresiones verbales mutuas.

Es importante resaltar que las historias dominantes son comprendidas como historias cargadas de poder, en las cuales aparecen, padres, maestros, profesionales de la salud, y que estas a su vez se presentan a partir de relatos saturados por el problema, los cuales se encuentran mediados por relaciones de poder y de actos de resistencia que logran saturar más el problema y a la vez contribuyen a construir la identidad desde el déficit. 


\section{LA DESERCIÓN ESCOLAR COMO PRETEXTO PARA CONVERSAR SOBRE IDENTIDAD, FAMILIA Y ESCUELA

Por otra parte, existe la posibilidad de visualizar a las organizaciones insertas en una red de relaciones, con actores sociales diversos interactuando permanentemente e influyendo en su desarrollo, posibilitando la apertura a cambios en el modo en que los padres y los docentes interactúan. Lo anterior es tenido en cuenda debido a que en el contexto actual sigue funcionando el modelo escolar tradicional, desde el cual las personas posicionan al maestro como el centro del proceso de formación, teniendo en cuenta que para la sociedad el es quien cuenta con todo el conocimiento, desconociendo los aprendizajes previos de los estudiantes, por esta razón, se plantea que el sistema escolar debería convocar al sistema familiar y poder trabajar conjuntamente, generando espacios de interacción y protección para ellos, este sistema relacional seria inclusivo y el adolescente se ubicaría en el centro del proceso educativo, mientras que el contexto educativo y el familiar se fortalecerán y brindaran apoyo a todo el proceso formativo.

La importancia del fenómeno problema se sustenta en la dificultad que se presenta en el sistema familiar de una adolescente que lleva varios años desescolarizada, generando una ruptura en la configuración de los vínculos parentales y filiales, provocando un distanciamiento en el sistema relacional familiar y social.

El interés del ejercicio interventivo es conocer y comprender como se construye la identidad de una adolescente en situación de deserción escolar a partir de narrativas conversacionales, y la incidencia de las historias dominantes en esa construcción. Un acercamiento a la realidad del sistema familiar, que permita construir una narrativa posibilitadora para hablar de sus experiencias de vida y de las relaciones que construyen con los otros, lo que va a posibilitar construir como familia una identidad propia, estableciendo relaciones con otros contextos e interactuar de manera individual. 


\section{LA DESERCIÓN ESCOLAR COMO PRETEXTO PARA CONVERSAR SOBRE IDENTIDAD, FAMILIA Y ESCUELA

\section{Pregunta que orienta la investigación/ intervención}

¿Cómo se relacionan los contextos educativo y familiar, para aportar en la construcción y co- construcción narrativa de la identidad de una adolescente en condición de deserción escolar?

\section{Objetivos}

\section{Objetivo General}

Comprender como se construye y co-construye narrativamente la identidad de una adolescente en situación de deserción escolar a partir de la relación con su contexto familiar y escolar para movilizar nuevas versiones identitarias que se descentren de la experiencia de deserción.

\section{Objetivo Específicos}

Comprender las narrativas identitarias que organizan la experiencia de deserción escolar en la relación entre la joven, la familia y la institución educativa.

Facilitar la emergencia de memorias y relatos alternos que permitan la construcción narrativa de la adolescente y la familia.

Fortalecer la co-construcción identitaria en el tiempo a través de los relatos y las memorias generadoras de cambio. 


\section{LA DESERCIÓN ESCOLAR COMO PRETEXTO PARA CONVERSAR SOBRE IDENTIDAD, FAMILIA Y ESCUELA

\section{Hipótesis}

Los procesos conversacionales del sistema terapéutico propician la co- evolución del problema a niveles vinculares y de respeto entre los consultantes centrándose en la experiencia de deserción escolar. Así se busca generar procesos de corresponsabilidad en las construcciones relacionales que han mantenido las pautas de déficit en el sistema familiar, para poder construir nuevas posibilidades identitarias que vayan más allá de la deserción escolar que los ha definido en su historia.

En el proceso terapéutico la emergencia de las narrativas de la adolescente, el sistema familia y el sistema educativo evolucionan hacia la construcción de su identidad, en la medida que se construyen nuevos relatos. 


\section{LA DESERCIÓN ESCOLAR COMO PRETEXTO PARA CONVERSAR SOBRE IDENTIDAD, FAMILIA Y ESCUELA

\section{Estado del Arte Documental}

Este capítulo presenta las categorías investigativas- interventivas en los niveles, y temas específicos que serán tratados a lo largo de este documento, permitiendo presentar procesos investigativos previos que desde su interés ofrecen a esta investigación-intervención referentes teóricos, investigativos, y técnicos alrededor de la construcción narrativa de la identidad, la deserción escolar y la relación entre adolescente, familia e institución educativa, para la convergencia compleja de dichos factores, dentro de las comprensiones del fenómeno de estudio.

\section{Comprensiones sobre la etapa de la Adolescencia}

La etapa de la adolescencia puede ser vista como un momento en el ciclo vital, el cual se presenta en relación con los cambios que el individuo afronta desde la etapa de la pubertad hasta llegar a convertirse en un adulto (Valdivieso, 2013). Es por esta razón que la adolescencia es considerada como un estado en el que el individuo empieza a sentirse en un limbo, su cuerpo empieza a tener cambios físicos y emocionales, ya no es niño/niña, pero tampoco es un adulto. Además, en esta etapa se afrontan cambios relacionados con la organización del "self", al igual que en la configuración de relaciones interpersonales, como por ejemplo en el sistema familiar, por lo anterior, la adolescencia es entendida como una etapa que tiene dos miradas diferentes: una es la lectura que el adolescente tiene de sí mismo y otra la de los padres que lo observan.

En relación a los adolescentes, ellos experimentan diferentes sensaciones aparentemente opuestas, de rabia o felicidad, de amor o de odio, para el adolescente es difícil comprender ¿por qué? Se les quiere controlar, generalmente argumentan querer más independencia y no comprenden porque sus padres se irritan con tanta facilidad, en ocasiones se sienten dueños 


\section{LA DESERCIÓN ESCOLAR COMO PRETEXTO PARA CONVERSAR SOBRE IDENTIDAD, FAMILIA Y ESCUELA

del mundo, en otras ocasiones los invade la inseguridad, les cuesta concentrarse, se aburren con facilidad, son desafiantes de la autoridad, ya sea en la familia o en el colegio, mientras tanto, algunas veces los padres se sienten como si no conocieran a este nuevo miembro de la familia, añoran al niño de antes, no saben o no quieren apoyar al adolescente en su deseo de tener mayor independencia.

Ahora bien, los padres temen perder el control de la situación y sienten temor al mundo de las drogas, el alcohol y al sexo, padres que necesitan entender y negociar normas mediáticas entre todos los miembros del sistema familiar (Lillo, 2017). Lo anterior, se tiene en cuenta con el fin de reconocer los posibles mapas de relaciones en las que los adolescentes construyen su identidad, desde la generación de procesos de independencia y los marcos referenciales de la familia o el escenario escolar, de manera que puedan realizar comprensiones sobre los cambios emocionales y de autopercepción que pueden estar relacionados en el proceso de deserción escolar.

El adolescente en el siglo XXI se encuentra que existen nuevas formas de construirse e identificarse, apropiándose de su cuerpo, utilizándolo como una forma de construcción identitaria, pero también una forma de revelarse a las normas sociales (Camargo, Álvarez y Velasco Acosta, 2015). Un ejemplo de ello, son los tatuajes, los piercings, las expansiones, las formas de vestir, las cirugías estéticas, los implantes y las modas prohibidas en la sociedad, interpretadas como un tabú, y que en la actualidad se han normalizado, estas marcas en sus cuerpos hacen parte de su generación, buscando con ello ser individuos autónomos y con ello construir su auto concepto.

Por consiguiente, al analizar la postura que tienen los padres y los temores que sienten de su hijo adolescente y los peligros sociales a los que están expuestos se puede hacer un 


\section{LA DESERCIÓN ESCOLAR COMO PRETEXTO PARA CONVERSAR SOBRE IDENTIDAD, FAMILIA Y ESCUELA

paralelo entre la actualidad y el pasado, en donde los padres buscaban tener el control sobre lo que hacían sus hijos, frente a los cambios culturales y la autonomía de los jóvenes del siglo XXI, puesto que estos se han modificado notoriamente, ellos han adoptado nuevas formas de construirse e identificarse como adolescentes.

Los jóvenes se construyen a partir de las prácticas cotidianas de una cultura cambiante, debido a que en la actualidad existe una carga de información proveniente del medio exterior la cual puede saturar a los jóvenes, pero también hace parte de los sistemas de interacción y de construcción de ellos, más si se tiene en cuenta que la información se encuentran en constante dinamismo.

Ahora bien, en relación con los intentos por demostrar independencia frente a los padres entran en discusión por las creencias, las justificaciones y las vivencias, provocando interacciones de violencia que llevan a romper las relaciones parento filiales y un distanciamiento que deja al adolescente a la deriva frente al desarrollo de los procesos básicos que necesitan el acompañamiento de los padres o de un adulto cuidador.

Por su parte Lillo, (2017) encuentra que las características que describen a los adolescentes en su etapa de crecimiento y de comportamiento se destacan tres características fundamentales, estas son:

- La adolescencia como duelo por la pérdida del mundo infantil.

- Como renovación de la problemática psíquica establecida en la infancia y su resolución.

- Finalmente, por ser una etapa llena de nuevas expectativas, ilusiones y descubrimientos vitales. Se analizan los significados de los cambios corporales en la configuración de la identidad definitiva como adulto. Se detallan las tendencias o movimientos emocionales que están presentes en la adolescencia, tanto los regresivos como los progresivos. 


\section{LA DESERCIÓN ESCOLAR COMO PRETEXTO PARA CONVERSAR SOBRE IDENTIDAD, FAMILIA Y ESCUELA

Se dice que la adolescencia es una etapa donde se construye la identidad reflejada posteriormente en la vida adulta, construida de manera gradual y llena de dificultades, razón que debe ser tenida en cuenta porque generalmente se convierte en una etapa en la que los jóvenes se avergüenzan por los cambios físicos, fisiológicos y psicológicos; terminando finalmente a ser confinada a la esfera de los malos sueños y negando su existencia, incidiendo de manera directa en la relación del adolescente con la familia y el escenario escolar, provocando cambios en los comportamientos académicos y sociales que pueden organizar una conducta de deserción escolar.

La adolescencia es una etapa de la vida que se caracteriza por brindar a los jóvenes oportunidades, capacidades, aspiraciones, energía y creatividad, pero también por ser una etapa de vulnerabilidad que marca el momento de su desarrollo. Es un período de cambios positivos inspirados por la importante capacidad de los y las adolescentes para aprender rápidamente, experimentar nuevas y diversas situaciones, acrecentar y utilizar el pensamiento crítico y ejercer más y nuevos espacios de libertad y autonomía, ser creativos y socializar.

Los y las adolescentes son agentes de cambio fundamentales para contribuir positivamente al desarrollo de una sociedad más justa, diversa y atenta al desarrollo sostenible y cuidado del medio ambiente (UNICEF, 2017. pp. 6).

En este orden de ideas, se comprende la adolescencia como una etapa de transición, el paso de la infancia a la edad adulta, en la cual todos los cambios que afronta el adolescente están mediados por la cultura y el contexto social, y por tanto se considera una etapa en la cual los jóvenes necesitan de una atención especial proporcionada por los contextos familiar e institucional de cuidado y protección. 


\section{LA DESERCIÓN ESCOLAR COMO PRETEXTO PARA CONVERSAR SOBRE IDENTIDAD, FAMILIA Y ESCUELA

Aular (2011), considera que la adolescencia es un periodo psicológico con gran influencia de los pares, es una etapa de cambios, físicos, cognitivos y afectivos; igualmente comprendida como una etapa de experimentación natural que puede llevar a los adolescentes a probar algunas sustancias para experimentar que se siente, experimentar nuevas sensaciones. Es una etapa en la que se ponen en juego los valores y las relaciones sociales.

Por ser una etapa de transición esta presenta una fuerte influencia de los pares, generalmente inicia con la experimentación de temas relacionados con la sexualidad y bajos niveles de actividad física, aumenta la curiosidad por experimentar sensaciones nuevas, y se puede dar paso al consumo de bebidas alcohólicas y de otro tipo de sustancias.

Adicionalmente existen factores de riesgo y factores protectores como son; hogares estables, motivación al logro, buenas relaciones padres e hijos, supervisión, disciplina de los padres y la relación con instituciones sociales. Lo cual permite establecer un vínculo de confianza y comprensión entre el adolescente y su familia, al igual que con los contextos amplios para romper con la etiqueta de "adolescentes problemáticos".

\section{Construcción de la Identidad}

Desde el paradigma de la complejidad, la identidad es comprendida como el núcleo de la mente, producto de la experiencia que permanece constante, es un proceso dinámico de intercambios en el que las personas se analizan, se comparan, se aprueban o desaprueban, esta construcción esta mediada por las relaciones sociales, pues es en esta interacción experiencial que se construyen los procesos identitarios (Linares, 1996). La identidad del adolescente se construye en las relaciones con sus pares y de otros modelos como los líderes, sin embargo, la confianza y las relaciones de su contexto familiar, juegan un papel importante en la relación con otros contextos. 


\section{LA DESERCIÓN ESCOLAR COMO PRETEXTO PARA CONVERSAR SOBRE IDENTIDAD, FAMILIA Y ESCUELA

Renau, Oberst \& Carbonell (2013), plantean que la construcción de la identidad es derivada y mantenida por la construcción social, realizada entre grupos de personas que comparten opiniones y percepciones de un fenómeno, desde el construccionismo, el "self" social se construye a través de las interacciones que se establecen con los otros.

Por consiguiente, es una construcción dada a partir de la interacción, en la que el "yo" es el producto de estas relaciones entre seres, ahora bien, esta puede ser válida o cambiante a partir de los procesos sociales los cuales están mediados por la comunicación de los participantes, por tanto, esta realidad se transforma constantemente, un ejemplo de ello es el uso de las redes sociales online (RSO), puesto que este es un medio de interacción social que facilita la construcción de la identidad de los adolescentes, y permite obtener información diversa que moviliza los procesos de cambio.

Las redes sociales online, son posiblemente el medio más usado por los adolescentes para establecer interacciones sociales, a través de este medio se narran historias acerca de los sucesos que acontecen en el diario vivir, todos estos intercambios sociales están asociados con el bienestar psicológico del adolescente, por medio de la significación que los otros construyen alrededor del adolescente, se debe tener en cuenta que estas etiquetas y formas de definir a la persona se relaciona con la construcción de su propio auto concepto y la significación del mismo.

Benítez (2011) considera que la escuela juega un papel importante en la socialización y en la construcción identitaria de los adolescentes, también sobre las asociaciones que los estudiantes hacen con la palabra proyecto, dichas asociaciones están relacionadas con el estudio, el trabajo, las ocupaciones y finalmente con la configuración de relaciones para el futuro, al igual que la construcción de sus proyectos en la construcción de su identidad. El 


\section{LA DESERCIÓN ESCOLAR COMO PRETEXTO PARA CONVERSAR SOBRE IDENTIDAD, FAMILIA Y ESCUELA

contexto social tiene gran influencia en las representaciones sociales, especialmente en las diferencias de género, el origen social y las experiencias de vida cotidiana.

El contexto educativo cumple el papel de orientador en la construcción del proyecto de vida, un ejemplo de ello son las prácticas de orientación vocacional, las cuales le permiten al adolescente construir proyectos personales y estrategias para consolidarlos. En este orden de ideas se entiende cómo la construcción de la identidad de la adolescente del caso se vio afectada, los procesos relacionales con sus pares no se presentaron o fueron escasos, al estar desescolarizada no pudo acceder a las herramientas de orientación para realizar su proyecto de vida, encontrándose en desventajas en relación con otros jóvenes de su edad.

Por su parte, Zamora (2013) señala que la etapa de la adolescencia, además de involucrar cambios biológicos, también involucra cambios cognitivos y emocionales que incluyen transformaciones culturales, sociales, económicas y políticas, lo cual indica un reto para apropiarse de un lugar en el mundo, a través de interacciones directas con la familia, la escuela, la comunidad y los acontecimientos ambientales socio - históricos, que al integrar su totalidad se convierte en un entramado complejo.

Lo expuesto anteriormente permite hacer una lectura ecológica del papel que tiene el adolescente en diferentes contextos, el modelo a seguir son sus redes de apoyo más cercanas, contribuir al desarrollo y fortalecimiento de la identidad del adolescente es una tarea que le corresponde a la familia y al contexto social, la equivocación y la dificultad son parte del aprendizaje, el cual le va a permitir adquirir experiencia para situaciones futuras.

Gómez y Carrasco (2010) consideran que la identidad representa una parte importante del desarrollo humano, es un periodo complejo en el que se lleva a cabo una re-construcción de significados, la adolescencia abarca casi una década de la vida, es una época de grandes 


\section{LA DESERCIÓN ESCOLAR COMO PRETEXTO PARA CONVERSAR SOBRE IDENTIDAD, FAMILIA Y ESCUELA

cambios en todas las esferas de la vida, se trata de un periodo visto socialmente, como un periodo de vulnerabilidad y de grandes oportunidades de cambio y avance en diferentes ámbitos, lo que se conoce como conflicto en esta etapa, es el paso que indica para el adolescente la re significación de su identidad, es un momento en el que se le invita a apartarse de todo aquello que hasta el momento le ofrecía seguridad, se considera que estos eran aspectos que dependían de otros como la familia y que deben ser revaluados para elaborar su propio lugar en el mundo, la conquista del sentimiento de identidad constituye la subjetividad, la adolescencia implica la tarea de desprenderse de lazos familiares de dependencia a los que estaba sometido y acostumbrado, convirtiéndose en requisito fundamental para el proceso de individuación y la adquisición de roles de adulto en la sociedad.

Se concluye que, la familia es el núcleo vital al que se pertenece desde el momento de nacer, generando un vínculo de pertenencia y transmisión genética acerca de quiénes somos, el cual se va consolidando a lo largo de las etapas del ciclo vital. La infancia es la etapa en la que se produce la primera transmisión identitaria por parte de la familia a la que se pertenece.

En la adolescencia se construye la identidad individual en las relaciones con los pares, de esta manera se construye una identidad que permite diferenciarse de la familia de origen, siendo este el proceso de individuación el cual obliga a la familia a adaptarse a la nueva posición identitaria del adolescente.

\section{Deserción escolar a nivel global}

Desde una mirada ecológica se visualizan diferentes factores que inciden en la deserción escolar en los jóvenes, estos son: embarazos en los adolescentes, trabajo infantil, violencia intrafamiliar, la situación de pobreza, suicidio y el bullying del que son víctimas algunos 


\section{LA DESERCIÓN ESCOLAR COMO PRETEXTO PARA CONVERSAR SOBRE IDENTIDAD, FAMILIA Y ESCUELA

adolescentes. A continuación, se presentan las investigaciones que se han centrado en dichos factores de riesgo y que para la investigación- intervención resultan relevantes para la comprensión del fenómeno de estudio.

De acuerdo con lo expuesto, y para hablar específicamente de embarazo adolescente y la maternidad infantil a nivel mundial, la UNICEF (2014) describe que el embarazo adolescente y la maternidad infantil se encuentran mediados por un conjunto de representaciones culturales en torno a la maternidad. En algunos sectores sociales la maternidad se constituye simbólicamente en el paso hacia la adultez y mejoramiento de estatus dentro de la comunidad. Convertirse en madre es una manera de inspirar respeto y ser una mujer completa en la visión de su entorno. Así, la maternidad adolescente es vista como una opción que proporciona sentido y un proyecto de vida. Esto representa un factor importante en la deserción escolar, la responsabilidad de cuidado que demanda la maternidad, obliga a que los adolescentes abandonen el escenario escolar por no contar con garantías institucionales de continuidad y permanencia.

Para la UNICEF la maternidad en los adolescentes no ha tenido una respuesta apropiada desde las políticas públicas en Latinoamérica. Las iniciativas para prevenir y sancionar la violencia sexual como una de las causas críticas del embarazo en adolescentes, particularmente en menores de 15 años; la impunidad y justicia son temas ausentes en el análisis y desarrollo de políticas públicas sobre embarazo adolescente y en lo que puede estar relacionado con deserción escolar.

La Organización para la Cooperación y el Desarrollo Económico (OCDE), plantea que en México la Violencia intrafamiliar es una de las principales causas de deserción escolar en los jóvenes, siendo uno de los países que ocupa el primer lugar en abandono escolar con 


\section{LA DESERCIÓN ESCOLAR COMO PRETEXTO PARA CONVERSAR SOBRE IDENTIDAD, FAMILIA Y ESCUELA

estudiantes entre los 15 y los 18 años, el tercer país con mayor número de jóvenes que no estudian ni trabajan.

De esta manera, el abandono escolar se presenta en relación a situaciones de violencia intrafamiliar, como la falta de afecto y la poca atención de los padres hacia sus hijos. Un segundo aspecto que se detecta es, las actitudes de los docentes para denigrar a sus alumnos, es casi una constante en la relación maestro-alumno (Gutiérrez, 2016). Los mensajes despectivos, amenazantes y discriminatorios con expresiones como "eres un burro", "tú no vas a pasar el semestre", "pon tu cerebro a trabajar" o "agita tus neuronas", desalientan y bajan la autoestima de los estudiantes, quienes prefieren distanciarse de sus maestros. A nivel personal, la falta de identidad y una propuesta real de futuro para insertarse en el mundo laboral y social se convierten en las principales causas de deserción escolar.

En este sentido Lindsay (2011) menciona que el suicidio en los adolescentes se encuentra asociado a la deserción escolar y con el ambiente biopsicosocial, según las estadísticas los adolescentes que mueren por suicidio padecen trastornos psiquiátricos, como trastornos depresivos, pérdidas, problemas legales o disciplinarios, problemas familiares, antecedentes de conductas suicidas, problemas padres e hijos, abuso físico y sexual, dificultades en la escuela, orientación homosexual o bisexual. De acuerdo con ello algunos factores protectores para reducir el potencial de suicidio incluyen, hacer frente a los problemas, generar habilidades para la resolución de conflictos, conectar la escuela y los padres, potenciar en los adolescentes la resiliencia.

En relación al fenómeno de deserción escolar, se concluye que esta es una problemática de orden social que se presenta a nivel mundial y está enfocada principalmente en edades tempranas, así mismo, existen múltiples factores asociados al fenómeno, el más sobresaliente 


\section{LA DESERCIÓN ESCOLAR COMO PRETEXTO PARA CONVERSAR SOBRE IDENTIDAD, FAMILIA Y ESCUELA

es cuando los jóvenes deciden desertar en los primeros años escolares, posiblemente por problemas económicos, probablemente el mercado laboral les ofrece mejores incentivos que seguir estudiando, este problema se agudiza cuando no se tiene una idea clara de lo que ellos harán a largo plazo, porque estos jóvenes enfrentan problemas para integrarse al mercado laboral y conseguir un trabajo mejor remunerado generando un alto costo social en la mano de obra calificada.

\section{Deserción escolar en Colombia}

A nivel nacional Román (2013), propone analizar la incidencia de los diferentes factores no académicos, socioeconómicos, familiares y personales relacionados con la deserción escolar en los adolescentes de la comuna $8^{\mathrm{a}}$, parte sur de Sincelejo, describiendo que la vulnerabilidad y exclusión social pueden llegar a configurar fenómenos como la deserción escolar; principalmente en estudiantes o jóvenes que habitan en esas comunas, debido a que ellas tienen características propias de comunidades abandonadas por las políticas gubernamentales y de pobreza extrema.

La Universidad del Caldas también muestra los hallazgos en la relación que existe entre el embarazo en las adolescentes, la deserción escolar y la influencia que tiene el grado escolar como factor de riesgo de deserción, Gardner, Dusan y Montoya (2016) utilizaron como herramienta una encuesta voluntaria, la cual fue aplicada a 180 instituciones educativas oficiales del Valle del Cauca, correspondientes a 112.470 estudiantes mujeres, de las cuales 605 se encontraban embarazadas, de este grupo fueron seleccionadas 564 que fueron entrevistadas por un profesional en psicología al inicio del año escolar y haciendo un proceso de seguimiento a lo largo del periodo lectivo, identificando la deserción escolar en este grupo, del total de las adolescentes escolarizadas embarazadas; el 24.6\% desertaron de la institución 


\section{LA DESERCIÓN ESCOLAR COMO PRETEXTO PARA CONVERSAR SOBRE IDENTIDAD, FAMILIA Y ESCUELA

educativa durante el periodo escolar; en el análisis de la información se encontró que las menores escolarizadas embarazadas con edades comprendidas entre los 16 y los 18 años desertan menos que aquellas que están entre los 12 y los 15 años y que a menor grado de escolaridad alcanzado durante el embarazo, mayor es la probabilidad de deserción, siendo este un elemento clave como factor de riesgo. El estudio concluye que se deben incentivar acciones preventivas del embarazo principalmente en los grados menores de secundaria.

En relación con las investigaciones presentadas anteriormente, se puede entender que el embarazo en adolescentes y la vulnerabilidad socio económica, son factores de riesgo que están presentes a nivel mundial, los cuales se convierten en factores de riesgo para que el adolescente abandone la escuela a temprana edad. Al retomar la deserción escolar a nivel global se comprende que existen factores que están asociados al fenómeno, como se puede evidenciar en las indagaciones, en algunas culturas el embarazo en la adolescencia tiene otras connotaciones para la futura madre, paso a la adultez, mejoramiento del estatus dentro de la comunidad entre otros mitos, sin embargo lo que dejan ver los estudios es que los jóvenes terminan abandonando sus estudios, porque no se evidencian iniciativas que prevengan y sancionen la violencia sexual en esta población, las jóvenes menores de 15 años son las principales víctimas. Colombia no es la excepción el embarazo se presenta en jóvenes de 12 a 18 años, en cuyo caso tanto el padre como la madre deben abandonar la escuela.

“De acuerdo con la Encuesta Nacional de Deserción Escolar (ENDE) del año 2010, cerca del 1,1\% de los estudiantes matriculados entre quinto y undécimo grado en establecimientos educativos oficiales, se han desvinculado del sistema escolar por esta causa."

La desescolarización en Colombia se convierte en un problema de orden sociopolítico, es una población susceptible de convertirse en víctima de reclutamiento por grupos al margen de 


\section{LA DESERCIÓN ESCOLAR COMO PRETEXTO PARA CONVERSAR SOBRE IDENTIDAD, FAMILIA Y ESCUELA

la ley, grupos delictivos organizados, víctimas de violencia sexual, sea forzada o por engaño, ya sea por condiciones personales o del contexto familiar en el que se encuentran o por enfrentar un embarazo en esta etapa de sus vidas (Ministerio de Educación, 2018)

A continuación se presentan estudios sobre suicidio en adolescentes y los factores que inciden en la toma de esta decisión. En los casos de suicidio en adolescentes existe un denominador común son cerebros en formación que se abruman fácilmente, la presión escolar, falta de madurez, criterio, capacidad en la toma de decisiones son factores que se consideran importantes en el momento que el adolescente toma la decisión de suicidarse.

Climent (2010) realizó un estudio epidemiológico que revela que la prevalencia de vida de las ideas suicidas mantiene un 15\% para las mujeres y $9 \%$ para los hombres. La prevalencia de vida para los planes y los intentos suicidas es de $4 \%$ siendo mayor entre las mujeres que entre los hombres; $60 \%$ de los adolescentes con planes suicidas realizaron un intento. Desde el momento en el que se contemplan las ideas suicidas, hasta el acto suicida transcurren doce meses. La edad de inicio de estas ideas suicidas ocurre alrededor de los 12 años. Este es un importante hallazgo pues plantea que la gran mayoría de los pacientes que terminan atentando contra su vida han consultado a un profesional. Muy a pesar de esa intervención terapéutica, en el curso de los siguientes 12 meses, atentaron contra su vida. La investigación plantea que la intervención terapéutica no puede solo estar centrada en los adolescentes, también propone convocar a las familias y las redes sociales en las que se encuentra para favorecer la disminución del riesgo de suicidio.

Estas cifras sobre la conducta de suicidio en adolescentes, representa un factor de análisis dentro de la deserción escolar, configura elementos de la identidad, la proyección vital y la dinámica relacional en la que se desarrolla el adolescente, los datos permiten definir los 


\section{LA DESERCIÓN ESCOLAR COMO PRETEXTO PARA CONVERSAR SOBRE IDENTIDAD, FAMILIA Y ESCUELA

riesgos en los cuales se encuentran los adolescentes y que pueden ser transformados desde la construcción de políticas públicas y educativas que se definan sobre protección y atención a las necesidades de los adolescentes, a partir de los recursos emocionales propios de esta etapa de vida.

Sumado a lo anterior, el suicidio en adolescentes está estrechamente relacionado con el matoneo, según la fundación Friends United Foundation y su departamento de Analistas en Violencia Juvenil y Delitos Contra Menores de Edad (2013), hicieron una encuesta en las principales ciudades de Colombia, la cual arrojo reveladoras cifras que evidencian el aumento de casos de matoneo y violencia escolar en los colegios de Colombia.

Entre los datos revelados por la encuesta se evidenció que una de las clases más comunes de matoneo son a causa de la homofobia con un 30\%, seguida de bullying racial (25\%), el ataque a personas hinchas de algún equipo contrario (20\%), rechazo o matoneo por alguna discapacidad con un $10 \%$ y el matoneo por aspecto físico con un $10 \%$. El bullying por alguna otra condición diferente a las nombradas ocupó un 5\% en la encuesta.

Otro factor de riesgo que incide en la deserción escolar es el trabajo infantil, según el DANE el año 2015, para la población de 5 a 14 años fue de 4,6 \% y presentó una disminución de 0,8 puntos porcentuales frente al cuarto trimestre de 2014 cuando había registrado 5,4\%, sin embargo, continúa siendo una cifra significativa para la población del país.

En un estudio realizado en el Colegio José Eustasio Rivera de Leticia (2016), denominado factores que inciden en la deserción escolar en el colegio Meléndez, con una muestra de 207 estudiantes de secundaria, de los cuales 75 asistían a la jornada matinal y 132 en la jornada nocturna. Como resultado, identificaron que de los estudiantes de la jornada matinal el 68.9\% eran hombres y el $31.1 \%$ mujeres, con rango de edades entre 13 a 18 años. De estos, el $89.4 \%$ 


\section{LA DESERCIÓN ESCOLAR COMO PRETEXTO PARA CONVERSAR SOBRE IDENTIDAD, FAMILIA Y ESCUELA

no había desertado de sus estudios, mientras que el 10.6\% lo había hecho en algún momento de su vida, por causa de la violencia escolar (8,5\%), las sanciones y castigos en la escuela $(6,9 \%)$, por padecer enfermedades $(7,6 \%)$, por fallecimiento de algún familiar $(7,2 \%)$ y la falta de apoyo familiar (6,9\%). Por otro parte los estudiantes de la jornada nocturna el 62,7\% eran hombres y el 37,3\% mujeres, con rango de edades entre 16 a 19 años, de los cuales el $86,7 \%$ había desertado de sus estudios, mientras que el 13,3\% no. Las principales causas para dicha deserción son los problemas económicos (12,8\%), embarazo a temprana edad (12,3\%), desmotivación $(11,8 \%)$, cambio de inmueble $(8,4 \%)$ y motivos pasionales $(7,9 \%)$

Los estudios referidos permiten tener una visión amplia de los factores que inciden en la deserción escolar en los jóvenes colombianos, encontrando que es un fenómeno multicausal, lo cual invita a realizar lecturas ecológicas sobre la deserción escolar, con todo lo anterior es importante comprender los factores de riesgo que se configuran a nivel social, familiar e institucional y los cambios propios de esta etapa.

Existe una estrecha relación en los factores que inciden en la deserción escolar y la población expuesta, los jóvenes (adolescentes) cuyas edades oscilan entre los 13 y los 18 años. Para las familias tener hijos adolescentes es preocupante, en muchas ocasiones no saben cómo abordarlos, los cambios físicos y de humor son constantes, generalmente el adolescente termina encasillado en el modelo de rebeldía y desacato a la norma, situación que permite hacer reflexiones acerca del papel de los padres en la educación y el acompañamiento y confianza que tienen con sus hijos, la escuela es el contexto que tienen para socializar, es el primer contacto que ellos tienen con el mundo exterior, el no contar con unas bases sólidas y una nutrición emocional los lleva a convertirse en personas vulnerables para enfrentarse al mundo social, el matoneo se ha convertido en un tema de moda en las escuelas, generalmente 


\section{LA DESERCIÓN ESCOLAR COMO PRETEXTO PARA CONVERSAR SOBRE IDENTIDAD, FAMILIA Y ESCUELA

los jóvenes que son víctimas de sus compañeros no se atreven a denunciar o de contarle a sus padres, en estos casos optan por no volver a la escuela inventando excusas para justificar su abandono, en otras ocasiones cuando los jóvenes no cuentan con la confianza y el apoyo de sus padres terminan por suicidarse porque la presión social es más alta que su autoestima y la capacidad de decisión para afrontar el problema.

Comprender las relaciones vinculares que se entretejen entre familia y escuela además de la forma como cada contexto puntúa al adolescente como un joven con mal comportamiento, y los conceptos que giran en torno a ellos como jóvenes difíciles, con problemas o rebeldes. Fonseca y Rodríguez, (2012) refieren que los contextos se ocupan de tratar la dificultad o el problema, llámese delincuencia, problemas de alcoholismo, drogadicción, problemas del comportamiento entre otros, pero no en su contexto relacional.

En el estudio realizado por Díaz (2006), se manifiesta que la escuela y la familia se han concebido como referentes de formación de educación del ser humano, conformando alianzas interconectadas en el tiempo, por periodos largos o cortos dependiendo del ciclo vital del sistema familiar y con pautas de relación que se mantienen a lo largo de la vida, convirtiendo estas dos instituciones en las instancias con mayores recursos para producir cambios. Sin embargo, en esta relación surgen diversos aspectos que dificultan la formación de los adolescentes y es así, cuando cada uno de los contextos empieza a inculpar al otro como artífice de las dificultades en la formación.

Se concluye que la deserción escolar en Colombia está asociada a múltiples factores y que se presenta en los primeros años de educación media. Igualmente se aborda la importancia que tiene la educación en los comportamientos reproductivos de los adolescentes, y en la forma como es asumida la maternidad y el cuidado del bebe, puesto que cuando la madre 


\section{LA DESERCIÓN ESCOLAR COMO PRETEXTO PARA CONVERSAR SOBRE IDENTIDAD, FAMILIA Y ESCUELA

cuenta con un nivel alto de educación menor es la mortalidad infantil y los problemas de desnutrición, lo anterior debido a que la educación es un vehículo para superar los círculos de pobreza y de exclusión social.

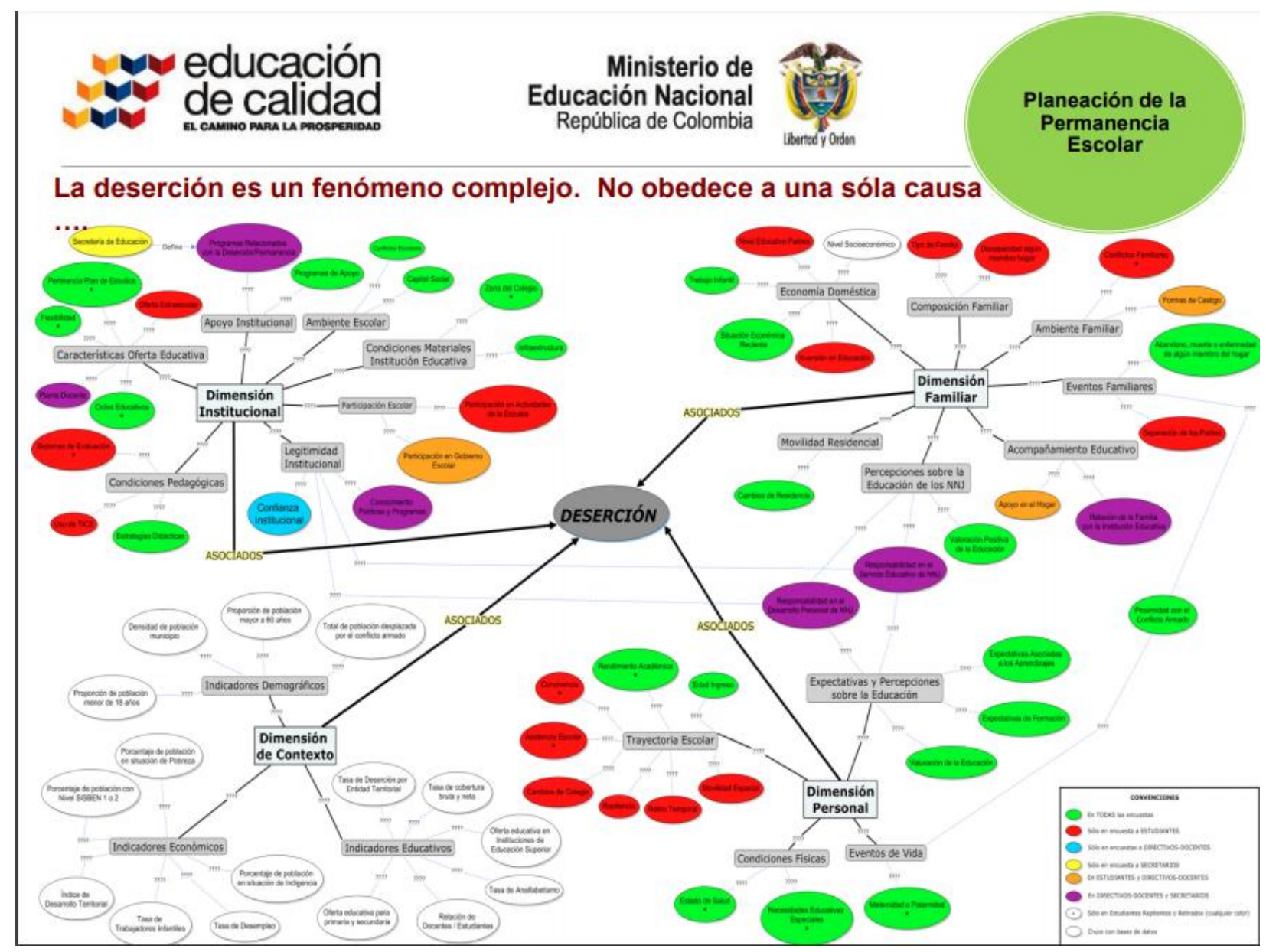

Figura 1. La deserción es un fenómeno complejo. No obedece a una sola causa. Adaptado de "Segundo encuentro de Secretarios de Educación", por el Ministerio de Educación Nacional, 2012.

En la Figura 1 se evidencian cuatro (4) dimensiones que están asociados a la deserción escolar. La primera dimensión es el "contexto social”, el cual aborda las condiciones políticas, socio económicas y culturales, de las cuales dependen las familias, ya sea en condiciones generales o particulares para la permanencia o de deserción del estudiante, a su vez se analiza la 


\section{LA DESERCIÓN ESCOLAR COMO PRETEXTO PARA CONVERSAR SOBRE IDENTIDAD, FAMILIA Y ESCUELA

interacción estudiante - institución, teniendo en cuenta la especificidad del campo educativo y las condiciones institucionales y académicas de las instituciones educativas.

La segunda dimensión es la “dimensión familiar”, en esta se lleva a cabo el análisis del proyecto de vida familiar. El rol de los padres y las dinámicas relacionales, por su parte el capital económico, refiere a las condiciones de ingreso familiar, condiciones de vida, nivel ocupacional, condiciones de la vivienda y el hacinamiento familiar, igualmente el capital cultural, contempla el nivel educativo de las familias, las prácticas culturales y el clima educacional y por último se encuentra el capital social, que refiere a como está estructurada la familia, la región de procedencia y la disposición de servicios básicos. A su vez el proyecto de vida familiar y el capital económico dan una idea de las percepciones y expectativas familiares, en torno a la educación, la toma de decisiones, el trabajo infantil.

Mientras que el capital cultural, habla de las interacciones de los padres con la escuela, la participación en actividades de seguimiento escolar, actividades extraescolares y en las asociaciones de padres de familia; el capital social, hace referencia a los eventos de vida de las familias como: muerte de familiares, pérdidas económicas, traslados a otras ciudades o desplazamiento forzoso.

La tercera dimensión es la "Personal "esta se enfoca en la demografía y las condiciones de diversidad. Edad, género, grupo étnico y discapacidad o capacidad excepcional.

En el desempeño de roles, se habla de la dependencia económica o eventos de vida enmarcados en el embarazo, la maternidad o paternidad temprana, el trabajo infantil y el estado civil, mientras que, en las motivaciones y expectativas, se tienen en cuenta las expectativas que tiene frente al estudio, la pertenencia y estima y la seguridad. Por otra parte, en cuanto a la trayectoria académica y antecedentes escolares, se encuentran asociados factores como extra- 


\section{LA DESERCIÓN ESCOLAR COMO PRETEXTO PARA CONVERSAR SOBRE IDENTIDAD, FAMILIA Y ESCUELA

edad, educación preescolar, repetición, desvinculaciones previas y rendimiento académico, en relación con las condiciones generales de salud la deserción se presenta por enfermedad o desnutrición en los niños.

Finalmente, el último factor lo constituye la dimensión "institucional educativa" compuesta por cuatro ítems características institucionales. Hacen referencia a la jornada y a la modalidad educativa. Las características de la gestión institucional, el profesional docente y directivo y los procesos académicos.

El conjunto de estas cuatro dimensiones amplía las comprensiones sobre el fenómeno de deserción escolar en Colombia y los riesgos que se encuentran asociados, lo que permite concluir que la deserción escolar es un fenómeno multicausal. La grafica muestra las cuatro dimensiones que intervienen en la deserción escolar, y la forma como se asocian entre sí. Se busca identificar los factores de riesgo y las condiciones de permanencia en el sistema educativo, la deserción escolar y la permanencia son fenómenos multidimensionales de contexto social regional, condiciones de las instituciones educativas, condiciones familiares y condiciones individuales, contexto social, condiciones políticas, socioeconómicas y culturales, las cuales tienen una fuerte incidencia en las condiciones familiares, por consiguiente, estas condiciones no facilitan la emergencia para que las familias puedan hacer un afrontamiento a la problemática de deserción, al tener incidencia en la familia, los efectos se ven reflejados en las condiciones individuales de los sujetos. Ahora bien, las anteriores condiciones están sujetas a nuevos factores como es la interacción estudiante- institución y las características de las instituciones educativas, todo este conjunto de condiciones y características son las que favorecen o impiden que haya deserción escolar o por el contrario favorecen la permanencia de los estudiantes en las instituciones educativas. 


\section{LA DESERCIÓN ESCOLAR COMO PRETEXTO PARA CONVERSAR SOBRE IDENTIDAD, FAMILIA Y ESCUELA

En el contexto familiar se encuentran nuevos factores como son: proyecto de vida familiar, capital económico, capital social, capital cultural, percepciones y expectativas, interacción padre- escuela y eventos de vida. Los anteriores factores son decisivos en el momento de tomar decisiones frente a una de estas problemáticas, las cuales conservan una estrecha relación, en ocasiones a nivel familiar se presenta más de una de estas condiciones que obligan a la familia a tomar decisiones frente a la permanencia o abandono de su hijo de la institución educativa.

En cuanto a la dimensión individual está orientada a factores demográficos y de diversidad, desempeño de roles, dependencia económica y expectativas, eventos de vida, trayectoria económica, formación extraescolar y condiciones generales de salud, como se había mencionado anteriormente la dimensión familiar e individual conservan una estrecha relación, se puede decir que existe una dependencia que influye en las dos dimensiones posibilitando o anclando al estudiante y a su familia, si uno de estos factores se hace presente.

En cuanto a la dimensión institución educativa se tiene las características institucionales, específicamente la jornada escolar, las características de gestión institucional con las características de eficacia y eficiencia escolar, el personal docente y directivo, la experiencia, la motivación y el compromiso, los procesos académicos; las características socio económicas de la población estudiantil, el clima escolar, condiciones de conflictividad, recursos; infraestructura y materiales, estas características inciden directamente en el desempeño de los estudiantes, cuando la institución cumple con las expectativas de los estudiantes y las dificultades son inferiores a las ganas de aprender es muy posible que no haya deserción escolar, por consiguiente esta dimensión aunque juega un papel primordial en la vida de los estudiantes es la que menos incidencia tiene en el fenómeno de deserción escolar. Ahora bien, si se analizan la deserción escolar a nivel global y a nivel nacional se puede evidenciar que 


\section{LA DESERCIÓN ESCOLAR COMO PRETEXTO PARA CONVERSAR SOBRE IDENTIDAD, FAMILIA Y ESCUELA

existen factores comunes: embarazo en adolescentes, trabajo infantil, violencia intrafamiliar, suicidio entre otros factores que se hacen presentes en las familias y en la vida de los adolescentes para que tomen la decisión de abandonar sus estudios temporal o definitivamente.

\section{Relación joven, familia e institución educativa en torno a la deserción escolar}

En este apartado se busca entender la vinculación que tiene la familia con la escuela, las relaciones que se entretejen entre los dos contextos, con el fin de generar espacios que propicien el aprendizaje, la convivencia y la socialización dentro de la institución educativa. El papel relacional que juegan las familias y los contextos escolares para que el joven se mantenga en el sistema educativo, busca crear escenarios de apoyo y comprensión frente a las problemáticas que los jóvenes tienen al sentirse confundidos, solos o incomprendidos, sirviendo como contexto de cambio desde el que los dilemas se afrontan y se continua con la perspectiva de vida. El objetivo de la investigación -intervención es comprender como se relacionan la familia y la escuela como contextos que trabajan de manera interrelacionada dando respuesta a la retención y permanencia de los jóvenes en las instituciones educativas. En este ejercicio es importante pensar el grado de responsabilidad que tiene cada uno de los actores que participan en el proceso educativo.

Dabas (1988) menciona que "constantemente se escucha la necesidad de modificar las relaciones entre la escuela y la familia." Sin embargo ese cambio necesita del compromiso de cada uno de los actores que participan en el proceso educativo; este cambio es posible cuando se establecen formas de relacionarse padres y docentes y de las percepciones que se tiene de las familias y el rol que debe tener la familia en la educación de los hijos, de igual forma saber cuál es el papel de la escuela, puesto que si se sigue considerando la transmisora del conocimiento o si por el contrario permite la construcción, búsqueda y 


\section{LA DESERCIÓN ESCOLAR COMO PRETEXTO PARA CONVERSAR SOBRE IDENTIDAD, FAMILIA Y ESCUELA

creación del conocimiento, en este sentido se puede decir que falta construir un trabajo en red, en donde el conocimiento no se centre de manera jerárquica, por el contrario que permita que el conocimiento se construya en la relación que se establece entre las personas y el mundo que las rodea, en el cual interviene la cultura, el medio ambiente, respetando la diversidad y coconstruyendo con un fin común, modificar la relación entre dos contextos con el fin de sentar nuevas bases para los futuros estudiantes.

La encuesta realizada en el año 2009 sobre las pruebas PISA a los estudiantes de diferentes colegios del país, refieren que los resultados están condicionados a varios factores. Los profesores, los compañeros o el contexto escolar. La encuesta busca conocer la opinión de los jóvenes de 15 años sobre lo aprendido en la escuela y la utilidad que tiene en el contexto inmediato y a futuro.

La evaluación realizada a los estudiantes indaga sobre la incidencia de la escuela y su preparación para la vida adulta luego de dejar la escuela o si por el contrario ha sido una pérdida de tiempo, igualmente pregunta a los estudiantes si la escuela ha contribuido a darles confianza para tomar decisiones y se les ha enseñado cosas que puedan ser útiles en el momento de conseguir un empleo.

En la mayoría de los países los estudiantes que se desempeñaron bien en la prueba de lectura tienden a afirmar que la escuela es útil (PISA, 2013).

La adolescencia es una etapa que quiere ser ella misma, romper el cordón umbilical que vincula al joven con los padres para el adolescente no es un camino fácil, los jóvenes se emancipan, pero existen padres que les resulta difícil distanciarse. Ellos buscan independencia. Algunos se inician con el consumo de alcohol, el consumo de anfetaminas, trasgresión a las normas con el fin de mostrarle al grupo de amigos que ya no son los niños de antes, iniciándose de esta manera en la construcción de su identidad. 


\section{LA DESERCIÓN ESCOLAR COMO PRETEXTO PARA CONVERSAR SOBRE IDENTIDAD, FAMILIA Y ESCUELA

Urria (2014), plante que una buena relacione entre padres y adolescentes esta mediada por la confianza, y el tiempo diario y de calidad, se puede conocer a los hijos, se puede caminar y disfrutar juntos, sin confundir el ser amigos con ser colega, pues los padres han de marcar límites. Todo adolescente tiene derecho y precisa de un espacio personal, donde su intimidad sea respetada, donde pueda encontrarse consigo mismo. Quizás en la adolescencia, éste recluirse en sí mismo conlleve momentos de angustia, que han de ser acompañados desde el respeto y la distancia por los padres, pero ayudan a crecer. Para lograr un desarrollo equilibrado en los adolescentes, es preciso incrementar la comunicación (no trivializarla), compartir el tiempo de ocio, potenciar en él la voluntad y el autodominio, la motivación, impedir que se quemen etapas demasiado rápido.

De acuerdo con los razonamientos que se han venido realizando, la mayor parte de los problemas que se presentan en el sistema familiar están relacionados con el control extremo que los padres quieren tener sobre sus hijos, les exigen que adopten normas disciplinarias y que desarrollen hábitos. Sin embargo, se encuentra una comunicación doble vincular o confusa puesto que por una parte se quiere controlar al adolescente en todos los ámbitos sociales y por otras se hacen reclamos y exigencias porque no asume responsabilidades, cuando los padres no asumen un discurso coherente se infringen castigos y maltrato a los hijos, rompiendo los vínculos emocionales que una vez los unieron, generando distanciamiento tal y como se evidencia en el caso de investigación- intervención, en el cual existe mucha exigencia pero no existe un ambiente favorable para el desarrollo de identidad de la adolescente.

Los estudios revisados entorno a la etapa de la adolescencia y la relación entre el joven, la familia y el contexto educativo, permite entender esta dinámica como un atrapamiento para el 


\section{LA DESERCIÓN ESCOLAR COMO PRETEXTO PARA CONVERSAR SOBRE IDENTIDAD, FAMILIA Y ESCUELA

adolescente del cual es difícil salir. Comienza con las exigencias del contexto escolar y continuo con las expectativas de la familia entorno a lo que debe hacer el adolescente. El hecho de crecer provoca tensiones para el implicado y para su contexto familiar y social, es inevitable pensar en el proceso metamórfico que afrontan los adolescentes, dejar de ser niño y salir de su zona de confort es un proceso doloroso pero gratificante que le permite encontrarse así mismo e ir construyendo su proceso identitario.

Las redes sociales son un excelente medio para la construcción de relaciones sociales que permite que la realidad se viva negociando constantemente, existe temor en los padres por el excesivo uso de esta herramienta ya que los adolescentes se ven expuestos a mayores riesgos, como usuarios que crean perfiles falsos, otros que solicitan información personal para ser usada para otros fines o intentar dañar la reputación de los jóvenes, sin embargo la mayoría de ellos conocen los peligros que se pueden presentar por esta razón piden la ayuda de sus padres para estar protegidos, mientras que en otras familias se vivencian diferentes experiencias que están relacionadas con el uso y el abuso de la tecnología, en los hogares la comunicación es limitada, puesto que las redes sociales invadieron los espacios más íntimos de la familia generando una fractura en las relaciones familiares y sociales, en el caso de la adolescente las redes sociales fue el recurso que ella utilizo para mantener contacto con algunas personas, sin embargo este espacio era revisado constantemente por la madre quien no permitía que su hija tuviera una vida social aunque fuera en redes sociales, situación que generaba conflicto y distanciamiento en la relación madre e hija.

Para concluir, en el recorrido del estado del arte se pudo evidenciar que no existen datos que hablen específicamente del rol de las instituciones educativas y su relación con la deserción escolar, sin embargo se identificaron aspectos socio económicos, la calidad de los 


\section{LA DESERCIÓN ESCOLAR COMO PRETEXTO PARA CONVERSAR SOBRE IDENTIDAD, FAMILIA Y ESCUELA

contenidos impartidos, el nivel académico de la última institución en la que estuvo

matriculado el adolescente, las actividades extraescolares y el recurso humano, los cuales son considerados factores que inciden en la deserción escolar, en relación con la familia, se puede comprender que el apoyo escolar que reciben los estudiantes al asistir a clase se ve reflejados en la motivación y el rendimiento académico, el cual permite que el estudiante se sienta a gusto en el colegio, por último se entiende que la relación familia y escuela son distantes, la escuela debe mantener una estrecha relación con las familias, de manera que los dos sistemas promuevan lasos de cooperación hasta conformar redes vinculares que brinden soporte a los estudiantes.

\section{Tendencias y comprensiones de la deserción escolar}

En este sentido se mira al Estado y a los gobiernos no sólo como los garantes de la disponibilidad, el acceso, la permanencia y la calidad de la educación, sino en su perspectiva de orientadores y planificadores de las políticas públicas para la sociedad como los mayores responsables del estado de cosas en una sociedad. Es claro que se ven las acciones y las políticas de educación, en torno del estudiante y su permanencia en el sistema escolar.

Existe preocupación de los gobiernos en relación con el fenómeno de deserción escolar. Entendiendo que no existen estudios que planteen soluciones concretas a la problemática, se hace una caracterización de las familias y los dilemas que inciden en los jóvenes para que tomen la decisión de abandonar el sistema escolar, sin embargo, la problemática es diferente en cada país y la respuesta de acción depende de las políticas que el Estado tenga contempladas para tal fin. En el caso de Colombia la Constitución Política en el Artículo. 67 es muy contundente en lo referente al derecho de los colombianos a la educación, sin embargo los resultados muestran otra realidad (Corte Constitucional, 1991). 


\section{LA DESERCIÓN ESCOLAR COMO PRETEXTO PARA CONVERSAR SOBRE IDENTIDAD, FAMILIA Y ESCUELA

Lo expuesto anteriormente permite concluir que al respecto se puede hacer una comprensión ecológica de la realidad en la que intervienen diferentes sistemas de manera que unos contienen a otros, se establece un orden jerárquico de dependencia, que invita a visualizar la problemática como fenómeno eco-eto-antropológico complejo, con diversas posibilidades de solución; el artículo 67 de la constitución política de Colombia, refiere el papel que tiene la educación con respecto a los derechos que adquieren los ciudadanos colombianos, a que sean respetados los derechos a la educación, al trabajo, la recreación, a los avances científicos y tecnológicos, la protección del medio ambiente y habla de los contextos sociales, Estado, sociedad y familia, ellos están encargados y son responsables de velar y garantizar la educación desde los 5 años hasta terminar la media vocacional de manera gratuita en las instituciones estatales, sin embargo en el fenómeno de investigación esta lectura ecológica de lo plasmado en el artículo 67 no corresponde con la realidad que viven las familias colombianas, no existe una coherencia entre lo que está escrito y lo que se vivencia en las diferentes zonas del país. Al observar el fenómeno de la deserción escolar en los jóvenes versus los avances tecnológicos y el auto aprendizaje, permite plantear interrogantes acerca de cómo están los adolescentes vivenciando la educación convencional frente a las expectativas que tienen para su perspectiva vital y las posibilidades de acceder a la educación superior, o de desempeñarse en un oficio especifico que le permita generar procesos de autonomía e identidad, en este sentido la investigación- intervención propone crear espacios conversacionales reflexivos que promuevan nuevas posibilidades para que la adolescente continúen el proceso de formación, adquiriendo múltiples conocimientos y desempeñándose en tareas que sean de su agrado, permitiendo de esta manera el empoderamiento de su proceso de autonomía sin que ello implique abandonar la educación, 


\section{LA DESERCIÓN ESCOLAR COMO PRETEXTO PARA CONVERSAR SOBRE IDENTIDAD, FAMILIA Y ESCUELA

por lo tanto se reconoce la importancia de escuchar la voz del adolescente, sino también de la familia y la institución educativa.

\section{Sistema Teórico}

El presente capítulo, se construye con el propósito de indagar y comprender en los constructos teóricos, el fenómeno de deserción escolar desde la perspectiva epistemológica y paradigmática que brinda el enfoque sistémico construccionista-constructivista complejo.

\section{Comprensiones sobre la construcción de identidad}

Desde el paradigma de la complejidad, se define como la visión que cada ser humano tiene de sus múltiples identidades (Morín 1990). La complejidad nace de la simplicidad en la emergencia de la cotidianidad en diferentes contextos, en la interacción con los otros donde se entretejen relaciones que llevan a construir diferentes mundos y especialmente durante la adolescencia, la cual, es un momento donde los cambios del ciclo vital se experimentan como un reto frente a la generación y emergencia de estrategias de afrontamiento de tipo familiar y personal.

La construcción identitaria de la adolescente nace en la cotidianidad y se complejiza en la medida que emerge en el mundo social, proceso que exalta acontecimientos que van desde lo ridículo hasta las experiencias más sublimes las cuales empiezan a tener significados particulares para el sujeto (Morin 1990). En la vida cotidiana, cada individuo juega distintos roles en diferentes ámbitos interactuando con personas del medio laboral, social y hasta los mismos desconocidos quienes se convierten en un mundo de fantasmas y de sueños que acompañan la vida.

Así las interacciones son un punto clave para la comprensión de la construcción de los procesos identitarios desde la complejidad, Morín (2004, citado por Barberousse, 2008) 


\section{LA DESERCIÓN ESCOLAR COMO PRETEXTO PARA CONVERSAR SOBRE IDENTIDAD, FAMILIA Y ESCUELA

refiere que la complejidad nace de la interacción de las partes que componen el sistema complejo, es decir, aparece como el resultado de la organización del todo bajo las combinaciones e interacciones que forman la parte constitutiva del mismo y así se establecen los procesos identitarios en las interacciones de sentidos y significados que emergen de las relaciones y los múltiples contextos.

Lo expuesto anteriormente, permite comprender que el ser humano se constituye como un sistema auto organizado, el cual se va construyendo a sí mismo de manera constante siendo un sistema dinámico, con una relativa independencia respecto al contexto lo que permite evolucionar y construir su propia identidad, por medio de la apertura comunicacional que mantiene consigo mismo y con otros contextos.

De la misma manera, se retoma a Bruner (1969, citado por Estupiñán y González, 2012) quienes refieren que la narrativa es un instrumento simbólico de la cultura a través del cual se construye, reproduce, mantiene y transforma la realidad e identidad de los seres humanos. Todo esto de manera colectiva, social y cultural, mediado por un proceso dialectico a través del cual el "self" adquiere sentido.

Desde esta perspectiva, la construcción de la identidad permite entender lo que se es como persona y también como cada ser humano se reconoce a partir de la construcción que hace de su ser y su ambiente social comenzando en el ámbito familiar, seguido del contexto escolar y continuando con las relaciones y las interacciones a lo largo de la vida. Por tanto, las interacciones que construyen al sujeto, las experiencias vividas y el entramado de significados van a influir en la manera como se actúa.

En este mismo orden de ideas se comprende la influencia que tiene la cultura en la construcción narrativa como lo plantea Spratly (1979, citado por Estupiñán y González, 


\section{LA DESERCIÓN ESCOLAR COMO PRETEXTO PARA CONVERSAR SOBRE IDENTIDAD, FAMILIA Y ESCUELA

2012), al considerar que la cultura permite pensar en un sistema compartido de significados y de formas que le dan sentido a la vida, mediado por todos los aspectos, proporcionándole un significado a toda la experiencia, seleccionándola y organizándola. Por consiguiente, las narrativas son parte de un proceso de socialización con sus semejantes en diferentes contextos siendo susceptibles a múltiples interpretaciones de acuerdo con las experiencias. La forma de expresar todo ese mundo interno es la narrativa, a través de la cual se construye, reproduce mantiene y transforma la realidad de los grupos y sus integrantes dándoles forma y sentido a la vida.

El construccionismo social considera la identidad como un proceso elaborado mediante la interacción social trasmitido culturalmente e interpretado por cada individuo (Payne, 2012). En este sentido, posee una visión cambiante, compleja e interactiva de los seres humanos mediados por la individualidad y las redes sociales que cada uno maneja.

Slugoski y Ginsburg (1989, citados por Linares, 1996) refieren que al hombre le surgen diferentes interrogantes por saber qué cambia o qué permanece, qué se asemeja o qué lo diferencia de su contexto y cuáles son las experiencias que le dan sentido y que constituyen el núcleo de la identidad. La identidad también se traduce en una relación consigo mismo, en la conformación de su personalidad. Linares (2012) refiere que la identidad es cambiante, los cambios se producen lentamente y no se presentan porque alguien los imponga, es susceptible a relaciones negativas, se limita a temas delimitados y definidos como el género, la orientación sexual, la política y la religión entre otras, de hecho, la narrativa identitaria está estrechamente anclada a la personalidad, los sujetos se reconocen en todas las narraciones, pero especialmente con las que se siente identificado. 


\section{LA DESERCIÓN ESCOLAR COMO PRETEXTO PARA CONVERSAR SOBRE IDENTIDAD, FAMILIA Y ESCUELA

Por su parte la narrativa se entiende como la experiencia relacional, que se va complejizando a lo largo de la existencia desde la concepción hasta la vejez, la narrativa es una parte constitutiva de la personalidad mediatizada por un proceso que dura toda la vida. Linares (2012) explica la forma como los bebés y los niños se convierten en máquinas narrativas capaces de construir infinidad de historias a través de las cuales se conjugan ideas, afectos y comportamientos, con una estructura coherente de significado, de sentimiento y de afecto aportando una dimensión pragmática en el plano de las relaciones. Complejizar es garantía de equilibrio, de salud mental y de madurez; adquirida por el individuo en narraciones diversas de su realidad relacional.

Para finalizar se puede decir que la identidad se construye en la relación del individuo con su entorno, a partir de los procesos comunicacionales. En esta construcción se concibe al individuo como un narrador de historias, contadas en orden, con coherencia y significado a cerca de su experiencia vital. En este proceso la familia es considerada el primer contexto y fuente principal para la construcción de los procesos identitarios.

\section{La Narrativa}

Tanto la identidad como la narrativa son el resultado de la relación del sujeto con la sociedad a lo largo de las etapas del ciclo vital, las cuales proceden de las experiencias acumuladas a partir de la interacción con el medio social. Narrar es colocar un conjunto de acontecimientos de manera secuencial orientados al cambio.

Ramos (2001) menciona que el proceso narrativo tiene una serie de órdenes, el orden cronológico, el cual menciona que en una narración existe una temporalidad, hay cosas que pasaron antes, otras que se presentaron en simultáneo y otras que ocurren después. El orden lógico, dice que en la narración suceden cosas lógicas y cosas que suceden con la lógica, por 


\section{LA DESERCIÓN ESCOLAR COMO PRETEXTO PARA CONVERSAR SOBRE IDENTIDAD, FAMILIA Y ESCUELA

consiguiente, debe ser verosímil para generar algún tipo de convicción. El orden

configuracional, es el orden en que sucedieron los acontecimientos y cómo se cuenta lo que sucedió. El orden interactivo, el cual se debe ir configurando, ya sea para la persona que narra o para el terapeuta.

Para Linares (1996) las narraciones familiares, se distribuyen en grandes rasgos, inicialmente a través de la familia de origen, la pareja y la familia nuclear se configuran las vivencias y creencias de los hijos, las experiencias infantiles que se caracterizan en las relaciones entre progenitores y hermanos y finalmente, las personas significativas del núcleo familiar.

Las familias son grupos con identidad propia, desde este contexto se inicia un hilo conductor que viene de la infancia y que es más grueso o débil en la medida en que se fortalezca el sistema de relaciones parentales, la comunicación y la interacción.

La narrativa de la adolescente es interpretada como una forma de aproximación a la realidad de acuerdo con los recursos que tiene a sus alcances justificados por las condiciones del contexto social y familiar. El pensamiento narrativo según lo refiere Bruner, (1998, citado por Riveros \& Garzón, 2014):

No está interesado en generar certezas sino perspectivas múltiples o cambiantes, ensanchando así el abanico de realidades posibles; sitúa a la persona como protagonista de su propio mundo, un mundo de actos interpretados, de significados construidos y trasformados en relación con otros en un contexto determinado (pp. 215).

La construcción narrativa corresponde a un proceso evolutivo que emerge en el sistema más próximo para los sujetos y la familia, permeándose y alimentándose de acuerdos lingüísticos más amplios como por ejemplo los ofrecidos por las instituciones educativas, lo 


\section{LA DESERCIÓN ESCOLAR COMO PRETEXTO PARA CONVERSAR SOBRE IDENTIDAD, FAMILIA Y ESCUELA

que lleva a rescatar los acuerdos, límites, descripciones y comprensiones en torno al adolescente y su identidad.

Para entender la construcción de la identidad se retoma a Echeverría (1994) quien plantea que:

la ontología del lenguaje representa un esfuerzo por ofrecer una nueva interpretación de lo que significa ser humano, interpretación que reivindica situarse fuera de los parámetros del programa metafísico que ha servido de base durante largo tiempo a la forma como observamos la vida y entenderlo desde la comprensión del lenguaje como organizador y transformador de la identidad, él postula que el lenguaje es acción y, por lo tanto, evita la separación entre ambos, particularmente entre el pensamiento y la acción, planteando que "la acción genera ser y que ésta, constituye al individuo que habla y al que actúa” (pp. 64). El autor sostiene que además de intervenir en la creación del futuro, los seres humanos modelamos nuestra identidad y el mundo en el que vivimos a través del lenguaje. La forma como operamos en el lenguaje es el factor quizás más importante para definir la forma como seremos vistos por lo demás y por nosotros mismos, puesto que por medio de este descubrimos y construimos la identidad personal y la de los demás, convirtiendo la realidad en un fenómeno estrictamente lingüístico.

Linares (1996) la define como el núcleo de la mente, el producto de la decantación de la experiencia, en este caso, el ser, permanece constante al reconocerse a sí mismo, lo que lo hace resistente al cambio, mientras que las narrativas son negociables para aquellos sujetos que sienten que su identidad está siendo atacada, de esta manera la defienden encarnizadamente en batallas que ponen en juego su propia supervivencia. 


\section{LA DESERCIÓN ESCOLAR COMO PRETEXTO PARA CONVERSAR SOBRE IDENTIDAD, FAMILIA Y ESCUELA

Lo anterior, también es sustentado bajo la propuesta de Echeverría (1994), quien describe que el lenguaje nace de la interacción social entre los seres humanos. En consecuencia, el lenguaje es un fenómeno social; fuera del lenguaje no existe un lugar en el que podamos apoyarnos para poder construir acuerdos sobre la experiencia vital. Esta investigaciónintervención, retoma el lenguaje como el camino de comprensión, creación y transformación de la realidad, posibilitando aperturas conversacionales alrededor de la experiencia de deserción escolar, la cual está alejada de descripciones sociales deficitarias y entendiendo cuales son las posibilidades de transformación y cambio que pueden emerger.

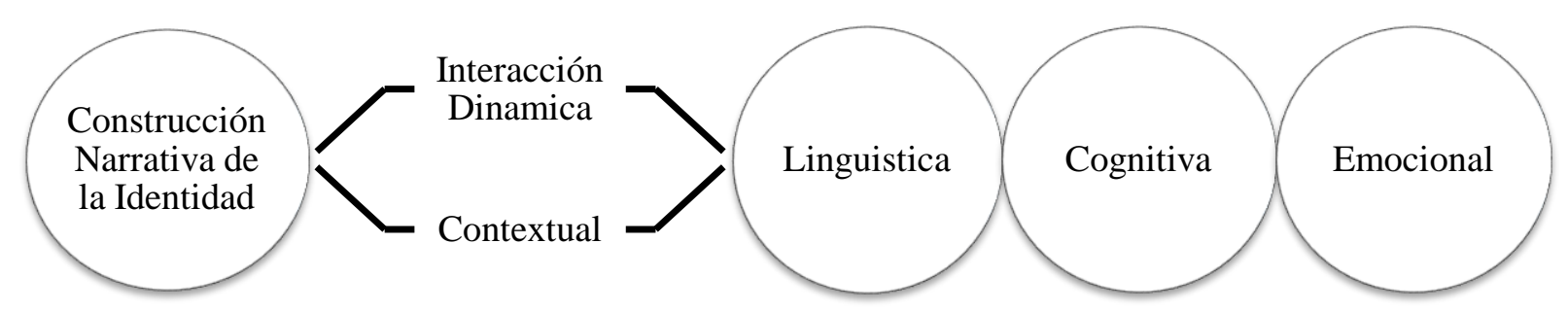

Figura 2. Construcción narrativa de la identidad en adolescentes. Fuente Propia, 2018

En la figura 2, se presentan los elementos expuestos anteriormente permitiendo realizar una lectura alrededor de la construcción narrativa de la identidad desde la comprensión del entramado dinámico, reciproco y contextual que organizan las experiencias lingüísticas, cognitivas y emocionales de los adolescentes, entendiendo que la construcción narrativa sugiere modos de operar en la experiencia vital del adolescente y también estas interacciones definen y constituyen la identidad de este.

Teniendo en consideración todas las comprensiones expuestas sobre la construcción narrativa de la identidad, se entiende la adolescencia como una categoría del ciclo vital, en la que el hito más grande, es el desarrollo o construcción de la identidad. El adolescente siente la necesidad de saber ¿quién es?, así como de merecer respeto y amor por parte de las personas 


\section{LA DESERCIÓN ESCOLAR COMO PRETEXTO PARA CONVERSAR SOBRE IDENTIDAD, FAMILIA Y ESCUELA

que lo rodean identificándose con sus padres o adultos de su entorno. Se entiende que la construcción narrativa se da en relación con un conjunto de características propias de un individuo o de un grupo que le permite distinguirse de otros, esto a partir de la comprensión de que estos se encuentran inmersos por lo menos en dos contextos. El primero, es el contexto más cercano conformado por la familia y el segundo, es el contexto amplio en el que están inmersos otros escenarios tales como la escuela, la religión, los partidos políticos, entre otros.

Ahora bien, la familia tiene un rol fundamental en el proceso de la construcción narrativa de los sujetos y principalmente en la relación madre e hijo por la vinculación afectiva que se da desde los primeros años de vida. Por su parte, la adolescencia es la etapa en la que los sujetos empiezan a interactuar en diferentes contextos y a socializar con diferentes grupos permitiéndoles tomar decisiones acerca de sus intereses personales y particulares, siendo esta, una etapa inconclusa que puede abarcar todo el ciclo de vida construyéndose a partir de la historia de vida de manera personal.

Considerando todo lo anterior, las historias de los actores de la familia adquieren sentido y significado para aquel que lo narra. Cada sujeto tiene su propia verdad de acuerdo con su experiencia de vida, sin embargo, se generaron consensos encaminados a solucionar el problema y proyectarse a futuro.

Retomando a Morín (2001) citado por García (2008) y las comprensiones que la terapeuta hace, en relación con la técnica utilizada mediante el bucle recursivo, a partir de la pregunta ¿Quién soy yo? la relación que tiene con el mundo y con los otros, posibilitando una relación con la respuesta evolutiva de identificación de gustos, acuerdos e intereses particulares que comienza a generarse en la familia durante la infancia y luego se nutre por los contextos más amplios como el contexto escolar. El bucle recursivo, convoca a reconocer los puntos de la 


\section{LA DESERCIÓN ESCOLAR COMO PRETEXTO PARA CONVERSAR SOBRE IDENTIDAD, FAMILIA Y ESCUELA

historia personal que emerge en la interacción social y que puede llegar a alimentar narrativas identitarias de seguridad, confianza y autonomía.

Finalmente los procesos narrativos de los individuos son un mecanismo para construir la realidad, y por tanto las mismas dependen de las experiencias de vida y el contexto en el cual se encuentran las personas. Ahora bien, las narrativas se evidencian en relatos emergentes y dominantes los cuales son de vital importancia para el terapeuta ya que a partir de estos se direcciona el proceso de acompañamiento, en el cual se generan historias alternativas, que reconstruyen la forma de significar y comprender el problema y los acontecimientos para permitir que el problema deje de ser protagonista y de paso a narrativas alternas.

\section{La Adolescencia}

Para entender la adolescencia se retoma a Hernández (2003), quien manifiesta que los adolescentes y hasta los adultos están siendo consumidos por la globalización, el ser humano gira y vive en un mundo lleno de preocupaciones materiales y físicas dejando a un lado aquellas experiencias que no tienen precio económico pero que se desarrollan en todo el proceso de la vida diaria, a través de las relaciones sociales, se encuentran amistades que permiten establecer un vínculo de aceptación importante, lo que significa que las acciones están en concordancia con los consensos sociales.

Las experiencias adquiridas a través de los años van forjando en los adolescentes sus procesos identitarios, inicialmente entender que los cambios fisiológicos, cognitivos y la interacción con el medio social generan desajustes en las normas y reglas que se establecen en la familia, sin embargo esta situaciones han generado una fractura del vínculo afectivo que antes los unía, este es un periodo de transición para el adolescente, los jóvenes reclaman la presencia de los padres, además de pedir que respeten sus gustos en el vestuario, la música, 


\section{LA DESERCIÓN ESCOLAR COMO PRETEXTO PARA CONVERSAR SOBRE IDENTIDAD, FAMILIA Y ESCUELA

los tatuajes, la comida y en general la nueva construcción de mundo, pues este es un gran paso en la construcción de su identidad.

De la misma manera Lillo (2002), menciona que existen momentos de regresión al mundo

infantil, que los llevan a repetir algunas experiencias vividas durante los cinco primeros años de vida, pero ya en otro plano, convirtiéndose en un vaivén hacia diferentes mundos infantiles, de esta manera cada paso a la construcción de la madurez genera ansiedad, confusión, desorganización, y un constante retorno a la infancia que lo lleva a debatirse entre el mundo infantil y avanzar hacia el mundo adulto.

En esta transición del mundo infantil a la madurez se presenta una oportunidad que le permite al adolescente tener al pasado disponible en el presente para transformar y reinterpretar eventos que marcaron su vida, porque ya ha adquirido las habilidades necesarias para su afrontamiento.

La adolescencia representa una etapa importante en lo que se conoce como desarrollo humano, Gómez \& Carrasco (2010), lo definen como un periodo complejo en el que se resignifica lo que fueron los elementos que conformaron el mundo infantil, es una etapa de conflictos porque implica dar el paso a la significación de su identidad, a nivel familiar le implica desprenderse de lazos a los que estaba sometido y acostumbrado, requisito fundamental para desempeñar roles de adulto en el contexto social.

El adolescente en esta etapa va construyendo su versión de sí mismo, de acuerdo con su realidad, en un primer momento defiende o ratifica su criterio frente al acto de resignificar al otro en toda su dimensión, esto implica reflexionar sobre sí mismo, sobre la cotidianidad, los eventos que suceden en el mundo y sobre la familia, se vuelve crítico, contraria las leyes, en este sentido aparecen diferentes tendencias y exigencias sociales, la belleza corporal, el 


\section{LA DESERCIÓN ESCOLAR COMO PRETEXTO PARA CONVERSAR SOBRE IDENTIDAD, FAMILIA Y ESCUELA

cuidado del cuerpo y la moda, generando en el contexto familiar conflicto porque se considera una etapa en la que los jóvenes pierden el tiempo y descuidan otros deberes como el estudio o los deberes del hogar.

Por su parte, Hernández (2009) menciona que la etapa de la adolescencia causa temores a padres y maestros, debido al significado que se ha construido en relación a la brecha generacional, asociada a una situación de ruptura, conflicto y riesgo. Siendo esta una etapa que requiere de muchos más ajustes, los jóvenes maduran más rápido y se empieza a consolidar el cambio de identidad individual, valorando más las apreciaciones de sus pares que las de su sistema familiar. Llevando a que se incrementen los conflictos padres e hijos, se cuestionan las normas y se generan diferencias en creencias de la vida, llevando al adolescente a desencadenar conductas de rebeldía, siendo este el inicio de problemas más graves que vienen a ser reflejados en la edad adulta.

En concordancia con lo expuesto anteriormente Velásquez (2007) menciona, la adolescencia es considerada como una etapa vital de transición social y psicológica en la que el adolescente se prepara para asumir el rol de adulto, productor de una sociedad, responsable de una familia, se considera que esta edad está en un rango de 15 a 21 años, inducida por cambios fisiológicos y hormonales que conducen a una orientación física y sexual, los cuales son asumidos de maneta variable de acuerdo a la cultura, la edad y la clase social y la época histórica en que este viviendo el adolescente.

De igual forma en la etapa de la adolescencia se encuentra una convergencia entre los autores que trabajan esta parte del ciclo vital, siendo así como Frachia (2015) aborda la adolescencia como los cambios evolutivos que afectan a todas las generaciones del sistema familiar, el adolescente debe encontrar su propia identidad, dejar de lado su narcisismo 


\section{LA DESERCIÓN ESCOLAR COMO PRETEXTO PARA CONVERSAR SOBRE IDENTIDAD, FAMILIA Y ESCUELA

infantil, desarrolla las habilidades sociales y tomar distancia del sistema familiar para ser más independiente, igualmente implica la ruptura padre e hijo, promueve una gradual negociación de ese vínculo, desde la autoridad de la niñez hacia una reciprocidad en la edad adulta, se promueve el aprendizaje, la aceptación de las reglas sociales, una de las características del adolescente es querer ser el centro de atención familiar.

Se concluye que, la adolescencia es una etapa importante del desarrollo humano en la que surgen los conflictos a nivel familiar, se presenta un desprendimiento de los lazos a los que estaban sometidos parentalmente, se presenta una confrontación personal entre el mundo infantil y el mundo adulto generando confusión en el adolescente, se encuentra más afinidad con los pares, lo que genera fractura en el sistema relacional familiar, optando por tomar distancia para ser más independiente, en una etapa en la que el adolescente desarrolla habilidades sociales dando continuidad a su construcción identitaria y de preparación para la vida adulta.

\section{Deserción escolar}

El fracaso escolar es un término que plantea que un estudiante no cumplió con todos los logros académicos establecidos por la institución educativa, tales como los parámetros de edad, su historial académico, y el nivel socio-económico establecido en el currículo de la institución, así mismo el fracaso escolar es comprendido como una perturbación en el proceso escolar el cual puede expresarse en repitencia o en deserción, lo que puede ser un desencadenante de posteriores fracasos personales y académicos, los cuales pueden dar paso a la deserción o a desistir de la escolarización, así lo plantean García \& Sánchez (2014). Ahora bien, la deserción escolar desde los relatos dominantes de la sociedad están relacionadas con la construcción social y los procesos de desarrollo de los estudiantes desde la infancia hasta 


\section{LA DESERCIÓN ESCOLAR COMO PRETEXTO PARA CONVERSAR SOBRE IDENTIDAD, FAMILIA Y ESCUELA

la actualidad, teniendo en cuenta para ello que estas versiones son adaptadas y mediadas por las relaciones en el núcleo familiar, el contexto educativo y las narrativas de la persona que le han permitido tomar como opción el abandono de su proceso educativo. Adicionalmente, en el campo de la deserción educativa se reconoce el rol de las instituciones educativas en la construcción del individuo, puesto que este contexto interviene en el desarrollo, la realidad y las comprensiones entorno a los procesos de formación. En este orden de ideas se puede considerar que es aquí en donde empieza a manifestarse algunos indicios del fracaso escolar, como la repetición de cursos o el retraso en los aprendizajes. En este sentido se puede entender que la escuela como institución se ha mantenido inalterable en su estructura y en su concepción de espacios y de objetivos.

Además de lo expuesto anteriormente se ponen de manifiesto elementos extraescolares que influyen en la deserción escolar, Peña, Soto \& Calderón (2016) hacen mención a la violencia del el ámbito educativo y la relación profesor- alumno. En el fracaso escolar pueden existir elementos asociados al maltrato o violencia dentro de los establecimientos educativos, episodios de agresión o violencia los cuales producen en los niños daños físicos, emocionales, estrés, desmotivación, ausentismo, entre otros factores que pueden afectan directamente el rendimiento escolar.

En la relación entre docentes y estudiantes, estás se encuentran asociadas a las necesidades e intereses y al mismo tiempo a la transmisión de conocimientos, el contexto educativo, el cual es conocido y compartido por las personas que forman parte de él, y cada uno lo interpreta y reconoce de manera particular, lo que preocupa en el fenómeno de la deserción escolar es el escaso compromiso de los profesores en la situaciones cotidianas que afectan a sus alumnos, existiendo un total desconocimiento de las situaciones que afectan a 


\section{LA DESERCIÓN ESCOLAR COMO PRETEXTO PARA CONVERSAR SOBRE IDENTIDAD, FAMILIA Y ESCUELA

sus estudiantes, los cuales pueden llegar a desertar y muy pocos profesores lo identifican o lo recuerdan.

Al observar la relación existente entre familia y escuela entorno al adolescente y la manera como se desarrollan ciertas acciones. Dabas (1997) menciona que constantemente se escucha acerca de la necesidad de modificar estas relaciones, sin embargo, para la autora es evidente que los cambios no se presentan de manera externa, los cambios están en cada uno de los actores que intervienen en el proceso educativo, en las relaciones de los docentes con los padres y en el rol que tienen los padres en la educación de los hijos.

Por consiguiente el tema de la deserción escolar afecta directamente a las familias, al no existir una correlación en las dinámicas del contexto familiar y escolar, lo que permite que no exista un trabajo en red. Ahora bien existen diversas formas de ser y entender a la familia, sin embargo en la mayoría de los casos se deja solo al adolescente, y por ello se propone asumir responsabilidades conjuntas que posibiliten compartir criterios en común, con el fin de promover la participación de los padres en la vida institucional.

La deserción escolar, es el abandono del sistema educativo por parte de los estudiantes, en él se evidencian factores relacionados en la escuela, en la sociedad, en la familia y en lo personal (Moreno, 2013). Algunos teóricos han preferido llamar a esta situación “abandono escolar", otros alejarse de los estudios por voluntad propia; y otros a aspectos externos, como la pobreza o el conflicto armado.

Lo anterior permite reconocer que en la deserción escolar se presentan factores internos y externos o multi-causales, lo cual tiene gran incidencia en la vida de los adolescentes debido a que no cuentan con las herramientas necesarias para ser competitivos en el mundo laboral, disminuyendo así la posibilidad de acceder a una mejor calidad de vida individual y social, la 


\section{LA DESERCIÓN ESCOLAR COMO PRETEXTO PARA CONVERSAR SOBRE IDENTIDAD, FAMILIA Y ESCUELA

deserción escolar está relacionada con el desempleo y los bajos estándares de educación al igual que con la mano de obra y la economía.

Igualmente se generan otras comprensiones sobre la deserción escolar concluyendo que es el abandono que los estudiantes hacen de las escuelas, después de haber asistido por algún tiempo a ellas para no regresar; la deserción implica el abandono en forma definitiva, y se encuentra asociado a factores que se generan en las mismas escuelas y en otros contextos.

La tasa de deserción escolar se define como la proporción de estudiantes que abandonan las actividades escolares por un año o más, antes de haber concluido el nivel educativo que estaba cursando el año anterior.

\section{Metodología}

En este capítulo, se muestra la metodología utilizada durante la investigaciónintervención, así como la producción de datos expresados en un lenguaje natural regida por criterios lógicos los cuales permiten hacer un análisis de la descripción del fenómeno que se presenta a lo largo del documento.

La metodología utilizada para el desarrollo de la investigación- intervención, es el método abductivo, el cual es definido por Bar (2001 citado por Vargas, 2008) “como un esquema que permite hablar de hechos que aún pueden ser explicados” (pp, 4). Es así como Mejía (2002) propone una construcción de conocimiento de manera amplia en la cual, el investigador logre impactar y retroalimentar las relaciones de los participantes de la investigación donde se coconstruye el conocimiento, lo cual amplia la comprensión que se tiene del problema para así construir nuevas hipótesis acerca el funcionamiento de los sistemas humanos. 


\section{LA DESERCIÓN ESCOLAR COMO PRETEXTO PARA CONVERSAR SOBRE IDENTIDAD, FAMILIA Y ESCUELA

\section{Modelización}

La modelización, intenta explicar, entender o mejorar un sistema interpretando los significados que tienen las personas implicadas, y para ello se describen sus rutinas y las formas en que el sistema familiar debe funcionar, al igual que los procesos conversacionales en los cuales se evidencian las situaciones problema que adquieren significado en la vida de las personas; también permite que el investigador se involucre en sus propias observaciones y en las experiencias de los demás con el fin de co- construir y transformar narrativamente sus dilemas generando cambios en las actitudes y comportamientos del sistema familiar.

Según Pakman (2007 citado por Ballón, 2012) la construcción de significados y realidades se presenta en relación con la percepción que se tiene alrededor del problema, al igual que con la generación de procesos reflexivos que surgen en la investigadora y en la familia los cuales intervienen en el proceso.

De igual forma Von Forster (2006), menciona que en la ciencia compleja es de vital importancia el uso del pensamiento abductivo, el cual se explica como el conocimiento nace a partir de la relación con los otros de una manera activa. Este tipo de pensamiento, permite el reconocimiento circular entre la causa y el efecto, entendiendo que estos funcionan de forma bidireccional, lo cual posibilita la emergencia de múltiples respuestas a diferentes situaciones de los contextos relacionales. Así mismo, se habla de procesos intersubjetivos y subjetivos, en donde la realidad es construida, ahora bien, la posición del investigador debe ser reflexiva y participativa, con el fin de reconocer que cada sujeto es particular.

En la investigación de segundo orden es importante reconocer al otro como sujeto activo que construye su relación dentro de su propia experiencia, aportando así a la construcción de la realidad; en consecuencia la investigación- intervención que se realiza en este trabajo, está 


\section{LA DESERCIÓN ESCOLAR COMO PRETEXTO PARA CONVERSAR SOBRE IDENTIDAD, FAMILIA Y ESCUELA

orientada a comprender y transformar narrativamente el fenómeno de la deserción escolar en

la vida de la adolescente que se encontraba directamente involucrada con el fenómeno

investigativo, la posición de la madre frente a la problemática de su hija desde su propia

perspectiva y como la investigadora interviene en la construcción del relato para transformar

narrativamente lo que para el sistema familiar es un problema.

El fenómeno de estudio está orientado a comprender y transformar narrativamente

mediante un proceso terapéutico las historias dominantes del sistema familiar, las cuales han generado un atrapamiento en el discurso dominante en la diada madre- hija, reflejados en castigos físicos, maltrato psicológico y agresiones verbales mutuas, situación que ha llevado al sistema familiar a buscar ayuda profesional con el fin de solucionar el problema.

\section{Descripción de las fases del trabajo}

Tabla 1.

Modelización de los procesos de la Investigación-Intervención.

$\begin{array}{ccc}\text { Fase } & \text { Objetivo } & \text { Ajustes del } \\ \text { fenómeno }\end{array}$

\begin{tabular}{|c|c|c|c|}
\hline $\begin{array}{l}\text { Definir el } \\
\text { interés de la } \\
\text { investigación } \\
\text { - Intervención }\end{array}$ & $\begin{array}{l}\text { Mediante la narrativa } \\
\text { conversacional comprender } \\
\text { cómo se construye y co- } \\
\text { construye la identidad de una } \\
\text { adolescente y su familia, en } \\
\text { un caso de deserción escolar }\end{array}$ & $\begin{array}{l}\text { La investigación- intervención se } \\
\text { llevó a cabo como trabajo de grado } \\
\text { para optar al título de Magister en } \\
\text { Psicología Clínica y de la Familia } \\
\text { de la Universidad Santo Tomas, } \\
\text { inscrita en el macroproyecto } \\
\text { Historias y Narrativas Familiares } \\
\text { en Diversidad de Contextos. Que } \\
\text { se encuentra vinculado a la línea } \\
\text { de investigación Psicología, } \\
\text { Sistemas Humanos y Salud } \\
\text { Mental, la cual está adscrita al } \\
\text { grupo de investigación Psicología, } \\
\text { Familia y Redes de la Facultad de } \\
\text { Psicología de la USTA. }\end{array}$ & $\begin{array}{l}\text { Construcción y co- } \\
\text { construcción narrativa de la } \\
\text { identidad en la relación } \\
\text { entre la joven, la familia y } \\
\text { la institución educativa, en } \\
\text { una situación de deserción } \\
\text { escolar. }\end{array}$ \\
\hline $\begin{array}{l}\text { Construcción } \\
\text { del estado del } \\
\text { arte }\end{array}$ & $\begin{array}{l}\text { Realizar un rastreo sobre las } \\
\text { comprensiones que diversas } \\
\text { disciplinas y paradigmas } \\
\text { hacen sobre la deserción }\end{array}$ & $\begin{array}{l}\text { Para la elaboración del estado } \\
\text { del arte documental, se realizó } \\
\text { un recorrido por diferentes }\end{array}$ & $\begin{array}{l}\text { La narrativa conversacional } \\
\text { permitió comprender los } \\
\text { postulados teóricos y las } \\
\text { posturas de los participantes }\end{array}$ \\
\hline
\end{tabular}




\section{LA DESERCIÓN ESCOLAR COMO PRETEXTO PARA CONVERSAR SOBRE IDENTIDAD, FAMILIA Y ESCUELA

escolar, este recorrido permitió ver que la deserción escolar tiene diferentes significados, por una parte, el estudiante y por otro lado lo que puede inferir un observador de ese comportamiento.

- Comprender desde los referentes teóricos, investigativos, y técnicos la construcción narrativa de la identidad, la deserción escolar y la relación entre la adolescente, la familia y la institución educativa, desde una mirada compleja que permita la convergencia de diferentes factores para dar respuesta al fenómeno de estudio. fuentes bibliográficas como: tesis, artículos, libros. Documentos que permitieron ampliar las comprensiones sobre los ejes temáticos abordados en la investigaciónintervención.

- Se diseñaron cinco escenarios conversacionales, dos en los que participaron diez profesores de la institución educativa, diez estudiantes de diferentes grados de la misma institución y tres escenarios conversacionales con la familia.

- Tres transcripciones y matriz de análisis, para las comprensiones paradigmáticas de cada categoría. y la familia en torno al fenómeno de deserción escolar desde el paradigma de la complejidad, de igual forma se definieron los ejes temáticos abordados para la investigación- intervención así:

Construcción narrativa de la identidad, intervención narrativa en situación de deserción escolar, relación adolescente, familia e institución educativa entorno a la deserción escolar.
Sistema

Teórico

Abordar el problema y el
fenómeno de investigación-
intervención desde el
paradigma de la complejidad,
a partir de conceptos teóricos
y epistemológicos.

y epistemológicos.
Comprender desde el enfoque sistémico y el paradigma complejo, construccionistaconstructivista desde el cual se sustenta la Maestría en psicología clínica y de la familia y desde el macroproyecto Historias y Narrativas Familiares en diversidad de Contextos en la cual se encuentra inscrito el proyecto, abordado desde el desarrollo de los ejes temáticos que lo sustentan.

-La narrativa como el resultado de la relación del sujeto con la sociedad a lo largo de las etapas del ciclo vital. Linares (1996). -La adolescencia: Los adolescentes están siendo consumidos y hasta nosotros mismos por la globalización Hernández (2003).

-Deserción Escolar: Los cambios están en cada uno de los actores que intervienen en el proceso educativo, en las relaciones de los docentes con los padres y en el rol que tienen los padres en la educación de los hijos. Dabas (1997)

Presentar la forma como se operó en el proceso de investigación- intervención
Método
Construcción de cinco escenarios

- Escenario1. Comprender mediante la narrativa conversacional que entienden los estudiantes por deserción escolar.

- Identificar casos puntuales de compañeros y las estrategias utilizadas para continuar en el sistema escolar.
Definición de los principios operadores: Reflexividad, desde una lectura ecológica permite incluir al observador en lo observado para comprender el fenómeno. La recursividad. Recurso para la comprensión de diferentes niveles explicativos del fenómeno. La autorreferencia. Permite la 


\section{LA DESERCIÓN ESCOLAR COMO PRETEXTO PARA CONVERSAR SOBRE IDENTIDAD, FAMILIA Y ESCUELA

- Escenario 2. Entender mediante el relato conversacional, las experiencias que los profesores tienen sobre deserción escolar.

- Comprender cual es el manejo que la institución educativa le da a la deserción escolar.

Escenario 3. Redefinir el motivo de consulta de la familia.

Escenario 4. Identificar el

significado construido entorno a la deserción escolar.

Escenario 5. Articular en la narración de la joven, la familia y la escuela co -construcciones y transformaciones de significados.

Neo- diseños

-Escenario 1. Desarrollar el motivo de intervención de la familia, comprendiendo la construcción de los consultantes por medio del relato de su experiencia.

-Escenario 2. Indagar el relato que tiene el sistema familiar acerca de la deserción escolar y la identidad construida en familia.

Comprender la construcción identitaria a través de la historia del sistema familiar en las narrativas.

Escenario 3. Identificar el significado construido en torno a la deserción escolar en adolescentes, teniendo en cuenta la repercusión de este fenómeno en la configuración de experiencia y en los relatos identitarios Metodología de análisis de la información. Análisis de la narrativa conversacional. Matriz de análisis de resultados

Hacer el análisis de resultados desde los conceptos metodológicos, Resultados explorando de manera reflexiva las historias dominantes, las memorias y los relatos que surgieron

Para ello se utilizaron tres matrices

de análisis de información, una por cada escenario conversacional, conformada por los siguientes campos: Textualidad, categorías, macroproyecto, autorreferencia, heterorreferencia, y categorías emergencia del observador en la realidad de la familia haciéndonos responsables de lo que se construye. La co-construcción. Posibilita nuevas comprensiones del fenómeno a partir de la narrativa conversacional.

\section{Conceptos Metodológicos}

Análisis del campo narrativo en donde emergen historias dominantes en el sistema familiar. Memorias, entendida como el relato que esta encubierto en la historia, insumo para la comprensión de otros dilemas en el sistema familiar. El relato, surge de las situaciones, acontecimientos y demás actos experienciales de las personas en sus contextos.
Desde el análisis narrativo se generó la posibilidad de co-construir conversaciones con el sistema familiar a través del proceso psicoterapéutico facilitando la emergencia de procesos 


\section{LA DESERCIÓN ESCOLAR COMO PRETEXTO PARA CONVERSAR SOBRE IDENTIDAD, FAMILIA Y ESCUELA

durante el proceso narrativo conversacional emergentes, a través de estas matrices se realizó el análisis de resultados.

de individuación y movilizando transformaciones de cambio vinculadas a las narrativas emergentes. Pasando de las historias dominantes a los relatos posibilitadores.

Comprender las movilizaciones que se generaron en el sistema familiar, corroborar las hipótesis y dar respuesta a los objetivos y la pregunta problema planteada inicialmente

Discusión

\section{Conclusiones}

\section{Realizar una síntesis} comprensiva de cada uno de los capítulos abordados en el proceso de investigaciónintervención y de los aportes que se hacen a la psicología clínica, a la maestría, al macroproyecto y a la investigadora- interventora.

\section{Discutir los resultados desde los} objetivos, las hipótesis y la pregunta problema. Poner a conversar los autores que se abordaron en el estado del arte y el sistema teórico para comprender como la narrativa conversacional se organiza posibilitando nuevas formas de relación en el sistema familiar.
A partir del proceso conversacional, se transformaron las historias de vida del sistema familiar, cambiar el discurso dominante e imposibilitador, por uno que genera apertura para el contexto familiar, social y escolar y dar cuenta de los cambios que se posibilitaron durante el proceso terapéutico, el cual se pueden evidenciar mediante los seguimientos realizados al sistema familiar dos años después de haber terminado la intervención.

\author{
Se realizó una síntesis por \\ capítulo, tomando los aspectos más \\ relevantes de cada uno de ellos, se \\ generaron comprensiones acerca \\ de los ejes temáticos, los \\ conceptos metodológicos y los \\ principios operadores, mediante un \\ proceso de articulación que \\ permitió tener una lectura \\ compleja y ecológica del \\ fenómeno de deserción escolar. \\ El proceso conversacional \\ abordado con el sistema \\ familiar permitió hacer \\ comprensiones y \\ movilizaciones acerca del \\ problema que mantenía \\ anclado la familia, \\ igualmente emergieron \\ relatos alternos en relación \\ con las historias \\ dominantes, las memorias \\ fueron relatos \\ subdominantes que \\ posibilitaron la \\ comprensión del problema \\ generando el cambio \\ esperado en el sistema \\ familiar.
}

Fuente propia, 2018. 


\section{LA DESERCIÓN ESCOLAR COMO PRETEXTO PARA CONVERSAR SOBRE IDENTIDAD, FAMILIA Y ESCUELA

\section{Principios Operadores}

Desde los principios epistemológicos y paradigmáticos que sustentan el proyecto de grado se retoma los principios operadores para la modelización, la reflexividad, la recursividad, la autorreferencia y la narrativa conversacional, a través de ellos se puede comprender el fenómeno de estudio desde una cibernética de segundo orden, la cual nos invita a incluirnos en el proceso como "observadores participantes" (Estupiñán, 2006).

La Reflexividad, es definida por De la cuesta (2011), como el proceso que permite volver sobre sí mismo, para analizar los efectos que se están produciendo en la investigación, desafiando la objetividad, poniendo de manifiesto la conciencia del investigador y su conexión con la investigación. En este sentido la reflexividad es asumida como una invitación a involucrarse y formar parte del problema generando movilizaciones y reflexiones al interior del sistema familiar para qué de esta manera se pueda tener una lectura ecológica de la demanda.

Varela \& Maturana (1980, citado por Estupiñán, 2006) define la Reflexividad, de las siguientes maneras, como un proceso lógico, operacional y generativo, estos procesos nos invitan a pensar no como seres preexistentes, sino como seres que emergen y se ubican en el mundo a través de las practicas lingüísticas adoptadas como instrumentos para las relaciones y la convivencia de las personas.

La Recursividad, citado por Estupiñán y Gonzáles (2012) orienta y conecta niveles y dominios diferentes de información, con el propósito de proponer explicaciones y comprensiones de los fenómenos. En este sentido se hace necesario seguir el hilo conductor de la persona que narra para ir entretejiendo sus experiencias al relatar su historia de vida y comprender, por ejemplo, como la experiencia de vida de la madre de la adolescente, al ser 


\section{LA DESERCIÓN ESCOLAR COMO PRETEXTO PARA CONVERSAR SOBRE IDENTIDAD, FAMILIA Y ESCUELA

madre soltera a los 14 años se orienta a la protección y cuidado de su hija, para así evitar que enfrente su misma experiencia, sin embargo, la adolescente tiene una lectura diferente porque los contextos socio culturales en los que se desarrollaron son diferentes, lo que hace necesario conectar todo este relato y llevarlo a comprensiones reflexivas de las cuales hace parte la investigadora con su historia de vida.

La auto referencia, implica la postura de reconocer las propias narrativas, creencias, valores, prejuicios, ideas, emociones y acciones que construyen la realidad de la familia vivida y narrada desde el principio de la observación, haciéndonos responsables de tales construcciones y su incidencia en la práctica investigativa - interventiva (Estupiñán \& Gonzales, 2012). De esta manera la terapeuta trae al contexto su historia de vida la cual comparte con el sistema familiar a partir de procesos narrativos promoviendo nuevas lecturas de las relaciones y de las interacciones.

El cuarto principio conversacional hace referencia a la co- construcción, cuyo principio es la transformación de las prácticas narrativas y relacionales en los sistemas familiares y sociales hacia historias o versiones posibilitadoras que den paso a experiencias de vida más productivas en los contextos familiar y social (Estupiñán, González y Serna 2006).

De esta manera el proceso conversacional vivenciado en los escenarios permitió develar las experiencias vividas por cada miembro del sistema familiar, evocando viejos y nuevos relatos de las experiencias personales, los cuales adquieren sentido y significado en las nuevas formas de relacionarse y de proyectarse en los diferentes contextos.

\section{Estudio de Caso}

El trabajo de Investigación- intervención se aborda desde el estudio de caso, el cual es definido desde el enfoque sistémico por Niño (2011) como un proceso formativo e 


\section{LA DESERCIÓN ESCOLAR COMO PRETEXTO PARA CONVERSAR SOBRE IDENTIDAD, FAMILIA Y ESCUELA

interventivo, a través del cual se evidencian los conocimientos adquiridos en orientación académica a terapeutas o consultores, es un proceso de entrenamiento, el cual le permite al estudiante conversar y reflexionar sobre el caso, haciendo lecturas complejas sobre la forma de intervenir, además de ser un pretexto para conversar con el equipo reflexivo con el cual se amplían las comprensiones sobre la forma en la cual el terapeuta realiza la lectura del caso permitiéndole involucrarse como observador a parir de su autorreferencia.

Según Walker (1983, citado por Grupo L.A.C.E, 1999), el estudio de caso ofrece la posibilidad de extendernos hacia explicaciones más amplias acerca de las experiencias vividas, facilitando una reconstrucción de significados en relación con dichas experiencias.

La importancia del estudio de caso se sustenta en la dificultad que se presenta en el sistema familiar de una adolescente que lleva varios años desescolarizada, generado una ruptura en los vínculos parentales y filiales provocando un distanciamiento en el sistema relacional familiar y social. El objetivo es dar respuesta a la demanda de la madre a través de un trabajo terapéutico que permita nuevas comprensiones y movilizaciones sobre el fenómeno de deserción escolar y la construcción identitaria de la adolescente, utilizando como estrategia la narrativa conversacional desde las historias, memorias y relatos para ir comprendiendo las dinámicas relacionales en las que se mueve el sistema familiar.

\section{Estrategias para el proceso de intervención}

Las estrategias utilizadas en el proceso de investigación- intervención fueron:

- Preguntas circulares: Estas facilitaron indagar sobre la problemática que agobiaba al sistema familia permitiendo co- construir un nuevo sistema de creencias.

- Confrontación: Propone una interacción entre el mundo del terapeuta con el sistema familiar, de manera que el sentimiento y la emoción de la terapeuta, también cobre 


\section{LA DESERCIÓN ESCOLAR COMO PRETEXTO PARA CONVERSAR SOBRE IDENTIDAD, FAMILIA Y ESCUELA

sentido cuando confronta desde su experiencia como madre, la forma tan despectiva y descalificante como esta madre visualiza a su hija, responsabilizándola de las desgracias de la familia. Mediante esta estrategia, se pudo evolucionar de manera dinámica para la transformación y el cambio.

- Externalización: Sirvió como vehículo liberador del estigma y la etiqueta con que había sido rotulada la adolescente, desde el sistema familiar y escolar permitiendo construir posibilidades de cambio.

De igual forma el sistema metodológico aborda los principios operadores, los conceptos metodológicos, el contexto, los participantes, el diseño de los escenarios y los neo- diseños los cuales se desarrollaron en esta investigación- intervención los cuales van a ser puestos en escena en este capítulo.

\section{Conceptos metodológicos de la investigación- intervención}

Los conceptos metodológicos del proceso de investigación -intervención están enmarcados en la línea del macroproyecto historias y narrativas familiares en diversidad de contextos, vinculado a la línea de investigación Psicología, Sistemas Humanos y Salud Mental, la cual está adscrita al grupo de investigación Psicología, Familia y Redes de la Facultad de Psicología de la USTA, a través de ellos se comprenden los fenómenos clínicos familiares como son los dilemas, las crisis y los síntomas, igualmente se generan los recursos para su afrontamiento, los cuales son construidos narrativamente con las familias, estos recursos se construyen narrativamente con las familias (Dossier. Macroproyecto de investigación, Historias y narrativas familiares en diversidad de contextos. 2006). 


\section{LA DESERCIÓN ESCOLAR COMO PRETEXTO PARA CONVERSAR SOBRE IDENTIDAD, FAMILIA Y ESCUELA

\section{Descripción de los Conceptos Metodológicos}

Los conceptos metodológicos del proceso de investigación -intervención emergen de las comprensiones del fenómeno a intervenir. Estos son revelados mediante el proceso de construcción narrativo conversacional, el cual permite comprender como las familias construyen historias, develan con timidez sus memorias y relatos para ponerlos en juego en un escenario conversacional.

\section{Las historias dominantes y su incidencia en la construcción narrativa de la identidad}

A continuación, se presentan los conceptos metodológicos del macroproyecto y los de la investigación- intervención

\section{Comprensiones sobre las historias dominantes}

Las historias son concebidas como una dimensión de la existencia humana, a través de la cual se impulsan o impiden la realización de ciertos actos, los cuales son conocidos como los efectos de la historia dominante. Ahora bien, esta se caracteriza por una narrativa cargada de problemas, con sentimientos de desesperanza, frustración o angustia, y desde la cual al ser dominante se relatan las otras, por lo general este tipo de historia es concebida como real para la persona que la narra, si se tiene en cuenta que tiene una fuerte carga comunicacional que se replica constantemente, lo que le permite mantenerse a sí misma, ahora bien esta versión dominante genera un bloqueo en los procesos discursivos y en la forma de significar las experiencias vividas y las formas de relacionarse con otros contextos sociales para así dar continuidad a su proceso de construcción identitaria.

\section{Memorias}

Otro concepto que se abordó como parte de la metodología fueron las memorias y su accionar en la intervención narrativa en situación de deserción escolar, estas son 


\section{LA DESERCIÓN ESCOLAR COMO PRETEXTO PARA CONVERSAR SOBRE IDENTIDAD, FAMILIA Y ESCUELA

consideradas las versiones subdominantes que se encuentran en la periferia de las narrativas son marginales e incluso en muchas ocasiones se encuentran escasamente articuladas al relato, configuran una versión casi insignificante, sin embargo, a través de ellas se configuran versiones del sentido y significado de las experiencias vividas y narradas permitiendo explorar otros campos y, posibilitando la emergencia de nuevos acontecimientos para la intervención. Para Estupiñán \& Gonzáles (2006), las memorias se entienden como las versiones subdominantes que se articulan al relato encontrando sentido y significado a las experiencias vividas y narradas por los sistemas.

\section{Relatos alternos}

El relato es definido como un acontecimiento por el cual transitan las emociones, dando un significado a las experiencias vividas temporo-espacialmente, además, se encuentra estrechamente ligado a los acontecimientos, el relato organiza y le da sentido a la experiencia propia, permite construir y narrar nuevas historias, generar reflexiones acerca de los acontecimientos vividos, permitiendo narrar historias más posibilitadoras.

\section{Descripción del Contexto}

La presente investigación- intervención se desarrolló en la Institución Educativa San Jerónimo Emiliani de la ciudad de Tunja (Boyacá). Contexto que sirvió como pretexto para la identificación del caso que se está interviniendo. Esta es una Institución de carácter Público, actualmente el Colegio cuenta con dos sedes, una ubicada en la calle 55 con carrera 2 barrio Santa Ana (Sede bachillerato) y otra en la calle 5 con carrera 7 sur oriente (sede Primaria). El colegio es dirigido por el Padre Rector, Genaro Espitia. El número de estudiantes en las dos sedes es de 1470 correspondiente a los estratos 1 y 2. Esta institución es una de la más reconocida de la Ciudad de Tunja por las especialidades en las que cuentan los estudiantes 


\section{LA DESERCIÓN ESCOLAR COMO PRETEXTO PARA CONVERSAR SOBRE IDENTIDAD, FAMILIA Y ESCUELA

desde el grado noveno: Ebanistería, metalistería, electricidad, electrónica, sistemas y

mecánica.

Los estudiantes inician su profundización facilitando de esta manera escoger una carrera profesional o para la consecución de un empleo.

\section{Descripción de los Participantes}

En un primer encuentro, se trabajó con 10 estudiantes de diferentes grados, seleccionados al azar por la coordinadora académica y en un segundo momento se trabajó con 10 profesores, el objetivo entender cómo vivencia el fenómeno de deserción escolar el colegio. En el encuentro con los profesores se comprendió como la Institución Educativa aborda el tema de la deserción escolar y porque no existe un reporte de los estudiantes que abandonan o suspenden sus estudios. Sin embargo, durante este encuentro, una de las docentes menciono que conocía el caso de una adolescente que estaba desescolarizada, porque había perdido varios sextos, según ella, la niña llevaba varios años desescolarizada. Por medio de esta profesora se ubicó a la madre de la adolescente, después de un encuentro informal que tenía como objetivo explicarle la intensión del trabajo con el sistema familiar, se acordó trabajar tres (3) encuentros conversacionales, cada uno con un intervalo de 15 días. Estos encuentros se desarrollaron en la institución educativa; la cual sirvió como contexto y a la vez como pretexto de la demanda para abordar el caso.

Se realizó un estudio de caso con el sistema familiar compuesto por la madre. M, de 39 años, soltera y madre de tres hijos. J, A y L. A, de 15 años, Identificada como la persona que presenta el problema. El motivo de consulta se relaciona con el problema que ha presentado A, al no aprobar el grado sexto, repitencia que ha tenido en tres colegios diferentes de la 


\section{LA DESERCIÓN ESCOLAR COMO PRETEXTO PARA CONVERSAR SOBRE IDENTIDAD, FAMILIA Y ESCUELA

ciudad de Tunja. En el momento de abordar el caso la adolescente llevaba varios años desescolarizada.

\section{Diseños y neo- diseños de Investigación}

Los escenarios fueron diseñados desde las comprensiones y reflexiones que emergieron de la investigación- intervención desde el paradigma de la complejidad, el constructivismo y construccionismo, la narrativa conversacional y la investigadora- interventora como observadora y participe en la co- construcción del cambio.

\section{Construcción de diseños}

A continuación, se presentan los cinco (5) diseños que se realizaron con los estudiantes, los profesores y el sistema familiar, el objetivo comprender que entienden y como asume cada uno de los actores la deserción escolar, desde los estudiantes hasta la familia.

Tabla 2.

\section{Primer escenario conversacional}

- Comprender mediante la narrativa conversacional que entienden los estudiantes por deserción escolar.

Objetivo - Identificar casos puntuales de compañeros y las estrategias utilizadas para continuar en el sistema escolar.

\begin{tabular}{ll}
\hline Actores & 10 estudiantes de diferentes grados de la Institución Educativa San Gerónimo Emiliani. \\
Participantes & Investigadora/interventora \\
\hline & $\bullet \quad$ Encuadre. \\
Focos & $\bullet \quad$ Objetivos del proceso. \\
& $\bullet \quad$ Comprensiones sobre deserción escolar \\
& $\bullet \quad$ Experiencias propias y de otros. \\
\hline
\end{tabular}

Preguntas orientadoras ¿Cómo entienden ustedes el tema de deserción escolar?

¿En algún momento han pensado abandonar el Colegio? ¿Qué factores creen ustedes que intervienen para que un joven abandone el colegio?

Guion ¿Alguno de los presentes ha estado desescolarizado y por cuánto tiempo?

conversacional ¿Qué esperan ustedes del Colegio? ¿Qué diferencia existe entre asistir al Colegio y estar en casa? ¿Conocen casos de compañeros o conocidos que estén desescolarizados? 


\section{LA DESERCIÓN ESCOLAR COMO PRETEXTO PARA CONVERSAR SOBRE IDENTIDAD, FAMILIA Y ESCUELA

Tabla 3.

\section{Segundo escenario conversacional}

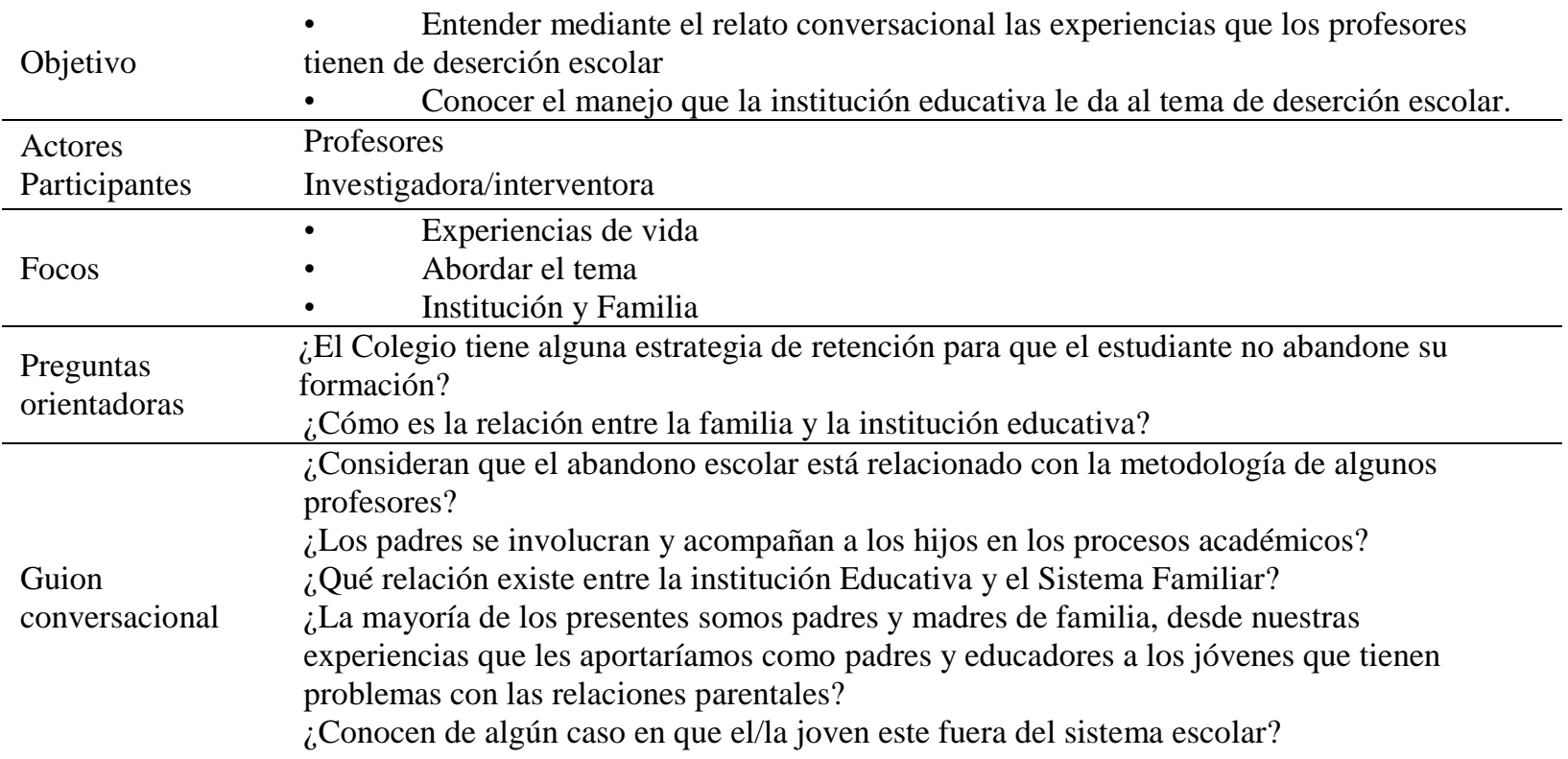

Tabla 4.

Tercer escenario conversacional

Objetivo Identificar el significado construido entorno a la deserción escolar, la incidencia del fenómeno en la construcción identitaria de la adolescente y la familia.

\begin{tabular}{ll}
\hline \multirow{2}{*}{$\begin{array}{l}\text { Actores } \\
\text { Participantes }\end{array}$} & $\begin{array}{l}\text { Familia } \\
\text { Joven } \\
\text { Investigadora/interventora }\end{array}$ \\
\hline \multirow{2}{*}{ Focos } & $1 . \quad$ Soluciones intentadas. \\
& $2 . \quad$ Deserción escolar \\
& $3 . \quad$ Familia. \\
\hline \multirow{3}{*}{$\begin{array}{l}\text { Preguntas } \\
\text { orientadoras }\end{array}$} & ¿Cómo la deserción escolar se puede convertir en una oportunidad de cambio para la joven y \\
& la familia? \\
& ¿En qué momento la deserción escolar se convirtió en un pretexto para mantener a la familia \\
& unida? \\
\hline \multirow{3}{*}{ Guion } & ¿Cómo ha cambiado la relación con la familia a partir de la situación de deserción \\
conversacional & escolar? \\
& ¿Cómo es la relación de A con los otros miembros de la familia? \\
& ¿M considera que el castigo que le impuso a su hija, al mantenerla marginada del medio \\
& social de aporto algo positivo? \\
& ¿Describan la relación de ustedes dos, en que momento comparten? \\
& ¿Cómo era la relación de M con el colegio que estudiaba A?
\end{tabular}




\section{LA DESERCIÓN ESCOLAR COMO PRETEXTO PARA CONVERSAR SOBRE IDENTIDAD, FAMILIA Y ESCUELA

¿Por qué era importante para usted enterar al colegio del diagnóstico que tiene A? ¿Qué situaciones se presentaron para que el proceso psicológico no tuviera continuidad? ¿Cómo se han sentido con los encuentros que hemos tenido? ¿Encuentran alguna diferencia con las experiencias anteriores?

Tabla 5.

\section{Cuarto Escenario conversacional}

Objetivo

Articular en la narración del joven, la familia y la escuela co-construcciones y trasformaciones de significados que emergen en el proceso, en torno a las categorías de análisis.

\begin{tabular}{|c|c|}
\hline $\begin{array}{c}\text { Actores } \\
\text { Participantes }\end{array}$ & $\begin{array}{l}\text { Familia } \\
\text { Joven } \\
\text { Investigadora/interventora }\end{array}$ \\
\hline Focos & $\begin{array}{l}\text { Emergencia de nuevos relatos en relación con la situación de deserción escolar, en la familia, la } \\
\text { adolescente y la institución. }\end{array}$ \\
\hline $\begin{array}{l}\text { Preguntas } \\
\text { orientadoras }\end{array}$ & $\begin{array}{l}\text { ¿Qué nuevos relatos se generan en el proceso terapéutico entorno a la situación de deserción } \\
\text { escolar en la familia, la joven y la institución, y como estos permiten la consolidación de } \\
\text { relatos emergentes? }\end{array}$ \\
\hline $\begin{array}{l}\text { Guion } \\
\text { conversacional }\end{array}$ & $\begin{array}{l}\text { En este momento ¿cómo comprenden la situación escolar de la adolescente? } \\
\text { ¿Han observado cambios como familia? ¿Cómo adolescente y como familia esto qué les } \\
\text { dice? } \\
\text { ¿Qué herramientas consideras tu (adolescente) que surgen en un momento de dificultad? } \\
\text { ¿Cómo crees que estas pueden ayudar al otro? } \\
\text { ¿Creen que el conocimiento que tienen de ustedes y el mismo proceso terapéutico, en un } \\
\text { futuro puede ayudarlos a enfrentar y solucionar una situación similar? ¿Cómo pasaría esto? } \\
\text { ¿Cómo podría ser esto de ayuda para ustedes en un futuro? }\end{array}$ \\
\hline
\end{tabular}

Tabla 6 .

Quinto escenario conversacional 


\section{LA DESERCIÓN ESCOLAR COMO PRETEXTO PARA CONVERSAR SOBRE IDENTIDAD, FAMILIA Y ESCUELA

$\begin{array}{ll}\text { Articular en la narración del joven, la familia y la escuela co-construcciones y } \\ \text { Objetivo } & \text { trasformaciones de significados que emergen en el proceso, en torno a las categorías de }\end{array}$ análisis.

\begin{tabular}{ll}
\hline Actores & Familia \\
Participantes & Joven \\
& Investigadora/interventora \\
\hline
\end{tabular}

Focos Emergencia de nuevos relatos en relación con la situación de deserción escolar, en la familia, la adolescente y la institución.

\begin{tabular}{|c|c|}
\hline $\begin{array}{l}\text { Preguntas } \\
\text { orientadoras }\end{array}$ & $\begin{array}{l}\text { ¿Qué nuevos relatos se generan en el proceso terapéutico entorno a la situación de deserción } \\
\text { escolar en la familia, la joven y la institución, y como estos permiten la consolidación de } \\
\text { relatos emergentes? }\end{array}$ \\
\hline $\begin{array}{l}\text { Guion } \\
\text { conversacional }\end{array}$ & $\begin{array}{l}\text { En este momento ¿cómo comprenden la situación escolar de la adolescente? } \\
\text { ¿Han observado cambios como familia? ¿Cómo adolescente y como familia esto qué les } \\
\text { dice? } \\
\text { ¿Qué herramientas consideras tu (adolescente) que surgen en un momento de dificultad? } \\
\text { ¿Cómo crees que estas pueden ayudar al otro? } \\
\text { ¿Creen que el conocimiento que tienen de ustedes y el mismo proceso terapéutico, en un } \\
\text { futuro puede ayudarlos a enfrentar y solucionar una situación similar? ¿Cómo pasaría } \\
\text { esto? } \\
\text { ¿Cómo podría ser esto de ayuda para ustedes en un futuro? }\end{array}$ \\
\hline
\end{tabular}

\section{Diseños}

Para la construcción de los escenarios de investigación-intervención, se realizaron cinco (5) escenarios con preguntas que orientan el proceso conversacional, el propósito era indagar acerca de la demanda del sistema familiar y llevar a cabo un proceso terapéutico que le permita redefinir el motivo de consulta. Estos escenarios se plantean de acuerdo con

las necesidades identificadas al definir el fenómeno a investigar, de igual manera, conllevaron a las revisiones teóricas sobre los ejes temáticos a abordar.

Los niveles desde los cuales se aborda la narrativa conversacional son; Nivel Familiar, Nivel Parental y Nivel Escolar.

\section{Nivel Familiar.}




\section{LA DESERCIÓN ESCOLAR COMO PRETEXTO PARA CONVERSAR SOBRE IDENTIDAD, FAMILIA Y ESCUELA

Comprender como la familia se visualiza como institución social, las relaciones que establecen internamente y las formas como cada miembro del sistema familiar se proyecta al mundo social, identificando de esta manera las causas del problema y los factores que han incidido para que este se mantenga.

Para llevar a cabo el ejercicio terapéutico fue necesario la revisión de lecturas que orienten el ejercicio, así como la redefinición del problema y el planteamiento de nuevas hipótesis

\section{Nivel Parental.}

El propósito fue comprender la forma como se vincula madre e hija, como se asumen los roles y las dinámicas relacionales en el sistema familiar, también fue importante comprender como desde las historias de vida, emergieron relatos que facilitaron comprender las dinámicas desde las cuales se organizan como familia.

\section{Nivel Escolar.}

El colegio San Gerónimo Emiliani de la Ciudad de Tunja (Boyacá) fue el escenario que sirvió como contexto y pretexto para llevar a cabo el estudio de caso, allí se realizaron los encuentros conversacionales, los cuales fueron un recurso importante para la comprensión del fenómeno de investigación- intervención.

\section{Neo-diseños.}

Los neo diseños fueron utilizados como estrategia metodológica, a través de los cuales se ejecuta la acción de investigación-intervención de procesos reflexivos. Para abordar el caso se diseñaron cinco neo -diseños con el sistema familiar, a partir de estos encuentros se generaron nuevas comprensiones para la familia y la investigadora- interventora. 


\section{LA DESERCIÓN ESCOLAR COMO PRETEXTO PARA CONVERSAR SOBRE IDENTIDAD, FAMILIA Y ESCUELA

Tabla 7.

Primer Neo-Diseño

\begin{tabular}{ll} 
& \multicolumn{1}{c}{ Primer Escenario Conversacional } \\
\hline & \multicolumn{1}{c}{ Investigador/ Participantes } \\
\hline Tema/Categoría & Inicio del proceso Intervenido \\
\hline Objetivo & $\begin{array}{l}\text { Desarrollar el motivo de intervención de la familia, comprendiendo la construcción de } \\
\text { los consultantes por medio del relato de su experiencia. }\end{array}$ \\
\hline Focos & - Motivo de consulta. \\
& - Encuadre. \\
\hline Preguntas & 1. ¿Ejetivos del proceso. \\
orientadoras & para la familia y para la sociedad??? \\
& 2. ¿Porque es tan importante para usted mamá que su hija sea bachiller, cuando ella \\
& puede aprender un oficio que le permita vivir de él? \\
\hline Guion & $\bullet$ ¿Cómo entienden ustedes como familia el problema de la deserción escolar? \\
interventivo & ¿Cuáles son las soluciones intentadas que se presentan \\
& $\bullet$ ¿En qué momento consideran importante asistir a consulta? \\
& $\bullet$ ¿Qué acontecimientos y momentos hacen que el problema se mantenga? \\
& $\bullet$ ¿Qué personas han estado involucradas en lo que ustedes consideran el problema? \\
& $\bullet$ ¿Qué esperan del proceso?
\end{tabular}

Tabla 8 .

Segundo Neo-Diseño

Segundo Escenario Conversacional

\begin{tabular}{|c|c|}
\hline \multicolumn{2}{|r|}{ Actores/ Participantes } \\
\hline & Investigador/ Interventor \\
\hline Tema/Categoría & Construcción narrativa de la familia. Inicio del proceso Intervenido \\
\hline Objetivo & $\begin{array}{l}\text { - Indagar el relato que tiene el sistema familiar acerca de la deserción escolar y la } \\
\text { identidad construida en familia } \\
\text { - Comprender la construcción identitaria a través de la historia del sistema familiar en } \\
\text { las narrativas. }\end{array}$ \\
\hline Focos & $\begin{array}{l}\text { - Historia de la familia } \\
\text { - Deserción escolar }\end{array}$ \\
\hline $\begin{array}{l}\text { Preguntas } \\
\text { orientadoras }\end{array}$ & $\begin{array}{l}\text { 1. ¿En la historia de vida de la madre existen momentos que fueron trascendentales, } \\
\text { madre adolescente, que le quiere trasmitir a su hija con esta lección de vida que le está } \\
\text { dando? } \\
\text { 2. ¿Qué pensaría si su hija le comentara que está embarazada? ¿Teniendo la misma edad } \\
\text { que usted tenía cuando fue madre? }\end{array}$ \\
\hline
\end{tabular}




\section{LA DESERCIÓN ESCOLAR COMO PRETEXTO PARA CONVERSAR SOBRE IDENTIDAD, FAMILIA Y ESCUELA

Guion

interventivo

- ¿Qué significa para ustedes ser familia? Describan este momento.

- ¿Cómo sucedió la deserción escolar?

- ¿Cómo familia como la perciben?

- De acuerdo con la situación que plantean ¿Qué impacto ha tenido este hecho en sus vidas?

- ¿Qué papel juega la deserción en su familia?

- ¿De qué manera concibe cada uno este momento?

- ¿Actualmente qué consideran ustedes, que los mantiene unidos, buscando ayuda?

- ¿Qué han hecho ustedes para sobrellevar la dificultad?

Tabla 9.

Tercer Neo-Diseño

Tercer Escenario Conversacional Investigador/ Interventor

\begin{tabular}{ll}
\hline Tema/Categoría & Deserción escolar y adolescencia. \\
\hline Objetivo & $\begin{array}{l}\text { Identificar el significado construido en torno a la deserción escolar en adolescentes, } \\
\text { teniendo en cuenta la repercusión de este fenómeno en la configuración de experiencia y } \\
\text { en los relatos identitarios. }\end{array}$ \\
\hline Focos & Deserción escolar en la adolescente \\
\hline $\begin{array}{l}\text { Preguntas } \\
\text { orientadoras }\end{array}$ & $\begin{array}{l}\text { 1. Adolescente. ¿Si compara su vida con otras niñas de su edad, que cree que le falta y } \\
\text { que le gustaría tener? } \\
\end{array}$ \\
$\begin{array}{l}\text { 2. ¿Cómo cree que sería su vida hoy si no hubiese perdido ningún año? Esta pregunta es } \\
\text { para madre e hija. }\end{array}$
\end{tabular}

Guion interventivo
- ¿Qué es para ti la deserción escolar?

- ¿Cómo creen que te perciben los demás?

- ¿Cómo ha cambiado la relación con tu familia a partir de la situación de deserción escolar?

- ¿Cuáles crees tú que son los elementos que una familia debe tener para manejar la deserción escolar de uno de sus miembros? ¿Cuál de estas crees que hacen falta?

- Si no hubieras pasando por esta situación ¿Cómo crees que serias?

- ¿Cómo perciben a su hijo?

- ¿Cómo te percibes tú?

- ¿Cómo te gustaría que te vieran los demás?

- ¿Qué aspectos del pasado rescatarías?

- ¿Qué impacto ha tenido este hecho en tu vida?

- ¿Qué sentimientos cree que se originan en su hija?

Tabla 10.

Cuarto Neo-Diseño

Cuarto Escenario Conversacional 


\section{LA DESERCIÓN ESCOLAR COMO PRETEXTO PARA CONVERSAR SOBRE IDENTIDAD, FAMILIA Y ESCUELA

Investigador/ Interventor

\begin{tabular}{|c|c|}
\hline Tema/Categoría & Seguimiento al proceso Terapéutico \\
\hline Objetivo & $\begin{array}{l}\text { Realizar seguimiento al proceso interventivo, para evidenciar los cambios en el sistema } \\
\text { familiar después de un año de haber concluido el proceso. }\end{array}$ \\
\hline Focos & $\begin{array}{l}\text { - } \quad \text { Comprender las dinámicas relacionales del sistema familiar } \\
\text { - Entender como se ha generado el proceso de adaptación de la adolescente al nuevo } \\
\text { sistema escolar }\end{array}$ \\
\hline $\begin{array}{l}\text { Preguntas } \\
\text { orientadoras }\end{array}$ & $\begin{array}{l}\text { 1. ¿Después de un año de haber cerrado el proceso de intervención que ha pasado con } \\
\text { ustedes como familia? } \\
\text { 2. ¿Cuáles han sido los cambios de la joven a nivel escolar? } \\
\text { 3. ¿Qué piensan hoy de las instituciones educativas? }\end{array}$ \\
\hline $\begin{array}{l}\text { Guion } \\
\text { interventivo }\end{array}$ & $\begin{array}{l}\text { - ¿Mamá, cuéntenos que pasado con su hija en este año? } \\
\text { - ¿Se han generado cambios en las actitudes de su hija? } \\
\text { - ¿Cómo es la relación de ustedes dos? } \\
\text { - } \text { Adolescente. ¿Cómo ha sido el proceso de adaptación a la nueva institución? } \\
\text { - ¿Cómo son sus compañeros, le gusta compartir con ellos, hay jóvenes de su misma } \\
\text { edad? } \\
\text { - ¿Le gusta estudiar allí? }\end{array}$ \\
\hline
\end{tabular}

Tabla 11.

Quinto Neo-Diseño

Quinto Escenario Conversacional

\begin{tabular}{|c|c|}
\hline \multicolumn{2}{|r|}{ Actores/ Participantes } \\
\hline \multicolumn{2}{|r|}{ Investigador/ Interventor } \\
\hline Tema/Categoría & Seguimiento 2 al proceso Terapéutico \\
\hline Objetivo & $\begin{array}{l}\text { Corroborar las movilizaciones que se generaron durante el proceso interventivo- } \\
\text { terapéutico al sistema familiar y los avances del caso. }\end{array}$ \\
\hline Focos & $\begin{array}{l}\text { - Mediante el proceso narrativo identificar como se ha ido construyendo los procesos } \\
\text { identitarios de la adolescente. } \\
\text { - Posibilitar espacios conversacionales para comprender que paso con el diagnostico } \\
\text { que por tantos años mantuvo a la adolescente rotulada desde el déficit. }\end{array}$ \\
\hline $\begin{array}{l}\text { Preguntas } \\
\text { orientadoras }\end{array}$ & $\begin{array}{l}\text { 1. ¿Qué consideran ustedes que género el cambio, teniendo en cuenta que ya habían } \\
\text { asistido a varios procesos psicológicos? } \\
\text { 2. ¿Qué les deja hoy como familia de toda la experiencia de deserción escolar? } \\
\text { 3. ¿Qué tiene proyectado apenas termine el bachillerato? }\end{array}$ \\
\hline $\begin{array}{l}\text { Guion } \\
\text { interventivo }\end{array}$ & $\begin{array}{l}\text { - ¿Hablemos de la experiencia que vivieron entorno a la deserción escolar? } \\
\text { - ¿Cuáles fueron los aprendizajes? } \\
\text { - ¿Cómo es la relación de ustedes dos hoy? } \\
\text { renamá que tan cercana es hoy la relación con su hija, quisiera decirle algo } \\
\text { ¿ que le dijo en los primeros encuentros conversacionales que hicimos? }\end{array}$ \\
\hline
\end{tabular}




\section{LA DESERCIÓN ESCOLAR COMO PRETEXTO PARA CONVERSAR SOBRE IDENTIDAD, FAMILIA Y ESCUELA

\section{Análisis de la Información}

A partir de la propuesta de Estupiñán \& González (2012) se plantean dos órdenes de significados, en el orden de los significados de la narrativa y el del sentido relacional de la narrativa.

En el primer orden se genera una aproximación a los procesos de significado de los individuos y de los contextos, desde dos perspectivas.

La primera perspectiva, permite hacer el análisis del contenido de las narrativas de los sistemas participantes en relación con los acontecimientos y las experiencias vividas en las relaciones, las cuales son transformadas en el proceso terapéutico.

La segunda perspectiva, posibilita la reconstrucción de los procedimientos dialógicos, de los cuales hacen parte los sistemas que participan del proceso terapéutico y cuyas transformaciones se vinculan al proceso de cambio.

En cuanto al sentido relacional de la narrativa, considera que las producciones narrativas se organizan en la interacción conversacional, adquieren sentido y llegan a convertirse en construcciones meta-contextuales. Adicionalmente, al reconstruir las condiciones sociales y relacionales se generan nuevas producciones narrativas que circulan, transmiten y transforman con un sentido contextual. En este sentido la narrativa conversacional como método de construcción social de la realidad permite la deconstrucción y co-construccion de ciertos relatos, permitiendo la construcción de narrativas emergentes que son las que dan cuenta de los cambios.

Desde los órdenes de comprensión, Estupiñán \& Gonzáles (2012), definen el método de análisis conversacional, como "una aproximación rigurosamente empírica que evita la construcción prematura de teorías y emplea métodos inductivos. Se examina una serie de 


\section{LA DESERCIÓN ESCOLAR COMO PRETEXTO PARA CONVERSAR SOBRE IDENTIDAD, FAMILIA Y ESCUELA

conversaciones naturales, se buscan patrones recurrentes, con el objetivo de describir la forma en que, quienes conversan producen su propia conducta y comprenden y tratan la de otros" ( $p$. 99), el análisis conversacional se define no como un medio para comprender los fenómenos sociales sino como el generador de la realidad humana.

Para la realización del análisis terapéutico se utilizó la narrativa conversacional como perspectiva metodológica como lo exponen Estupiñán y González (2015) “ en el acto narrativo generamos comprensiones de la vida humana referidas a nuestros dilemas, problemas y conflictos" (p.82) es decir los actos narrativos están estructurados en dimensiones de tiempo y acontecimientos en los cuales se incluyen los sucesos del mundo físico y social, desde donde se deben comprender y asimilar para poder relacionarse con ella. Los actos narrativos siempre están relacionados con la experiencia vivida.

De acuerdo a lo expuesto por Estupiñán y González (2012) el carácter conversacional e interaccional de la psicoterapia se caracteriza por una construcción teórica interdisciplinar, en la que convergen diferentes ciencias las cuales han contribuido de manera significativa a la terapia sistémica, compleja, constructivista y construccionista, desde la cual se ofrece una alternativa de exploración multidimensional de las experiencias humanas, a partir de la cual se propone incorporar las diferencias y singularidades del self, de la familia y de la comunidad, mediados por las historias y sus relatos de vida. Por lo tanto, mediante el proceso terapéutico emergen historias, memorias y relatos que permiten la comprensión del problema y a su vez aportan elementos que se modelan a partir de la búsqueda de transformaciones o cambios y la interacción de los sistemas consultantes.

Desde los principios operadores se busca comprender la complejidad de los fenómenos que viven los seres humanos y a su vez sus soluciones. 


\section{LA DESERCIÓN ESCOLAR COMO PRETEXTO PARA CONVERSAR SOBRE IDENTIDAD, FAMILIA Y ESCUELA

A continuación, se presenta el modelo de la matriz utilizado para el análisis de resultados.

Tabla 12.

Formato para el análisis de Resultados

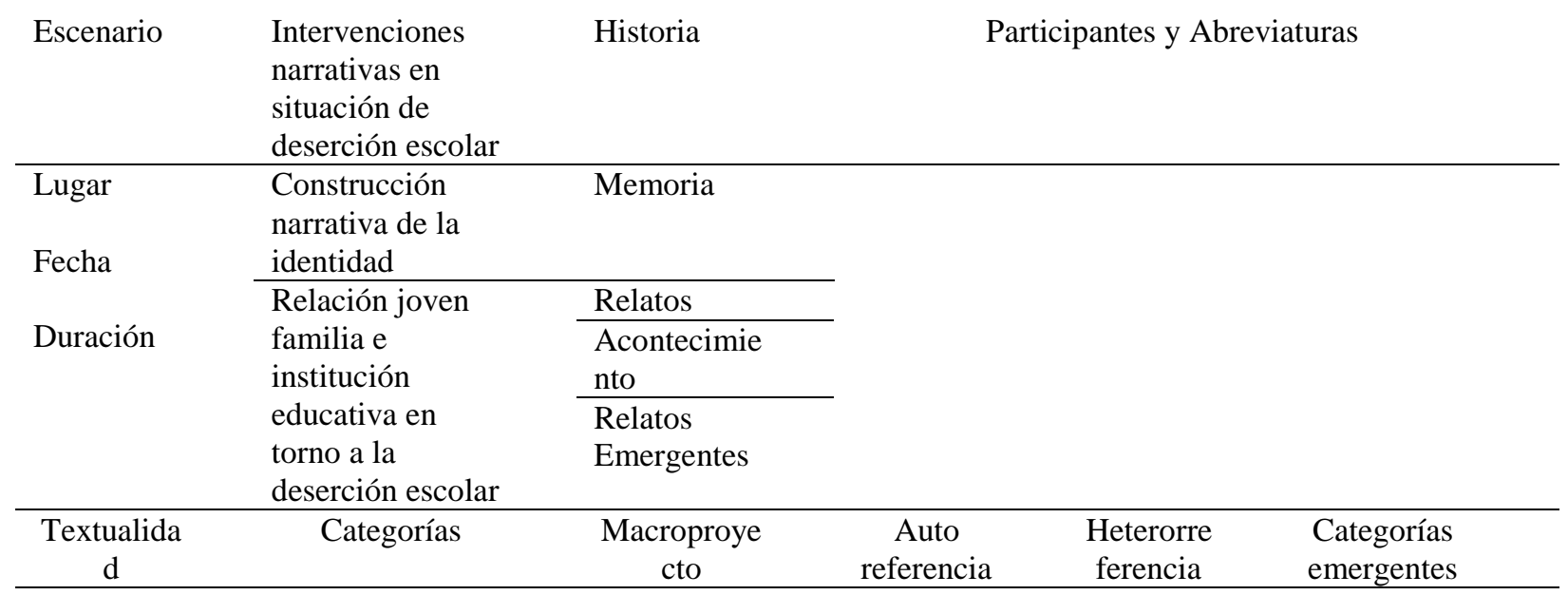




\section{LA DESERCIÓN ESCOLAR COMO PRETEXTO PARA CONVERSAR SOBRE IDENTIDAD, FAMILIA Y ESCUELA

\section{Resultados}

A continuación, se muestran los resultados obtenidos en el presente trabajo de investigación / intervención, y son abordados de la siguiente manera:

a. Se desarrollaron dos escenarios en el contexto educativo con docentes y estudiantes para comprender el fenómeno de la deserción. Desde estos encuentros se identificó el caso a tratar.

b. Se llevaron a cabo cinco escenarios con consultantes, realizados con el sistema familiar, tres con su respectivas grabaciones y transcripciones (ver anexos) y dos de seguimiento, con un intervalo de un año entre el cuarto y quinto escenario.

c. Construcción de matrices de análisis de resultados por cada escenario realizado.

d. Construcción de resultados organizados por conceptos metodológicos.

El análisis de la información se elabora a partir del proceso narrativo conversacional como perspectiva metodológica, al ser parte del macroproyecto de investigación de la maestría en Psicología Clínica y de la familia. Historias y narrativas familiares en diversidad de contextos.

Los resultados se organizan a partir de los tres conceptos metodológicos:

a. Las historias dominantes y su incidencia en la construcción narrativa de la identidad.

b. Las memorias como recurso para comprender como intervenir narrativamente.

c. La relación joven, familia e institución educativa entorno a la deserción escolar y el significado que adquieren los relatos en estos contextos. En cada uno de ellos se encuentran tres órdenes comprensivos de la línea de investigación- intervención (historias, memorias y relatos) los cuales se conectan narrativamente con los tres ejes temáticos.

La construcción narrativa de la identidad, la intervención narrativa en situación de deserción escolar, la relación adolescente, la familia e institución educativa en torno a la 


\section{LA DESERCIÓN ESCOLAR COMO PRETEXTO PARA CONVERSAR SOBRE IDENTIDAD, FAMILIA Y ESCUELA

deserción escolar; en todo este proceso se busca dar cuenta de cómo se ha venido configurando el problema, las movilizaciones y los cambios emergentes en cada uno de los escenarios conversacionales. De la misma manera se presentan los aspectos autorreferenciales y hetero referenciales del proceso conversacional, de la investigadora- interventora y de la familia desde las experiencias vividas dando paso a una co-construccion de aprendizaje mutuo frente a un dilema que fue comprendido desde los diferentes contextos como un problema de la adolescente, dejando de lado las relaciones interinstitucionales y la responsabilidad que debían asumir cada uno frente al fenómeno.

Es importante mencionar que el colegio sirvió como contexto físico para llevar a cabo los encuentros conversacionales y que al hacer el encuentro con los profesionales de la institución educativa ellos referenciaron el caso manifestando que: Esta es una familia que necesita ser atendida.

\section{Encuentro con estudiantes y profesores}

El encuentro con los estudiantes (10 de diferentes grados) tuvo como objetivo, conversar con ellos sobre la deserción escolar, los estudiantes de los grados 9,10 y 11, son quienes más han vivenciado este fenómeno de cerca, comentan haber conocido compañeros que han perdido algún grado escolar o por temas personales se han retirado del colegio, sin embargo existe un punto en el cual confluyen todos, en el colegio si hay deserción u abandono del sistema educativo, los factores son múltiples y ya están consignados en el sistema teórico, sin embargo los estudiantes que pierden el año escolar, generalmente, los estudiantes de los últimos grados (10 y 11) eligen validar o hacer el bachillerato por ciclos, mientras que otros estudiantes cambian de colegio y terminan su bachillerato en otra institución. 


\section{LA DESERCIÓN ESCOLAR COMO PRETEXTO PARA CONVERSAR SOBRE IDENTIDAD, FAMILIA Y ESCUELA

\section{Descripción del caso}

Se realizó un estudio de caso con el sistema familiar compuesto por la madre. M, de 42 años, soltera y madre de tres hijos de relaciones diferentes. Su hija mayor de 27 años, su segunda hija de17 años y su hijo menor de 6 años; actualmente convive con su compañero sentimental y padre del niño. La joven de 17 años es identificada como la persona que requiérela ayuda profesional, teniendo en cuenta los problemas que ha presentado desde la etapa preescolar cuando fue diagnosticada con hiperactividad y dificultades en el aprendizaje, los problemas para la adolescente se agravan al tener una repitencia de tres grados sextos, situación que llevo a la madre a tomar la decisión de desescolarizarla, para que asumiera los roles de ama de casa. En el momento en que se aborda el caso lleva varios años desescolarizada.

\section{Motivo de Consulta}

Identificar las dinámicas relacionales del sistema familiar y escolar, para comprender el motivo de la repitencia de tres grados sexto y las consecuencias que ha tenido en la vida de la adolescente al llevar varios años fuera del sistema escolar.

\section{Sistema Familiar}

El sistema familiar está conformado por la madre (M), dos hijas una de 27 años (D), la segunda de 17 años - consultante - (A) y un hijo de 6 años (L). Cada uno de padres diferentes. Actualmente la madre tiene una relación de pareja activa con el padre (R) su último hijo desde hace 6 años-.

El sistema familiar se conformó de la siguiente manera: la madre (M) tuvo su primera hija a los 14 años, producto de un encuentro sexual de una sola noche, sin tener una relación definida con el padre. De una segunda relación, que se caracterizaba por tener un mayor 


\section{LA DESERCIÓN ESCOLAR COMO PRETEXTO PARA CONVERSAR SOBRE IDENTIDAD, FAMILIA Y ESCUELA

compromiso ya que la relación duro aproximadamente 12 meses y la mantenía en la

clandestinidad, nace otra niña que hoy tienen 17 años; dicho embarazo fue el motivo para que la relación terminara por tanto la relación paterno filial fue de abandono. La tercera relación de pareja que estableció M tiene un tiempo de 6 años y se considera una relación estable, donde este hombre $(\mathrm{R})$ ha servido como figura paterna para la segunda hija, de esta relación hay un niño de 6 años. Esta relación se caracteriza por vínculos de amor y de acercamiento entre sus miembros (madre, padrastro e hijo), sin embargo, las relaciones fraternales son distantes y conflictivas, con el actual compañero de la madre y la joven de 17 años, no se presenta conflicto, aunque las relaciones son distantes e invalidantes.

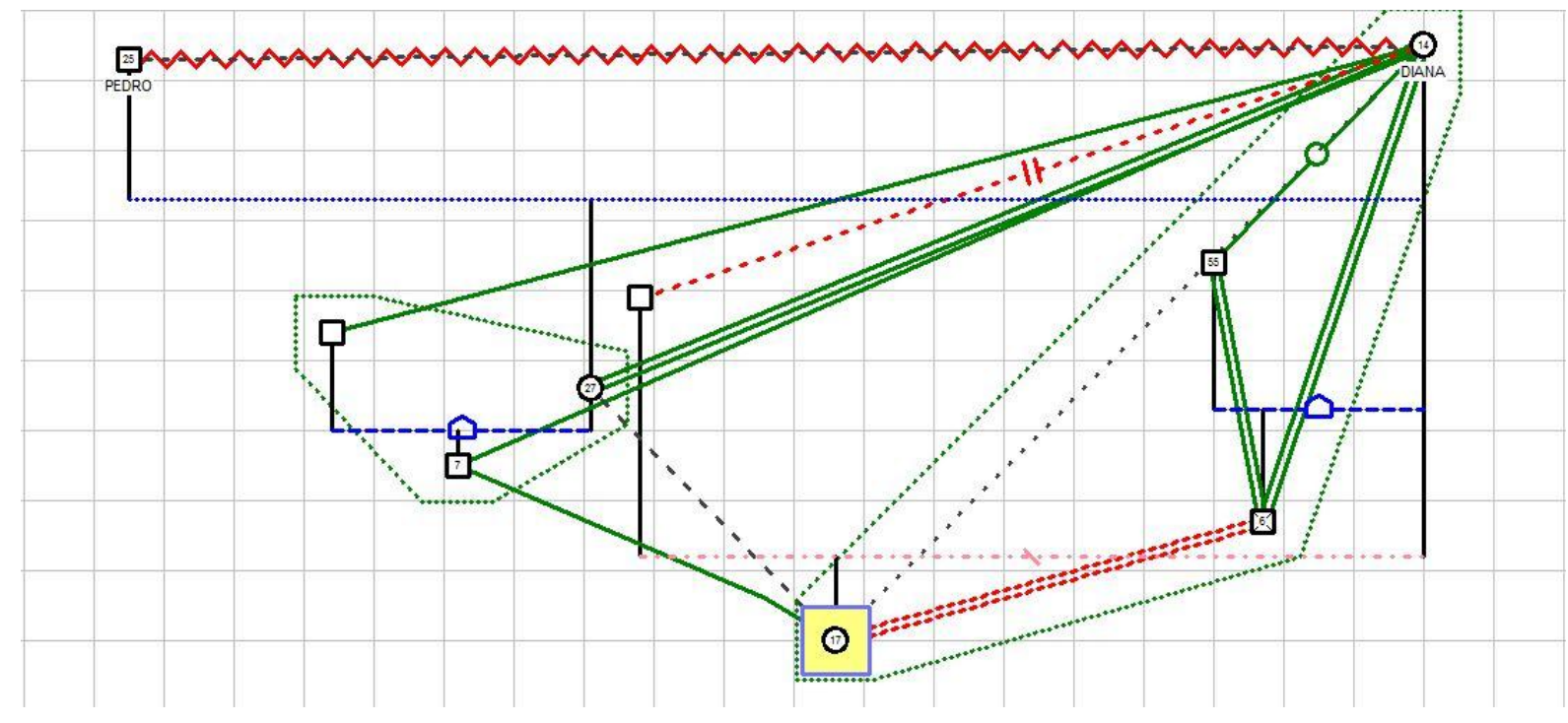

Figura 3. Genograma Familiar. La hija mayor (H1) no convive con el sistema consultante, ella, tienen una relación de pareja legalmente conformada y un hijo de 7 años.

\section{Lectura ecosistémica del caso}

En el sistema familiar se percibe unos vínculos afectivos difusos en la relación parental, y un escaso compromiso de la madre en relación con el problema de repitencia y desescolarización que ha venido presentando su hija, refiriendo " ya estoy cansada de llevarla 


\section{LA DESERCIÓN ESCOLAR COMO PRETEXTO PARA CONVERSAR SOBRE IDENTIDAD, FAMILIA Y ESCUELA

a todos lados pero ella no quiere estudiar ni hacer nada" desde el primer encuentro la madre aborda un relato dominante, y descalificante entorno al problema de su hija, invalidando por completo su voz, y responsabilizándola del problema que está viviendo, no se percibe intención de movilizarse en torno a él. Por su parte las instituciones no asumieron su responsabilidad frente a la situación problema, siempre lo direccionaron a otros profesionales, posiblemente buscando ayudar a la joven o con la intensión de evadir su responsabilidad, quedando triangulada en medio de dos sistemas sociales que tienen la responsabilidad de generar espacios de convivencia y bienestar a la adolescente.

\section{Proceso terapéutico}

A partir de tres encuentros conversacionales y dos seguimientos al caso se generaron movilizaciones en torno al problema de investigación- intervención. Se aborda el sistema familiar desde los recursos y posibilidades que tienen para lograr los objetivos propuestos inicialmente, para ello se utilizan preguntas circulares las cuales permitieron indagar sobre la problemática, también se utilizó la confrontación a partir de la cual se generó una interacción entre la experiencia de la terapeuta como madre y las vivencias del sistema familiar posibilitando la evolución y transformación del cambio, finalmente se aborda la externalización estrategia que posibilitó la lectura del problema fuera de la adolescente quitando la etiqueta con la cual había sido rotulada desde el sistema familiar y escolar generando nuevas posibilidades.

Durante este proceso se emergieron relatos alternos que permitieron que la adolescente se reintegrara al sistema educativo, bajo la modalidad de educación por ciclos, de igual forma se posibilitaron estrategias para la adolescente, encaminadas a su construcción identitaria y su 


\section{LA DESERCIÓN ESCOLAR COMO PRETEXTO PARA CONVERSAR SOBRE IDENTIDAD, FAMILIA Y ESCUELA

proyecto de vida, el restablecimiento de los vínculos parentales y las pautas comunicacionales con los miembros del sistema familiar y social.

En el año 2016 se realizó un seguimiento presencial al caso. Desde el que se evidenció la evolución del sistema familiar, en tanto, la joven está cursando noveno grado y ha sido una de las mejores estudiantes, no ha tenido dificultades de socialización y se ha adaptado al nuevo sistema educativo. A nivel familiar, refiere la madre, los cambios han sido significativos, al narrar a la joven como una joven responsable y autónoma. A mediados del año 2017 se realizó el último seguimiento vía telefónica al caso, con avances significativos en el área escolar, familiar y social, la joven está terminando su bachillerato, cursa grado decimo y entre sus proyectos a corto plazo esta ingresar a la Universidad a estudiar Ingeniería Ambiental. Con este último seguimiento se da por cerrado el caso.

A continuación, se presenta la secuencia de las sesiones de intervención que se desarrollaron, teniendo en cuenta sus objetivos, estrategias y efectos, como forma de modelizar y operacionalizar el proceso de cambio que tuvo el caso.

Tabla 13.

Información por sesiones

Información de las sesiones llevadas a cabo en el caso I

\begin{tabular}{|c|c|c|c|c|c|c|}
\hline Sesión & Asistente & $\begin{array}{c}\text { Efectos de la } \\
\text { sesión anterior }\end{array}$ & $\begin{array}{l}\text { Resumen de la } \\
\text { sesión }\end{array}$ & $\begin{array}{c}\text { Cierre de la } \\
\text { sesión }\end{array}$ & Objetivos & Estrategias \\
\hline 1 & $\begin{array}{l}\text { Madre e } \\
\text { Hija }\end{array}$ & & $\begin{array}{l}\text { Sesión cargada de } \\
\text { relatos } \\
\text { dominantes(madr } \\
\text { e), escasa } \\
\text { movilización para } \\
\text { la adolescente, } \\
\text { invalidación en su } \\
\text { construcción } \\
\text { identitaria, }\end{array}$ & $\begin{array}{l}\text { Se generan } \\
\text { reflexiones, } \\
\text { orientadas a } \\
\text { movilizar al } \\
\text { sistema familiar } \\
\text { entorno al } \\
\text { problema, se } \\
\text { dejan algunas } \\
\text { tareas y se }\end{array}$ & $\begin{array}{l}\text { Desarrollar el } \\
\text { motivo de } \\
\text { intervención de la } \\
\text { familia, } \\
\text { comprendiendo la } \\
\text { construcción de } \\
\text { los consultantes } \\
\text { por medio del } \\
\text { relato de su }\end{array}$ & $\begin{array}{l}\text { Encuentro } \\
\text { conversacional, } \\
\text { traído al contexto } \\
\text { mediante la } \\
\text { narrativa y } \\
\text { preguntas } \\
\text { circulares }\end{array}$ \\
\hline
\end{tabular}




\section{LA DESERCIÓN ESCOLAR COMO PRETEXTO PARA CONVERSAR SOBRE IDENTIDAD, FAMILIA Y ESCUELA

maltrato

psicológico y

físico termina la

sesión

preguntando que

se llevan de este

encuentro.

\begin{tabular}{|c|c|c|c|c|c|c|}
\hline 2 & $\begin{array}{l}\text { Madre e } \\
\text { Hija }\end{array}$ & $\begin{array}{l}\text { En el relato } \\
\text { de la madre, } \\
\text { no se } \\
\text { evidencian } \\
\text { cambios con } \\
\text { su hija, en la } \\
\text { lectura que } \\
\text { hace la } \\
\text { terapeuta } \\
\text { existe un } \\
\text { desafío de la } \\
\text { hija hacia la } \\
\text { madre, de } \\
\text { acuerdo con } \\
\text { su postura } \\
\text { corporal }\end{array}$ & $\begin{array}{l}\text { Es una sesión de } \\
\text { confrontación, se } \\
\text { moviliza el } \\
\text { sistema familiar } \\
\text { entorno al } \\
\text { problema, se } \\
\text { abordan los } \\
\text { factores que han } \\
\text { incidido en el } \\
\text { problema de } \\
\text { deserción escolar } \\
\text { de la joven y la } \\
\text { responsabilidad } \\
\text { que tiene el } \\
\text { sistema escolar y } \\
\text { familiar. }\end{array}$ & $\begin{array}{l}\text { Es una sesión } \\
\text { que le permite } \\
\text { visualizar a la } \\
\text { madre nuevas } \\
\text { posibilidades } \\
\text { para su hija, } \\
\text { dejar de tratarla } \\
\text { como la } \\
\text { causante de } \\
\text { todos los } \\
\text { problemas y } \\
\text { generar relatos } \\
\text { alternos, } \\
\text { disminuye la } \\
\text { culpa de la } \\
\text { adolescente. }\end{array}$ & $\begin{array}{l}\text { Indagar el relato } \\
\text { que tiene el } \\
\text { sistema familiar } \\
\text { acerca de la } \\
\text { deserción escolar } \\
\text { y la identidad } \\
\text { construida en } \\
\text { familia } \\
\text { Comprender la } \\
\text { construcción } \\
\text { identitaria a } \\
\text { través de la } \\
\text { historia del } \\
\text { sistema familiar } \\
\text { en las narrativas. }\end{array}$ & $\begin{array}{l}\text { Relato } \\
\text { conversacional, } \\
\text { de } \\
\text { confrontación, } \\
\text { las historias } \\
\text { cambian por } \\
\text { memorias, } \\
\text { posibilitando } \\
\text { nuevos recursos } \\
\text { para las } \\
\text { comprensiones } \\
\text { del caso. }\end{array}$ \\
\hline & $\begin{array}{l}\text { Madre e } \\
\text { Hija }\end{array}$ & \begin{tabular}{l}
\multicolumn{1}{c}{ Se } \\
producen \\
cambios \\
significativos \\
en la actitud \\
de la madre, \\
a partir de su \\
experiencia \\
de vida se \\
identifican \\
relatos \\
alternos, \\
igualmente, \\
la \\
adolescente \\
propone \\
alternativas \\
para dar fin \\
al problema \\
de deserción \\
escolar, \\
comunicándo \\
le a la madre \\
cuáles son \\
sus intereses \\
para dar \\
continuidad a \\
sus estudios.
\end{tabular} & $\begin{array}{l}\text { Se generan relatos } \\
\text { alternos, que dan } \\
\text { respuesta a la } \\
\text { pregunta } \\
\text { problema de la } \\
\text { investigación- } \\
\text { intervención, se } \\
\text { restablecen los } \\
\text { vínculos } \\
\text { parentales, la } \\
\text { madre acepta la } \\
\text { propuesta de su } \\
\text { hija de dar } \\
\text { continuidad a sus } \\
\text { estudios a través } \\
\text { de la modalidad } \\
\text { por ciclos. }\end{array}$ & $\begin{array}{l}\text { Se hace el cierre } \\
\text { del caso, } \\
\text { recogiendo con } \\
\text { el sistema } \\
\text { familiar los } \\
\text { momentos más } \\
\text { relevantes de los } \\
\text { encuentros y lo } \\
\text { que cada } \\
\text { consultante se } \\
\text { lleva de la } \\
\text { experiencia } \\
\text { vivida. } \\
\text { Encontrando } \\
\text { gran } \\
\text { satisfacción en } \\
\text { el sistema } \\
\text { familiar, ellas } \\
\text { comprendieron } \\
\text { el papel que } \\
\text { tienen las } \\
\text { instituciones } \\
\text { frente a las } \\
\text { dificultades de } \\
\text { los estudiantes, } \\
\text { al no existir una } \\
\text { co- relación } \\
\text { entre los dos } \\
\text { sistemas, } \\
\text { igualmente se } \\
\text { abordó toda la } \\
\text { experiencia } \\
\text { vivida por la }\end{array}$ & $\begin{array}{l}\text { Identificar el } \\
\text { significado } \\
\text { construido en } \\
\text { torno a la } \\
\text { deserción escolar } \\
\text { en adolescentes, } \\
\text { teniendo en } \\
\text { cuenta la } \\
\text { repercusión de } \\
\text { este fenómeno en } \\
\text { la configuración } \\
\text { de experiencia y } \\
\text { en los relatos } \\
\text { identitarios. }\end{array}$ & $\begin{array}{l}\text { Se utilizaron } \\
\text { estrategias } \\
\text { como la } \\
\text { autorreferencia, } \\
\text { la hetero } \\
\text { referencia, la } \\
\text { confrontación y } \\
\text { la } \\
\text { externalización } \\
\text { para la } \\
\text { movilización } \\
\text { del caso, las } \\
\text { hipótesis } \\
\text { iniciales fueron } \\
\text { cambiando } \\
\text { hasta llegar a la } \\
\text { co-evolución } \\
\text { del problema a } \\
\text { niveles } \\
\text { vinculares de } \\
\text { respeto entre las } \\
\text { consultantes. }\end{array}$ \\
\hline
\end{tabular}

experiencia. 


\section{LA DESERCIÓN ESCOLAR COMO PRETEXTO PARA CONVERSAR SOBRE IDENTIDAD, FAMILIA Y ESCUELA

\begin{tabular}{|c|c|c|c|c|c|}
\hline & & & $\begin{array}{l}\text { adolescente. La } \\
\text { madre agradece } \\
\text { a su hija } \\
\text { reconociendo } \\
\text { como su } \\
\text { dificultad le } \\
\text { sirvió a ella para } \\
\text { lograr los } \\
\text { objetivos que } \\
\text { tenía para su } \\
\text { proyecto de vida }\end{array}$ & & \\
\hline $\begin{array}{l}\text { Madre e } \\
\text { Hija }\end{array}$ & $\begin{array}{l}\text { Pasado un } \\
\text { año de haber } \\
\text { realizado la } \\
\text { última sesión } \\
\text { de los neo- } \\
\text { diseños, se } \\
\text { realiza un } \\
\text { encuentro } \\
\text { ocasional } \\
\text { con la madre } \\
\text { y la joven, se } \\
\text { evidencian } \\
\text { cambios } \\
\text { significativos } \\
\text { en la relación } \\
\text { parental, } \\
\text { hablan de los } \\
\text { acercamiento } \\
\text { s } \\
\text { emocionales } \\
\text { que han } \\
\text { tenido, están } \\
\text { planeando la } \\
\text { fiesta de los } \\
\text { 15 años de la } \\
\text { joven y la } \\
\text { dinámica } \\
\text { relacional } \\
\text { familia e } \\
\text { institución } \\
\text { El } \\
\text { rendimiento } \\
\text { académico es } \\
\text { sobresaliente } \\
\text { y el sistema } \\
\text { familiar ha } \\
\text { retomado sus } \\
\text { diferentes } \\
\text { roles. }\end{array}$ & $\begin{array}{l}\text { Fue una sesión } \\
\text { corta, en la que se } \\
\text { pudo evidenciar } \\
\text { claramente los } \\
\text { cambios } \\
\text { comportamentales } \\
\text { de la adolescente, } \\
\text { una construcción } \\
\text { identitaria en } \\
\text { proceso, claridad } \\
\text { en relación con } \\
\text { las metas } \\
\text { propuestas y una } \\
\text { madurez } \\
\text { emocional. }\end{array}$ & $\begin{array}{l}\text { Un sistema } \\
\text { familiar } \\
\text { diferente al que } \\
\text { se atendido } \\
\text { inicialmente, } \\
\text { existen roles } \\
\text { definidos, } \\
\text { cambios } \\
\text { significativos en } \\
\text { las dinámicas } \\
\text { relacionales y } \\
\text { sociales. }\end{array}$ & $\begin{array}{l}\text { Realizar } \\
\text { seguimiento al } \\
\text { proceso } \\
\text { interventivo, para } \\
\text { evidenciar los } \\
\text { cambios en el } \\
\text { sistema familiar } \\
\text { después de un } \\
\text { año de haber } \\
\text { concluido el } \\
\text { proceso. }\end{array}$ & $\begin{array}{l}\text { Un pretexto } \\
\text { para hacer } \\
\text { seguimiento al } \\
\text { caso y conocer } \\
\text { los efectos de la } \\
\text { terapia. }\end{array}$ \\
\hline 5 Madre & $\begin{array}{l}\text { Se realiza } \\
\text { una llamada } \\
\text { telefónica a } \\
\text { la madre con } \\
\text { el objetivo }\end{array}$ & $\begin{array}{l}\text { Fue una sesión en } \\
\text { la que la madre } \\
\text { genera } \\
\text { comprensiones } \\
\text { que le permiten }\end{array}$ & $\begin{array}{l}\text { Se realiza el } \\
\text { cierre definitivo } \\
\text { del caso, con un } \\
\text { balance } \\
\text { satisfactorio por }\end{array}$ & $\begin{array}{l}\text { Corroborar las } \\
\text { movilizaciones } \\
\text { que se generaron } \\
\text { durante el } \\
\text { proceso }\end{array}$ & \\
\hline
\end{tabular}




\section{LA DESERCIÓN ESCOLAR COMO PRETEXTO PARA CONVERSAR SOBRE IDENTIDAD, FAMILIA Y ESCUELA

\begin{tabular}{|c|c|c|c|}
\hline $\begin{array}{l}\text { de hacer el } \\
\text { cierre final al } \\
\text { caso. } \\
\text { Emerge por } \\
\text { parte de ella } \\
\text { un discurso } \\
\text { generativo, } \\
\text { con palabras } \\
\text { que } \\
\text { describen lo } \\
\text { orgullosa que } \\
\text { se siente de } \\
\text { los logros } \\
\text { obtenidos } \\
\text { por su hija, } \\
\text { se destaca } \\
\text { entre las } \\
\text { mejores } \\
\text { estudiantes } \\
\text { de la } \\
\text { institución, } \\
\text { además de } \\
\text { ser la } \\
\text { personera. }\end{array}$ & $\begin{array}{l}\text { comprender como } \\
\text { fue abordado el } \\
\text { caso de su hija } \\
\text { desde el déficit, la } \\
\text { responsabilidad } \\
\text { de las } \\
\text { instituciones, la } \\
\text { culpabilidad que } \\
\text { siente al haber } \\
\text { sido parte del } \\
\text { rotulo que durante } \\
\text { años le colocaron } \\
\text { a su hija y la falta } \\
\text { de afecto y de } \\
\text { apoyo que le falto } \\
\text { darle. }\end{array}$ & $\begin{array}{l}\text { los efectos de la } \\
\text { intervención, a } \\
\text { través de este } \\
\text { seguimiento se } \\
\text { pudo evidenciar } \\
\text { que el tiempo } \\
\text { que estuve } \\
\text { trabajando en el } \\
\text { proyecto de } \\
\text { grado, no se } \\
\text { presentó } \\
\text { desligamiento } \\
\text { del caso, hoy } \\
\text { que está a punto } \\
\text { de concluir este } \\
\text { trabajo, la joven } \\
\text { está culminando } \\
\text { su bachillerato y } \\
\text { tiene proyectado } \\
\text { ingresar a la } \\
\text { Universidad a } \\
\text { estudiar } \\
\text { Ingeniería } \\
\text { Ambiental. }\end{array}$ & $\begin{array}{l}\text { interventivo- } \\
\text { terapéutico al } \\
\text { sistema familiar y } \\
\text { los avances y } \\
\text { efectos de la } \\
\text { terapia sistémica } \\
\text { breve. }\end{array}$ \\
\hline
\end{tabular}

A partir de estos encuentros conversacionales, de las comprensiones del sistema consultante y la terapeuta se lograron movilizaciones acerca de cómo el sistema organiza las historias y los propósitos que cada miembro tiene en dicha organización.

Las voces convocadas en los tres escenarios hablan de la experiencia narrativa de la terapeuta, una madre y su hija que se encuentra desescolarizada desde hace varios años. En este proceso emergen historias dominantes de la madre en relación con lo que ha sido el problema de su hija desde que inicio el grado sexto, permitiendo la apertura de relatos alternos a través de estos se ampliaban las comprensiones del problema. Durante el proceso la investigadora- interventora comprendió y movilizo la experiencia narrada del sistema familia, al igual que los relatos dominantes de la madre.

\section{Comprensiones sobre la operación de los conceptos metodológicos}

Construcción Narrativa de la identidad. 


\section{LA DESERCIÓN ESCOLAR COMO PRETEXTO PARA CONVERSAR SOBRE IDENTIDAD, FAMILIA Y ESCUELA

La construcción narrativa de la identidad del sistema familiar y de la adolescente ha transitado generacionalmente desde el déficit, bajo la premisa que a los hijos se les debe demostrar afecto solo cuando están pequeños, en este sentido no existe una nutrición emocional y un escaso reconocimiento para la adolescente. Desde los escenarios conversacionales se generaron reflexiones acerca de la importancia de establecer relaciones con diferentes contextos para que la joven se sintiera reconocida, valorada y que le permitiera experimentar un bienestar interno, con el fin de articular el contexto familiar y social que le permitiera definir un rol. Igualmente se generaron espacios reflexivos orientados a restablecer el vínculo parental y afectivo, posibilitando un acercamiento y una comunicación clara que les permitiera ir co-construyendo mutuamente una nueva identidad.

Sin embargo, se entiende que la identidad es una construcción que cambia de acuerdo con determinadas situaciones.

Lo expuesto anteriormente, permite comprender que el ser humano se constituye como un sistema auto organizado, el cual se va construyendo a sí mismo de manera constante siendo un sistema dinámico, con una relativa independencia respecto al contexto lo que permite ir evolucionando y construyendo su propia identidad, por medio de la apertura comunicacional que mantiene consigo mismo y con otros contextos.

Desde esta perspectiva, la construcción de la identidad es vista en esta relación con el significado del ser persona, y por tanto se reconoce el rol que tiene la persona y su ambiente más cercano en dicho proceso de construcción, reconociendo principalmente la labor que tiene la familia, la escuela y los contextos de interacción social, debido a que las interacciones que construyen al sujeto, las experiencias vividas y el entramado de significados influyen en la manera en la que el mismo se define y se comporta. 


\section{LA DESERCIÓN ESCOLAR COMO PRETEXTO PARA CONVERSAR SOBRE IDENTIDAD, FAMILIA Y ESCUELA

Por consiguiente, las narrativas son parte de un proceso de socialización, las cuales pueden contar con múltiples interpretaciones derivadas de la experiencia, así mismo, la forma de expresar todo ese mundo interno es la narrativa, a través de la cual se construye, reproduce mantiene y transforma la realidad de los grupos y sus integrantes dándoles forma y sentido a la vida. El orden lógico, dice que en la narración suceden cosas lógicas y cosas que suceden con la lógica, por consiguiente, debe ser verosímil para generar algún tipo de convicción. El orden de configuración es el orden en que sucedieron los acontecimientos y cómo se cuenta lo que sucedió, mientras que el orden interactivo, es aquel que se configura a partir de la persona que narra o el terapeuta.

Para la comprensión de cómo los procesos identitarios se configuran se tendrán en cuenta las historias, memorias y relatos alternos emergentes en los escenarios de investigación/ intervención.

\section{Historias.}

\section{Escenario 1 Construcción Narrativa de la Identidad.}

La historia que configura la identidad de la adolescente, evidencian situaciones conflictivas con su contexto familiar y escolar, en este caso la construcción narrativa de la identidad es borrosa, no existen situaciones anexas que permitan la construcción de nuevos relatos, su narrativa es pobre, tornándose repetitiva frente a las experiencias vividas de dolor y desesperanza, las cuales involucran sentimientos más profundos expresados a través del silencio y del llanto su corporalidad confirma como se está narrando aun sin palabras, la madre narra esta situación como un desacato a lo que ella espera que su hija diga, quisiera que ella se expresara y dijera como se siente pero su hija esta tan invalidada que prefiere callar. 


\section{LA DESERCIÓN ESCOLAR COMO PRETEXTO PARA CONVERSAR SOBRE IDENTIDAD, FAMILIA Y ESCUELA

En ese aspecto yo le he dicho a ella, se inscribió a un curso virtual del Sena, y las dos primeras semanas eso mejor dicho no hacía sino metida en eso, y dije bueno...De un momento a otro no volvió a hacer, ¿Qué paso con lo del curso? Si, si ahí voy, si, si y el que días le dije, pues no, yo no lo he vuelto a hacer, no volvió a hacer nada, no es que es difícil, y a todo lado donde uno vaya uno va a encontrar, dulzura y candor, entonces tú no puedes esperar de llegar, hoy puede ser el colegio, mañana es un trabajo, pasado mañana es una familia... el mundo (C1, esc1, linea134).

Desde la experiencia de la madre, intenta hacer una reflexión a su hija, sin embargo, se evidencia un total control en las actividades que le tiene planeadas, invalidando los procesos identitarios y de toma de decisiones de la adolescente.

\section{Escenario 2 Construcción Narrativa de la Identidad.}

La construcción identitaria de la consultante y la madre se encuentra atravesada por relatos asociados al afecto, y a la creencia que el que da afecto pierde. Además, consideran que para triunfar en la vida uno se debe hacer fuerte, narrando esa fuerza como la imposibilidad de ser sensible para no ser afectado en el mundo. La madre de nuevo manifiesta en cada intervención que no puede hacer nada, o que ya no sabe qué hacer, anclando el problema dentro de sus raíces. Para la consultante continúa siendo difícil intervenir, y construir fácilmente historias que le permitan explorar lo que siente. La madre de la consultante se narra desde el déficit desde la experiencia vivida en las etapas de su ciclo vital, su relato es poco posibilitador, aunque habla desde su historia de vida, pero no se ve una transformación que le permita reinventarse. 


\section{LA DESERCIÓN ESCOLAR COMO PRETEXTO PARA CONVERSAR SOBRE IDENTIDAD, FAMILIA Y ESCUELA

Pues sí, por lo general, yo le hablo a ella...o sea le pregunto alguna cosa. Por ejemplo, llego". Jum se queda mirándome fijo y no me responde absolutamente nada. $\mathrm{O}$ algo, por ejemplo, que ella haga algo malo y yo le digo “¿por qué hizo esto?” igual, queda hermética y no me contesta una sola palabra. (C1, esc 2. Línea 19).

La madre intenta establecer comunicación con su hija, es evidente que la forma de abordarla no permite que se abra la posibilidad al diálogo, provocando frustración en ella, evidenciando a través de este acto, la imposibilidad de la adolescente frente a su construcción identitaria, su silencio es una forma de corroborarlo.

A partir del segundo escenario se generan relatos alternos, dando paso a otras formas de concebir el mundo, aparte de ser bachiller, la invitación que hace la terapeuta es a explorar esas alternativas.

Y si ella lo tomara como una alternativa para futuro otras cosas que la hagan feliz y que la hagan sentir realizada ¿Qué pensarían? Por ejemplo, L, ¿qué ha pensado? “Listo yo...puede que no sea muy buena para matemáticas ni para inglés, pero tengo otra opción" en qué han pensado. Porque es que yo las veo tan en línea recta, que si no es el bachillerato no hay otras alternativas, entonces ¿L se va a quedar ahí en casa eternamente? (P, esc 2, línea 100).

Ser bachiller para la madre es sinónimo de conseguir un trabajo y poder acceder a un trabajo que le permita independencia económica a su hija, la propuesta que hace la terapeuta es contemplar la posibilidad de aprender un arte, el cual también le va a proveer recursos e independencia económica. Así se gira en torno a la historia dominante que tiene la familia por el ser alguien en la vida y se confrontan dichos significados quedando debelado el nivel emocional y vincular de la relación. 


\section{LA DESERCIÓN ESCOLAR COMO PRETEXTO PARA CONVERSAR SOBRE IDENTIDAD, FAMILIA Y ESCUELA

\section{Escenario 3 Construcción Narrativa de la Identidad.}

Se construye con la consultante nuevas perspectivas identitarias, dentro del problema, explorando otras posibilidades como los aciertos que tiene frente a los retos que se impone para aprender cosas nuevas, se propone elaborar una bitácora de actividades semanales que le permita planear las actividades del día a día con el fin de aprovechar el tiempo libre en actividades que le agraden, dejando de lado el ocio y la desmotivación, se utilizaron las experiencias vividas como recurso de aprendizaje para el fortalecimiento de su perspectiva vital.

En estos nuevos aprendizajes se puede visualizar el cambio, es decir, el aprendizaje de una acción simple dentro de un contexto determinado le permite una adaptación al medio, en el cual se pueden reconocer diferentes formas de aprendizaje y de adaptación, para el caso que se está interviniendo estos nuevos aprendizajes le permiten a la consultante tener un cambio correctivo en relación con su situación de desescolarización y los proyecto que tiene planeados a futuro. A través de la experiencia vivida durante los dos años que lleva sin asistir al colegio se han generado diferentes crisis las cuales le permiten al sistema de- construirse generan cambios co- evolutivos.

"Sí, yo te todo esto le dije que...lo que su merced dice es cierto o sea desde...desde...si me lo vendieron a mí, imagínese a ella, que era pues...una niña. De que "no podía" y que "no podía”.” (C1, esc 3. Línea 135)

La madre genera un proceso reflexivo, desde donde cuestiona de manera crítica la postura de otros al leer a su hija como incapaz y donde ella también se sumó a estas voces, asumiéndolas como una verdad, así admite que siempre le hicieron creer a ella y a su hija, que 


\section{LA DESERCIÓN ESCOLAR COMO PRETEXTO PARA CONVERSAR SOBRE IDENTIDAD, FAMILIA Y ESCUELA

(A) era incapaz de aprender, identifica la narrativa dominante que siempre mantuvieron los dos sistemas, escolar y familiar.

En este escenario se evidencia con más claridad como el sistema familiar se moviliza en busca de nuevas posibilidades, los relatos alternos emergen con más facilidad. Como lo muestra el relato la madre, a continuación:

Sí...si claro. Pero sí obviamente si yo se lo he dicho a ella, si yo no la quisiera "no, que me importa, pues yo mejor tenerla ahí y quien me cocine" yo antes le diría "no, no, no, no vaya a estudiar...quédese ahí quieta (C1, esc 3, línea 163).

La madre reconoce su cambio, manifiesta querer a su hija y preocuparse por su desescolarización, es evidente que es consiente que pudo hacer muchas cosas por su hija, pero que sus intereses personales primaron sobre los de su hija.

\section{Memorias.}

\section{Escenario 1 Construcción Narrativa de la Identidad.}

En la construcción narrativa de la identidad de la adolescente se aprecian diferentes situaciones que dan cuenta de los dilemas que viven madre e hija los cuales se construyen desde la circularidad manteniendo la pauta de interacción comunicacional como cuando la madre recuerda "siempre que la mando a tender la cama"(C1, esc1, línea 106), lo que muestra un entramado de significados de invalidación que se conectan de manera simétrica en la cotidianidad, generando mensajes que se enmarcan en contradicciones como hago caso de lo que no deseo y reconozco que el otro hace aunque hace sin querer hacer.

En la interacción institución educativa y estudiante se puede percibir que existen patrones sociales preestablecidos, una normatividad rígida que impide construir su identidad a partir de 


\section{LA DESERCIÓN ESCOLAR COMO PRETEXTO PARA CONVERSAR SOBRE IDENTIDAD, FAMILIA Y ESCUELA

la aceptación y de la diferencia, "ella es otro niño en el colegio” (C1, esc1, Línea 33) es lo que opinan los profesores de ella por gustarle jugar futbol.

Desde la intervención clínica se busca la creación de nuevos significados más que la corrección de las disfunciones o del déficit, convirtiendo lo que para otros es lo no normativo, en un recurso de la propia identidad.

C2. "Pues creo que, ósea, el Gran Colombiano y psi si, el ambiente era como muy muy feo y malas amistades fume" (C2, esc1, línea 89).

La narrativa da cuenta de la percepción que tiene cada una, en el caso de la hija es capaz de asumir su realidad y de enfrentarse a ella, aun por encima de lo que piense la mamá.

\section{Escenario 2. Construcción Narrativa De La Identidad.}

Se generan memorias frente a la llegada del hermano de la consultante, y los cambios que ocurrieron en ese momento, el cambio de primaria a bachillerato, y las nuevas adaptaciones necesarias dentro de la adecuación de un nuevo contexto familiar y escolar, y como estas pudieron ser factores dentro de la percepción actual de problema, en consecuencia se concibe la familia como un sistema que a su vez forma parte de sistemas más amplios y complejos, en este proceso el sistema consultante ha ido participando de la danza interrelacionar facilitando la comunicación como medio de ayuda, permitir el afrontamiento, aliviar el malestar y ajustar las expectativas que tienen en relación con el proceso adelantando.

"No...no le paraba bolas (risa) por decirlo así, porque todas las terapias que recibía eran solo "dime tu nombre, dibuja a tu familia, has un rompecabezas..." y ahí terminaba" (C2, esc2, línea 27). 


\section{LA DESERCIÓN ESCOLAR COMO PRETEXTO PARA CONVERSAR SOBRE IDENTIDAD, FAMILIA Y ESCUELA

Los intentos fallidos en las intervenciones terapéuticas ayudan a que el problema se mantenga, convirtiéndose en dilema para familia más que en recurso para solucionar problemas.

\section{Relatos Alternos.}

\section{Escenario 1 Construcción Narrativa de la Identidad.}

En este caso no se identificaron relatos alternos. Posiblemente el sistema necesita reflexionar sobre lo conversado durante el encuentro, las confrontaciones que se han generado de interacción conversacional, las preguntas circulares y reflexivas les ha permitido visualizar otras posibilidades frente al problema.

\section{Escenario 2 Construcción Narrativa de la Identidad.}

Dentro de las comprensiones que se generan en este escenario, se visualizó la construcción que hace A, frente a su gusto por la música, la sensación de realización de parte de ella, se empiezan a generar nuevas narrativas, la madre, sin embargo, se mantiene escéptica, y se desliga para ver el problema desde afuera, desde la cibernética de segundo orden la cual incluye el observador como parte de lo observado, en la que los mecanismos de comunicación y control permiten que el sistema reoriente su camino para alcanzar su objetivo, lo que se percibe es una falta de compromiso de parte de la madre para construir con su hija nuevas alternativas en relación con el problema, sin embargo L, contempla opciones alternas como la música, diferentes a ser bachiller.

"Pues hasta ahora, me he concentrado más...en lo que más he pensado es en lo de la música" (C2, esc2, línea, 120) Se retoma la construcción que hace $\mathrm{A}$, de pensar en alternativas diferentes a ser bachiller, sin embargo, se evidencia una ambivalencia en sus palabras, ella 


\section{LA DESERCIÓN ESCOLAR COMO PRETEXTO PARA CONVERSAR SOBRE IDENTIDAD, FAMILIA Y ESCUELA

finalmente sabe que su madre no va a aprobar esta alternativa porque va a ser una alternativa que no va a generar recursos económicos para que ella pueda ser independiente económicamente.

\section{Escenario 3. Construcción Narrativa De La Identidad.}

Se identifican nuevas narrativas, y posibilidades, las cuales le permiten al adolescente sentir que hay una apertura para su futuro, disminuir la tensión de la madre es generar un ambiente más tranquilo para A.

De hecho, de todos los años que llevo con ella en terapias, es la primera vez que veo una luz (risa) en el camino, porque antes no, llegó un momento en el que nos aburrimos porque como que llegamos ahí pero "qué hacemos aquí" "qué sacamos de esto" "pa’ donde vamos" (C1, esc3, linea132)

Se identifican relatos alternos frente al problema ya que la madre menciona que ha sido complejo el hecho de abordar la problemática, sin embargo, logra ver una luz de solución, lo cual implica una postura generativa frente al problema.

\section{Nuevas comprensiones de la deserción escolar}

La relevancia del presente trabajo surge del aporte que hace la terapia sistémica a una familia en un contexto de vulnerabilidad en el que se encuentra una adolescente "L" al llevar varios años desescolarizada. Esta intervención se realiza con el sistema familiar (madre e hija). Retomando las construcciones epistemológicas y paradigmáticas del enfoque sistémico constructivista-construccionista, a partir de los cuales los sistemas son vistos de manera compleja. 


\section{LA DESERCIÓN ESCOLAR COMO PRETEXTO PARA CONVERSAR SOBRE IDENTIDAD, FAMILIA Y ESCUELA

Este proceso interventivo buscó un acercamiento respetuoso, no culposo. Se ve a las personas como expertos en sus vidas, al externalizar el problema se asume que las personas tienen habilidades, competencias y compromisos que los lleva a reducir la influencia del problema. Mediante la técnica de externalización y confrontación se llevó a cabo el proceso terapéutico, permitiendo la apertura de un espacio para que el sistema familiar actuara en contra del problema, logrando visualizar nuevas posibilidades, reduciendo de manera significativa la culpa que le habían impuestos otros sistemas involucrados en el fenómeno que L estaba viviendo.

\section{Historias.}

\section{Escenario 1 Intervenciones Narrativas en situación de deserción escolar.}

En las intervenciones se configuraron historias, acerca de cómo percibe la mamá a su hija por no responder a las expectativas académicas que tiene visualizadas para ella, "Para que no se quede ahí pa' que la mangoneen de aquí a mañana pa' lado y lado”. En este sentido se percibe una parentalidad poco nutricia que se liga por el deber ser a nivel productivo y no por el cómo construimos familia. La adolescente se convierte en el problema, en este escenario la voz de L no se escucha, en su rostro se percibe dolor, sus ojos están llenos de lágrimas al escuchar como su mama la descalifica duramente. La madre busca desvincularse dejándole toda la responsabilidad a su hija (C1, esc 1, línea 117).

Honestamente yo la miro y le veo todo lo malo por todas partes, cosas que le digo haga y no lo ha hecho y todos los días es el mismo problema entonces yo le decía a ella, no por mí, porque yo no espero de aquí a mañana que me dé, pero por lo menos decir ella tiene, aunque sea con qué defenderse (C1, esc 1, línea 108). 


\section{LA DESERCIÓN ESCOLAR COMO PRETEXTO PARA CONVERSAR SOBRE IDENTIDAD, FAMILIA Y ESCUELA

La madre expresa abiertamente el desagrado que siente por su hija, nominándola como una carga más. La intervención de la terapeuta va más allá de comprender como una madre es tan descalificante con su hija, cuando ella ha estado por años encerrada en su casa colaborando para que su mamá pueda cristalizar sus proyectos, se genera un espacio en el cual se pide respeto por la menor y ser consecuente frente a lo expresado

\section{Escenario 2 Intervención Narrativa en situación de deserción escolar.}

Continúan las narrativas dominantes, la madre culpa a su hija de irresponsable, se genera una fractura en el sistema parental, la madre no asume su rol en la construcción del problema, esta situación le permite juzgar el problema poniéndolo en la hija y no en la relación, así se mantienen el problema en la interacción sin solución. Las narraciones de la madre están orientadas a imposibilitar a su hija para que se produzca un cambio, describiéndolo como una falta de responsabilidad frente a su futuro al no interesarse por el estudio. Por ser una persona relajada que no hace caso, que no hace nada. Lo que A, relata es diferente al referirse a una rutina diaria, cuidar a su hermano de 5 años, abrir y atender una miscelánea, vender minutos y encargarse de los oficios de la casa. Sin embargo a la madre no quiere reconocer que su hija le aporta mucho más de lo que ella percibe, para ella su hija es "un caso perdido", el silencio que A guarda ante las acusaciones de su mamá, causan ira, llevándola a exteriorizar el castigo que le ha impuesto a su hija por la pérdida de los años escolares, si estudia y no pierde los años, no trabaja más en la casa, pero mientras no tome la decisión de responsabilizarse frente al estudio seguirá en casa haciendo todas las labores y solo tiene como recompensa la comida.

Muchas veces yo se lo he dicho si me quiere decir "no la admiro" "la odio" "vieja desgraciada" dígamelo, pero dígamelo no me importa lo que me diga, pero dígamelo, pero 


\section{LA DESERCIÓN ESCOLAR COMO PRETEXTO PARA CONVERSAR SOBRE IDENTIDAD, FAMILIA Y ESCUELA

hable, exprese algo. Muchas veces la he molestado, mejor dicho, me toca casi amenazarla para que me suelte, aunque sea una palabra (C1, Esc2, Lin8).

La madre describe la comunicación que existe entre las dos como una generación de narrativas en contextos amenazantes y obligantes.

\section{Escenario 3 Intervenciones Narrativas en situación de deserción escolar.}

En este escenario se exploran las narrativas del problema en tiempo pasado generando nuevas comprensiones de un mejor futuro que permitan utilizar las lecciones aprendidas y generar nuevas comprensiones del problema para el sistema familiar.

A, habla de lo importante que es para ella sentirse valorada y reconocida en la familia, le cuenta a la mamá que factores incidieron en la perdida de los años escolares, el desacierto que tuvieron algunos profesores al rotularla como la niña problema y los compañeros al discriminarla por jugar futbol, la llegada del hermanito a la familia, sentirse desplazada por él bebe e ignorada por su hermana mayor al igual que no sentirse amada por su mamá, fueron relatos que al escuchar la madre la sorprendieron, debido a la falta de comunicación y de vinculación emocional entre ellas.

Vamos, averiguamos y mira las instalaciones, hablas con la gente toca mirar porque, de todas maneras, pues tampoco puedo ir a dejarla en el primer lugar que haya...

Tampoco... hay gente demasiado mayor, gente que ya no es para ti, gente con más experiencia de muchas cosas, entonces pues no es bueno, lo ideal sería en ese sitio que he visto que hay como más o menos muchachos... (C1, Esc3, Lin 50). 


\section{LA DESERCIÓN ESCOLAR COMO PRETEXTO PARA CONVERSAR SOBRE IDENTIDAD, FAMILIA Y ESCUELA

Se construye una nueva narrativa para el afrontamiento del problema, hay un acercamiento no solo físico si no emocional madre e hija, que permite evidenciar nuevas formas de relación, la madre empieza a posibilitar procesos de autonomía a su hija.

\section{Memorias.}

\section{Escenario 1 Intervenciones Narrativas en situación de deserción escolar.}

Mediante las experiencias vividas y narradas por la joven y la madre se generaron relatos que amplían las comprensiones del problema, L, habla de la escasa comunicación que hay entre ellas, desvinculación afectiva y desconfianza, igualmente se genera incomprensión de la forma como era rotulada, una niña con dificultades para aprender, con déficit de atención, además parece otro niño, le gusta el futbol, lo que llevo a la adolescente a sentirse desmotivada para seguir estudiando.

"varias veces en el colegio se tocó ese tema con los profesores, porque los niños, pero entonces las quejar eran que "ella era la que les pegaba, que los molestaba, que no ¡sí!”, entonces ella empezó a tratarla como un niño, hasta una profesora misma dijo “A es un niño más en el salón... (C1, esc1, línea 26).

Todo esto generó un impacto negativo, su rol como estudiante se desconfiguraba, dando paso a la marginalidad social influyendo negativamente en su construcción identitaria.

\section{Escenario 2 Intervenciones Narrativas en una situación de deserción escolar.}

Las intervenciones se centran en las percepciones de la consultante frente a la llegada de su hermano, considerándolo como un posible factor en la pérdida de interés por el estudio, sentirse desplazada por la llegada de un nuevo miembro al hogar impacto negativamente en el colegio, su actitud cambio, se aíslo, buscaba llamar la atención con actos de indisciplina para 


\section{LA DESERCIÓN ESCOLAR COMO PRETEXTO PARA CONVERSAR SOBRE IDENTIDAD, FAMILIA Y ESCUELA

que le pusieran cuidado. "Y pasó un año y nada...entonces sí que fue peor.” (C1, esc 2, línea 86).

En este sentido se presentan acontecimientos relevantes que cambian la historia de A, mientras ella, buscaba con sus actos ser reconocida y comprendida, en la familia, la marginaban y cada vez le exigían más, se había convertido en un verdadero problema, lo mismo sucedía en el colegio, no recibían niños repitentes, así que debía buscar otro colegio, en la nueva institución las cosas no cambiaron mucho, ignorada, rotulada, comparada con los niños por gustarle jugar futbol, otro año perdido, la situación empeoraba para A, castigos físicos, otro año, es recibida en otro colegio pero allí solo asiste un mes y decide no volver, sin embargo todo este dilema siempre fue asumido por A, quien termino llevando la peor parte, tres años desescolarizada asumiendo roles que eran propios de la madre.

\section{Escenario 3 Intervenciones Narrativa en situación de deserción escolar.}

En este escenario se realizan reflexiones acerca del futuro de A, se confronta la situación con la adolescente, preguntándole si quiere seguir con la misma rutina, a lo que ella responde con la cabeza que no, la terapeuta, recoge la experiencia vivida en los años que estuvo en casa, las cosas que dejo de vivir como adolescente y las implicaciones que tiene para su futuro, la madre menciona que esos años fueron de angustia puesto que no sabía que iba a pasar con su hija.

\section{Relatos Alternos.}




\section{LA DESERCIÓN ESCOLAR COMO PRETEXTO PARA CONVERSAR SOBRE IDENTIDAD, FAMILIA Y ESCUELA

\section{Escenario 1 Intervención Narrativa en situación de deserción escolar.}

Se construyeron las primeras comprensiones en cuanto a la relación madre e hija, fomentando el inicio de una conversación más clara. A, empieza a expresar con timidez todo aquello que le generaba temor.

"C2 (...) Pues...Si. Pero pues tanto como... que solo me pusieran atención a mí y no a mi hermano...pero pues de todos modos mi hermano...es un bebé. Pues ahí era más chiquito y pues obviamente, no tenía la misma atención ¿no?” (C2, esc 1, línea 68).

A, busca la validación de su mamá o de la terapeuta, tratando justificar su comportamiento frente a la llegada del bebé y expresar como toda la atención era para él, mientras ella era ignorada.

\section{Escenario 2 Intervenciones Narrativas En Deserción Escolar.}

La percepción que A, tiene acerca de la llegada del bebe permite nuevas comprensiones del caso, y la incidencia que tiene en los comportamientos de ella en casa y en el colegio. Obviamente, no tenía la misma atención ¿no?... (C2, escenario 2, línea 61). Los temores iniciales fueron corroborados con el pasar de los días. Aunque existe un reconocimiento por parte de la madre sobre las labores que la joven realiza en casa, su narrativa continúa siendo dominante frente al problema de su hija, como último recurso contempla la posibilidad de que A, aprender un arte, algo que le permita ser autosuficiente económicamente. Mediante la confrontación la terapeuta emerge en el caso a partir de su experiencia de vida, hablando de los errores que se cometen en la adolescencia como posibilidades que nos permiten reflexionar y aprender una lección, incitando con esto al sistema familiar para que contemplen nuevas posibilidades. 


\section{LA DESERCIÓN ESCOLAR COMO PRETEXTO PARA CONVERSAR SOBRE IDENTIDAD, FAMILIA Y ESCUELA

\section{Escenario 3 Intervención Narrativa en situación de deserción escolar.}

Pues, lastimosamente, pues de su tragedia me beneficié yo (risas). Pero si, gracias a ti he podido hacer mis cosas, tú me has colaborado mucho. Tú has tenido mucho que ver en mi proceso tú no quisiste estudiar, no quisiste aprovechar esa oportunidad la voy a aprovechar yo...y lo hice (C1, escenario 3- línea 34).

La madre inicialmente habla del cambio que ha tenido su hija, sin embargo, su narrativa sigue siendo dominante y de escasa generatividad, considera que la experiencia vivida por A, le ayudo a madurar y a aprender la lección para que no la vuelva a repetir, le cuesta reconocer que gran parte de su éxito como estudiante y como profesional es por la ayuda que A, le ha proporcionado en estos años que estuvo desescolarizada, sin embargo continua culpándola por no haber aprovechado la oportunidad que le dio y por no haber querido estudiar.

Para finalizar este apartado se reconfiguraron nuevas comprensiones sobre los relatos alternos, por su parte A, comunica a su madre todos los eventos que le generaban temor, igualmente la madre, reconoce como su hija contribuido a su proceso de formación, finalmente en el contexto conversacional se posibilito un espacio en el que madre e hija se ponen de acuerdo para buscar una alternativa de estudio que ponga fin al proceso de desescolarización de A.

\section{Relación Joven, Familia e Institución Educativa en Torno a la Deserción Escolar}

La familia y la escuela son dos contextos que comparten la misma persona, la hija y alumna a la vez, existe la necesidad de que estos dos contextos se acerquen y compartan las relaciones escuela y familia, se hace necesario comprender el papel que juega la familia en la educación de los hijos, y las interacciones posibles que surgen en torno a estas relaciones, sin embargo, es necesario mencionar las configuraciones de las nuevas familias, las cuales se 


\section{LA DESERCIÓN ESCOLAR COMO PRETEXTO PARA CONVERSAR SOBRE IDENTIDAD, FAMILIA Y ESCUELA

alejan un poco de los modelos sociales preconcebidos, de la misma manera se encuentran familias que sufrieron procesos migratorios, con situaciones de inestabilidad laboral y económica encontrando una gran diversidad en estas familias que no les permite encuadrar en los grupos convencionales tradicionales, igualmente existen diferencias en las relaciones que se establecen entre los docentes y los padres de familia y la forma como la escuela genera esos acercamientos.

\section{Historia.}

\section{Escenario 1 Relación joven, familia e institución educativa, en torno a la deserción}

\section{escolar.}

La madre relata el problema que vive al estar su hija desescolarizada, a su vez la adolescente menciona las dificultades que tiene para comunicarse con su madre, y el miedo que siente de la reacción que pueda tener ante una experiencia vivida, situación que emerge en el contexto y que altera a la madre, reclamándole por las veces que la ha defendido, llevándola a no aceptar lo que su hija le expresa, finalmente la madre confirma que trata a su hija con dureza porque lo considera necesario.

Pues es un problema grandísimo, es un problema que no solamente del momento, sino uno lo piensa (la mamá tose) a futuro, sobre todo pues el futuro de ella. El problema percibido por la madre representa una construcción narrativa dominante, relacionándola dentro de los diferentes contextos, que se configuran como preocupaciones y la forma como visualiza el futuro de su hija (C1, esc 1, línea 9).

Se mantiene el problema desde la narrativa dominante del déficit, es decir, desde la discriminación que vivió L. Se percibe narrativas estereotipadas ligadas a la práctica del 


\section{LA DESERCIÓN ESCOLAR COMO PRETEXTO PARA CONVERSAR SOBRE IDENTIDAD, FAMILIA Y ESCUELA

futbol, al gustarle un deporte que supuestamente solo es practicado por el género masculino, sin embargo, la situación más relevante para que el problema se mantuviera fue el enterar a los profesores del diagnóstico que tenía la joven desde temprana edad, lo que género que desde un primer encuentro ya fuera identificada como una niña con dificultades para poder avanzar en su proceso escolar.

\section{Escenario 2 Relación joven, familia e institución educativa en torno a la deserción} escolar.

En este escenario las historias son deficitarias, la adolescente trata de evadir las preguntas, dándole la razón a la madre al referirse a ella como una persona poco comunicativa.

\section{Escenario 3 Relación joven, familia e institución educativa en torno a la deserción} escolar.

En este escenario se empiezan a generar movilizaciones en torno al caso, la madre expresa su preocupación por la situación actual de A, contemplando otras posibilidades que le permitan aprender un arte o algo que le guste, su relato sigue siendo dominante al reprocharle a su hija por el dinero que ha invertido sin tener resultados, le entrega nuevamente la responsabilidad del futuro a su hija, siendo esta una forma de evadir la responsabilidad que tiene como madre, por su parte la joven manifiesta en el contexto de terapia que desea validar su bachillerato, siendo este el recurso que sirvió para movilizar el caso y darle un giro a las narrativas dominantes de la madre, el cambio es evidente, se percibe un acercamiento, una preocupación de la madre por el bienestar de su hija, de igual forma la joven hace un acto reflexivo acerca de la experiencia vivida en el colegio, las inasistencias y sus experiencias como ama de casa, se genera un espacio autorreferencial en el cual la madre comenta su 


\section{LA DESERCIÓN ESCOLAR COMO PRETEXTO PARA CONVERSAR SOBRE IDENTIDAD, FAMILIA Y ESCUELA

experiencia como estudiante y los temores que la embargaban al enfrentarse a un contexto social ajeno a ella.

\section{Memorias.}

\section{Escenario 1 Relación Joven, Familia e Institución Educativa En torno a la Deserción}

\section{Escolar.}

La adolescente expresa el temor que siente de contarle a su mamá como los niños se burlan de ella y le ponen apodos, las relaciones con sus compañeros de clase son escasas al igual que con los profesores, igualmente refiere sentirse muy sola y no tener a quien contarle lo que le pasa, la terapeuta indaga si en algún momento han consultado otros profesionales, entonces sorpresivamente la madre, muestra la carpeta con los diagnósticos que le han dado a su hija los diferentes profesionales. fisiatría, piscología y neuropsicología, menciona que desde la etapa de preescolar su hija ha asistido con diferentes profesionales y que los diagnósticos son dificultades para aprender y déficit de atención, con un coeficiente intelectual por debajo de lo normal, sin embargo con esfuerzo puede lograr lo que se proponga, igualmente refiere que ella siempre le comenta a los profesores la dificultad que tiene su hija con el fin de que le dediquen un poco más de tiempo y le presten más atención. En esta historia se hace difícil comprender cuál es la posición de la madre frente a la dificultad que presenta su hija, al parecer poco le importarle lo que su hija le dice, vuelve a las historias dominantes acerca de la desobediencia y la falta de interés en el estudio. Desde una lectura ecológica del caso se puede evidenciar una desmotivación de parte de A, al sentir que nadie se interesa por ella o por lo que le pasa, existe una comunicación vertical, la madre ordena, la hija obedece, los vínculos afectivos son difusos y las relaciones parentales son poco nutricias, en relación con 


\section{LA DESERCIÓN ESCOLAR COMO PRETEXTO PARA CONVERSAR SOBRE IDENTIDAD, FAMILIA Y ESCUELA

los procesos relacionales con otros contextos se ven fracturados, existe una escasa interacción con otras personas por consiguiente sus narrativas son escasas, situación que se ve reflejada en la inseguridad y el temor que siente para expresarse, en la lectura que se hace de la comunicación analógica, se evidencia que la joven siempre busca la aprobación de la madre para saber que puede decir o si es mejor callar.

\section{Escenario 2 Relación joven, familia e institución educativa en torno a la deserción} escolar.

Se evocan especialmente los intentos infructuosos de terapia psicológica, la cual abandonaron por considerar que no se obtenían resultados. Por otra parte, se retoma el papel del padrastro en la vida de la joven, hallando una buena aceptación de parte de la adolescente, a lo que la madre refiere ella lo reconoce como padre y así lo presenta en el medio social. En relación con el contexto escolar hay una desarticulación en las relaciones familia e institución educativa, se comprende que no existió una relación que les permitiera vincularse y trabajar conjuntamente, para dar solución al problema de A, el colegio solicitaba que llevaran la niña a un psicólogo, la madre la llevaba, pero no existió una correlación, ni estrategia que permitiera abordar la dificultad que presentaba la joven.

\section{Escenario 3 Relación joven, familia e institución educativa en torno a la deserción} escolar.

En este escenario se presentan movilizaciones significativas en la adolescente que le permiten empoderarse de su proceso identitario, la experiencia vivida durante los años de desescolarización la llevaron a reflexionar acerca del futuro que le esperaba si no tomaba decisiones. La oportunidad que tiene de validar y de compartir con otras personas la llenan de 


\section{LA DESERCIÓN ESCOLAR COMO PRETEXTO PARA CONVERSAR SOBRE IDENTIDAD, FAMILIA Y ESCUELA

motivación, comprender que el problema no era ella y que se debía atacar el problema, género en el sistema familiar nuevas comprensiones de la situación, el restablecimiento de las relaciones parentales y posible restructuración de los vínculos afectivos genera en A, seguridad al saber que cuenta con el apoyo de la madre.

\section{Relatos - Alternos.}

\section{Escenario1 Relación joven, familia e institución educativa en torno a la deserción}

escolar.

Se generan compresiones del problema, y la manera como inciden los contextos amplios en la vida de una niña, que desde el inicio de la etapa escolar estuvo identificada como el problema, por no acatar las normas establecidas allí.

Ella tuvo prácticamente desde Kínder, la he llevado al psicólogo, le han hecho terapias de unas de otras, terapia ocupacional, terapia de lenguaje, de psicología, ha estado en neurología, neurología infantil, en psiquiatría infantil, exámenes físicos le estuvo en el neuro fisiatra (C1, escenario 1, línea 40).

Sin embargo, los resultados nunca fueron satisfactorios para la madre, ni para el colegio, se esperaba que la niña mejorara con unas cuantas consultas, pero los resultados eran los mismo, la madre no fue involucrada en los procesos que se adelantaban con la niña, el problema siempre recaía en ella, se pasaba por alto lo que ocurría en el sistema familiar y las relaciones entre profesores y padres de familia.

"Siempre han dicho que ella tiene hiperactividad y atención dispersa, a ella inclusive la medicaron, pero pues el medicamento no se lo quise dar, le dieron ritalin pero no se lo quise dar" (C1 escenario 1- línea 42). 


\section{LA DESERCIÓN ESCOLAR COMO PRETEXTO PARA CONVERSAR SOBRE IDENTIDAD, FAMILIA Y ESCUELA

Inicialmente la madre menciona que no le dio el medicamento, luego acepta que, si se lo dio, pero que le causo efectos secundarios y que no se vieron los efectos que ella esperaba, que su hija mejorara en la parte académica, la madre también habla de unas terapias psicológicas, pero refiere que no hubo ningún cambio, ella esperaba que le hicieran un tratamiento para que su hija mejorara su comportamiento y su desempeño académico. Es evidente que la familia esperaba que fueron otras personas las que llegaran a solucionar el problema, el trabajo realizado por los diferentes profesionales no tuvo ningún efecto en la vida de A, al trabajar desarticuladamente llevo a que se hiciera una lectura lineal del problema, en la que A, era culpable por su mal comportamiento y falta de interés en el estudio.

\section{Escenario 2 Relación joven, familia e institución educativa en torno a la deserción}

escolar.

En este escenario, la consultante empieza a reconocer que se falló así misma y a su familia, generando relatos periféricos en los que resalta la falta de confianza y de voluntad para retomar su futuro, se manifiesta sentimientos difusos en relación con su realidad actual.

El proceso de individuación y autonomía se empieza a construir, sin embargo, la falta de confianza en las decisiones que debe tomar y la búsqueda de aprobación especialmente de la madre son un obstáculo para avanzar, aunque no está de acuerdo en la forma como su madre le organiza la rutina diaria, la acepta con disgusto, pero en ocasiones se revela y contradice las ordenes, aunque después tenga que aceptar las consecuencias, en este momento su narrativa está orientada a un discurso posibilitador. Terminar su bachillerato. Menciona que, aunque lo 


\section{LA DESERCIÓN ESCOLAR COMO PRETEXTO PARA CONVERSAR SOBRE}

IDENTIDAD, FAMILIA Y ESCUELA

había pensado no lo había comentado porque estaba esperando a que su mama terminara el tecnólogo en el SENA.

No, pues porque... por ese lado no recibo quejas. Porque eso llegó un momento en que el colegio se volvió una tortura para mí, yo cruzaba esa puerta y ya me imaginaba los profesores “ta, ta, ta, ta”...pero... La madre intenta construir una narrativa diferente del problema, pero es evidente que es más fácil asumir que le van a dar muchas quejas de su hija, girando de nuevo en torno al problema (C1, esc 2, línea 87).

\section{Escenario 3 Relación joven, familia e institución educativa entorno a la deserción}

\section{escolar.}

En este último escenario, se evidencian las movilizaciones realizadas en el sistema familiar, lo que inicio como otro proceso psicológico, concluyo como un proceso posibilitador de cambios y comprensiones sobre un problema que se había cristalizado frente a la deserción escolar.

De parte mía también le doy las gracias de todo corazón, le doy las gracias a Dios porque pienso que èl fue quien la puso en mi camino y porque desde el día en que su merced me conoció, fijó sus ojos en mi caso. La madre finalmente concluye agradeciendo el proceso, los cambios y nuevas comprensiones que se hicieron durante el proceso $(\mathrm{C} 1$, esc 3 , línea 222).

Se posibilitaron espacios para el restablecimiento de las relaciones parentales, igualmente se generaron comprensiones sobre el problema de deserción escolar, encontrando que la madre aprovecho las supuestas dificultades académicas de su hija, las cuales le reforzaba constantemente con la historia dominante acerca de la falta de interés para estudiar, todo el 


\section{LA DESERCIÓN ESCOLAR COMO PRETEXTO PARA CONVERSAR SOBRE IDENTIDAD, FAMILIA Y ESCUELA

problema podía sustentarlo con los diagnósticos médicos que tenía, convirtiéndose en el motivo que la madre necesitaba para dar continuidad a su proyecto de vida, en este sentido se puede entender que A, fue utilizada en una situación que sirvió como excusa para cumplir los objetivos de la madre. A pesar de las experiencias desagradables que tuvo que vivir, el proceso adelantado en la intervención terapéutica se ve reflejado en el desempeño académico que tres años después ha adelantado A, actualmente está cursando grado decimo y se espera que a finales de este año (2018) se esté graduando como bachiller, en el seguimiento realizado telefónicamente el día 29 de abril, la madre menciona que su hija es otra persona, se han producido cambios significativos en su comportamiento, académicamente es una de las mejores estudiantes de la institución en la que está cursando el bachillerato por ciclos y actualmente se desempeña como personera.

A manera de conclusión se dice que los procesos identitarios de la familia se resignificaron a partir de la interacción que se generó entre sus miembros, se posibilitaron estrategias de afrontamiento personal y familiar, a partir de un proceso dialógico articulado y dinámico, respetando las individualidades pero a su vez manteniendo la interrelación entre sus miembros, restableciendo los vínculos afectivos, permitiendo que la familia genere estrategias de afrontamiento ante situaciones futuras. En relación con las comprensiones que el sistema familiar hizo del problema, madre e hija comprendieron que el problema se generaba y mantenía, en las formas en las que se comunicaban al generarse postura de desconfianza e invalidación se fracturaron las relaciones filiales y parentales. Crear espacios conversacionales generó la externalización del problema por parte de la adolescente, de esta manera madre e hija comprendieron que se debía trabajar en darle solución al problema y no culpar a la joven por las dificultades que había tenido años atrás. 


\section{LA DESERCIÓN ESCOLAR COMO PRETEXTO PARA CONVERSAR SOBRE IDENTIDAD, FAMILIA Y ESCUELA

\section{Consideraciones Auto-Referenciales}

Las Historias que se tejieron en este proceso conversacional y autorreferencial entre la investigadora- interventora y el sistema familiar, tiene como objetivo la búsqueda de las comprensiones del problema y las historias dominante que se cristalizaron en la narrativa de los miembros del sistema familiar; sobre la construcción narrativa de la identidad en la relación entre la joven, la familia y la institución educativa en una situación de deserción escolar.

Mediante el proceso de intervención que se realizó con el sistema familiar, se vivieron momentos difíciles que permitieron que la terapeuta dejara de ser observadora y entrara a formar parte de lo observado, es así como al escuchar la forma en la cual la madre se refiere a su hija, la terapeuta se movilizo como madre y pone un alto al maltrato psicológico y verbal del que está siendo víctima la adolescente, comprensiones que se hacen inicialmente desde el respeto y el cuidado que se debe tener hacia los hijos y luego como terapeuta, al frenar los ataques verbales que la madre emanaba hacia su hija. De la misma forma se interrogo a la señora acerca de cómo se define como madre, pregunta qué se hace la terapeuta desde su autorreferencia llegando a momentos de reflexión sobre lo que implica el amor y el cuidado de un hijo, el deber moral, social y emocional de proporcionarle bienestar y respeto; a partir de estos espacios reflexivos se generaron comprensiones acerca de los modelos de crianza que habían sido transmitidos generacionalmente y los cuales supuestamente habían funcionado, situación que permitió comprender que en determinadas situaciones se utilizan modelos arcaicos que justifican el maltrato físico y verbal, y de acuerdo a las conveniencias se hacen exigencias que obligan a estar frente a un sistema social de alta exigencia para poder ser competitivo. 


\section{LA DESERCIÓN ESCOLAR COMO PRETEXTO PARA CONVERSAR SOBRE IDENTIDAD, FAMILIA Y ESCUELA

Otro momento de movilización se presentó ante la respuesta que dio la madre frente a su hija, el objetivo de la terapeuta era frenar los niveles de agresividad de la madre, los cuales se evidenciaron en su postura corporal, en el lenguaje verbal y no verbal y llevarla a comprender que su hija no era la responsable de las decisiones que ella había tomado. L, no debía seguir pagando por el error que ella cometió, su deber era proteger y apoyar a su hija, no descalificarla y menos darle los castigos de los que hasta el momento había sido víctima, se trae al escenario aparte de la historia personal de la terapeuta con el fin de que el sistema familiar comprenda que todos vivimos situaciones difíciles, la diferencia está en las alternativas que se tienen para el afrontamiento y las redes de apoyo para salir del problema. Se enfatiza en que la principal red de apoyo es el sistema familiar, y desde este se escuchan las dificultades de los miembros que lo conforman.

\section{Consideraciones Hetero referenciales}

En un primer encuentro se encontró con una madre con un discurso saturado y poco generativo en relación con el problema que tiene su hija, su narrativa gira en torno al poco interés que tiene la consultante A en terminar su bachillerato, siendo este el motivo que llevo a la consultante $\mathrm{M}$ a tomar la decisión de asignarle los trabajos de casa a su hija como una forma de castigo, de esta manera la individuación y Autonomía de la consultante dos se divide en dos mundos, uno el de las obligaciones que han sido impuestas por la madre y un segundo mundo que es el internet y las redes sociales, el cual es configurado como su mundo personal.

En relación con la comunicación es muy escasa, la madre ordena y la hija obedece, no existe una interacción conversacional ni una vinculación afectiva, la configuración del mundo personal de la consultante no existe porque su mamá es quien planea todas sus actividades. 


\section{LA DESERCIÓN ESCOLAR COMO PRETEXTO PARA CONVERSAR SOBRE IDENTIDAD, FAMILIA Y ESCUELA

Este escenario se caracterizó por ser un discurso saturado de la madre para con su hija, fue doloroso escuchar de la voz de la madre los diferentes insultos que lanzaba contra su hija sin ningún tipo de consideración, en el segundo escenario, la voz de la consultante fue traída a escenario, las pocas veces que hablo fue muy asertiva aunque con cierto temor hacia la madre, estos diálogos se convirtieron en el grito de la adolescente para decir, existo y estoy cansada de la situación que estoy viviendo, estas expresiones se convirtieron en posibilidades para la construcción de nuevas alternativas que entorno al problema que las convocaba.

En el escenario tres (3) se realizan movilizaciones terapéuticas que dan la posibilidad a la joven de nuevas alternativas para su futuro, la madre reconoce que la posibilidad que ha tenido de prepararse académicamente se la debe a su hija y a los años que ha estado en casa, manejando el negocio y asumiendo tareas que no le corresponden. En relación con este último escenario fue muy satisfactorio ver como a nivel terapéutico se logró movilizar al sistema consultante para que se tuvieran en cuenta otras posibilidades, de igual manera la madre comprendió que el problema no es solo de su hija, que es un problema que involucra a todo el sistema familiar y que todos deben comprometerse con el proceso que está por iniciar su hija. 


\section{LA DESERCIÓN ESCOLAR COMO PRETEXTO PARA CONVERSAR SOBRE IDENTIDAD, FAMILIA Y ESCUELA

\section{Discusión}

En este capítulo se presentan las reflexiones y hallazgos de los resultados, en conversación con los referentes teóricos frente al fenómeno de Construcción y co-construccion narrativa de la identidad en la relación entre la joven, la familia y la institución educativa, en una situación de deserción escolar.

Desde el paradigma de la complejidad se pudo comprender como estaba estructurada la identidad de la adolescente, para Morín (1990) la complejidad nace de la simplicidad en la emergencia de la cotidianidad en diferentes contextos, en la interacción con los otros donde se entretejen relaciones que llevan a construir diferentes mundos, especialmente durante la adolescencia, caracterizada momentos donde los cambios del ciclo vital se experimentan como un reto frente a la generación y emergencia de estrategias de afrontamiento de tipo familiar y personal.

La construcción identitaria nace de la cotidianidad y se va complejizando en la medida en que se emerge en el mundo social, conformando redes significativas, una red social personal que es la que brinda soporte a la joven, en el caso que se intervino terapéuticamente esta red fue escasa, su mundo social era reducido, se limitaba a las interacciones familiares y las personas que llegaban al negocio ocasionalmente, esa característica personal influyó para que el proceso de construcción identitario se generara de manera lenta e insegura.

Las interacciones sociales son el punto desde donde emergen los procesos identitarios para Morín (2004 citado por Barberousse, 2008) la complejidad nace de la interacción de las partes que componen el sistema complejo, es decir, aparece como el resultado de la organización del todo bajo las combinaciones e interacciones que forman la parte constitutiva del mismo, así se establecen los procesos identitarios en las interacciones de sentidos y 


\section{LA DESERCIÓN ESCOLAR COMO PRETEXTO PARA CONVERSAR SOBRE IDENTIDAD, FAMILIA Y ESCUELA

significados que emergen de las relaciones y los múltiples contextos. Lo anterior permitió

comprender que el ser humano se constituye como un sistema auto- organizado e independiente que se va construyendo de manera dinámica, el cual siempre va a estar permeado por el contex to relacional, situación que le permite ir evolucionando y construyendo su propia identidad mediante el lenguaje; a partir de él cada persona se reconoce mediante la construcción que hace de su ser y de su ambiente social, en el que la familia juega el papel más importante, a través de los padres el niño se mira y se va construyendo así mismo, en este contexto se forma el auto concepto y el marco de referencia desde el que interpreta la realidad externa y las propias experiencias generando motivación o desmotivación, según las experiencias vividas, contribuyendo a la salud y al equilibrio personal, es por ello que las interacciones sociales que construye el ser humano y las experiencias vividas tienen gran influencia en la manera como se actúa a lo largo de la vida. Por su parte, Bruner (1969 citado por Estupiñán y González, 2012) refieren que la narrativa es un instrumento simbólico de la cultura a través del cual se construye, reproduce, mantiene y transforma la realidad e identidad de los seres humanos. Todo esto de manera colectiva, social y cultural.

Para Echeverría (1994) la ontología del lenguaje representa una nueva interpretación de lo que significa ser humano, lo cual ha contribuido a la forma como se observa la vida para entender como desde el lenguaje se organiza y transforma la identidad, evitando la separación entre el pensamiento y la acción, él plantea que la acción genera ser, de esta manera se constituye al individuo que habla y al que actúa. En el estudio de caso, cada miembro del sistema familiar, hacia lecturas y comprensiones de las actitudes de los demás miembros, eran interpretadas bajo suposiciones de lo que estaba interpretando, esa dinámica provocaba 


\section{LA DESERCIÓN ESCOLAR COMO PRETEXTO PARA CONVERSAR SOBRE IDENTIDAD, FAMILIA Y ESCUELA

distanciamiento en las relaciones parentales, hecho que se evidencio en los escenarios

conversacionales, porque allí se revelaron situaciones que eran novedosas o de total desconocimiento para los miembros del sistema familiar.

El objetivo general desde el cual se dio respuesta a la investigación- intervención fue comprender como se construye y co-construye narrativamente la identidad de una adolescente en situación de deserción escolar a partir de la relación con su contexto familiar y escolar para movilizar nuevas versiones identitarias que se descentren de la experiencia de deserción. La narrativa conversacional sirvió como hilo conductor a través del cual se tejieron historias de diferentes matices, en algunos momentos cambiaban de color, de blanco a negro profundo, todo este pincelado de colores variaba dependiendo de la persona que narraba la historia, lo que se pudo evidenciar en todo este proceso de pintar y recrear, fue que tanto madre como hija se acostumbraron a pintar sus historias en blanco y negro, olvidando que entre estos dos colores hay una gran gama, si la hija intentaba colorear de un tono diferente no encontraba la aprobación de la madre, por lo tanto solo eran intentos infructuosos por cambiar el color de su historia, es así como la construcción de la identidad de esta adolescente empezó a emerger en la medida que el sistema familiar comprendió que la interacción con el medio social, le permitiría vivir una serie de experiencias y acontecimientos que van a ser reconocidos y guardados significativamente como una experiencia personal y única. Así se pasa de la historia dominante al relato alterno, el cual como un abanico de posibilidades se muestra para ir construyendo y evolucionando de manera dinámica.

Los objetivos específicos permitieron comprender las narrativas identitarias que organizaron la experiencia de deserción escolar en la relación entre la joven, la familia y la institución educativa. 


\section{LA DESERCIÓN ESCOLAR COMO PRETEXTO PARA CONVERSAR SOBRE IDENTIDAD, FAMILIA Y ESCUELA

En este sentido se encontró que en la dimensión personal de la adolescente se construyó una historia imposibilitadora, apoyada en un diagnostico que la rotulo desde el inicio de su escolaridad, generando en la madre inseguridad respecto de las habilidades de su hija, y reforzada en los contextos escolares en los que estuvo la joven matriculada, con mensajes descalificantes y dedicando poca atención a su proceso de aprendizaje, según algunos maestros porque la joven tenía dificultades para aprender, la falta de estrategias pedagógicas y los cambios frecuentes de colegio, que se vieron reflejados en la perdida de cursos en los primeros años de la educación media de la joven. En relación con el rol de las instituciones y los sistemas familiares Dabas (1997) menciona que constantemente se escucha acerca de la necesidad de modificar estas relaciones, sin embargo, para la autora es evidente que los cambios no se dan de manera externa, los cambios están en cada uno de los actores que intervienen en el proceso educativo, en el compromiso que debe existir de parte de los padres para involucrarse en los procesos formativo de sus hijos, en el acompañamiento y en la calidad de tiempo que dedican a ellos. en las relaciones de los docentes con los padres estableciendo canales de comunicación abierta con el fin de generar redes de apoyo para los estudiantes. Es evidente que cada sistema social pide un cambio para que los jóvenes puedan acceder y permanecer en el sistema educativo, sin embargo, los cambios se deben presentar en cada uno de los actores que intervienen en el proceso educativo, en las excelentes relaciones que deben generarse entre padres y maestros, pero también en el compromiso que debe existir de parte de los padres en la educación de sus hijos.

Facilitar la emergencia de memorias y relatos alternos que permitan la construcción narrativa de la adolescente y la familia. En los escenarios conversacionales emergieron memorias subdominantes que le dieron sentido al replanteamiento del problema y 


\section{LA DESERCIÓN ESCOLAR COMO PRETEXTO PARA CONVERSAR SOBRE IDENTIDAD, FAMILIA Y ESCUELA

posibilitaron la apertura de nuevas comprensiones para la intervención clínica, generando relatos alternos desde los sentimientos y vivencias del sistema familiar. Díaz (2006) manifiesta que la escuela y la familia se han concebido como referentes de formación de educación del ser humano, conformando alianzas interconectadas en el tiempo, por periodos largos o cortos dependiendo del ciclo vital del sistema familiar y con pautas de relación que se mantienen a lo largo de la vida, convirtiendo estas dos instituciones en las instancias con mayores recursos para producir cambios.

Fortalecer la co-construccion identitaria a través del tiempo en el que los relatos y las memorias den cuenta del cambio. A través de los seguimientos realizados al caso, se vieron consolidados los procesos identitarios de la adolescente, en el desenvolvimiento y apertura comunicacional con sus pares y maestros, igualmente en la toma de decisiones, el restablecimiento de las relaciones parentales y fraternas y en su perspectiva de vida, en la proyección que tiene como futura ingeniera ambiental.

De igual forma se aborda la pregunta problema. ¿Cómo se relacionan los contextos educativo y familiar, para aportar en la construcción y co- construcción narrativa de la identidad de una adolescente en condición de deserción escolar? Lo que se responde desde la experiencia del caso atendido, desde lo fenomenológico, que posibilita dar respuestas a los fenómenos en su particularidad. Así lo expuesto y comprendido por el sistema familiar y terapéutico, se basó en la no conexión con el sistema educativo, lo que se puede comprender lo menciona Dabas (1988), la familia crea expectativas altas en relación con el éxito escolar de los jóvenes, pero su comportamiento real no coincide con ellas, los comentarios de los padres o de los miembros del sistema familiar modifican o anclan las posibilidades de aprendizaje de sus miembros, ahora se observa cómo funciona la escuela, en este proceso se 


\section{LA DESERCIÓN ESCOLAR COMO PRETEXTO PARA CONVERSAR SOBRE IDENTIDAD, FAMILIA Y ESCUELA

encuentra que funciona como eje articulador de redes, cuya misión es que toda la comunidad educativa participe para fortalecer los sistemas de relación entre los jóvenes y también entre sus familias, en este periodo están aprendiendo a convivir con otros, se presentan momentos de conflictos y de convivencia que es justo lo que están aprendiendo, y la escuela está en la obligación de mostrar otros modelos de convivencia, diferentes a los que traen los estudiantes de sus casas, en esta relación es que se construye y co- construye narrativamente la identidad.

En el caso de estudio la deserción escolar fue el pretexto que encontró la adolescente para hacerse sentir, era un grito desesperado en busca de ayuda el cual decía. Aquí estoy no soy invisible, existo, y fue el mejor pretexto que puedo usar para poder enfrentarse a su contexto familiar y social. Por su parte Benítez (2011) considera que la escuela juega un papel importante en la socialización y en la construcción identitaria de los adolescentes, igualmente sobre las asociaciones que los estudiantes hacen con la palabra proyecto, dichas asociaciones están relacionadas con el estudio, el trabajo, las ocupaciones y finalmente en establecer relaciones para el futuro, al igual que algunos proyectos que anticipan en la construcción de su identidad, también el contexto social tiene gran influencia en las representaciones sociales, especialmente en las diferencias de género, el origen social y las experiencias de vida cotidiana. Se concluye que el cambio de actitud, el restablecimiento de los vínculos parentales y la responsabilidad que cada miembros del sistema familiar asume en relación con el problema, son factores que se ven reflejados en las expectativas que la madre se había planteado inicialmente con su hija, dejar de hablar desde el déficit y co-construir nuevas posibilidades permitió el cambio en todo el sistema familiar y en el nuevo sistema escolar, el cual permitió que la joven dejara de ser vista como el problema, dando la apertura a nuevos retos académicos y sociales, recuperar el tiempo que estuvo fuera del sistema escolar y 


\section{LA DESERCIÓN ESCOLAR COMO PRETEXTO PARA CONVERSAR SOBRE IDENTIDAD, FAMILIA Y ESCUELA

demostrarse a ella y a su familia que era posible cambiar una historia que la había sido cristalizada frente a su problema de aprendizaje y de incapacidad.

Para concluir se abordaron las hipótesis que fueron planteadas inicialmente. Los procesos conversacionales del sistema terapéutico propician la co- evolución del problema a niveles vinculares y de respeto entre los consultantes centrándose en la experiencia de deserción escolar.

Las narrativas de la adolescente evolucionan hacia la construcción de su identidad, en la medida que el sistema familiar construye nuevas lecturas del problema. Se pudo confirmar que a partir de los procesos conversacionales con el sistema terapéutico se propició la coevolución del sistema familiar a niveles vinculares entre los consultantes centrándose en la experiencia de deserción escolar. Las narrativas de la adolescente evolucionaron hacia la construcción de su identidad, en la medida que el sistema familiar resignifico el problema. El sistema familiar, había tenido varias experiencias a nivel terapéutico, con resultados desfavorables para todos; la narrativa se había anclado en una historia dominante e imposibilitadora para la adolescente.

A continuación, se presenta una confrontación de los resultados y los aportes que hacen los diferentes autores desde el estado del arte y el sistema teórico frente a la construcción del fenómeno y las movilizaciones que se presentaron durante el proceso psicoterapéutico en los diferentes escenarios conversacionales. El análisis de la información se elabora a partir del proceso narrativo conversacional como perspectiva metodológica, el cual es parte del macroproyecto de investigación de la maestría en Psicología Clínica y de la familia. Historias y narrativas familiares en diversidad de contextos.

Los resultados se organizan a partir de los tres conceptos metodológicos: 


\section{LA DESERCIÓN ESCOLAR COMO PRETEXTO PARA CONVERSAR SOBRE IDENTIDAD, FAMILIA Y ESCUELA

a. Las historias dominantes y su incidencia en la construcción narrativa de la identidad.

b. Las memorias como recurso para comprender como intervenir narrativamente.

c. La relación joven, familia e institución educativa entorno a la deserción escolar y el significado que adquieren los relatos en estos contextos conversacionales.

Mediante el proceso conversacional se logra comprender como emergen los procesos identitarios en los seres humanos, entendiendo que es un proceso que nace a partir de la experiencia relacional, considerado complejo e ininterrumpido, que se hace presente desde el momento de la concepción y que puede ir hasta la edad avanzada, este planteamiento lo sustentan, Renau, Oberst \& Carbonell (2013), quienes plantean que la construcción de la identidad es derivada y mantenida por la construcción social, realizada entre grupos de personas que comparten opiniones y percepciones de un fenómeno, desde el construccionismo, el "self" social se construye a través de las interacciones que se establecen con los otros. Por consiguiente, es una construcción relacional, en la que el yo es el producto de las relaciones entre seres humanos mediante la comprensión de la realidad. Lo expuesto anteriormente permite comprender que los procesos identitarios de la adolescente se construían en una red social escasa, al no tener la posibilidad de interactuar, inicialmente con sus pares y más ampliamente con el contexto social, sin embargo, mediante el proceso interventivo se trajo al contexto terapéutico la importancia de tener una interacción con otros contextos para empezar a emerger en el mundo social.

De igual forma se abordan las historias como conceptos metodológicos las cuales se identificaron dominantes, especialmente aquellas que eran narradas por la madre, convirtiéndose en una historia circular que le impedía ver otras alternativas. ¿Cómo se comprendieron las historias dominantes en este proceso? La deserción escolar enmarca para 


\section{LA DESERCIÓN ESCOLAR COMO PRETEXTO PARA CONVERSAR SOBRE IDENTIDAD, FAMILIA Y ESCUELA

las jóvenes historias dominantes del sistema familiar, las cuales pasan por los castigos físicos, el maltrato psicológico y las agresiones verbales mutuas.

En este sentido las historias son comprendidas como historias cargadas de poder, en ellas aparecen, padres, maestros profesionales de la salud. Estas historias vienen saturadas de problemas, de relaciones de poder y de actos de resistencia que saturan más el problema y a la vez construyen la identidad desde el déficit, tal y como lo menciona Estupiñán \& González (2006):

Existen relatos personales y colectivos dentro de otros relatos históricos, culturales, sociales y familiares, estos pueden llegar a ser dominantes y compartidos, (historias) marginalizando o imposibilitando la articulación del relato o versión propia, siendo aquellos asumidos como la versión única y correcta para la interpretación y orientación de la propia experiencia y acción (pp.60).

En este sentido la historia dominante de la madre hablaba del deber ser de su hija. Ser bachiller, para que pudiera acceder a un trabajo que le permitiera tener independencia económica, pero a su vez la madre le emitía un mensaje paradójico que le decía usted no lo puede hacer porque es inconstante con sus metas y objetivos. Así gira la historia dominante que tiene la familia por el ser alguien en la vida; se confrontan dichos significados quedando debelado el nivel emocional y vincular de la relación.

Las memorias, a través de ellas se puedo dar cuenta de los cambios en el sistema familiar escenario por el que transita el fenómeno, se encontró que la memoria habla de la experiencia vital organizando y confiriendo sentido a las experiencia propias en sus diferentes dimensiones, presente, pasado y futuro, es partir de estas memorias que se transforma y encuentra sentido a los dilemas de las familias y de otros contextos, en este 


\section{LA DESERCIÓN ESCOLAR COMO PRETEXTO PARA CONVERSAR SOBRE IDENTIDAD, FAMILIA Y ESCUELA

caso, las memorias fueron primordiales para comprender como estaban vinculados

afectivamente los miembros del sistema familiar, cómo se construían las relaciones de poder en el sistema familiar y a su vez comprender, el discurso imposibilitador de la madre en relación con el deber ser de su hija, situación que se comprendió como un mensaje de doble vinculo, en el cual se daba una exigencia clara de parte de la madre en relación con lo que esperaba que hiciera su hija, sin embargo su relato es poco generativo al referirse constantemente a la imposibilidad y la falta de compromiso de ella.

A partir de estas memorias se generaron movilizaciones de apertura al cambio, las valoraciones positivas de sentimientos de satisfacción y de esperanza, en el caso abordado se deconstruyeron las historias para legitimar la memoria como base para la construcción de un relato alterno. Tal y como lo mencionan Estupiñán \& González (2006) las memorias son entendidas como versiones subdominantes, periféricas o marginales, no articuladas en el relato, son versiones que hablan de los acontecimientos y las experiencias vividas y narradas, las memorias aparecen solo en algunas partes del sistema humano que narra.

En relación con los relatos alternos, estos facilitaron la movilización a estadios de coconstrucción e interacción madre e hija, posibilitaron un acercamiento emocional y el restablecimiento de los vínculos parentales, en un primer momento estos relatos fueron de inseguridad por parte de la adolescente, siempre buscando la aprobación de los otros frente a lo expresado, de esta manera se empezó a configurar nuevas formas de comprender y movilizar el problema para su redefinición.

Se construyeron las primeras comprensiones en cuanto a la relación madre e hija, fomentando el inicio de una conversación más clara. La adolescente expresó con timidez todo aquello que le generaba temor. Se presentó un reconocimiento de parte de la madre en 


\section{LA DESERCIÓN ESCOLAR COMO PRETEXTO PARA CONVERSAR SOBRE IDENTIDAD, FAMILIA Y ESCUELA

relación con la ayuda de su hija en las labores de casa, sin embargo, su narrativa continúo siendo dominante frente al problema de desescolarización. Como último recurso contemplo la posibilidad de que su hija aprendiera un arte que le permitiera ser autosuficiente económicamente.

Se utilizó la confrontación de parte de la terapeuta a partir de su historia de vida y de los errores que se comenten en la adolescencia como un aprendizaje que le permite reflexionar y aprender una lección, invitando de esta manera al sistema familiar a contemplar nuevas posibilidades para el cambio.

Es evidente que en este proceso se encontró resistencia al cambio, las historias estaban tan cristalizadas que convertían la narrativa en un relato circular que no permitía avanzar, sin embargo al lograr romper la pauta que los mantenía anclados sobre la deserción y la imposibilidad que veía la madre en su hija, el problema se terminó, dando paso a las narrativas alternas en la resignificación de las historias de vida y los procesos de afrontamiento, de esta manera los acontecimientos y las experiencias son re-narradas como oportunidades para el cambio.

En estos relatos emergieron los nuevos proyectos de la adolescente al proponerle a la madre validar el bachillerato por ciclos, encontrando apoyo en ella, finalmente este proceso llega a su fin, cuando la joven se integra al nuevo sistema escolar, con grandes sorpresas para el sistema familiar pues a la fecha está terminando su bachillerato con excelentes calificaciones, unas buenas relaciones con sus compañeros y maestros, además de ser la personera de la institución, cargo que le ha permitido interactuar con pares de otras instituciones, situación que le ha permitido proyectarse como futura ingeniera ambiental, este recorrido se ha realizado después de los tres escenarios conversacionales y dos seguimientos, 


\section{LA DESERCIÓN ESCOLAR COMO PRETEXTO PARA CONVERSAR SOBRE IDENTIDAD, FAMILIA Y ESCUELA

uno por año, dando por terminado este proceso de manera satisfactoria para el sistema familiar y para la terapeuta.

Los principios operadores utilizados en los escenarios conversacionales fueron otra fuente importante en la movilización del caso. Lo que se evidencian en los resultados obtenidos, la reflexividad, la cual permitió desde la mirada de la terapeuta involucrarse en el caso sin buscar culpables, sin juzgar generando cambios en el sistema consultante mediante los procesos dialógicos, así lo define Varela \& Maturana (1980, citado por Estupiñán, 2006) como un proceso lógico, operacional y generativo. Estos procesos nos invitan a pensar no como seres pre- existentes, por el contrario, emerger y ubicarse en el mundo a través de las prácticas lingüísticas adoptadas como instrumentos para las relaciones y la convivencia de los humanos. De la misma manera se trajo al escenario conversacional la recursividad a través de ella se posibilitaron comprensiones sobre el fenómeno a investigar, entrelazando las historias de la madre con la de la adolescente, las cuales tienen miradas diferentes sobre la socialización y los contextos culturales, escolares y familiares, entretejer estas historias y darles sentido y significado permitió hacer reflexiones con el sistema familiar sobre la situación actual de la adolescente, así lo explican Estupiñán y Gonzales (2012) orienta y conecta niveles y dominios diferentes de información, con el propósito de proponer explicaciones y comprensiones de los fenómenos.

La auto referencia, implica la postura de reconocer y explicitar las propias narrativas, creencias, valores, prejuicios, ideas, emociones, acciones que construyen la realidad de la familia vivida y narrada desde el principio del observador en su observación, haciéndonos responsables de tales construcciones y su incidencia en la práctica investigativainterventiva, como lo mencionan Estupiñán \& Gonzales (2012), de esta manera la terapeuta 


\section{LA DESERCIÓN ESCOLAR COMO PRETEXTO PARA CONVERSAR SOBRE IDENTIDAD, FAMILIA Y ESCUELA

trae al contexto su historia de vida la cual comparte con el sistema familiar a partir de procesos narrativos promoviendo nuevas lecturas de las relaciones y de las interacciones.

En la co- construcción, cuyo proceso se vincula a la transformación de las prácticas narrativas y relacionales en los sistemas familiares y sociales hacia historias más posibilitadoras, generando experiencias de vida productivas en los contextos familiar y social. (Estupiñán, González y Serna 2006) de esta manera el principio conversacional vivenciado en los escenarios permitió comprender las experiencias vividas por cada miembro del sistema familiar, evocando historias y nuevos relatos de las experiencias personales, los cuales adquieren sentido y significado en las nuevas formas de relacionarse y de proyectarse en los diferentes contextos.

\section{Alcances de la investigación- intervención}

El proceso de desescolarización no es infinito en el tiempo, en la mayoría de los casos se presenta una suspensión temporal de los estudios, este factor se presenta cuando el estudiante ha presentado perdida del año escolar o repitencia, por lo general es una opción que se presenta para los jóvenes que cursan los últimos grados, ellos deciden hacer un aplazamiento temporal mientras buscan la opción que más se ajuste a sus necesidades, algunos deciden trabajar y continuar sus estudios en la jornada nocturna, otros prefieren la opción de validar y otros de hacer el bachillerato por ciclos, en otros casos las perspectivas de vida pueden cambiar y deciden optar por otra alternativa, en este caso los jóvenes deciden explorar sus habilidades y profundizar en ellas, es decir, adquirir unas competencias que les van a ser útiles para desempeñarse en el contexto laboral.

El fenómeno de deserción escolar permitió comprender que desde la psicología clínica se deben generar más investigaciones encaminadas a comprender como están vivenciando los 


\section{LA DESERCIÓN ESCOLAR COMO PRETEXTO PARA CONVERSAR SOBRE IDENTIDAD, FAMILIA Y ESCUELA

jóvenes la experiencia de la educación tradicional, cuando existen otras formas de adquirir el conocimiento, los jóvenes son polifacéticos, los contextos socioculturales y los avances tecnológicos les han permitido desarrollar múltiples habilidades, por consiguiente estar encasillados en un modelo de educación tradicional los limita y terminan por abandonar estas instituciones, porque sienten que no tienen la libertad para crear y demostrar sus habilidades. 


\section{LA DESERCIÓN ESCOLAR COMO PRETEXTO PARA CONVERSAR SOBRE IDENTIDAD, FAMILIA Y ESCUELA

\section{Conclusiones}

A continuación, se presenta una síntesis de los de los capítulos que fueron abordados durante el proceso de investigación- intervención, a través de ellos se comprendieron los aportes al fenómeno de la deserción escolar.

\section{Comprensiones sobre el estado del arte}

En este capítulo se abordaron las categorías investigativas- interventivas entorno a la construcción narrativa de la identidad, la deserción escolar y la relación entre el adolescente, la familia y la institución educativa a partir de las comprensiones del fenómeno de estudio, de igual forma se realizaron comprensiones sobre la adolescencia, etapa en la que los jóvenes empieza a sentirse en el limbo, se presentan los cambios físicos y emocionales, se debate entre el ser niño o ser adulto, se producen cambios en las relaciones familiares, generando conflicto entre padres e hijos, se realizan comprensiones sobre los dilemas que se generan en los sistemas familiares, los padres sienten temor por los peligros a los que se exponen sus hijos fuera de casa, se genera una sobreprotección que termina agobiando al adolescente, los padres quieren y desean saber todo lo que hacen sus hijos, con quien comparten, invaden sus espacios vitales generando una fractura en la relaciones parentales que llegan desde las agresiones verbales hasta los castigos físicos y las supuestas lecciones de vida para que no lo vuelva a ser o aprenda, sin tener en cuenta que están interfiriendo en un proceso que empezó desde el mismo momento en que el niño nació y que se ha venido construyendo a lo largo de la vida, solo que esta etapa debe comprenderse como coyuntural porque es dejar de ser niño y continuar construyendo su identidad para enfrentarse a su adultez. 


\section{LA DESERCIÓN ESCOLAR COMO PRETEXTO PARA CONVERSAR SOBRE IDENTIDAD, FAMILIA Y ESCUELA

Igualmente se revisan los aportes que hacen los diferentes autores sobre el problema y las relaciones que se entretejen entre los contextos familiar y escolar aportando a la construcción y co- construcción narrativa de la identidad, desde el recorrido que se hace para la construcción del estado del arte se comprende que la deserción escolar es un fenómeno que se presenta a nivel mundial y que conservan una estrecha relación entre los fenómenos que viven los adolescentes en Colombia y en otros países del mundo, ellos son: embarazos, trabajo infantil, violencia intrafamiliar, la situación de pobreza, suicidio y el bullying. Factores que adquieren gran relevancia en la deserción de los adolescentes del sistema escolar, sin embargo, el papel de algunas Instituciones educativas ha sido de apoyo al adolescente para que no aplace sus estudios e incluso ha servido como mediador entre padres e hijos realizando un trabajo en red que da apoyo a los futuros padres, en otros casos se trabaja de manera desarticulada, tal y como lo menciona Díaz (2006), al referirse al papel que tiene la escuela y la familia como referentes de educación de los jóvenes, considerados referentes de formación, con alianzas interconectadas en el tiempo, dependiendo del ciclo vital del sistema familiar, convirtiendo estos dos contextos en las instancias con mayores recursos para producir cambios. Sin embargo, en esta relación surgen diversos aspectos que dificultan la formación de los adolescentes y es así, cuando cada uno de los contextos empieza a inculpar al otro como artífice de las dificultades en la formación.

Para concluir se comprende la deserción escolar como un fenómeno multicausal que involucra diferentes sistemas, con un llamado a realizar un trabajo en red para disminuir o terminar con él teniendo en cuenta la importancia de los jóvenes y del rol que tienen en la construcción y desarrollo económico del país, de sus procesos de individuación y autonomía, 


\section{LA DESERCIÓN ESCOLAR COMO PRETEXTO PARA CONVERSAR SOBRE IDENTIDAD, FAMILIA Y ESCUELA

la construcción identitaria y su perspectiva de vida, como perspectiva para mejorar su calidad de vida y la de su contexto familiar.

\section{Comprensiones Teóricas}

En relación con el sistema Teórico, sirvió para realizar comprensiones acerca de la construcción de la identidad, desde el paradigma de la complejidad y la visión que cada ser humano tiene de sus múltiples identidades.

Morín (1990) el cual muy acertadamente refiere que la complejidad nace de la simplicidad, en los momentos cotidianos en la relación que se establece con los diferentes contextos, especialmente durante la adolescencia, en donde se empiezan a experimentar diferentes cambios y a generar estrategias personales y familiares de preparación para la vida adulta.

En relación con el papel de la narrativa en el proceso de investigación- intervención se comprendió que es el resultado de las relaciones que establece el sujeto con la sociedad en las diferentes etapas del ciclo vital, a través de las experiencias acumuladas y las interacciones con el contexto social, narra es contar una serie de acontecimientos en un orden secuencial orientados a generar un cambio, existen diferentes tipos de narraciones de acuerdo a los acontecimientos que se deseen abordar, igualmente se entiende la narrativa como un proceso evolutivo, conformado por unas características propias de un individuo o grupo, en el proceso de construcción narrativo de la identidad la familia es fundamental especialmente en la relación madre e hijo debido a la relación vincular que se da en los primeros años de vida, siendo la madre el modelo en el que el niño empieza a reflejarse.

En relación con la adolescencia los jóvenes viven en un mundo lleno de preocupaciones materiales y físicas dejando de lado las experiencias que se desarrollan en la vida diaria mediante las relaciones sociales, siendo estas experiencias las que van forjando en los 


\section{LA DESERCIÓN ESCOLAR COMO PRETEXTO PARA CONVERSAR SOBRE IDENTIDAD, FAMILIA Y ESCUELA

adolescentes los procesos identitarios, también es considerada una etapa de temores para padres y maestros debido a la brecha generacional, los jóvenes maduran más rápido y se empieza a presentar una fractura en los vínculos familiares porque los adolescentes se sienten más identificados con sus pares.

\section{Comprensiones sobre la Metodología}

El proceso metodológico sirvió para comprender como se co-construye el conocimiento y las comprensiones que se hacen del problema, para ello se utiliza la modelización a través de la cual se intenta explicar los significados que tiene para las personas implicadas describir las diferentes rutinas, además mediante los procesos conversacionales se identifican las situaciones problema, este es uno de los procesos más interesantes a nivel terapéutico porque permite que el terapeuta se involucre en sus propias observaciones y en las experiencias de los otros con el fin de llevar un hilo conductor que facilita co-construir y transformar conjuntamente, además de generar procesos reflexivos en los sistemas convocados, el proceso de investigación-intervención se llevó a cabo mediante el estudio de caso el cual es definido por Niño (2011) como un proceso formativo e interventivo a través del cual se muestran los conocimientos adquiridos y las formas de intervenir terapéuticamente, para ello se diseñaron estrategias de intervención que fueron puestas en práctica durante el proceso, estas estrategias fueron seleccionadas porque con ellas se pretendía hacer lecturas complejas para la comprensión del caso, las cuales fueron abordadas durante los diferentes encuentros conversacionales, los principios operadores epistemológicos y paradigmáticos sirvieron para comprender el fenómeno de la deserción escolar desde la cibernética de segundo orden la cual nos invita a involucrarnos en el proceso como observadores participantes. 


\section{LA DESERCIÓN ESCOLAR COMO PRETEXTO PARA CONVERSAR SOBRE IDENTIDAD, FAMILIA Y ESCUELA

A través de los conceptos metodológicos las historias, las memorias y los relatos se comprendieron los dilemas del sistema familiar, igualmente se generaron recurso para su afrontamiento, el contexto utilizado como pretexto para llevar a cabo el proceso de investigación -intervención fue la institución educativa San Jerónimo Emiliani de la ciudad de Tunja. En la construcción de los diseños se realizaron cinco (5) diseños, uno con estudiantes, uno con profesores y tres con el sistema familiar, en la construcción de los neo diseños, se diseñaron tres (3) neo- diseños con el sistema familiar los cuales fueron grabados y transcritos y dos seguimientos después de haber terminado el proceso terapéutico con los cuales se dio cierre al caso con resultados satisfactorios para el sistema familiar y para la terapeuta.

\section{Comprensiones sobre los resultados}

Los resultados dan cuenta del proceso terapéutico que se trabajó con el sistema familiar a partir del proceso narrativo conversacional, organizados desde los conceptos metodológicos para comprender como las historias dominantes mantenían anclado el problema en el sistema familiar y a su vez la incidencia que tenían en la construcción narrativa de la identidad de la adolescente. Entender como operaban las historias en la narrativa, pero a su vez poder identificar a través de las memorias el relato subdominante que permitía identificar otros recursos para ampliar las comprensiones del caso y poder generar movilizaciones al interior del sistema familiar, al igual que la relación que existe entre la adolescente, la familia y la institución educativa en torno a la deserción escolar. Estos cambios emergieron en cada uno de los escenarios conversacionales mediados por confrontaciones auto y hetero referenciales de la terapeuta y de la familia. 


\section{LA DESERCIÓN ESCOLAR COMO PRETEXTO PARA CONVERSAR SOBRE IDENTIDAD, FAMILIA Y ESCUELA

En un primer momento se quiso abordar el problema con jóvenes y docentes de la institución educativa, esto se llevó a cabo dos encuentros, de donde se generó la remisión al sistema familiar con el que se trabajó.

Los encuentros con los estudiantes, para conversar sobre como entienden ellos la deserción escolar, este encuentro posibilito comprensiones sobre la deserción escolar y los factores que inciden en este fenómeno, también se abordó el termino deserción escolar, encontrando en los estudiantes nuevas comprensiones y explicaciones que ellos no comparten, de igual forma posibilitó reflexiones acerca de cómo viven ellos el contexto escolar, el manejo de las normas, la disciplina, los llamados de atención y el uso del uniforme entre otros temas.

El proceso terapéutico se evidencio a partir de las movilizaciones en torno al problema, se abordó el sistema familiar desde los recursos y posibilidades que tenían para lograr los objetivos propuestos inicialmente, para ello se utilizan preguntas circulares las cuales permitieron indagar sobre la problemática, también se utilizó la confrontación a partir de la cual se generó una interacción entre la experiencia de la terapeuta como madre y las vivencias del sistema familiar, posibilitando la evolución y transformación del cambio, finalmente se aborda la externalización estrategia que posibilitó la lectura del problema fuera de la adolescente quitando la etiqueta con la cual había sido rotulada desde el sistema familiar y escolar generando posibilidades de transformación.

Durante este proceso emergieron relatos alternos que permitieron que la adolescente se reintegrara al sistema educativo, bajo la modalidad de educación por ciclos, de igual forma se posibilitaron estrategias para la adolescente, encaminadas a su construcción identitaria y su perspectiva vital, el restablecimiento de los vínculos parentales y las pautas comunicacionales con los miembros del sistema familiar y social. 


\section{LA DESERCIÓN ESCOLAR COMO PRETEXTO PARA CONVERSAR SOBRE IDENTIDAD, FAMILIA Y ESCUELA

En el año 2017 se realizó un seguimiento presencial al caso, desde él, se evidenció la evolución relacional del sistema familiar, la joven está cursando noveno grado y ha sido una de las mejores estudiantes, no ha tenido dificultades de socialización y se ha adaptado al nuevo sistema educativo. A nivel familiar, refiere la madre, los cambios han sido significativos, al narrar a su hija como una joven responsable y autónoma. A mediados del año 2018 se realizó el último seguimiento vía telefónica, con avances significativos en el área escolar, familiar y social, la joven está terminando su bachillerato, cursa grado décimo y entre sus proyectos a corto plazo esta ingresar a la Universidad a estudiar Ingeniería Ambiental. Con este último seguimiento se da por cerrado el caso.

Aportes a la psicología clínica. Este trabajo de grado es una invitación para pensar en una posibilidad de cambio entre la educación, el sistema familiar y la psicología clínica, de generan nuevas posibilidades para los sujetos, aparte de las formas tradicionales de aprender y de transmitir el conocimiento, un dialogo entre saberes que posibilite la apertura a una coconstrucción entre contextos de manera articulada, en el que el objetivo final sea el estudiante. Además, convoca a repensar a la psicología frente a la educación, teniendo en cuenta que desde la psicología clínica no se responde a un solo tipo de estudiante o de aprendizaje, si no que se tiene en cuenta la diversidad de estudiantes y versiones de aprendizajes que definen la identidad y abren la posibilidad de tejer versiones de sí mismo más coherentes con el ser y no con el deber ser. Esto lleva a contextualizar a la persona, a los sistemas familiares y a los contextos educativos.

Aportes a la maestría y al macroproyecto. Esta investigación posibilita la apertura de un trabajo en red, la inclusión de los estudiantes, los padres de familia y los docentes de participar en las dinámicas de inclusión de un nuevo modelo para la educación, desde la 


\section{LA DESERCIÓN ESCOLAR COMO PRETEXTO PARA CONVERSAR SOBRE IDENTIDAD, FAMILIA Y ESCUELA

ecología se propone comprender la diversidad y apuntar a generar nuevas estructuras

curriculares acorde con las exigencias de las futuras generaciones, la globalización y la competitividad laboral a la que se enfrentan los futuros estudiantes. Invita también a conversar con las instituciones desde las historias construidas y las memorias que pueden establecer futuros posibles.

Aportes de la investigadora Interventora. Se generaron comprensiones en relación con el rol que tiene el psicólogo clínico en el proceso terapéutico, la formas de abordar los diferentes sistemas, con una mirada de comprensión a partir de los procesos autorreferenciales, comprender como se deconstruye un problema para entrar a coconstruirlo con el otro posibilitando cambios y reflexiones no solo para el sistema consultante, también la terapeuta, posibilitar espacios nutricios con el asesor para poder tener una mirada ecológica del problema, acatando las sugerencias e interpretaciones desde la mirada y el aporte de un tercero generando comprensiones y autorreflexiones para futuras intervenciones. 


\section{LA DESERCIÓN ESCOLAR COMO PRETEXTO PARA CONVERSAR SOBRE IDENTIDAD, FAMILIA Y ESCUELA

\section{Post- escrito}

Pensar en cambiar o reconfigurar el término "deserción escolar", es todo un reto, sin embargo, es una apuesta que se hace en el momento de hablar de los jóvenes que hacen un alto en su aprendizaje, muchos de ellos cambian de institución educativa ya sea por perdida del año escolar, por aplazamiento temporal, voluntario o forzoso, y esto se convierte casi que, en su pasado judicial, queda rotulado académicamente, llegando a marcar sus vidas de manera negativa. Al indagar el significado de desertor se encontró que hace referencia a dejar de lado los ideales, alejarse de una causa, definición que no coincide con los jóvenes que deben hacer un aplazamiento temporal o definitivo de sus estudios, en muchas ocasiones involuntariamente. La propuesta está dirigida a reconfigurar el término por “AUSENTISMO”. El cual significa la inasistencia de un estudiante a su escuela, teniendo en cuenta que cuando estas faltas se repiten con frecuencia terminan convirtiéndose en un problema social y educativo. Dentro de la narrativa este término es configurado por el sistema escolar y familiar como un desertor de las aulas y del sistema educativo, sin haber comprendido que fue el sistema educativo quien excluyo al joven, por considerar que estaba en edad extraescolar, además de los problemas por las continuas pérdidas convirtiéndolo en un desertor, sin embargo en este caso particular la joven logro ingresar a una nueva modalidad de educación y hoy está concluyendo sus estudios de educación media, existen otros jóvenes que no cuentan con la misma suerte, sin llegar a significar que todos aquellos que no puedan concluir su educación básica y vocacional son desertores, ya que existen otras posibilidades no todos servimos para hacer lo mismo; en estos casos los jóvenes deciden explorar sus habilidades y profundizar en ellas con el fin de adquirir las herramientas y especializarse en un oficio específico que les permita desempeñarse en el futuro.

Durante el proceso terapéutico en el estudio de caso, la construcción identitaria de la familia, los procesos de autonomía y las manifestaciones afectivas, se construyeron en una red relacional interna propia del sistema familiar que no apuntaba a ser la que más les aportaba como sistema familiar, de esta manera se habían configurado como sistema desde un proceso deficitario que los mantenía anclados en preceptos que habían sido transmitidos generacionalmente, así se relacionaban y lo transmitían al sistema escolar, el cual termino 


\section{LA DESERCIÓN ESCOLAR COMO PRETEXTO PARA CONVERSAR SOBRE IDENTIDAD, FAMILIA Y ESCUELA

adoptando la misma postura del sistema familiar, es decir cada sistema evadiendo y delegando la responsabilidad al otro y esperando que uno de ellos tomara la iniciativa de cambio, funcionando de manera desarticulada. Los procesos conversacionales entre los dos sistemas se enmarcaron en una jerarquía de poder en el que sistema educativo colocaba las normas y el familiar obedecía, olvidando que debe existir una correlación basada en el respeto, la comprensión y la colaboración, elementos importantes para transmitir a los jóvenes que se están formando y que necesitan de un modelo con el que se sientan identificados. Al abordar las expresiones de afecto de la familia se lograron identificar varios focos que no les permitía vincularse afectivamente.

El primero es la rabia que siente la madre por su hija, al haber quedado embarazada y por esta situación haber perdido al amor de su vida, luego el abandono del padre de su hija, lo que implico para ella volver a la casa materna con dos hijas pequeñas y ambos sin padre y por último, los constantes reclamos de su hija por saber quién es su padre.

Este entramado relacional se convierte en un arma poderosa para esta madre frente a la inhabilidad de su hija. Al igual que el colegio asumió una actitud de poder frente a ella, castigándola física, verbal y emocionalmente por todo lo que ella sufrió, entendiendo que los castigos que le propiciaba la hacían sentir mejor.

En los escenarios conversacionales emergen estas historias, hiladas a través de una narrativa que la invita a evocar situaciones difíciles que ella no consideraba importantes en este momento. Las memorias que la madre trae al escenario permiten comprender el dolor por la pérdida del hombre que ella ama y también la rabia que siente hacia su hija, culpándola por su falta de compromiso y responsabilidad frente al estudio, es en este proceso autorreferencial es en donde más que ubicarme en el rol de psicóloga o terapeuta me pongo en el rol de madre y no logro comprender como esta mujer es tan cruel e inhumana con su hija, al extremo de decirle que es lo peor que le ha pasado en su vida, todo está mano de reproches me invitan a frenar cada insulto que le propiciaba a su hija, hasta llegar a confrontarla duramente sobre el rol que tiene como madre, el cuidado y respeto a sus hijos y las consecuencias que estas formas de relación pueden traer para el futuro. En este proceso se posibilitaron espacios reflexivos, de autocontrol pero también nace una nueva forma de reconocerse en la relación y como familia, comprendiendo que haber 


\section{LA DESERCIÓN ESCOLAR COMO PRETEXTO PARA CONVERSAR SOBRE IDENTIDAD, FAMILIA Y ESCUELA

hablado de manera abierta les permitido cerrar ciclos para dar paso a nuevas formas de relacionarse e identificarse de manera individual y como sistema familiar, posibilitando la construcción identitaria de esta joven y los procesos relacionales para avanzar en su autonomía y toma de decisiones frente a su perspectiva vital. 


\section{LA DESERCIÓN ESCOLAR COMO PRETEXTO PARA CONVERSAR SOBRE IDENTIDAD, FAMILIA Y ESCUELA

\section{Referencias Bibliográficas}

Academic Medicine, Vol. 86, No. 3 / March 2011

Aular. Y (2011). Adolescencia y drogas. Revista Scielo, 15 (2). Recuperado de http://www.scielo.org.ve/scielo.php?script=sci_arttext\&pid=S131671382011000200004 .

Benítez, A.D. (2011). Representaciones sociales y construcción de proyectos e identidad de jóvenes escolarizados. Espacios en blanco serie indagaciones, 21. Pp 155-182. Buenos Aires Argentina Recuperado de http://www.scielo.org.ar/pdf/eb/v21n2/v21n2a01.pdf.

Barberousse, P. (2008). Fundamentos teóricos del pensamiento complejo de Edgar Morín. Revista Educare, 12 (2), pp. 95-113.

Camargo, B., Álvarez, D. Y Velasco Acosta, J. (2015). El cuerpo como símbolo e identidad en los adolescentes: creencias sobre la estética del cuerpo. Actualidades Pedagógicas. Pp 65-87. Recuperado de https://www.google.com.co/search?q=Camargo+Arias\%2C+B.\%2C+Álvarez+Robayo \%2C+D.+Y.+y+Velasco+Acosta\%2C+D.+J.+(2015).+El+cuerpo+como+símbolo+e+i dentidad+en+los+adolescentes $\% 3$

Cambio en Educación [en línea], 2013. Recuperado de http://www.redalyc.org/articulo.oa?id=55127024002 ISSN.

CASEN. (2009). Encuesta de Caracterización Socioeconómica Nacional. Recuperado de http://www.superacionpobreza.cl/wpcontent/uploads/2014/01/resultados_casen_2009.pdf. 


\section{LA DESERCIÓN ESCOLAR COMO PRETEXTO PARA CONVERSAR SOBRE IDENTIDAD, FAMILIA Y ESCUELA

Colombia Digital. (2013) Una nueva plataforma para promover la apropiación y análisis de las TIC y su impacto en la educación, las empresas y la vida cotidiana. https://colombiadigital.net/actualidad/experiencias/item/5837-app-colombiadigital.html.

Corte Constitucional. (1991). Constitución Política de Colombia https://www.ramajudicial.gov.co/documents/10228/1547471/CONSTITUCIONInteriores.pdf/8b580886-d987-4668-a7a8-53f026f0f3a2

De la cuesta, C. 2011.La reflexividad: un asunto crítico en la investigación cualitativa. El sevierdoima. Articulo especial. Enfermería clínica. [Artículo en línea] Recuperado de web https://dps.ua.es/es/documentos/pdf/2011/la-reflexividad.pdf.

Estupiñan.J (2012) Narrativa conversacional, relatos de vida y Tramas Humanas: Hacia la comprensión de la emergencia del self en interacción en contextos Ecológicos.

Estupiñan.J, Gonzalez. O, Serna. A. (2006). Historias y narrativas familiares en diversidad de contextos, dossier 2. Universidad Santo Tomas.

Estupiñan, J \&Gonzalez, O (2012).Narrativa conversacional, Relatos de vida y tramas Humana: hacia la comprensión de la emergencia del self en interacción en contextos ecológicos Universidad Santo Tomas. Bogotá.

Flores, S \& Valdivieso, M (2013) Características Bio- Psicosociales del Adolescente. Dontol Pediatr, 12 (2), 2013, pp 11.

Fonseca, A., Rodríguez, A. (2012). Comprensión y movilización de la dinámica vincular en el sistema conformado por la escuela y la familia, en un contexto de intervención sistémica entorno a un grupo de adolescentes que los definen con comportamientos inadecuados del colegio distrital. 


\section{LA DESERCIÓN ESCOLAR COMO PRETEXTO PARA CONVERSAR SOBRE IDENTIDAD, FAMILIA Y ESCUELA

Frachia, C (2015) Análisis de la dinámica familiar en adolescentes en conflicto con la ley desde un enfoque sistémico [Trabajo final de grado]. Recuperado de https://www.google.com.co/search?q=Frachia\%2C+C+(2015)Analisis+de+la+din\%C3 \%A1mica+familiar+en+adolescentes+en+conflicto+con+la+ley+desde+un+enfoque+s ist\%C3\%A9mico.+Trabajo+final+de+grado\&oq=Frachia\%2C+C+(2015)Analisis+de+ la+din\%C3\%A1mica+familiar+en+adolescentes+en+conflicto+con+la+ley+desde+un +enfoque+sist\%C3\%A9mico.+Trabajo+final+de+grado\&aqs=chrome..69i57.1212j0j8 \&sourceid=chrome\&ie $=\mathrm{UTF}-8$

García, A \& Sánchez, O (2014) una mirada sistémica del abandono escolar a través del apego y la familia. Master en terapia familiar. Universidad autónoma de Barcelona. Recuperado de http://tipo2.es/wp-content/uploads/2014/11/Articulo-abandono-escolarapego-familia.pdf

García, A. (2008). Identidad y representaciones sociales: La construcción de las minorías. Revista Critica de Ciencias Sociales Y Jurídicas, 1-12.

Gardner. L. Dussan. C. Montoya. L. (2016). Aproximación causal al estudio de la deserción en la Universidad de Caldas. Periodo 2012-2014. Revista Colombiana de Educación, 70. Recuperado de http://www.scielo.org.co/pdf/rcde/n70/n70a15.pdf

Gergen (2006). El "Yo" en cuestión: ensamblajes y voces múltiples. Barcelona, Buenos Aires, México: Paidós.

Gergen (2007) citado por Vásquez, A.M. (2012).Narrativas de los adolescentes que se auto infringen cortes y el proceso de construcción de identidad en el contexto de sus relaciones familiares (tesis de maestría) Universidad de chille. Santiago de chile. 


\section{LA DESERCIÓN ESCOLAR COMO PRETEXTO PARA CONVERSAR SOBRE IDENTIDAD, FAMILIA Y ESCUELA

Gómez, P.D. Carrasco, T.N (2010) Construcción de la identidad adolescente en los contextos socio histórico y culturales contemporáneos. Revista pensando en psicología, 6 (11), pp. 95-102.

Grupo L.A.C.E. (2013). Los estudios de caso. Barcelona: Universidad de Barcelona. Recuperado de http://hdl.handle.net/2445/33367

Gutiérrez, M. (2016). Deserción escolar en México por violencia familiar, exclusión y falta de identidad en los jóvenes. Recuperado de https://desinformemonos.org/desercionescolar-en-mexico-por-violencia-familia.

Hernández, A. (2003). Familia, ciclo Vital y Psicoterapia Breve. (E. El Búho, Ed.). Bogotá, D.C., Colombia.

Hofman, 1996 citado por Rozo, J.2002). La terapia desde el punto de vista del construccionismo social. Revista PsicologiaCientifica.com. Recuperado de http://www.psicologiacientifica.com/construccionismo-social-terapia/.

Josefina, D. S. (2006) Identidad, adolescencia y cultura- jóvenes. Revista Mexicana de Investigación Educativa, 11 (29), pp. 431-457. Recuperado de http://www.redalyc.org/pdf/140/14002906.pdf.

Lillo, J.L. Crecimiento y comportamiento en la adolescencia. Rev. Asoc. Esp. Neuropsiq. [Online]. 2004, n.90 [citado 2017-10-14], pp.57-71. Recuperado de $<$ http://scielo.isciii.es/scielo.php?script=sci_arttext\&pid=S021157352004000200005\&lng=es\&nrm=iso>. ISSN 2340-2733.

Linares, J. (1996) Identidad y Narrativa. La terapia familiar en la práctica clínica. Paidós. Barcelona, Buenos Aires, México. 


\section{LA DESERCIÓN ESCOLAR COMO PRETEXTO PARA CONVERSAR SOBRE IDENTIDAD, FAMILIA Y ESCUELA

Linares, J. L. (1996). Identidad y Narrativa. (S. A. Ediciones Paidós Ibérica, Ed.) (Primera Ed). España.

Linares, J. (2012) Terapia Familiar Ultramoderna. La inteligencia terapéutica. Herder Editorial, S.L., Barcelona

Lindsay A. Wagman B, (2011). Physician Education: A Promising Strategy to Prevent Adolescent Suicide.

Meléndez, M. Y. Salgado, R. N. Correa, R. C. Rico, C.A. (2016).Factores no académicos relacionados con la deserción escolar en jóvenes de instituciones educativas Colombianas. [Revista en línea]. Pp 214-225

Ministerio de Educación Nacional (2009-2010) Encuesta Nacional de Deserción con dos estrategias complementarias: la primera profundizando en las condiciones de los desertores y sus hogares (actualmente en ejecución con el DANE y la UNAL) y la segunda alrededor de las condiciones de las instituciones educativas y la acción institucional.

Ministerio de Educación Nacional (2018) comunicación interna. Recuperado el día 30 de julio de 2018 de la pagina wep https://www.mineducacion.gov.co/1759/articles366208_pdf.pdf.

Moreno, D. (2013). La Deserción Escolar: Un problema de Carácter Social. Revista In VestigiumIre, 6, 115-124.

Morín, E, (1990). Introducción al pensamiento complejo.

Morín, E. (2003). Introducción al pensamiento complejo. Barcelona: Gedisa Morín, E. (2011). ¿Hacia dónde va el mundo? Paidós, México.

Niño (2011).Estudio de caso en la formación sistémica. Bogotá. D.C. Universidad de la salle. 


\section{LA DESERCIÓN ESCOLAR COMO PRETEXTO PARA CONVERSAR SOBRE IDENTIDAD, FAMILIA Y ESCUELA

Pakman (2007) citado por Ballon, F.O. (2015). Entre la subjetividad y la complejidad propuesta y pertinencia para una psicología clínica de enfoque sistémico crítico. Recuperado de http://integracionacademica.org/attachments/article/80/01\%20Subjetividad\%20comple jidad\%20-\%20CO\%20Bailon.pdf

Payne, M. (2002). Terapia Narrativa, Una introducción para profesionales. Buenos Aires: Paidós.

Peña, J.Soto, V. \&Calderón. (2016). La influencia de la familia en la deserción escolar. Revista mexicana de investigación educativa, 21. pp. 881-899.

PISA IN FOCUS 2013/01 (Enero) - @ OECD. Recuperado de https://www.oecd.org/pisa/pisaproducts/pisainfocus/pisa\%20in\%20focus\%20n\%C2\% B024\%20(esp).pdf

Ramos, R (2001) Narrativas contadas, Narrativas vividas. Un enfoque sistémico en la terapia narrativa. Paidós. Barcelona, Buenos Aires, México.

Renau, V. Oberst, U. Carbonell, Xavier. (2013) Construcción de la identidad a través de las redes sociales online: una mirada desde el construccionismo social. Anuario de Psicología, 43 (2). 2013, pp. 159-170. Universitat de Barcelona, España. Recuperado de http://www.redalyc.org/pdf/970/97029454002.pdf.

Rivas, C. 2015.Bullyng problemas sin resolver, Dos historias una misma realidad [Libro en línea] Recuperado de http://repository.urosario.edu.co/bitstream/handle/10336/10610/1032431620-2015.pdf.

Riveros, M. \& Garzón, D (2014). Terapia familiar en problemas de adicción: narrativa conversacional y reconfiguración de identidades. Revista Latinoamericana de Estudios 


\section{LA DESERCIÓN ESCOLAR COMO PRETEXTO PARA CONVERSAR SOBRE IDENTIDAD, FAMILIA Y ESCUELA

de Familia, 6, 211-226. Recuperado de 20documentos/maria\%20cristina\%20y\%20dora.pdf.

Roman, M. (2013). Factores asociados al abandono y la deserción escolar en américa latina, una mirada en conjunto. REICE. Revista Iberoamericana Sobre Calidad, Eficacia Y Cambio En La Educación., 11, 33-59. Recuperado de http://www.rinace.net/reice/numeros/arts/vol11num2/art2.pdf.

Sitaram. CHA. 2016. Maestría en Filosofía en Estudios Indígenas [Tesis en Línea] tesis sobre Nepal pdf.

UNESCO (2018). ¿Cómo el sector de la educación debe hacer frente al consumo de alcohol, tabaco y drogas?

UNICEF (2014). Vivencias y relatos sobre el embarazo en adolescentes.

UNICEF. (2017). Posicionamiento sobre adolescencia. Para cada adolescente una oportunidad Recuperado de .https://www.unicef.org/argentina/spanish/Unicef-AdolescenciaWeb.pdf.

Urria, J. 13 de mayo 2014. Relaciones entre padres y adolescentes. Hacer familia. Recuperado de http://www.hacerfamilia.com/adolescentes/noticia-relaciones-padres-adolescentes20140513123458.html

Velásquez, A (2007) Lenguaje e identidad en los adolescentes [Pagina web]. https://www.google.com.co/search?q=Velasquez\%2C+A+(2007)+Lenguaje+e+identid ad+en+los+adolescentes.\&oq=Velasquez\%2C+A+(2007)+Lenguaje+e+identidad+en+ los+adolescentes.\&aqs=chrome...69i57.1298j0j8\&sourceid=chrome\&ie=UTF-8 el día 02-05-2018. 


\section{LA DESERCIÓN ESCOLAR COMO PRETEXTO PARA CONVERSAR SOBRE IDENTIDAD, FAMILIA Y ESCUELA

Von Foerster, H. (2006). La cibernética de segundo orden. Las semillas de la cibernética.

Obras escogidas Heinz von Foerster. Barcelona: Gedisa. 


\title{
LA DESERCIÓN ESCOLAR COMO PRETEXTO PARA CONVERSAR SOBRE IDENTIDAD, FAMILIA Y ESCUELA

\section{Anexos}

\section{Anexo 1. Consentimientos Docentes}

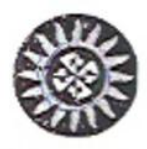 \\ Universidad Santo Tomás \\ División de Ciencias de la Salud \\ Facultad de Psicologia \\ Maestría en Psicologia Clinica y de Familia \\ Consentimiento Informado Para la Participación en Investigación
}

Fecha: Dia 04 Mes 11 Año 2014

Titulo de la Investigación: Narrativas de la Relación padres-Hijos-Colegio entorno a la deserción escolar en jóvenes entre los 13 y los 17 años

Duración Estimada y Procedimiento:

Instituciōn donde se Realizará el Estudio: Institucion Educativa San Jeronimo Emiliani

Investigador(es)/interventor(es):

ESMERALDA Ramos G

Nombre del (los) Director (es):

Dora Isabel Gazon y Ricardo

Jaramillo

Nombre del Participante:

Mediante este documento se ie esta invitando a participar de la investigaciön cuyo titulo se mencionó al principio Antcs de decidir su participación, debe conocer y comprender cada uno de los siguientes apartados. Usted es libre de preguntar sobre los aspectos o dudas o proposito de este proceso de investigación. Una vez comprendida la investigación se le pedirá que fime esle consentimiento, en caso de que su decisión sea participar de la misma.

Objetivo de la investigación: dar cuenta de los relatos e ideologías que se vinculan comprensivamente con la emergencia de los fenómenos que se estudian en el campo narrativo; de tal manera que todos podamos conocer las logicas, las epistemologías, las teorias e ideologias que encarnan esos relatos y narrativas de los participantes a partir de la convocatoria y el reconocimiento de las voces narradas de los actores sociales según su identidad en el campo narrativo particular de este estudio. Entre otros actores estarán. Las instituciones que hablaran a traves de sus interlocutores, las familias y las personas identificadas como "pacientes" consultantes así como sus redes sociales y vinculares propias de su sistema de relación.

Beneficios de la Investigación: Realizar comprensiones que contribuyan a la comprension del fenúmeno de la desercion escolar en esta población 


\section{LA DESERCIÓN ESCOLAR COMO PRETEXTO PARA CONVERSAR SOBRE IDENTIDAD, FAMILIA Y ESCUELA

Riesgos Asociados con la investigación:

\section{Aclaraciones:}

1. Su decisión de participar en el estudio es voluntaria.

2. En caso de decidir no participar en esta investigación, no habra ninguna consecuencia desfavorable para usted. su farrilia o su institución.

3. Si decide participar en la investigación usted puede retirarse en el momento que asi lo disponga, únicamente se le solicitara que informe las razones de su decisión, las cuales serán respetadas totaimente.

4. En el transcurso de la investigación podrá solicitar infornación actualizada de la misma al (los) investigadar (es), quienes está en el deber de proporcionársela oportunamente. Esto solo can fines informativos que sólo se brindará a los participantes de la investigación, en ningùn caso se entregarán informes técnicos (valoraciones, peritazgos, evaluaciones, conceptos, etc.) a terceros, que impliquen una responsabilidad más alla de los acuerdos de investigación aqui estipulados.

5. Las sesiones seràn video-grabadas o en su defecto audio grabadas en su totalidad. Estas sesiones seràn registradas en instrumentos para la recolección y archivo de la infomación (Historias Clínicas, formatos de observación y registros de campo\}. Las grabaciones e instumentos de registro serán utilizados únicamente con fines academicos e investigativos; una vez finalice la investigación, serán archivados para dar soporte a los resultados.

6. La información obtenida en este estudio, utlizada para la identificación de caso, mantendra estricta confidencialidad acerca de los participantes, sus familias o las instituciones involucradas. Esta sera compartida con los Directores, Asesores y equipos de investigacion en los espacios académicos y tutorias desamollados can el fin de avanzar en la obra de conocimiento y el proceso de formación de investigadores

7. Los resultados de este estudio serán utiuzados con fines acadérnicos y podrán ser publicados a traves de medios de divulgación de interés cientifico, guardando la confidenciaidad de sus participantes.

8 Por la participación en esta investigación usted no recibirá ninguna remuneración de tipo económico

Una vez considere que sus dudas han sido aclaradas y que no tiene ninguna pregunta sobre su participación en la investigacion, usted puede, si asi lo decide, fimar la siguiente carta de Consentimiento informado. 


\section{LA DESERCIÓN ESCOLAR COMO PRETEXTO PARA CONVERSAR SOBRE IDENTIDAD, FAMILIA Y ESCUELA

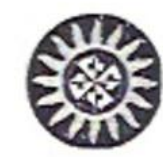

Yo, Alvaro Pulido Cuadros. he leido y comprendido la información anterior y mis preguntas han sido respondidas de manera satisfactoria. He sido enterado(a) de los procedirnientos de esta investigación y entiendo que la información obtenida puede ser publicada o difundida con fines cientificos, respetando mi anonimato.

Convengo en participar en csta investigación. Recibiré una copia fimada y fechada de este cansentimiento informado.

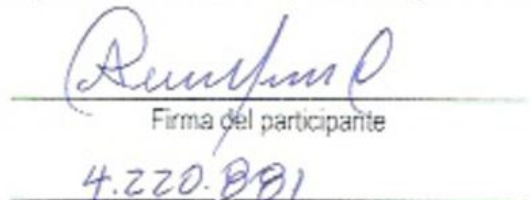

No. de Identificacion

[Espacio para diligenciamiento por parte del (los) investigador (es)]

Hemos explicado al (la) señon(a). He Jude la la naturaleza y los propositos de la investigaciön; le hemos explicado acerca de los riesgos y beneficios que implica su participación. Hemos contestodo a las preguntas en la medica de lo posible y hemos proguntado si tiene alguna duda. Aceptamos que hemos leido y conccemos la normatividad correspondiente para reaizar investigación con seres humanos y nos apegamos a ella 


\title{
LA DESERCIÓN ESCOLAR COMO PRETEXTO PARA CONVERSAR SOBRE IDENTIDAD, FAMILIA Y ESCUELA

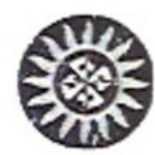 \\ Universidad Santo Tomás \\ Division de Ciencias de la Salud \\ Facultad de Psicologia \\ Maestria en Psicologia Clinica y de Familia \\ Consentimiento Informado Para la Participación en Investigación
}

Fecha: Día 04 Mes Nor. Año 201 t

Titulo de la Investigación: Narrativas de la Relación padres-Hijos-Colegio entorno a la deserción escolar en jóvenes entre los 13 y los 17 años

Duración Estimada y Procedimiento:

Institución donde se Realizarà el Estudio: Institucion Educativa San Jeronimo Emiliani

Investigador(es)linterventor(es):

ESMERALDA Ramos G

Nombre del (los) Director (es):

Dora Isabel Garzon y Ricardo

Jaramillo

Nombra del Participante:

Mediante este documento se le está invitando a participar de la investigación cuyo título se menciono al principio Antes de decidir su participación, debe conocer y comprender cada uno de los siguientes apartados. Usted es libre de proguntar sobre los aspectos o dudas o propósito de este procesa de investigación. Una vez comprendida la investigaciän se le pedirá que firme este consentimiento, en caso de que su decision sea particioar de la misma

Objetivo de la Investigacion: dar cuenta de los relatos e ideologías que se vinculan comprensivamente con la emergencia de los fenómenos que se estudian en el campo narrativo, de tal manera que todos podamos conocer las logicas, las epistemologias, las teorias e ideologias que encarnan esos relatos y narrativas de los participantes a partir de la convocatoria y el reconocimiento de las voces narradas de los actores sociales según su identidad en el campo narrativo particular de este estudio. Entre otros actores estarán: Las instituciones que hablaran a través de sus interlocutores, las familias y las personas identificadas como "pacientes" consultantes así como sus redes sociales y vinculares propias de su sistema de relación.

Beneficios de la Investigación: Realizar comprensiones que contribuyan a la comprension del fenómeno de la deserción escolar en esta población 


\section{LA DESERCIÓN ESCOLAR COMO PRETEXTO PARA CONVERSAR SOBRE IDENTIDAD, FAMILIA Y ESCUELA

Riesgos Asociados con la investigación:

\section{Aclaraciones:}

1. Su decisión de participar en el estudio es voluntaria.

2. En caso de decidir no participar en esta investigación, no habrá ninguna consecuencia desfavorable para usted, su familia o su institución.

3. Si decide participar en la investigación usted puede retirarse en el momento que asi lo disponga, únicamente se le solicitara que iniorme las razones de su decisión, las cuales serän respetadas totalmente.

4. En el transcurso de la investigación podrá solicitar información actuaizada de la misma al (los) investigador (es), quienes está en el deber de proporcionársela oportunamente. Esto solo con fines informativos que sólo se brindará a los participantes de la investigacion, en ningún caso se entregarán informes técnicos (valoraciones, peritazgos, evaluaciones, conceptos, etc.\} a tercoros, que impliquen una responsabilidad más allá de los acuerdos de investigación acui estipulados.

5. Las sesiones serán videa-grabadas 0 en $s u$ detecto audio-grabadas en su fotalidad. Estas sesiones seràn registradas en instrumentos para la recolección y archivo de la información (Historias Clinicas, formatos de observación y registros de campo). Las grabaciones e instrumentos de registro serán utilizados únicamente con fines acadérnicos e investigativos; una vez finalice la investigación, serán archivados para dar sopcrte a los resultados.

6. La información obtonida en este estudio, utlizada para la identificación de caso, mantendra estricta confidencialidad acerca de los participantes, sus familias o las instituciones involucradas. Esta sera compartida con los Directores, Asesores y equipos de investigación en los espacios académicos y tutorias desarrollados con el fin de avanzar en la obra de conccimiento y el proceso de formación de investigadores.

7. Los resultados de este estudio serán utilizados con fines académicos y podrản ser publicados a traves de medios de divulgación de interés cientifico, guardando la confidencialidad de sus participantes.

8. Por la participación en esta investigación usted no recibirá ninguna tẹmuneración de tipa econömico.

Una vez considere que sus dudas han sido aclaradas y que no tiene ninguna pregunta sobre su participación en la investigacion, usted puede, si así lo decide, fimar la siguiente carta de Consentimiento Iniormado. 


\section{LA DESERCIÓN ESCOLAR COMO PRETEXTO PARA CONVERSAR SOBRE IDENTIDAD, FAMILIA Y ESCUELA \\ 158}

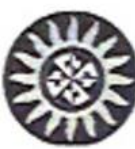

CARTA DE CONSENTIMIENTO INFORMADO DE MAYOR DE EDAD

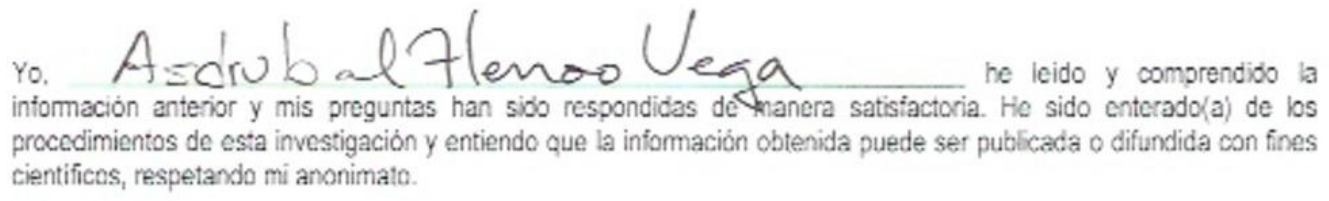

Convengo en participar en esta investigación. Recibiré una copia firmada y fechada de este consentimiento informado.

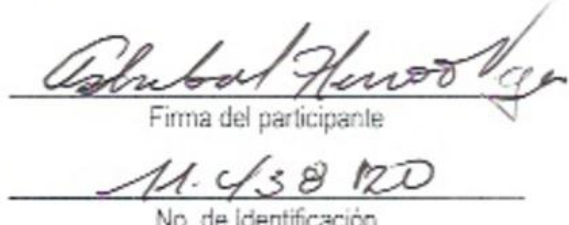

No. de identificación

[Espacio para diigenciamiento por parte del (los) investigador (es)]

\footnotetext{
Hemos explicado al (la) serior(a). Qdunbaf.- la naturaleza y ios propósitos de la investigación; le hemos expicado acerca de los riesgos y benveficios que implica su particioación. Hemos contestado a las preguntas en la medida de lo posible y hemos preguntado si tiene alguna duda. Aceptamos que hemos leido y conocernos la nornatividad correspondiente para reaizar investigación con seres humanos y nos apegamos a ella.
} 


\section{LA DESERCIÓN ESCOLAR COMO PRETEXTO PARA CONVERSAR SOBRE IDENTIDAD, FAMILIA Y ESCUELA

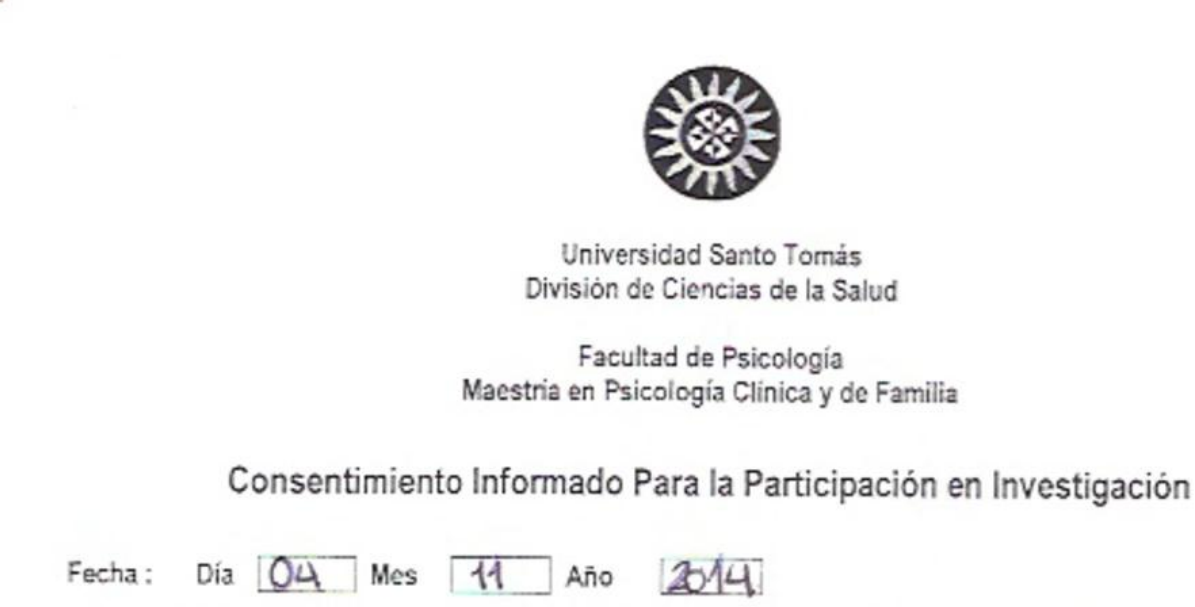

Titulo de la Investigación: Narrativas de la Relación padres-Hijos-Colegio entomo a la deserción escolar en jövenes entre los 13 y los 17 años

Duración Estimada y Procedimiento:

Institución donde se Realizará el Estudio: Institucion Educativa San Jeronimo Emiliani

Investigador(es)/interventor(es):

ESMERALDA Ramos G

Nombre del (los) Director (es):

Dora Isabel Garzon y Ricardo

Jaramillo

Nombre del Participante:

Mediante este documento se le está invitando a participar de la investigación cuyo titulo se mencionó al principio. Antes de decidir su participación, debe conocer y comprender cada uno de los siguientes apartados. Usted es libre do preguntar sobre los aspectos o dudas o propćsito de este proceso de investigación. Una vez comprendida la investigación se le pedira que firme este consentimiento, en caso de que su decisión sea participar de la misma.

Objetivo de la Investigación: dar cuenta de los relatos e ideologias que se vinculan comprensivamente con la emergencia de los fenómenos que se estudian en el campo narrativo; de tal manera que todos podamos conocer las lógicas, las epistemologías, las teorias e ideologías que encarnan esos relatos y narrativas de los participantes a partir de la convocatoria y el reconocimiento de las voces narradas de los actores sociales según su identidad en el campo narrativo particular de este estudio. Entre otros actores cstarán: Las instituciones que hablaran a través de sus interlocutores, las familias y las personas identificadas como "pacientes" consultantes así como sus redes sociales y vinculares propias de su sistema de relación.

Beneficios de la investigaciön: Realizar comprensiones que contribuyan a la comprensión del fenómeno de la desercoón escolar en esta población 


\section{LA DESERCIÓN ESCOLAR COMO PRETEXTO PARA CONVERSAR SOBRE IDENTIDAD, FAMILIA Y ESCUELA

Riesgos Asociados con la investigación:

Aclaraciones:

1. Su decision de participar en el estudio es voluntaria.

2. En caso de decidir no participar en esta investigación, no habrá ninguna consecuencia destavorable para usted. su familia o su institución.

3. Si decide participar en la investigación usted puede retirarse en el momento que asi lo dispanga, únicamente se le solicitará que informe las razones de su decisión, las cuales serán respetadas totaimente.

4. En el transcurso de la investigaciön podrà solicitar información actualizada de la misma al (los) investigador (es). quienes está en el deber de proporcionársela oportunamente. Esto solo con fines informativos que sólo se brindará a los participantes de la investigación, en ningún caso se entregarán informes técricos (valoraciones, peritazgos, evaluaciones, conceptos, etc.) a terceros, que impliquen una responsabilidad más allà de ks acuerdos de investigación aqui estipulados.

5. Las sesiones serán videc-grabadas a en Su defecto audic-grabadas en su totalidad. Estas sesiones serán registradas en instrumentos para la recolección y archivo de la información (Historias Clinicas, formatos de observación y registros de campo). Las grabaciones $e$ instrumentos de registro serán utilizados únicamente con fines acadérnicos e investigativos; una vez finalice la investigación, serán archivados para dar sooorte a los resultados.

6. La información obtenida en este estudio, utilizada para la identificación de caso, mantendrá estricta confidencialidad acerca de los participantes, sus familias o las instituciones involucradas. Esta será compartida con los Directores, Asesores y equipos de investigación en los espacios académicos y tutorias desarrollados con el fin de avanzar en la obra de conocimiento y el proceso de formación de investigadores.

7. Los resultados de este estudio serán utilizados con fines académicos y podrản ser publicados a través de medios de divuigación de interés cientifico, guardando la confidencialidad de sus participantes.

8. Por la participaciōn en esta investigación usted no recibirá ninguna remuneración de tipo económico.

Una vez considere que sus dudas han sido aclaradas y que no tene ninguna pregunta sobre su participacion en la investigación, usted puede, si asi lo decide, firmar la siguiente carta de Consentimiento informado. 


\section{LA DESERCIÓN ESCOLAR COMO PRETEXTO PARA CONVERSAR SOBRE IDENTIDAD, FAMILIA Y ESCUELA

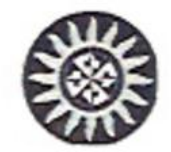

CARTA DE CONSENTIMIENTO INFORMADO DE MAYOR DE EDAD

Yo, tura Comila Evafacín tuertos he leido y comprendido la información anterior y mis preguntas han sido respondidas de manera satisfactoria. He sido enterado(a) de los procedimientos de esta investigación y entiendo que la información obtenida puede ser publicada o difundida con fines cientificos, respetando mi anonimato.

Convengo en participar en esta investigación. Recibiré una copia fimada y fechada de este consentimiento informado.

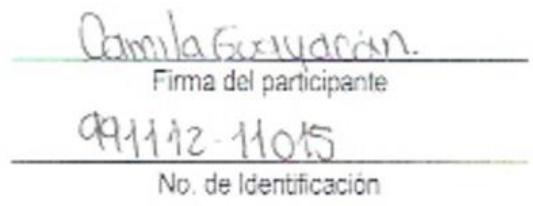

[Espacio para diagenciamiento por parte del (los) investigador (es)]

Hemos expicado al (la) scrior(a). Auno Com (a la naturaleza y los propósitos de la investigación; le hemos explicado acerca de los riesgos y beneficios que implica su particicación. Hemos contestado a las preguntas en la medida de lo posible y hemcs preguntado si tiene alguna duda. Aceptamos que hemos kido y conocemos la narmatividad correspondiente para realizar investigación con seres humanos y nos apegamos a ella.

Una vez canciuida la sesión de preguntas y respuestas, se procedió a fimar el presente documento. 


\section{LA DESERCIÓN ESCOLAR COMO PRETEXTO PARA CONVERSAR SOBRE IDENTIDAD, FAMILIA Y ESCUELA

Focha: Dia 04 Mes 11 Año 2014

Título de la Investigación: Narrativas de la Relaciōn padres-Hijos-Colegio entorno a la deserción escolar en jovenes entre los 13 y los 17 años

Duración Estimada y Procedimiento:

Institución donde se Realizará el Estudio: Institucion Educativa San Jeronimo Emiliani

Investigador(es)Vinterventor(es):

ESMERALDA Ramos G

Nombre del (los) Director (es):

Dora Isabel Garzon y Ricardo

Jaramillo

Nombre del Participante:

Mediante este documento se le está invitando a participar de la investigación cuyo título se mencionó al principio. Antes de decidir su participación, debe conocer y comprender cada uno de los siguientes apartados. Usted es libre de preguntar scbre los aspectos o dudas o propćsito de este proceso de investigaciōn. Una vez comprendida la investigación se le pedirá que firme este consentimiento, en caso de que su decisión sea participar de la misma.

Objetivo de la Investigación: dar cuenta de los relatos e ideologías que se vinculan comprensivamente con la emergencia de los fenómenos que se estudian en el campo narrativo; de tal manera que todos podamos conocer las lógicas, las epistemologías, las teorias e ideologias que encaman esos relatos y narrativas de los participantes a partir de la convocatoria y el reconocimiento de las voces narradas de los actores sociales según su identidad en el campo narrativo particular de este estudio. Entre otros actores estarán: Las instituciones que hablaran a través de sus interlocutores, las familias y las personas identificadas como "pacientes" consultantes asi como sus redes sociales y vinculares propias de su sistema de relación.

Beneficios de la Investigación: Reaizar comprensiones que contribuyan a la compronsión del fenómeno de la desercion escolar en esta población 


\section{LA DESERCIÓN ESCOLAR COMO PRETEXTO PARA CONVERSAR SOBRE IDENTIDAD, FAMILIA Y ESCUELA \\ 163}

Riesgos Asociados con la investigación:

Aclaraciones:

1. Su decisión de participar en el estudio es voluntaria.

2. En caso de decidir no participar en esta investigación, no habrá ninguna consecuencia destavorable para usted. su familia o su institución.

3. Si decide participar en la investigación usted puede retirarse en el momento que asi lo disponga, únicamente se le solicitará que informe las razones de su decision, las cuales serán respetadas totaimente.

4. En el transcurso de la investigación podrá soícitar información actualizada de la misma al (los) investigador (es), quienes está en el deber de proporcionársela oportunamente. Esto solo con fines informativos que sólo se brindará a los participantes de la investigación, en ningún caso se entregarán informes técnicos (valoraciones, peritazgos, evaluaciones, conceptos, etc.) a terceros, que impliquen una responsabilidad más allá de los acuerdos de investigación aqui estipulados.

5. Las sesiones seràn videc-grabadas o en su defecto audio-grabadas en su totalidad. Estas sesiones serán registradas en instrumentos para la recolección y archivo de la información (Historias Clinicas, formatos de observaciön y registros de campo). Las grabaciones e instrumentos de registro serán utilizados únicamente con fines acadérnicos e investigativos; una vez finalice la investigación, serán archivados para dar soporte a los resultados.

6. La información obtenida en este estudio, utilizada para la identificación de caso, mantendrá estricta confidencialidad acerca de los participantes, sus familias o las instituciones involucradas. Esta será compartida con los Directores, Asesores y equipos de invesligación en los espacios acadénicos y tutorias desarrollados con el fin de avanzar en la obra de conocimiento y el proceso de formación de investigadores.

7. Los resultados de este estudio serán utilizados con fines academicos y podrản ser publicados a través de medios de divulgación de interés cientifico, guardando la confidencialidad de sus participantes.

8. Por la participación en esta investigación usted no recibirá ninguna remuneración de tpo económico.

Una vez considere que sus dudas han sido aclaradas y que no tene ninguna pregunta sobre su participacion en la investigación, usted puede, si asi lo decide, firmar la siguiente carta de Consentimiento Informado. 


\section{LA DESERCIÓN ESCOLAR COMO PRETEXTO PARA CONVERSAR SOBRE IDENTIDAD, FAMILIA Y ESCUELA

Yo, Gimstian David Bapón BerNac he leido y comprendido la información anterior y mis preguntas han sida respondidas de manera satistactoria. He sido enterado(a) de los procedimientos de esta investigación y entiendo que la información obtenida puede ser publicada o difundida con fines cientificos, respetando mi anonimato.

Convengo en participar en esta investigación. Recibirc una copia fimada y fechada de este consentimiento intormado.

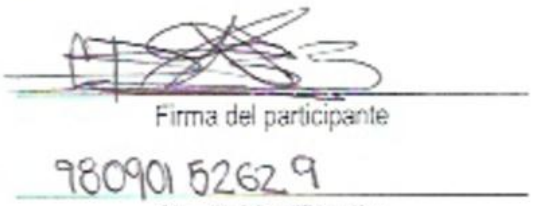

No. de identificación

[Espacio para diligenciamiento por parte del (los) investigador (esi)]

Hemos explicado al (la) sefíor(a). -...-...-.......... la naturaleza y los propósitos de la investigacion; le hemos explicado acerca de los riesgos y beneficins que implica su participacion. Hemos contestado a las preguntas en la medida de lo posibie y hemos preguntado si tene alguna duda. Accotamos que hemos lédo y conocemos la nomatividad correspondiente para realizar investigación con seres humanos y nos apegamos a ella. 


\title{
LA DESERCIÓN ESCOLAR COMO PRETEXTO PARA CONVERSAR SOBRE IDENTIDAD, FAMILIA Y ESCUELA

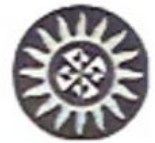 \\ Universidad Santo Tomás \\ División de Ciencias de la Salud \\ Facultad de Psicología \\ Maestria en Psicología Clínica y de Familia

\section{Consentimiento Informado Para la Participación en Investigación}

\begin{abstract}
Fecha: Día OY Mes 11 Año 14
Titulo de la Investigación: Narrativas de la Relación padres-Hijos-Colegio entorno a la deserción escolar en jóvenes entre los 13 y los 17 años

Duración Estimada y Procedimiento:

Institución donde se Realizará el Estudio: Institucion Educativa San Jeronimo Emiliani

Investigador(es)/interventor(es):

ESMERALDA Ramos $G$

Nombre del (los) Director (es):

Dora Isabel Garzon y Ricardo

Jaramillo

Nombre del Participante:

Mediante este documento se le está invitando a participar de la investigación cuyo título se mencionó al principio Antes de decidir su participación, debe conocer y comprender cada uno de los siguientes apartados. Usted es libre de preguntar sobre los aspectos o dudas o propósito de este proceso de investigación. Una vez comprendida la investigación se le pedirá que firme este consentimiento, en caso de que su decisión sea participar de la misma.

Objetivo de la Investigación: dar cuenta de los relatos e ideologias que se vinculan comprensivamente con la emergencia de los fenómenos que se estudian en el campo narrativo; de tal manera que todos podamos conocer las lógicas, las epistemologias, las teorias e ideologias que encarnan esos relatos y narrativas de los participantes a partir de la convocatoria y el reconocimiento de las voces narradas de los actores sociales según su identidad en el campo narrativo particular de este estudio. Entre otros actores estarản: Las instituciones que hablaran a través de sus interlocutores, las familias y las personas identificadas como "pacientes" consultantes así como sus redes sociales y vinculares propias de su sistema de relación.
\end{abstract}

Beneficios de la Investigación: Realizar comprensiones que contribuyan a la comprensión del fenómeno de la deserción escolar en esta poblaciön 


\section{LA DESERCIÓN ESCOLAR COMO PRETEXTO PARA CONVERSAR SOBRE IDENTIDAD, FAMILIA Y ESCUELA

Riesgos Asociados con la investigación:

Aclaraciones:

1. Su decisión de participar en el estudio es voluntaria.

2. En caso de decidir no participar en esta investigación, no habrá ninguna consecuencia desfavorable para usted, su familia o su institución.

3. Si decide participar en la investigación usted puede retirarse en el momento que asi lo disponga, únicamente se le solicitará que informe las razones de su decisión, las cuales serán respetadas totalmente.

4. En el transcurso de la investigación podra solicitar información actualizada de la misma al (los) investigador (es), quienes está en el deber de proporcionàrsela oportunamente. Esto solo con fines informativos que sólo se brindara a los participantes de la investigación, en ningún caso se entregarán informes técnicos (valoraciones. peritazgos, evaluaciones, conceptos, etc.) a terceros, que impliquen una responsabilidad más allá de los acuerdos de investigación aqui estipulados.

5. Las sesiones serán video-grabadas o en su defecto audio-grabadas en su totalidad. Estas sesiones serán registradas en instrumentos para la recolección y archivo de la información (Historias Clínicas, formatos de observación y registros de campo). Las grabaciones e instrumentos de registro serán utilizados únicarnente con fines acadèmicos e investigativos; una vez finalice la investigación, serán archivados para dar soporte a los resultados.

6. La información obtenida en este estudio, utilizada para la identificación de caso, mantendrá estricta confidencialidad acerca de las participantes, sus familias o las instituciones involucradas. Esta serà compartida con los Directores, Asesores y equipos de investigación en los espacios acadèmicos y tutorias desarrollados con el fin de avanzar en la obra de conocimiento y el proceso de formación de investigadores.

7. Los resultados de este estudio serán utilizados con fines académicos y podrán ser publicados a través de medios de divulgación de interés cientifico, guardando la confidencialidad de sus participantes.

8. Por la participación en esta investigación usted no recibirá ninguna remuneración de tipo económico.

Una vez considere que sus dudas han sido aclaradas y que no tiene ninguna progunta sobre su participación en la investigación, usted puode, si asi lo decide, firmar la siguiente carta de Consentimiento Informado. 


\section{LA DESERCIÓN ESCOLAR COMO PRETEXTO PARA CONVERSAR SOBRE IDENTIDAD, FAMILIA Y ESCUELA

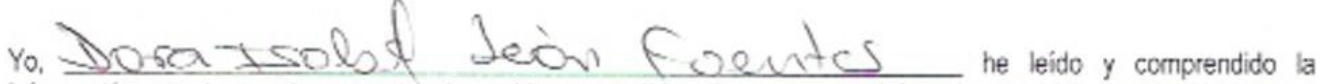
información anterior y mis preguntas han sido respondidas de manera satisfactoria. He sido enterado(a) de los procedimientos de esta investigación y entiendo que la información obtenida puede ser publicada o difundida con fines cientificos, respetando mi anonimato.

Convengo en participar en esta investigación. Recibiré una copia firmada y fechada de este consentimiento informado.

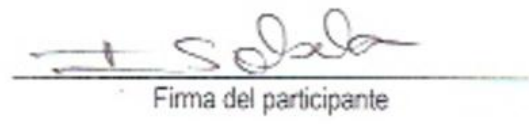

No. de Identificación

[Espacio para diligenciamiento por parte del (los) investigador (es)]

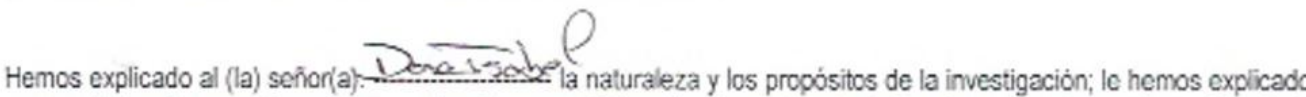
acerca de los riesgos y beneficios que implica su participación. Hemos contestado a las preguntas en la medida de lo posible y hemos preguntado si tiene alguna duda. Aceptamos que hemos leido y conocemos la nomatividad correspondiente para realizar investigación con seres humanos y nos apegamos a ella.

Una vez concluida la sesión de preguntas y respuestas, se procedió a firmar el presente documento. 


\title{
LA DESERCIÓN ESCOLAR COMO PRETEXTO PARA CONVERSAR SOBRE IDENTIDAD, FAMILIA Y ESCUELA

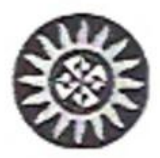 \\ Universidad Santo Tomás \\ División de Ciencias de la Salud \\ Facultad de Psicología \\ Maestria en Psicoiogia Clínica y de Familia

\section{Consentimiento Informado Para la Participación en Investigación} \\ Fecha: Día 4 Mes 11 Año 2014 \\ Titulo de la Investigación: Narrativas de la Relación padres-Hijos-Colegio entorno a la deserción escolar en \\ jóvenes entre los 13 y los 17 años \\ Duracion Estimada y Procedimiento: \\ Institución donde se Realizara cl Estudio: Institucion Educativa San Jeronimo Emiliani \\ Investigador(es)Vinterventor(es): \\ ESMERALDA Ramos G \\ Nombre del (los) Director (es): \\ Dora Isabel Garzon y Ricardo \\ Jaramillo \\ Nombre del Participante: \\ Mediante este documento se le está invitando a participar de la investigación cuyo titulo se menciono al principio \\ Antes de decidir su participación, debe conocer y comprender cada uno de los siguientes apartados. Usted es libre de \\ preguntar sobre los aspectos o dudas o propósito de este proceso de investigación. Una vez comprendida la \\ investigación se le pedirá que firme este consentimiento, en caso de que su decisión sea participar de la misma. \\ Objetivo de la Investigación: dar cuenta de los relatos e ideologias que se vinculan \\ comprensivamente con la emergencia de los fenómenos que se estudian en el campo \\ narrativo; de tal manera que todos podamos conocer las logicas, las epistemologias, las \\ teorias e ideologias que encarnan esos relatos y narrativas de los participantes a partir \\ de la convocatoria y el reconocimiento de las voces narradas de los actores sociales \\ segün su identidad en el campo narrativo particular de este estudio. Entre otros actores \\ estarán: Las instituciones que hablaran a través de sus interlocutores, las familias y las \\ personas identificadas como "pacientes" consultantes asi como sus redes sociales y \\ vinculares propias de su sistema de relación.
}

Beneficios de la Investigación: Realizar comprensiones que contribuyan a ia comprensión del fenámeno de la deserción escolar en esta población 


\section{LA DESERCIÓN ESCOLAR COMO PRETEXTO PARA CONVERSAR SOBRE IDENTIDAD, FAMILIA Y ESCUELA

Riesgos Asociados con la investigación:

Aclaraciones:

1. Su decisión de participar en el estudio es voluntaria.

2. En caso de decidir no participar en esta investigaciōn, no habrá ninguna consecuencia desfavorable para usted su familia o su institución.

3. Si decide participar en la investigación usted puede retirarse en el momento que asi lo disponga, ùnicamente se le solicitará que informe las razones de su decisión, las cuales serän respetadas totaimente.

4. En el transcurso de la investigación podra solicitar información actualizada de la misma al (los) investigaoor (es), quienes está en el deber de proporcionärsela oportunamente. Esto solo con fines informativos que sólo se brindará a los participantes de la investigación, en ningún caso se entregarán informes tècnicos (vaioraciones, peritargos, evaluaciones, conceptos, etc.) a terceros, que impliquen una responsabilidad més allà de los acuerdos de investigación acui estipulados.

5. Las sesiones serän video-grabadas 0 en su defecto audio-grabadas en su totalidad Estas sesiones serán registradas en instrurnentos para la recolección y archivo de la informaciōn (Historias Clínicas, tormatos de observación y registros de campo). Las grabaciones e instrumentos de registro serán utilizados únicamente con fines acadérnicos e investigativos; una vez finalice la investigación, serán archivados para dar soporte a los resultados.

6. La intormación obtenida en este estudio, utilzada para la identificación de caso, mantendrá estricta confidencialidad acerca de los participantes, sus familias o las instituciones involucradas. Esta será compartida con los Directores, Asesores y equipos de investigación en los espacios acadèmicos y tutorias desamollados con el fin de avarizar en la obra de conocimiento y el proceso de formación de investigadores.

7. Los resultados de cste estudio serán utifizados con fines académicos y podrán ser publicados a través de medios de divulgación de interés cientifico, guardando la confidencialidad de sus participantes.

8. Por la participación en csta investigación usted no recibirá ninguna remuneración de tipo oconómico.

Una vez considere que sus dudas han sido aclaradas y que no jene ninguna pregunta sobre su participación en la investigación, usted puede, si asi lo decide, firmar la siguiente carta de Consentimiento Informado. 


\section{LA DESERCIÓN ESCOLAR COMO PRETEXTO PARA CONVERSAR SOBRE IDENTIDAD, FAMILIA Y ESCUELA

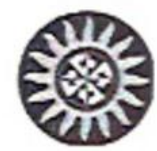

CARTA DE CONSENTIMIENTO INFORMADO DE MAYOR DE EDAD

yo, Jame $\varepsilon$. 2oa $F$ he leido y comprendido la información anterior y mis preguntas han sido respondidas de manera satisfactoria. He sido enterado(a) de los procedimientos de esta investigación y entiendo que la información obtenida puede ser publicada o difundida con fines cientificos, respetando mi anonimato.

Convengo en participar en esta investigación. Recibire una copia firmada y techada de este consentimiento infomado.

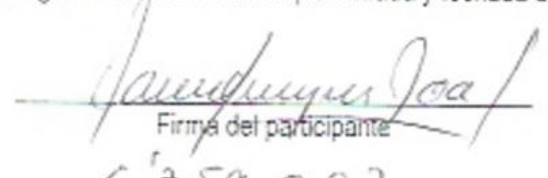

6759.087

No. de identificación

[Espacio para diligenciamiento por parte del (los) investigador (es)]

Hemos explicado al (la) señoria). Roa.

- la naturacza y los propósitos de la investigación; le hemos exolicado acerca de los riesgos y beneficios que impica su participación. Herros contestado a las preguntas en la medida de lo posible y hemos preguntado si tiene alguna duda. Aceptarnos que hemos leido y canocemos la nomatividad correspondiente para realizar investigación con seres humanos y nos apegamos a ella.

Una vez concluida la sesión de preguntas y respuestas, se procedió a firrrar el presente documento 


\title{
LA DESERCIÓN ESCOLAR COMO PRETEXTO PARA CONVERSAR SOBRE IDENTIDAD, FAMILIA Y ESCUELA

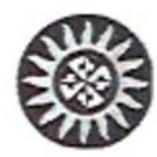 \\ Universidad Santo Tomás \\ Division de Clencias de la Salud \\ Facultad de Psicologia \\ Maestria en Psicologia Clinica y de Familia \\ Consentimiento Informado Para la Participación en Investigación
}

Fecha: Dia 04 Mes 11 Año bon

Titulo de la Investigación: Narrativas de la Relación padres-Hijos-Colegio entorno a la deserción escolar en jóvenes entre los 13 y los 17 años

Duración Estimada y Procedimiento:

Institución donde se Realizará el Estudio: Institucion Educativa San Jeronimo Emiliani

Investigador(es)/interventor(es):

ESMERALDA Ramos G

Nombre del (los) Director (es):

Dora Isabel Garzon y Ricardo

Jaramillo

Nombre del Participante:

Mediante este documento se lo está invitando a participar de la investigacöón cuyo titulo se mencionó al principio Antes de decidir su participación, debe conocer y comprender cada uno de los siguientes apartados. Usted es libre de preguntar sobre los aspectes a dudas o proposito de este proceso de investigación. Una vez comprendida la investigación se le pedirà que firme este consentimiento, en caso de que su decision sea particigar de la misma.

Objetivo de la Investigación: dar cuenta de los relatos e ideologias que se vinculan comprensivamente con la emergencia de los fenómenos que se estudian en el campo narrativo; de tal manera que todos podamos conocer las iogicas, las epistemologias, las teorias e ideologías que encarnan esos relatos y narrativas de los participantes a partir de la convocatoria y el reconocimiento de las voces narradas de los actores sociales segün su identidad en el campo narrativo particular de este estudio. Entre otros actores estarán: Las instituciones que hablaran a travẻs de sus interlocutores, las familias y las personas identificadas como "pacientes" consultantes asi como sus redes sociales y vinculares propias de su sistema de relación.

Beneficios de la investigación: Realizar comprensiones que controuyan a la comprensión del feriómeno de la deserción escolar en esta población 


\section{LA DESERCIÓN ESCOLAR COMO PRETEXTO PARA CONVERSAR SOBRE IDENTIDAD, FAMILIA Y ESCUELA

Riesgos Asociados con la investigación:

\section{Aclaraciones:}

1. Su decisión de participar en el estudio es voluntana.

2. En caso de decidir no participar en esta investigación, no habra ninguna consecuencia desfaworable para usted, su familia o su instituciōn.

3. Si decide participar en la investigación usted puede retirarse en el momento que asi lo disponga, únicamente se le solicitará que informe las razones de su decisión, las cuales serán respetadas totaimente.

4. En el transcurso de la investigaciỏn podrá soficitar información actualizada de la misma al (los) investigador (es) quienes esta en el deber de proporcionársela oportunamente. Esto solo con fines informativos que sólo se brindara a los participantes de la investigacón, en ningún caso se entregarán informes técniccos (valoraciones. peritazgos, evaluaciones, conceptos, etc.) a terceros, que impliquen una responsabilidad más alia de los acuerdos de investigación aqui estipulados.

5. Las sesiones seran video-grabadas o en su defecto audio-grabadas en su totalidad. Estas sesiones serár registradas en instrumentos para la recolección y archivo de la informaciön (historias Clinicas, formaics de observación y registros de campo). Las grabaciones e instrumentos de registro serán ublizadios únicamente con fines acadèmicas e investigativos; una vez finalice la investigación, serán archivados para dar soporte a los resultidos.

6. La información obtenida en este estudio, utilizada para la identificación de caso, mantendrá estricta confidencialidad acerca de las participantes, sus familias o las instituciones involucradas. Esta será compartida con los Dircctores, Asescres y equipos de investigación en los espacios académicos y tutorias desarrollados con el fin de avanzar en la obra de conocimiento y el proceso de formación de investigadores.

7. Los resultados de este estudio serán utilizados con fines académicos y podrán ser publicados a traves de medios de divulgación de interés cientifico, guardando la confidencialidad de sus participantes.

8. Por la participación en esta investigación usted no recibirá ninguna remuneración de tipo económico.

Una vez considere que sus dudas han sido aclaradas y que no tene ninguna pregunta sobre su participación en la investigación, usted puede, si asi lo decide, firmar la siguiente carta de Consentimiento Informado. 


\section{LA DESERCIÓN ESCOLAR COMO PRETEXTO PARA CONVERSAR SOBRE IDENTIDAD, FAMILIA Y ESCUELA \\ 173}

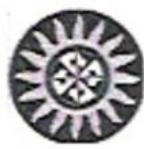

CARTA DE CONSENTIMIENTO INFORMADO DE MAYOR DE EDAD

Yo, Jarro andios locos cates he leido y comprendido la infomación anteriar y mis preguntas han sido respondidas de manera satisfactoria. He sido enterado(a) de los procedimientos de esta investigación y entiendo que la información obtenida puede ser publicada o difundida con fines cientificos, respetando mi anonimato.

Convengo en participar en esta investigación. Recibiré una copia firmada y fechada de este consentimiento informado.

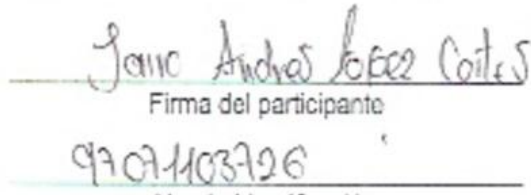

No. de identificación

[Espacio para diligenciamiento por parte del (los) investigador (es)]

Hemos explicado al (la) señor(a). Smarracen la naturaieza y los propósilos de la investigación; le hemos explicado acerca de los riesgos y beneficios que impuca su participación. Hemos contestado a las preguntas en la medida de lo posible $y$ hemos preguntado si tiene alguna duda. Aceptamos que hemos leido y conocemos la normatividad comespondiente para realizar investigación con seres humanos y nos apegamos a ella.

Una vez concluida la sesion de preguntas y respuestas, se procedió a firmar el presente documento. 


\section{LA DESERCIÓN ESCOLAR COMO PRETEXTO PARA CONVERSAR SOBRE IDENTIDAD, FAMILIA Y ESCUELA

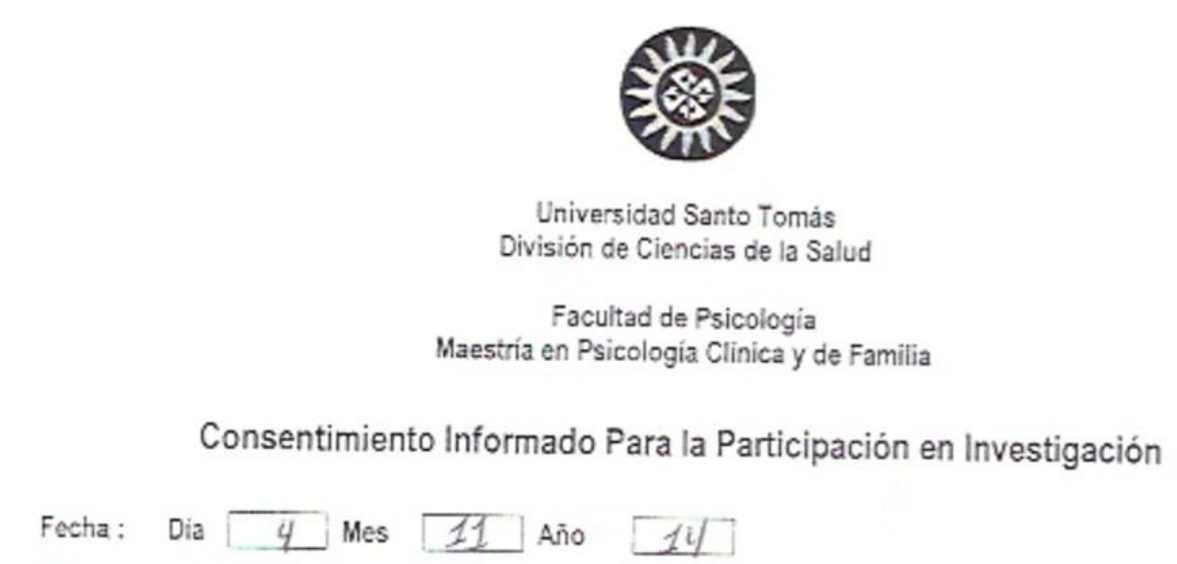

Título de la Investigación: Narrativas de la Relación padres-Hijos-Colegio entorno a la deserción escolar en jóvenes entre los 13 y los 17 años

Duración Estimada y Procedimiento:

Institución donde se Realizarả el Estudio: institucion Educativa San Jeronimo Emiliani

Investigador(es) Vinterventor(es):

ESMERALDA Ramos G

Nombre del (los) Director (es):

Dora Isabel Garzon y Ricardo

Jaramillo

Nombre del Participante:

Mediante este documento se le está invitando a participar de la investigación cuyo titulo se mencionó al principio. Antes de decidir su participación, debe conccer y comprender cada uno de los siguientes apartados. Usted es libre je preguntar sobre los aspectos o dudas o proposito de este proceso de investigación. Una vez comprendida ta investigarión se le pedirá que firme este consentimiento, en caso de que su decisión sea particioar de la misma.

Objetivo de la Investigación: dar cuenta de los relatos e ideologias que se vinculan comprensivamente con la emergencia de los fenómenos que se estudian en el campo narrativo; de tal manera que todos podamos conocer las logicas, las epistemologias. las teorias e ideologías que encarnan esos relatos y narrativas de los participantes a partir de la convocatoria y el reconocimiento de las voces narradas de los actores sociales según su identidad en el campo narrativo particular de este estudio. Entre otros actores estaràn: Las instituciones que hablaran a través de sus interlocutores, las familias y las personas identificadas como "pacientes" consultantes asi como sus redes sociales y vinculares propias de su sistema de relación

Beneficios de la investigación: Realizar comprensic e: que contrbuyan a la comprensión del fentmeno de ba desercion estolar en esta pobiación 


\section{LA DESERCIÓN ESCOLAR COMO PRETEXTO PARA CONVERSAR SOBRE IDENTIDAD, FAMILIA Y ESCUELA

Riesgos Asociados con la investigación:

Aclaraciones:

1. Su decisión de participar en el estudio es voluntaria.

2. En caso de decidit no participar en esta investigación, no habrá ninguna consecuencia desfavorable para usted. su familia o su institución.

3. Si decide participar en la investigacion usted puede retirarse en el momento que asi lo disponga, únicamente se le solicitara que informe las razones de su decisión, las cuales serán respetadas totaimente.

4. En el transcurso de la investigación podrá solicitar información actuaizada de la misma al (los) investigador (es), quienes está en el deber de proporcionársela oportunamente. Esto solo con fines informativos que sólo se brindará a los participantes de la investgación, en ningún caso se entregaran informes tėcnicos (valoraciones, peritazgos, evaluaciones, conceptos, etc.) a terceros, que impliquen una responsabilidad más allá de lcs acuerdos de investigación aqui estipulados.

5. Las sesiones serán videc-grabadas o en su defecto audio-grabadas en su totalidad. Estas sesiones seràn registradas en instrumentos para la recolección y archivo de la información (Historias Clinicas, formatos de observación y registros de campo). Las grabaciones e instrumentos de registro serản utilizados únicamente con fines acadérnicos e investigativos; una vez finalice la investigación, serản archivados para dar scoponte a los resultados.

6. La información obtenida en este estudia, utilizada para la identificación de caso, mantendrá estricta confidencialicad acerca de los participantes, sus farmilias o las instituciones involucradas. Esta sera compartida con las Directores, Asesores y equipos de investigación en los espacios academicos y tutorias desarrollados con el fin de avanzar en la obra de conocimiento y el proceso de formacion de investigadores.

7. Lo5 resultados de este estudio serản utilizados con fines académicos y podrán ser publicados a través de medics de divulgacion de interés cientifico, guardando la confidencialidad de sus participantes.

8. Por la participación en esta investigaciön usted na recibirả ninguna remuneración de tipo económico.

Una vez considere que sus dudas han sido aclaradas y que no tiene ninguna pregunta sobre su participación en la investigación, usted puede, si asi lo decide, firmar la siguiente carta de Consentimiento Informado. 


\section{LA DESERCIÓN ESCOLAR COMO PRETEXTO PARA CONVERSAR SOBRE IDENTIDAD, FAMILIA Y ESCUELA \\ 176}

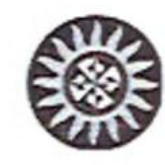

Yo, Eefersen cristobos Daz therañoles leido y comprendido la información anterior y mis preguntas han sido respondidas de manera satisfactoria. He sido enterado(a) de los procedimientos de esta investigación y entiendo que la información obtenida puede ser publicada o difundida con fines cientifices, respetando mi ancrimato.

Convengo en participar en esta investigación. Recibiré una copia fimada y iechada de este consentimiento informado.

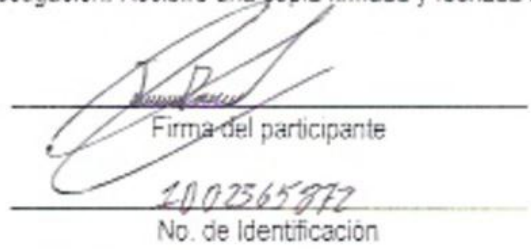

[Espacio para diligenciamiento por parte del (bs) investigador (es)]

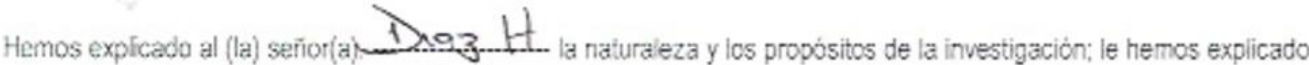
acerca de los riesgos y beneficios que implica su participación. Hemos contestado a las preguntas en la medida de lo posible y hemos preguntado si tene aguna duda. Aceptamos que hemos leido y conocemos la normatividad correspondiente para realizar investigación con seres humanos y nos apegamos a ella. 


\section{LA DESERCIÓN ESCOLAR COMO PRETEXTO PARA CONVERSAR SOBRE IDENTIDAD, FAMILIA Y ESCUELA

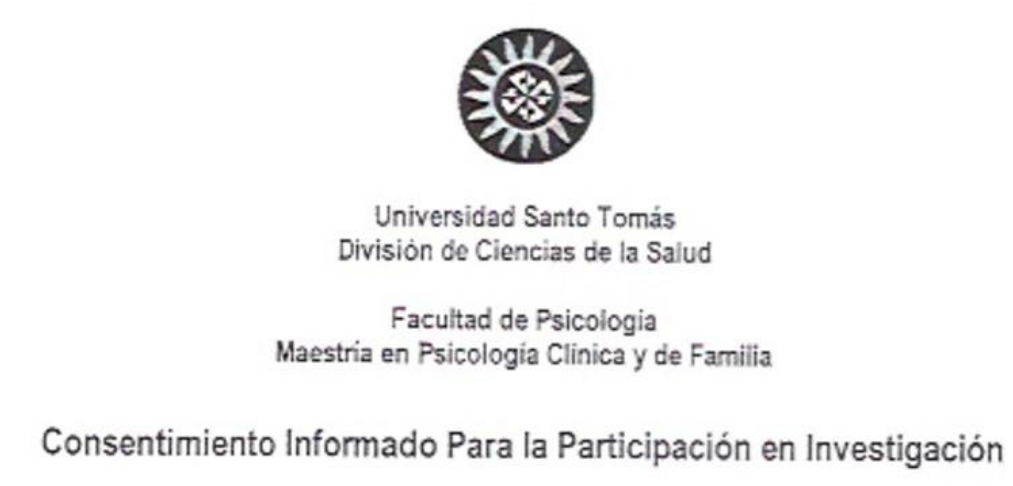

Fecha: Día 04 Mes 11 Año 2014

Título de la Investigación: Narrativas de la Relación padres-Hijos-Colegio entorno a la deserción escolar en jövenes entre ios 13 y los 17 años

Duración Estimada y Procedimiento:

Institución donde se Realizará el Estudio: Institucion Educativa San Jeronimo Emiliani

Investigadories)/interventor(es):

ESMERALDA Ramos G

Nombre del (los) Director (es):

Dora Isabel Garzon y Ricardo

Jaramillo

Nombre del Participante:

Mediante este documento se le está invitando a participar de la investigación cuyo tífulo se menciono al principio. Antes de decidir su participación, debe conocer y comprender cada uno de los siguientes apartados. Usted es libre de preguntar sabre los aspectos o dudas o propósito de este proceso de investigación. Una vez comprendida la investigación se le pedira que firme este consentimiento, en caso de que su decisión sea participar de la misma.

Objetivo de la Investigación: dar cuenta de los relatos e ideologías que se vinculan comprensivamente con la emergencia de los fenómenos que se estudian en el campo narrativo; de tal manera que todos podamos conocer las lógicas, las episternologias, las teorias e ideologias que encarnan esos relatos y narrativas de los participantes a partir de la convocatoria y el reconocimiento de las voces narradas de los actores sociales según su identidad en el campo narrativo particular de este estudio. Entre otros actores estaran: Las instituciones que hablaran a través de sus interlocutores, las familias y las personas identificadas como "pacientes" consultantes asi como sus redes sociales y vinculares propias de su sistema de relación.

Beneficios de la Investigación: Realizar comprensiones que contribuyan a la comprensión del fenómeno de la deserción escolar en esta poblaciön 


\section{LA DESERCIÓN ESCOLAR COMO PRETEXTO PARA CONVERSAR SOBRE IDENTIDAD, FAMILIA Y ESCUELA

Riesgos Asociados con la investigación:

Aclaraciones:

1. Su decisión de participar en el estudio es voluntaria.

2. En caso de decidir no participar en esta investigación, no habrá ninguna consecuencia desfavorable para usted, su familia o su institución,

3. Si decide participar en la investigación usted puede retirarse en el momento que asi lo disponga, únicamente se le solicitará que informe las razones de su decision, las cuales serán respetadas totaimente.

4. En el transcurso de la investigación podrá solicitar información actualizada de la misma al (los) investigador (es), quienes está en el deber de proporcionársela oportunamente. Esto solb con fines informativos que súlo se brindaráa a los participantes de la investigación, en ningùn caso se entregarán informes técnicos (valoraciones. peritazgos, evaluaciones, conceptos, etc.) a terceros, que impliquen una responsabilidad más allá de los acuerdos de investigación aqui estipulados.

5 Las sesiones seràn video-grabedas o en su defecto audio-grabadas en su totalidad. Estas sesiones serán registradas en instrumentos para la recolección y archivo de la iniormación (Historias Clinicas, formatos de observación y registros de campo). Las grabaciones e instrumentos de registro serán utilizadics únicamente con fines académicos e investigativos; una vez finalice la investigación, serán archivados para dar soporie a los resultados.

6. La información obtenida en este estudio, utilizada para la identificación de caso, mantendrá estricta confidencialidad acerca de los participantes, sus familias o las instituciones involucradas. Esta sera compartida con los Directores, Asesores y equipos de investigación en los espacios acadèmicos y tutorias desarrollados con el fin de avanzar en la obra de conocimiento y el proceso de formación de investigadores.

7. Los resultados de este estudio serán utiizados con fines acadérnicos y podrán ser publicados a través de medios de divulgación de interés cientifico, guardando la confidencialidad de sus participantes.

8. Por la participación en esta investigación usted no recibirá ninguna remuneracion de tipo económico.

Lina vez considere que sus dudas han sido aclaradas y que no tiene ninguna pregunta sobre su participación en la investigación, usited puede, si asi lo decide, fimar la siguiente carta de Consentimiento Informado. 


\section{LA DESERCIÓN ESCOLAR COMO PRETEXTO PARA CONVERSAR SOBRE IDENTIDAD, FAMILIA Y ESCUELA

Yo, Marilyn Pico-Ta-pias he leido y comprendido la información anterior y mis preguntas han sido respondidas de manera satisfactoria. He sida enterado(a) de los procedimientos de esta investigación y entiendo que la información obtenida puede ser publicada o difundida con fines científicos, respetando mi anonimato.

Convengo en participar en esta investigación. Recibire una copia fimada y fechada de este consentimiento informado

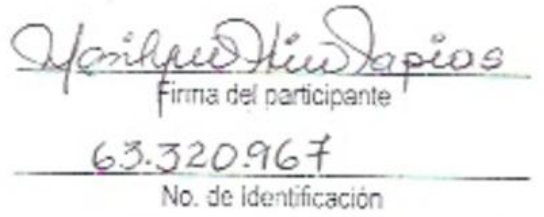

[Espacio para diligenciamiento por parte del (los) investigador (es)]

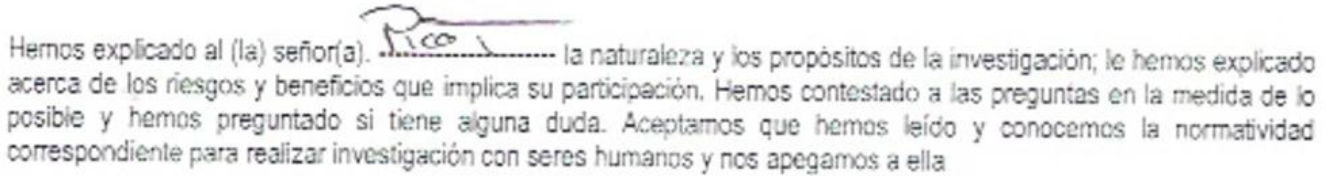

Una vez concluida la sesión de preguntas y respuestas, se procedić a fimar el presente documento. 


\title{
LA DESERCIÓN ESCOLAR COMO PRETEXTO PARA CONVERSAR SOBRE IDENTIDAD, FAMILIA Y ESCUELA

\section{Anexo 2. Consentimientos del sistema Familiar}

\author{
Universidad Santo Tomás \\ División de Ciencias de la Salud \\ Facultad de Psicologia \\ Macstria en Psicología Clinica y de la Familia
}

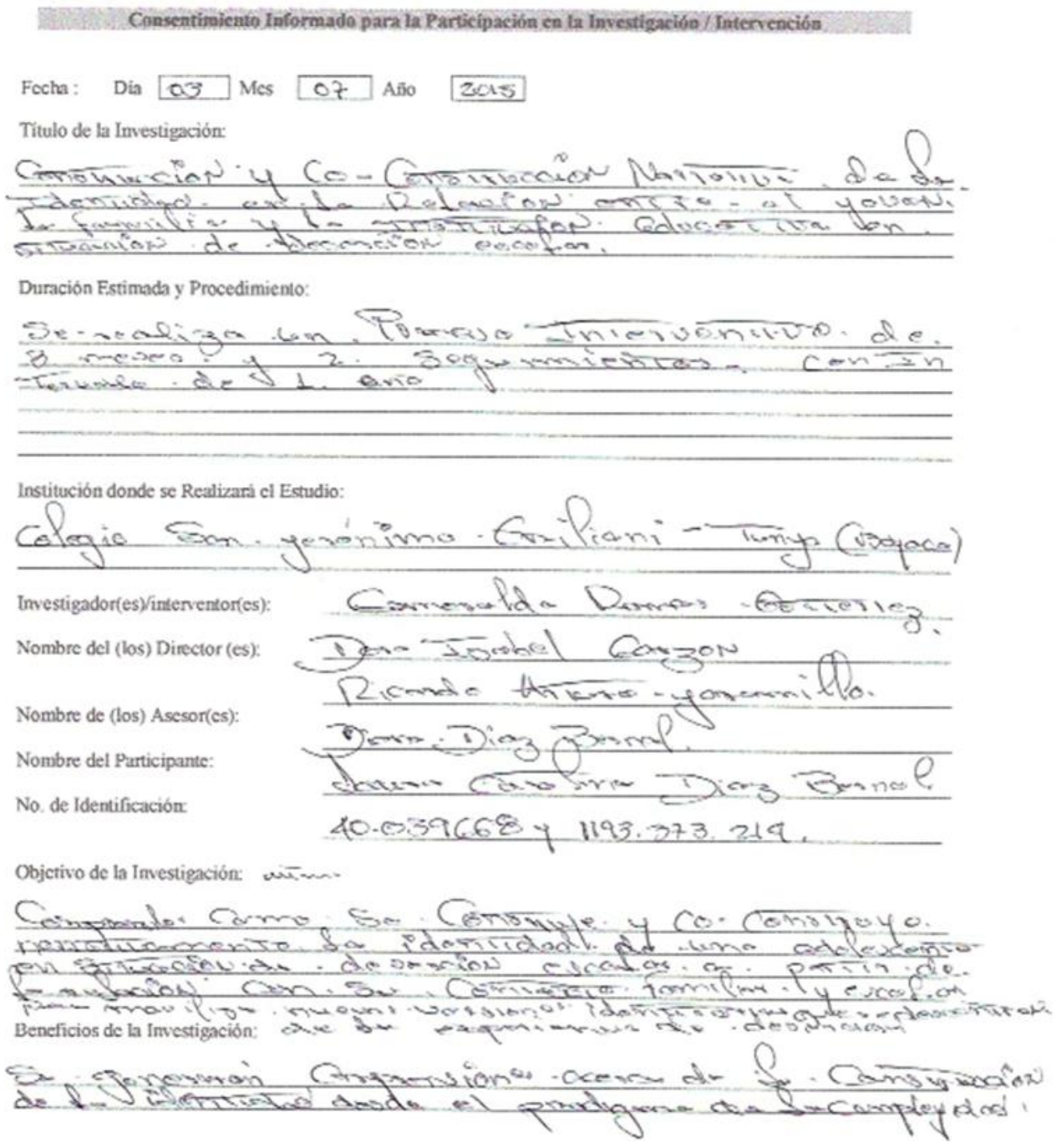




\section{LA DESERCIÓN ESCOLAR COMO PRETEXTO PARA CONVERSAR SOBRE IDENTIDAD, FAMILIA Y ESCUELA

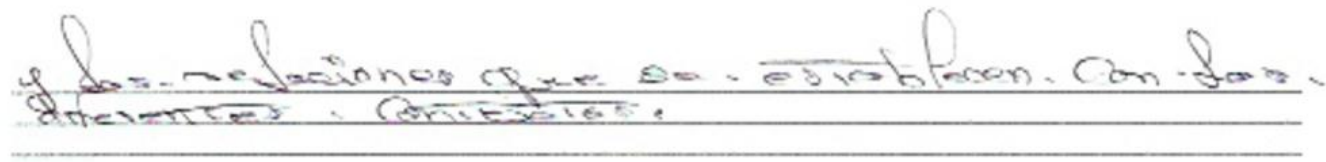

Riesgos Asociados con la investigación:

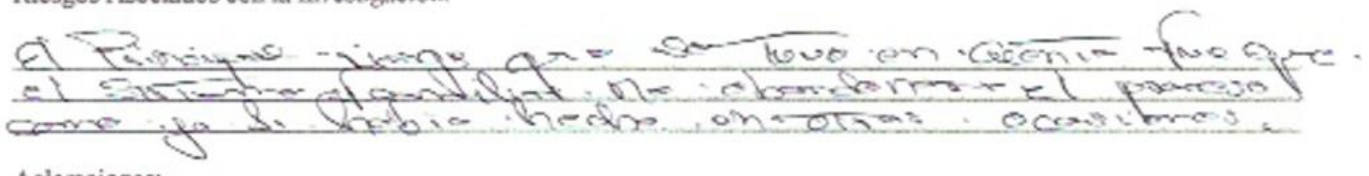

Aclaraciones:

1. Sa decisión de participar en el estudio es voluntaria.

2. En caso de docidir no participar en esta irvestigación, no habrá ninguma consecuencia desfavorable para usted, su familia o su institución.

3. Si decide participar en la imvestigación usted puede retirarse en el momento que así lo disponga, úmicamente se le solicitará que informe las razones de su decisión, las cuales serán respetadas totalmente.

4. En el transcurso de la imvestigación podrá solicitar información actualizada de la misma al (los) irvestigador (es), quienes está en el deber de proporcionárscla oportunamentc. Esto solo con fines informativos que sólo se brindará a los participantes de la investigación, en ningún caso se cntregarán informes tóenicos (valoraciones, peritazgos, evaluaciones. conceptos, etc.) a terocros, que impliquen una responsabilidad más allá de los acuerdos de investigación aqui estipulados.

5. Las sesiones serín video-grabadas o $\mathrm{en}$ su defecto andio-grabadas en su totalidad. Estas sesiones serin registradas en instrumentos para la recolección y archivo de la información (Historias Clínicas, formatos de observación y registros de campo). I as grabaciones c instrumentos de registro serán utilizados únicamente con fines académicos e investigativos; una ver. finalioe la investigación, serán archivados para dar soporte a los resultados.

6. La información obtenida en este estuctio, utilizada para la identificación de caso, mantendrá estricta confidencialidad acerca de los participantes. sus familias o las instituciones involucradas. Esta será compartida con los Directores, Asesores y equipos de investigación en los espacios académicos y tutorias desarrollados con el fín de avanzar en la obra de conocimiento y el proceso de formación de investigadores.

7. Los resultados de este estudio serán utilizados con fines académicos y podrán ser publicados a través de medios de divulgación de interés cientifico, guardando la confidencialidad de sus participantes.

8. Por la participación en esta investigación usted no recibirá ninguna remuneración de tipo económico.

Una vez considere que sus dudas han sido aclaradas y que no tiene ninguna pregunta sobre su participación en la investigación, usted puede, si asi lo decide, firmar la siguiente carta de Consentimiento Informado.

\section{Carta de Consentimiento Informado de Mayor de Edad (Asentimiento informado)}

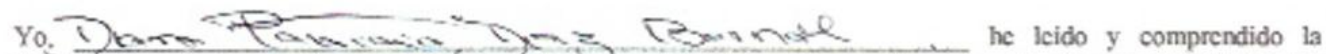
información anterior y mis preguntas han sido respondidas de manera satisfactoria. He sido enterado(a) de los 


\section{LA DESERCIÓN ESCOLAR COMO PRETEXTO PARA CONVERSAR SOBRE IDENTIDAD, FAMILIA Y ESCUELA

procedimientos de esta investigación y entiendo que la información obtenida puede ser publicada o difundida con fines cicntificos, respetando mi anonimato.

Convengo en participur en esta investigación. Recibiré una copia firmada y fechada de este consentimiento informado.

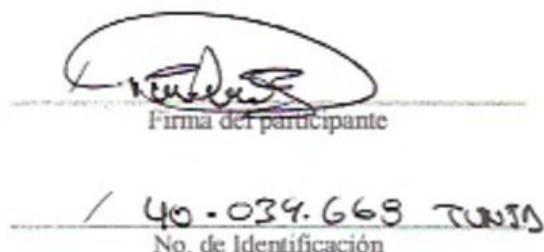

[Espacio para diligenciamiento por parte del (los) imvestigador (es)]

Hemos explicado al (la) señor(a). Therran

la naturaleza y los propósitos de lar invístigación; le hemos explicado acerca de los riesgos y beneficios que implica su participación. Hemos contestado a tas preguntas en la modida de lo posible y hemos preguntado si tienc alguna duda. Aceptamos que hemos leido y conocemos la normatividad correspondiente para realizar investigación con seres humanos y nos apegamos a ella.

Una vez concluida la sesión de preguntas y respuestas, se procedió a firmar el presente documento.

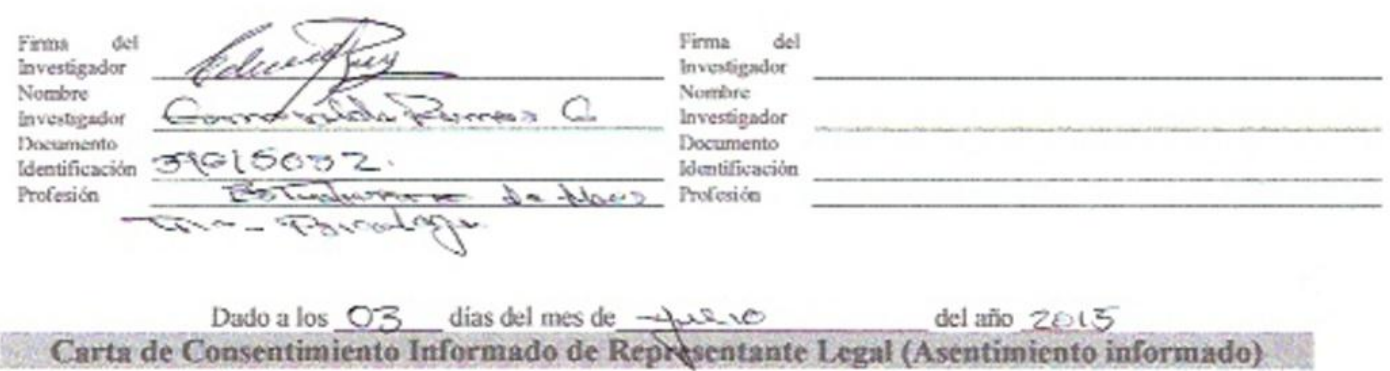

Yo, Triman he leido y comprendido la informacion anterior y mis preguntas ban sido respondidas de manera satisfactoria. He sido enterado(a) de los procedimientos de esta investigación y entiendo que la infomación obtemida puede ser publicada o difundida con fines cientificos, respetando mi anonimato.

He estado presente en las explicaciones que los investigadores le han dado a mi hijo / hija / representado y convengo su participación. Recibiré una copia firmada y fechada de este consentimiento informado. 


\section{LA DESERCIÓN ESCOLAR COMO PRETEXTO PARA CONVERSAR SOBRE IDENTIDAD, FAMILIA Y ESCUELA

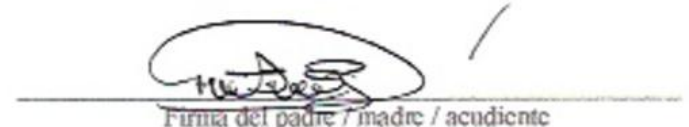

Firma de padie Fimadre / acudicnte

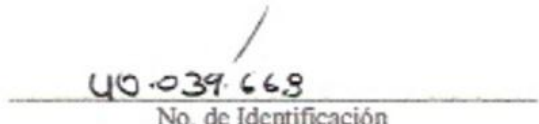

No, de Identificación
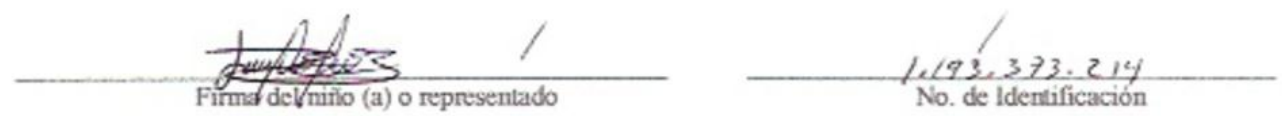

[Espacio para diligenciamiento por parte del (los) investigador (es)]

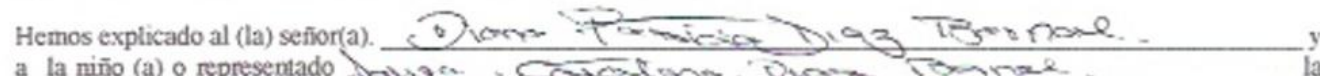

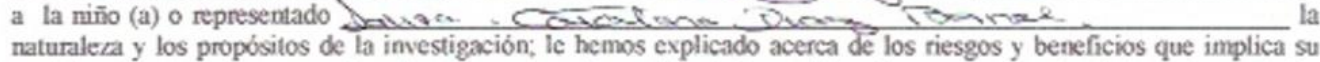
participación. Hemos contestado a las preguntas en la medida de lo posible y bemos preguntado si tiene alguna duda. Aceptamos que hemos leido y conocemos la normatividad correspondiente para realizar investigación con seres humanos y nos apegamos a ella.

Una vez, conchuida la sesión de preguntas y respuestas, se procedió a firmar el presente documento.

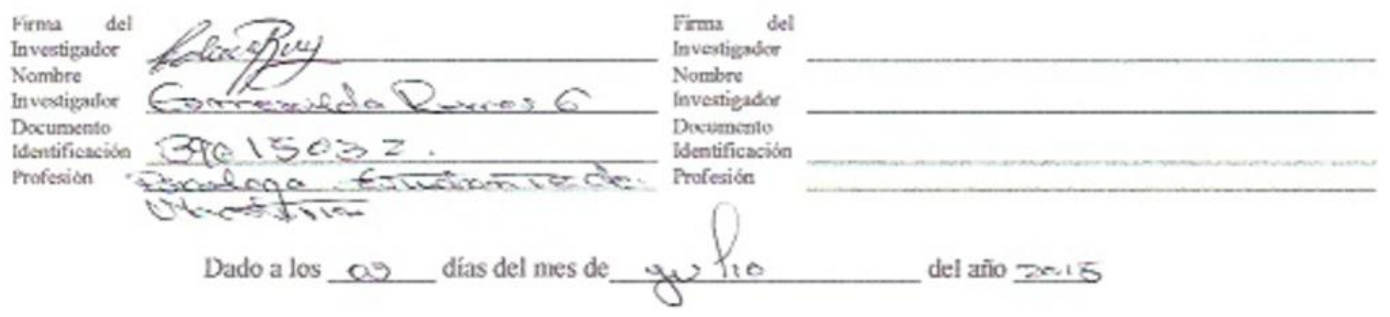




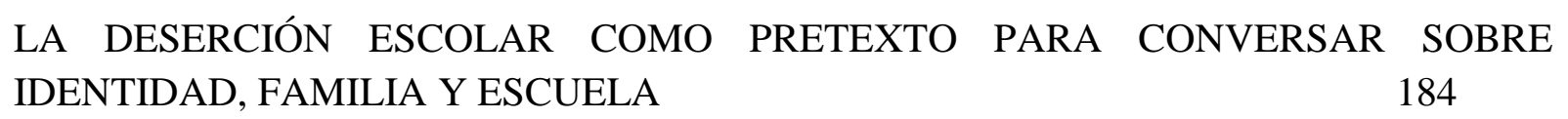

\section{Anexo 3. Historia Clínica}

\begin{tabular}{|l|l|l|l|}
\hline 2. UNIIVERIDAD SANTOIOMAS & \multicolumn{3}{|c|}{ HISTORIA CLINICA } \\
& \multicolumn{3}{|c|}{} \\
\hline C6digo: 2612-F-317 & Versión:01 & Emisión: 10-07-2009 & Página 1 de 8 \\
\hline
\end{tabular}

H.C. No: $\square$

\begin{tabular}{|c|c|c|c|c|c|c|c|c|c|c|}
\hline \multirow[b]{2}{*}{ Fecha de elaboradón: } & \multirow{2}{*}{\multicolumn{3}{|c|}{\begin{tabular}{|c|c|c|}
$D 0$ & $M M$ & $A A$ \\
30 & $O B$ & $2-015$ \\
\end{tabular}}} & & & & & & & \\
\hline & & & & \multicolumn{2}{|c|}{ Hora de elaboración: } & \multicolumn{5}{|c|}{$2.00-1$} \\
\hline \multicolumn{11}{|c|}{ DATOS DE TDENMIFICACIÓN } \\
\hline 1er apellido: & \multicolumn{2}{|c|}{ 2do apellido: } & & \multicolumn{2}{|l|}{ Nombres: } & \multirow{2}{*}{\multicolumn{3}{|c|}{ Sexco: $M$}} & \multirow{2}{*}{\multicolumn{2}{|c|}{$\mathbf{F}$}} \\
\hline 3 & \multicolumn{2}{|c|}{$P$} & & \multicolumn{2}{|l|}{ A } & & & & & \\
\hline \multicolumn{4}{|c|}{ Fecha de nacimiento: } & EDAD: & \multicolumn{6}{|c|}{ ESTADO CIVIL } \\
\hline ex. & - & $\mathrm{ecc}$ & & 17 & Ca & 90 & UL & SE & MS & $\mathbf{v}$ \\
\hline
\end{tabular}

DIRECCTón DOMICTLO CONSULTANTE: Crolle zz $=16=2.3$

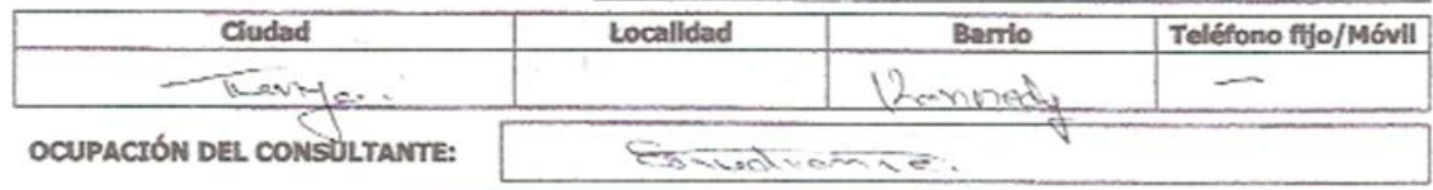

NOMBRE DEL ACUDIENTE: "Wh Madve.

\begin{tabular}{|c|c|c|c|}
\hline & Parentesco del acudilente & \multicolumn{2}{|c|}{ Teléfono } \\
\hline & int actine & \multicolumn{2}{|c|}{$310791862-28$} \\
\hline \multicolumn{2}{|c|}{ Psicologo/terapeuta responsable: } & Pregrado: & Postgrado: \\
\hline Exr & aldo $\sqrt{2 \ldots m o s}$ & Semestre: & $\sqrt{1}$ \\
\hline Supervisor: & Ah क्ष & $\therefore$ & \\
\hline
\end{tabular}

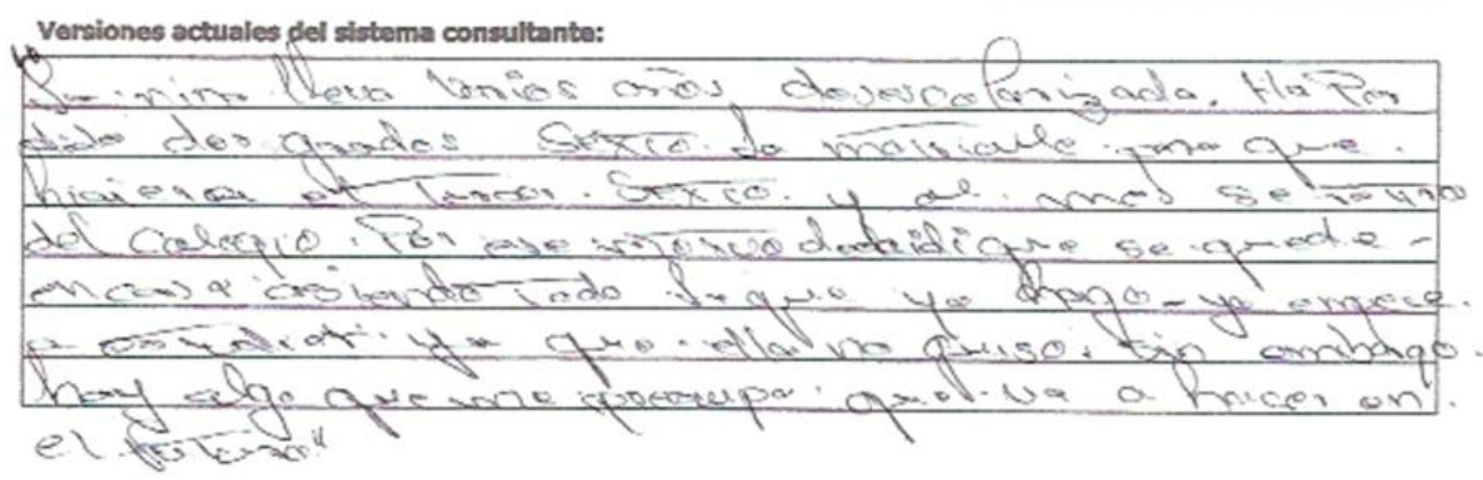




$\begin{array}{lccc}\text { LA DESERCIÓN ESCOLAR COMO } & \text { PRETEXTO PARA CONVERSAR SOBRE } \\ \text { IDENTIDAD, FAMILIA Y ESCUELA } & & 185\end{array}$

\begin{tabular}{|c|c|c|c|}
\hline 8. ÜNIVESIDAD SANTOTOMAS & \multicolumn{3}{|c|}{ HISTORIA CLINICA } \\
& \multicolumn{3}{|c|}{} \\
\hline Código: 2612-F-317 & Versión:01 & Emisión: 10-07-2009 & Páglna 2 de 8 \\
\hline
\end{tabular}

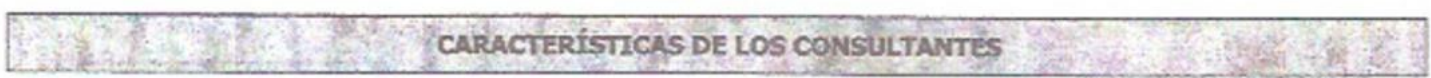

Famillograma vincular: (este famillograma debe estar relacionado a la historia familiar y del contexto relacional).

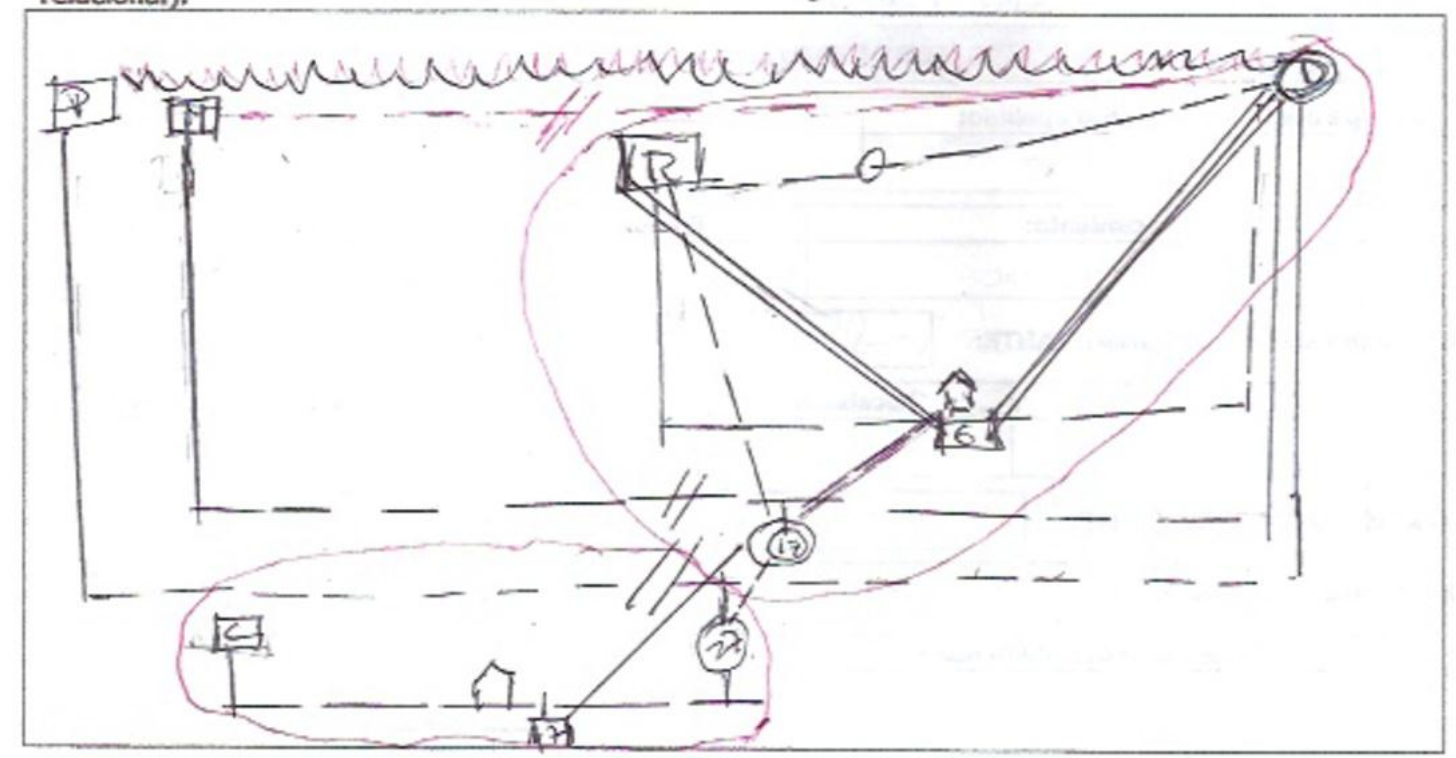

Caracteristicas soclodemográficas de los miembros de la familla significativos para la comprensión del caso: (colocar un * al lado de los datos del consultanto).

\begin{tabular}{|c|c|c|c|c|c|c|}
\hline $\begin{array}{c}\text { Nombre y } \\
\text { apellido }\end{array}$ & $\begin{array}{c}\text { Rol en la } \\
\text { familia }\end{array}$ & $\begin{array}{l}\text { Edad } \\
\text { años }\end{array}$ & Estudios & Ocupadión & Estado Cvill & $\begin{array}{c}\text { Lugar de } \\
\text { nacimiento }\end{array}$ \\
\hline $\mathrm{Ne}^{\circ}$ & Medro & 39 & Tenc & $-\infty$ ud & & Twnya. \\
\hline "R" & Padr - & 53 & $1 \neq 2$ hil & $\log \sqrt{510}$ & S. & ㄴ․ \\
\hline${ }^{*} J^{\prime \prime}$ & Hifa-1 & 27 & Imulas 5 & Espdenima & s. & $\sqrt{G}$ \\
\hline "it" & $\lim _{x \rightarrow}=$ & 17 & $x=0 r t$ of & Erajolor & U. & $\sqrt{1+\gamma})^{3}$ \\
\hline & & & & & & \\
\hline & & & & & & \\
\hline & & & & & & \\
\hline & & & & & & \\
\hline & & & & & & \\
\hline
\end{tabular}




\section{LA DESERCIÓN ESCOLAR COMO PRETEXTO PARA CONVERSAR SOBRE IDENTIDAD, FAMILIA Y ESCUELA

\begin{tabular}{|l|c|c|c|}
\hline & \multicolumn{3}{|c|}{ HISTORIA CLINICA } \\
\hline Códigive: $2612-F-317$ & Versión: 01 & Emisión: $10-07-2009$ & Página 3 de 8 \\
\hline
\end{tabular}

\begin{tabular}{|c|c|c|c|c|c|c|c|}
\hline Rol fam & \multicolumn{7}{|c|}{ Rol familiar (madre, padre, cuidador, etc } \\
\hline $\begin{array}{l}\text { MNE.: } \\
\text { secund } \\
\text { interme }\end{array}$ & \multicolumn{7}{|c|}{$\begin{array}{l}\text { MNE.: menor no escolar. AN.: analfabeta. PREESC: préescolar. PR.: Primários. SEC IN.: } \\
\text { secundaria incompleta. SEC COM.: secundaria complete. UNI. IN.: Universitários } \\
\text { intermédios o incompletos. UNI COM.: Universitarios completos. }\end{array}$} \\
\hline OCUPACrÓN: & \multicolumn{7}{|c|}{$\begin{array}{l}\text { HOGAR.EMP.EST.: empleado estable. EMP.INES.: empleado Inestable (sin contrato). } \\
\text { TRA. IND.: trabajador independiente. ESTUD.: estudlante. JUB.: jubilado o retirado. }\end{array}$} \\
\hline ESTADO CIVIL: & \multicolumn{7}{|c|}{ Soltero, casado, viudo. SEP.: separado. UL.: unlón libre. MS.: madre soltera. } \\
\hline LUGAR DE NACTMIENTO: & \multicolumn{7}{|c|}{$\begin{array}{l}\text { Anotar nombre de la ciudad, sl es capital de departamento, si nació en municipio o en } \\
\text { zona rural; o del pais, si es extranjero. }\end{array}$} \\
\hline \multicolumn{8}{|c|}{$\begin{array}{l}\text { PERFIL DE VULNERABILIDAD / GENERATIVIDAD } \\
\text { (Adaptación del modelo solidario del ICBF. 2003) }\end{array}$} \\
\hline \multirow{2}{*}{$\begin{array}{l}\text { INDICADORES DE CADA } \\
\text { PARÁMETRO }\end{array}$} & \multirow{2}{*}{$\begin{array}{l}\text { CRTIERIOS DE VULNERABILIDAD } \\
\text { Y GENERATIVIDAD }\end{array}$} & \multicolumn{3}{|c|}{ VUUNCRABMIIDAD } & \multicolumn{3}{|c|}{ GENERATIVIDAD } \\
\hline & & 1 & 2 & 3 & 4 & 5 & 6 \\
\hline \multirow{2}{*}{$\begin{array}{l}\text { Red vincular: Constituida por } \\
\text { miembros de la familla que conviven } \\
\text { en el momento, parientes con los que } \\
\text { cuentan, instubuciones que dan apoyo, } \\
\text { grupos políticos, religiosos, } \\
\text { deportivos, sociales, etc. a los que } \\
\text { pertenece. }\end{array}$} & \multirow{2}{*}{$\begin{array}{l}\text { 1. Pequeño tamaño y o desligamiento } \\
\text { de la red familiar-red suficiente y } \\
\text { vínculos familiares significativos. } \\
\text { 2. Escasez/suficiencla de fuentes de } \\
\text { apoyo soclal e institudional }\end{array}$} & & & & メ & & \\
\hline & & & & & & & \\
\hline \multirow{4}{*}{$\begin{array}{l}\text { Fillación: Tipos de vinculos entre } \\
\text { miembros de la familia y su red; } \\
\text { consanguinidad; parento-filiales; } \\
\text { adopdón; custodia; patria potestad; } \\
\text { conyugales: tpo de unión; } \\
\text { económicos: dependencla- autonomia } \\
\text { económica de los miembros; sociales: } \\
\text { pertenencia-anonirnato-exclusión de } \\
\text { su comunidad. }\end{array}$} & \multirow{4}{*}{$\begin{array}{l}\text { Confusiones o conflictos/caridad y } \\
\text { acuerdo en: } \\
\text { 1. Vinculo parento-fillales. } \\
\text { 2. Vinculos conyugales. } \\
\text { 3. Vínculos económicos. } \\
\text { 4. Exclusión/inclusión en la comunidad }\end{array}$} & & & & & & \\
\hline & & & & & & & \\
\hline & & & & & & & \\
\hline & & & & & & & \\
\hline \multirow{2}{*}{$\begin{array}{l}\text { Sociocultural: Clrcunstancias y } \\
\text { valores sociales, tradiclonales, } \\
\text { religiosos y poíticos relevantes; } \\
\text { sentido atribuido a los eventos que } \\
\text { motivan el contacto; circunstancias } \\
\text { sociales y politicas especificas que } \\
\text { inciden sobre el proceso de atencón }\end{array}$} & \multirow{2}{*}{$\begin{array}{l}\text { 1. Crrounstandas soclales y politicas } \\
\text { agravan el problema/favorecen su } \\
\text { solución. } \\
\text { 2. Circunstancias sociales y políticas } \\
\text { obstaculizan/favorecen la intervención }\end{array}$} & & & & & $\times$ & \\
\hline & & & & & & & \\
\hline $\begin{array}{l}\text { Vulnerabillidad Soclal: } \\
\text { Riesgos/aprobación de recursos. } \\
\text { condiciones y acceso a: vivienda, } \\
\text { salud, educación, ingreso/empleo, } \\
\text { servicios públicos, calidad del entorno } \\
\text { amblental, transporte, equipamiento } \\
\text { de servicios, etc. }\end{array}$ & $\begin{array}{l}\text { Escasa/suficiente aprobación de } \\
\text { recursos para el bienestar } \\
\text { socioeconómico de la famlila y el } \\
\text { afrontamiento de sus problemas. }\end{array}$ & & & & & & \\
\hline
\end{tabular}




\section{LA DESERCIÓN ESCOLAR COMO PRETEXTO PARA CONVERSAR SOBRE IDENTIDAD, FAMILIA Y ESCUELA

\begin{tabular}{|l|l|l|l|}
\hline 7. UNIVERIDAD SANTOTOMAS & \multicolumn{3}{|c|}{ HISTORIA CLINICA } \\
\hline Código: 2612-F-317 & Vorsión:01 & Emisión: 10-07-2009 & Página 4 de 8 \\
\hline
\end{tabular}

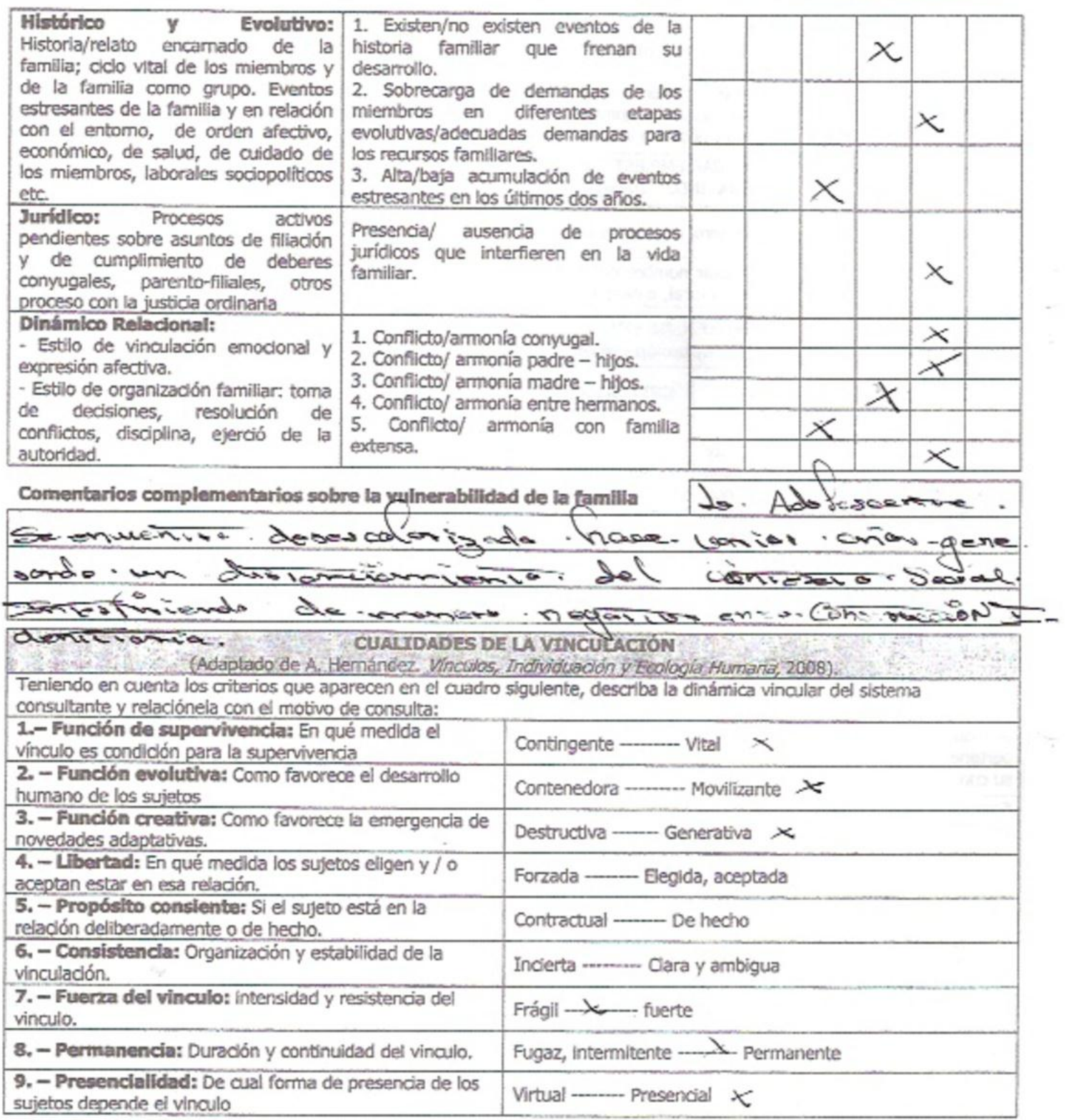




\section{LA DESERCIÓN ESCOLAR COMO PRETEXTO PARA CONVERSAR SOBRE IDENTIDAD, FAMILIA Y ESCUELA

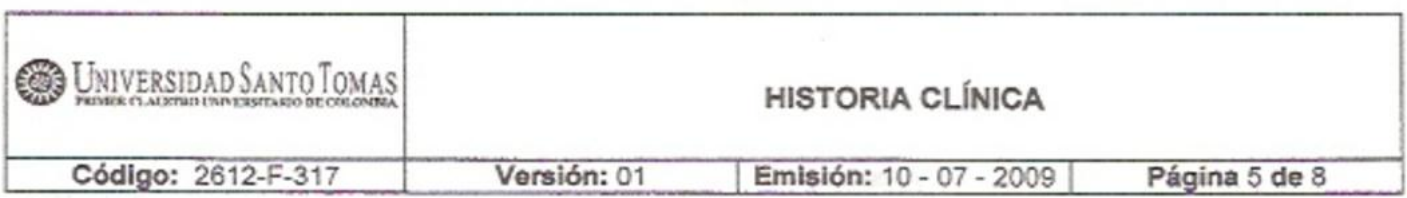

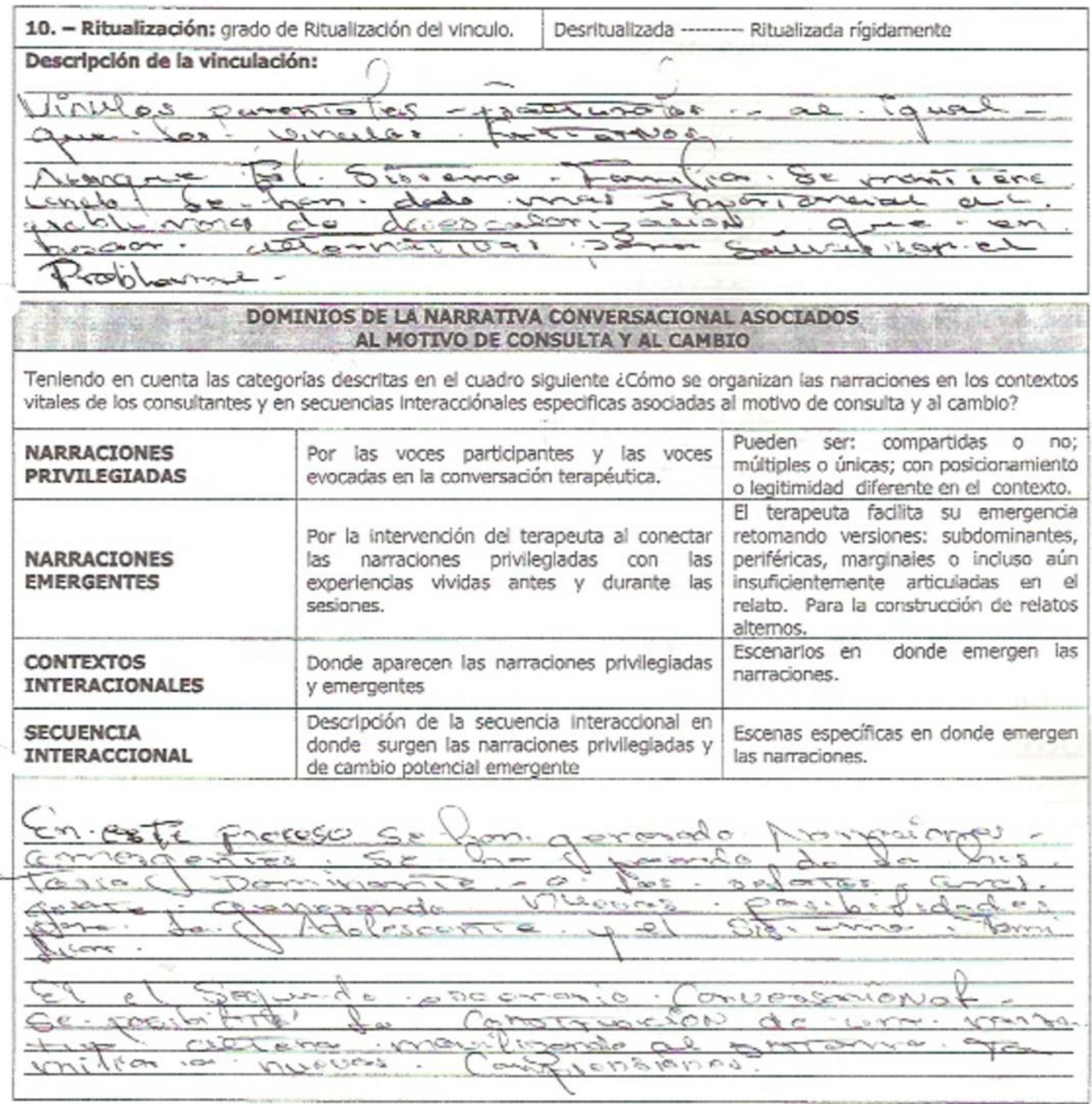




\section{LA DESERCIÓN ESCOLAR COMO PRETEXTO PARA CONVERSAR SOBRE IDENTIDAD, FAMILIA Y ESCUELA

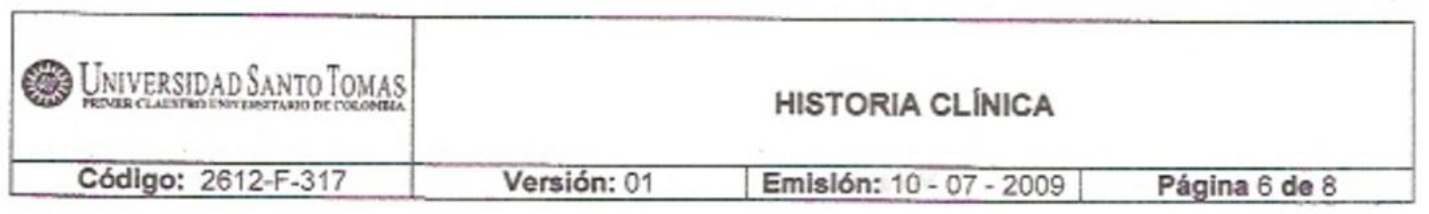

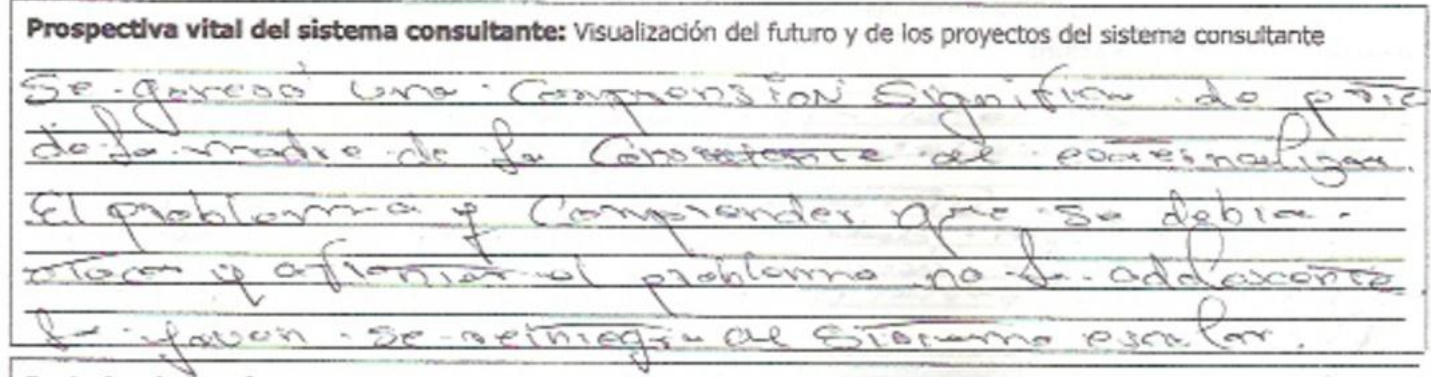

Portador de los síntomas: Describa al portador de los síntomas en términos de su desarrollo, intelectual- cognitivo, interpersonal, su funcionamiento emocional, su estllo para solucionar sus problemas, su proyecto vital y los síntomas específicos si los tlene.

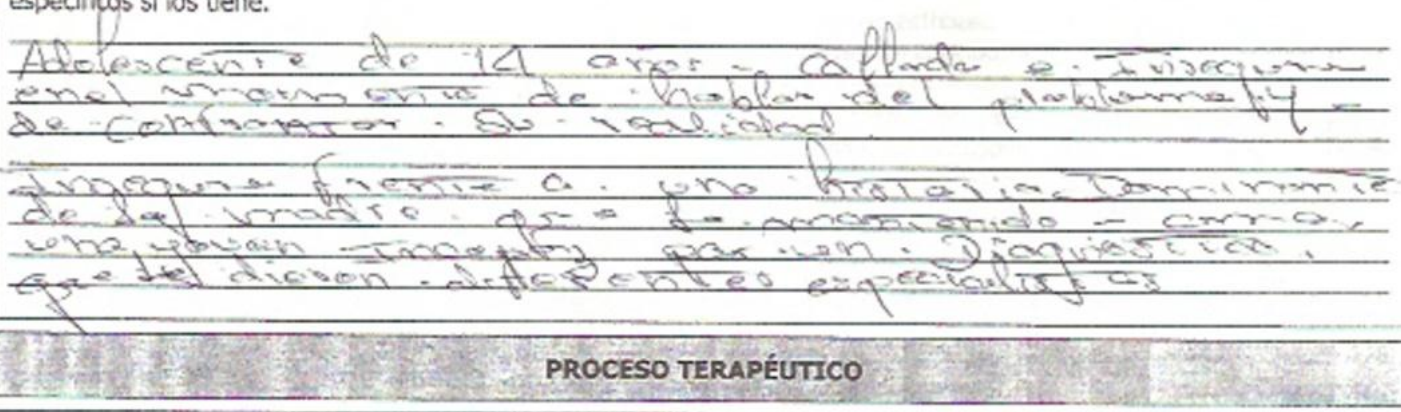

\section{Lectura ecosistémica del problema acordado con el y/o los consultante (s) como objeto de la intervención:}

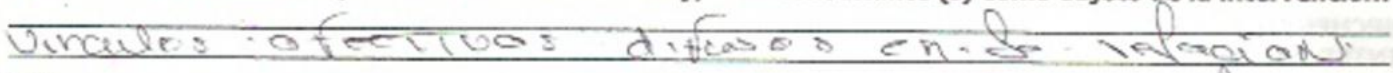

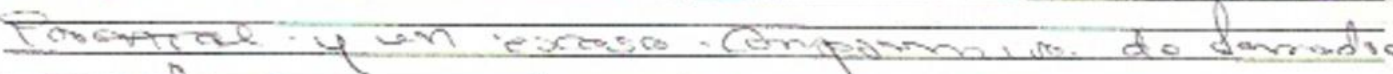

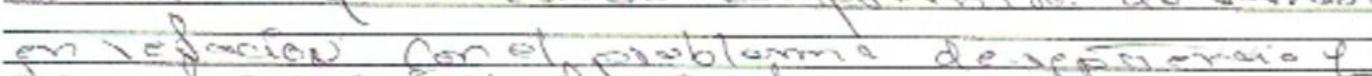

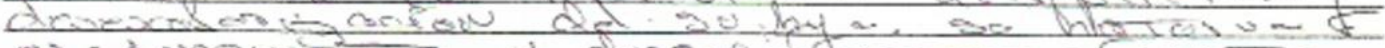

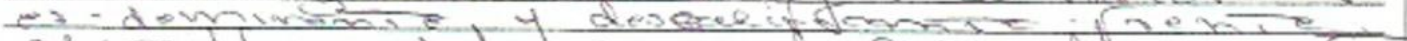

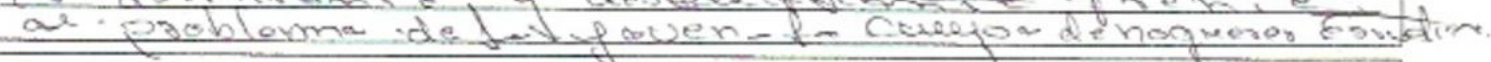

\section{Objetivos terapéuticos acorados con el y/o los consultante (s):}

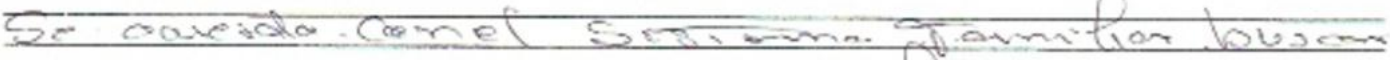
de्रer nowiverd

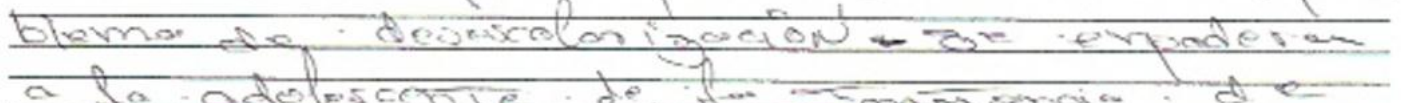

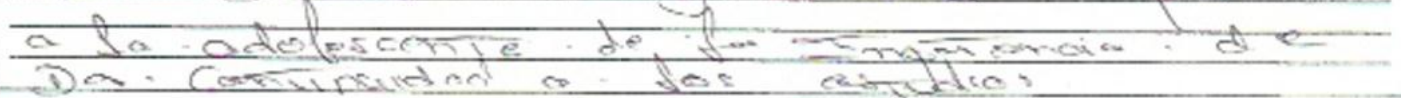




\section{LA DESERCIÓN ESCOLAR COMO PRETEXTO PARA CONVERSAR SOBRE IDENTIDAD, FAMILIA Y ESCUELA

\begin{tabular}{|c|c|c|c|}
\hline 4. UNIVERSIDAD SANTOTOMAS & \multicolumn{3}{|c|}{ HISTORIA CLINICA } \\
\hline & \multicolumn{3}{|c|}{} \\
\hline Código: $2612-F-317$ & Versión: 01 & EmIslón: 10-07 - 2009 & Página 7 de 8 \\
\hline
\end{tabular}

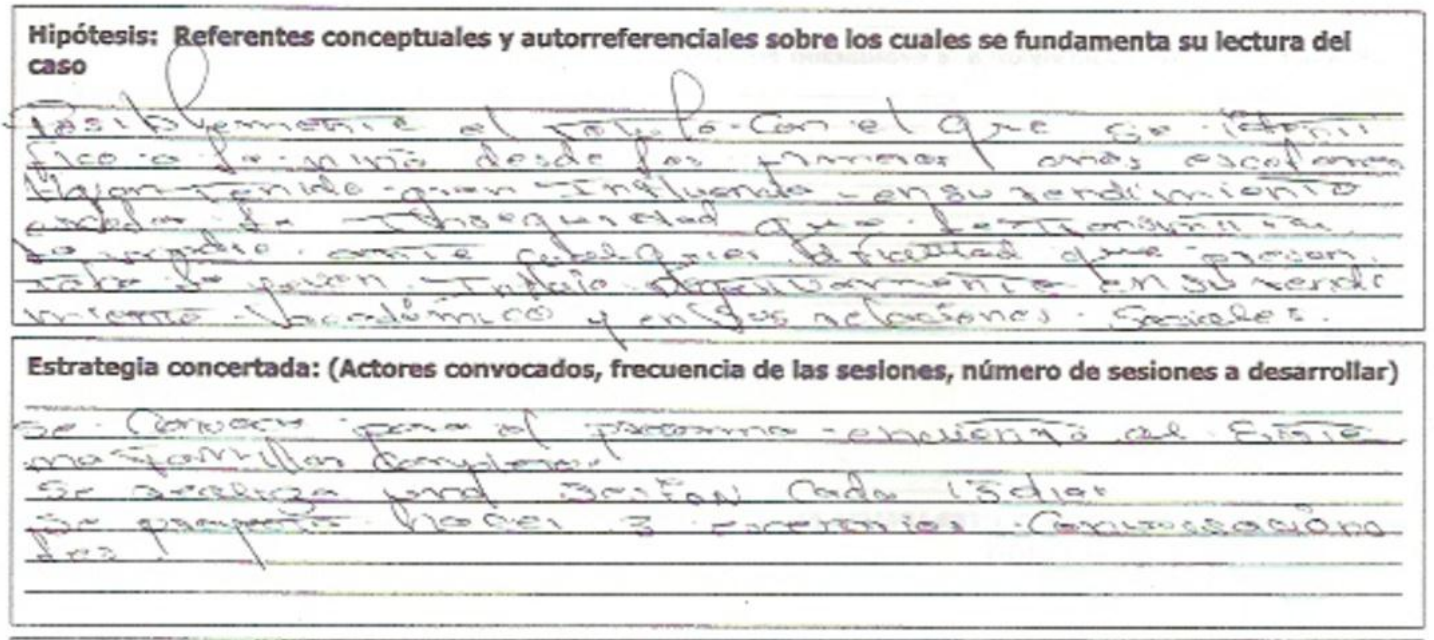

Evaiuación del proceso por parte del terapeuta: (Caracterización del sistema terapéutico con base en los procesos autorreferenciales, heterorreferenciales y la prospectiva del terapeuta.

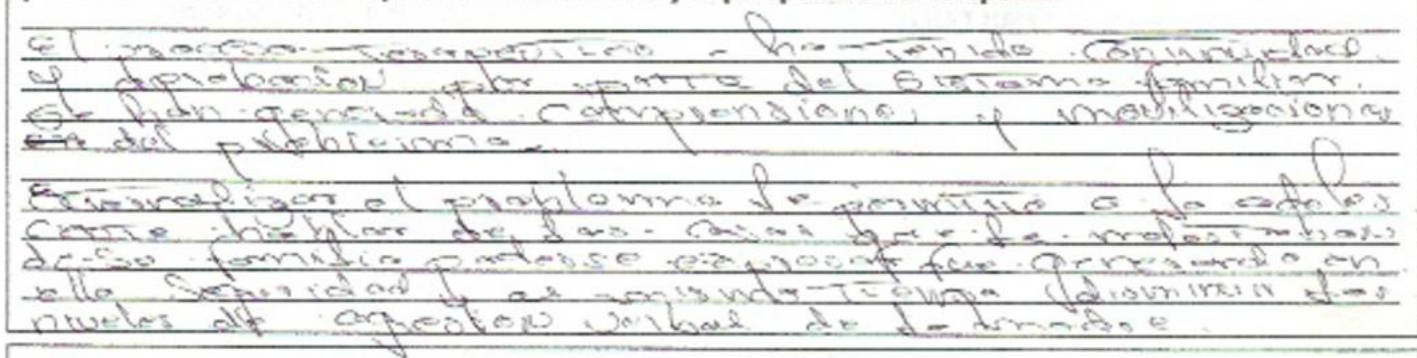

Otras personas, instituciones o redes convocadas a la sesión en calidad de qué, y si asistieron. 
LA DESERCIÓN ESCOLAR COMO PRETEXTO PARA CONVERSAR SOBRE IDENTIDAD, FAMILIA Y ESCUELA

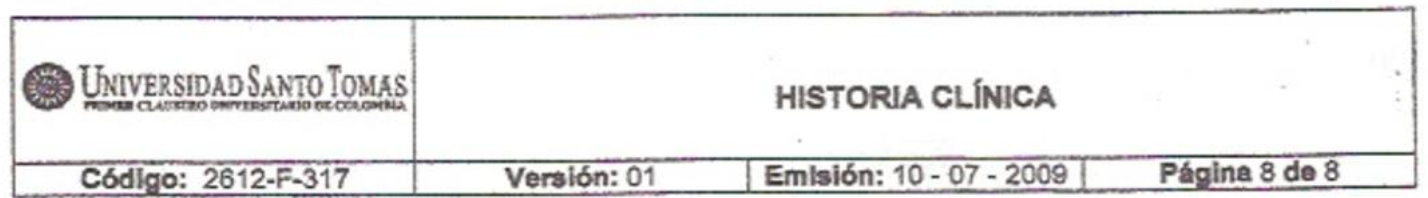
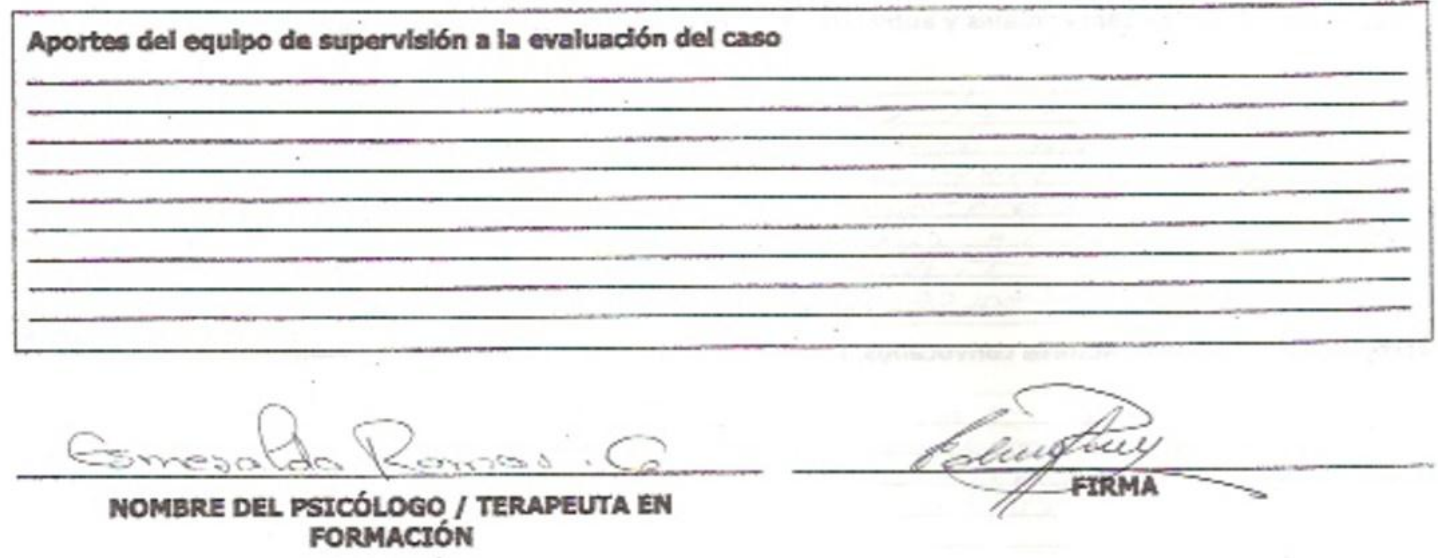


\section{LA DESERCIÓN ESCOLAR COMO PRETEXTO PARA CONVERSAR SOBRE IDENTIDAD, FAMILIA Y ESCUELA \\ 192}

\begin{tabular}{|c|c|c|c|}
\hline II UNIVERSIDAD SANTO TOMAS & \multicolumn{3}{|c|}{ EVOLUCIÓN DEL PROCESO TERAPÉUTICO } \\
\hline Códlgo: $2612-F-325$ & Verslón: 01 & Emisión: $10-07-2009$ & Página 1 de 1 \\
\hline
\end{tabular}

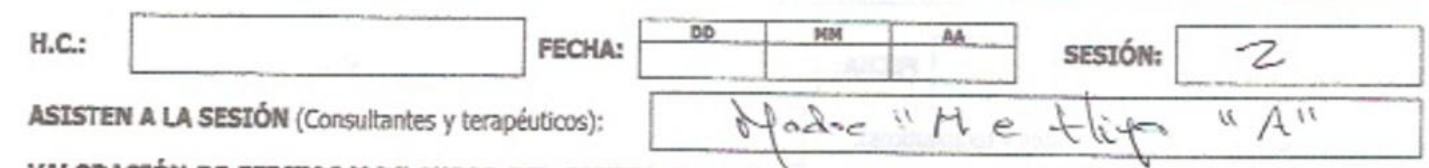

VALORACIÓN DE EFECTOS Y DE CURSO DEL CAMBIO (Prescripciontes, sugerencias, acontecimientos y acuerdios hechos en la sesión anterior)

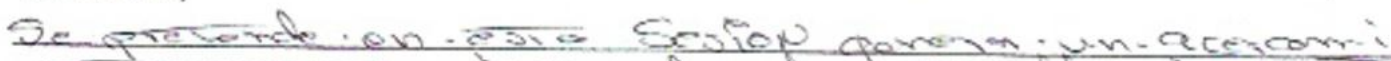

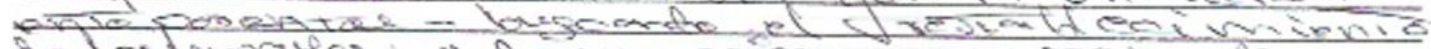

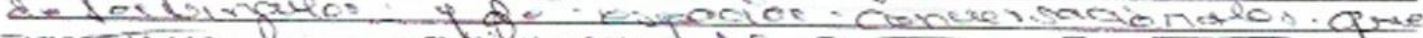

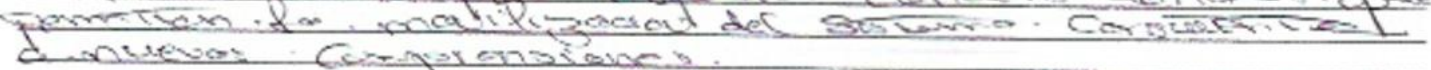
DINÁMICA DE LA SESIóN (Proceso conversadional, posición de los participantes, relatos emergentes)

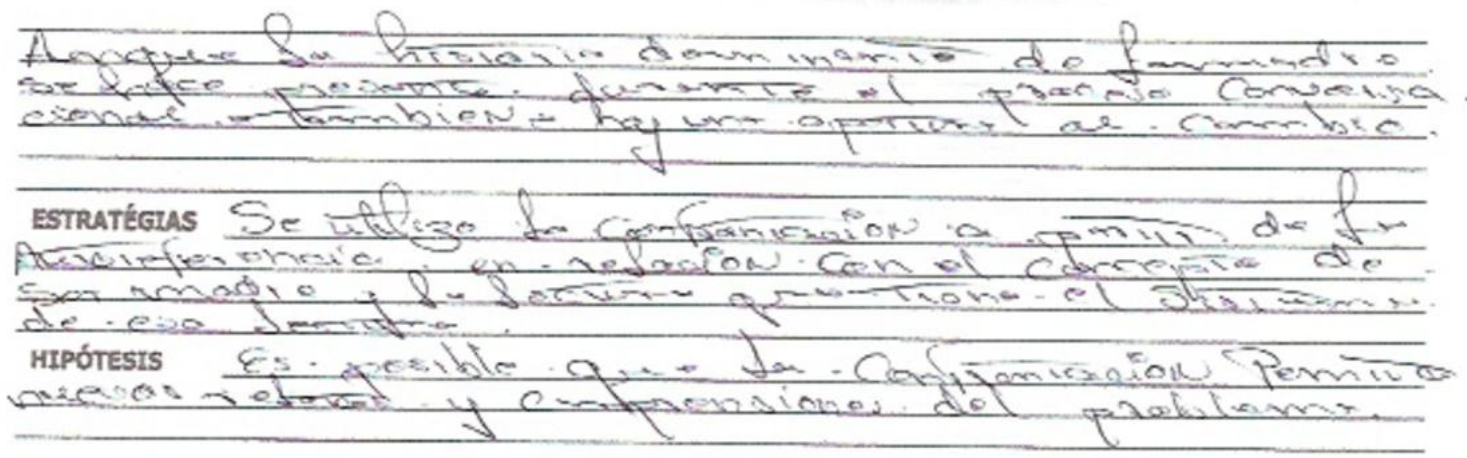

CIERRE DE LA SESIÓN (prescripciones, mensaje, sugerencias, acuerdos y cambios emergentes)

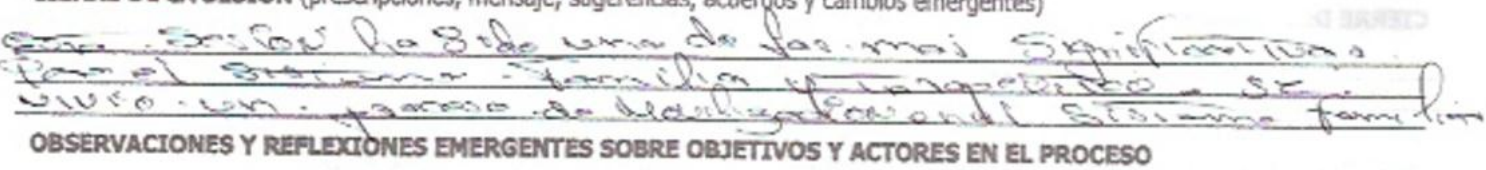

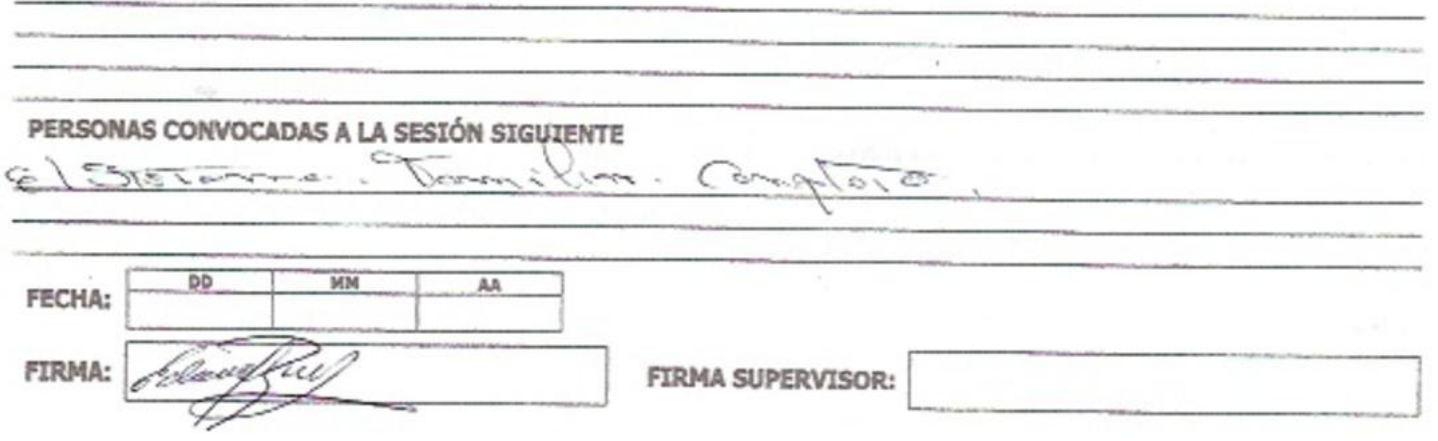




\section{LA DESERCIÓN ESCOLAR COMO PRETEXTO PARA CONVERSAR SOBRE IDENTIDAD, FAMILIA Y ESCUELA

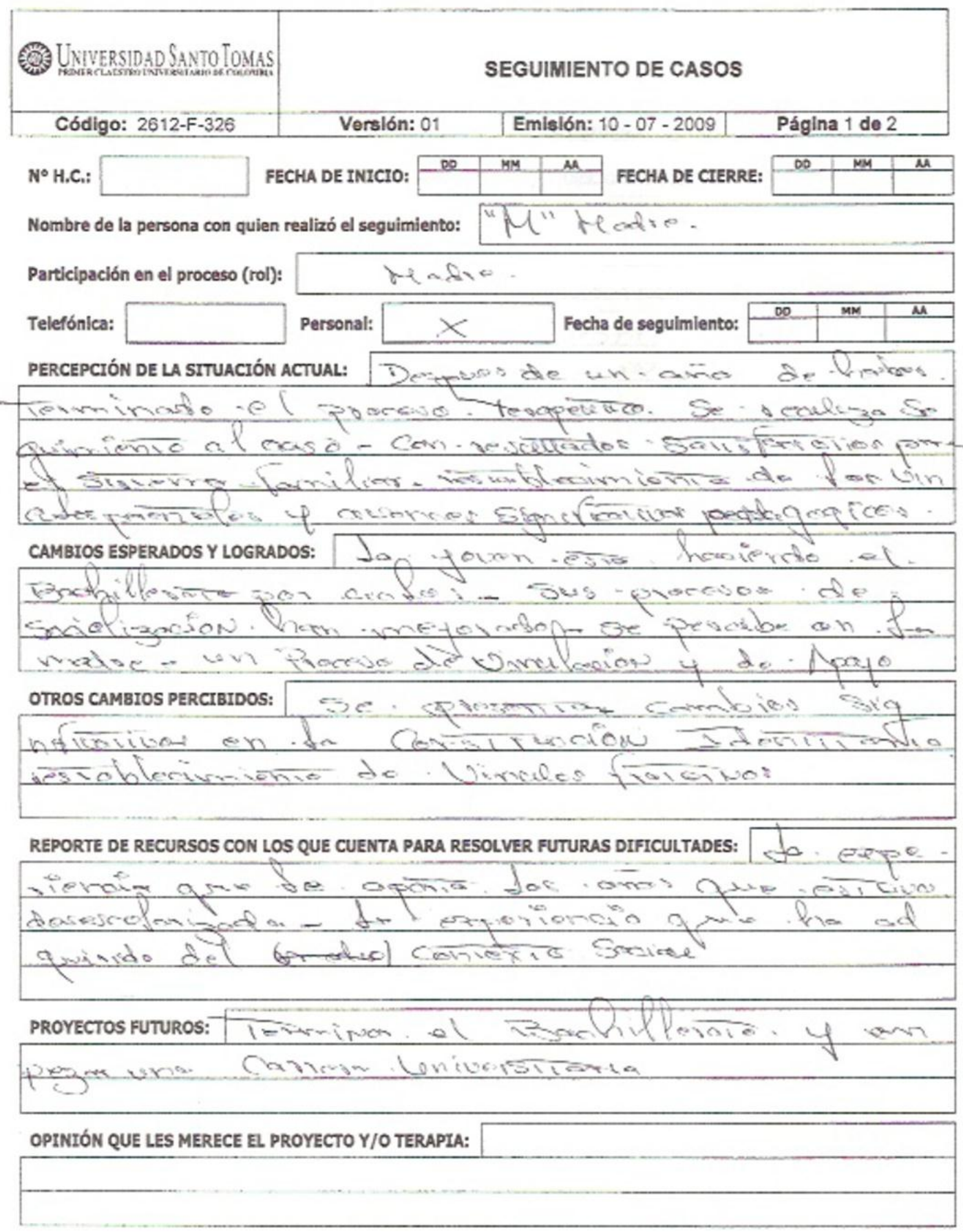




\section{LA DESERCIÓN ESCOLAR COMO PRETEXTO PARA CONVERSAR SOBRE IDENTIDAD, FAMILIA Y ESCUELA
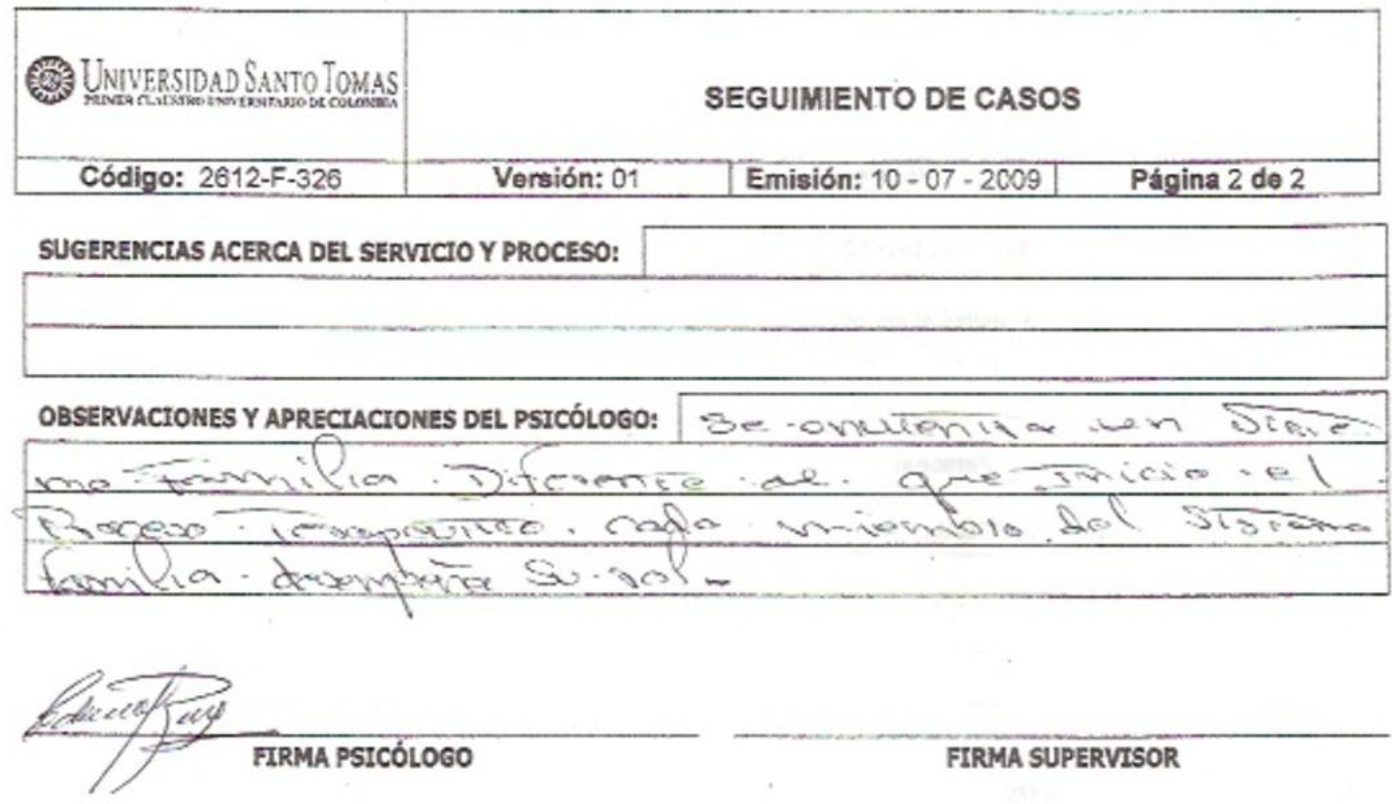


LA DESERCIÓN ESCOLAR COMO PRETEXTO
IDENTIDAD, FAMILIA Y ESCUELA

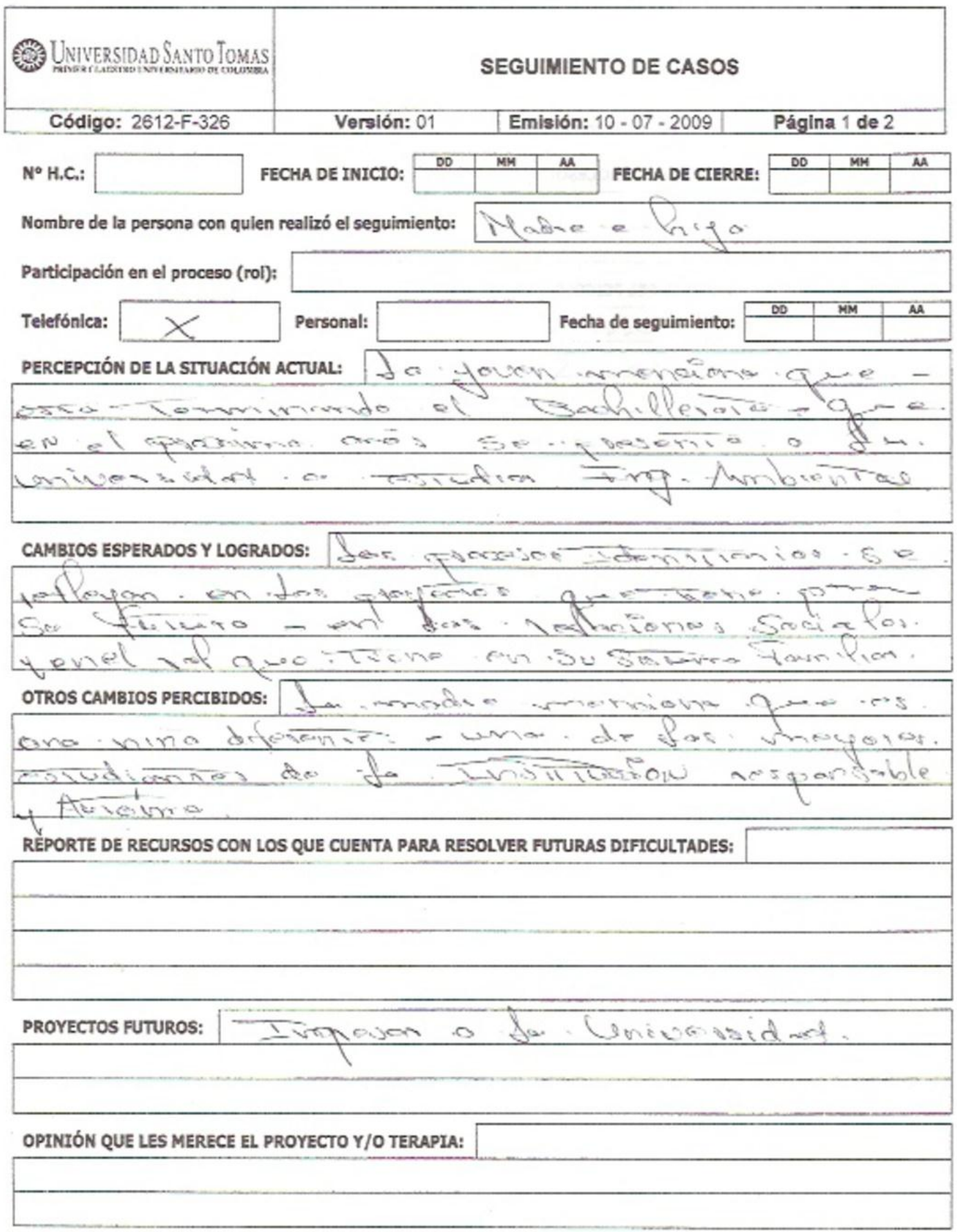




\section{LA DESERCIÓN ESCOLAR COMO PRETEXTO PARA CONVERSAR SOBRE IDENTIDAD, FAMILIA Y ESCUELA
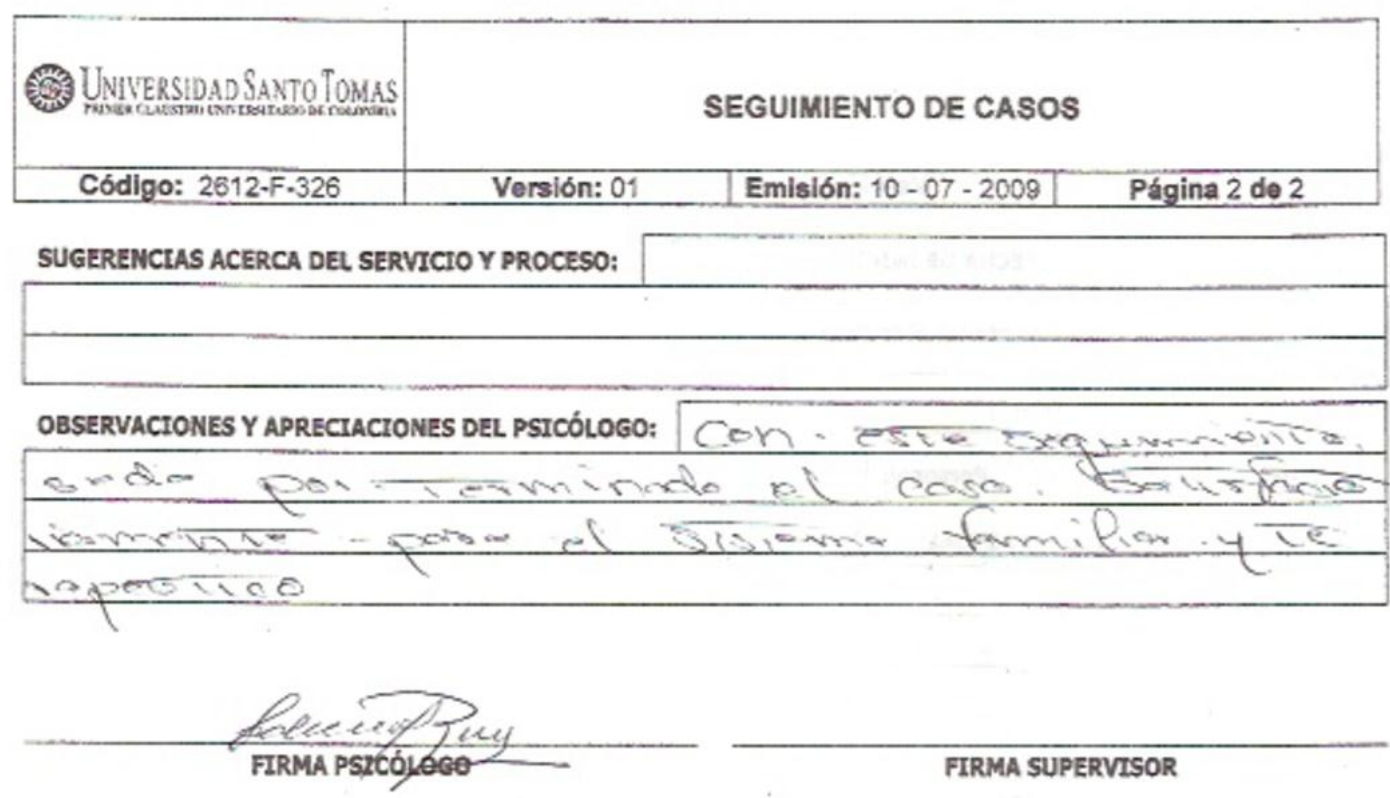

FIRMA SUPERVISOR 


\section{LA DESERCIÓN ESCOLAR COMO PRETEXTO PARA CONVERSAR SOBRE IDENTIDAD, FAMILIA Y ESCUELA \\ 197}

\section{Anexo 4. Escenarios}

\section{TRANSCRIPCIÓN PRIMER ESCUENTRO.}

Datos de la Sesión.

\begin{tabular}{lc}
\hline Número de la Sesión. & 1 \\
\hline Fecha y Hora. & \\
\hline Lugar. & \\
\hline Duración. & P: Psicóloga C1: Consultante uno (madre) C2: Consultante dos (Hija) \\
\hline Actores y Siglas. & Actores y Participación.
\end{tabular}

Línea.

\begin{tabular}{|c|c|}
\hline 1 & $\begin{array}{l}\text { Interventora: El motivo que nos convoca hoy en esta reunión es conversar un poco acerca de } \\
\text { cómo han vivido ustedes el proceso de deserción de su hija de la parte académica. Entonces } \\
\text { como familia, sobre todo usted mamita ¿Cómo entienden el problema que los trae aquí?, } \\
\text { ¿Cómo es para ustedes un problema el hecho de que Laura este desescolarizada? }\end{array}$ \\
\hline 2 & $\begin{array}{l}\text { Mamá: Pues es un problema grandísimo, es un problema que no solamente del momento, sino } \\
\text { uno lo piensa (la mamá tose) a futuro, sobre todo pues el futuro de ella. }\end{array}$ \\
\hline 3 & $\begin{array}{l}\text { Interventora: El futuro de ella es lo que no.... (la mamá tose)¿Hace cuánto tiempo que están } \\
\text { viviendo esta situación? ¿Cuánto hace que Laura dejo el colegio? }\end{array}$ \\
\hline 4 & Mamá: Ehhh desde que dejó el colegio tres años \\
\hline 5 & Interventora: ¿Y en esos tres años qué ha pasado Laura, qué ha pasado contigo?(la mamá tose) \\
\hline 6 & $\begin{array}{l}\text { Hija: (Dura un tiempo en silencio, alrededor de } 7 \text { segundos) Pues no se (exhala algo de aire en } \\
\text { una especie de sonrisa) }\end{array}$ \\
\hline 7 & $\begin{array}{l}\text { Interventora: Ósea ¿Es lo mismo estar asistiendo al colegio en una jornada como la que tu } \\
\text { tenías en este colegio? Ó ¿Es diferente estar en la casa? ¿Cómo has vivido ese proceso? ¿Qué } \\
\text { sientes cuando vez que tus compañeros o los niños de tu edad salen para el colegio y tú te } \\
\text { quedas en casa? }\end{array}$ \\
\hline 8 & $\begin{array}{l}\text { Hija: (Dura un tiempo en silencio, alrededor de } 6 \text { segundos) mmm (dura un tiempo en } \\
\text { silencio, alrededor de } 5 \text { segundos) Como aburrida }\end{array}$ \\
\hline 9 & Interventora: Como aburrida, ¿Por qué? haber cuéntanos un poco más \\
\hline 10 & Hija: ummm (dura un tiempo en silencio, alrededor de 3 segundos) \\
\hline 11 & $\begin{array}{l}\text { Interventora: Mira no te preocupes esto es solo una conversación, saca lo que tú tienes allá } \\
\text { adentro, porque eso forma parte de lo que posiblemente vamos a llegar a trabajar contigo en la } \\
\text { parte clínica. }\end{array}$ \\
\hline 12 & $\begin{array}{l}\text { Hija: (Dura un tiempo en silencio, alrededor de } 5 \text { segundos) ummm (dura un tiempo en } \\
\text { silencio, alrededor de } 4 \text { segundos) pues que ehh, pues aburrida por la parte que (dura un } \\
\text { tiempo en silencio, alrededor de } 3 \text { segundos) ehhh se siente muy (dura un tiempo en silenci }\end{array}$ \\
\hline
\end{tabular}




\section{LA DESERCIÓN ESCOLAR COMO PRETEXTO PARA CONVERSAR SOBRE IDENTIDAD, FAMILIA Y ESCUELA

alrededor de 5 segundos)

\begin{tabular}{|c|c|}
\hline 13 & $\begin{array}{l}\text { Interventora: No te preocupes mi amor (la niña empieza a respirar un poco más rápido y } \\
\text { fuerte) }\end{array}$ \\
\hline 14 & Hija: (dura un tiempo en silencio, alrededor de 8 segundos)(hay algunos sollozos y lágrimas) \\
\hline 15 & Interventora: Cuéntanos preciosa, ¿Te gustaría volver al colegio? \\
\hline 16 & $\begin{array}{l}\text { Hija: (dura un tiempo en silencio, alrededor de } 5 \text { segundos y tiene su voz un poco gruesa) ES } \\
\text { que (dura un tiempo en silencio, alrededor de } 5 \text { segundos, tiene lágrimas en sus ojos y su voz } \\
\text { algo gruesa evitando llorar) era más que todo por el colegio, porque en el que estábamos (las } \\
\text { últimas dos silabas las pronuncia con voz más baja, dura un tiempo en silencio, alrededor de } 3 \\
\text { segundos, intenta toser) no me gustaba y mm (dura un tiempo en silencio, alrededor de } 15 \\
\text { segundos, a los } 8 \text { segundos de este tiempo sube la cremallera de su chaqueta, llora un poco) }\end{array}$ \\
\hline 17 & $\begin{array}{l}\text { Interventora: En el colegio en el que estabas no te gustaba, pero ahora ¿Si te gustaría volver al } \\
\text { colegio? }\end{array}$ \\
\hline 18 & $\begin{array}{l}\text { Hija: (Esforzando la voz, para evitar llorar) si pero a otro (dura un tiempo en silencio, } \\
\text { alrededor de } 4 \text { segundos) no se me sentía sola (al pronunciar la palabra sola lo hace elevando } \\
\text { el tono de su voz) y todo el mundo me molestaba y me ponía apodos y eso y (con algo de } \\
\text { llanto) pero tenía miedo de decirlo }\end{array}$ \\
\hline 19 & Interventora: ¿A quién, a tu mami? \\
\hline 20 & Hija: (Afirma con su cabeza) \\
\hline 21 & Interventora: Y ¿Por qué sentías ese miedo, cómo es la relación hay con la mamita? \\
\hline 22 & $\begin{array}{l}\text { Hija: Pues (dura un tiempo en silencio, alrededor de } 3 \text { segundos) es que no sé, no sentía la } \\
\text { confianza para decírselo, yyy no creí que me fuera a ayudar }\end{array}$ \\
\hline 23 & Interventora: ¿Sumercé que piensa? (la niña está llorando) \\
\hline 24 & $\begin{array}{l}\text { Mamá: Ejje, pues me sorprende, me sorprende porqué ósea hay cosas en las que uno dice, } \\
\text { ósea digamos cosas como mami perdí una evaluación, o mami sii, me regañaron en el colegio, } \\
\text { hice una falta, son cosas que a uno como estudiante lo atemorizan, pero por lo contrario, mira } \\
\text { que yo se lo he demostrado muchas veces, como la he defendido, la he defendido, entonces } \\
\text { eso sí me parece que no .... }\end{array}$ \\
\hline
\end{tabular}




\section{LA DESERCIÓN ESCOLAR COMO PRETEXTO PARA CONVERSAR SOBRE IDENTIDAD, FAMILIA Y ESCUELA

Mamá: Pues como para ese tipo de cosas, que alguien le haga algo, pues si, haya mismo en el negocio, que uno supuestamente le dice a los clientes, uno tiene que, alguien que de pronto me le levante la voz o me le diga algo, yo inmediatamente brinco como dicen. (Existe un pequeño silencio) $\mathrm{Y}$ varias veces en el colegio se tocó ese tema de con los profesores, porque los niños, pero entonces las quejar eran que "ella era la que les pegaba, que los molestaba, que no ¡sí!”, entonces ella empezaron a tratarla como un niño, hasta una profesora misma dijo, dijo "Laura es un niño más en el salón"

\begin{tabular}{|c|c|}
\hline 27 & Interventora: ¿Cuándo decían "un niño más” se referían al género o... \\
\hline 28 & $\begin{array}{l}\text { Mamá: Al por el modo de ser de ella, de ser brusca, y ella desde chiquita siempre le ha } \\
\text { gustado, pues siempre le ha gustado el fútbol y amm parte del rechazo de las niñas con ella } \\
\text { fue eso, como a ella le gustaba jugar fútbol en el barrio y le gustaba jugar con los niños, las } \\
\text { niñas la rechazaban por eso, más que todo las niñas la rechazaban por eso, porque ella era } \\
\text { muy brusca }\end{array}$ \\
\hline 29 & $\begin{array}{l}\text { Interventora: Pero también es algo cruel ¡no!, porqué pues miremos hoy las niñas por } \\
\text { ejemplo están representando a nuestro país, y que han salido han representarnos en Canadá y } \\
\text { todo, pues son niñas que les va muy bien en el fútbol }\end{array}$ \\
\hline 30 & $\begin{array}{l}\text { Mamá: Si pero a esas edad los niños son entre comillas muy crueles y ellos no } \\
\text { dimensionan el daño que pueden causar }\end{array}$ \\
\hline 31 & $\begin{array}{l}\text { Interventora: Sí, caramba. Bueno y como familia como ¿Cómo han hecho para manejar } \\
\text { esta situación? la desescolarización de Laura, ¿Qué papel juega el colegio? }\end{array}$ \\
\hline 32 & $\begin{array}{l}\text { Mamá: Pues en un principio porque ella perdió dos sextos, en este momento ella con } \\
\text { catorce años, casi quince, esta con quinto de primaria aprobado y perdió el primer sexto y } \\
\text { listo, le dieron el cupo, volvió a entrar allá al mismo colegio, el segundo sexto fue peor, el } \\
\text { primer sexto lo perdió por dos materias, el segundo lo perdió por todas, después de ahí pues } \\
\text { ya perdió el cupo. La pase a otro colegio entonces pues lo que ella dice, que ese colegio no le } \\
\text { gustaba que quería otro, se pasó a otro y fue peor, así que nada. }\end{array}$ \\
\hline 33 & Interventora: Ósea ¿el problema ha sido como la adaptación de ella? \\
\hline 34 & $\begin{array}{l}\text { Mamá: Mjum, no en el otro colegio duro, creo q no alcanzó a durar un mes, y en un mes } \\
\text { que estuvo allá las quejas fueron las mismas (al pronuncias la palabra mismas, eleva un poco } \\
\text { el tono de su voz) que me daban en el Boyacá, que era brusca, que era grosera, que era } \\
\text { irrespetuosa (dura un tiempo en silencio, alrededor de } 3 \text { segundos) }\end{array}$ \\
\hline 35 & Interventora: Sii \\
\hline 36 & $\begin{array}{l}\text { Mamá: Entonces dije fue peor, porque empezó a no entrar a clase y esas cosas, entonces } \\
\text { ahí fue cuando yo tome la decisión de sacarla, porque dije si ella no quiere estudiar, para que } \\
\text { la dejo aquí a que se dañe, porque eso era lo que estaba pasando, en meno que duro hay en ese } \\
\text { colegio }\end{array}$ \\
\hline
\end{tabular}




\section{LA DESERCIÓN ESCOLAR COMO PRETEXTO PARA CONVERSAR SOBRE IDENTIDAD, FAMILIA Y ESCUELA

$37 \quad$ Interventora: ¿El ambiente muy pesado?

38 Mamá: Sii, eso sí, pesado el ambiente si porque le toco en un colegio donde llega de todo, entonces uyy no, se llega a encontrar con niños con mañas terribles, de droga, de ehh bueno, de muchas cosas entonces no, preferí sacarla y pues no, ya ella manifestó que no quería estudiar

39 Interventora: Bueno, y fuera de todo lo que ha pasado en la parte académica de Laura, ¿en algún momento tuvieron la orientación psicológica de alguien?, ¿pensaste en que ella asistiera a algunas consultas algunas terapias?, ehhh ¿cómo comentar esta situación fuera de todo el contexto que se había generado a nivel académico?, ¿cómo buscar una alternativa?, una ayuda alterna digamos para solucionar el problema de Laura. Lo hicieron como familia.

40 Mamá: Ella tuvo prácticamente desde Kinder la he llevado al psicólogo, ha estado, le han hecho terapias de unas de otras, terapia ocupacional, terapia del lenguaje, de psicología, ha estado en neurología, neurología infantil, en psiquiatría infantil, ehhh jummm, exámenes físicos le hicieron, ehhh estuvo en el neurofisiatra

\begin{tabular}{cc}
\hline 41 & Interventora: Y finalmente cual ha sido el diagnóstico de todos esos profesionales \\
\hline 42 & $\begin{array}{l}\text { Mamá: Siempre han dicho que hiperactividad y atención dispersa, a ella inclusive la } \\
\text { medicaron, pero pues el medicamento no se lo quise dar, le dieron ritalin pero no se lo quise } \\
\text { dar }\end{array}$ \\
\hline 43 & $\begin{array}{l}\text { Interventora: Y el psiquiatra le dio el psiquiatra infantil le formulo el ritalin, y ¿Cómo } \\
\text { sugirió él, qué esperaba el que sucediera, o qué les explicó él a ustedes que iba a suceder con } \\
\text { ese medicamento donde ella consumiera el medicamento? }\end{array}$ \\
\hline 44 & Mamá: Que la, pues que era algo como allá, pues me explico así como para que \\
& $\begin{array}{c}\text { entendiera, que era como un corto que había en el cerebro y que eso el ritalin lo que hacía era } \\
\text { hacer que siguiera una línea recta como que encaminara y centrara su pensamiento }\end{array}$ \\
\hline 45 & Interventora: Ummjum y ¿Por qué tu tomaste la determinación de no darle el \\
& medicamento? \\
\hline 46 & Mamá: Pues yo se lo di como dos semanas, y pues la verdad lo único que lo único que \\
& hizo fue causarle efectos secundarios, le daba rebote, le daba dolor de cabeza, permanecía \\
& pálida, de resto en el colegio nada, en la parte académica que se suponía que era en lo que iba \\
a mejorar, no hizo ningún efecto
\end{tabular}




\section{LA DESERCIÓN ESCOLAR COMO PRETEXTO PARA CONVERSAR SOBRE IDENTIDAD, FAMILIA Y ESCUELA

$51 \quad$ Interventora: ¿Y la volviste a llevar?

52 Mamá: Si, la volvimos a llevar yy después hay le formularon unas terapias, pero entonces en esas terapias pues nunca vi que le hicieran, ósea como, pues uno espera que se haga un tratamiento

\begin{tabular}{|c|c|}
\hline 53 & Interventora: umjum \\
\hline 54 & $\begin{array}{l}\text { Mamá: Que le digan bueno le vamos a aplicar este método, no nunca, ósea las siempre } \\
\text { terapias fueron, “y ¿Qué hiciste? y ¿Cómo te sientes? Yyyy ¿Te comprometes a hacer esto?” y } \\
\text { de ahí nunca paso, entonces ya tanto ella como yo nos cansamos, y ya un día ella dijo “ya para } \\
\text { que más terapias mamí, siempre es lo mismo” y pues sí, yo no veía un beneficio, un cambio, } \\
\text { un aporte, entonces también me canse de eso, y ya, y pues ya considero que ya, con la edad } \\
\text { que tiene hoy ella (la niña está sollozando) ella ya con catorce años, uno a los catorce años ya } \\
\text { es consciente de que está bien y que está mal }\end{array}$ \\
\hline 55 & $\begin{array}{l}\text { Interventora: ¿Cómo mamá tu como ves a Laura? ¿La consideras madura para la edad que } \\
\text { tiene, o su comportamiento es como más infantil? ¿Cómo la vez tú a ella? }\end{array}$ \\
\hline 56 & $\begin{array}{l}\text { Mamá: Ehh si a veces ella tiene comportamientos y actuaciones de niña, como si fuera una } \\
\text { niña de } 1011 \text { años }\end{array}$ \\
\hline 57 & $\begin{array}{l}\text { Interventora: ¿Alguna vez le aplicaron una prueba de coeficiente intelectual para medir su } \\
\text { coeficiente? }\end{array}$ \\
\hline 58 & $\begin{array}{l}\text { Mamá: Si si, yo le había traído eso, porque, si ella tiene todo, ella tiene todo el historial } \\
\text { clínico donde tiene todo, le hicieron, dos veces le aplicaron pruebas aquí, la mandaron a } \\
\text { Bogotá, estuvo en una prueba de coeficiente esa otra que es de coeficiente intelectual, pero le } \\
\text { midieron otras otras cosas }\end{array}$ \\
\hline 59 & Interventora: ¿Y qué salió, recuerdas? \\
\hline 60 & $\begin{array}{l}\text { Mamá: (Tose) Pues el coeficiente sale por debajo del normal, pero pues según el fisiatra } \\
\text { está dentro del rango normal, ósea }\end{array}$ \\
\hline 61 & Interventora: En lo limite \\
\hline 62 & Mamá: Tiene una dificultad pero lo puede lograr \\
\hline 63 & Interventora: Umjum \\
\hline 64 & Mamá: Ya es cuestión de querer \\
\hline 65 & $\begin{array}{l}\text { Interventora: ¿Qué será lo que hace que el problema se mantenga? Están, a veces, cuando } \\
\text { hablamos o las oigo así y Laura como tan callada, como que no, solo escucha, es como si } \\
\text { alguien, ósea ella siempre estuviera como dispuesta a a obedecer y a no opinar, ¿Tú que } \\
\text { piensas Diana, como mama de Laura? Tú que la conoces más }\end{array}$ \\
\hline 66 & $\begin{array}{l}\text { Mamá: No eso si, mejor dicho para sacarle una palabra, muchas veces me toca } \\
\text { amenazarla para que me responda algo }\end{array}$ \\
\hline
\end{tabular}




\section{LA DESERCIÓN ESCOLAR COMO PRETEXTO PARA CONVERSAR SOBRE IDENTIDAD, FAMILIA Y ESCUELA 202}

68 Mamá: Aquí, porque ósea yo no sé si saca su agresividad y tiene problemas en otros lado y es por eso, porque en otros lados tiende a ser brusca, porque en la casa pues obviamente yo no se lo permito, yo le tengo reglas, le tengo parámetros, le tengo límites isi!

\begin{tabular}{|c|c|}
\hline 69 & $\begin{array}{l}\text { Interventora: Y desde que tú tienes uso de razón Laura ha sido así, callada, introvertida, o } \\
\text { en qué etapa }\end{array}$ \\
\hline 70 & $\begin{array}{l}\text { Mamá: Noo, chiquita, pues era, pues normal, ósea, nada, ni, ni nada, y que yo recuerde, no } \\
\text { nunca le he dicho o que le haya pegado por decir usted porque hablo, no, ¡no! yo siempre he } \\
\text { dicho de las cosas y soy de las que piensa que uno debe decir las cosas cuando son, como son } \\
\text { y en el momento que son, decentemente obviamente, pero (existe un pequeño silencio) no sé, } \\
\text { como desde que empezaron más o menos desde que empezó el problema con el Boyacá, en } \\
\text { grado sexto, en grado sexto fue cuando empezó todo, toda la locura }\end{array}$ \\
\hline 71 & $\begin{array}{l}\text { Interventora: ¿Y ahí fue donde tú te volviste introvertida, por qué callas Laura, por qué no } \\
\text { comentas, por qué te guardas tantas cosas, como es tu mundo? }\end{array}$ \\
\hline 72 & Hija: No sé, raro (existe una leve pausa) creo \\
\hline 73 & Interventora: ¿Por qué raro mi amor, explícanos cómo es eso, cómo lo entiendes? \\
\hline 74 & $\begin{array}{l}\text { Hija: Umm (dura un tiempo en silencio, alrededor de } 3 \text { segundos) pues lo que dice mi } \\
\text { mami es cierto ¡No!, pues a veces me cree como (existe un sonido de risa) muy niña, y iya!, } \\
\text { pues creo que ese también era el problema en el colegio, que (existe una breve pausa) pues } \\
\text { más que todo era por los apodos }\end{array}$ \\
\hline 75 & $\begin{array}{l}\text { Interventora: Te molestaban los apodos y ¿tú te empezaste a aislar que mecanismo usaste, } \\
\text { cómo era esa reacción? }\end{array}$ \\
\hline 76 & $\begin{array}{l}\text { Hija: Ummm (existe una breve pausa) sentía ira (al mencionar la palabra ira, eleva el tono } \\
\text { de su voz, enfatizando en su sentimiento) }\end{array}$ \\
\hline 77 & Interventora: Y por \\
\hline 78 & Hija: Ira con todos (eleva su tono de voz) \\
\hline 79 & Interventora: ¿Y por eso era la agresividad? \\
\hline 80 & $\begin{array}{l}\text { Hija: Un poco sí (existe una respiración marcada y profunda, junto con un tono de voz } \\
\text { elevado) }\end{array}$ \\
\hline 81 & $\begin{array}{l}\text { Interventora: Pero te quedaste ahí, te quedaste en la agresividad, pero pero bueno mami nos } \\
\text { dice en un colegio fue, y en ese colegio bueno solamente perdió dos materias, y bueno, y hubo } \\
\text { un cambio de colegio, y, pero ahí fue peor, entonces como ¿Cómo nos quieres contar que } \\
\text { sucedió ahí, ósea? }\end{array}$ \\
\hline 82 & $\begin{array}{l}\text { Hija: Pues creo que, ósea, era el era el Gran Colombiano y ps si, el ambiente era como muy } \\
\text { muy feo y malas amistades jumm }\end{array}$ \\
\hline
\end{tabular}




\section{LA DESERCIÓN ESCOLAR COMO PRETEXTO PARA CONVERSAR SOBRE IDENTIDAD, FAMILIA Y ESCUELA

convenían ¿Cómo actuabas frente a ellos?

\begin{tabular}{|c|c|}
\hline 84 & Hija: Umm, nada \\
\hline 85 & $\begin{array}{l}\text { Interventora: ¿Ellos llegaban a buscarte a ti o tú los buscabas a ellos, cómo se relacionaban, } \\
\text { cómo socializaban, de qué hablaban, hablaban, no hablaban, cómo era? }\end{array}$ \\
\hline 86 & $\begin{array}{l}\text { Hija: Pues no nada, el (dura un tiempo en silencio, alrededor de } 3 \text { segundos) no, ósea, como, } \\
\text { ehh normal, si como estamos hablando así en este momento }\end{array}$ \\
\hline 87 & Interventora: $\mathrm{Si}$ \\
\hline 88 & Hija: Y ya, pero no, así que alguien buscara a alguien para hablar, no \\
\hline 89 & Interventora: Y entonces tu como me dices que ¿cómo sabías que eran malas amistades? \\
\hline 90 & $\begin{array}{l}\text { Hija: Porque, ehh, mmm, pues ellos me hicieron faltar a clase (hay una expresión de risa en la } \\
\text { niña) ellos, me, dijeron, "venga y vamos y tal parte” y en una clase, en una materia, la } \\
\text { profesora no, no iba, en todas las clases, que teníamos con ella no iba, era tecnología y } \\
\text { entonces pues todos se salían y pues salíamos era como a jugar, y ya, pero era como la única } \\
\text { clase }\end{array}$ \\
\hline 91 & $\begin{array}{l}\text { Interventora: } \mathrm{Si} \text {, de ahí fue de donde los conociste a ellos, y ahí, pero tú ya sabías que salirte } \\
\text { de clase, o ir a donde tú no debías era malo, o no estaba bien, más bien entonces ¿Qué te } \\
\text { impulsaba a llevarte allá? }\end{array}$ \\
\hline 92 & Hija: No sé \\
\hline 93 & Interventora: ¿Te amenazaban, te prometían algo, ooo? \\
\hline 94 & Hija: Niega de manera no verbal \\
\hline 95 & Interventora: ¿Y entonces? \\
\hline 96 & Hija: No pensaba \\
\hline 97 & $\begin{array}{l}\text { Interventora: No pensabas ¿Simplemente te ibas y vivías el momento y ya, y luego, las } \\
\text { consecuencias? }\end{array}$ \\
\hline 98 & Hija: Pues, (hay un breve silencio) no pensaba en eso \\
\hline 99 & Interventora: ¿No pensabas en las consecuencias, ni en lo que podía decir tú mamá? \\
\hline 100 & Hija: (Existe un breve silencio) ayyyahhh (la mamá tose) \\
\hline 101 & $\begin{array}{l}\text { Interventora: A ver esta pregunta va para las dos ¿Qué otras personas han estado involucradas } \\
\text { en eso que para ustedes es un problema, o lo han manejado solamente ustedes dos como } \\
\text { madre e hija, o tu otra hija, o tu compañero, toda la familia, cómo? De acuerdo a la situación } \\
\text { que plantean ¿Qué impacto ha tenido este hecho en sus vidas?, cuéntame algo Diana }\end{array}$ \\
\hline
\end{tabular}




\section{LA DESERCIÓN ESCOLAR COMO PRETEXTO PARA CONVERSAR SOBRE IDENTIDAD, FAMILIA Y ESCUELA

102 Madre: Ummm, pues mi esposo pues pues ay, viendo toda la situación y pues hay él en lo que yo haga él me apoya, si, me ayuda a estar pendiente de ella, eso, y pues indirectamente, ósea digamos, ummm digamos digamos que no que me ayuden pero pues obviamente están enterados de la situación pues si, mi familia, mis hermanos, mi mamá, mi hija mayor, todos ahí.

103 Interventora: ¿Qué han hecho ustedes para sobrellevar la dificultad?

104 Madre: pues jmmm todo el mundo le ha hablado, es que quién no le ha hablado (existe una expresión de risa, y un pequeño silencio) yo realmente en este punto, lo que yo le decía me siento tan cansada de todo esto que (existe un breve silencio) ya cómo que (existe un breve silencio), para mí todo esto es una repetición de algo que no me lleva a nada

105 Interventora: ¿Será Diana?

106 Mamá: Pues lo hablo por ella, porque, todo va en la voluntad de ella, yo lo digo por la cosa más mínima, ósea algo mínimo digo yo, Laura todos los días levántese y tienda la cama jmm, sumercé vaya y yo le hago ... (21:00) un rato en esa pieza, entonces es algo que ella no, nada, listo no le gusta estudiar, digamos que hay gente, no todos nacimos para estudiar, digamos que no le gusta el estudio, pero tampoco le gusta hacer nada nada nada, es que no hay algo que yo diga si ella lo hace sin que uno tenga que decirle, no, pa' que no se demore bañándose, esta mañana me toco pararme como un policía en la ducha con ella, porque puede durar perfectamente una hora en la ducha (dura un tiempo en silencio, alrededor de 3 segundos) entonces es como un desgaste que digo ay, ya me siento (existe un breve silencio) agotada, que ya siento que siento con ella ya no puedo más (hay algo de llanto)

107 Interventora: Bueno Diana y Laura ¿Cómo creen ustedes que lo que estamos haciendo aquí el proceso que vamos a empezar a nivel clínico, les puede ayudar?

108 Mamá: Ushhh yo pienso es que mucho, por lo menos por lo menos por mi parte es mucho, porque a mí eso me ha enfermado, pp pueda que yo no lo manifieste o de pronto se lo manifiesto a ella ya con rabia, ósea ya el mismo de verla a ella, ya es como a la defensiva, honestamente yo la miro y le veo todo lo malo por todas partes porque yo llego y no, ósea veo que esta mañana se quedó este papel hay y ella paso diez veces por encima y no lo alzó (existe un breve silencio) cosas que le digo yo haga esto y llego y no lo ha hecho y todos los días es el mismo problema entonces ya va, entonces sí, ya como que yo quiero algo y espero de esto, por lo menos aunque sea que esto, lo que yo le decía a ella, por ella, no por mí porque yo no espero de aquí a mañana que me dé ni más nada, pero por lo menos decir ella tiene aunque sea con que defenderse

109 Interventora: Mjumm

110 Mamá: Para que no se quede ahí pa’ que la mangoneen de aquí a mañana pa' lado y lado 


\section{LA DESERCIÓN ESCOLAR COMO PRETEXTO PARA CONVERSAR SOBRE IDENTIDAD, FAMILIA Y ESCUELA

111 Interventora: Umjumm, y sumercé ¿Qué piensa Laura, qué piensas tú que podemos lograr?, claro con la compañía de tú mamá, porque un proceso no se empieza solo, aquí vamos a necesitar cuando empecemos a intervenir vamos a necesitar de tu hermana, vamos a involucrar otras personas, para buscar cómo ayudarte ¿Tú qué esperas, qué te gustaría que pasara aquí con nosotras?

112 Hija: Noo, pues (dura un tiempo en silencio, alrededor de 2 segundos) pues que (dura un tiempo en silencio, alrededor de 6 segundos) lograr entrar a estudiar y pasar los años

\begin{tabular}{ll}
\hline 113 & Interventora: ¿Y de quién depende eso Laura? \\
\hline 114 & Hija: De mí \\
\hline 115 & Interventora: ¿Y qué tienes para darle a este proceso? \\
\hline 116 & Hija: (Dura un tiempo en silencio, alrededor de 3 segundos) voluntad \\
\hline 117 & Interventora: ¿Seguro y qué otra cosa, y por qué no miras a Diana y le dices eso, a tú mamá? \\
\hline 118 & Hija: (Existe algo de risa de la niña) \\
\hline 119 & Interventora: Pero con compromiso, no por decirlo, pues cierto Diana, o tu que piensas
\end{tabular}

120 Mamá: Yo sí, yo le he dicho doctora a ella, ósea lo que usted haga ósea es por usted, piense en usted, ósea de lo que yo le decía, ella ya está en edad de saber lo que es bueno y lo que es malo, yo le decía uno, a mí me la ofrecieron, yo no, fue lo primero yo sé que eso es malo para que lo voy a probar si sé que eso me va a causar daño, que lo haga mi amigo quiere decir que porque yo no lo haga, o si él me deja de hablar porque yo no lo probé ese no es amigo y para mí, mejor que esa persona se aleje de mí, pero independientemente de todo es uno el que toma las decisiones y uno piensa en uno, lo que es bien para uno, yo la estuviera mandando, vaya Laura vaya allí venga camine le enseño a robar, cree que eso estaría bien, yo le he dicho de una y mil formas, para que le sirve el estudio, que días se lo dije creo que fue esta semana o la semana pasada, se lo dije, sí usted quiere estudiar música, estudie música, sí quiere estudiar educación física, estudie educación física, a mi realmente lo que estudie yo no le voy a decir es que tiene que estudiar esto, no, pero lo que quiera estudiar, que le dije yo que necesitaba para poder estudiar

\begin{tabular}{|c|c|}
\hline 121 & Hija: Bachillerato \\
\hline 122 & Mamá: es lo minimo, $. . \ldots \ldots \ldots \ldots \ldots \ldots . \ldots$ Entonces \\
\hline 123 & $\begin{array}{l}\text { Interventora: jumjumjum ....... Como te ves ahí, compromiso tu nos hablaste de algo } \\
\text { importante de un compromiso ..... pero un compromiso con quien, con tu mamá, conmigo, } \\
\text { contigo. }\end{array}$ \\
\hline 124 & Hija: con todos \\
\hline 125 & $\begin{array}{l}\text { Interventora: con todos, que colegio te gustaría?, en que colegio te gustaría estar?, en } \\
\text { donde?......... tal vez ummm hayas pensado en algún colegio }\end{array}$ \\
\hline
\end{tabular}




\section{LA DESERCIÓN ESCOLAR COMO PRETEXTO PARA CONVERSAR SOBRE IDENTIDAD, FAMILIA Y ESCUELA

126

Hija: pues un colegio fijo todavía no, no se cual

$127 \quad$ Interventora: ¿por qué?

128 Hija mmmmm no, no sé, no he pensado como en eso no?, pues mi mami dice que en el rosario pero

\begin{tabular}{cl}
\hline 129 & Interventora: y a ti te gusta el rosario? \\
\hline 130 & Hija: pues no sé cómo será ahí, ps \\
\hline 131 & Interventora: qué esperas encontrar en un colegio?... o que te gustaría más bien encontrar? \\
\hline 132 & Hija: no sé, no ... Pues no normal lo... o sea ... como que no sea igual emm, que en el \\
& BOYACA
\end{tabular}

133 Interventora: ese colegio te marco definitivamente... y sufres cuando hablas de ello .... OK

134 Mamá: en ese aspecto yo le he dicho a ella, que día, que día inclusive se lo dije ella se inscribió a un curso virtual del sena, y las dos primeras semanas eso mejor dicho no hacia si no metida en eso, y dije bueno ..... jumm.... De un momento a otro no volvió a hacer, y le dije y todos los días le decía, Laura ¿Qué paso con lo del curso? Si si ahí voy, si si y el que días le dije, pues no es yo no la he vuelto a hacer, ver hacer nada ósea, no volvió a hacer nada, no es que es difícil, entonces le dije, le dije pues es que nada es fácil en la vida, lo fácil es malo, todo lo que uno consigue fácil nunca, o no dura o le hace a uno daño, o bueno no se ve, entonces le dije que tal Dios la quiera de aquí a mañana tenga un hijo ...... y se le hace difícil entonces va y lo bota ..... y a todo lado donde uno vaya uno va a encontrar, no va a encontrar, todo el mundo no va a ser dulzura y candor Laura ...... entonces tú no puedes esperar de llegar, ni hoy puede ser el colegio, mañana es un trabajo, pasado mañana es una familia ... el mundo ..... y uno no puede vivir todo el tiempo de que, del que dirán, o de lo que los demás le digan ...... entonces graves por que como, imagine nos tocaría sentar, ponernos a hacer encuesta por todos los colegios si son malos o no los niños pa poder entrar a estudiar o no doña Laura

135 Interventora: jum jum jum

136 Mamá: uno tiene que aprender a manejar esas situaciones y yo le he dicho...... Cuantas veces le he dicho, ósea uno por que se tiene que dejar afectar por que a uno le digan, si a mí me dicen que soy fea, bueno usted cree que soy fea, si soy fea, bueno usted crea lo que quiera a mí que me importa ¿sí? .....ósea uno no tiene por qué dejarse tocar de lo que los demás le digan ósea, uno tiene su convicción y uno, yo digo, yo soy bonita, yo soy grande, yo soy gorda, yo soy flaca, yo soy ......lo que yo crea es lo que importa..... Pero si al del lado le pareció que no, pues problema de él, ..... ¿o no? .....entonces tiene que aprender a enfrentarse a esas cosas, no puede esperar a que llegue a donde llegue todo mundo le vaya a decir Laurita, que no que uno no es monedita de oro pa gustarle a todo el mundo mija 


\section{LA DESERCIÓN ESCOLAR COMO PRETEXTO PARA CONVERSAR SOBRE IDENTIDAD, FAMILIA Y ESCUELA

137 Interventora: siempre las conversaciones de ustedes son así?

\begin{tabular}{|c|c|}
\hline 138 & Mamá: si yo a ella le hablo duro \\
\hline 139 & Interventora: y Laura escucha y no replica nada \\
\hline 140 & Mamá: no \\
\hline 141 & $\begin{array}{l}\text { Interventora: queeee quisieras decirle a tu mamá Laura, en relación con lo que ella } \\
\text { menciona? }\end{array}$ \\
\hline 142 & $\begin{array}{l}\text { Mamá: de lo que yo que te acabe de decir que que piensas?, mi mamá está loca, que le } \\
\text { pasa? }\end{array}$ \\
\hline 143 & Hija: risa \\
\hline 144 & Mamá: eso no es así \\
\hline 145 & Hija: $m m m m$..... no pues si tengo que ..... Creer en mí misma ...... \\
\hline 146 & $\begin{array}{l}\text { Interventora: eso ya vamos desenvolviendo un poquito la cabuya es creer en ella misma, y } \\
\text { después que tu empieces a creer es potencializar eso que tu sabes que tu puedes llegar a ser, } \\
\text { pero es que solamente tu lo puedes hacer, la familia es muy importante y yo sé que cuando tu } \\
\text { des el primer paso la familia va a estar ahí apoyándote, pero es que se necesita la iniciativa. }\end{array}$ \\
\hline 147 & $\begin{array}{l}\text { Mamá: la iniciativa si ósea que uno diga, bueno si Laura se está esforzando lo está } \\
\text { haciendo, listo vamos vamos pa lante, pero si esta así como... }\end{array}$ \\
\hline 148 & Interventora: tambaleando \\
\hline 149 & $\begin{array}{l}\text { Mamá: como que si como que no, uno....... Ósea .... Yo me voy por el lado de que hay no } \\
\text { eso no va a hacer nada, pero si usted me demuestra yyyyy mire la mejor manera de uno callar } \\
\text { a la gente es así, así sea a su misma mamá mijita, bueno voy a demostrarle a mi mamá que si } \\
\text { puedo ... pero es demostrarlo ..... para su bien por que la única que se va a beneficiar es } \\
\text { usted... que, que, que te dije yo un día a uno lo tratan como uno trata, y si tu tratas a alguien } \\
\text { mal como vas a esperar por q esa persona te sonría, si a ti alguien te trata mal, tu vas a } \\
\text { sonreírle... es exactamente lo mismo, de lo que uno da uno recibe... }\end{array}$ \\
\hline 150 & $\begin{array}{l}\text { Interventora: ok.... Bueno les agradezco, de verdad les agradezco muchísimo este, este } \\
\text { encuentro, yo la verdad desearía que para el próximo encuentro eee Laura este mucho mas } \\
\text { suelta, ¿si?, por que es que la voz de ella tiene que cobrar vida aquí para poder comprender y } \\
\text { avanzar un poco en lo que estamos viviendo, en lo que ustedes están viviendo como familia y } \\
\text { en el proceso que, en el cual yo estoy involucrada también de una u otra forma me toca desde, } \\
\text { desde lo que yo soy como persona y como terapeuta que me estoy formando veo una situación } \\
\text { un poco compleja pero siento que, que Laura tiene mucho que contar, mucho que decir y } \\
\text { cuando ella saque todo eso posiblemente vamos a encontrar caminos }\end{array}$ \\
\hline
\end{tabular}




\section{LA DESERCIÓN ESCOLAR COMO PRETEXTO PARA CONVERSAR SOBRE IDENTIDAD, FAMILIA Y ESCUELA

152

Interventora: porque en este momento lo que yo percibo es e que tú tienes una idea de ella y ella calla si como si no hubiera realmente una dinámica relacional que e permita que Laura se suelte y nos comente toda esta situación pero si estamos aquí, pues la verdad yo si les pido el favor es de que Laura se suelte e sin temores y hable ..... nos cuente como estas viviendo esto, porque si veo es mucho sufrimiento en ella ... veo tristeza, dolor, sufrimiento cosas que quiere decir pero que las calla, entonces eso me ....

153 Mamá: si yo me he dado cuenta de eso y ella es de las que....... Se crea, se ahoga en un vaso de agua, por decirlo palabras más palabras menos, se está creando así como rencores y odios por cosas bobas

154 Interventora: entonces en el próximo encuentro Laura ..... Vamos a hablar y vamos a hablar mucho te pido ese favor, listo Laurita muchísimas gracias

TRANSCRIPCIÓN SEGUNDO ESCUENTRO.

Datos de la Sesión.

Número de la Sesión. 2

Fecha y Hora.

Lugar.

Duración.

Actores y Siglas.

P: Psicóloga C1: Consultante uno (madre) C2: Consultante dos (Hija)

\# Actores y Participación.

$D e$

Línea.

1. P: Pues han pasado ya quince días, casi quince días desde que nos vimos la última vez y hoy arrancamos con nuestro segundo encuentro. Entonces me gustaría saber ¿qué cambios han tenido? Si se han notado algún cambio...qué ha pasado a nivel de ustedes dos, de la familia...cómo se han sentido después de que tuvimos nuestro primer encuentro a hoy que tenemos nuestro segundo encuentro.

2. C1: (Silencio) Pues de un encuentro para acá, pues no, L cambios cambios...no. Ninguno, o sea ella sigue en la misma tónica de no hacer caso...mmm no quiere, no quiere y no quiere hacer nada, realmente es nada. Sentada, relajada mirando televisión o en el computador.

3. P: Y ... ¿L qué nos dice al respecto? Usted siente que sí ha habido algún cambio o que por el contrario D tiene razón, que no se ha generado ningún cambio, que todo sigue igual plano "fuimos, hablamos y no pasó nada más". Cuéntame L.

\begin{tabular}{|c|c|}
\hline 4. & C2: Pues si (Risa nerviosa), no. Mmm nada, todo sigue igual. \\
\hline 5. & $\begin{array}{l}\text { P: ¿Y qué creen que hace falta, por qué todo seguirá igual? O sea, todo está como } \\
\text { muy... amalgamado ¿sí? Ahí, como que no. ¿Qué creen que hace falta? }\end{array}$ \\
\hline 6. & $\begin{array}{l}\text { C1: Pues yo me imagino que es como que ella exprese qué es lo que quiere, qué es lo que } \\
\text { espera...de nosotros o qué es lo que piensa de ella a veces o... (silencio) }\end{array}$ \\
\hline 7. & P: ¿D considera que es eso...que es algo que L debe contar? \\
\hline
\end{tabular}




\section{LA DESERCIÓN ESCOLAR COMO PRETEXTO PARA CONVERSAR SOBRE IDENTIDAD, FAMILIA Y ESCUELA

he dicho que si me quiere decir "no la admiro" "la odio" "vieja desgraciada" dígamelo pero, dígamelo. O sea, no me importa lo que me diga pero dígamelo, pero hable, exprese algo. Muchas veces la he molestado, hay veces hasta mejor dicho me toca casi amenazarla pa' que me suelte aunque sea una palabra.

\begin{tabular}{|c|c|}
\hline 9. & P: ¿La comunicación entre ustedes siempre ha sido así? \\
\hline 10. & C2: (Silencio) Mmm sí, creo que sí (risa) \\
\hline 11. & $\begin{array}{l}\text { P: ¿Cómo así "creo"? o sea, ¿cómo se comunican? Normalmente es...dando órdenes y “yo } \\
\text { obedezco" o ¿cómo es la dinámica ahí? }\end{array}$ \\
\hline 12. & $\begin{array}{l}\text { C1: Pues sí, por lo general, yo le...yo le hablo a ella...o sea le pregunto alguna cosa. Por } \\
\text { ejemplo llego "L por qué no ha hecho tal cosa". Jum se queda mirándome fijo y no me responde } \\
\text { absolutamente nada. O algo, por ejemplo que ella haga algo malo y yo le digo "¿por qué hizo } \\
\text { esto?" igual, queda hermética y no me contesta una sola palabra. }\end{array}$ \\
\hline 13. & $\mathrm{P}: ¿$ Qué creen ustedes que ha generado ese distanciamiento? \\
\hline 14. & $\begin{array}{l}\text { C1: Pues yo pienso que tanta cosa...por ejemplo desde que L era pequeñita ella...ya L desde } \\
\text { que inició su vida escolar la he llevado a psicólogo, le han hecho terapias, le han hecho que una } \\
\text { cosa, la otra, psiquiatría, lo del medicamento que finalmente no se lo di y llegó un punto en que } \\
\text { yo me cansé. Creo que tanto ella como yo, o sea, llegó un punto en el que yo dije..."ya...ya que } \\
\text { más hago" "ya le hicieron exámenes físicos, le han hecho terapias de una de otra, compromisos } \\
\text { de uno de otro, que póngala allí que tráigala acá, que hágale esto, que hágale lo otro...” y llegó } \\
\text { un momento en el que ya me cansé y me desesperé...y ya, mejor dicho ya sentí que ya con ella } \\
\text { no más. }\end{array}$ \\
\hline 15. & $\begin{array}{l}\text { P: ¿Y L, cómo ha percibido todas esas situaciones, todo lo que tu mamita ha hecho? Porque } \\
\text { básicamente todo se ha generado desde el momento en que ella como que ingresó a la escuela } \\
\text { ¿cierto? Desde que ingresó al mundo escolar... }\end{array}$ \\
\hline 16. & $\begin{array}{l}\text { C1: Es que inició desde el jardín, desde chiquita siempre "uy esa niña es terrible" o sea } \\
\text { cuando era chiquita me decían "esa niña es terrible" "esa niña (...) no se queda quieta" ¿sí? } \\
\text { Cosas así, desde el jardín. }\end{array}$ \\
\hline 17. & P: ¿Y usted se creyó también todo eso? \\
\hline 18. & $\begin{array}{l}\text { C1: No pues yo en ese momento a eso no le paré bolas porque es como si ahorita de D me } \\
\text { dicen eso, como decía mi abuelo "no ve que está vivo" (risa). Entonces... si, no o sea en ese } \\
\text { momento, pues un niño de tres años de cuatro años pues ¿qué hace?, jugar, correr y como } \\
\text { explorar ¿no? Ya cuando empezó en el kínder, ya en un buen colegio como tal, ya pues...hice el } \\
\text { paso a seguir, ya la psicóloga me sugirió que le sacara cita psicológica por la EPS, ya de la EPS } \\
\text { la mandaron a terapias y sí, pues hasta ahí todo fue normal. Prácticamente hasta quinto de } \\
\text { primaria yo no le di ninguna importancia a las quejas porque las quejas eran...mmm...pues lo } \\
\text { normal de un niño, que es que se paró, que habló, pues hasta ahí no...pues yo la llevaba bien a } \\
\text { sus terapias y eso, pero...y académicamente pues nunca fue un nivel superior, pero tampoco } \\
\text { perdía. }\end{array}$ \\
\hline 19. & $\begin{array}{l}\text { P: Pero y los avances a nivel psicológico se veían o siempre hubo como no sé...me gustaría } \\
\text { que me compartiera algo de cómo fue esa parte psicológica, pero que L también nos cuente a } \\
\text { través de su voz, qué sentía ella en ese momento. }\end{array}$ \\
\hline 20. & $\begin{array}{l}\text { C2: No...no le paraba bolas (risa) por decirlo así, porque todas las terapias que recibía eran } \\
\text { solo "dime tu nombre, dibuja a tu familia, has un rompecabezas..." y ahí terminaba. }\end{array}$ \\
\hline 21. & P: O sea, nunca fueron más allá. \\
\hline
\end{tabular}




\section{LA DESERCIÓN ESCOLAR COMO PRETEXTO PARA CONVERSAR SOBRE IDENTIDAD, FAMILIA Y ESCUELA

23. C1: Si...o sea yo esperaba que dijeran "bueno, vamos a aplicar esta técnica o esta terapia" ¿sí? O "hagámosle esto o hágale lo otro" pero no nada...

24. P: Y las cosas continuaban igual, o avanzaron

25. C1: Siguieron igual, se fue creciendo como una bola de nieve. Y empeoró, empeoró o sea ya se convirtió en un problema real cuando ella pasó a sexto grado. O sea no sé si fue una coincidencia, o no sé si lo estoy tomando a mal y coincidieron las cosas, pero entonces ella entró, pues cambió, hubo ese cambio de primaria a bachillerato. En ese mismo año llegó el bebé. Entonces no sé, como fue todo como un revolcón al mismo tiempo y porque fue de ahí en adelante cuando las cosas ya se empezaron a salir de ahí.

26. $\quad$ P: ¿Y L? cuéntanos, participa en nuestra conversación, porque tú eres aquí la persona más importante para nosotros, tú eres básicamente el centro de toda esta conversación. En relación con lo que tu mami nos cuenta ¿qué pasó ahí? ¿qué sucedió? Has un poco de memoria, cuéntame.

27. C2: Ehh, pues (risa), pues como yo era la consentida, entonces me da como un poquito de rabia con D (risa).

28. P: O sea, todo fue como...

29. C2: Si, ahí si fue un revuelto de todo y pues...no sé, nuevos amigos...mmm...pero como que no sé. Pues de todos modos perdía las materias y todo pero pues, trataba de concentrarme, pero no.

30. P: ¿En qué pensabas? Cuando te salías de la clase, de la explicación ¿en qué pensabas? ¿A dónde iban tus pensamientos?

\begin{tabular}{|c|c|}
\hline 31. & C2: mmm...no pues lo que le decía antes. Me ponía a dibujar o a rayar, o me distraía. \\
\hline 32. & P: Pero había una situación especial, por ejemplo ¿pensabas en D (hermano)? \\
\hline 33. & C2: No, pues no. \\
\hline 34. & $\begin{array}{l}\text { P: Entonces ¿cómo manejó lo de D (hermano). Cuéntanos esa parte. Dices "sentí un poquito } \\
\text { de rabia. ¿Alguna vez le dijiste a tu mamá eso? }\end{array}$ \\
\hline 35 . & C2: ehhh no. \\
\hline 36. & P: Hoy lo estás confesando, que sentías celos. \\
\hline 37. & C2: Sí. \\
\hline 38. & $\begin{array}{l}\text { P: ¿Cómo era esa parte? ¿Qué querías hacer con ese bebé? ¿cómo te sentiste ahí como } \\
\text { desplazada? A ver. Porque por ahí podemos ir marcando nuestro rumbo. }\end{array}$ \\
\hline 39. & $\begin{array}{l}\text { C2: ehhh, pues en ese entonces a mí me daba como que "Ahhh y ahora él es el centro de la } \\
\text { atención" }\end{array}$ \\
\hline 40. & P: Ajá \\
\hline 41. & C2: Pero no pues, no más. No pensaba que "ayy que se fuera", no. No tanto (risa) \\
\hline 42. & P: ¿No tanto? \\
\hline 43. & C2: (risa) \\
\hline 44. & P: Llegaste a pensarlo. \\
\hline 45. & C2: (risa) Ehhh si \\
\hline 46. & $\begin{array}{l}\text { P: Y ¿cómo querías ver a tu hermano? Cómo, ¿te imaginabas que sería mejor la vida sin tu } \\
\text { hermano? O cómo. }\end{array}$ \\
\hline 47. & $\begin{array}{l}\text { C2: (Silencio) No, no imaginaba eso. La verdad no, decía como que "ash que mamera" "ash } \\
\text { ahora...(no sé) Ahora le van a prestar muchas más atención a él" }\end{array}$ \\
\hline
\end{tabular}




\section{LA DESERCIÓN ESCOLAR COMO PRETEXTO PARA CONVERSAR SOBRE IDENTIDAD, FAMILIA Y ESCUELA

48. $\quad \mathrm{P}: \mathrm{Y}$ eso te molestaba.

49. $\quad \mathrm{C} 2: \mathrm{Si}$, me daba fastidio. Pues ya...obviamente pues ya no, ¿no?

50. $\quad$ P: Ajá, y todo esto que tú sentías coincidió con la pérdida del año.

51. C2: Sí. Y pues como que perdí por matemáticas, nunca me fue bien en matemáticas, solo en quinto grado que fue con la profesora Diana. Ehh pues ella...la mejor profesora (risa), que he tenido. Si había un momento, ella se sentaba con uno y le explicaba hasta que le entendiera y pues eso la...es bien ¿no? Y pues ya después fue con otra profesora que ponía ejercicios que ni ella podía desarrollar. Y...con todos, era muy gritona y seria...y seca.

52. P: Ahh ok. Muy gritona, seria, seca. ¿será que tu mamá se parece a esa profesora? ¿En algo?

\begin{tabular}{|c|c|}
\hline 53. & C2: (risa) No \\
\hline 54. & P: ¿en algo te la recuerda? \\
\hline 55. & C2: (risa) No, no...es enorme la diferencia. \\
\hline 56. & P: Porque ella también es brava. \\
\hline 57. & $\begin{array}{l}\text { C2: Pues sí, es estricta, pero...no (risa). Pero no pues obviamente esa profesora era todo el } \\
\text { tiempo de mal humor y...ehh no explicaba, para todos eran malas notas y...bueno. No explicaba } \\
\text { bien y...bueno. }\end{array}$ \\
\hline 58. & $\begin{array}{l}\text { P: Pero entonces así, debo comprender que en tu cabeza se formó como un caos porque llegó } \\
\text { tu hermano, porque tú ya no eras el centro de atención, porque encima de todo entonces con una } \\
\text { profesora pasaste matemáticas, pero con la otra era horrible. Entonces todo eso, ¿A dónde iba } \\
\text { encaminado? ¿qué querías? }\end{array}$ \\
\hline 59. & $\mathrm{C} 2:$ (silencio) $\mathrm{mmm}$. \\
\hline 60. & P: ¿Querías decir “aquí estoy mundo”? ¿Tal vez? \\
\hline 61. & $\begin{array}{l}\text { C2: Pues...Si. Pero pues tanto como... que solo me pusieran atención a mí y no a mi } \\
\text { hermano...pero pues de todos modos mi hermano...es un bebé. Pues ahí era más chiquito y pues } \\
\text { obviamente, no tenía la misma atención ¿no? }\end{array}$ \\
\hline 62. & P: ¿D en algún momento percibió eso? \\
\hline 63. & $\begin{array}{l}\text { C1: Sí claro. Si, muchas veces le explicamos a ella que...pues que cuando ella fue bebé pues } \\
\text { también se tuvo los mismos cuidados. Le decía yo... a mi hija mayor tampoco le dejaba alzar a } \\
\text { L...y cuando yo la tuve a ella la mayor tenía ocho años. Yo a ella "no, no se la puedo dejar alzar } \\
\text { porque va y la suelta, la lastima” ¿sí́ Y era lo mismo ¿sí? Que cuidado con la niña, que no se le } \\
\text { acerque, que cuidado que la ahoga, que cuidado que la lastima, que cuidado esto, que... ¿sí? Que } \\
\text { si lloró alce la niña, ¿sí? Eso le explicábamos...y mi hija mayor un día la cogió también y le dijo } \\
\text { "yo también sentí celos cuando usted llegó, pero ya lo superé y ya pasó”. Le dijo así y sin } \\
\text { embargo; no fue que a ella...o sea nunca la hicimos a un lado, nunca. Bueno...y siempre hemos } \\
\text { estado...para donde vamos nosotros va ella, nunca hemos dicho "no, usted se queda y nos vamos } \\
\text { nosotros con el niño" nunca. }\end{array}$ \\
\hline 64. & $\begin{array}{l}\text { P: Y no seria que también anexo a la llegada de D (hijo), estaba también la llegada de tu } \\
\text { compañero también a la vida...o ya... }\end{array}$ \\
\hline 65. & $\mathrm{C} 1$ y C2: No \\
\hline 66. & C2: Desde que yo tenía tres años. \\
\hline 67. & P: Si. Con él ya era...ya era la familia. Hace rato \\
\hline 68. & $\begin{array}{l}\text { C1: Sí, de hecho ella formó su figura paterna en él. Ella en el colegio, a todo el mundo le } \\
\text { decía que el papá es él. }\end{array}$ \\
\hline
\end{tabular}




\section{LA DESERCIÓN ESCOLAR COMO PRETEXTO PARA CONVERSAR SOBRE IDENTIDAD, FAMILIA Y ESCUELA

69. P: Ajá...y entonces qué de positivo le han podido sacar ustedes como familia al hecho de que L no esté en el colegio, porque algo debe de haber de positivo.

\begin{tabular}{|c|c|}
\hline 70. & C1: ¿De positivo? \\
\hline 71. & P: O ¿cómo lo perciben, cómo lo ven? \\
\hline 72. & C1: No, pues yo honestamente de positivo no... \\
\hline 73. & P: No le ves nada. \\
\hline 74. & C1: No le veo nada. \\
\hline 75. & P: ¿y L? \\
\hline 76. & $\begin{array}{l}\text { C2: Mmm...pues que, pues al principio dije "pues bueno, estar fuera del colegio (risa) pues } \\
\text { es como bueno" pero pues ya...me hace falta. }\end{array}$ \\
\hline 77. & $\begin{array}{l}\text { P: O sea, en ese momento para ti fue como una descarga. "ay no tengo que cumplir con } \\
\text { tareas, ay que pereza... por lo menos voy a poder dormir un ratico más" }\end{array}$ \\
\hline 78. & $\mathrm{C} 2: \mathrm{Si}$, eso pensaba (risa) \\
\hline 79. & $\begin{array}{l}\text { P: (risa) Cuán equivocada estabas. Y D... ¿en verdad no le has visto nada de positivo a esta } \\
\text { situación? }\end{array}$ \\
\hline 80. & $\begin{array}{l}\text { C1: No, pues porque...pues por el lado de que por ese lado no recibo quejas. Porque eso } \\
\text { llegó un momento en que el colegio se volvió una tortura para mí, yo cruzaba esa puerta y ya me } \\
\text { imaginaba los profesores "ta ta ta ta"...pero... }\end{array}$ \\
\hline 81. & $\begin{array}{l}\text { P: Pero y ¿en relación con lo que } \mathrm{L} \text { hace? Porque yo entiendo que } \mathrm{L} \text { en la casa colabora } \\
\text { bastante... }\end{array}$ \\
\hline 82. & $\mathrm{C} 1: \mathrm{Si}$ \\
\hline 83. & $\begin{array}{l}\text { P: A nivel de los oficios, a nivel del almuerzo, a nivel de la loza, a nivel de las cosas de la } \\
\text { casa, del que hacer de la casa, aun así ¿no hay nada positivo en eso? }\end{array}$ \\
\hline 84. & $\begin{array}{l}\text { C1: Pues eso de los oficios, yo se lo impuse como castigo. Yo le dije "si usted no estudia, yo } \\
\text { no voy a tener una... (Así se lo dije en esas palabras) no voy a tener una persona vaga aquí en la } \\
\text { casa" le dije "si no estudia por perder dos años el castigo de hoy va a ser la cocina" le dije "de } \\
\text { aquí en adelante usted lava, cocina, todo" yo le dije "de aquí a mañana usted no estudia, ¿para } \\
\text { qué va a servir?" de empleada de servicio. O sea yo lo hacía como tratando de aplicarle } \\
\text { psicología inversa. (risa) Como para que ella dijera "soy sirvienta"... ¿sí? }\end{array}$ \\
\hline 85. & P: Pero fijese que ya llevamos ahí... \\
\hline 86. & C1: Y pasó un año y nada...entonces sí que fue peor. \\
\hline 87. & $\begin{array}{l}\text { P: Bueno, pero D aun así, ¿tú estás convencida que si L no termina el bachillerato la vida de } \\
\text { ella va a tener que seguir siendo esa?¿o cómo percibes tú ahí la situación? Porque ¿Cuándo } \\
\text { piensas levantar ese castigo? }\end{array}$ \\
\hline 88. & $\begin{array}{l}\text { C1: Pues en algún momento tiene que...jum pues la verdad no veo cómo se puede defender } \\
\text { sin estudio. O sea en un cargo...en algo importante. A menos de que ella aprenda a hacer un arte } \\
\text { y algo independiente. }\end{array}$ \\
\hline 89. & $\begin{array}{l}\text { P: Y eso, ¿no le suena a ninguna de las dos? Porque puede ser otra posibilidad, otra } \\
\text { alternativa. }\end{array}$ \\
\hline
\end{tabular}

90. C1: No...y porque yo siento que...lo que tal vez se lo alcancé a comentar la sesión pasada, yo sigo, sigo y sigo con mi insistencia de estudiar porque yo digo, si mi mamá me hubiera cogido así de esa manera y mejor dicho es que casi de una oreja "camine a averiguar lo de la universidad" o al menos... ¿sí? En algún lado un curso. De pronto me hubiera ayudado a que yo tuviera una vida mejor, mis hijos tendrían una vida mejor. Entonces yo no quiero que L vaya a 


\section{LA DESERCIÓN ESCOLAR COMO PRETEXTO PARA CONVERSAR SOBRE IDENTIDAD, FAMILIA Y ESCUELA

pasar necesidades ella y si Dios la tiene para tener hijos, otros niños a tener necesidades de que "quiero unos zapatos" "no hay plata", "quiero un vestido" "no hay plata"

91. P: Y ¿usted está convencida de que eso solo se puede lograr a través del estudio? De ir a un colegio; sentarse seis, siete, ocho horas a aprender la regla de tres, a aprender fraccionarios y luego trigonometría, algebra, química y todo lo demás.

92. C1: Pues de hecho en el colegio si yo digo "para qué", o sea son cosas que yo decía una vez "yo nunca voy a necesitar $\mathrm{Pi}$, para qué me enseñan $\mathrm{Pi}$, por qué tengo que aprender Pi" (risa) pero...pero es un proceso del colegio, es una exigencia del bachillerato y hay que hacerlo. Y yo le decía ella...hace poquito se lo dije "de aquí a mañana cuando usted quiera estudiar, yo no le estoy diciendo que usted tiene que ser abogada, tiene que ser ingeniera, no. Si usted quiere estudiar música, estudie música, si quiere estudiar artes estudie artes, si quiere ser futbolista, ir a estudiar deportes, lo que sea (le dije) no me importa lo que usted estudie, pero para lo que quiera estudiar necesita el bachillerato, porque en ninguna parte la van a recibir a estudiar otra cosa si no tiene el bachillerato".

93. P: Y si ella lo tomara como una alternativa para futuro y en este momento ella empezara a hacer otras cosas que la hagan feliz y que la hagan sentir realizada ¿Qué pensaría? Por ejemplo L, ¿qué ha pensado? "Listo yo...puede que no sea muy buena para matemáticas ni para inglés, pero tengo otra opción" en qué ha pensado, en qué han pensado. Porque es que yo las veo tan en línea recta, que si no es el bachillerato no hay otras alternativas, entonces ¿L se va a quedar ahí en casa eternamente?

94. C1: Hay mucha gente que me dice a mi "¿bueno y es que este oficio que usted hace a ella no le gusta? ¿No le gusta el manicure?”...pues no sé...pero desde mi propia experiencia que vivamos de esto...no es que vivamos. La situación económica de nosotros no es fácil y ella lo sabe, mejor dicho escacitamente hay para comer. Mejor dicho si se le rompen hoy los zapatos...quien sabe hasta cuándo se los pueda comprar, es hasta ahí ese punto. Y yo no quiero que ella viva eso, yo no quiero, yo quiero que mis hijos tengan un futuro mejor. O sea que si quieren vayan y tengan cien pares de zapatos...pero por lo menos que no tengan que pasar esas necesidades.

95. P: ¿Bueno L y usted qué opina de todo lo que su mamá dice? Porque o sea, ella tiene tan claro lo que tú debes hacer y ¿eso es lo que tú quieres hacer?

96. C2: (silencio) Pues...todavía no sé.

97. P: ¿Qué te falta para poder saberlo?

98. C2: intentar.

99. P: ¿Cómo intentarías?

100. C2: Mmm, pues a mí en el colegio siempre iba bien más que todo en educación física y artística.

101. P: Sí, o sea que eres hábil con las manitas. Con las manualidades y eso.

102. C2: $\mathrm{mmm}$, sí...un poco sí.

103. P: Ok. Y entonces ¿qué solución plantearía?

104. C2: Mmm... (Silencio)

105. P: A ver. Siento que a tus quince años aun no has logrado como cortar ese cordón umbilical que tiene con $\mathrm{D}$, o ies que me parece? Porque yo a los quince años ya tomo mis propias decisiones y me puedo equivocar claro, pero del error...eh lo convierto ese error en positivo y lo pongo a funcionar y nuevamente emerjo. Porque es lo único $\mathrm{D}$, porque yo no creo que tú tampoco hayas pasado así siempre en línea recta, uno tiene que equivocarse y eso es lo que hace 


\section{LA DESERCIÓN ESCOLAR COMO PRETEXTO PARA CONVERSAR SOBRE IDENTIDAD, FAMILIA Y ESCUELA

la vida. Pero y ¿entonces L?

106. C1: Entonces que no se vaya a dar cuenta demasiado tarde como me pasó a mí. Yo vi la oportunidad de estudiar y se dieron las cosas, o sea, un día por casualidad entré a internet y vi que estaban las convocatorias, me inscribí y pasé y en esas estoy. Sufriendo (risa), vuelta nada pero estoy haciendo algo que siempre quise hacer.

\begin{tabular}{|c|c|}
\hline 107. & C2: Ya casi muerta \\
\hline 108. & $\begin{array}{l}\text { C1: Pero en este momento yo por ejemplo digo, qué día me sentaba y dije "¿será que si vale } \\
\text { la pena todo este esfuerzo? Yo ya casi con } 42 \text { años ¿quién me va a dar trabajo?" }\end{array}$ \\
\hline 109. & C2: ¿42? \\
\hline 110. & C1: Cuando termine, de aquí a que termine ya voy a tener 42 años. \\
\hline 111. & $\begin{array}{l}\text { P: Bueno, y L entonces ¿hasta cuándo va a esperar para tomar esas riendas de su vida y decir } \\
\text { "esto es lo que yo quiero y lo puedo hacer porque tengo las habilidades, pero necesito que crean } \\
\text { en mí, yo tener esa red de apoyo para poder salir”? o ¿hasta cuando vas a seguir ahí pegada a ese } \\
\text { cordón umbilical? Y creces y entonces de } 20 \text { años “imamá puedo ir a la esquina?” dónde está } \\
\text { esa independencia, donde está esa autonomía, donde está tu proyecto, el ser L; no el ser la } \\
\text { sombra de D. }\end{array}$ \\
\hline 112. & $\begin{array}{l}\text { C2: Pues hasta ahora, me he concentrado más...en lo que más he pensado es en lo de la } \\
\text { música. }\end{array}$ \\
\hline 113. & $\begin{array}{l}\text { P: Lo de la música... ¿cómo has pensado llevarlo a cabo? ¿Qué has pensado para poder llegar } \\
\text { hasta allá? ¿Has hablado eso con D? }\end{array}$ \\
\hline 114. & C2: ehhh no. \\
\hline 115. & $\begin{array}{l}\text { P: Y entonces ¿cómo piensas hacerlo si no lo expresas? Tú eres una mujer con muchas ideas } \\
\text { y todas muy buenas, porque L tiene muy buenas ideas y muchas capacidades, pero a veces siento } \\
\text { que no ha habido quien confíe en ella. Porque a través de esos ojos y de esa mirada a veces uno } \\
\text { ve es tristeza, dolor; y yo siento que uno vino aquí fue a ser feliz. La vida es tan corta, que uno } \\
\text { amargarse porque no tiene un bachillerato, si definitivamente uno logra el cartón de bachiller y } \\
\text { sale allí a la esquina y se lo lleva un carro y luchó toda la vida por ese cartón pero no fue feliz. } \\
\text { ¿entonces? Y una niña tan bonita, porque yo le veo mucho futuro L, la verdad se lo veo, yo no sé } \\
\text { si es porque me inspira tanto amor y tanta ternura, o porque sé que tiene las } \\
\text { capacidades...porque a través de nuestros encuentros y nuestras conversaciones lo he podido } \\
\text { percibir y lo ha manifestado. No sé, ¿tú que piensas D? }\end{array}$ \\
\hline 116. & $\begin{array}{l}\text { C1: Pues en estos momentos, pues sí, pues uno dice, pues el camino o la ruta sería... como } \\
\text { dicen el camino tradicional o el camino obvio... }\end{array}$ \\
\hline 117. & P: ¿Sería ese? \\
\hline 118. & C1: es ese \\
\hline 119. & $\begin{array}{l}\text { P: Pero ¿y si no? Por ejemplo miramos aquí, a todos estos campesinos y esta gente tan } \\
\text { prospera como son los boyacenses y uno va a ver la cantidad de tierras, la cantidad de dinero que } \\
\text { tienen en especies, en vacas, en cultivos. La mayoría de ellos no saben siquiera leer, entonces ahí } \\
\text { uno se hace muchísimas preguntas, pues yo me las hago cuando pienso en L. ¿Ustedes no se las } \\
\text { han llegado a hacer? }\end{array}$ \\
\hline 120. & $\begin{array}{l}\text { C1: Pues yo la verdad yo la miro y yo no sé ni qué ponerla a hacer (risa). O sea, es que esa es } \\
\text { la otra... }\end{array}$ \\
\hline 121. & $\begin{array}{l}\text { P: ¿Será que tú tienes que ponerla a hacer? O ¿será que es que hay que darle independencia } \\
\text { para que ella haga? Y dejar de pensar en lo que ella tiene que hacer y que tú la ordenes, sino que } \\
\text { ella tenga la iniciativa y lo haga por la misma necesidad. }\end{array}$ \\
\hline
\end{tabular}




\section{LA DESERCIÓN ESCOLAR COMO PRETEXTO PARA CONVERSAR SOBRE IDENTIDAD, FAMILIA Y ESCUELA

122. C1: yo no sé, yo la veo tan desorientada que yo creo que ella no, o sea yo lo percibo así, como que ella vive el día a día y "tengo mi comida y mi techo, pa' qué busco más"

123. P: ¿Y será que eso la hace feliz? ¿D, tú te has preguntado si L es feliz con la vida que lleva?

124. C1: Pues no, yo pienso que feliz no, quién va a ser feliz así.

125. P: ¿Y no te preocupa eso?

126. C1: Pues sí porque va directo al fracaso.

127. P: ¿Pero por qué hablas de fracaso D?

128. C1: Porque una persona que no quiere hacer nada, porque es que una cosa es querer...si ella me dice "es que yo quiero hacer esto" pero no ve que no.

129. P: ¿Entonces a qué horas hablan, en qué momento es ese momento de ustedes, para que se encuentren como madre y como hija y decir "mamá yo quiero, a mí me gustaría intentarlo"? oír sus propias palabras, no sé, o que tú le generaras ese espacio para que $L$ tal vez se acerque y diga "mamá mi sueño es..." no sé. Cuantas veces se abrazan me pregunto, son tan parecidas físicamente y al mismo tiempo las veo tan distantes, es como si un abismo las separara, ¿o es solamente mi percepción?

130. C1: No, sí. Debido a tantas cosas y esto ya...sí, yo con ella...o sea de hecho yo no soy de las que quichiqueo, a D (el hijo) porque es el bebé y yo le he dicho a ella que "cuando usted era chiquita era igual" a ella la cogía la besaba, la alzaba, la subía, la baja...hasta cierta edad, después ya no. Igual con mi hija mayor...empezando que no sé, no me gusta que me abracen, yo por ejemplo ya dormir con ellas no.

\begin{tabular}{|c|c|}
\hline 131. & P: ¿No te gusta que te abracen? ¿No recibiste muchos abrazos? \\
\hline 132. & C1: No \\
\hline 133. & P: ¿Y por lo mismo tal vez hay que castigar a quien quiere un abrazo? \\
\hline 134. & $\begin{array}{l}\text { C1: (risa nerviosa) } \mathrm{Si} \text {, no sé. Yo creo que la vida me enseñó a ser dura y aprendí a ser fuerte } \\
\text { porque me pisotearon mucho }\end{array}$ \\
\hline 135. & P: Pero por lo mismo ¿tus hijos tienen que pagar eso? \\
\hline 136. & C1: entonces aprende a que si uno da...(silencio) \\
\hline 137. & P: ¿Qué pasa si uno da? \\
\hline 138. & C1: pierde (risa) \\
\hline 139. & P: ¿Será que pierde? O ¿será que gana $\mathrm{D}$ ? \\
\hline 140. & C1: Silencio \\
\hline 141. & $\begin{array}{l}\text { P: Yo pensaría que uno gana. Yo creo que para mí la recompensa más grande de la vida es el } \\
\text { abrazo de mis hijos. De verdad. Ehhh cambio una comida, ehhh cambio una tarde con mis } \\
\text { amigos, cambio todo por estar por ejemplo con mi hija. Que es una niña que tiene } 22 \text { años y lo } \\
\text { que más disfruto de ella es sus abrazos, los apodos que nos ponemos, el reírnos juntas, } \\
\text { acostarnos en la cama de ella, hablar de las cosas que a ella le pasan, de las cosas que a mí me } \\
\text { pasan...o sea, compartimos mucho. Yo pienso que yo eso no lo cambio por toda la plata que me } \\
\text { puedan dar por una tarde, por decirlo algo así; que me digan son tres consultas y son trecientos } \\
\text { mil pesos, no lo cambio por estar con mi hija. Porque yo entendí que los abrazos curan, que los } \\
\text { abrazos sanan, que el contacto con el otro me hace más humana...y puedo comprender al otro en } \\
\text { toda su esencia, cuando lo siento tibio, cuando lo siento frío, tal vez cuando lo abrazo y siento el } \\
\text { latir de su corazón a mi lado y puedo comprender que estamos conectados el uno con el otro. } \\
\text { Entonces yo nunca diría que pierdo, yo diría que gano y yo a veces siento que eso es lo que les }\end{array}$ \\
\hline
\end{tabular}




\section{LA DESERCIÓN ESCOLAR COMO PRETEXTO PARA CONVERSAR SOBRE IDENTIDAD, FAMILIA Y ESCUELA

hace falta a ustedes dos, ese fundirse en un solo abrazo y saber que está la una para la otra, pero no tal vez con el miedo y el temor que yo le veo a $L$ en los ojitos cuando la mira a usted. Porque es que ella no tiene la culpa de lo duro que le haya tocado D.

142. C1: No, yo se eso. Pero llegó un punto en que sentí que sufrí tanto por la situación con ella que un vacío sí se formó y ella me abraza y yo no siento nada. Entonces es como si ella me abrazara pero no sinceramente, entonces no lo siento. Porque sí obviamente, de pronto mi hija mayor me abraza y es muy diferente a lo que siento con L. Mi hijo menor pues obviamente es diferente por ser chiquito...

143. P: Por ser el bebé. Pero es que yo te siento aún herida, es como si le quisieras pasar una cuenta de cobro a L por algo y yo siento que L ha sido víctima, no sé de qué situación. Pero abrieron una brecha terrible entre ustedes dos, es como si estuvieran midiendo fuerzas y me duele mucho ver así a L, de verdad D. Y usted sabe que yo la estimo mucho a usted, porque fue mi aprendiz, por toda esa situación...pero también pienso en L y no me parece justo. No sé, siento que ella sufre, la veo sufrir, la veo llorar, la veo como con desesperanza, como el no saber qué hacer, pero tú eres el timón de la vida de ella... y ¿entonces...qué hacemos?

144. C1: Jum no sé, yo con ella no sé qué hacer. Un día le dije "haga lo que quiera"

145. P: Yo creería que si tú buscas en tu corazón como mamá vas a saber qué hacer con tu hija. Tal vez si tú le permitieras que ella se acerque y que ustedes abran ese espacio para sanar, para conversar, para llegar a acuerdos, para...

146. C1: No sé, yo ya estoy tan prevenida y tan decepcionada de ella que... siento que cuando le doy una oportunidad o algo me decepciona

147. P: Pero bueno, es que está chiquita y está aprendiendo... ¿no crees?

148. C1: No, chiquita ya no es. No chiquita ya no la veo chiquita (risa)

149. P: Pero es que solo son quince años, quince años que aún no ha cumplido y que ella no ha tenido la autonomía para vivirlos. ¿o sí? Porque uno cuando habla con L, con sus palabras no se atreve a decir cosas, pero ella es todo como "bueno, pero es que me tocó... (Silencio) pues sí" y lo piensa mucho. Es como si siempre tuviera miedo de expresar, ¿es eso L?

\begin{aligned} \hline 150. & C2: Si. \\ \hline 151. & P: Miedo a expresarle a D cosas... ¿cómo cuáles? \\ \hline 152. & C2: (silencio) Pues...con la única persona con la que me expreso bien es con mi prima que a \\ & veces...que de vez en cuando nos vemos. Pero con ella es con la que hablo. \\ \hline 153. & P: ¿Es con la única persona con la que puedes hablar? \\ \hline 154. & C2: (Silencio) \\ \hline 155. & P: ¿Tú que piensas D? \\ \hline 156. & C1: (Silencio) \\ \hline 157. & P: ¿No será que tú estás siendo muy dura? \\ & $\begin{array}{c}\text { C1: De pronto si...lo que le digo yo estoy muy prevenida con ella porque me ha mentido en } \\ \text { tantas cosas que ya esas lágrimas y eso, ya para mí son lágrimas de cocodrilo. Porque la he visto } \\ \text { mentir una y otra vez, una y otra vez, y es tan convincente, que una persona que no la conoce } \\ \text { dice "pero es que está diciendo la verdad”, pero yo sí ya la conozco, por eso es que no le creo. } \\ \text { Para mí las palabras de ella ya no tienen valor, o sea a mí ya no me hable, ya no me diga "voy a } \\ \text { hacer esto" ya no me diga, hágalo. }\end{array} \\$\hline 159. & P: Bueno y ¿qué herramientas le has dado para que ella haga lo que... \\ \hline 160. & C1: Porque no sé qué es lo que quiere, entonces un día le dije "haga lo que quiera" "haga lo \end{aligned}




\section{LA DESERCIÓN ESCOLAR COMO PRETEXTO PARA CONVERSAR SOBRE IDENTIDAD, FAMILIA Y ESCUELA

que quiera". (silencio)

\begin{tabular}{|c|c|}
\hline 161. & P: Qué pensarías tu D, si de repente L tomara la decisión de irse de casa. \\
\hline 162. & C1: Ya lo hizo una vez \\
\hline 163. & P: ¿Cuántos años tenía? \\
\hline 164. & $\mathrm{C} 1: 12$ \\
\hline 165. & P: Bueno pero con doce uno no va muy lejos. ¿Pero ahora? \\
\hline 166. & $\begin{array}{l}\text { C1: Pues por ley, por cosas legales, pues inmediatamente toca que la policía la busque y la } \\
\text { encuentre...y yo se lo he dicho a ella, si tiene ganas de decir...tómelo porque yo ya no puedo. }\end{array}$ \\
\hline 167. & P: ¿Será que una mamá se vence así de rápido? \\
\hline 168. & C1: Yo siento que sí. \\
\hline 169. & P: Pero yo sentiría que el papel de nosotras...nunca termina. \\
\hline 170. & $\begin{array}{l}\text { C1: O sea, es que como una ésta de "vaya, viva y dese cuenta por usted misma de que lo que } \\
\text { yo le estoy diciendo es lo que va a pasar". }\end{array}$ \\
\hline 171. & P: ¿Y si no fuese así? \\
\hline 172. & $\begin{array}{l}\text { C1: Bueno, me gustaría que me callara la boca de esa forma y yo he pensado que es de esa } \\
\text { forma en que uno calla la gente así sea la mamá, estar uno diciéndole "vea que sí pudo". Igual yo } \\
\text { ya les he dicho a ellas "yo de mis hijos no espero nada" y yo les he dicho "yo no quiero que } \\
\text { ustedes sean profesionales y que tengan una economía buena para que me den a mí, a mí no me } \\
\text { den nada. Pero si yo los veo a ustedes bien yo voy a estar feliz" }\end{array}$ \\
\hline 173. & P: ¿Qué es lo que más le afecta de que L no estudie? De que no termine su bachillerato. \\
\hline 174. & C1: Pues que si no termina el bachillerato no va a poder acceder a la educación superior. \\
\hline 175. & P: Bueno... \\
\hline 176. & C1: Y si no accede a la educación superior pues a qué se va a dedicar... \\
\hline 177. & P: ¿para ella no hay otras alternativas? \\
\hline 178. & $\begin{array}{l}\text { C1: Y si no se dedica a algo que le de plata pa' vivir, porque desafortunadamente la plata no } \\
\text { lo es todo pero si no la hay, con qué se va a mantener, con qué va a comprarse su comida...al } \\
\text { menos su comida. O sea, eso es una realidad porque algo tiene que hacer. }\end{array}$ \\
\hline 179. & $\begin{array}{l}\text { P: Pero bueno, ¿y si no es el bachillerato habrán otras alternativas, otras posibilidades? } \\
\text { Porque yo veo que eso es lo que ha generado todo el conflicto. }\end{array}$ \\
\hline 180. & C1: Sí claro, el hecho de que ella esté desescolarizada sí. \\
\hline 181. & P: Y entonces todo... \\
\hline 182. & $\begin{array}{l}\text { C1: ...Empezando porque todos como que me dicen a mí "pero a usted qué le pasa por qué } \\
\text { no la tiene estudiando" }\end{array}$ \\
\hline 183. & P: ¿Y L cómo se percibe ahí? \\
\hline 184. & C2: (silencio) No sé. \\
\hline 185. & P: No, yo sé que usted sí ha pensado en eso. \\
\hline 186. & C2: (silencio) Pues todo el mundo me dice que sin un bachiller... \\
\hline 187. & P: ¿Y usted qué cree? \\
\hline 188. & C2: Pues según lo que me dice la gente creo que sí es cierto. \\
\hline 189. & $\begin{array}{l}\text { P: Bueno, ¿y si la gente estuviese equivocada? Y usted tuviera habilidades para otras cosas, si } \\
\text { las explorara, ¿cree que podría vivir sin un bachillerato? }\end{array}$ \\
\hline
\end{tabular}




\section{LA DESERCIÓN ESCOLAR COMO PRETEXTO PARA CONVERSAR SOBRE IDENTIDAD, FAMILIA Y ESCUELA

190. C2: No sé. (silencio)

191. P: Como familia, no como D, sino como familia ¿qué han intentado para poder apoyar a L? No solamente D; que D sea la que ordena, que D sea la que hace... sino como familia, con su nuevo compañero, con su hija de pronto, incluso hasta con el bebé, con tu mamá ¿sí? ¿Qué han pensado? ¿Cómo han intentado organizarse para poder apoyar a L?

192. C1: No, que alguien me diga a mi "mire hagamos esto" no. Yo con la situación de ella siempre he estado como sola en ese sentido, o sea, está mi mamá mi esposo y sí se enteran de lo que pasa y eso pero pues de ahí a decir...a plantear una solución o apoyar, ayudarla, no.

193. P: ¿Por qué? ¿Usted qué cree que ha faltado? ¿Porque usted sola se ha echado el problema encima? ¿Porque no lo ha comentado con los otros?

194. C1: Sí claro ellos saben, le digo "es que pasa esto" "es que L hizo esto"...pero sí o sea, de pronto decir "haga esto" "intente esto" o "yo le ayudo con esto" no. Y bueno también mucha gente se ha cansado de hablarle (risa)...

195. P: ¿Bueno y en algún momento la familia le ha reconocido lo que ella es? ¿Le han visto todas las cosas positivas que $\mathrm{L}$ tiene?

196. C1: Claro, todos le decimos, que ella tiene muchas habilidades.

197. P: Pero no se han movilizado para sacarle esas habilidades adelante, porque todos están centrados en un bachillerato.

198. C1: $\mathrm{Si}$, pero por ejemplo ella es buena con los computadores pero ¿en dónde carajos le dan un curso sin bachillerato?

199. P: Bueno y empíricamente, por internet...ehhh en fin.

200. C1: Yo le he dicho a ella que busque arto por internet y no, coge es a mirar otras cosas. Entonces es que yo no le veo el interés por ninguna parte. Sumerced cree que es que yo no le digo...qué no le he dicho, eso busque por internet, uno busca ahí tutoriales, ella me ha visto estudiando a punta de tutoriales. Y yo le he dicho...

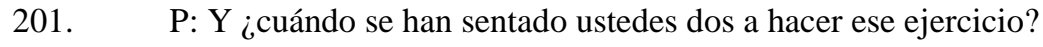

202. C1: No

203. P: ¿Por qué? ¿Es por falta de qué?

204. C1: No, de pronto... sí es por muchos factores. O sea, como el tiempo, como...por ejemplo en este momento me tiene absorbida el SENA y en este momento tengo hasta conflictos con mi pareja por eso.

205. P: Sí, es exigente... Pero recuerdo que en la entrevista pasada, en el encuentro pasado decíamos que "cómo ha cambiado la situación de L la vida de la familia". ¿No ha avanzado nada, sino se ha quedado ahí estancado? O sea, ¿el problema se generó y ahí está y no se ha movilizado? O ¿sí ha tomado algún otro rumbo D? o ¿Qué ha pasado ahí?

206. C1: Pues en este momento tanto como el bachillerato no, porque en este momento...asumimos que el otro año ya si va a estudiar. Esa es la idea que nosotros tenemos de lo que ella ha dicho, ya el problema se ha ido es como a otras situaciones, a otras actitudes de ella.

207. P: El problema se ha ido agrandando... ¿y han pensado en que L viva en otro sitio? ¿Que no sea contigo $\mathrm{D}$ ?

208. C1: No, es que no hay donde más viva. A parte del papá ella no tiene familia, o sea la tiene pero jum no se en donde...y por parte de mi familia pues quién se va a hacer cargo de alguien que no es de uno.

209. P: O sea...nos tocó vivir con $\mathrm{L}$. 


\section{LA DESERCIÓN ESCOLAR COMO PRETEXTO PARA CONVERSAR SOBRE IDENTIDAD, FAMILIA Y ESCUELA

210. C1: Sí

211. P: Es básicamente lo que me estás diciendo.

212. C1: Si o sea, yo decir "la mando para algún lado" no. O sea yo no le puedo dar un problema a otra persona que no tiene por qué asumirlo.

213. P: Y dentro de las soluciones que tú has pensado, ¿qué has visto? Es decir, si ella no logra ingresar el otro año a validar ¿cómo va a continuar la vida de ella?

214. C1: Jum, pues si ella no quiere estudiar ¿qué la pongo a hacer? No la puedo poner a trabajar, trabajar ahí en el negocio que ya me lo tiene casi en quiebra, ¿en qué más va a trabajar?

215. P: Pero tengo entendido que ella trabaja ahí y le colabora en el negocio.

216. C1: Aparentemente

217. P: ¿Cómo es eso? L.

218. C2: Pues es que casi no hay plata... y casi no hay estudiantes, casi no quieren entrar. Ya solo son pocos estudiantes los que quedan en el barrio que van a sacar fotocopias, impresiones. Ya lo que preguntan más es lo de peluquería.

219. P: ¿Y usted maneja el negocio es en la parte de fotocopias, minutos, impresiones? (silencio). ¿L y entonces qué harías con tu vida?

220. C2: (silencio) Mmm, no sé.

221. P: ¿Qué necesitarías para hacer lo que tú quieres?

222. C2: (Silencio) Mmm, bachiller.

223. P: ¿Definitivamente?

224. C2: Pues sí. (Silencio)

225. P: Bueno, y entonces hoy ¿qué se llevan? ¿Qué puede sacar cada una de conclusiones, de reflexión de este encuentro?

226. C1: Pues que sí que la enana se ha ido creciendo y entre más pasa el tiempo, o sea entre más crece digo hay unas cosas que me desesperan a mí más.

227. P: ¿Eso es lo que te llevas del día de hoy?

228. C1: Mmm no...pues (risa) que ella se siente aburrida obviamente y que quiere que su vida cambie, pero no hace nada para que cambie.

229. P: ¿Pero será que la vida de ella solo depende del cambio de ella? O ¿será del cambio de la familia?

230. C1: Pues yo le he dicho a ella, cuando uno quiere que las cosas cambien empieza por cambiar uno. Pero si no cambia y no cede.

231. P: ¿Y L...?

232. C1:...Lo que pasa es que yo ya lo he intentado tantas veces doctora, por eso es que yo digo que...por ejemplo esta semana, pienso mandarla con mi mamá para Bogotá, que cambie de ambiente, que no me vea a mí, que no vea...pero igual pasará esa semana y tendrá que volver aquí y si no llega con otra actitud y si ella no es consciente de cómo son las cosas. Sí porque una cosa es que haya poquitos clientes en este momento y otra cosa es que ella los ha ido desterrando los pocos que quedan. Ya varia gente me ha dicho "no es que uno viene y no, no hay" "no hay" y ahí sentada en el computador, mirando una película y si llegan a hacer una impresión "no, no hay" porque no le interrumpan la película. Cosas como yo estando ahí, le dice a la gente que no estoy, hoy otra señora me dijo. Entonces son cosas que uno dice...o sea yo lo siento como si ella dijera "yo no quiero atender esto acá acabémoslo". Así lo percibo yo.

233. P: ¿D y usted no se ha preguntado si es que a ella no le gusta hacer ese trabajo...y de repente lo hace pues porque no le gusta? 


\section{LA DESERCIÓN ESCOLAR COMO PRETEXTO PARA CONVERSAR SOBRE IDENTIDAD, FAMILIA Y ESCUELA

234. C1: Jum....ipero entonces qué? Un zángano ahí en la casa, ¿sin producir nada? No es justo. Porque sí, listo si ella no colabora en la casa entonces ¿de dónde le voy a dar yo? Si ese negocio fracasa en este momento, es nuestra única entrada...entonces no hay ni pa' darle comida a ella misma. Entonces mantener a una persona, tenerla ahí todo el día como un zángano pegada a un televisor porque es lo que ella quiere hacer, porque ella es así. Ese es el televisor y ella está así y la gente le está hablando "niña una fotocopia" ella jum.

235. P: L ¿Qué te llevas del encuentro de hoy?

236. C2: Mmm... (Silencio). Pues no sé la verdad.

237. P: Ok. Bueno, pues en este orden de ideas, solo me resta decirles que les agradezco realmente el tiempo que me han dado para poder compartir con ustedes. Pero yo si tengo una reflexión y no me puedo quedar con ella porque siento que la debo manifestar. Siento que ustedes se han lastimado muchísimo, muchísimo, muchísimo y yo no estoy aquí como para culpar a nadie ¿sí? Porque cada uno trae una historia de vida, pero hay cosas que no comparto y por ejemplo, se hieren tanto que no puedo comprender cómo puede pasar eso. Yo pienso que lo mismo que las distancia, es lo mismo parecidas que son y tal vez por lo mismo no encuentran cómo comunicarse, pero yo creo que ustedes como mamá y como hija necesitan encontrar un espacio para poder hablar de ustedes; y tal vez cuando eso suceda las cosas empiezan a cambiar, porque yo siento que uno no se puede cansar de un hijo D...porque es mi responsabilidad hasta el final. $\mathrm{Y}$ a veces entiendo que el silencio de L dice más cosas de las que ella nos puede expresar con sus palabras; su lenguaje no verbal, su actitud, su conformismo con su misma vida, habla de su no proyección hacia futuro, o sea de...está estancada, la veo estancada y yo que voy a seguir llevando el caso de L, yo les pediría que busquen un espacio, pero que vayan dispuestas a escucharse mutuamente, no juzgando sino hablando, poder hablar de lo que ha pasado. Ir reconociendo, pero ir construyendo a partir de lo que el otro dice, porque tal vez ahí está la clave de toda la situación...en ir construyendo a través de lo que el otro me cuenta, de lo que el otro me expresa y también no estar como tan a la defensiva, sino poder escuchar para poder transformar, porque fijate D que tú misma lo dices cuando dices "yo no le puedo dejar el problema a otro, no le puedo trasladar el problema al otro porque es mío" ¿sí? Y nadie se va a hacer cargo de ese supuesto problema, pero yo no lo vería como un problema, yo lo vería como una posibilidad para que ustedes se acerquen, como esa posibilidad. Eso es lo que me llevo de la sesión de hoy y las invitaría a que se quiten tantos prejuicios tal vez de lo que el otro ha dicho, de lo que éste dice, como de todos esos rótulos que le han puesto a $\mathrm{L}$ y vernos tal vez al desnudo, con lo que es L, con sus quince años, que aunque parezcan muchos no son tantos en relación con los que usted tiene y la experiencia de vida que usted tiene. ¿sí? Para nuestro ejercicio nos queda un escenario, pero para el proceso que vamos a seguir nos quedan varios encuentros. Entonces yo les pediría que piensen un poco en lo que sucedió hoy aquí, en este espacio y que reflexionemos, todos tenemos que reflexionar un poco acerca de la conversación que hoy tuvimos y poder ver qué podemos rescatar de todo eso, para poder ir transformando porque definitivamente, la situación no se va a transformar sola. La situación DEBEMOS transformarla y ustedes son quienes van a empezar a transformar a partir de estos encuentros ¿sí? Entonces lo pensamos y nos vemos en el próximo encuentro. Me dicen que L se va una semana, entonces yo la estoy contactando para hacer la última parte del ejercicio y continuar en forma con la terapia.

238. C1: Bueno doctora, muchas gracias.

\section{TRANSCRIPCIÓN TERCER ESCUENTRO.}

\section{Datos de la Sesión.}




\section{LA DESERCIÓN ESCOLAR COMO PRETEXTO PARA CONVERSAR SOBRE IDENTIDAD, FAMILIA Y ESCUELA

Número de la Sesión.

3

\begin{tabular}{lc}
\hline Fecha y Hora. & Lunes 21 de septiembre 3.00 p.m \\
\hline Lugar. & Institucion Educativa San Jeronimo Emiliani \\
\hline Duración. & $\mathbf{6 0}$ minutos \\
\hline Actores y Siglas. & P: Psicóloga C1: Consultante uno (madre) C2: Consultante dos (Hija) \\
\hline \# De & Actores y Participación. \\
Línea. & \\
\hline
\end{tabular}

1 P: Bueno, de acuerdo al último encuentro que tuvimos hace casi veinte días ¿cierto? Ehhh vamos a hacer el cierre de lo que...estos tres escenarios que hemos estado grabando, o sea estos tres encuentros que hemos tenido con usted señora D y con L. Ehhh, la idea de esta última conversación que vamos a tener, es mirar los planes que ustedes como familia tienen para L. Ehhh ahí sería que usted señora D nos comentara qué ha pensado, cómo ha pensado que puede ser el otro año el futuro escolar de L; y L, pues que nos hable de esa proyección a futuro, cómo es que ella piensa, pues organizar su vida escolar, su vida personal, ya pues son quince años en donde ella ya tiene mucha más independencia, mucha más autonomía en relación con lo que va a ser su proyecto de vida a futuro, su proyecto de vida sobe todo en la parte escolar, que es lo que nos ha convocado en los otros dos encuentros. Ehhh a partir de todo eso que hemos venido hablando, en donde el segundo escenario fue tan fuerte para ustedes dos por la forma como confrontamos las situaciones, en donde usted me decía "es que estoy cansada, no sé qué hacer con ella porque no me habla..." y L pues también había optado como por ese silencio ¿no? que finalmente logramos que nos dijera algo y era cuando retomábamos la situación de D (el hijo menor) que ella decía "pues para mí fue muy duro cuando llegó D, dejé de ser el centro de atención..." ¿sí? Eso fue interesante porque creo que usted como que no lo sabía D, digamos como directamente, pero que logramos que L nos comentara esa parte. Entonces hoy vamos a mirar ya lo que es el futuro de ella y cómo han logrado como visualizarlo. Entonces a partir de ahí yo les pregunto ¿cómo comprenden la situación de L? La situación a nivel escolar, ¿cómo la comprende usted D?

2 C1: Pues... mmm...que ella, pues no sé, ella tiene como cierta pereza. Yo pienso que es más pereza al estudio que otra cosa, entonces pues, mi ideal claramente es que ella continúe, retome su estudio ¿no? Pero pues yo quiero saber si ella realmente quiere eso. (Silencio) Pero si no quiere estudiar, ¿qué es lo que quiere? Porque o sea, otro año ahí en la cocina no. Yo ya le dije, el otro año, o sea, el otro año algo se tiene que poner a hacer, si no es el bachillerato, es otro curso de lo que a ella le guste, yo ya le he dicho, algo que le guste.

\begin{tabular}{|c|c|}
\hline 3 & : Pero ya estamos mirando otras alternativas claro. \\
\hline 4 & $\begin{array}{l}\text { C1: Pues sí, porque yo dije "qué saco yo con ir a gastar un poco de plata otra vez en matrículas, en } \\
\text { cosas en gastos, pa' que en un mes me lo bote" entonces no, yo quiero que ella misma tome la decisión } \\
\text { y me diga "yo quiero esto" pero que lo cumpla. }\end{array}$ \\
\hline 5 & $\begin{array}{l}\text { P: Ahhh ok. ¿Usted qué nos tiene que mencionar al respecto? ¿Qué ha pensado en relación con su } \\
\text { futuro? }\end{array}$ \\
\hline 6 & C2: (Silencio) Mmm... \\
\hline 7 & C1: ¿Qué has pensado hacer el otro año L? \\
\hline 8 & $\begin{array}{l}\text { C2: (Silencio) Pues que... pues los cursos. Pues serían de informática que es en lo que mejor me } \\
\text { va...(silencio) }\end{array}$ \\
\hline 9 & $\begin{array}{l}\text { P: O sea, debo de entender con ese silencio que no has pensado en volver a un colegio tradicional, o } \\
\text { ¿qué has pensado en relación con tu bachillerato o piensas que solamente con los cursos de informática } \\
\text { son suficiente...cómo te visualizas ahí? ¿Qué quieres? ¿qué piensas hacer? ¿O continúas con la rutina } \\
\text { que ya has venido llevando durante tres años? }\end{array}$ \\
\hline 10 & C2: Mmm... (Silencio) ehhh... pues no, no me he visualizado (risa) la verdad. \\
\hline & P: ¿Para usted es cómodo estar en la casa y seguir la rutina que va llevando hace dos años ya \\
\hline
\end{tabular}




\section{LA DESERCIÓN ESCOLAR COMO PRETEXTO PARA CONVERSAR SOBRE IDENTIDAD, FAMILIA Y ESCUELA

quiere seguir con eso?

\begin{tabular}{ll}
\hline 12 & C2: (niega con la cabeza) \\
\hline 13 & P: “No" con tu cabeza me dices "no" pero entonces, cuéntanos ¿qué quiere hacer? ¿Cómo te vez \\
proyectada el otro año? porque yo pienso que cada año que viene, uno tiene como expectativas con lo \\
que viene ese año, con lo que trae, uno se atreve a pensar, a soñar, imaginar, a crear, ¿usted qué ha \\
pensado?
\end{tabular}
cuando yo llego a donde $\mathrm{D}$ a decirle "D por favor, es tarde, podemos venir al colegio, aquí a grabar el escenario que nos hace falta" entonces yo tengo que hablarlo con ella, yo no asumo que ella lo sabe, sino yo tengo que hablarlo con ella, pero es que si yo no lo hablo y con usted, no ve que yo estoy contando con un tiempo que no es mío, es de ella. Entonces yo le digo "D, podemos vernos en el colegio, podemos encontrarnos, ehhh ¿puede llevar a L...?" Porque yo no sé si usted esté aquí o como la semana pasada que no estuvo. Pero es que ¿eso se hace cómo? Hablándolo. Si usted se dio cuenta, esta mañana le hice llamadas, no se pudo, hasta que nos conectamos, nos hablamos y nos pusimos de acuerdo y ahora estamos aquí en el colegio grabando. Pero hablándolo, porque yo no puedo asumir o me puedo parar aquí en la puerta del colegio esperando a que D llegue si yo nunca lo hablé con ella... eso es lo mismo que yo te digo, háblalo con tu mamá, háblalo, mira ahí está D. Y D en estos encuentros, ella me ha demostrado que es una persona...o nos ha demostrado a usted y a mí...que es una persona que se deja hablar, que está dispuesta para hablar, pero si yo no le digo nada, pues ella simplemente se queda callada porque...entonces eso es lo que ha pasado con ustedes, háblenlo. Dile, 


\section{LA DESERCIÓN ESCOLAR COMO PRETEXTO PARA CONVERSAR SOBRE IDENTIDAD, FAMILIA Y ESCUELA

dile que es lo que quieres, dile cuáles son tus planes para el otro año, cómo lo piensas hacer, si puedes contar con ella, cómo ella la va a apoyar...eso es lo que quiero que hablen. Ese es el futuro de usted, el que se está poniendo en juego ahí. Cuéntale a $\mathrm{D}$. ya hablaste de los cursos informáticos, me parecen geniales, ¿A qué hora los piensas hacer? ¿En dónde los piensas hacer? Eso es planear para el futuro. Ya no piensas volver al colegio tradicional, ya nos dijiste que no...que ahora piensas validar ¿en dónde? Cuéntanos. Pero todo eso se hace mirándola, yo no me puedo meter debajo de la mesa, de ésta mesa, a peguntarle a D si me puede dar un espacio para que hablemos

\begin{tabular}{|c|c|}
\hline 24 & C2: (Silencio) \\
\hline 25 & P: Mira a tu mamá y dile. \\
\hline 26 & C2: Ehhh, pues validar yo pensé que era entre semana (risa)... \\
\hline 27 & $\begin{array}{l}\text { C1: Pero es que, o sea eso hay diferentes opciones L. hay diferentes...o sea eso depende de cada } \\
\text { instituto, o hay un instituto que tiene varios horarios, o sea, hay de lunes a viernes o hay solo los } \\
\text { sábados o sábados y domingos, o sea eso hay diferentes. }\end{array}$ \\
\hline 28 & $\begin{array}{l}\text { P: A usted, ¿cómo le gustaría validar? En qué horario, de acuerdo a lo que D nos está comentando, } \\
\text { porque si ella nos está comentando fue porque ella averiguó. ¿En qué horario le gustaría a usted ir a } \\
\text { validar? }\end{array}$ \\
\hline 29 & C2: Mmm, pues si, de ¿lunes a viernes? \\
\hline 30 & P: Mmm, interesante, muy interesante. De lunes a viernes, ¿en dónde? \\
\hline 31 & C2: (Risa) No sé, porque no... \\
\hline 32 & P: Ahhh, usted no ha ido con D a averiguar. \\
\hline 33 & C2: No \\
\hline 34 & $\begin{array}{l}\text { P: Pero pues, pregúntale a D dónde ha averiguado ella y de lo que ella te cuenta tu tomas una decisión } \\
\text { por ejemplo. Así como ya nos dijo, "de lunes a viernes” listo, ya sabemos que L quiere ir al colegio de } \\
\text { lunes a viernes a validar y ¿A qué instituto? A donde, a ver cuénteme D. }\end{array}$ \\
\hline 35 & $\begin{array}{l}\text { C1: Pues yo que haya averiguado, yo averigüé en el } \mathrm{SD} \text {, en el } \mathrm{R} \text { y en el que queda al frente de } \mathrm{C} \ldots \mathrm{y} \text { de } \\
\text { los tres me llama la atención el del R, sino que el R sí es solamente los sábados...y en el que queda al } \\
\text { frente de C, pues fue como el que más me llamó la atención como por el ambiente para ella, porque es } \\
\text { que en SD sí llega mucha gente pues como de todo. }\end{array}$ \\
\hline 36 & P: ¿y en el SD qué horarios hay? \\
\hline 37 & C1: Hay...(risa) \\
\hline 38 & C2: (risa) ¿En el SD qué horarios hay? \\
\hline 39 & $\begin{array}{l}\text { C1: Ahí hay de los tres horarios. Hay los fines de semana, de noche, en el día, en la tarde. Allá sí que } \\
\text { hay de todos. En el que es de lunes a viernes al frente de } \mathrm{C} \text { es de } 8 \text { a } 12 \text {, de lunes a viernes. Y en el R, } \\
\text { pues ese hay de...solo los sábados porque entre semana estudian las niñas que estudian de día. } \\
\text { Entonces en el R sí es solamente los sábados. }\end{array}$ \\
\hline 40 & C2: Mmm...pues sería mirar en el que queda al frente del C. \\
\hline 41 & C1: Eso, entonces pues, el miércoles que yo no tengo clase pues vamos y hacemos esa vuelta. \\
\hline 42 & P: Van a ir las dos... \\
\hline 43 & $\begin{array}{l}\mathrm{C} 1 \text { : Vamos y averiguamos y mira las instalaciones, hablas con la gente. Porque si, todo eso toca mirar } \\
\text { porque de todas maneras, pues tampoco puedo ir a meter, o yo por lo menos no puedo ir a dejarla que } \\
\text { meta la cabeza en el primer lugar que haya... porque pues tampoco...hay gente demasiado mayor, } \\
\text { gente que ya no es para ti, gente que de pronto ya con más experiencia de muchas cosas, entonces pues } \\
\text { no es bueno. O sea, lo ideal sería en ese sitio que he visto que hay como más o menos muchachos... }\end{array}$ \\
\hline 44 & P: ¿De la edad de ella? \\
\hline 45 & C1: De la edad de ella sí. \\
\hline 46 & P: ¿sí L, te llama la atención ir el miércoles con tu mami a mirar el sitio donde estarías? \\
\hline 47 & 2: S. \\
\hline
\end{tabular}




\section{LA DESERCIÓN ESCOLAR COMO PRETEXTO PARA CONVERSAR SOBRE IDENTIDAD, FAMILIA Y ESCUELA

48 P: Bueno L... y ya, estamos allá, ya es 2016. Eso fue rápido que llegamos allá...tu compromiso, ¿qué esperas encontrar allí? ¿Cómo te ves allí? ¿Te llama la atención? ¿Te pone feliz?

\begin{tabular}{ll}
\hline 49 & C2: Nerviosa (risa) \\
\hline 50 & P: ¿Nerviosa? ¿Por qué a ver? \\
\hline 51 & C2: Emmm \\
\hline 52 & P: Es un reto nuevamente para ti, ¿cómo asumes ese reto? \\
\hline 53 & C2: ¿intentando? \\
\hline 54 & P: Intentando. Y ¿qué vas a dar de ti? ¿Cómo va a ser ese compromiso? Más que con D, yo quiero que
\end{tabular}
usted se concientice de que ese no es un compromiso que usted va a adquirir con D por una inversión que ella va a hacer, porque le va a costar, sino es un compromiso con usted, ya después de haber vivido esa experiencia de estar desescolarizada y nuevamente volver a un aula, a sentarse, a aprender nuevas cosas, ¿Cuál va a ser ese compromiso? ¿cómo te sientes? Tal vez ¿por eso es que te dan nervios? O ¿por qué?

$55 \mathrm{C} 2: \mathrm{Mmm} \ldots$ no sé, nervios como de...de que no me vaya bien.

56 P: ¿pero por qué? Si usted es una niña con todas las facultades para poder responder a ese reto. La experiencia que tu viviste de años anteriores, solamente tiene que servirte para no volver a repetir esos errores. Como por ejemplo cuando tu evadías las clases, usted sabe que esa fue una experiencia que no fue muy benéfica para usted, porque mire todo lo que nos desencadenó, el hecho de que usted hubiese dejado el colegio, que nuevamente... ¿sí? Hubieras intentado en otro colegio y tampoco respondiste, que un mes sí, que un mes no, que no ibas, que te ibas con tus amigos...esa experiencia yo creo que para ti fue muy buena, porque te dejó una enseñanza ¿Cuál fue esa enseñanza?

\begin{tabular}{|c|c|}
\hline 57 & C2: Mmm...pues que no... no hay que salirse de clases. Porque no va a dejar nada bueno. \\
\hline 58 & P: Y para ti fue una experiencia dura todavía ¿cierto? Porque fueron ¿cuántos años? \\
\hline 59 & C2: Dos. \\
\hline 60 & P: Dos. ¿Haciendo qué? (risas) \\
\hline 61 & C2: (Risas) \\
\hline 62 & P: A ver, a veces uno tiene que repetirse a sí mismo para poderse convencer... \\
\hline 63 & C1: “Cuando mi mamá me pescó que me escapaba del colegio y me metió a la cocina” (risa) \\
\hline 64 & $\begin{array}{l}\text { P: (risa) Eso, mira como D lo cuenta así como tan folclóricamente...y lo que eso para ti implicó. } \\
\text { Dejaste de compartir con personas de tu edad, de vivir tu mundo de niña, de tu juventud, mira fueron } \\
\text { dos años que tu perdiste allá en la cocina ¿o no? }\end{array}$ \\
\hline 65 & C1: Aprendió a cocinar porque cocina muy rico. (risa) \\
\hline 66 & C2: Ash (risa) \\
\hline 67 & P: ¿Sí? ¿Cocina delicioso? \\
\hline 68 & C1: Sí \\
\hline 69 & $\mathrm{P}:$ Y para $\mathrm{D}$ ¿esos dos años cómo fueron? \\
\hline 70 & C1: No pues, amargos, de angustia, de estar ahí como en un... "qué va a pasar con ella" \\
\hline 71 & P: Pero yo creo que también fue como un beneficio para ti D, de cierta forma. \\
\hline 72 & $\begin{array}{l}\text { C1: Pues sí porque pienso que eso la ayudó a madurar y pienso que eso la ayuda a que, ya ahorita que } \\
\text { si de verdad va a retomar su vida escolar, se concientice de que es importante y de que ya hacer esas } \\
\text { cosas no la lleva a nada bueno. }\end{array}$ \\
\hline 73 & $\begin{array}{l}\text { P: Pero no, yo pienso que no solamente no fue el beneficio de la maduración para L. porque claro L sí } \\
\text { hoy ya ve la situación y tiene la capacidad de reflexionar y decir "sí, la embarre...sí, me equivoqué" } \\
\text { pero también para ti yo creo que fue un beneficio en el sentido de que te colaboró. }\end{array}$ \\
\hline 74 & C1: A sí, eso sí. Pues sobre todo cuando empecé a estudiar. \\
\hline 75 & $\begin{array}{l}\text { P: Ese fue un beneficio muy grande para ti. Donde las dos... o sea L a través de su experiencia poco } \\
\text { grata para ella, estuvo ahí colaborándote... }\end{array}$ \\
\hline
\end{tabular}




\section{LA DESERCIÓN ESCOLAR COMO PRETEXTO PARA CONVERSAR SOBRE IDENTIDAD, FAMILIA Y ESCUELA

76 C1: Sí, bastante. Sí, bastante porque hay semanas en que el SENA me absorbe totalmente y no tengo tiempo absolutamente para nada y pues la que está ahí al frente es ella.

77 P: Ehhh, D y si L ¿no se le hubiera presentado esa situación de tener que abandonar el colegio por todo lo que se presentó, cómo hubiese sido tu vida?

\begin{tabular}{ll}
\hline 78 & C1: No hubiera ingresado a estudiar. \\
\hline 79 & P: ¿No hubieras podido estudiar D? \\
\hline 80 & C1: No. No porque no tenía a quien dejar ahí. \\
\hline 81 & C2: Más que todo en las mañanas. \\
\hline 82 & $\begin{array}{l}\text { C1: Porque mi hija mayor, pues ella estudia...ella estudiaba, en ese momento estudiaba en la } \\
\text { universidad, entonces... }\end{array}$ \\
\hline
\end{tabular}

83 P: O sea que, si nosotros retomáramos todo lo que paso en el escenario dos, en donde en ese encuentro fue bastante fuerte porque tú fuiste dura con...con L cuando le decías que...a veces hasta la comida, porque como que sentías que ella no la pagaba, pero hoy, retomando todo esto, yo creo que ustedes se deben mucho mutuamente.

\begin{tabular}{ll}
\hline 84 & C1: Sí claro. \\
\hline 85 & P: Y ¿tú le has expresado a L eso alguna vez? \\
\hline 86 & C1: No \\
\hline 87 & P: Y ¿tú, qué le quisieras decir hoy a L? \\
\hline 88 & C1: Pues, lastimosamente, pues de su tragedia me beneficié yo (risas). Digo lastimosamente porque ya
\end{tabular}

88 C1: Pues, lastimosamente, pues de su tragedia me beneficié yo (risas). Digo lastimosamente porque ya mi tiempo de estudiar ya había pasado y era el tuyo. Pero lo que yo te dije el día que...pues se presentó esa oportunidad por cosas de Dios porque prácticamente me llegó ahí, sin estarla buscando y la cogí, decidí cogerla, y me ha costado porque....me ha costado mucho, pero si, gracias a ti he podido hacer mis cosas, tú me has colaborado mucho. Tú has tenido mucho que ver en mi proceso y he querido, lo quise hacer y te lo dije el día que empecé a estudiar, tú no quisiste estudiar, no quisiste aprovechar esa oportunidad la voy a aprovechar yo...y lo hice. Y me ha costado y ha sido difícil, pero dentro de todas las posibilidades que hay la única que no he contemplado es la de retirarme. Porque decidí asumirlo y dije tanto que esperé esta oportunidad para llegar y decir "ay no esto me quedó grande, chao" no.

89 P: Pero bueno D, ya en vista de que sí tú has sido un ejemplo, un gran ejemplo para... no solamente para L sino creo que para todos tus hijos, porque tú misma lo dices en el sentido de "me ha costado..." tal vez más de una vez pensaste en abandonarlo, pero la misma fuerza de voluntad y la misma...el mismo objetivo claro que tú tienes para seguir adelante, la misma proyección... ¿sí? Los mismos planes, podríamos decirlo que tienes a futuro, te han mantenido ahí, firme, perseverante siempre, entonces ehhh... ¿qué de todo eso le dejas a L? a partir de esa enseñanza...de toda esa experiencia, ¿sí? difícil que tú has tenido, de todos esos obstáculos que tú has vivido en estos dos años en el SENA... ¿qué le dejas a L, qué le compartes de todo eso? ¿cuál sería tu reflexión para ella sabiendo que ella ha sido una pieza muy importante, sabiendo que ella ha sido muy generativa para ti en ese sentido? Porque también tú eres muy consciente y lo manifiestas, "si L no hubiera estado ahí yo no lo hubiera podido hacer" o sea, ella ha jugado un papel muy importante en todo ese proceso que tú has adelantado y ha sido fundamental para ti en ese proceso, ahora tú ¿Qué le devolverías a L?

90 C1: Pues... primero que a mí ya se me había olvidado que era estudiar y en este momento, me pongo y también en ese momento estando estudiando entendí muchas cosas también de mi hija cuando estaba en la universidad, que no le quedaba tiempo para compartir un desayuno o un almuerzo...yo decía "pero cómo va a ser posible". Pues efectivamente, llega un momento en que llegas a un punto en el que uno se olvida de todo y se encierra en el estudio... cuando uno lo quiere lograr. Desde el punto de vista de estudiante, me pongo en los zapatos de ella y no es fácil, no es fácil estudiar. Y no es para cualquiera y todos no tenemos el mismo nivel de aprendizaje, allá en el salón hay unos que eso les dicen una vez y ni siquiera les dicen y ya las cogieron y fuuu, en cambio a mí me toca darle diez 


\section{LA DESERCIÓN ESCOLAR COMO PRETEXTO PARA CONVERSAR SOBRE IDENTIDAD, FAMILIA Y ESCUELA

veces...pero a la décima vez lo logré y lo entendí y lo saqué. Entonces eso es lo que yo quiero decirle a ella, que yo sé que no es fácil y que yo sé que estudiar no es para todo el mundo, pero si nos lo proponemos lo logramos, que de pronto a unos nos toca esforzarnos un poquito más para aprender lo que otro aprendió en una sola leída. A mí me toca leerla diez veces para cogerla, pero la termino cogiendo, pero si yo a la primera me venzo, pues no la cogí y no la voy a coger porque si no seguí insistiendo. Y que tiene todo mi apoyo para explicarle, para ayudarle a entender lo que se le dificulte, pues ella lo sabe. En primaria...y una de las críticas de mi hija mayor fue esa, yo a ella la ayudaba mucho y a la mayor pues a ella nunca lo hice porque yo nunca tuve la necesidad, ni ella me lo pidió, ni yo se lo ofrecí... pero L fue diferente, con L yo estaba ahí pa' decirle "mire esto se hace así" "esto está bien, esto está mal" "corrija esto" y lo voy a seguir haciendo...entonces académicamente si ella necesita ayuda...

91 P: O sea, puede contar contigo. Ok, pero también hay algo que me surge como inquietud y es que ya L con quince años, ya es hora de que ella tome sus propias decisiones...

\begin{tabular}{ll}
\hline 92 & C1: ajá \\
\hline 93 & P: o ¿tú que piensas D? y ¿Usted qué piensa L? \\
\hline 94 & C1: pues que ella...pues sí, hay cosas que ya está en capacidad de decidir ¿sí? Y pues yo como...pues \\
& mamá y ella por ser todavía menor de edad pues obviamente yo tengo que avalar esas decisiones si le \\
convienen o no ¿sí? y aconsejarla. Pues pienso que en este momento no va a tomar una decisión de \\
decir "me voy a ir con un hippie por ahí”...
\end{tabular}




\section{LA DESERCIÓN ESCOLAR COMO PRETEXTO PARA CONVERSAR SOBRE IDENTIDAD, FAMILIA Y ESCUELA

\begin{tabular}{|c|c|}
\hline 104 & C2: Sí. (Silencio) Pues sí, a validar. \\
\hline 105 & P: Y ¿eso te produce emoción? ¿Sí? \\
\hline 106 & C2: Sí... (Risa) los nervios. \\
\hline 107 & $\begin{array}{l}\text { P: no, pero emoción de que vas a conocer gente nueva, de que tu vida va a cambiar... de una u otra } \\
\text { forma va a cambiar, ya no es levantase a abrir el salón o a hacer el almuerzo... }\end{array}$ \\
\hline 108 & $\begin{array}{l}\text { C1: Y los temores son lo más normal...usted cree que yo el primer día que yo pisé el SENA a mí me } \\
\text { temblaba hasta el pelo, yo decía "no, yo voy a hacer el ridículo aquí, yo ya con treinta y nueve años al } \\
\text { lado de todos estos chinitos de diecisiete" porque habían chinos que todavía tenían diecisiete, yo } \\
\text { temblaba y yo decía "estos chinos me van a hacer bullying" yo decía "eso se van a burlar y todo lo } \\
\text { contrario... }\end{array}$ \\
\hline 109 & C2: Ja...antes le tienen un respeto. \\
\hline 110 & P: Por eso L...y para ti ¿cómo piensas que va a ser esa experiencia? \\
\hline 111 & C2: Pues buena. \\
\hline 112 & $\begin{array}{l}\text { P: Interesante ¿cierto? Nuevas cosas, nuevos amigos, otra vez otra vida social, rico volver a entrar en } \\
\text { ese rol de estudiante. Y posiblemente ya no con tu uniforme, uno para validar no necesita un uniforme } \\
\text { ¿cierto? }\end{array}$ \\
\hline 113 & C1: No, ella va es de particular. \\
\hline 114 & P: De particular \\
\hline 115 & $\begin{array}{l}\text { C1: Y allá ya no va a haber educación física, ni artes, no. solo las materias que va a necesitar para una } \\
\text { universidad...inglés, matemáticas...yo por ejemplo yo le digo a ella "L coja sus cuadernos, usted } \\
\text { todavía los tiene por ahí..." porque yo no los he botado, ahí están "al menos repace sobre esos } \\
\text { cuadernos los temas que..." porque en ese instituto de...el que es de lunes a viernes, le hacen un } \\
\text { examen y si ella pasa ese examen de sexto, no la hacen hacer sexto, la promueven a séptimo. }\end{array}$ \\
\hline 116 & P: Uy que bien L, ¿eso te llama la atención? \\
\hline 117 & C2: Ehhh...pues sí. \\
\hline 118 & $\begin{array}{l}\text { P: ¿Sí? Ok, bueno ¿cómo creen que todos estos encuentros y este proceso que hemos llevado las ha } \\
\text { podido ayudar para que lleguen a esta decisión? }\end{array}$ \\
\hline 119 & C1: Pues que lográramos que ella exprese algo... algo de que de pronto... \\
\hline 120 & P: Pero ¿sí les ha servido o...? \\
\hline 121 & C1: Bastante sí. Bastante, porque yo por lo menos en este momento me siento más relajada con ella. \\
\hline 122 & P: Siente que los canales se abrieron, que hay como más interacción... \\
\hline 123 & $\begin{array}{l}\text { C1: Sí, me ha ayudado a ver las cosas de otra manera diferente, me ha ayudado a...como a } \\
\text { tranquilizarme más y a aprender a esperar y a ser paciente...y a no acelerarme, o sea, a no enfrascarme } \\
\text { en que una cosa tiene que ser así y a entender... a entender mejor, a entenderla a ella mejor. }\end{array}$ \\
\hline 124 & P: Mmm...que bien D. Como me alegro que realmente este proceso haya sido así... \\
\hline 125 & $\begin{array}{l}\text { C1: De hecho de todos los años que llevo con ella en terapias, es la primer vez que veo una luz (risa) } \\
\text { en el camino, porque antes no, o sea, lo que ella dice...o sea, llegó un momento en el que nos } \\
\text { aburrimos porque o sea como que llegamos ahí pero "qué hacemos aquí" "qué sacamos de esto" "pa' } \\
\text { donde vamos" }\end{array}$ \\
\hline 126 & C2: “¿para qué? \\
\hline 127 & $\begin{array}{l}\text { P: Ok... D de verdad me alegro mucho de que realmente al menos sea esa luz que usted estaba } \\
\text { esperando, que se abran las posibilidades para ustedes como familia, pero sobre todo que la vida de } \mathrm{L} \text {, } \\
\text { dé ese cambio. ¿sí? Haya esa transformación, que estamos buscando L, que ella pueda tener una } \\
\text { proyección hacia lo que va a ser su futuro y ¿sí? Retomo sus palabras D, ehhh existen múltiples } \\
\text { posibilidades para que una persona salga adelante y si no puede terminar el bachillerato por A, por B o } \\
\text { por C circunstancia; porque no quiere, porque no le gusta, porque definitivamente no entiende o lo que }\end{array}$ \\
\hline
\end{tabular}




\section{LA DESERCIÓN ESCOLAR COMO PRETEXTO PARA CONVERSAR SOBRE IDENTIDAD, FAMILIA Y ESCUELA

sea...existen otras posibilidades en donde ella puede plantar su futuro tranquilamente y puede salir adelante, sin necesidad de que sea terminando un bachillerato. Porque yo estoy convencida de que L tiene muchas posibilidades, muchísimas.

\begin{tabular}{ll}
\hline 128 & $\begin{array}{l}\text { C1: Sí, yo te todo esto le dije que...lo que sumerced dice es cierto o sea desde...desde...si me lo } \\
\text { vendieron a mí, imagínese a ella, que era pues... una niña. De que "no podía" y que "no podía" }\end{array}$ \\
\hline 129 & P: No, yo estoy convencida... \\
\hline 130 & $\begin{array}{l}\text { C1: Y ya en este momento, o sea yo digo....no en este momento, ya... yo ya me había dado cuenta } \\
\text { que...viéndola hacer otras cosas que son más difíciles que el colegio... }\end{array}$ \\
\hline 131 & P: ajá \\
\hline 132 & C1: Yo dije, "L lo que sufre es de una pereza espantosa" \\
\hline 133 & P: Y una desmotivación... \\
\hline 134 & C1: Sí, ella la detienen...es eso. Porque ella se pone a hacer algo y lo entiende rápido. \\
\hline 135 & P: Mmm...la rotularon...la rotularon definitivamente y tal vez ustedes como familia cayeron en esa... \\
\hline 136 & C1: Sí. \\
\hline & $\begin{array}{l}\text { P: En ese... en esa postura que colocaron los colegios cuando decían "es que ella tiene un problema" } \\
\text { problema y claro, ella se quedó convencida de que definitivamente tenía un problema para aprender. }\end{array}$ \\
\hline 138 & Pero nos hemos dado cuenta de que... \\
\hline 139 & P. No es así. \\
\hline
\end{tabular}

139 P: No es así. L tiene igual, o tal vez diría yo, más capacidades que cualquiera de los chicos de su edad, porque es que ella maneja un discurso muy elaborado, muy coherente...y lo que sí veo muy coartado en ella es un poco la parte social, o sea, no expresa mucho pero creo que sí hemos avanzado.

\begin{tabular}{|c|c|}
\hline 140 & C1: Sí. \\
\hline 141 & $\begin{array}{l}\text { P: Para ya llegar a mirar a D y decirle "quiero validar y estoy cansada de..." hemos avanzado. Cuando } \\
\text { ella llegó aquí... }\end{array}$ \\
\hline 142 & C1: No hablaba nada. \\
\hline 143 & P: No hablaba nada. Y usted ¿Qué se lleva de todo esto? \\
\hline 144 & $\begin{array}{l}\text { C2: Qué me llevo...Mmm... ehhh...decir (risa), hablar (risa), ehhh abrir un espacio entre mi mami y } \\
\text { yo...y nuevas oportunidades. }\end{array}$ \\
\hline 145 & $\begin{array}{l}\text { P: Ok L. La verdad es que, me alegra mucho haber podido, pues ser como esa parte o esa persona } \\
\text { intermedia entre ustedes dos... y pues hay algo que todavía me queda como en sin sabor y es como la } \\
\text { parte del...la parte afectiva. Yo sí les pediría, no sé, yo siento que eso nace de cada cual...pero aún } \\
\text { siento que tienen como heridos esos corazones ¿sí? Y tal vez un abrazo D, tal vez un "te quiero", } \\
\text { diariamente les caería muy bien a ustedes dos. Porque hay amor, como madre puedo decirlo ¿no? o } \\
\text { sea, el ser de uno son sus hijos y yo pienso que un abrazo, un "te quiero”, un beso...es más benéfico } \\
\text { que tal vez la plata que uno les pueda dar para las onces ¿no? si a uno... }\end{array}$ \\
\hline 146 & C2: (risa) \\
\hline 147 & $\begin{array}{l}\text { P: Sí de verdad, si a uno no tienen para darle los dos mil pesos de la lonchera, pero ese día me abrazan } \\
\text { y me dicen "hija te amo" y "hoy no puedo darte porque las cosas han estado difíciles" yo creo que ese } \\
\text { día yo no voy a sentir la misma hambre...porque ese abrazo y ese "te quiero" me van a alimentar tal } \\
\text { vez más que el jugo que le pueda echar a mi estómago y la galleta...no sé, es mi sentir. No sé ustedes } \\
\text { cómo lo vean. }\end{array}$ \\
\hline 148 & C1: Sí claro. \\
\hline 149 & $\begin{array}{l}\text { P: Sí, yo pienso que a veces hay que romper esa pauta de ser tan estrictos D y...abrazar más, consentir } \\
\text { más. }\end{array}$ \\
\hline 150 & $\begin{array}{l}\text { C1: Sí, es que de pronto llegó un momento en que... en que de pronto yo decía "es que la acabo de } \\
\text { "basear" v me vov a desnedir y vov a ir a decirle te quiero mucho" entonces (risa). }\end{array}$ \\
\hline
\end{tabular}




\section{LA DESERCIÓN ESCOLAR COMO PRETEXTO PARA CONVERSAR SOBRE IDENTIDAD, FAMILIA Y ESCUELA

\begin{tabular}{|c|c|}
\hline 151 & C2: (risa) \\
\hline 152 & C1: ...Como que no concuerda...como que no combina (risa) \\
\hline 153 & $\mathrm{C} 2:($ risa $) \mathrm{Si}$ \\
\hline 154 & $\begin{array}{l}\text { C1: Entonces se convirtió en eso, en que desde que me levantaba era peleando con ella....entonces ya } \\
\text { cuando me iba "ta' luego" (risa). }\end{array}$ \\
\hline 155 & P: Estaban castigándose. \\
\hline 156 & $\begin{array}{l}\text { C1: Sí...si claro. Pero sí obviamente si yo se lo he dicho a ella, si yo no la quisiera "no, que me } \\
\text { importa, pues yo mejor tenerla ahí y quien me cocine" yo antes le diría "no no no, no vaya } \\
\text { estudiar...quédese ahí quieta"... }\end{array}$ \\
\hline 157 & C2: (risa) \\
\hline 158 & C1:...pero no \\
\hline 159 & P: Y usted ¿cuántas veces busca a D para darle un abrazo...? \\
\hline 160 & C1: Ahhh ellas si son melcochudas \\
\hline 161 & C2: (risa) \\
\hline 162 & P: ¿sí? \\
\hline 163 & C2: Sí, ahí pegada. \\
\hline 164 & C1 y C2: (risas) \\
\hline 165 & P: Eso es bueno. Eso es bueno, a mí me parece lo más sano, que ella te busque porque... \\
\hline 166 & C1: Sí y es como dice la doctora, eso va en cada...pues en cada ser ¿no? \\
\hline 167 & P: ajá \\
\hline 168 & $\begin{array}{l}\text { C1: Aunque sí pues uno con sus hijos pues obviamente. Yo por lo menos ya crecen... ya cuando } \\
\text { son... por ejemplo a mi hija mayor ya...tampoco. Yo la adoro y yo vivo pendiente de ella y eso, pero } \\
\text { ya por ejemplo que llegue y yo la coja, la abrace y la apapache, pues no porque ya la veo grande y ya } \\
\text { no es para eso ¿sí? (risa)... }\end{array}$ \\
\hline 169 & P: ¿Seguro? \\
\hline 170 & C2: (risa) \\
\hline 171 & $\begin{array}{l}\text { C1: ...Pero la amo. De pronto es mi modo de ser o así me criaron ¿no?...porque pues mi mamá } \\
\text { tampoco fue así como con nosotros, ni yo con ella. Yo a mi mamá tampoco... yo "quiubo mami” el } \\
\text { saludo en la mejilla y ya. Yo por ejemplo me aterro, mi hermana menor... }\end{array}$ \\
\hline 172 & C2: Uy no eso sí ya es pasado. \\
\hline 173 & C1: Sí \\
\hline 174 & C1 y C2: (risas) \\
\hline 175 & C2: Ya eso es exceso de amor sí (risa) \\
\hline 176 & $\begin{array}{l}\text { C1: Sí, ella sí...y ella es de las que "mi mamita” y la abraza y le da besos y la... ¿sí? Yo no. pues qué } \\
\text { le vamos a hacer, no me gusta... }\end{array}$ \\
\hline 177 & P: Eres un poco más fría... \\
\hline 178 & $\begin{array}{l}\text { C1: Sí, ni me gusta que ellas hagan eso conmigo tampoco, o sea, que me cojan ahí a melcocharme, a } \\
\text { babosearme... no me gusta. }\end{array}$ \\
\hline 179 & P: (risa) Bueno, pero el esposo sí. \\
\hline 180 & C1: Ah...pues sí (risa) \\
\hline 190 & C1, C2 y P: (Risas) \\
\hline 191 & C1: Y por ejemplo con mi bebé. \\
\hline 192 & P: Claro \\
\hline 193 & C1: Y yo le explicaba eso a L, con todos, eso sí, a todos... \\
\hline 194 & C2: ¿Hasta yo? ¿Hasta yo mami? \\
\hline 195 & C1: ...A todos los besaba, los apretaba, los mordía, los apapachaba, los...mejo \\
\hline
\end{tabular}




\section{LA DESERCIÓN ESCOLAR COMO PRETEXTO PARA CONVERSAR SOBRE IDENTIDAD, FAMILIA Y ESCUELA

\begin{tabular}{|c|c|}
\hline 196 & C2: Apapachaba... ¿mor-di-a? \\
\hline 197 & $\begin{array}{l}\text { C1: ... mi hija era la que me decía..."usted a cada uno de los que ha nacido algún alias le pone" porque } \\
\text { a ella le decía "mi ciela" y "mi ciela" y era "mi ciela". }\end{array}$ \\
\hline 198 & C1, C2 y P: (Risas) \\
\hline 199 & C1: Y a C (la hija mayor) era "mi gordis", "mi gordis" y " mi gordis" \\
\hline 200 & C2: Y todavía, en el celular la tiene como "gordis" (risa) \\
\hline 201 & C1: Sí (risa), pero ya pues llegó un punto en que crecieron y ya. \\
\hline 202 & P: Pero aún uno estando grande necesita... \\
\hline 203 & C1: Ya no...ya no es para... \\
\hline 204 & C2: (risas) \\
\hline 205 & P: O bueno, yo no sé. \\
\hline 206 & C2: (risa) A mí ya no me dicen fetico... me dicen feto. (risa) \\
\hline 207 & $\mathrm{C} 1, \mathrm{C} 2$ y $\mathrm{P}:$ (risas) \\
\hline 208 & P: A mí será porque todavía si soy muy...muy querendona. \\
\hline 209 & C1: Sí, eso va en cada... \\
\hline 210 & P: Pienso que sí. \\
\hline 211 & C1: ...en cada persona \\
\hline 212 & $\begin{array}{l}\text { P: Porque mi hijo siendo tan grande...tan grande en años y tan grande en estatura... mejor dicho } \\
\text { todavía cuando hablo con él "hola mi bebé, cómo te va" "cómo estas mi amor" y entonces ellos } \\
\text { piensan que es algún bebé que tengo. (risa) }\end{array}$ \\
\hline 213 & C1 y C2: (Risas) \\
\hline 214 & P: Pero ese bebé ya tiene 33 años. Pero sí, son estilos y formas de ser. \\
\hline 215 & C1: Formas de ser sí. \\
\hline 216 & $\begin{array}{l}\text { P: Entonces, pues la verdad no me queda más que agradecerles, agradecerles su tiempo, agradecerles } \\
\text { pues por...por esta experiencia que vivimos las tres y...pues d verdad espero que las cosas para } \\
\text { ustedes como familia cambien un poco...que usted } \mathrm{D} \text { tenga mucha más paz y mucha más tranquilidad } \\
\text { y confianza en lo que va a hacer L. Y pues L también, que empiece a vivir esos años que le quedan por } \\
\text { vivir de juventud que son tan bonitos, de niñez, de vivir cada momento... }\end{array}$ \\
\hline 217 & $\begin{array}{l}\text { C1: (no se entiende)...ella cumple los quince años y yo le decía "con quién le voy a hacer la fiesta de } \\
\text { quince si no tiene amigos" }\end{array}$ \\
\hline 218 & C2: A demás no me gustan las fiestas. \\
\hline 219 & P: Pero no...pero pues rico. Es una experiencia L...es una experiencia que hay que vivirla... \\
\hline 220 & C1: Entonces van a ser unos quince años diferentes a todas las niñas. \\
\hline 221 & P: Entonces pues si...agradecerles. Bueno...yo si voy a los quince. \\
\hline 222 & C2: (risa) \\
\hline 223 & P: (risa) Entonces de verdad, agradecerles este espacio y... \\
\hline 224 & $\begin{array}{l}\text { C1: De parte mía también le doy las gracias de todo corazón, le doy las gracias a Dios porque pienso } \\
\text { que Él fue quien la puso en mi camino y porque desde el día en que su merced me conoció allá en } \\
\text { clase, fijó sus ojos en mi caso...en nuestro caso y ... }\end{array}$ \\
\hline
\end{tabular}

\section{Anexo 5. Matrices de análisis}

\section{Escenario 1.}




\section{LA DESERCIÓN ESCOLAR COMO PRETEXTO PARA CONVERSAR SOBRE IDENTIDAD, FAMILIA Y ESCUELA

\begin{tabular}{|c|c|c|c|c|}
\hline $\begin{array}{l}\text { Intervenciones } \\
\text { narrativas en } \\
\text { situación de } \\
\text { deserción escolar }\end{array}$ & historias & \multicolumn{2}{|c|}{ Participantes y Abreviaturas } & \\
\hline $\begin{array}{l}\text { Construcción } \\
\text { narrativa de la } \\
\text { identidad }\end{array}$ & memorias & \multirow[t]{4}{*}{$\begin{array}{l}\quad \text { Madre: Abrev } \\
\text { Hija:( A) } \\
\text { Terapueta(I) }\end{array}$} & a ( M ) & \\
\hline \multirow{3}{*}{$\begin{array}{l}\text { Relación joven, } \\
\text { familia e institución } \\
\text { educativa en torno a } \\
\text { la deserción escolar. }\end{array}$} & relatos & & & \\
\hline & $\begin{array}{l}\text { acontecimi } \\
\text { ento }\end{array}$ & & & \\
\hline & $\begin{array}{c}\text { relatos } \\
\text { emergentes }\end{array}$ & & & \\
\hline Textualidad & $\begin{array}{c}\text { concepto } \\
\text { metodologico }\end{array}$ & $\begin{array}{c}\text { Categorias } \\
\text { Macroproyectos }\end{array}$ & $\begin{array}{l}\text { Heterroreferenci } \\
\text { ales }\end{array}$ & $\begin{array}{l}\text { Autorreferenci } \\
\text { ales }\end{array}$ \\
\hline $\begin{array}{l}\text { I: El motivo que } \\
\text { nos convoca hoy en } \\
\text { esta reunión es } \\
\text { conversar un poco } \\
\text { acerca de cómo han } \\
\text { vivido ustedes el } \\
\text { proceso de deserción } \\
\text { de su hija de la parte } \\
\text { académica. Entonces } \\
\text { como familia, sobre } \\
\text { todo usted mamita } \\
\text { ¿Cómo entienden el } \\
\text { problema que los trae } \\
\text { aquí?, ¿Cómo es para } \\
\text { ustedes un problema } \\
\text { el hecho de que Laura } \\
\text { este desescolarizada? }\end{array}$ & \begin{tabular}{l}
\multicolumn{1}{c}{ Relación } \\
joven, familia \\
e institución \\
educativa en \\
torno a la \\
deserción \\
escolar.
\end{tabular} & Historias & & \begin{tabular}{l}
\multicolumn{1}{c}{ La } \\
investigadora \\
presenta los \\
primeros \\
objetivos de la \\
intervención e \\
inicia con la \\
búsqueda de las \\
comprensiones \\
de problema que \\
existen en el \\
sistema.
\end{tabular} \\
\hline \begin{tabular}{l}
\multicolumn{1}{c}{ M: Pues pues es } \\
un problema \\
grandísimo, es un \\
problema que no \\
solamente del \\
momento, sino uno lo \\
piensa (la mamá tose) \\
a futuro, sobre todo \\
pues el futuro de ella.
\end{tabular} & \begin{tabular}{l}
\multicolumn{1}{c}{ Relación } \\
joven, familia \\
e institución \\
educativa en \\
torno a la \\
deserción \\
escolar.
\end{tabular} & Historias & \begin{tabular}{l}
\multicolumn{1}{c}{ El problema } \\
percibido por la \\
madre, representa \\
una construcción \\
narrativa saturada, \\
relacionándola \\
dentro de los \\
diferentes contextos \\
que se configuran a \\
través del futuro y \\
las preocupaciones \\
que se manifiestan.
\end{tabular} & \\
\hline
\end{tabular}




\section{LA DESERCIÓN ESCOLAR COMO PRETEXTO PARA CONVERSAR SOBRE IDENTIDAD, FAMILIA Y ESCUELA

I: El futuro de ella es lo que no.... (La mamá tose)¿Hace cuánto tiempo que están viviendo esta situación? ¿Cuánto hace que Laura dejo el colegio?
Relación

joven, familia

e institución

educativa en

torno a la

deserción

escolar.
Historias

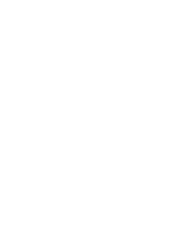

La

investigadora retoma su intervención, y busca retomar con preguntas las perspectivas y las circunstancias percibidas por la madre, dentro de la configuración del problema

\begin{tabular}{|c|c|c|c|}
\hline $\begin{array}{l}\text { M: Ehhh desde } \\
\text { que dejó el colegio } \\
\text { tres años }\end{array}$ & $\begin{array}{l}\quad \text { Relación } \\
\text { joven, familia } \\
\text { e institución } \\
\text { educativa en } \\
\text { torno a la } \\
\text { deserción } \\
\text { escolar. }\end{array}$ & Memorias & $\begin{array}{l}\quad \text { El recuerdo que } \\
\text { se genera, solo } \\
\text { presenta } \\
\text { información básica, } \\
\text { y puede llegar a } \\
\text { recordar la } \\
\text { dificultad percibida. }\end{array}$ \\
\hline
\end{tabular}

I: ¿Y en esos tres
años qué ha pasado
C2, qué ha pasado
contigo?(la mamá
tose)

Memorias
ón narrativa de la identidad La investigadora busca ingresar a la consultante buscando que enfrente los detalles del problema percibido, apelando a las memorias de lo que pudo haber ocurrido, y cual es la percepción actual de esos hechos.

$\quad$ A: (Dura un
tiempo en silencio,
alrededor de 7
segundos) Pues no se
(exhala algo de aire
en una especie de
sonrisa)

\begin{tabular}{|c|c|c|}
\hline $\begin{array}{l}\text { Construcci } \\
\text { ón narrativa de } \\
\text { la identidad }\end{array}$ & Experiencia & $\begin{array}{l}\quad \text { La consultante } \\
\text { mantiene una } \\
\text { distancia prudente } \\
\text { frente a la propia } \\
\text { comprensión de su } \\
\text { problema, y aun no } \\
\text { puede enfrentar } \\
\text { estas } \\
\text { comprensiones. }\end{array}$ \\
\hline
\end{tabular}




\section{LA DESERCIÓN ESCOLAR COMO PRETEXTO PARA CONVERSAR SOBRE IDENTIDAD, FAMILIA Y ESCUELA

\begin{abstract}
I: Ósea ¿Es lo mismo estar asistiendo al colegio en una jornada como la que tu tenías en este colegio? Ó ¿Es diferente estar en la casa? ¿Cómo has vivido ese proceso? ¿Qué sientes cuando vez que tus compañeros o los niños de tu edad salen para el colegio y tú te quedas en casa?
\end{abstract}

$$
\text { A: (Dura un }
$$
tiempo en silencio, alrededor de 6 segundos) $\mathrm{mmm}$ (dura un tiempo en silencio, alrededor de 5 segundos) Como aburrida

\author{
Relación \\ joven, familia \\ e institución \\ educativa en \\ torno a la \\ deserción \\ escolar. \\ Memorias
}

$\mathrm{La}$ investigadora busca enfrentar a la consultante con los detalles de su experiencia, para permitir relacionar sus realidades actuales con sus narrativas del problema.

\begin{tabular}{lll}
\multicolumn{1}{c}{ Relación } & Memorias & \multicolumn{1}{c}{ La consultante } \\
joven, familia & & continua \\
e institución & manteniendo sus \\
educativa en & narrativas al \\
torno a la & mínimo, evitando \\
deserción & explorar sus propias \\
escolar. & & experiencias en \\
& & torno a un tema que \\
& puede resultar \\
& difícil.
\end{tabular}

\begin{tabular}{lll}
\multicolumn{1}{c}{ I: Como aburrida, } & \multicolumn{1}{c}{ Construcci } & Historias \\
¿Por qué? haber & ón narrativa de & \\
cuéntanos un poco & la identidad &
\end{tabular}

más

\begin{tabular}{ll}
\multicolumn{1}{c}{ A: ummm (dura } & \multicolumn{1}{c}{ Construcci } \\
un tiempo en silencio, & ón narrativa de \\
alrededor de 3 & la identidad \\
segundos) &
\end{tabular}

Historias

El silencio, muestra que aun no hay una confianza a si mismo para explorar y hacer evidente las percepciones vividas dentro de su pasado.
La
interventora, busca que se explore de una manera mas profunda la percepción actual de la situación, retomando el tema anterior. 


\section{LA DESERCIÓN ESCOLAR COMO PRETEXTO PARA CONVERSAR SOBRE IDENTIDAD, FAMILIA Y ESCUELA

\author{
I: Mira no te \\ preocupes esto es \\ solo una \\ conversación, saca lo \\ que tú tienes allá \\ adentro, porque eso \\ forma parte de lo que \\ posiblemente vamos \\ a llegar a trabajar \\ contigo en la parte \\ clínica. \\ nes narrativas \\ en situaciones \\ de deserción \\ escolar
}

Historias

\begin{tabular}{|c|c|c|}
\hline $\begin{array}{l}\text { A: (Dura un } \\
\text { tiempo en silencio, } \\
\text { alrededor de } 5 \\
\text { segundos) ummm } \\
\text { (dura un tiempo en } \\
\text { silencio, alrededor de } \\
4 \text { segundos) pues que } \\
\text { ehh, pues aburrida } \\
\text { por la parte que (dura } \\
\text { un tiempo en silencio, } \\
\text { alrededor de } 3 \\
\text { segundos) ehhh se } \\
\text { siente muy (dura un } \\
\text { tiempo en silencio, } \\
\text { alrededor de } 5 \\
\text { segundos) }\end{array}$ & $\begin{array}{l}\text { Construcci } \\
\text { ón narrativa de } \\
\text { la identidad }\end{array}$ & Relatos \\
\hline $\begin{array}{l}\text { I: No te preocupes } \\
\text { mi amor (la niña } \\
\text { empieza a respirar un } \\
\text { poco más rápido y } \\
\text { fuerte) }\end{array}$ & $\begin{array}{l}\quad \text { Intervencio } \\
\text { nes narrativas } \\
\text { en situaciones } \\
\text { de deserción } \\
\text { escolar }\end{array}$ & Historia \\
\hline $\begin{array}{l}\quad \text { A: (dura un } \\
\text { tiempo en silencio, } \\
\text { alrededor de } 8 \\
\text { segundos)(hay } \\
\text { algunos sollozos y } \\
\text { lágrimas) }\end{array}$ & $\begin{array}{l}\text { Construcci } \\
\text { ón narrativa de } \\
\text { la identidad }\end{array}$ & Relatos \\
\hline
\end{tabular}

Dentro del contexto terapéutico era importante mostrar plataformas de confianza y buena fe, para poder abrir las narrativas dentro de todos los participantes.

\author{
Aun no hay una \\ comprensión del \\ problema, pero \\ empiezan a emerger \\ los verdaderos \\ sentimientos de la \\ paciente, \\ encuadrando el \\ contacto en trono a \\ esto.
}

\author{
De nuevo, se \\ busca intervenir \\ para mostrar que \\ hay un lugar \\ seguro en el cual \\ se puede \\ contextualizar y \\ emerger todos los \\ problemas \\ relacionados.
}




\section{LA DESERCIÓN ESCOLAR COMO PRETEXTO PARA CONVERSAR SOBRE IDENTIDAD, FAMILIA Y ESCUELA

I: Cuéntanos

preciosa, ¿Te gustaría volver al colegio?
Relación

joven, familia

e institución

educativa en

torno a la

deserción

escolar.
Historias

Relación joven, familia

e institución

educativa en

torno a la

deserción

escolar.

es que (dura un

tiempo en silencio,

alrededor de 5

segundos, tiene

lágrimas en sus ojos y

su voz algo gruesa

evitando llorar) era

más que todo por el

colegio, porque en el

que estábamos (las

últimas dos silabas

las pronuncia con voz

más baja, dura un

tiempo en silencio,

alrededor de 3

segundos, intenta

toser) no me gustaba

y mm (dura un

tiempo en silencio,

alrededor de 15

segundos, a los 8

segundos de este

tiempo sube la

cremallera de su

chaqueta, llora un

poco)

I: En el colegio en el que estabas no te gustaba, pero ahora ¿Si te gustaría volver al colegio?

\section{Relación} joven, familia e institución

educativa en

torno a la

deserción

escolar.
Se empieza a

encuadrar la intervención en torno a la relación entre el contexto escolar, y el personal.

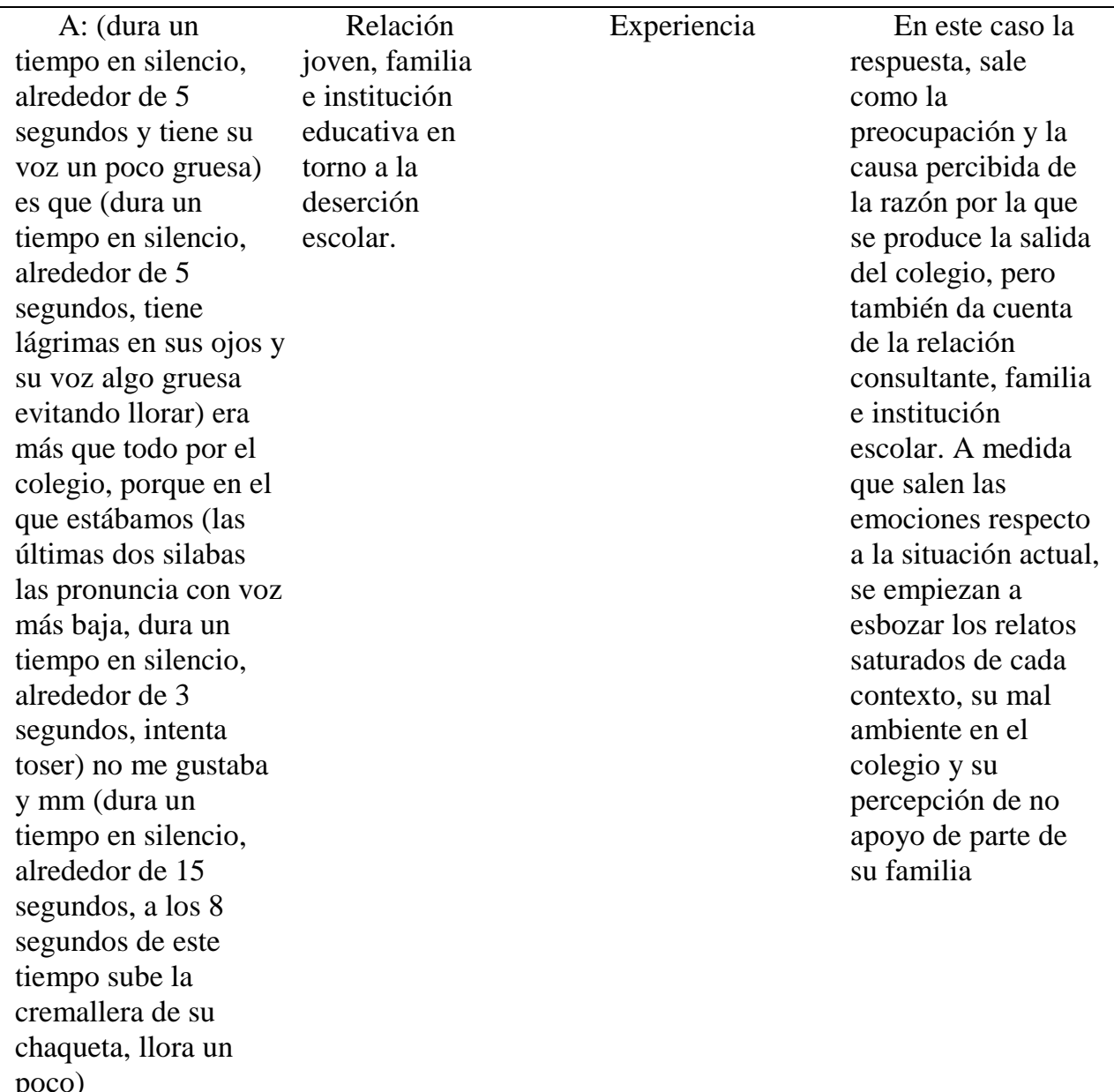




\section{LA DESERCIÓN ESCOLAR COMO PRETEXTO PARA CONVERSAR SOBRE IDENTIDAD, FAMILIA Y ESCUELA

\begin{tabular}{|c|c|c|}
\hline $\begin{array}{l}\text { A: (Esforzando la } \\
\text { voz, para evitar } \\
\text { llorar) si pero a otro } \\
\text { (dura un tiempo en } \\
\text { silencio, alrededor de } \\
4 \text { segundos) no se me } \\
\text { sentía sola (al } \\
\text { pronunciar la palabra } \\
\text { sola lo hace elevando } \\
\text { el tono de su voz) y } \\
\text { todo el mundo me } \\
\text { molestaba y me ponía } \\
\text { apodos y eso y (con } \\
\text { algo de llanto) pero } \\
\text { tenía miedo de } \\
\text { decirlo }\end{array}$ & $\begin{array}{l}\quad \text { Relación } \\
\text { joven, familia } \\
\text { e institución } \\
\text { educativa en } \\
\text { torno a la } \\
\text { deserción } \\
\text { escolar. }\end{array}$ & Memorias \\
\hline $\begin{array}{l}\text { I: ¿A quién, a tu } \\
\text { mami? }\end{array}$ & $\begin{array}{l}\quad \text { Relación } \\
\text { joven, familia } \\
\text { e institución } \\
\text { educativa en } \\
\text { torno a la } \\
\text { deserción } \\
\text { escolar. }\end{array}$ & Historias \\
\hline $\begin{array}{l}\text { A: (Afirma con su } \\
\text { cabeza) }\end{array}$ & \begin{tabular}{l}
\multicolumn{1}{c}{ Relación } \\
joven, familia \\
e institución \\
educativa en \\
torno a la \\
deserción \\
escolar.
\end{tabular} & Historias \\
\hline
\end{tabular}

joven, familia

e institución

sentía sola (a

todo el mundo me

molestaba y me ponía

decirlo pronunciar la palabra
La consultante, expresa su miedo y su percepción de soledad frente a un problema, en el que no percibe una red de apoyo y siente imposible enfrentarlo por si misma.

\begin{tabular}{|c|c|c|}
\hline $\begin{array}{c}\text { I: Y ¿Por qué } \\
\text { sentías ese miedo, } \\
\text { cómo es la relación } \\
\text { hay con la mamita? }\end{array}$ & $\begin{array}{l}\quad \text { Relación } \\
\text { joven, familia } \\
\text { e institución } \\
\text { educativa en } \\
\text { torno a la } \\
\text { deserción } \\
\text { escolar. }\end{array}$ & Historias \\
\hline
\end{tabular}
La consultante
de nuevo responde
lo mínimo, y
muestra la
importancia de su
relación con su
madre, dado que
evita explorarla.

La
interventora
reconoce en la
madre la figura
mas importante
para enfrentar
estas situaciones y
busca ahondar en
esa relación.

\begin{tabular}{l}
\multicolumn{1}{c}{ La } \\
interventora, \\
busca explorar esa \\
relación madre e \\
hija que se \\
configura como \\
una comprensión \\
poderosa para \\
dilucidar el \\
sistema.
\end{tabular}

\begin{tabular}{|c|c|c|c|}
\hline $\begin{array}{l}\quad \text { A: Pues (dura un } \\
\text { tiempo en silencio, } \\
\text { alrededor de } 3 \\
\text { segundos) es que no } \\
\text { sé, no sentía la } \\
\text { confianza para } \\
\text { decírselo, y no creí }\end{array}$ & $\begin{array}{l}\quad \text { Relación } \\
\text { joven, familia } \\
\text { e institución } \\
\text { educativa en } \\
\text { torno a la } \\
\text { deserción } \\
\text { escolar. }\end{array}$ & Historias & $\begin{array}{l}\quad \text { La consultante } \\
\text { evita la pregunta, } \\
\text { detallando } \\
\text { solamente la } \\
\text { situación de su } \\
\text { salida del colegio, y } \\
\text { su percepción. }\end{array}$ \\
\hline
\end{tabular}

que me fuera a

ayudar 


\section{LA DESERCIÓN ESCOLAR COMO PRETEXTO PARA CONVERSAR SOBRE IDENTIDAD, FAMILIA Y ESCUELA

I: ¿Sumercé que piensa? (la niña está llorando)
Relación

joven, familia

e institución

educativa en

torno a la

deserción

escolar.
Historias

$\mathrm{La}$

interventora

involucra a la

madre en la percepción de la hija para que pueda comprender como la ve y la construye dentro de sus narrativas.

\begin{tabular}{|c|c|c|c|c|}
\hline \begin{tabular}{l}
\multicolumn{1}{c}{ M: Ejje, pues me } \\
sorprende, me \\
sorprende porqué \\
ósea hay cosas en las \\
que uno dice, ósea \\
digamos cosas como \\
mami perdí una \\
evaluación, o mami \\
sii, me regañaron en \\
el colegio, hice una \\
falta, son cosas que a \\
uno como estudiante \\
lo atemorizan, pero \\
pero por lo contrario, \\
mira que yo se lo he \\
demostrado muchas \\
veces, como la he \\
defendido, la he \\
defendido, entonces \\
eso sí me parece que \\
no...
\end{tabular} & $\begin{array}{l}\quad \text { Relación } \\
\text { joven, familia } \\
\text { e institución } \\
\text { educativa en } \\
\text { torno a la } \\
\text { deserción } \\
\text { escolar. }\end{array}$ & Historias & $\begin{array}{l}\quad \text { La madre, } \\
\text { mantiene una } \\
\text { postura defensiva } \\
\text { frente a la situación, } \\
\text { y a pesar de que la } \\
\text { sorprende la } \\
\text { percepción de la } \\
\text { hija, aun no } \\
\text { legitima sus } \\
\text { sentimientos, y } \\
\text { mantiene su } \\
\text { postura de que ella } \\
\text { si la ha defendido. }\end{array}$ & \\
\hline $\begin{array}{l}\text { I: ¿Tú siempre le } \\
\text { has dado esa } \\
\text { confianza? }\end{array}$ & $\begin{array}{l}\quad \text { Intervencio } \\
\text { nes narrativas } \\
\text { en situaciones } \\
\text { de deserción } \\
\text { escolar }\end{array}$ & Historias & & $\begin{array}{l}\quad \text { Se empieza a } \\
\text { confrontar el } \\
\text { estado del } \\
\text { contexto familiar } \\
\text { frente a la } \\
\text { problemática } \\
\text { percibida }\end{array}$ \\
\hline \begin{tabular}{l}
\multicolumn{1}{c}{ M: Pues como } \\
para ese tipo de \\
cosas, que alguien le \\
haga algo, pues si, \\
haya mismo en el \\
negocio, que uno \\
supuestamente le dice \\
a los clientes, uno \\
tiene que, alguien \\
que de pronto me le \\
levante la voz o me le \\
diga algo, yo \\
inmediatamente \\
brinco como dicen. \\
(Existe un pequeño \\
silencio) Y varias \\
veces en el colegio se
\end{tabular} & $\begin{array}{l}\quad \text { Intervencio } \\
\text { nes narrativas } \\
\text { en situaciones } \\
\text { de deserción } \\
\text { escolar }\end{array}$ & $\begin{array}{l}\text { Acontecimie } \\
\text { ntos }\end{array}$ & $\begin{array}{l}\text { La madre, busca } \\
\text { defender su postura, } \\
\text { y comprender la } \\
\text { situación casi } \\
\text { exclusivamente al } \\
\text { ambiente del } \\
\text { colegio y sus } \\
\text { respuestas } \\
\text { insatisfactorias, } \\
\text { buscando desviar la } \\
\text { responsabilidad } \\
\text { hacia otras fuentes. }\end{array}$ & \\
\hline
\end{tabular}




\section{LA DESERCIÓN ESCOLAR COMO PRETEXTO PARA CONVERSAR SOBRE IDENTIDAD, FAMILIA Y ESCUELA

tocó ese tema de con

los profesores,

porque los niños,

pero entonces las

quejar eran que "ella

era la que les pegaba, que los molestaba,

que no ¡sí!”, entonces

ella empezaron a

tratarla como un niño,

hasta una profesora

misma dijo, dijo

"Laura es un niño

más en el salón”

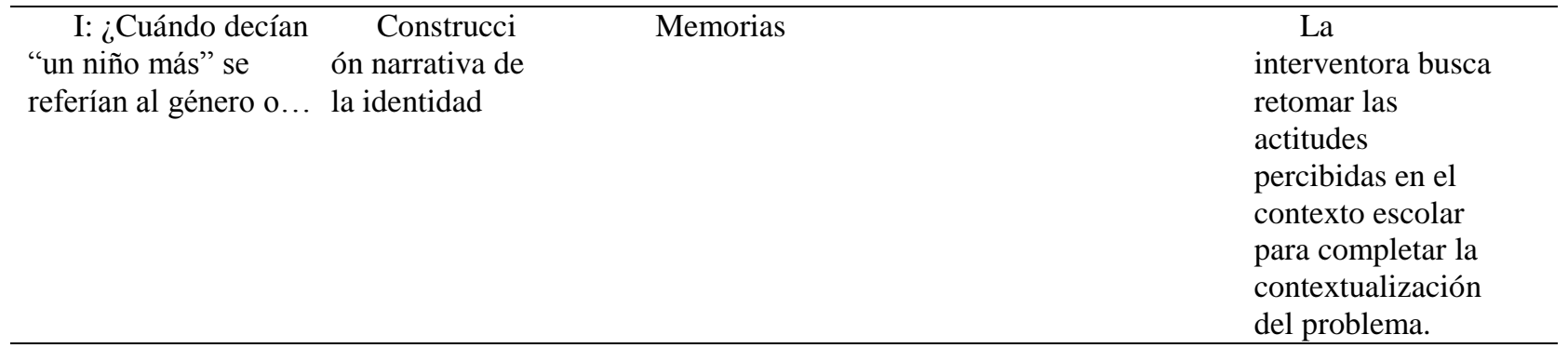

\begin{tabular}{|c|c|c|c|}
\hline $\begin{array}{l}\text { M: Al por el } \\
\text { modo de ser de ella, } \\
\text { de ser brusca, y ella } \\
\text { desde chiquita } \\
\text { siempre le ha } \\
\text { gustado, pues } \\
\text { siempre le ha gustado } \\
\text { el fútbol y amm parte } \\
\text { del rechazo de las } \\
\text { niñas con ella fue } \\
\text { eso, como a ella le } \\
\text { gustaba jugar fútbol } \\
\text { en el barrio y le } \\
\text { gustaba jugar con los } \\
\text { niños, las niñas la } \\
\text { rechazaban por eso, } \\
\text { más que todo las } \\
\text { niñas la rechazaban } \\
\text { por eso, porque ella }\end{array}$ & $\begin{array}{l}\text { Construcci } \\
\text { ón narrativa de } \\
\text { la identidad }\end{array}$ & Experiencia & $\begin{array}{l}\quad \text { En principio la } \\
\text { narrativa que genera } \\
\text { la madre, produce } \\
\text { una } \\
\text { retroalimentación } \\
\text { de esta narrativa, } \\
\text { que la llevo a el } \\
\text { futbol como escape, } \\
\text { y luego a la } \\
\text { agresividad como } \\
\text { una característica } \\
\text { definitoria. }\end{array}$ \\
\hline
\end{tabular}

era muy brusca

\begin{tabular}{|c|c|c|c|}
\hline $\begin{array}{l}\text { I: Pero también es } \\
\text { algo cruel ¡no!, } \\
\text { porqué pues miremos } \\
\text { hoy las niñas por } \\
\text { ejemplo están } \\
\text { representando a } \\
\text { nuestro país, y que } \\
\text { han salido han } \\
\text { representarnos en }\end{array}$ & $\begin{array}{l}\quad \text { Intervencio } \\
\text { nes narrativas } \\
\text { en situaciones } \\
\text { de deserción } \\
\text { escolar }\end{array}$ & $\begin{array}{l}\text { Acontecimie } \\
\text { ntos }\end{array}$ & $\begin{array}{l}\text { A través de las } \\
\text { narrativas } \\
\text { relacionadas con } \\
\text { la selección } \\
\text { femenina de } \\
\text { futbol, busca } \\
\text { borrar la } \\
\text { percepción } \\
\text { negativa. }\end{array}$ \\
\hline
\end{tabular}

entarnos en

Canadá y todo, pues

son niñas que les va 


\section{LA DESERCIÓN ESCOLAR COMO PRETEXTO PARA CONVERSAR SOBRE IDENTIDAD, FAMILIA Y ESCUELA

muy bien en el fútbol

\begin{tabular}{llll}
\multicolumn{1}{c}{ Mamá: Si pero a } & \multicolumn{1}{c}{ Intervencio } & Experiencia & $\begin{array}{l}\text { La madre } \\
\text { esas edad los niños }\end{array}$ \\
nes narrativas & & relaciona el \\
son entre comillas & en situaciones & comportamiento \\
muy crueles y ellos & de deserción & & general con una \\
no dimensionan el & escolar & justificación de los \\
daño que pueden & & & comportamientos y \\
causar & & & situaciones vividas.
\end{tabular}

\begin{tabular}{ll}
\hline \multicolumn{1}{c}{ I: Sí, caramba. } & \multicolumn{1}{c}{ Relación } \\
Bueno y como & joven, familia \\
familia como ¿Cómo & e institución \\
han hecho para & educativa en \\
manejar esta & torno a la \\
situación? la & deserción \\
desescolarización de & escolar. \\
Laura, ¿Qué papel & \\
juega el colegio? &
\end{tabular}

\begin{tabular}{|c|c|c|c|}
\hline $\begin{array}{l}\text { M: Pues en un } \\
\text { principio porque ella } \\
\text { perdió dos sextos, en } \\
\text { este momento ella } \\
\text { con catorce años, casi } \\
\text { quince, esta con } \\
\text { quinto de primaria } \\
\text { aprobado y perdió el } \\
\text { primer sexto y listo, } \\
\text { le dieron el cupo, } \\
\text { volvió a entrar allá al } \\
\text { mismo colegio, el } \\
\text { segundo sexto fue } \\
\text { peor, el primer sexto } \\
\text { lo perdió por dos } \\
\text { materias, el segundo } \\
\text { lo perdió por todas, } \\
\text { después de ahí pues } \\
\text { ya perdió el cupo. La } \\
\text { pase a otro colegio } \\
\text { entonces pues lo que } \\
\text { ella dice, que ese } \\
\text { colegio no le gustaba } \\
\text { que quería otro, se } \\
\text { pasó a otro y fue } \\
\text { peor, así que nada. }\end{array}$ & $\begin{array}{l}\quad \text { Relación } \\
\text { joven, familia } \\
\text { e institución } \\
\text { educativa en } \\
\text { torno a la } \\
\text { deserción } \\
\text { escolar. }\end{array}$ & $\begin{array}{l}\text { Acontecimie } \\
\text { ntos }\end{array}$ & $\begin{array}{l}\quad \text { La madre ve en } \\
\text { su éxito en el } \\
\text { colegio como de } \\
\text { una gran } \\
\text { importancia para la } \\
\text { construcción } \\
\text { identitaria de la } \\
\text { consultante de los } \\
\text { problemas que } \\
\text { ocurrieron con la } \\
\text { consultante, donde } \\
\text { al parecer la } \\
\text { percepción es que la } \\
\text { culpa gravita hacia } \\
\text { ella. }\end{array}$ \\
\hline
\end{tabular}




\section{LA DESERCIÓN ESCOLAR COMO PRETEXTO PARA CONVERSAR SOBRE IDENTIDAD, FAMILIA Y ESCUELA

\begin{tabular}{|c|c|c|c|c|}
\hline $\begin{array}{l}\text { I: Ósea ¿el } \\
\text { problema ha sido } \\
\text { como la adaptación } \\
\text { de ella? }\end{array}$ & $\begin{array}{l}\quad \text { Relación } \\
\text { joven, familia } \\
\text { e institución } \\
\text { educativa en } \\
\text { torno a la } \\
\text { deserción } \\
\text { escolar. }\end{array}$ & Memorias & & $\begin{array}{l}\quad \text { La } \\
\text { interventora } \\
\text { coconstruye el } \\
\text { problema a través } \\
\text { de la s } \\
\text { narraciones. }\end{array}$ \\
\hline $\begin{array}{l}\quad \text { M: Mjum, no en } \\
\text { el otro colegio duro, } \\
\text { creo q no alcanzó a } \\
\text { durar un mes, y en un } \\
\text { mes que estuvo allá } \\
\text { las quejas fueron las } \\
\text { mismas (al } \\
\text { pronuncias la palabra } \\
\text { mismas, eleva un } \\
\text { poco el tono de su } \\
\text { voz) que me daban en } \\
\text { el Boyacá, que era } \\
\text { brusca, que era } \\
\text { grosera, que era } \\
\text { irrespetuosa (dura un } \\
\text { tiempo en silencio, } \\
\text { alrededor de } 3 \\
\text { segundos) }\end{array}$ & $\begin{array}{l}\quad \text { Construcci } \\
\text { ón narrativa de } \\
\text { la identidad }\end{array}$ & $\begin{array}{l}\text { Acontecimie } \\
\text { ntos }\end{array}$ & $\begin{array}{l}\quad \text { La construcción } \\
\text { del contexto de la } \\
\text { consultante, resalta } \\
\text { en narrativas } \\
\text { negativas frente a } \\
\text { su agresividad }\end{array}$ & \\
\hline I: Sii & $\begin{array}{l}\quad \text { Construcci } \\
\text { ón narrativa de } \\
\text { la identidad }\end{array}$ & Memorias & & \\
\hline $\begin{array}{l}\quad \text { M: Entonces dije } \\
\text { fue peor, porque } \\
\text { empezó a no entrar a } \\
\text { clase y esas cosas, } \\
\text { entonces ahí fue } \\
\text { cuando yo tome la } \\
\text { decisión de sacarla, } \\
\text { porque dije si ella no } \\
\text { quiere estudiar, para } \\
\text { que la dejo aquí a que } \\
\text { se dañe, porque eso } \\
\text { era lo que estaba } \\
\text { pasando, en meno } \\
\text { que duro hay en ese } \\
\text { colegio }\end{array}$ & $\begin{array}{l}\quad \text { Relación } \\
\text { joven, familia } \\
\text { e institución } \\
\text { educativa en } \\
\text { torno a la } \\
\text { deserción } \\
\text { escolar. }\end{array}$ & Experiencia & $\begin{array}{l}\quad \text { La percepción } \\
\text { de un mal ambiente } \\
\text { y de una falta de } \\
\text { adaptación de la } \\
\text { consultante a el, } \\
\text { termino siendo un } \\
\text { catalizador grande } \\
\text { para la decision, } \\
\text { aparentemente } \\
\text { conjunta de sacar a } \\
\text { la consultante de los } \\
\text { estudios, esta } \\
\text { decisión. }\end{array}$ & \\
\hline $\begin{array}{l}\text { I: ¿El ambiente } \\
\text { muy pesado? }\end{array}$ & $\begin{array}{l}\quad \text { Relación } \\
\text { joven, familia } \\
\text { e institución } \\
\text { educativa en } \\
\text { torno a la } \\
\text { deserción } \\
\text { escolar. }\end{array}$ & Experiencia & & \\
\hline
\end{tabular}




\title{
LA DESERCIÓN ESCOLAR COMO PRETEXTO PARA CONVERSAR SOBRE IDENTIDAD, FAMILIA Y ESCUELA

\author{
M: Sii, eso sí, \\ Relación \\ pesado el ambiente si joven, familia \\ porque le toco en un e institución \\ colegio donde llega educativa en \\ de todo, entonces uyy torno a la \\ no, se llega a \\ deserción \\ encontrar con niños escolar. \\ con mañas terribles, \\ de droga, de ehh \\ bueno, de muchas \\ cosas entonces no, \\ preferí sacarla y pues \\ no, ya ya ella \\ manifestó que no \\ quería estudiar \\ I: Bueno, y fuera \\ de todo lo que ha \\ Relación \\ Experiencia \\ pasado en la parte \\ joven, familia \\ e institución \\ académica de Laura, educativa en \\ ¿en algún momento torno a la \\ tuvieron la \\ deserción \\ orientación \\ escolar. \\ psicológica de \\ alguien?, ¿pensaste \\ en que ella asistiera a \\ algunas consultas \\ algunas terapias?, \\ ehhh ¿cómo comentar \\ esta situación fuera \\ de todo el contexto \\ que se había \\ generado a nivel \\ académico?, ¿cómo \\ buscar una \\ alternativa?, una \\ ayuda alterna \\ digamos para \\ solucionar el \\ problema de Laura. \\ Lo hicieron como \\ familia.
}

Se generan en la

narrativas diversos

discursos

justificatorios de la

madre para permitir

que su hija saliera

del colegio, y que la

situación se

configurara fuera de

las intenciones de

ella o de su

responsabilidad. 


\section{LA DESERCIÓN ESCOLAR COMO PRETEXTO PARA CONVERSAR SOBRE IDENTIDAD, FAMILIA Y ESCUELA

M: Ella tuvo

prácticamente desde

Kínder la he llevado

al psicólogo, ha

estado, le han hecho

terapias de unas de

otras, terapia

ocupacional, terapia

del lenguaje, de

psicología, ha estado

en neurología,

neurología infantil,

en psiquiatría infantil,

ehhh jummm,

exámenes físicos le

hicieron, ehhh estuvo

en el neurofisiatra

$\quad$ I: Y finalmente
cual ha sido el
diagnóstico de todos
esos profesionales

Relación

joven, familia

e institución

educativa en

torno a la

deserción

escolar.
Acontecimie

ntos

$\quad$ Relación
joven, familia
e institución
educativa en
torno a la
deserción
escolar.

Acontecimie

ntos

dicho que

hiperactividad y

atención dispersa, a

ella inclusive la

medicaron, pero pues

el medicamento no se

Relación

joven, familia

e institución

educativa en

torno a la

deserción

escolar.

lo quise dar, le dieron

ritalin pero no se lo

quise dar

\begin{tabular}{lll}
\hline \multicolumn{1}{c}{ I: Y el psiquiatra } & \multicolumn{1}{c}{ Relación } & \multicolumn{1}{c}{ Acontecimie } \\
le dio el psiquiatra & joven, familia & ntos \\
infantil le formulo el & e institución & \\
ritalin, y ¿Cómo & educativa en & \\
sugirió él, qué & torno a la & \\
esperaba el que & deserción & \\
sucediera, o qué les & escolar. & \\
explicó él a ustedes & & \\
que iba a suceder con & & \\
ese medicamento & \\
donde ella & \\
consumiera el & \\
medicamento? & &
\end{tabular}

\author{
Se alimento \\ además, estas \\ narrativas, debido a \\ la inhabilidad de los \\ profesionales que \\ atendieron a la \\ consultante \\ anteriormente, $\mathrm{y}$ \\ que intentaron a \\ través de terapia y \\ medicamentos, \\ atacar los síntomas \\ de la problemática
}




\section{LA DESERCIÓN ESCOLAR COMO PRETEXTO PARA CONVERSAR SOBRE IDENTIDAD, FAMILIA Y ESCUELA

\begin{tabular}{|c|c|c|}
\hline $\begin{array}{l}\quad \text { M: Que la, pues } \\
\text { que era algo como } \\
\text { allá, pues me explico } \\
\text { así como para que } \\
\text { entendiera, que era } \\
\text { como un corto que } \\
\text { había en el cerebro y } \\
\text { que eso el ritalin lo } \\
\text { que hacía era hacer } \\
\text { que siguiera una línea } \\
\text { recta como que } \\
\text { encaminara y centrara } \\
\text { su su pensamiento }\end{array}$ & $\begin{array}{l}\quad \text { Relación } \\
\text { joven, familia } \\
\text { e institución } \\
\text { educativa en } \\
\text { torno a la } \\
\text { deserción } \\
\text { escolar. }\end{array}$ & $\begin{array}{l}\text { Acontecimie } \\
\text { ntos }\end{array}$ \\
\hline \begin{tabular}{l}
\multicolumn{1}{c}{ I: Ummjum y } \\
¿Por qué tu tomaste \\
la determinación de \\
no darle el \\
medicamento?
\end{tabular} & \begin{tabular}{l}
\multicolumn{1}{c}{ Relación } \\
joven, familia \\
e institución \\
educativa en \\
torno a la \\
deserción \\
escolar
\end{tabular} & $\begin{array}{l}\text { Acontecimie } \\
\text { ntos }\end{array}$ \\
\hline
\end{tabular}

escolar.

\begin{tabular}{|c|c|c|c|}
\hline $\begin{array}{l}\quad \text { M: Pues yo se lo } \\
\text { di como dos semanas, } \\
\text { y pues la verdad lo } \\
\text { único que lo único } \\
\text { que hizo fue causarle } \\
\text { efectos secundarios, } \\
\text { le daba rebote, le } \\
\text { daba dolor de cabeza, } \\
\text { permanecía pálida, de } \\
\text { resto en el colegio } \\
\text { nada, en la parte } \\
\text { académica que se } \\
\text { suponía que era en lo } \\
\text { que iba a mejorar, no } \\
\text { hizo ningún efecto }\end{array}$ & $\begin{array}{l}\quad \text { Relación } \\
\text { joven, familia } \\
\text { e institución } \\
\text { educativa en } \\
\text { torno a la } \\
\text { deserción } \\
\text { escolar. }\end{array}$ & $\begin{array}{l}\text { Acontecimie } \\
\text { ntos }\end{array}$ & $\begin{array}{l}\quad \text { Debido a la falta } \\
\text { de mejora y a un } \\
\text { cambio inexistente, } \\
\text { el sistema mantiene } \\
\text { su dinámica, y el } \\
\text { medicamento } \\
\text { resulta poco eficaz } \\
\text { para evitar el } \\
\text { confrontamiento } \\
\text { con las raíces de las } \\
\text { percepciones }\end{array}$ \\
\hline \begin{tabular}{l}
\multicolumn{1}{c}{ I: Ósea ¿No } \\
mermaba su \\
hiperactividad? ¿No \\
estaba más quieta? \\
¿Continuaba con los \\
mismos patrones?
\end{tabular} & $\begin{array}{l}\quad \text { Relación } \\
\text { joven, familia } \\
\text { e institución } \\
\text { educativa en } \\
\text { torno a la } \\
\text { deserción } \\
\text { escolar. }\end{array}$ & $\begin{array}{l}\text { Acontecimie } \\
\text { ntos }\end{array}$ & \\
\hline M: Igual, si & \begin{tabular}{l}
\multicolumn{1}{c}{ Relación } \\
joven, familia \\
e institución \\
educativa en \\
torno a la \\
deserción \\
escolar.
\end{tabular} & $\begin{array}{l}\text { Acontecimie } \\
\text { ntos }\end{array}$ & \\
\hline $\begin{array}{l}\quad \text { I: Solamente que } \\
\text { con esos efectos } \\
\text { secundarios a nivel } \\
\text { fisiológico }\end{array}$ & $\begin{array}{l}\quad \text { Relación } \\
\text { joven, familia } \\
\text { e institución } \\
\text { educativa en } \\
\text { torno a la } \\
\text { deserción }\end{array}$ & $\begin{array}{l}\text { Acontecimie } \\
\text { ntos }\end{array}$ & \\
\hline
\end{tabular}




\section{LA DESERCIÓN ESCOLAR COMO PRETEXTO PARA CONVERSAR SOBRE IDENTIDAD, FAMILIA Y ESCUELA

escolar.

\begin{tabular}{|c|c|c|c|}
\hline M: Si & $\begin{array}{l}\quad \text { Relación } \\
\text { joven, familia } \\
\text { e institución } \\
\text { educativa en } \\
\text { torno a la } \\
\text { deserción } \\
\text { escolar. }\end{array}$ & Memorias & \\
\hline $\begin{array}{l}\text { I: } i \text { Y la volviste a } \\
\text { llevar? }\end{array}$ & $\begin{array}{l}\quad \text { Relación } \\
\text { joven, familia } \\
\text { e institución } \\
\text { educativa en } \\
\text { torno a la } \\
\text { deserción } \\
\text { escolar. }\end{array}$ & Memorias & \\
\hline $\begin{array}{l}\text { M: Si, la } \\
\text { volvimos a llevar y } \\
\text { después hay le } \\
\text { formularon unas } \\
\text { terapias, pero } \\
\text { entonces en esas } \\
\text { terapias pues nunca } \\
\text { vi que le hicieran, } \\
\text { ósea como, pues uno } \\
\text { espera que se haga un } \\
\text { tratamiento }\end{array}$ & $\begin{array}{l}\quad \text { Relación } \\
\text { joven, familia } \\
\text { e institución } \\
\text { educativa en } \\
\text { torno a la } \\
\text { deserción } \\
\text { escolar. }\end{array}$ & $\begin{array}{l}\text { Acontecimie } \\
\text { ntos }\end{array}$ & \begin{tabular}{l}
\multicolumn{1}{c}{ Se genera una } \\
percepción de \\
imposibilidad en el \\
sistema, donde
\end{tabular} \\
\hline I: umjum & $\begin{array}{l}\quad \text { Relación } \\
\text { joven, familia } \\
\text { e institución } \\
\text { educativa en } \\
\text { torno a la } \\
\text { deserción } \\
\text { escolar. }\end{array}$ & $\begin{array}{l}\text { Acontecimie } \\
\text { ntos }\end{array}$ & \\
\hline
\end{tabular}




\section{LA DESERCIÓN ESCOLAR COMO PRETEXTO PARA CONVERSAR SOBRE IDENTIDAD, FAMILIA Y ESCUELA

M: Que le digan bueno le vamos a aplicar este método, no nunca, ósea las siempre terapias fueron, "y ¿Qué hiciste? y ¿Cómo te sientes? Yyyy $i$ Te comprometes a hacer esto?" y de ahí nunca paso, entonces ya tanto ella como yo nos cansamos, y ya un día ella dijo "ya ya para que más terapias mami, siempre es lo mismo" y pues sí, yo no veía un beneficio, un cambio, un aporte, entonces también me canse de eso, y ya, y pues ya considero que ya, con la edad que tiene hoy ella (la niña está sollozando) ella ya con catorce años, uno a los catorce años ya es consciente de que está bien y que está mal

\section{I: ¿Como mamá} tu como ves a Laura?

¿La consideras madura para la edad que tiene, o su comportamiento es como más infantil? ¿Cómo la vez tú a ella?

\begin{tabular}{|c|c|c|c|}
\hline \begin{tabular}{l}
\multicolumn{1}{c}{ I: ¿Como mamá } \\
tu como ves a Laura? \\
¿La consideras \\
madura para la edad \\
que tiene, o su \\
comportamiento es \\
como más infantil? \\
¿Cómo la vez tú a \\
ella?
\end{tabular} & $\begin{array}{l}\text { Intervencio } \\
\text { nes narrativas } \\
\text { en situaciones } \\
\text { de deserción } \\
\text { escolar }\end{array}$ & Historias & \\
\hline $\begin{array}{l}\quad \text { M: Ehh si a veces } \\
\text { ella tiene } \\
\text { comportamientos y } \\
\text { actuaciones de niña, } \\
\text { como si fuera una } \\
\text { niña de } 1011 \text { años }\end{array}$ & $\begin{array}{l}\quad \text { Intervencio } \\
\text { nes narrativas } \\
\text { en situaciones } \\
\text { de deserción } \\
\text { escolar }\end{array}$ & Historias & \begin{tabular}{l}
\multicolumn{1}{c}{ En el contexto } \\
no solo se identifica \\
la responsabilidad \\
de la edad de la \\
consultante, sin \\
embargo, ocurren \\
paradojas como ver \\
a la consultante de \\
una edad menor.
\end{tabular} \\
\hline
\end{tabular}

\author{
Acontecimie \\ La percepcionde \\ problema de la \\ mama conjuga la \\ imposibilidad de los \\ profesionales en \\ retomar las \\ realidades, y \\ mejorarlas, lo que \\ genera una \\ construcionde los \\ imposible, además \\ de la \\ responsabilidad \\ exclusiva de la hija \\ que ya "sabe que \\ esta bien y que esta \\ mal."
}

\begin{tabular}{cll} 
I: ¿Alguna vez le & \multicolumn{1}{c}{ Relación } & Memorias \\
aplicaron una prueba & joven, familia & \\
de coeficiente & e institución & \\
intelectual para medir & educativa en & \\
su coeficiente? & torno a la &
\end{tabular}




\section{LA DESERCIÓN ESCOLAR COMO PRETEXTO PARA CONVERSAR SOBRE IDENTIDAD, FAMILIA Y ESCUELA \\ deserción \\ escolar.}

\begin{tabular}{|c|c|c|c|}
\hline \begin{tabular}{l}
\multicolumn{1}{c}{ M: Si si, yo le } \\
había traído eso, \\
porque, si ella tiene \\
todo, ella tiene todo \\
el historial clínico \\
donde tiene todo, le \\
hicieron, dos veces le \\
aplicaron pruebas \\
aquí, la mandaron a \\
Bogotá, estuvo en \\
una prueba de \\
coeficiente esa otra \\
que es de coeficiente \\
intelectual, pero le \\
midieron otras otras \\
cosas
\end{tabular} & $\begin{array}{l}\quad \text { Relación } \\
\text { joven, familia } \\
\text { e institución } \\
\text { educativa en } \\
\text { torno a la } \\
\text { deserción } \\
\text { escolar. }\end{array}$ & Memorias & \begin{tabular}{l}
\multicolumn{1}{c}{ De nuevo la } \\
madre, resalta el \\
hecho de que las \\
cosas se hicieron \\
sin resultados, \\
retroalimentando la \\
percepcionde \\
imposibilidad.
\end{tabular} \\
\hline $\begin{array}{l}\mathrm{I}: \text { ¿Y qué salió, } \\
\text { recuerdas? }\end{array}$ & $\begin{array}{l}\quad \text { Relación } \\
\text { joven, familia } \\
\text { e institución } \\
\text { educativa en } \\
\text { torno a la } \\
\text { deserción } \\
\text { escolar. }\end{array}$ & Memorias & \\
\hline $\begin{array}{l}\text { M: (Tose) Pues el } \\
\text { coeficiente sale por } \\
\text { debajo del normal, } \\
\text { pero pues según el } \\
\text { fisiatra está dentro } \\
\text { del rango normal, } \\
\text { ósea }\end{array}$ & $\begin{array}{l}\quad \text { Relación } \\
\text { joven, familia } \\
\text { e institución } \\
\text { educativa en } \\
\text { torno a la } \\
\text { deserción } \\
\text { escolar. }\end{array}$ & Memorias & \\
\hline I: En lo limite & $\begin{array}{l}\quad \text { Relación } \\
\text { joven, familia } \\
\text { e institución } \\
\text { educativa en } \\
\text { torno a la } \\
\text { deserción } \\
\text { escolar. } \\
\end{array}$ & Memorias & \\
\hline $\begin{array}{l}\text { M: Tiene una } \\
\text { dificultad pero lo } \\
\text { puede lograr }\end{array}$ & $\begin{array}{l}\quad \text { Relación } \\
\text { joven, familia } \\
\text { e institución } \\
\text { educativa en } \\
\text { torno a la } \\
\text { deserción } \\
\text { escolar. }\end{array}$ & Memorias & \\
\hline I: Umjum & \begin{tabular}{l}
\multicolumn{1}{c}{ Relación } \\
joven, familia \\
e institución \\
educativa en \\
torno a la \\
deserción
\end{tabular} & Memorias & \\
\hline
\end{tabular}




\section{LA DESERCIÓN ESCOLAR COMO PRETEXTO PARA CONVERSAR SOBRE IDENTIDAD, FAMILIA Y ESCUELA

escolar.

\begin{tabular}{|c|c|c|c|}
\hline $\begin{array}{l}\text { M: Ya es cuestión } \\
\text { de querer }\end{array}$ & $\begin{array}{l}\quad \text { Relación } \\
\text { joven, familia } \\
\text { e institución } \\
\text { educativa en } \\
\text { torno a la } \\
\text { deserción } \\
\text { escolar. }\end{array}$ & Historias & \\
\hline $\begin{array}{l}\quad \text { I: ¿Qué será lo } \\
\text { que hace que el } \\
\text { problema se } \\
\text { mantenga? Están, a } \\
\text { veces, cuando } \\
\text { hablamos o las oigo } \\
\text { así y Laura como tan } \\
\text { callada, como que no, } \\
\text { solo escucha, es } \\
\text { como si alguien, ósea } \\
\text { ella siempre estuviera } \\
\text { como dispuesta a a } \\
\text { obedecer y a no } \\
\text { opinar, ¿Tú que } \\
\text { piensas Diana, como } \\
\text { mama de Laura? Tú } \\
\text { que la conoces más }\end{array}$ & $\begin{array}{l}\quad \text { Intervencio } \\
\text { nes narrativas } \\
\text { en situaciones } \\
\text { de deserción } \\
\text { escolar }\end{array}$ & Historias & \\
\hline $\begin{array}{l}\text { M: No eso si, } \\
\text { mejor dicho para } \\
\text { sacarle una palabra, } \\
\text { muchas veces me } \\
\text { toca amenazarla para } \\
\text { que me responda algo }\end{array}$ & $\begin{array}{l}\text { Intervencio } \\
\text { nes narrativas } \\
\text { en situaciones } \\
\text { de deserción } \\
\text { escolar }\end{array}$ & Historias & \begin{tabular}{l}
\multicolumn{1}{c}{ La } \\
comunicación \\
dentro de la familia \\
se afirma a través \\
de la violencia y la \\
relación de poder, \\
para obtener lo que \\
se quiere, no con la \\
confianza ni con al \\
intencionalidad de \\
construirla.
\end{tabular} \\
\hline
\end{tabular}

\section{I: Ósea es muy} introvertida, poco expresiva

\section{Construcci} ón narrativa de la identidad

\section{Historias}




\section{LA DESERCIÓN ESCOLAR COMO PRETEXTO PARA CONVERSAR SOBRE IDENTIDAD, FAMILIA Y ESCUELA

\begin{abstract}
M: Aquí, porque ósea yo no sé si saca su agresividad y tiene problemas en otros lado y es por eso, porque en otros lados tiende a ser brusca, porque en la casa pues obviamente yo no se lo permito, yo le tengo reglas, le tengo parámetros, le tengo límites ;si!
\end{abstract}

\section{Construcci \\ Experiencia} ón narrativa de

la identidad I: Y desde que tú tienes uso de razón Laura ha sido así, callada, introvertida, o en qué etapa

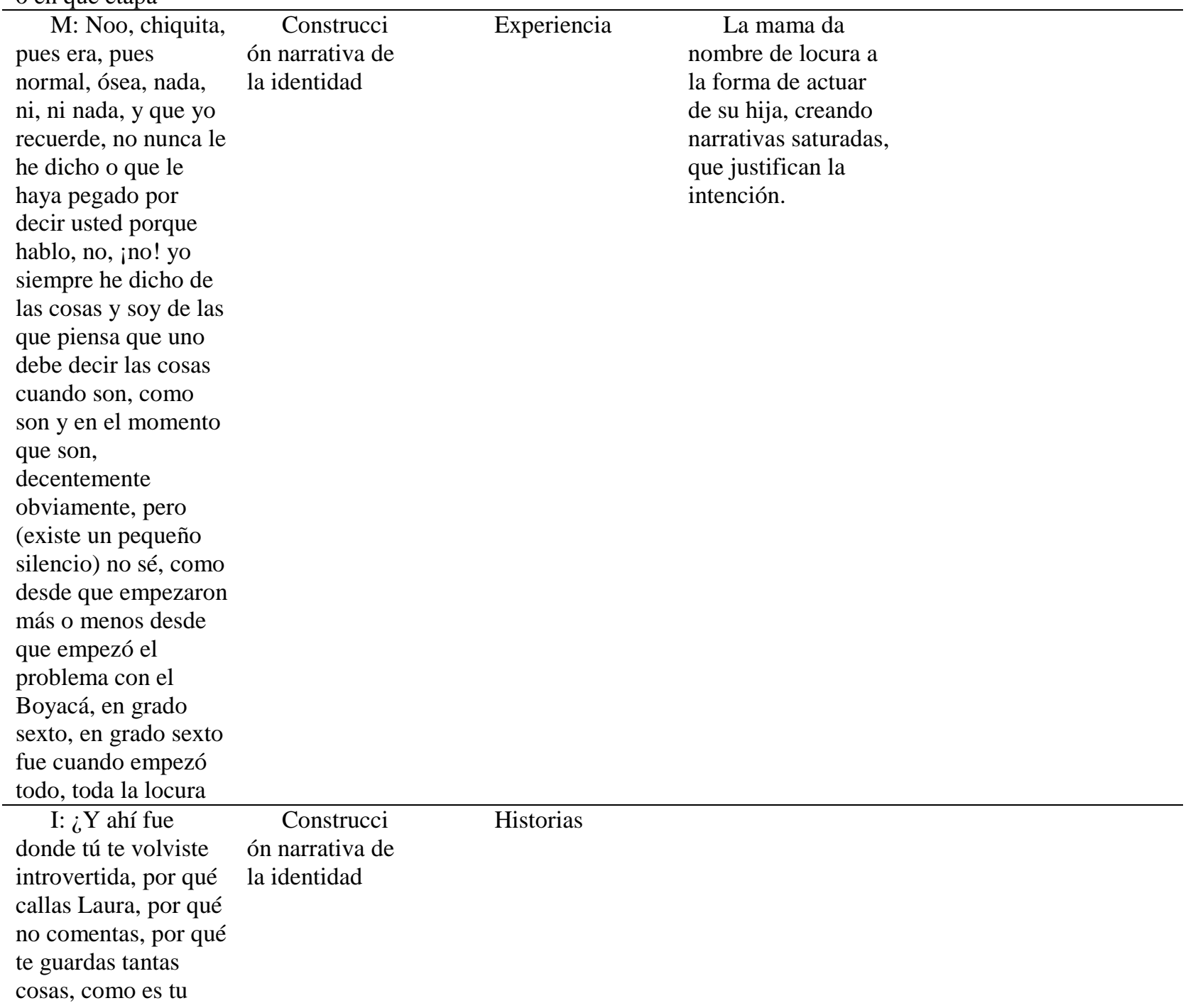

\author{
LA brusquedad \\ de la consultante se \\ configura \\ únicamente fuera de \\ casa y dentro no, \\ como se conjugan \\ los dos contextos, y \\ la construcción de \\ estas acciones \\ podría dar a \\ entender o que pasa.
}

Construcci
ón narrativa de
la identidad

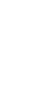

e




\section{LA DESERCIÓN ESCOLAR COMO PRETEXTO PARA CONVERSAR SOBRE IDENTIDAD, FAMILIA Y ESCUELA

mundo?

\begin{tabular}{lll}
\hline \multicolumn{1}{c}{ A: No sé, raro } & Construcci & Relato \\
(existe una leve & ón narrativa de & Lansultante \\
pausa) creo & la identidad & responde, aun con \\
& & reservas la \\
& construcción de su \\
& mundo, y como este \\
& realmente tiene una \\
& relación necesaria \\
& con los demás que \\
& existen.
\end{tabular}

\begin{tabular}{|c|c|c|c|}
\hline $\begin{array}{l}\text { I: ¿Por qué raro } \\
\text { mi amor, explícanos } \\
\text { cómo es eso, cómo lo } \\
\text { entiendes? }\end{array}$ & $\begin{array}{l}\text { Construcci } \\
\text { ón narrativa de } \\
\text { la identidad }\end{array}$ & Historias & \\
\hline $\begin{array}{l}\text { A: Umm (dura un } \\
\text { tiempo en silencio, } \\
\text { alrededor de } 3 \\
\text { segundos) pues lo } \\
\text { que dice mi mami es } \\
\text { cierto ¡No!, pues a } \\
\text { veces me cree como } \\
\text { (existe un sonido de } \\
\text { risa) muy niña, y } \\
\text { iya!, pues creo que } \\
\text { ese también era el } \\
\text { problema en el } \\
\text { colegio, que (existe } \\
\text { una breve pausa) } \\
\text { pues más que todo } \\
\text { era por los apodos }\end{array}$ & $\begin{array}{l}\text { Construcci } \\
\text { ón narrativa de } \\
\text { la identidad }\end{array}$ & Relato & $\begin{array}{l}\quad \text { La percepción } \\
\text { de la consultante se } \\
\text { construye dentro del } \\
\text { marco de las } \\
\text { creencias de su } \\
\text { madre, y dentro de } \\
\text { esta óptica se } \\
\text { genera un reacción } \\
\text { percibida como } \\
\text { negativa (apodos, } \\
\text { etc.) dentro del } \\
\text { contexto escolar. }\end{array}$ \\
\hline $\begin{array}{l}\text { I: Te molestaban } \\
\text { los apodos y ¿tú te } \\
\text { empezaste a aislar } \\
\text { que mecanismo } \\
\text { usaste, cómo era esa } \\
\text { reacción? }\end{array}$ & $\begin{array}{l}\quad \text { Intervencio } \\
\text { nes narrativas } \\
\text { en situaciones } \\
\text { de deserción } \\
\text { escolar }\end{array}$ & Memorias & \\
\hline $\begin{array}{l}\text { A: Ummm (existe } \\
\text { una breve pausa) } \\
\text { sentía ira (al } \\
\text { mencionar la palabra } \\
\text { ira, eleva el tono de } \\
\text { su voz, enfatizando } \\
\text { en su sentimiento) }\end{array}$ & $\begin{array}{l}\text { Construcci } \\
\text { ón narrativa de } \\
\text { la identidad }\end{array}$ & Relato & $\begin{array}{l}\quad \text { La consultante, } \\
\text { genera entonces } \\
\text { dentro de este } \\
\text { marco ira y } \\
\text { agresividad frente al } \\
\text { problema para } \\
\text { enfrentarlo y } \\
\text { defenderse. }\end{array}$ \\
\hline
\end{tabular}

\begin{tabular}{ccc}
\hline I: Y por & $\begin{array}{c}\text { Construcci } \\
\text { ón narrativa de } \\
\text { la identidad }\end{array}$ & Relato \\
\hline $\begin{array}{cc}\text { A: Ira con todos } \\
\text { (eleva su tono de voz) }\end{array}$ & $\begin{array}{c}\text { Construcci narrativa de } \\
\text { la identidad }\end{array}$ & Relato \\
\end{tabular}




\section{LA DESERCIÓN ESCOLAR COMO PRETEXTO PARA CONVERSAR SOBRE IDENTIDAD, FAMILIA Y ESCUELA

I: ¿Y por eso era la agresividad?
Construcci ón narrativa de la identidad

A:ummm
Construcci

ón narrativa de

la identidad
Relato

Relato

Relato Sin embargo, puede fácilmente evocar estos sentimientos de ira, y utilizarlos como punto defensivo, para construir su propia personalidad.

\begin{tabular}{|c|c|c|c|}
\hline $\begin{array}{l}\quad \text { I: Pero te quedaste } \\
\text { ahí, te quedaste en la } \\
\text { agresividad, pero } \\
\text { pero bueno mami nos } \\
\text { dice en un colegio } \\
\text { fue, y en ese colegio } \\
\text { bueno solamente } \\
\text { perdió dos materias, y } \\
\text { bueno, y hubo un } \\
\text { cambio de colegio, y, } \\
\text { pero ahí fue peor, } \\
\text { entonces como } \\
\text { ¿Cómo nos quieres } \\
\text { contar que sucedió } \\
\text { ahí, ósea? }\end{array}$ & $\begin{array}{l}\quad \text { Intervencio } \\
\text { nes narrativas } \\
\text { en situaciones } \\
\text { de deserción } \\
\text { escolar }\end{array}$ & Memorias & \\
\hline $\begin{array}{l}\text { A: Pues creo que, } \\
\text { ósea, era el era el } \\
\text { Gran Colombiano y } \\
\text { psi si, el ambiente era } \\
\text { como muy muy feo y } \\
\text { malas amistades jume }\end{array}$ & $\begin{array}{l}\text { Construcci } \\
\text { ón narrativa de } \\
\text { la identidad }\end{array}$ & Memorias & $\begin{array}{l}\quad \text { La narrativa da } \\
\text { cuenta de la } \\
\text { bidireccionalidad de } \\
\text { la percepción de } \\
\text { cada una, en este } \\
\text { caso la hija } \\
\text { confronta su } \\
\text { realidad antes de } \\
\text { cualquier cosa. }\end{array}$ \\
\hline
\end{tabular}

\begin{tabular}{|c|c|c|}
\hline \begin{tabular}{l}
\multicolumn{1}{c}{ I: De todo } \\
llegaba, y bueno, y si \\
tu sabías que no eran \\
las amistades que a ti \\
te convenían ¿Cómo \\
actuabas frente a \\
ellos?
\end{tabular} & $\begin{array}{l}\text { Intervencio } \\
\text { nes narrativas } \\
\text { en situaciones } \\
\text { de deserción } \\
\text { escolar }\end{array}$ & Historias \\
\hline A: Umm, nada & \begin{tabular}{l}
\multicolumn{1}{c}{ Intervencio } \\
nes narrativas \\
en situaciones \\
de deserción \\
escolar
\end{tabular} & Historias \\
\hline $\begin{array}{l}\quad \text { I: ¿Ellos llegaban } \\
\text { a buscarte a ti o tú los } \\
\text { buscabas a ellos, } \\
\text { cómo se } \\
\text { relacionaban, cómo } \\
\text { socializaban, de qué }\end{array}$ & $\begin{array}{l}\quad \text { Relación } \\
\text { joven, familia } \\
\text { e institución } \\
\text { educativa en } \\
\text { torno a la } \\
\text { deserción }\end{array}$ & Experiencia \\
\hline
\end{tabular}




\section{LA DESERCIÓN ESCOLAR COMO PRETEXTO PARA CONVERSAR SOBRE IDENTIDAD, FAMILIA Y ESCUELA

hablaban, hablaban, escolar.

no hablaban, cómo

era?

\begin{tabular}{|c|c|c|c|}
\hline $\begin{array}{l}\text { A: Pues no nada, } \\
\text { el (dura un tiempo en } \\
\text { silencio, alrededor de } \\
3 \text { segundos) no, ósea } \\
\text { como, ehh normal, si } \\
\text { como estamos } \\
\text { hablando así en este } \\
\text { momento }\end{array}$ & $\begin{array}{l}\quad \text { Relación } \\
\text { joven, familia } \\
\text { e institución } \\
\text { educativa en } \\
\text { torno a la } \\
\text { deserción } \\
\text { escolar. }\end{array}$ & Experiencia & \\
\hline $\mathrm{I}: \mathrm{Si}$ & $\begin{array}{l}\quad \text { Relación } \\
\text { joven, familia } \\
\text { e institución } \\
\text { educativa en } \\
\text { torno a la } \\
\text { deserción } \\
\text { escolar. }\end{array}$ & Memorias & \\
\hline $\begin{array}{l}\text { A: Y ya, pero no, } \\
\text { así que alguien } \\
\text { buscara a alguien } \\
\text { para hablar, no }\end{array}$ & $\begin{array}{l}\quad \text { Relación } \\
\text { joven, familia } \\
\text { e institución } \\
\text { educativa en } \\
\text { torno a la } \\
\text { deserción } \\
\text { escolar. }\end{array}$ & Memorias & $\begin{array}{l}\text { En las } \\
\text { percepciones y } \\
\text { construcciones de la } \\
\text { consultante existe } \\
\text { un apercepción de } \\
\text { seguridad muy } \\
\text { borrosa, que esta } \\
\text { dominada según su } \\
\text { sistema escolar y } \\
\text { como este le afecta. }\end{array}$ \\
\hline
\end{tabular}

\begin{tabular}{|c|c|c|c|}
\hline $\begin{array}{l}\quad \text { I: Y entonces tu } \\
\text { como me dices que } \\
\text { ¿cómo sabías que } \\
\text { eran malas } \\
\text { amistades? }\end{array}$ & $\begin{array}{l}\text { Intervencio } \\
\text { nes narrativas } \\
\text { en situaciones } \\
\text { de deserción } \\
\text { escolar }\end{array}$ & Experiencia & \\
\hline $\begin{array}{l}\text { A: Porque, ehh, } \\
\text { mmm, pues ellos me } \\
\text { hicieron faltar a clase } \\
\text { (hay una expresión de } \\
\text { risa en la niña) ellos, } \\
\text { me, dijeron, “venga y } \\
\text { vamos y tal parte” y } \\
\text { en una clase, en una } \\
\text { materia, la profesora } \\
\text { no, no iba, en todas } \\
\text { las clases, que } \\
\text { teníamos con ella no } \\
\text { iba, era tecnología y } \\
\text { entonces pues todos } \\
\text { se salían y pues } \\
\text { salíamos era como a } \\
\text { jugar, y ya, pero era } \\
\text { como la única clase }\end{array}$ & $\begin{array}{l}\text { Intervencio } \\
\text { nes narrativas } \\
\text { en situaciones } \\
\text { de deserción } \\
\text { escolar }\end{array}$ & Experiencia & $\begin{array}{l}\quad \text { Aun hay una } \\
\text { percepción de no } \\
\text { control frente a las } \\
\text { acciones de la } \\
\text { consultante, } \\
\text { especialmente } \\
\text { cuando narra como } \\
\text { actúa su sentido de } \\
\text { responsabilidad } \\
\text { dentro de sus actos. }\end{array}$ \\
\hline
\end{tabular}




\section{LA DESERCIÓN ESCOLAR COMO PRETEXTO PARA CONVERSAR SOBRE IDENTIDAD, FAMILIA Y ESCUELA

I: Si, de ahí fue de donde los conociste a ellos, y ahí, pero tú ya sabías que salirte de clase, $o$ ir a donde tú no debías era malo, o no estaba bien, más bien entonces ¿Qué te impulsaba a llevarte allá?

\begin{tabular}{|c|c|c|}
\hline A: No sé & $\begin{array}{l}\text { Intervencio } \\
\text { nes narrativas } \\
\text { en situaciones } \\
\text { de deserción } \\
\text { escolar }\end{array}$ & Memorias \\
\hline $\begin{array}{l}\mathrm{I}: \text { ¿ } \mathrm{Te} \\
\text { amenazaban, te } \\
\text { prometían algo, ooo? }\end{array}$ & \begin{tabular}{l}
\multicolumn{1}{c}{ Relación } \\
joven, familia \\
e institución \\
educativa en \\
torno a la \\
deserción \\
escolar.
\end{tabular} & Memorias \\
\hline $\begin{array}{c}\text { A: Niega de } \\
\text { manera no verbal }\end{array}$ & $\begin{array}{l}\quad \text { Relación } \\
\text { joven, familia } \\
\text { e institución } \\
\text { educativa en } \\
\text { torno a la } \\
\text { deserción } \\
\text { escolar. }\end{array}$ & Memorias \\
\hline I: ¿Y entonces? & $\begin{array}{l}\quad \text { Relación } \\
\text { joven, familia } \\
\text { e institución } \\
\text { educativa en } \\
\text { torno a la } \\
\text { deserción } \\
\text { escolar. }\end{array}$ & Historias \\
\hline A: No pensaba & $\begin{array}{l}\quad \text { Relación } \\
\text { joven, familia } \\
\text { e institución } \\
\text { educativa en } \\
\text { torno a la } \\
\text { deserción } \\
\text { escolar. }\end{array}$ & Historias \\
\hline \begin{tabular}{l}
\multicolumn{1}{c}{ Interventora: No } \\
pensabas \\
¿Simplemente te ibas \\
y vivías el momento \\
y ya, y luego, las \\
consecuencias?
\end{tabular} & $\begin{array}{l}\text { Intervencio } \\
\text { nes narrativas } \\
\text { en situaciones } \\
\text { de deserción } \\
\text { escolar }\end{array}$ & Experiencia \\
\hline
\end{tabular}

\section{Intervencio Memorias}

nes narrativas

situaciones

de deserción

escolar 


\section{LA DESERCIÓN ESCOLAR COMO PRETEXTO PARA CONVERSAR SOBRE IDENTIDAD, FAMILIA Y ESCUELA $\begin{array}{cr}\text { Hija: Pues, (hay } & \text { Construcci } \\ \text { un breve silencio) no } & \text { ón narrativa de }\end{array}$ pensaba en eso la identidad

\author{
Experiencia \\ La consultante \\ demuestra su poca \\ construcción \\ narrativa de su \\ identidad frente a la \\ relación con otros y \\ como afecta el \\ sistema sus \\ acciones y \\ percepciones
}

\begin{tabular}{|c|c|c|c|}
\hline \begin{tabular}{l}
\multicolumn{1}{c}{ I: ¿No pensabas } \\
en las consecuencias, \\
ni en lo que podía \\
decir tú mamá?
\end{tabular} & $\begin{array}{l}\text { Construcci } \\
\text { ón narrativa de } \\
\text { la identidad }\end{array}$ & Historias & \\
\hline $\begin{array}{l}\text { A: (Existe un } \\
\text { breve silencio) } \\
\text { ayyyahhh (la mamá } \\
\text { tose) }\end{array}$ & $\begin{array}{l}\text { Construcci } \\
\text { ón narrativa de } \\
\text { la identidad }\end{array}$ & Historias & \\
\hline $\begin{array}{l}\text { I: A ver esta } \\
\text { pregunta va para las } \\
\text { dos ¿Qué otras } \\
\text { personas han estado } \\
\text { involucradas en eso } \\
\text { que para ustedes es } \\
\text { un problema, o lo han } \\
\text { manejado solamente } \\
\text { ustedes dos como } \\
\text { madre e hija, o tu otra } \\
\text { hija, o tu compañero, } \\
\text { toda la familia, } \\
\text { cómo? De acuerdo a } \\
\text { la situación que } \\
\text { plantean ¿Qué } \\
\text { impacto ha tenido } \\
\text { este hecho en sus } \\
\text { vidas?, cuéntame } \\
\text { algo Diana }\end{array}$ & $\begin{array}{l}\quad \text { Intervencio } \\
\text { nes narrativas } \\
\text { en situaciones } \\
\text { de deserción } \\
\text { escolar }\end{array}$ & Experiencia & \\
\hline $\begin{array}{l}\text { M: Ummm, pues } \\
\text { mi esposo pues pues } \\
\text { ay, viendo toda la } \\
\text { situación y pues hay } \\
\text { él en lo que yo haga } \\
\text { él me apoya, si, me } \\
\text { ayuda a estar } \\
\text { pendiente de ella, } \\
\text { eso, y pues } \\
\text { indirectamente, ósea } \\
\text { digamos, ummm } \\
\text { digamos digamos que } \\
\text { no que me ayuden } \\
\text { pero pues obviamente } \\
\text { están enterados de la } \\
\text { situación pues si, mi } \\
\text { familia, mis }\end{array}$ & $\begin{array}{l}\text { Intervencio } \\
\text { nes narrativas } \\
\text { en situaciones } \\
\text { de deserción } \\
\text { escolar }\end{array}$ & Relato & $\begin{array}{l}\quad \text { La mama intenta } \\
\text { generar una } \\
\text { percepción de red } \\
\text { de apoyo, sin } \\
\text { embargo no } \\
\text { describe fácilmente } \\
\text { los roles que } \\
\text { debería llevar cada } \\
\text { parte de la familia } \\
\text { ni como } \\
\text { exactamente } \\
\text { podrían ayudar. }\end{array}$ \\
\hline
\end{tabular}




\section{LA DESERCIÓN ESCOLAR COMO PRETEXTO PARA CONVERSAR SOBRE IDENTIDAD, FAMILIA Y ESCUELA

hermanos, mi mamá, mi hija mayor, todos ahí.

\begin{tabular}{|c|c|c|c|}
\hline $\begin{array}{l}\text { I: ¿Qué han } \\
\text { hecho ustedes para } \\
\text { sobrellevar la } \\
\text { dificultad? }\end{array}$ & $\begin{array}{l}\quad \text { Relación } \\
\text { joven, familia } \\
\text { e institución } \\
\text { educativa en } \\
\text { torno a la } \\
\text { deserción } \\
\text { escolar. }\end{array}$ & Historias & \\
\hline $\begin{array}{l}\quad \text { M: pues jmmm } \\
\text { todo el mundo le ha } \\
\text { hablado, es que quién } \\
\text { no le ha hablado } \\
\text { (existe una expresión } \\
\text { de risa, y un pequeño } \\
\text { silencio) yo } \\
\text { realmente en este } \\
\text { punto, lo que yo le } \\
\text { decía me siento tan } \\
\text { cansada de todo esto } \\
\text { que (existe un breve } \\
\text { silencio) ya cómo que } \\
\text { (existe un breve } \\
\text { silencio), para mí } \\
\text { todo esto es una } \\
\text { repetición de algo } \\
\text { que no me lleva a } \\
\text { nada }\end{array}$ & $\begin{array}{l}\quad \text { Relación } \\
\text { joven, familia } \\
\text { e institución } \\
\text { educativa en } \\
\text { torno a la } \\
\text { deserción } \\
\text { escolar. }\end{array}$ & Experiencia & $\begin{array}{l}\quad \text { La mama de } \\
\text { nuevo insiste en que } \\
\text { sus posibilidades } \\
\text { esta cerca a estar } \\
\text { agotadas, y que hay } \\
\text { un cansancio frente } \\
\text { a un ciclo que se } \\
\text { repite y que se } \\
\text { antoja infructuoso. }\end{array}$ \\
\hline I: ¿Será Diana? & \begin{tabular}{l}
\multicolumn{1}{c}{ Relación } \\
joven, familia \\
e institución \\
educativa en \\
torno a la \\
deserción \\
escolar.
\end{tabular} & Memorias & \\
\hline
\end{tabular}




\section{LA DESERCIÓN ESCOLAR COMO PRETEXTO PARA CONVERSAR SOBRE IDENTIDAD, FAMILIA Y ESCUELA

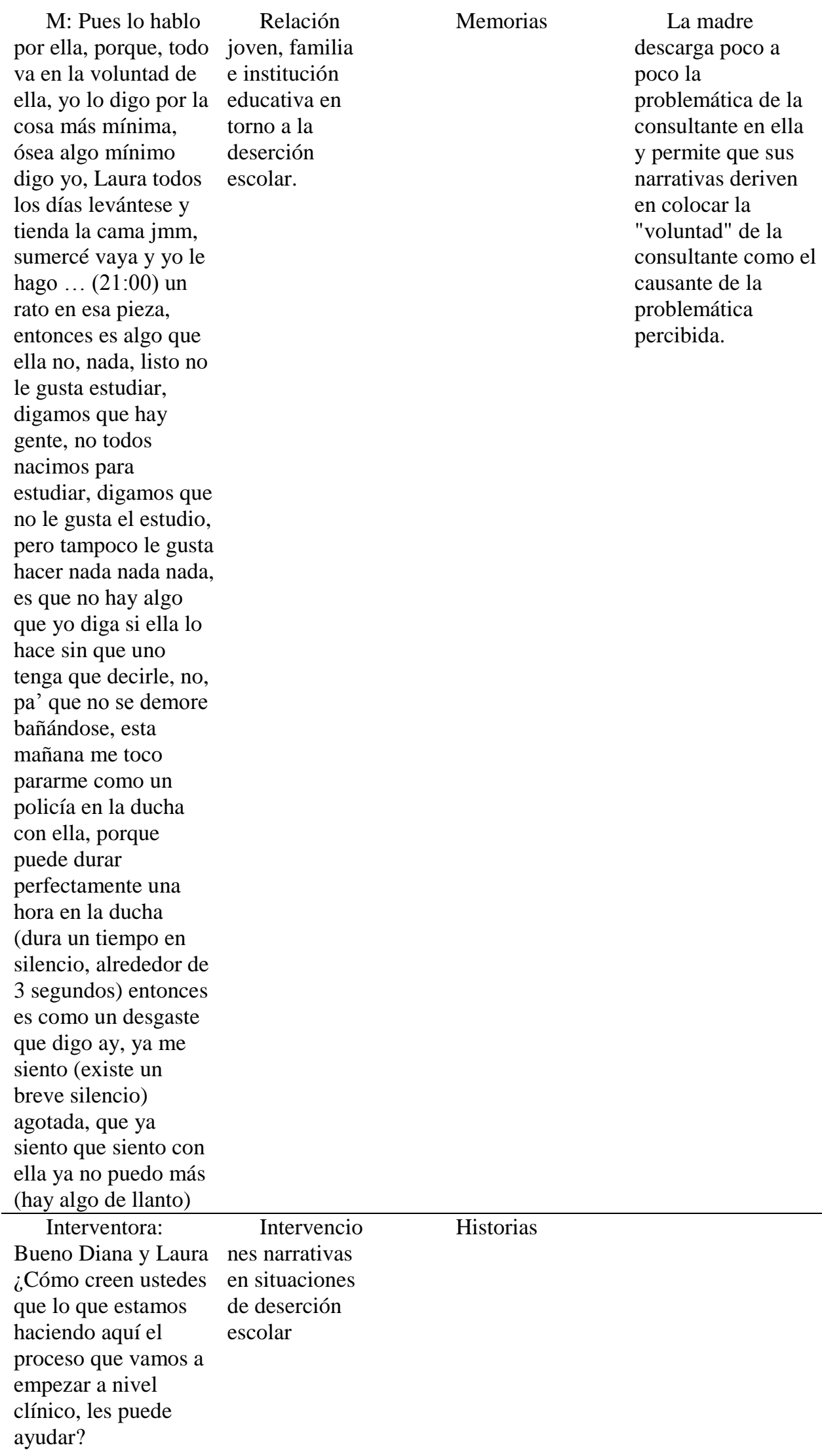

M: Pues lo hablo por ella, porque, todo va en la voluntad de ella, yo lo digo por la cosa más mínima, ósea algo mínimo digo yo, Laura todos los días levántese y tienda la cama jmm, sumercé vaya y yo le hago ... (21:00) un rato en esa pieza, entonces es algo que ella no, nada, listo no le gusta estudiar, digamos que hay gente, no todos nacimos para estudiar, digamos que no le gusta el estudio, pero tampoco le gusta hacer nada nada nada, es que no hay algo que yo diga si ella lo hace sin que uno tenga que decirle, no, pa' que no se demore bañándose, esta mañana me toco pararme como un policía en la ducha con ella, porque puede durar perfectamente una hora en la ducha (dura un tiempo en silencio, alrededor de 3 segundos) entonces es como un desgaste que digo ay, ya me siento (existe un breve silencio) agotada, que ya siento que siento con ella ya no puedo más (hay algo de llanto)

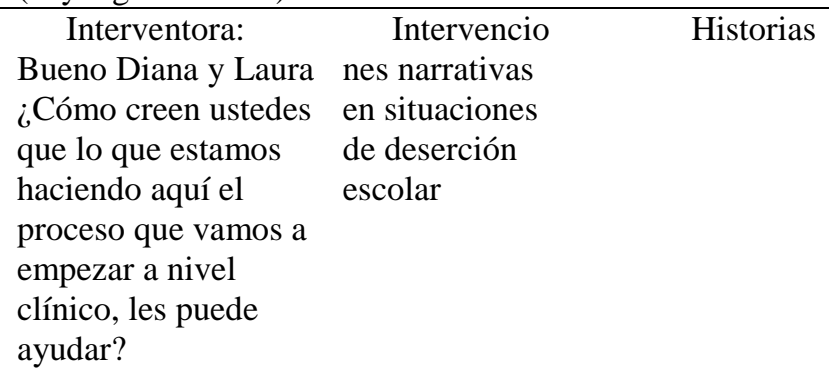

\begin{tabular}{|c|c|c|}
\hline $\begin{array}{l}\text { Relación } \\
\text { joven, familia } \\
\text { e institución } \\
\text { educativa en } \\
\text { torno a la } \\
\text { deserción } \\
\text { escolar. }\end{array}$ & Memorias & $\begin{array}{l}\quad \text { La madre } \\
\text { descarga poco a } \\
\text { poco la } \\
\text { problemática de la } \\
\text { consultante en ella } \\
\text { y permite que sus } \\
\text { narrativas deriven } \\
\text { en colocar la } \\
\text { "voluntad" de la } \\
\text { consultante como el } \\
\text { causante de la } \\
\text { problemática } \\
\text { percibida. }\end{array}$ \\
\hline
\end{tabular}




\section{LA DESERCIÓN ESCOLAR COMO PRETEXTO PARA CONVERSAR SOBRE IDENTIDAD, FAMILIA Y ESCUELA

M: Ushhh yo pienso es que mucho, por lo menos por lo menos por mi parte es mucho, porque a mí eso me ha enfermado, pp pueda que yo no lo manifieste o de pronto se lo

manifiesto a ella ya con rabia, ósea ya el mismo de verla a ella, ya es como a la defensiva, honestamente yo la miro y le veo todo lo malo por todas partes porque yo llego y no, ósea veo que esta mañana se quedó este papel hay y ella paso diez veces por encima y no lo alzó (existe un breve silencio) cosas que le digo yo haga esto y llego y no lo ha hecho y todos los días es el mismo problema entonces ya va, entonces sí, ya como que yo quiero algo $\mathrm{y}$ espero de esto, por lo menos aunque sea que esto, lo que yo le decía a ella, por ella, no por mí porque yo no espero de aquí a mañana que me dé ni más nada, pero por lo menos decir ella tiene aunque sea con que defenderse

\begin{tabular}{|c|c|c|}
\hline I: Mjumm & $\begin{array}{l}\quad \text { Intervencio } \\
\text { nes narrativas } \\
\text { en situaciones } \\
\text { de deserción } \\
\text { escolar }\end{array}$ & Historias \\
\hline $\begin{array}{l}\text { M: Para que no se } \\
\text { quede ahí pa' que la } \\
\text { mangoneen de aquí a } \\
\text { mañana pa' lado y } \\
\text { lado }\end{array}$ & $\begin{array}{l}\quad \text { Intervencio } \\
\text { nes narrativas } \\
\text { en situaciones } \\
\text { de deserción } \\
\text { escolar }\end{array}$ & Historias \\
\hline
\end{tabular}

$\begin{array}{ll}\quad \text { Intervencio } & \text { Relato } \\ \text { nes narrativas } & \text { La Madre de } \\ \text { en situaciones } & \text { retomar su rol como } \\ \text { de deserción } & \text { victima de una } \\ \text { escolar } & \text { problema percibido } \\ & \text { en cual ella no tiene } \\ & \text { parte, y ha hecho lo } \\ & \text { posible por mejorar, } \\ & \text { y fortalece su } \\ & \text { narrativa con } \\ & \text { ejemplos que le } \\ & \text { permitan justificar } \\ & \text { la posición. }\end{array}$




\section{LA DESERCIÓN ESCOLAR COMO PRETEXTO PARA CONVERSAR SOBRE IDENTIDAD, FAMILIA Y ESCUELA

\footnotetext{
I: Umjumm, y sumercé ¿Qué piensa Laura, qué piensas tú que podemos lograr?, claro con la compañía de tú mamá, porque un proceso no se empieza solo, aquí vamos a necesitar cuando empecemos a intervenir vamos a necesitar de tu hermana, vamos a involucrar otras personas, para buscar cómo ayudarte ¿Tú qué esperas, qué te gustaría que pasara aquí con nosotras?
}

\begin{tabular}{|c|c|c|c|}
\hline $\begin{array}{l}\text { A: Noo, pues } \\
\text { (dura un tiempo en } \\
\text { silencio, alrededor de } \\
2 \text { segundos) pues que } \\
\text { (dura un tiempo en } \\
\text { silencio, alrededor de } \\
6 \text { segundos) lograr } \\
\text { entrar a estudiar y } \\
\text { pasar los años }\end{array}$ & \begin{tabular}{l}
\multicolumn{1}{c}{ Relación } \\
joven, familia \\
e institución \\
educativa en \\
torno a la \\
deserción \\
escolar.
\end{tabular} & Experiencia & $\begin{array}{l}\quad \text { La consultante } \\
\text { aun demuestra } \\
\text { dificultad en } \\
\text { conectarse con su } \\
\text { propia historia, en } \\
\text { la que su situación } \\
\text { actual tiene mas que } \\
\text { ver que solo su } \\
\text { estudio, sin } \\
\text { embargo busca } \\
\text { cambiar su } \\
\text { percepción. }\end{array}$ \\
\hline
\end{tabular}

Historias

joven, familia

e institución

educativa en escolar.

\begin{tabular}{|c|c|c|}
\hline $\begin{array}{c}\mathrm{I}: \text { ¿Y de quién } \\
\text { depende eso Laura? }\end{array}$ & $\begin{array}{l}\quad \text { Relación } \\
\text { joven, familia } \\
\text { e institución } \\
\text { educativa en } \\
\text { torno a la } \\
\text { deserción } \\
\text { escolar. }\end{array}$ & $\begin{array}{l}\text { Relatos } \\
\text { Alternos }\end{array}$ \\
\hline A: De mí & \begin{tabular}{l}
\multicolumn{1}{c}{ Relación } \\
joven, familia \\
e institución \\
educativa en \\
torno a la \\
deserción \\
escolar.
\end{tabular} & $\begin{array}{l}\text { Relatos } \\
\text { Alternos }\end{array}$ \\
\hline $\begin{array}{l}\text { I: ¿Y qué tienes } \\
\text { para darle a este } \\
\text { proceso? }\end{array}$ & \begin{tabular}{l}
\multicolumn{1}{c}{ Relación } \\
joven, familia \\
e institución \\
educativa en \\
torno a la \\
deserción \\
escolar.
\end{tabular} & $\begin{array}{l}\text { Relatos } \\
\text { Alternos }\end{array}$ \\
\hline
\end{tabular}




\section{LA DESERCIÓN ESCOLAR COMO PRETEXTO PARA CONVERSAR SOBRE IDENTIDAD, FAMILIA Y ESCUELA

A: (Dura un tiempo en silencio, alrededor de 3 segundos) voluntad

\section{Relación}

joven, familia

e institución

educativa en

torno a la

deserción

escolar.
Relatos

Alternos
La hija se

encuadra en la

posición de la

madre, de que solo

necesita de su

voluntad para lograr

el cambio, tal vez

matizando sus

propias opiniones

frente a su relación.

\begin{tabular}{|c|c|c|c|}
\hline $\begin{array}{l}\text { I: ¿Seguro y qué } \\
\text { otra cosa, y por qué } \\
\text { no miras a Diana y le } \\
\text { dices eso, a tú mamá? }\end{array}$ & $\begin{array}{l}\quad \text { Intervencio } \\
\text { nes narrativas } \\
\text { en situaciones } \\
\text { de deserción } \\
\text { escolar }\end{array}$ & $\begin{array}{l}\text { Relatos } \\
\text { Alternos }\end{array}$ & \\
\hline $\begin{array}{l}\text { A: (Existe algo de } \\
\text { risa de la niña) }\end{array}$ & $\begin{array}{l}\text { Intervencio } \\
\text { nes narrativas } \\
\text { en situaciones } \\
\text { de deserción } \\
\text { escolar }\end{array}$ & $\begin{array}{l}\text { Relatos } \\
\text { Alternos }\end{array}$ & \begin{tabular}{l}
\multicolumn{1}{c}{ La consultante } \\
aun siente falta de \\
confianza dentro de \\
la posibilidad de \\
hablar directamente \\
lo que siente.
\end{tabular} \\
\hline
\end{tabular}

Intervencio

Historias

nes narrativas

en situaciones

de deserción

\footnotetext{
I: Pero con

compromiso, no por

decirlo, pues cierto

Diana, o tu que

piensas

M: Yo sí, yo le he

dicho doctora a ella,

ósea lo que usted

haga ósea es por

usted, piense en

usted, ósea de lo que

yo le decía, ella ya

está en edad de saber

lo que es bueno y lo

que es malo, yo le

decía uno, a mí me la

ofrecieron, yo no, fue

lo primero yo sé que

eso es malo para que

lo voy a probar si sé

que eso me va a

causar daño, que lo

haga mi amigo quiere

decir que porque yo

no lo haga, o si él me

deja de hablar porque

yo no lo probé ese no

es amigo y para mí,

mejor que esa

persona se aleje de

mí, pero

independientemente

de todo es uno el que
}

escolar

\begin{tabular}{lll}
$\quad$ Relación & Relato & \multicolumn{1}{c}{ La madre } \\
joven, familia & & configura su \\
e institución & narrativa a través de \\
educativa en & la defensa de sus \\
torno a la & propias acciones \\
deserción & como madre, y de \\
escolar. & como la decisión \\
& & completa esta en \\
& manos de la \\
& consultante, que ya \\
& tiene lo suficiente \\
& para tomar una \\
& decisión.
\end{tabular}




\section{LA DESERCIÓN ESCOLAR COMO PRETEXTO PARA CONVERSAR SOBRE IDENTIDAD, FAMILIA Y ESCUELA

toma las decisiones y uno piensa en uno, lo que es bien para uno, yo la estuviera mandando, vaya Laura vaya allí venga camine le enseño a robar, cree que eso estaría bien, yo le he dicho de una y mil formas, para que le sirve el estudio, que días se lo dije creo que fue esta semana o la semana pasada, se lo dije, sí usted quiere estudiar música, estudie música, sí quiere estudiar educación física, estudie educación física, a mi realmente lo que estudie yo no le voy a decir es que tiene que estudiar esto, no, pero lo que quiera estudiar, que le dije yo que necesitaba para poder estudiar

\begin{tabular}{cll}
\hline A: Bachillerato & \multicolumn{1}{c}{ Relación } & La consultante, \\
& joven, familia & Historias \\
& e institución & su madre \\
educativa en & construyendo \\
torno a la & seguramente un \\
deserción & relato recurrente \\
escolar. & entre las dos.
\end{tabular}

\begin{tabular}{|c|c|c|}
\hline $\begin{array}{l}\quad \text { M: es lo mínimo, } \\
\ldots \ldots \ldots \ldots \ldots \ldots \ldots \\
\text { Entonces }\end{array}$ & $\begin{array}{l}\quad \text { Relación } \\
\text { joven, familia } \\
\text { e institución } \\
\text { educativa en } \\
\text { torno a la } \\
\text { deserción } \\
\text { escolar. }\end{array}$ & Historias \\
\hline \begin{tabular}{l}
\multicolumn{1}{c}{ I: jumjumjum } \\
$\ldots . .$. Como te ves \\
ahí, compromiso tu \\
nos hablaste de algo \\
importante de un \\
compromiso ..... pero \\
un compromiso con \\
quien, con tu mamá, \\
conmigo, contigo.
\end{tabular} & $\begin{array}{l}\quad \text { Intervencio } \\
\text { nes narrativas } \\
\text { en situaciones } \\
\text { de deserción } \\
\text { escolar }\end{array}$ & Historias \\
\hline
\end{tabular}




\section{LA DESERCIÓN ESCOLAR COMO PRETEXTO PARA CONVERSAR SOBRE IDENTIDAD, FAMILIA Y ESCUELA

A: con todos

$\quad$ Intervencio
nes narrativas
en situaciones
de deserción
escolar

Historias

Su compromiso, aun se configura como algo muy amplio que no se construye narrativamente dentro de sus propios marcos de manera de tallada, o que aun no se puede expresar.

\begin{tabular}{|c|c|c|}
\hline $\begin{array}{l}\quad \text { I: con todos, que } \\
\text { colegio te gustaría?, } \\
\text { en que colegio te } \\
\text { gustaría estar?, en } \\
\text { donde?........ tal vez } \\
\text { ummm hayas } \\
\text { pensado en algún } \\
\text { colegio }\end{array}$ & $\begin{array}{l}\text { Intervencio } \\
\text { nes narrativas } \\
\text { en situaciones } \\
\text { de deserción } \\
\text { escolar }\end{array}$ & Historias \\
\hline $\begin{array}{l}\text { A: pues un } \\
\text { colegio fijo todavía } \\
\text { no, no se cual }\end{array}$ & $\begin{array}{l}\quad \text { Intervencio } \\
\text { nes narrativas } \\
\text { en situaciones } \\
\text { de deserción } \\
\text { escolar }\end{array}$ & Historias \\
\hline I: ¿por qué? & $\begin{array}{l}\quad \text { Intervencio } \\
\text { nes narrativas } \\
\text { en situaciones } \\
\text { de deserción } \\
\text { escolar } \\
\end{array}$ & Historias \\
\hline $\begin{array}{l}\quad \text { A: } \mathrm{mmmmm} \text { no, } \\
\text { no sé, no he pensado } \\
\text { como en eso no?, } \\
\text { pues mi mami dice } \\
\text { que en el rosario pero }\end{array}$ & $\begin{array}{l}\text { Intervencio } \\
\text { nes narrativas } \\
\text { en situaciones } \\
\text { de deserción } \\
\text { escolar } \\
\end{array}$ & Experiencia \\
\hline $\begin{array}{l}\text { I: y a ti te gusta el } \\
\text { rosario? }\end{array}$ & \begin{tabular}{l}
\multicolumn{1}{c}{ Intervencio } \\
nes narrativas \\
en situaciones \\
de deserción \\
escolar \\
\end{tabular} & Historias \\
\hline $\begin{array}{l}\text { A: pues no sé } \\
\text { cómo será ahí, psi }\end{array}$ & \begin{tabular}{l}
\multicolumn{1}{c}{ Intervencio } \\
nes narrativas \\
en situaciones \\
de deserción \\
escolar \\
\end{tabular} & Historias \\
\hline $\begin{array}{l}\quad \text { I: qué esperas } \\
\text { encontrar en un } \\
\text { colegio?... o que te } \\
\text { gustaría más bien } \\
\text { encontrar? }\end{array}$ & $\begin{array}{l}\text { Intervencio } \\
\text { nes narrativas } \\
\text { en situaciones } \\
\text { de deserción } \\
\text { escolar }\end{array}$ & Historias \\
\hline
\end{tabular}




\section{LA DESERCIÓN ESCOLAR COMO PRETEXTO PARA CONVERSAR SOBRE IDENTIDAD, FAMILIA Y ESCUELA

A: no sé, no ... Pues no normal lo... o sea ... como que no sea igual emm, que en el BOYACA
Intervencio

nes narrativas

en situaciones

de deserción

escolar
Historias

La consultante, construye sus decisiones a través de lo que dice su mama y no incluye su propia opinión, ni tampoco la construye a la par.

\begin{tabular}{lll}
\hline \multicolumn{1}{c}{ I: ese colegio te } & \multicolumn{1}{c}{ Relación } & Historias \\
marco & joven, familia \\
definitivamente... y & e institución \\
sufres cuando hablas & educativa en \\
de ello ... a OK & $\begin{array}{l}\text { torno a la } \\
\text { deserción } \\
\end{array}$ \\
& escolar.
\end{tabular}

\footnotetext{
M: en ese aspecto yo le he dicho a ella, que día, que día inclusive se lo dije ella se inscribió a un curso virtual del Sena, y las dos primeras semanas eso mejor dicho no hacia si no metida en eso, y dije bueno ..... jume.... De un momento a otro no volvió a hacer, y le dije y todos los días le decía, Laura ¿Qué paso con lo del curso? Si si ahí voy, si si y el que días le dije, pues no es yo no la he vuelto a hacer, ver hacer nada ósea, no volvió a hacer nada, no es que es difícil, entonces le dije, le dije pues es que nada es fácil en la vida, lo fácil es malo, todo lo que uno consigue fácil nunca, o no dura o le hace a uno daño, o bueno no se ve, entonces le dije que tal Dios la quiera de aquí a mañana tenga un hijo ...... y se le hace difícil entonces va y lo bota ...... y a todo lado
}

Construcci

Historias

ón narrativa de

la identidad
La percepción

de la madre es que

la consultante debe ser fuerte para poder enfrentarse a cualquier obstáculo en sus decisiones de vida, sin embargo no construye aun redes de apoyo que permitan a la consultante poder construir esa fuerza de la que habla. 


\section{LA DESERCIÓN ESCOLAR COMO PRETEXTO PARA CONVERSAR SOBRE IDENTIDAD, FAMILIA Y ESCUELA

donde uno vaya uno

va a encontrar, no va a encontrar, todo el mundo no va a ser dulzura y candor Laura ...... entonces tú no puedes esperar de llegar, ni hoy puede ser el colegio, mañana es un trabajo, pasado mañana es una familia ... el mundo ...... y uno no puede vivir todo el tiempo de que, del que dirán, o de lo que los demás le digan ...... entonces graves por que como, imagine nos tocaría sentar, ponernos a hacer encuesta por todos los colegios si son malos o no los niños pa poder entrar a estudiar o no doña Laura

\begin{tabular}{|c|c|c|c|}
\hline I: jum jum jum & $\begin{array}{l}\text { Construcci } \\
\text { ón narrativa de } \\
\text { la identidad }\end{array}$ & Historias & \\
\hline $\begin{array}{l}\quad \text { M: uno tiene que } \\
\text { aprender a manejar } \\
\text { esas situaciones y yo } \\
\text { le he dicho...... } \\
\text { Cuantas veces le he } \\
\text { dicho, ósea uno por } \\
\text { que se tiene que dejar } \\
\text { afectar por que a uno } \\
\text { le digan, si a mí me } \\
\text { dicen que soy fea, } \\
\text { bueno usted cree que } \\
\text { soy fea, si soy fea, } \\
\text { bueno usted crea lo } \\
\text { que quiera a mí que } \\
\text { me importa ¿sí? } \\
\text {....ósea uno no tiene } \\
\text { por qué dejarse tocar } \\
\text { de lo que los demás } \\
\text { le digan ósea, uno } \\
\text { tiene su convicción y } \\
\text { uno, yo digo, yo soy } \\
\text { bonita, yo soy } \\
\text { grande, yo soy gorda, } \\
\text { yo soy flaca, yo soy } \\
\text {......lo que yo crea es }\end{array}$ & $\begin{array}{l}\text { Construcci } \\
\text { ón narrativa de } \\
\text { la identidad }\end{array}$ & Relato & $\begin{array}{l}\quad \text { De nuevo la } \\
\text { percepción de la } \\
\text { madre se centra en } \\
\text { la construcción de } \\
\text { una fortaleza y una } \\
\text { realidad de persona } \\
\text { en la que ella no } \\
\text { tiene ningún tipo de } \\
\text { actuación, en la cual } \\
\text { esa misma ya se } \\
\text { encuentra en el } \\
\text { pasado, no como un } \\
\text { actor activo de la } \\
\text { construcción de } \\
\text { persona. }\end{array}$ \\
\hline
\end{tabular}




\section{LA DESERCIÓN ESCOLAR COMO PRETEXTO PARA CONVERSAR SOBRE IDENTIDAD, FAMILIA Y ESCUELA

lo que importa.....

Pero si al del lado le pareció que no, pues problema de él, ...... ¿o no? .....entonces tiene que aprender a enfrentarse a esas cosas, no puede esperar a que llegue a donde llegue todo mundo le vaya a decir Laurita, que no que uno no es monedita de oro pa gustarle a todo el mundo mija

\begin{tabular}{|c|c|c|}
\hline $\begin{array}{l}\text { I: siempre las } \\
\text { conversaciones de } \\
\text { ustedes son así? }\end{array}$ & $\begin{array}{l}\quad \text { Relación } \\
\text { joven, familia } \\
\text { e institución } \\
\text { educativa en } \\
\text { torno a la } \\
\text { deserción } \\
\text { escolar. }\end{array}$ & Historias \\
\hline $\begin{array}{l}\text { M: si yo a ella le } \\
\text { hablo duro }\end{array}$ & $\begin{array}{l}\quad \text { Relación } \\
\text { joven, familia } \\
\text { e institución } \\
\text { educativa en } \\
\text { torno a la } \\
\text { deserción } \\
\text { escolar. }\end{array}$ & Historias \\
\hline $\begin{array}{l}\text { I: y Laura escucha } \\
\text { y no replica nada }\end{array}$ & $\begin{array}{l}\quad \text { Relación } \\
\text { joven, familia } \\
\text { e institución } \\
\text { educativa en } \\
\text { torno a la } \\
\text { deserción } \\
\text { escolar. }\end{array}$ & Historias \\
\hline M: no & $\begin{array}{l}\quad \text { Relación } \\
\text { joven, familia } \\
\text { e institución } \\
\text { educativa en } \\
\text { torno a la } \\
\text { deserción } \\
\text { escolar. }\end{array}$ & Historias \\
\hline $\begin{array}{l}\quad \text { I: queeee } \\
\text { quisieras decirle a tu } \\
\text { mamá Laura, en } \\
\text { relación con lo que } \\
\text { ella menciona? }\end{array}$ & $\begin{array}{l}\quad \text { Relación } \\
\text { joven, familia } \\
\text { e institución } \\
\text { educativa en } \\
\text { torno a la } \\
\text { deserción } \\
\text { escolar. }\end{array}$ & Historias \\
\hline
\end{tabular}




\section{LA DESERCIÓN ESCOLAR COMO PRETEXTO PARA CONVERSAR SOBRE IDENTIDAD, FAMILIA Y ESCUELA

\begin{tabular}{llll} 
M: de lo que yo & \multicolumn{1}{c}{ Relación } & Relatos & \multicolumn{1}{c}{ La madre genera } \\
que te acabe de decir & joven, familia & & una narrativa \\
que que piensas?, mi & e institución & & defensiva, \\
mamá está loca, que & educativa en & & ridiculizando una \\
le pasa? & torno a la & posible respuesta de \\
& deserción & su hija, para \\
& escolar. & protegerse de esa \\
& & intervención.
\end{tabular}

\begin{tabular}{|c|c|c|c|}
\hline A: risa & $\begin{array}{l}\quad \text { Relación } \\
\text { joven, familia } \\
\text { e institución } \\
\text { educativa en } \\
\text { torno a la } \\
\text { deserción } \\
\text { escolar. }\end{array}$ & Historias & \\
\hline M: eso no es así & $\begin{array}{l}\quad \text { Relación } \\
\text { joven, familia } \\
\text { e institución } \\
\text { educativa en } \\
\text { torno a la } \\
\text { deserción } \\
\text { escolar. }\end{array}$ & Historias & \\
\hline $\begin{array}{l}\text { A: } \mathrm{mmmm}_{\text {...... no }} \\
\text { pues si tengo que ..... } \\
\text { Creer en mí misma } \\
\ldots . .\end{array}$ & $\begin{array}{l}\quad \text { Relación } \\
\text { joven, familia } \\
\text { e institución } \\
\text { educativa en } \\
\text { torno a la } \\
\text { deserción } \\
\text { escolar. }\end{array}$ & $\begin{array}{l}\text { Relatos } \\
\text { Alternos }\end{array}$ & \begin{tabular}{l}
\multicolumn{1}{c}{ La hija genera } \\
un atisbo de una \\
relato alterno donde \\
su actitud debe estar \\
dirigida a al \\
construcción de si \\
misma, sin embargo \\
no es claro si \\
realmente cree en \\
esta posibilidad.
\end{tabular} \\
\hline
\end{tabular}

\footnotetext{
I: eso ya vamos desenvolviendo un poquito la cabuya es creer en ella misma, y después que tu empieces a creer es potencializar eso que tu sabes que tu puedes llegar a ser, pero es que solamente tu lo puedes hacer, la familia es muy importante y yo sé que cuando tu des el primer paso la familia va a estar ahí apoyándote, pero es que se necesita la iniciativa.

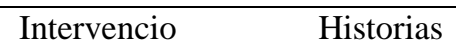




\section{LA DESERCIÓN ESCOLAR COMO PRETEXTO PARA CONVERSAR SOBRE IDENTIDAD, FAMILIA Y ESCUELA

M: la

iniciativa si ósea

que uno diga,

bueno si Laura

se está

esforzando lo

está haciendo,

listo vamos

vamos pa lante,

pero si esta así

como...

\begin{tabular}{cll}
\hline $\mathrm{I}:$ & \multicolumn{1}{c}{ Intervencio } & Historias \\
tambaleando & nes narrativas & \\
& en situaciones \\
& de deserción \\
& escolar &
\end{tabular}

M: como que

si como que no,

uno....... Ósea

.... Yo me voy

por el lado de

que hay no eso

no va a hacer

nada, pero si

usted me

demuestra yyyyy

mire la mejor

manera de uno

callar a la gente

es así, así sea a

su misma mamá

mijita, bueno

voy a

demostrarle a mi

mamá que si

puedo ... pero es

demostrarlo .....

para su bien por

que la única que

se va a

beneficiar es

usted... que,

que, que te dije

yo un día a uno

lo tratan como

uno trata, y si tu

tratas a alguien

mal como vas a

esperar por q esa

persona te

sonría, si a ti

alguien te trata

mal, tu vas a

sonreírle... es

exactamente lo

\section{Intervencio Historias}

nes narrativas

en situaciones

de deserción

escolar escolar

Relación

joven, familia

e institución

educativa en

torno a la

deserción

Relato

escolar.

La madre insiste

en una narrativa de

"yo contra el

mundo" en la que la

consultante debe

enfrentar las

percepciones de si

misma sola, y debe

realizar la

construcción de su

yo, a pesar de la

dificultades

contextuales. 


\section{LA DESERCIÓN ESCOLAR COMO PRETEXTO PARA CONVERSAR SOBRE IDENTIDAD, FAMILIA Y ESCUELA

mismo, de lo

que uno da uno

recibe...

\begin{tabular}{|c|c|c|}
\hline $\begin{array}{l}\text { I: ok.... } \\
\text { Bueno les } \\
\text { agradezco, de } \\
\text { verdad les } \\
\text { agradezco } \\
\text { muchísimo este, } \\
\text { este encuentro, } \\
\text { yo la verdad } \\
\text { desearía que } \\
\text { para el próximo } \\
\text { encuentro eee } \\
\text { Laura este } \\
\text { mucho mas } \\
\text { suelta, ¿si?, por } \\
\text { que es que la } \\
\text { voz de ella tiene } \\
\text { que cobrar vida } \\
\text { aquí para poder } \\
\text { comprender y } \\
\text { avanzar un poco } \\
\text { en lo que } \\
\text { estamos } \\
\text { viviendo, en lo } \\
\text { que ustedes } \\
\text { están viviendo } \\
\text { como familia y } \\
\text { en el proceso } \\
\text { que, en el cual } \\
\text { yo estoy } \\
\text { involucrada } \\
\text { también de una u } \\
\text { otra forma me } \\
\text { toca desde, } \\
\text { desde lo que yo } \\
\text { soy como } \\
\text { persona y como } \\
\text { terapeuta que me } \\
\text { estoy formando } \\
\text { veo una } \\
\text { situación un }\end{array}$ & $\begin{array}{l}\quad \text { Intervencio } \\
\text { nes narrativas } \\
\text { en situaciones } \\
\text { de deserción } \\
\text { escolar }\end{array}$ & Historias \\
\hline
\end{tabular}




\section{LA DESERCIÓN ESCOLAR COMO PRETEXTO PARA CONVERSAR SOBRE IDENTIDAD, FAMILIA Y ESCUELA

poco compleja

pero siento que,

que Laura tiene

mucho que

contar, mucho

que decir y

cuando ella

saque todo eso

posiblemente

vamos a

encontrar

caminos

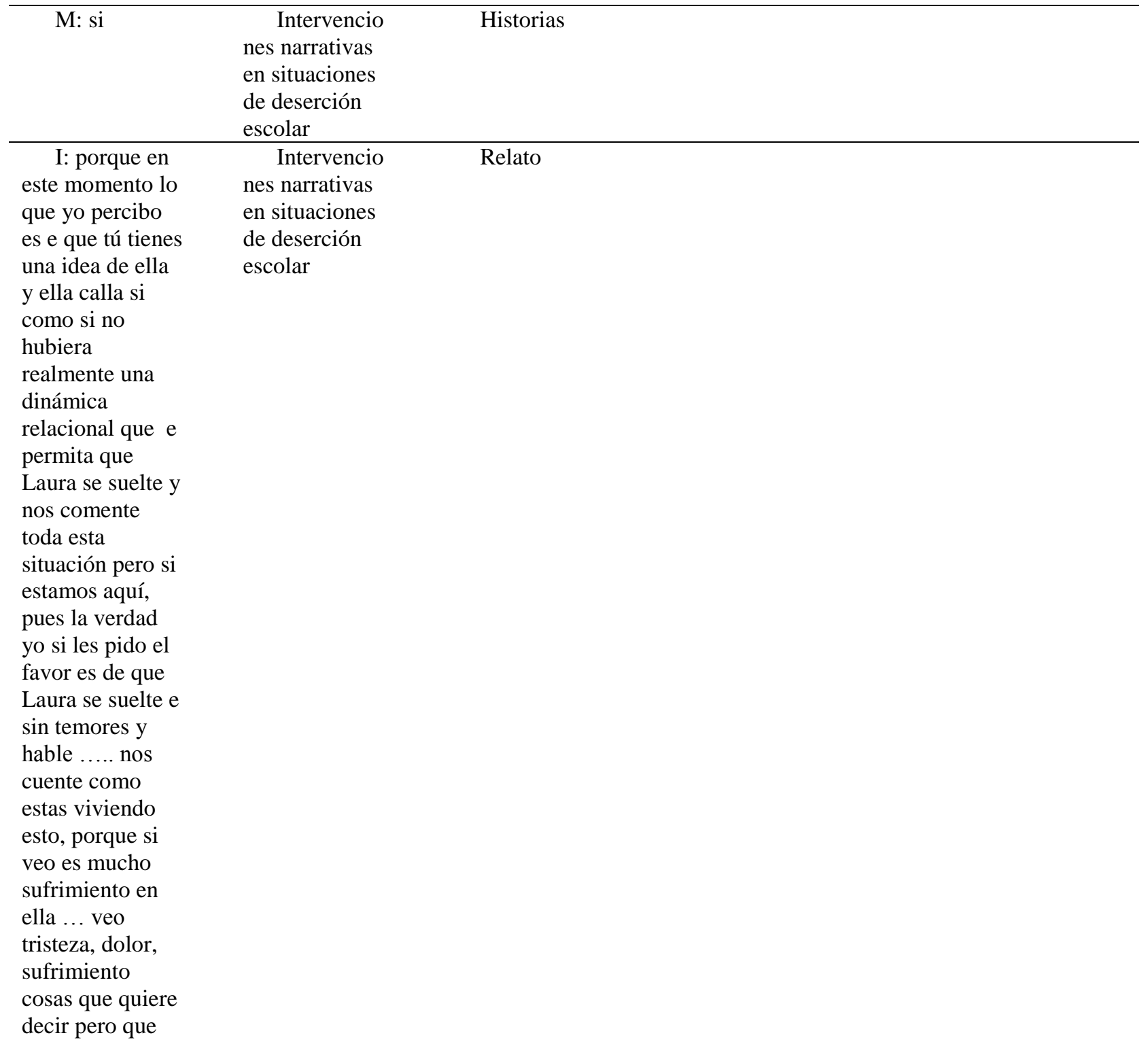




\section{LA DESERCIÓN ESCOLAR COMO PRETEXTO PARA CONVERSAR SOBRE IDENTIDAD, FAMILIA Y ESCUELA

las calla,

entonces eso me

....

\begin{tabular}{lll}
\hline \multicolumn{1}{c}{ M: si yo me } & \multicolumn{1}{c}{ Intervencio } & \multicolumn{1}{c}{ La madre } \\
he dado cuenta & nes narrativas & Historias \\
de eso y ella es & en situaciones & intenta crear \\
de las que....... & de deserción & narrativas en las \\
Se crea, se & escolar & que su hija, y su \\
ahoga en un & & actitud son los \\
vaso de agua, & & culpables del \\
por decirlo & problema percibido, \\
palabras más & realimentando lo \\
palabras menos, & & que hasta ahora se \\
se está creando & & configura en un \\
así como & relato saturado, que \\
rencores y odios & & parece hace que las \\
por cosas bobas & & dos choquen y \\
& & genere situaciones \\
& & de este tipo.
\end{tabular}

\begin{tabular}{|c|c|c|}
\hline \begin{tabular}{l}
\multicolumn{1}{c}{ I: entonces } \\
en el próximo \\
encuentro Laura \\
.... Vamos a \\
hablar y vamos a \\
hablar mucho te \\
pido ese favor, \\
listo Laurita \\
muchísimas \\
gracias
\end{tabular} & $\begin{array}{l}\quad \text { Intervencio } \\
\text { nes narrativas } \\
\text { en situaciones } \\
\text { de deserción } \\
\text { escolar }\end{array}$ & Historias \\
\hline
\end{tabular}

Escenario 2.

Intervenciones historias Participantes y Abreviaturas

narrativas en

situación de

deserción escolar

Construcción

narrativa de la

identidad

Relación joven,

familia e institución

educativa en torno a

la deserción escolar.
Hija:( A)

Terapueta(I)

\section{relatos}

acontecim

iento

relatos

emergentes 


\section{LA DESERCIÓN ESCOLAR COMO PRETEXTO PARA CONVERSAR SOBRE IDENTIDAD, FAMILIA Y ESCUELA

\begin{tabular}{|c|c|c|c|c|}
\hline Textualidad & $\begin{array}{c}\text { concepto } \\
\text { metodologico }\end{array}$ & $\begin{array}{l}\text { Categorias } \\
\text { Macroproyecto } \\
\mathrm{s}\end{array}$ & $\begin{array}{l}\text { Heterroreferen } \\
\text { ciales }\end{array}$ & $\begin{array}{l}\text { Autorreferen } \\
\text { ciales }\end{array}$ \\
\hline \begin{tabular}{l}
\multicolumn{1}{c}{ I: Pues han } \\
pasado ya quince \\
días, casi quince días \\
desde que nos vimos \\
la última vez y hoy \\
arrancamos con \\
nuestro segundo \\
encuentro. Entonces \\
me gustaría saber \\
¿qué cambios han \\
tenido? Si se han \\
notado algún \\
cambio...qué ha \\
pasado a nivel de \\
ustedes dos, de la \\
familia...cómo se \\
han sentido después \\
de que tuvimos \\
nuestro primer \\
encuentro a hoy que \\
tenemos nuestro \\
segundo encuentro.
\end{tabular} & $\begin{array}{l}\quad \text { Intervenci } \\
\text { ones } \\
\text { narrativas en } \\
\text { situaciones de } \\
\text { deserción } \\
\text { escolar }\end{array}$ & $\begin{array}{l}\text { Acontecimi } \\
\text { entos }\end{array}$ & & \\
\hline $\begin{array}{l}\quad \text { M: (Silencio) } \\
\text { Pues de un } \\
\text { encuentro para acá, } \\
\text { pues no, L cambios } \\
\text { cambios...no. } \\
\text { Ninguno, o sea ella } \\
\text { sigue en la misma } \\
\text { tónica de no hacer } \\
\text { caso...mmm no } \\
\text { quiere, no quiere y } \\
\text { no quiere hacer } \\
\text { nada, realmente es } \\
\text { nada. Sentada, } \\
\text { relajada mirando } \\
\text { televisión o en el } \\
\text { computador. }\end{array}$ & $\begin{array}{l}\quad \text { Construcci } \\
\text { ón narrativa } \\
\text { de la } \\
\text { identidad }\end{array}$ & Historias & $\begin{array}{l}\text { La madre de la } \\
\text { consultante, } \\
\text { mantiene la } \\
\text { percepcion de } \\
\text { imposibilidad de } \\
\text { cambio }\end{array}$ & \\
\hline $\begin{array}{l}\quad \text { I: Y... ¿L qué } \\
\text { nos dice al respecto? } \\
\text { Usted siente que sí } \\
\text { ha habido algún } \\
\text { cambio o que por el } \\
\text { contrario D tiene } \\
\text { razón, que no se ha } \\
\text { generado ningún } \\
\text { cambio, que todo } \\
\text { sigue igual plano } \\
\text { "fuimos, hablamos y } \\
\text { no pasó nada más". } \\
\text { Cuéntame L. }\end{array}$ & $\begin{array}{l}\quad \text { Intervenci } \\
\text { ones } \\
\text { narrativas en } \\
\text { situaciones de } \\
\text { deserción } \\
\text { escolar }\end{array}$ & Historias & & \\
\hline
\end{tabular}




\section{LA DESERCIÓN ESCOLAR COMO PRETEXTO PARA CONVERSAR SOBRE IDENTIDAD, FAMILIA Y ESCUELA

\begin{tabular}{lll}
\multicolumn{1}{l}{ A: Pues si (Risa } & \multicolumn{1}{c}{ Construcci } & Historias \\
nerviosa), no. Mmm & ón narrativa & \\
nada, todo sigue & de la & \\
igual. & identidad &
\end{tabular}

$\begin{array}{ll} & \text { que se encamina a } \\ & \text { construir un deafio } \\ & \text { frente a la } \\ & \text { desesperacion de } \\ & \text { la madre. }\end{array}$

\begin{tabular}{|c|c|c|c|}
\hline $\begin{array}{l}\quad \text { I: ¿Y qué creen } \\
\text { que hace falta, por } \\
\text { qué todo seguirá } \\
\text { igual? O sea, todo } \\
\text { está como } \\
\text { muy... amalgamado } \\
\text { ¿sí? Ahí, como que } \\
\text { no. ¿Qué creen que } \\
\text { hace falta? }\end{array}$ & $\begin{array}{l}\quad \text { Intervenci } \\
\text { ones } \\
\text { narrativas en } \\
\text { situaciones de } \\
\text { deserción } \\
\text { escolar }\end{array}$ & Historias & \\
\hline $\begin{array}{l}\quad \text { M: Pues yo me } \\
\text { imagino que es } \\
\text { como que ella } \\
\text { exprese qué es lo } \\
\text { que quiere, qué es lo } \\
\text { que espera...de } \\
\text { nosotros o qué es lo } \\
\text { que piensa de ella a } \\
\text { veces o... (silencio) }\end{array}$ & $\begin{array}{l}\quad \text { Intervenci } \\
\text { ones } \\
\text { narrativas en } \\
\text { situaciones de } \\
\text { deserción } \\
\text { escolar }\end{array}$ & Historias & \begin{tabular}{l}
\multicolumn{1}{c}{ La madre } \\
busca generar la \\
comunicacion con \\
la hija, \\
construyendo una \\
anarratva aun \\
esceptica del \\
resultado final.
\end{tabular} \\
\hline $\begin{array}{l}\text { I: ¿M considera } \\
\text { que es eso...que es } \\
\text { algo que L debe } \\
\text { contar? }\end{array}$ & $\begin{array}{l}\quad \text { Intervenci } \\
\text { ones } \\
\text { narrativas en } \\
\text { situaciones de } \\
\text { deserción } \\
\text { escolar }\end{array}$ & Historias & \\
\hline \begin{tabular}{l}
\multicolumn{1}{c}{ M: Si, es algo } \\
que ella...muchas \\
veces yo se lo he \\
dicho, muchas veces \\
yo se lo he dicho. Le \\
he dicho que si me \\
quiere decir "no la \\
admiro" "la odio" \\
"vieja desgraciada" \\
dígamelo pero, \\
dígamelo. O sea, no \\
me importa lo que \\
me diga pero \\
dígamelo, pero \\
hable, exprese algo. \\
Muchas veces la he \\
molestado, hay \\
veces hasta mejor \\
dicho me toca casi \\
amenazarla pa' que \\
me suelte aunque sea \\
una palabra.
\end{tabular} & $\begin{array}{l}\quad \text { Intervenci } \\
\text { ones } \\
\text { narrativas en } \\
\text { situaciones de } \\
\text { deserción } \\
\text { escolar }\end{array}$ & Experiencia & \begin{tabular}{l}
\multicolumn{1}{c}{ La madre } \\
describe la \\
comunicacion que \\
existe entre las dos \\
como una \\
generacion de \\
narrativas en \\
contextos \\
amenazantes y \\
obligantes.
\end{tabular} \\
\hline
\end{tabular}




\section{LA DESERCIÓN ESCOLAR COMO PRETEXTO PARA CONVERSAR SOBRE IDENTIDAD, FAMILIA Y ESCUELA

\section{I: ¿La}

comunicación entre ustedes siempre ha sido así?

Mmm sí, creo que sí (risa)

\section{Construcci Historias}

ón narrativa

de la

identidad

Construcci Memorias

ón narrativa

de la

identidad
La consultante,

concuerda y de

nuevo rie frente a

las posibilidades e intenciones con su

madre y las

construcciones que

ella expresa.

\begin{tabular}{|c|c|c|c|}
\hline $\begin{array}{l}\text { I: ¿Cómo así } \\
\text { “creo”? o sea, ¿cómo } \\
\text { se comunican? } \\
\text { Normalmente } \\
\text { es...dando órdenes y } \\
\text { "yo obedezco" o } \\
\text { ¿cómo es la } \\
\text { dinámica ahí? }\end{array}$ & $\begin{array}{l}\quad \text { Intervenci } \\
\text { ones } \\
\text { narrativas en } \\
\text { situaciones de } \\
\text { deserción } \\
\text { escolar }\end{array}$ & Historias & \\
\hline $\begin{array}{l}\quad \text { M: Pues sí, por lo } \\
\text { general, yo le...yo le } \\
\text { hablo a ella...o sea } \\
\text { le pregunto alguna } \\
\text { cosa. Por ejemplo } \\
\text { llego "L por qué no } \\
\text { ha hecho tal cosa". } \\
\text { Jum se queda } \\
\text { mirándome fijo y no } \\
\text { me responde } \\
\text { absolutamente nada. } \\
\text { O algo, por ejemplo } \\
\text { que ella haga algo } \\
\text { malo y yo le digo } \\
\text { "¿por qué hizo } \\
\text { esto?" igual, queda } \\
\text { hermética y no me } \\
\text { contesta una sola } \\
\text { palabra. }\end{array}$ & $\begin{array}{l}\text { Construcci } \\
\text { ón narrativa } \\
\text { de la } \\
\text { identidad }\end{array}$ & Historias & \begin{tabular}{l}
\multicolumn{1}{c}{ La madre } \\
expresa las \\
frustraciones que \\
conlleva la \\
comunicacion con \\
su hija, y como \\
esta se entiende a \\
traves de sus ojos.
\end{tabular} \\
\hline $\begin{array}{l}\text { I: ¿Qué creen } \\
\text { ustedes que ha } \\
\text { generado ese } \\
\text { distanciamiento? }\end{array}$ & $\begin{array}{l}\quad \text { Intervenci } \\
\text { ones } \\
\text { narrativas en } \\
\text { situaciones de } \\
\text { deserción } \\
\text { escolar }\end{array}$ & Historias & \\
\hline
\end{tabular}




\section{LA DESERCIÓN ESCOLAR COMO PRETEXTO PARA CONVERSAR SOBRE IDENTIDAD, FAMILIA Y ESCUELA

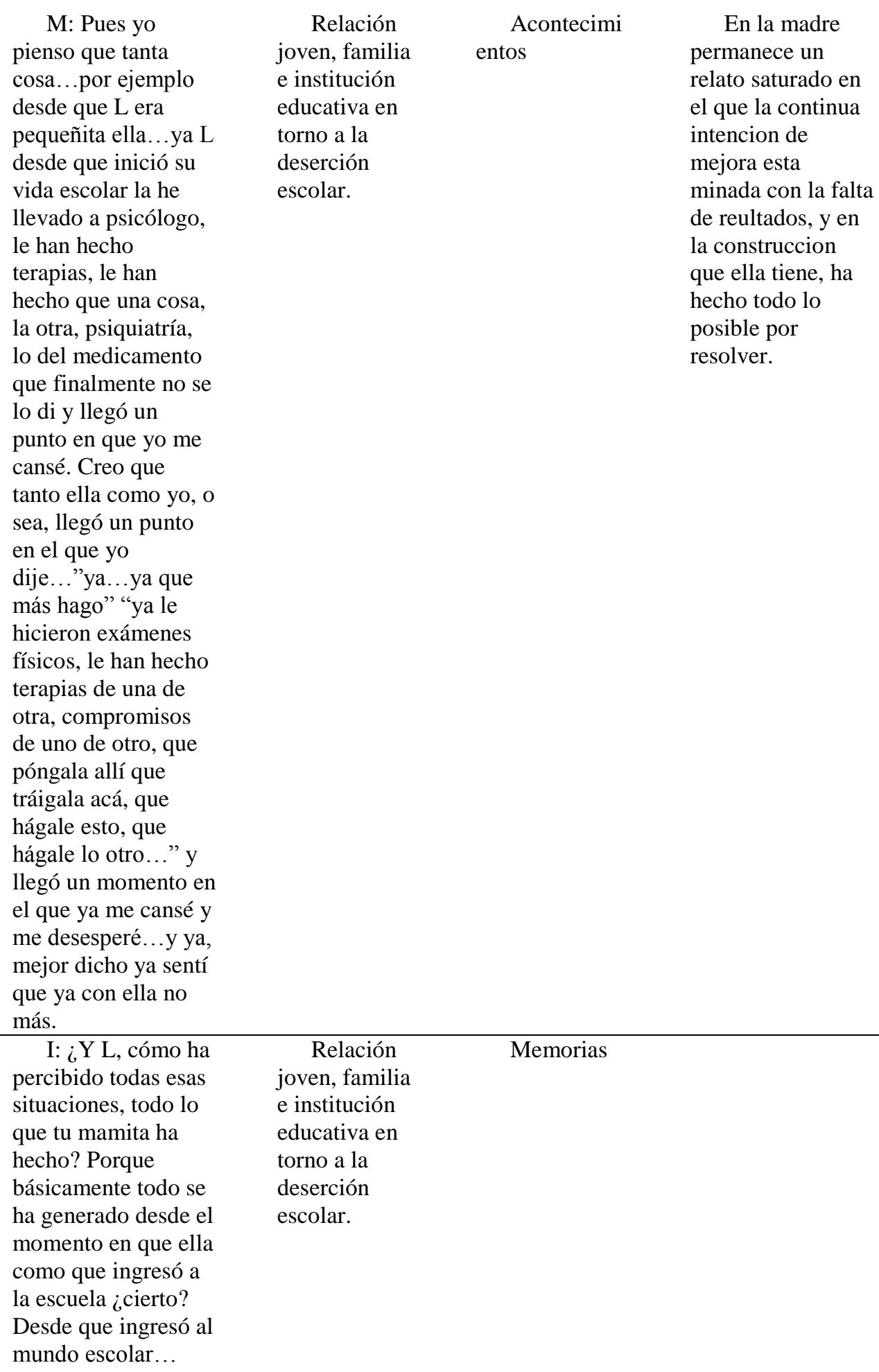

M: Pues yo pienso que tanta cosa...por ejemplo desde que L era pequeñita ella...ya L desde que inició su vida escolar la he llevado a psicólogo, le han hecho terapias, le han hecho que una cosa, la otra, psiquiatría, lo del medicamento que finalmente no se lo di y llegó un punto en que yo me cansé. Creo que tanto ella como yo, o sea, llegó un punto en el que yo dije..."ya...ya que más hago" "ya le hicieron exámenes físicos, le han hecho terapias de una de otra, compromisos de uno de otro, que póngala allí que tráigala acá, que hágale esto, que hágale lo otro..." y llegó un momento en el que ya me cansé y me desesperé...y ya, mejor dicho ya sentí que ya con ella no más.

I: ¿Y L, cómo ha percibido todas esas situaciones, todo lo que tu mamita ha hecho? Porque básicamente todo se ha generado desde el momento en que ella como que ingresó a la escuela ¿cierto? Desde que ingresó al mundo escolar...

\author{
Relación \\ e institución \\ educativa en \\ torno a la \\ deserción \\ escolar.
}

joven, familia

Acontecimi
entos

\section{En la madre} permanece un relato saturado en el que la continua intencion de mejora esta minada con la falta de reultados, y en la construccion que ella tiene, ha hecho todo lo posible por resolver.

$\quad$ Relación
joven, familia
e institución
educativa en
torno a la
deserción
escolar.




\section{LA DESERCIÓN ESCOLAR COMO PRETEXTO PARA CONVERSAR SOBRE IDENTIDAD, FAMILIA Y ESCUELA \\ 273}

\footnotetext{
M: Es que inició desde el jardín, desde chiquita siempre "uy esa niña es terrible" o sea cuando era chiquita me decían "esa niña es terrible" "esa niña quieta" ¿sí? Cosas así, desde el jardín.

\section{M: No pues yo} en ese momento a eso no le paré bolas porque es como si ahorita de D me dicen eso, como decía mi abuelo "no ve que está vivo" (risa). Entonces... si, no o sea en ese momento, pues un niño de tres años de cuatro años pues ¿qué hace?, jugar, correr y como explorar ¿no? Ya cuando empezó en el kínder, ya en un buen colegio como tal, ya pues...hice el paso a seguir, ya la psicóloga me sugirió que le sacara cita psicológica por la EPS, ya de la EPS la mandaron a terapias y sí, pues hasta ahí todo fue normal. Prácticamente hasta quinto de primaria yo no le di ninguna importancia a las quejas porque las quejas eran...mmm...pues lo normal de un niño, que es que se paró, que habló, pues hasta ahí no...pues yo la
}

Relación joven, familia e institución educativa en torno a la deserción escolar.

\author{
Las \\ percepciones y \\ narrativas \\ construidas por los \\ contextos sobre la \\ consultante la \\ describen siempre \\ a traves de la \\ optica de la \\ violencia.
}

\begin{tabular}{lll} 
I: ¿Y usted se & \multicolumn{1}{c}{ Construcci } & Historias \\
creyó también todo & $\begin{array}{l}\text { ón narrativa } \\
\text { de la } \\
\text { identidad }\end{array}$ & \\
eso? & ide
\end{tabular}

$\quad$ Intervenci
ones
narrativas en
situaciones de
deserción
escolar

narrativas en

situaciones de

deserción

escolar

Experiencia

\author{
La percepcion \\ de problema, se \\ origina bien \\ entrada la etapa \\ escolar de la \\ consultante, sin \\ embargo, en el \\ relato saturado, se \\ incluye siempre \\ desde el principio \\ de la edad escolar \\ el surgimiento del \\ problema.
}




\section{LA DESERCIÓN ESCOLAR COMO PRETEXTO PARA CONVERSAR SOBRE IDENTIDAD, FAMILIA Y ESCUELA

llevaba bien a sus

terapias y eso,

pero...y

académicamente

pues nunca fue un

nivel superior, pero

tampoco perdía.

\begin{tabular}{|c|c|c|c|}
\hline $\begin{array}{l}\quad \text { I: Pero y los } \\
\text { avances a nivel } \\
\text { psicológico se veían } \\
\text { o siempre hubo } \\
\text { como no sé...me } \\
\text { gustaría que me } \\
\text { compartiera algo de } \\
\text { cómo fue esa parte } \\
\text { psicológica, pero } \\
\text { que L también nos } \\
\text { cuente a través de su } \\
\text { voz, qué sentía ella } \\
\text { en ese momento. }\end{array}$ & $\begin{array}{l}\text { Construcci } \\
\text { ón narrativa } \\
\text { de la } \\
\text { identidad }\end{array}$ & $\begin{array}{l}\text { Relatos } \\
\text { alternos }\end{array}$ & \\
\hline $\begin{array}{l}\quad \text { A: No...no le } \\
\text { paraba bolas (risa) } \\
\text { por decirlo así, } \\
\text { porque todas las } \\
\text { terapias que recibía } \\
\text { eran solo "dime tu } \\
\text { nombre, dibuja a tu } \\
\text { familia, has un } \\
\text { rompecabezas..." y } \\
\text { ahí terminaba. }\end{array}$ & $\begin{array}{l}\text { Construcci } \\
\text { ón narrativa } \\
\text { de la } \\
\text { identidad }\end{array}$ & Memorias & $\begin{array}{l}\quad \text { A traves de las } \\
\text { intervenciones } \\
\text { fallidas, se genera } \\
\text { una narrativa, en la } \\
\text { cual hay inutilidad } \\
\text { de la terapia al } \\
\text { igual que la } \\
\text { problematica se } \\
\text { convertia mas y } \\
\text { mas en un } \\
\text { problema sin } \\
\text { solucion. }\end{array}$ \\
\hline $\begin{array}{l}\text { I: O sea, nunca } \\
\text { fueron más allá. }\end{array}$ & \begin{tabular}{l}
\multicolumn{1}{c}{ Relación } \\
joven, familia \\
e institución \\
educativa en \\
torno a la \\
deserción \\
escolar.
\end{tabular} & Memorias & \\
\hline
\end{tabular}




\section{LA DESERCIÓN ESCOLAR COMO PRETEXTO PARA CONVERSAR SOBRE IDENTIDAD, FAMILIA Y ESCUELA

\begin{tabular}{|c|c|c|c|}
\hline $\begin{array}{l}\text { A: No. Hasta mi } \\
\text { mami se dio cuenta } \\
\text { de eso...pues no... }\end{array}$ & $\begin{array}{l}\quad \text { Intervenci } \\
\text { ones } \\
\text { narrativas en } \\
\text { situaciones de } \\
\text { deserción } \\
\text { escolar }\end{array}$ & Memorias & \\
\hline $\begin{array}{l}\text { M: Si...o sea yo } \\
\text { esperaba que dijeran } \\
\text { "bueno, vamos a } \\
\text { aplicar esta técnica o } \\
\text { esta terapia" ¿sí? O } \\
\text { "hagámosle esto o } \\
\text { hágale lo otro" pero } \\
\text { no nada... }\end{array}$ & $\begin{array}{l}\quad \text { Relación } \\
\text { joven, familia } \\
\text { e institución } \\
\text { educativa en } \\
\text { torno a la } \\
\text { deserción } \\
\text { escolar. }\end{array}$ & Experiencia & \\
\hline $\begin{array}{l}\text { I: Y las cosas } \\
\text { continuaban igual, o } \\
\text { avanzaron }\end{array}$ & $\begin{array}{l}\quad \text { Intervenci } \\
\text { ones } \\
\text { narrativas en } \\
\text { situaciones de } \\
\text { deserción } \\
\text { escolar } \\
\end{array}$ & Memorias & \\
\hline $\begin{array}{l}\quad \text { M: Siguieron } \\
\text { igual, se fue } \\
\text { creciendo como una } \\
\text { bola de nieve. Y } \\
\text { empeoró, empeoró o } \\
\text { sea ya se convirtió } \\
\text { en un problema real } \\
\text { cuando ella pasó a } \\
\text { sexto grado. O sea } \\
\text { no sé si fue una } \\
\text { coincidencia, o no sé } \\
\text { si lo estoy tomando a } \\
\text { mal y coincidieron } \\
\text { las cosas, pero } \\
\text { entonces ella entró, } \\
\text { pues cambió, hubo } \\
\text { ese cambio de } \\
\text { primaria a } \\
\text { bachillerato. En ese } \\
\text { mismo año llegó el } \\
\text { bebé. Entonces no } \\
\text { sé, como fue todo } \\
\text { como un revolcón al } \\
\text { mismo tiempo y } \\
\text { porque fue de ahí en } \\
\text { adelante cuando las } \\
\text { cosas ya se } \\
\text { empezaron a salir de } \\
\text { ahí. }\end{array}$ & $\begin{array}{l}\text { Construcci } \\
\text { ón narrativa } \\
\text { de la } \\
\text { identidad }\end{array}$ & $\begin{array}{l}\text { Acontecimi } \\
\text { entos }\end{array}$ & $\begin{array}{l}\quad \text { En el momento } \\
\text { en que el balance } \\
\text { de la familia } \\
\text { cambia, inician } \\
\text { narrativas } \\
\text { diferentes dentro } \\
\text { de la problematica } \\
\text { percibida, que } \\
\text { generan acciones } \\
\text { critica en ambos } \\
\text { lados. }\end{array}$ \\
\hline
\end{tabular}




\section{LA DESERCIÓN ESCOLAR COMO PRETEXTO PARA CONVERSAR SOBRE IDENTIDAD, FAMILIA Y ESCUELA

I: ¿Y L?

cuéntanos, participa

en nuestra

conversación, porque tú eres aquí

la persona más

importante para

nosotros, tú eres

básicamente el

centro de toda esta

conversación. En

relación con lo que

tu mami nos cuenta

¿qué pasó ahí? ¿qué

sucedió? Has un

poco de memoria,

cuéntame.

\begin{tabular}{|c|c|c|c|}
\hline \begin{tabular}{l}
\multicolumn{1}{c}{ M: Ehh, pues } \\
(risa), pues como yo \\
era la consentida, \\
entonces me da \\
como un poquito de \\
rabia con D (risa).
\end{tabular} & \begin{tabular}{l}
\multicolumn{1}{c}{ Construcci } \\
ón narrativa \\
de la \\
identidad
\end{tabular} & Memorias & \\
\hline $\begin{array}{l}\text { I: O sea, todo fue } \\
\text { como... }\end{array}$ & $\begin{array}{l}\quad \text { Intervenci } \\
\text { ones } \\
\text { narrativas en } \\
\text { situaciones de } \\
\text { deserción } \\
\text { escolar } \\
\end{array}$ & Memorias & \\
\hline \begin{tabular}{l}
\multicolumn{1}{c}{ A: Si, ahí si fue } \\
un revuelto de todo y \\
pues...no sé, nuevos \\
amigos...mmm...per \\
o como que no sé. \\
Pues de todos modos \\
perdía las materias y \\
todo pero pues, \\
trataba de \\
concentrarme, pero \\
no.
\end{tabular} & $\begin{array}{l}\quad \text { Relación } \\
\text { joven, familia } \\
\text { e institución } \\
\text { educativa en } \\
\text { torno a la } \\
\text { deserción } \\
\text { escolar. }\end{array}$ & Memorias & \begin{tabular}{l}
\multicolumn{1}{c}{ Inicia una } \\
reconstruccion de \\
momentos, en los \\
que surgen \\
comprensiones \\
frente a su \\
crecimeinto \\
personal y su \\
impacto dentro del \\
contexto familiar.
\end{tabular} \\
\hline $\begin{array}{l}\text { I: ¿En qué } \\
\text { pensabas? Cuando te } \\
\text { salías de la clase, de } \\
\text { la explicación ¿en } \\
\text { qué pensabas? ¿A } \\
\text { dónde iban tus } \\
\text { pensamientos? }\end{array}$ & $\begin{array}{l}\quad \text { Intervenci } \\
\text { ones } \\
\text { narrativas en } \\
\text { situaciones de } \\
\text { deserción } \\
\text { escolar }\end{array}$ & Memorias & \\
\hline
\end{tabular}

Intervenci

ones

narrativas en

situaciones de

deserción

escolar
Memorias 


\section{LA DESERCIÓN ESCOLAR COMO PRETEXTO PARA CONVERSAR SOBRE IDENTIDAD, FAMILIA Y ESCUELA

\begin{tabular}{ll}
\multicolumn{1}{r}{ A: mmm...no } & \multicolumn{1}{c}{ Construcci } \\
pues lo que le decía & ón narrativa \\
antes. Me ponía a & de la \\
dibujar o a rayar, o & identidad \\
me distraía. &
\end{tabular}

\author{
Memorias
}

La no

verbalizacion de su construccion actual frente a las nuevas circunstancias del contexto genera, una narrativa saturada en la que no se enfrenta el problema sino que se permite salir de su mente.

\begin{tabular}{|c|c|c|}
\hline $\begin{array}{l}\text { I: Pero había una } \\
\text { situación especial, } \\
\text { por ejemplo } \\
\text { ¿pensabas en D } \\
\text { (hermano)? }\end{array}$ & $\begin{array}{l}\quad \text { Intervenci } \\
\text { ones } \\
\text { narrativas en } \\
\text { situaciones de } \\
\text { deserción } \\
\text { escolar }\end{array}$ & Memorias \\
\hline A: No, pues no. & $\begin{array}{l}\quad \text { Intervenci } \\
\text { ones } \\
\text { narrativas en } \\
\text { situaciones de } \\
\text { deserción } \\
\text { escolar }\end{array}$ & Memorias \\
\hline $\begin{array}{l}\quad \text { I: Entonces } \\
\text { ¿cómo manejó lo de } \\
\text { D (hermano). } \\
\text { Cuéntanos esa parte. } \\
\text { Dices “sentí un } \\
\text { poquito de rabia. } \\
\text { ¿Alguna vez le } \\
\text { dijiste a tu mamá } \\
\text { eso? }\end{array}$ & $\begin{array}{l}\quad \text { Intervenci } \\
\text { ones } \\
\text { narrativas en } \\
\text { situaciones de } \\
\text { deserción } \\
\text { escolar }\end{array}$ & Memorias \\
\hline A: ehhh no. & $\begin{array}{l}\quad \text { Intervenci } \\
\text { ones } \\
\text { narrativas en } \\
\text { situaciones de } \\
\text { deserción } \\
\text { escolar }\end{array}$ & Memorias \\
\hline $\begin{array}{l}\quad \text { I: Hoy lo estás } \\
\text { confesando, que } \\
\text { sentías celos. }\end{array}$ & \begin{tabular}{l}
\multicolumn{1}{c}{ Intervenci } \\
ones \\
narrativas en \\
situaciones de \\
deserción \\
escolar
\end{tabular} & Memorias \\
\hline A: Sí. & $\begin{array}{l}\quad \text { Intervenci } \\
\text { ones } \\
\text { narrativas en } \\
\text { situaciones de } \\
\text { deserción } \\
\text { escolar }\end{array}$ & Memorias \\
\hline
\end{tabular}




\section{LA DESERCIÓN ESCOLAR COMO PRETEXTO PARA CONVERSAR SOBRE IDENTIDAD, FAMILIA Y ESCUELA

\author{
I: ¿Cómo era esa \\ parte? ¿Qué querías \\ hacer con ese bebé? \\ ¿cómo te sentiste ahí \\ como desplazada? A \\ ver. Porque por ahí \\ podemos ir \\ marcando nuestro \\ rumbo.
}

\begin{tabular}{|c|c|c|c|}
\hline $\begin{array}{l}\text { A: ehhh, pues en } \\
\text { ese entonces a mí me } \\
\text { daba como que } \\
\text { "Ahhh y ahora él es } \\
\text { el centro de la } \\
\text { atención" }\end{array}$ & $\begin{array}{l}\quad \text { Construcci } \\
\text { ón narrativa } \\
\text { de la } \\
\text { identidad }\end{array}$ & Memorias & \\
\hline I: Ajá & $\begin{array}{l}\quad \text { Intervenci } \\
\text { ones } \\
\text { narrativas en } \\
\text { situaciones de } \\
\text { deserción } \\
\text { escolar } \\
\end{array}$ & Memorias & \\
\hline $\begin{array}{l}\text { A: Pero no pues, } \\
\text { no más. No pensaba } \\
\text { que "ayy que se } \\
\text { fuera", no. No tanto } \\
\text { (risa) }\end{array}$ & $\begin{array}{l}\quad \text { Construcci } \\
\text { ón narrativa } \\
\text { de la } \\
\text { identidad }\end{array}$ & Memorias & $\begin{array}{l}\quad \text { Empiezan a } \\
\text { surgir narrativas, } \\
\text { en las que se } \\
\text { reconstruyen los } \\
\text { eventos y los } \\
\text { renconres no } \\
\text { verbalizados frente } \\
\text { al nacimiento de } \\
\text { su nuevo hermano. }\end{array}$ \\
\hline I: ¿No tanto? & $\begin{array}{l}\quad \text { Intervenci } \\
\text { ones } \\
\text { narrativas en } \\
\text { situaciones de } \\
\text { deserción } \\
\text { escolar } \\
\end{array}$ & Memorias & \\
\hline A: (risa) & $\begin{array}{l}\quad \text { Construcci } \\
\text { ón narrativa } \\
\text { de la } \\
\text { identidad }\end{array}$ & Memorias & \\
\hline $\begin{array}{l}\text { I: Llegaste a } \\
\text { pensarlo. }\end{array}$ & $\begin{array}{l}\quad \text { Intervenci } \\
\text { ones } \\
\text { narrativas en } \\
\text { situaciones de } \\
\text { deserción } \\
\text { escolar } \\
\end{array}$ & Memorias & \\
\hline A: (risa) Ehhh si & $\begin{array}{l}\quad \text { Construcci } \\
\text { ón narrativa } \\
\text { de la } \\
\text { identidad }\end{array}$ & Memorias & \\
\hline $\begin{array}{l}\text { I: Y ¿cómo } \\
\text { querías ver a tu } \\
\text { hermano? Cómo, ¿te } \\
\text { imaginabas que sería }\end{array}$ & $\begin{array}{l}\quad \text { Construcci } \\
\text { ón narrativa } \\
\text { de la } \\
\text { identidad }\end{array}$ & Memorias & \\
\hline
\end{tabular}

\section{Construcci Memorias}

ón narrativa

de la

identidad 


\section{LA DESERCIÓN ESCOLAR COMO PRETEXTO PARA CONVERSAR SOBRE IDENTIDAD, FAMILIA Y ESCUELA

mejor la vida sin tu

hermano? O cómo.

\begin{tabular}{|c|c|c|c|}
\hline $\begin{array}{l}\text { A: (Silencio) No, } \\
\text { no imaginaba eso. } \\
\text { La verdad no, decía } \\
\text { como que "ash que } \\
\text { mamera" "ash } \\
\text { ahora...(no sé) } \\
\text { Ahora le van a } \\
\text { prestar muchas más } \\
\text { atención a él" }\end{array}$ & $\begin{array}{l}\quad \text { Construcci } \\
\text { ón narrativa } \\
\text { de la } \\
\text { identidad }\end{array}$ & Memorias & $\begin{array}{l}\quad \text { La falta de } \\
\text { atencion, parece } \\
\text { generar una } \\
\text { construccion de } \\
\text { miedo en la } \\
\text { consultante, y de } \\
\text { sozobra frente a su } \\
\text { rol e importancia } \\
\text { en la familia. }\end{array}$ \\
\hline $\begin{array}{l}\text { I: Y eso te } \\
\text { molestaba. }\end{array}$ & $\begin{array}{l}\quad \text { Construcci } \\
\text { ón narrativa } \\
\text { de la } \\
\text { identidad }\end{array}$ & Memorias & \\
\hline $\begin{array}{l}\text { A: Si, me daba } \\
\text { fastidio. Pues } \\
\text { ya...obviamente } \\
\text { pues ya no, ¿no? }\end{array}$ & $\begin{array}{l}\quad \text { Construcci } \\
\text { ón narrativa } \\
\text { de la } \\
\text { identidad }\end{array}$ & $\begin{array}{l}\text { Relatos } \\
\text { alternos }\end{array}$ & \\
\hline $\begin{array}{l}\text { I: Ajá, y todo } \\
\text { esto que tú sentías } \\
\text { coincidió con la } \\
\text { pérdida del año. }\end{array}$ & $\begin{array}{l}\quad \text { Relación } \\
\text { joven, familia } \\
\text { e institución } \\
\text { educativa en } \\
\text { torno a la } \\
\text { deserción } \\
\text { escolar. }\end{array}$ & Memorias & \\
\hline $\begin{array}{l}\quad \text { A: Sí. Y pues } \\
\text { como que perdí por } \\
\text { matemáticas, nunca } \\
\text { me fue bien en } \\
\text { matemáticas, solo en } \\
\text { quinto grado que fue } \\
\text { con la profesora } \\
\text { Diana. Ehh pues } \\
\text { ella...la mejor } \\
\text { profesora (risa), que } \\
\text { he tenido. Si había } \\
\text { un momento, ella se } \\
\text { sentaba con uno y le } \\
\text { explicaba hasta que } \\
\text { le entendiera y pues } \\
\text { eso la...es bien ¿no? } \\
\text { Y pues ya después } \\
\text { fue con otra } \\
\text { profesora que ponía } \\
\text { ejercicios que ni ella } \\
\text { podía desarrollar. } \\
\text { Y...con todos, era } \\
\text { muy gritona y } \\
\text { seria...y seca. }\end{array}$ & $\begin{array}{l}\quad \text { Relación } \\
\text { joven, familia } \\
\text { e institución } \\
\text { educativa en } \\
\text { torno a la } \\
\text { deserción } \\
\text { escolar. }\end{array}$ & relato & \begin{tabular}{l}
\multicolumn{1}{c}{ Empieza a } \\
generarse una \\
construccion de \\
memorias, en las \\
que su relacion \\
con los profesores \\
y la forma en la \\
que era tratada se \\
torna en un relato \\
posibilitador o \\
saturado \\
dependiendo del \\
impoacto que tiene \\
frente a su propia \\
construccion.
\end{tabular} \\
\hline
\end{tabular}




\section{LA DESERCIÓN ESCOLAR COMO PRETEXTO PARA CONVERSAR SOBRE IDENTIDAD, FAMILIA Y ESCUELA

I: Ahh ok. Muy
gritona, seria, seca.
¿será que tu mamá
se parece a esa
profesora? ¿En algo?

ones

narrativas en

situaciones de

deserción

escolar

\begin{tabular}{clc}
\hline A: (risa) No & $\begin{array}{c}\text { Relación } \\
\text { joven, familia }\end{array}$ & Historias \\
& e institución & \\
& educativa en & \\
& torno a la & \\
& deserción & \\
& escolar. & Memorias \\
& Relación & \\
I: ¿en algo te la & joven, familia & \\
recuerda? & e institución & \\
& educativa en & \\
& torno a la & \\
& deserción &
\end{tabular}

Relación Memorias

joven, familia

e institución

educativa en

torno a la

deserción

escolar.

\begin{tabular}{|c|c|c|c|}
\hline $\begin{array}{l}\text { I: Porque ella } \\
\text { también es brava. }\end{array}$ & $\begin{array}{l}\quad \text { Relación } \\
\text { joven, familia } \\
\text { e institución } \\
\text { educativa en } \\
\text { torno a la } \\
\text { deserción } \\
\text { escolar. }\end{array}$ & Historias & \\
\hline $\begin{array}{l}\quad \text { A: Pues sí, es } \\
\text { estricta, pero...no } \\
\text { (risa). Pero no pues } \\
\text { obviamente esa } \\
\text { profesora era todo el } \\
\text { tiempo de mal } \\
\text { humor y...ehh no } \\
\text { explicaba, para todos } \\
\text { eran malas notas } \\
\text { y...bueno. No } \\
\text { explicaba bien } \\
\text { y...bueno. }\end{array}$ & $\begin{array}{l}\quad \text { Relación } \\
\text { joven, familia } \\
\text { e institución } \\
\text { educativa en } \\
\text { torno a la } \\
\text { deserción } \\
\text { escolar. }\end{array}$ & $\begin{array}{l}\text { Acontecimi } \\
\text { entos }\end{array}$ & $\begin{array}{l}\text { La consultante } \\
\text { no relaciona la } \\
\text { experiencia de su } \\
\text { profesora con su } \\
\text { mama, sino que } \\
\text { puede separa } \\
\text { efectivamente las } \\
\text { dos narrativas. }\end{array}$ \\
\hline $\begin{array}{l}\text { I: Pero entonces } \\
\text { así, debo } \\
\text { comprender que en } \\
\text { tu cabeza se formó } \\
\text { como un caos } \\
\text { porque llegó tu } \\
\text { hermano, porque tú }\end{array}$ & $\begin{array}{l}\quad \text { Relación } \\
\text { joven, familia } \\
\text { e institución } \\
\text { educativa en } \\
\text { torno a la } \\
\text { deserción } \\
\text { escolar. }\end{array}$ & Memorias & \\
\hline
\end{tabular}




\section{LA DESERCIÓN ESCOLAR COMO PRETEXTO PARA CONVERSAR SOBRE IDENTIDAD, FAMILIA Y ESCUELA

encima de todo

entonces con una

profesora pasaste

matemáticas, pero

con la otra era

horrible. Entonces

todo eso, ¿A dónde

iba encaminado?

¿qué querías?

\begin{tabular}{|c|c|c|c|}
\hline $\begin{array}{l}\text { A: (silencio) } \\
\text { mmm. }\end{array}$ & $\begin{array}{l}\quad \text { Intervenci } \\
\text { ones } \\
\text { narrativas en } \\
\text { situaciones de } \\
\text { deserción } \\
\text { escolar }\end{array}$ & Memorias & $\begin{array}{l}\quad \text { El silencio } \\
\text { construye dudas } \\
\text { frente a si la } \\
\text { relacion realmente, } \\
\text { era una percepcion } \\
\text { que tenia en un } \\
\text { determinado } \\
\text { momento. }\end{array}$ \\
\hline $\begin{array}{l}\text { I: ¿Querías decir } \\
\text { “aquí estoy mundo”? } \\
\text { ¿Tal vez? }\end{array}$ & $\begin{array}{l}\quad \text { Intervenci } \\
\text { ones } \\
\text { narrativas en } \\
\text { situaciones de } \\
\text { deserción } \\
\text { escolar }\end{array}$ & Memorias & \\
\hline \begin{tabular}{l}
\multicolumn{1}{c}{ A: Pues...Si. } \\
Pero pues tanto \\
como... que solo me \\
pusieran atención a \\
mí y no a mi \\
hermano...pero pues \\
de todos modos mi \\
hermano...es un \\
bebé. Pues ahí era \\
más chiquito y pues \\
obviamente, no tenía \\
la misma atención \\
¿no?
\end{tabular} & \begin{tabular}{l}
\multicolumn{1}{c}{ Intervenci } \\
ones \\
narrativas en \\
situaciones de \\
deserción \\
escolar
\end{tabular} & $\begin{array}{l}\text { Relatos } \\
\text { alternos }\end{array}$ & \begin{tabular}{l}
\multicolumn{1}{c}{ La percepcion } \\
de la consultante, \\
aun busca la \\
validacion de \\
alguien para tomar \\
fuerza en su propio \\
discurso a pesar de \\
seguridad.
\end{tabular} \\
\hline $\begin{array}{l}\text { I: ¿D en algún } \\
\text { momento percibió } \\
\text { eso? }\end{array}$ & $\begin{array}{l}\quad \text { Intervenci } \\
\text { ones } \\
\text { narrativas en } \\
\text { situaciones de } \\
\text { deserción } \\
\text { escolar }\end{array}$ & Memorias & \\
\hline
\end{tabular}




\section{LA DESERCIÓN ESCOLAR COMO PRETEXTO PARA CONVERSAR SOBRE IDENTIDAD, FAMILIA Y ESCUELA

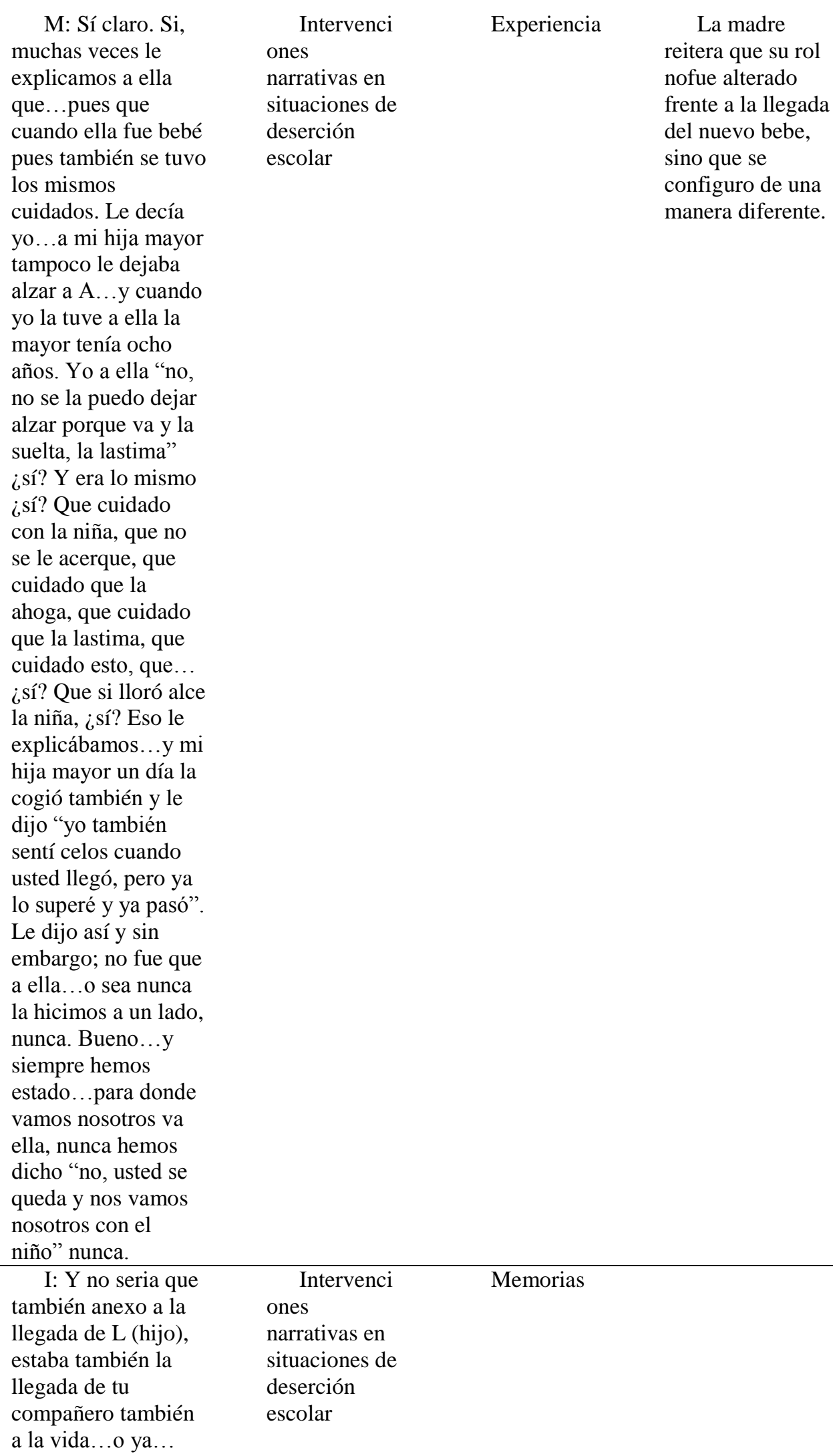

M: Sí claro. Si, muchas veces le explicamos a ella que...pues que cuando ella fue bebé pues también se tuvo los mismos cuidados. Le decía yo... a mi hija mayor tampoco le dejaba alzar a A...y cuando yo la tuve a ella la mayor tenía ocho años. Yo a ella "no, no se la puedo dejar alzar porque va y la suelta, la lastima" ¿sí? Y era lo mismo ¿sí? Que cuidado con la niña, que no se le acerque, que cuidado que la ahoga, que cuidado que la lastima, que cuidado esto, que... ¿sí? Que si lloró alce la niña, ¿sí? Eso le explicábamos...y mi hija mayor un día la cogió también y le dijo "yo también sentí celos cuando usted llegó, pero ya lo superé y ya pasó". Le dijo así y sin embargo; no fue que a ella...o sea nunca la hicimos a un lado, nunca. Bueno...y siempre hemos estado...para donde vamos nosotros va ella, nunca hemos dicho "no, usted se queda y nos vamos nosotros con el niño" nunca.

I: Y no seria que también anexo a la llegada de L (hijo), estaba también la llegada de tu compañero también a la vida...o ya...

$\quad$ Intervenci
ones
narrativas en
situaciones de
deserción
escolar

Experiencia

La madre reitera que su rol nofue alterado frente a la llegada del nuevo bebe, sino que se configuro de una manera diferente. 


\section{LA DESERCIÓN ESCOLAR COMO PRETEXTO PARA CONVERSAR SOBRE IDENTIDAD, FAMILIA Y ESCUELA

\begin{tabular}{|c|c|c|c|}
\hline M y A: No & $\begin{array}{l}\quad \text { Intervenci } \\
\text { ones } \\
\text { narrativas en } \\
\text { situaciones de } \\
\text { deserción } \\
\text { escolar } \\
\end{array}$ & Memorias & $\begin{array}{l}\quad \text { El tajante no de } \\
\text { ambas } \\
\text { consultantes, } \\
\text { muestra que hay } \\
\text { una construccion } \\
\text { muy fuerte con el. }\end{array}$ \\
\hline $\begin{array}{l}\text { A: Desde que yo } \\
\text { tenía tres años. }\end{array}$ & $\begin{array}{l}\quad \text { Intervenci } \\
\text { ones } \\
\text { narrativas en } \\
\text { situaciones de } \\
\text { deserción } \\
\text { escolar } \\
\end{array}$ & Memorias & \\
\hline $\begin{array}{l}\text { I: Si. Con él ya } \\
\text { era...ya era la } \\
\text { familia. Hace rato }\end{array}$ & $\begin{array}{l}\quad \text { Construcci } \\
\text { ón narrativa } \\
\text { de la } \\
\text { identidad }\end{array}$ & Memorias & \\
\hline $\begin{array}{l}\text { M: Sí, de hecho } \\
\text { ella formó su figura } \\
\text { paterna en él. Ella en } \\
\text { el colegio, a todo el } \\
\text { mundo le decía que } \\
\text { el papá es él. }\end{array}$ & \begin{tabular}{l}
\multicolumn{1}{c}{ Relación } \\
joven, familia \\
e institución \\
educativa en \\
torno a la \\
deserción \\
escolar.
\end{tabular} & Memorias & $\begin{array}{l}\text { La narrativa } \\
\text { parece muy solida, } \\
\text { en cuanto al rol de } \\
\text { figura paterna. }\end{array}$ \\
\hline \begin{tabular}{l}
\multicolumn{1}{c}{ I: Ajá...y } \\
entonces qué de \\
positivo le han \\
podido sacar ustedes \\
como familia al \\
hecho de que L no \\
esté en el colegio, \\
porque algo debe de \\
haber de positivo.
\end{tabular} & \begin{tabular}{l}
\multicolumn{1}{c}{ Relación } \\
joven, familia \\
e institución \\
educativa en \\
torno a la \\
deserción \\
escolar.
\end{tabular} & relato & \\
\hline M: ¿De positivo? & \begin{tabular}{l}
\multicolumn{1}{c}{ Relación } \\
joven, familia \\
e institución \\
educativa en \\
torno a la \\
deserción \\
escolar.
\end{tabular} & Historias & \\
\hline $\begin{array}{l}\text { I: O ¿cómo lo } \\
\text { perciben, cómo lo } \\
\text { ven? }\end{array}$ & \begin{tabular}{l}
\multicolumn{1}{c}{ Intervenci } \\
ones \\
narrativas en \\
situaciones de \\
deserción \\
escolar \\
\end{tabular} & Historias & \\
\hline $\begin{array}{l}\text { M: No, pues yo } \\
\text { honestamente de } \\
\text { positivo no... }\end{array}$ & $\begin{array}{l}\text { Construcci } \\
\text { ón narrativa } \\
\text { de la } \\
\text { identidad } \\
\end{array}$ & Historias & \\
\hline I: No le ves nada. & \begin{tabular}{l}
\multicolumn{1}{c}{ Intervenci } \\
ones \\
narrativas en \\
situaciones de \\
deserción
\end{tabular} & Historias & \\
\hline
\end{tabular}




\section{LA DESERCIÓN ESCOLAR COMO PRETEXTO PARA CONVERSAR SOBRE IDENTIDAD, FAMILIA Y ESCUELA

escolar

\begin{tabular}{|c|c|c|c|}
\hline $\begin{array}{l}\text { M: No le veo } \\
\text { nada. }\end{array}$ & \begin{tabular}{l}
\multicolumn{1}{c}{ Construcci } \\
ón narrativa \\
de la \\
identidad
\end{tabular} & Historias & $\begin{array}{l}\quad \text { La madre aun } \\
\text { se encuentra } \\
\text { dentro del relato } \\
\text { saturado, generado } \\
\text { por la situacion, } \\
\text { que le impide la } \\
\text { reconstruccion de } \\
\text { la memorias } \\
\text { recientes. }\end{array}$ \\
\hline I: ¿y L? & \begin{tabular}{l}
\multicolumn{1}{c}{ Intervenci } \\
ones \\
narrativas en \\
situaciones de \\
deserción \\
escolar \\
\end{tabular} & Historias & \\
\hline $\begin{array}{l}\quad \text { A: Mmm...pues } \\
\text { que, pues al } \\
\text { principio dije "pues } \\
\text { bueno, estar fuera } \\
\text { del colegio (risa) } \\
\text { pues es como } \\
\text { bueno" pero pues } \\
\text { ya...me hace falta. }\end{array}$ & $\begin{array}{l}\quad \text { Construcci } \\
\text { ón narrativa } \\
\text { de la } \\
\text { identidad }\end{array}$ & $\begin{array}{l}\text { Relatos } \\
\text { alternos }\end{array}$ & $\begin{array}{l}\quad \text { La } \\
\text { construccion de la } \\
\text { realidad, aun se } \\
\text { relaciona } \\
\text { solamente con los } \\
\text { aspectos escolares } \\
\text { no con lo que estos } \\
\text { aspectos afectan su } \\
\text { vida. }\end{array}$ \\
\hline $\begin{array}{l}\quad \text { I: O sea, en ese } \\
\text { momento para ti fue } \\
\text { como una descarga. } \\
\text { "ay no tengo que } \\
\text { cumplir con tareas, } \\
\text { ay que pereza... por } \\
\text { lo menos voy a } \\
\text { poder dormir un } \\
\text { ratico más" }\end{array}$ & $\begin{array}{l}\quad \text { Intervenci } \\
\text { ones } \\
\text { narrativas en } \\
\text { situaciones de } \\
\text { deserción } \\
\text { escolar }\end{array}$ & Memorias & \\
\hline $\begin{array}{c}\text { A: } \mathrm{Si} \text {, eso } \\
\text { pensaba (risa) }\end{array}$ & $\begin{array}{l}\quad \text { Construcci } \\
\text { ón narrativa } \\
\text { de la } \\
\text { identidad }\end{array}$ & Memorias & \\
\hline \begin{tabular}{l}
\multicolumn{1}{c}{ I: (risa) Cuán } \\
equivocada estabas. \\
Y D... ¿en verdad \\
no le has visto nada \\
de positivo a esta \\
situación?
\end{tabular} & $\begin{array}{l}\quad \text { Intervenci } \\
\text { ones } \\
\text { narrativas en } \\
\text { situaciones de } \\
\text { deserción } \\
\text { escolar }\end{array}$ & Historias & \\
\hline
\end{tabular}




\section{LA DESERCIÓN ESCOLAR COMO PRETEXTO PARA CONVERSAR SOBRE IDENTIDAD, FAMILIA Y ESCUELA

\begin{tabular}{|c|c|c|c|}
\hline $\begin{array}{l}\qquad \text { M: No, pues } \\
\text { porque...pues por el } \\
\text { lado de que por ese } \\
\text { lado no recibo } \\
\text { quejas. Porque eso } \\
\text { llegó un momento en } \\
\text { que el colegio se } \\
\text { volvió una tortura } \\
\text { para mí, yo cruzaba } \\
\text { esa puerta y ya me } \\
\text { imaginaba los } \\
\text { profesores "ta ta ta } \\
\text { ta"...pero... }\end{array}$ & $\begin{array}{l}\quad \text { Relación } \\
\text { joven, familia } \\
\text { e institución } \\
\text { educativa en } \\
\text { torno a la } \\
\text { deserción } \\
\text { escolar. }\end{array}$ & $\begin{array}{l}\text { Relatos } \\
\text { alternos }\end{array}$ & $\begin{array}{l}\quad \text { La madre } \\
\text { intenta porder } \\
\text { construir algo } \\
\text { diferente de la } \\
\text { situacion } \\
\text { problema, pero } \\
\text { aun se mantiene } \\
\text { dentro de el } \\
\text { circulo de la } \\
\text { problematica. }\end{array}$ \\
\hline $\begin{array}{l}\text { I: Pero y ¿en } \\
\text { relación con lo que L } \\
\text { hace? Porque yo } \\
\text { entiendo que L en la } \\
\text { casa colabora } \\
\text { bastante... }\end{array}$ & $\begin{array}{l}\quad \text { Intervenci } \\
\text { ones } \\
\text { narrativas en } \\
\text { situaciones de } \\
\text { deserción } \\
\text { escolar } \\
\end{array}$ & $\begin{array}{l}\text { Relatos } \\
\text { alternos }\end{array}$ & \\
\hline $\mathrm{M}: \mathrm{Si}$ & $\begin{array}{l}\quad \text { Intervenci } \\
\text { ones } \\
\text { narrativas en } \\
\text { situaciones de } \\
\text { deserción } \\
\text { escolar } \\
\end{array}$ & $\begin{array}{l}\text { Relatos } \\
\text { alternos }\end{array}$ & \\
\hline $\begin{array}{l}\text { I: A nivel de los } \\
\text { oficios, a nivel del } \\
\text { almuerzo, a nivel de } \\
\text { la loza, a nivel de las } \\
\text { cosas de la casa, del } \\
\text { que hacer de la casa, } \\
\text { aun así ¿no hay nada } \\
\text { positivo en eso? }\end{array}$ & $\begin{array}{l}\quad \text { Construcci } \\
\text { ón narrativa } \\
\text { de la } \\
\text { identidad }\end{array}$ & $\begin{array}{l}\text { Relatos } \\
\text { alternos }\end{array}$ & \\
\hline $\begin{array}{l}\text { M: Pues eso de } \\
\text { los oficios, yo se lo } \\
\text { impuse como } \\
\text { castigo. Yo le dije } \\
\text { "si usted no estudia, } \\
\text { yo no voy a tener } \\
\text { una... (Así se lo dije } \\
\text { en esas palabras) no } \\
\text { voy a tener una } \\
\text { persona vaga aquí en } \\
\text { la casa" le dije "si no } \\
\text { estudia por perder } \\
\text { dos años el castigo } \\
\text { de hoy va a ser la } \\
\text { cocina" le dije "de } \\
\text { aquí en adelante } \\
\text { usted lava, cocina, } \\
\text { todo" yo le dije “de } \\
\text { aquí a mañana usted } \\
\text { no estudia, ¿para qué } \\
\text { va a servir?" de } \\
\text { empleada de }\end{array}$ & $\begin{array}{l}\quad \text { Construcci } \\
\text { ón narrativa } \\
\text { de la } \\
\text { identidad }\end{array}$ & Experiencia & \begin{tabular}{l}
\multicolumn{1}{c}{ La madre } \\
construye una \\
situacion de \\
castigo frente a la \\
situacion de \\
desercion de la \\
consultante, \\
buscando reforzar \\
su pensamiento y \\
percepcion frente a \\
la vida.
\end{tabular} \\
\hline
\end{tabular}




\section{LA DESERCIÓN ESCOLAR COMO PRETEXTO PARA CONVERSAR SOBRE IDENTIDAD, FAMILIA Y ESCUELA

servicio. O sea yo lo

hacía como tratando

de aplicarle

psicología inversa.

(risa) Como para que

ella dijera "soy

sirvienta"... ¿sí?

\begin{tabular}{|c|c|c|c|}
\hline $\begin{array}{l}\text { I: Pero fíjese que } \\
\text { ya llevamos ahí... }\end{array}$ & \begin{tabular}{l}
\multicolumn{1}{c}{ Intervenci } \\
ones \\
narrativas en \\
situaciones de \\
deserción \\
escolar
\end{tabular} & Historias & \\
\hline $\begin{array}{l}\quad \text { M: Y pasó un } \\
\text { año y } \\
\text { nada...entonces sí } \\
\text { que fue peor. }\end{array}$ & $\begin{array}{l}\quad \text { Construcci } \\
\text { ón narrativa } \\
\text { de la } \\
\text { identidad }\end{array}$ & Memorias & \\
\hline $\begin{array}{l}\quad \text { I: Bueno, pero D } \\
\text { aun así, ¿tú estás } \\
\text { convencida que si L } \\
\text { no termina el } \\
\text { bachillerato la vida } \\
\text { de ella va a tener que } \\
\text { seguir siendo esa?¿o } \\
\text { cómo percibes tú ahí } \\
\text { la situación? Porque } \\
\text { ¿Cuándo piensas } \\
\text { levantar ese castigo? }\end{array}$ & $\begin{array}{l}\quad \text { Intervenci } \\
\text { ones } \\
\text { narrativas en } \\
\text { situaciones de } \\
\text { deserción } \\
\text { escolar }\end{array}$ & $\begin{array}{l}\text { Relatos } \\
\text { alternos }\end{array}$ & \\
\hline $\begin{array}{l}\quad \text { M: Pues en algún } \\
\text { momento tiene } \\
\text { que...jum pues la } \\
\text { verdad no veo cómo } \\
\text { se puede defender } \\
\text { sin estudio. O sea en } \\
\text { un cargo...en algo } \\
\text { importante. A menos } \\
\text { de que ella aprenda a } \\
\text { hacer un arte y algo } \\
\text { independiente. }\end{array}$ & $\begin{array}{l}\quad \text { Intervenci } \\
\text { ones } \\
\text { narrativas en } \\
\text { situaciones de } \\
\text { deserción } \\
\text { escolar }\end{array}$ & $\begin{array}{l}\text { Relatos } \\
\text { alternos }\end{array}$ & \begin{tabular}{l}
\multicolumn{1}{c}{ La madre } \\
configura la \\
percepcion de vida \\
de la consultante \\
como una directa \\
relacion frente a lo \\
que pasa con su \\
propia vida, y \\
como puede esta \\
llegar a convertirse \\
en lo que \\
considera un \\
fracaso.
\end{tabular} \\
\hline $\begin{array}{l}\quad \text { I: Y eso, ¿no le } \\
\text { suena a ninguna de } \\
\text { las dos? Porque } \\
\text { puede ser otra } \\
\text { posibilidad, otra } \\
\text { alternativa. }\end{array}$ & $\begin{array}{l}\quad \text { Intervenci } \\
\text { ones } \\
\text { narrativas en } \\
\text { situaciones de } \\
\text { deserción } \\
\text { escolar }\end{array}$ & $\begin{array}{l}\text { Relatos } \\
\text { alternos }\end{array}$ & \\
\hline
\end{tabular}




\section{LA DESERCIÓN ESCOLAR COMO PRETEXTO PARA CONVERSAR SOBRE IDENTIDAD, FAMILIA Y ESCUELA

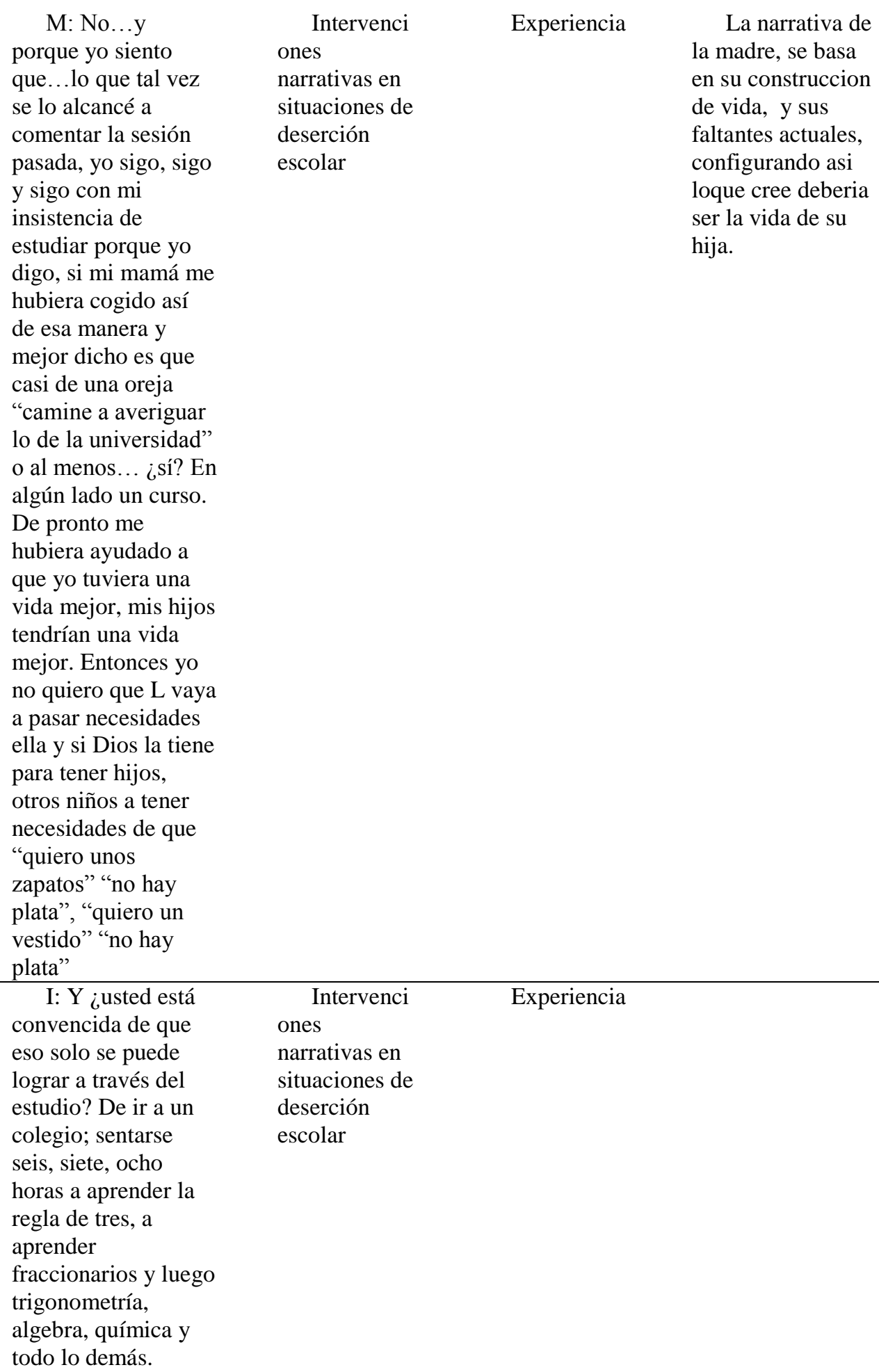

M: No...y porque yo siento

que...lo que tal vez se lo alcancé a comentar la sesión pasada, yo sigo, sigo y sigo con mi insistencia de estudiar porque yo digo, si mi mamá me hubiera cogido así de esa manera y mejor dicho es que casi de una oreja "camine a averiguar lo de la universidad" o al menos... ¿sí? En algún lado un curso. De pronto me hubiera ayudado a que yo tuviera una vida mejor, mis hijos tendrían una vida mejor. Entonces yo no quiero que L vaya a pasar necesidades ella y si Dios la tiene para tener hijos, otros niños a tener necesidades de que "quiero unos zapatos" "no hay plata", "quiero un vestido" "no hay plata"

$$
\text { I: Y ¿usted está }
$$
convencida de que eso solo se puede lograr a través del estudio? De ir a un colegio; sentarse seis, siete, ocho horas a aprender la regla de tres, a aprender fraccionarios y luego trigonometría, algebra, química y todo lo demás.

In

narrativas en

situaciones de

deserción

escolar

Experiencia

La narrativa de la madre, se basa en su construccion de vida, y sus faltantes actuales, configurando asi loque cree deberia ser la vida de su hija. 


\section{LA DESERCIÓN ESCOLAR COMO PRETEXTO PARA CONVERSAR SOBRE IDENTIDAD, FAMILIA Y ESCUELA

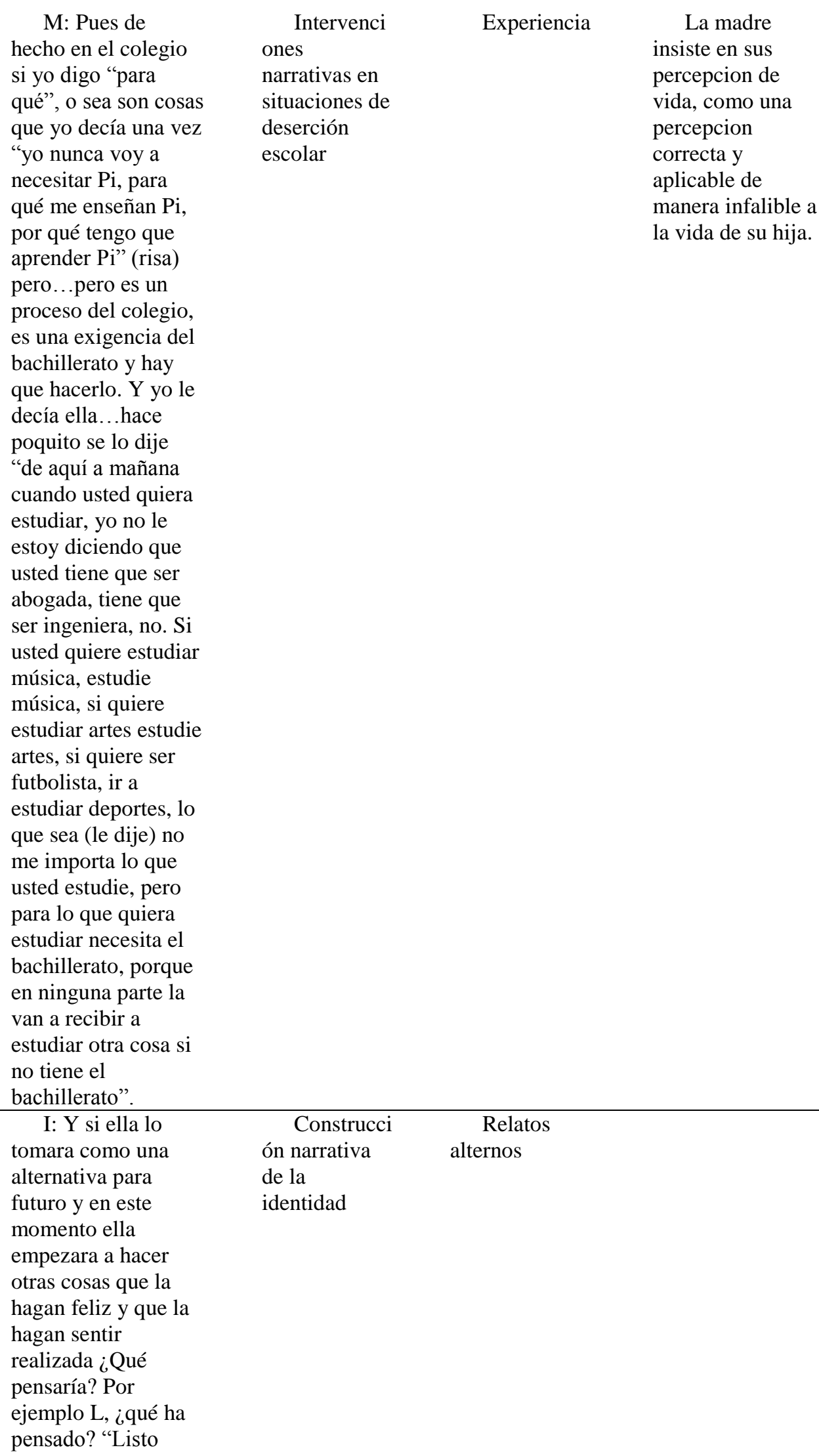

M: Pues de hecho en el colegio si yo digo "para qué", o sea son cosas que yo decía una vez "yo nunca voy a necesitar Pi, para qué me enseñan $\mathrm{Pi}$, por qué tengo que aprender Pi” (risa) pero...pero es un proceso del colegio, es una exigencia del bachillerato y hay que hacerlo. Y yo le decía ella...hace poquito se lo dije "de aquí a mañana cuando usted quiera estudiar, yo no le estoy diciendo que usted tiene que ser abogada, tiene que ser ingeniera, no. Si usted quiere estudiar música, estudie música, si quiere estudiar artes estudie artes, si quiere ser futbolista, ir a estudiar deportes, lo que sea (le dije) no me importa lo que usted estudie, pero para lo que quiera estudiar necesita el bachillerato, porque en ninguna parte la van a recibir a estudiar otra cosa si no tiene el bachillerato".

\section{I: Y si ella lo} tomara como una alternativa para futuro y en este momento ella empezara a hacer otras cosas que la hagan feliz y que la hagan sentir realizada ¿Qué pensaría? Por ejemplo L, ¿qué ha pensado? "Listo

$\quad$ Intervenci
ones
narrativas en
situaciones de
deserción
escolar

Experiencia

La madre insiste en sus percepcion de vida, como una percepcion correcta y aplicable de manera infalible a la vida de su hija. 


\section{LA DESERCIÓN ESCOLAR COMO PRETEXTO PARA CONVERSAR SOBRE IDENTIDAD, FAMILIA Y ESCUELA

yo... puede que no

sea muy buena para

matemáticas ni para

inglés, pero tengo

otra opción" en qué

ha pensado, en qué

han pensado. Porque

es que yo las veo tan

en línea recta, que si

no es el bachillerato

no hay otras

alternativas,

entonces $i L$ se va a

quedar ahí en casa

eternamente?

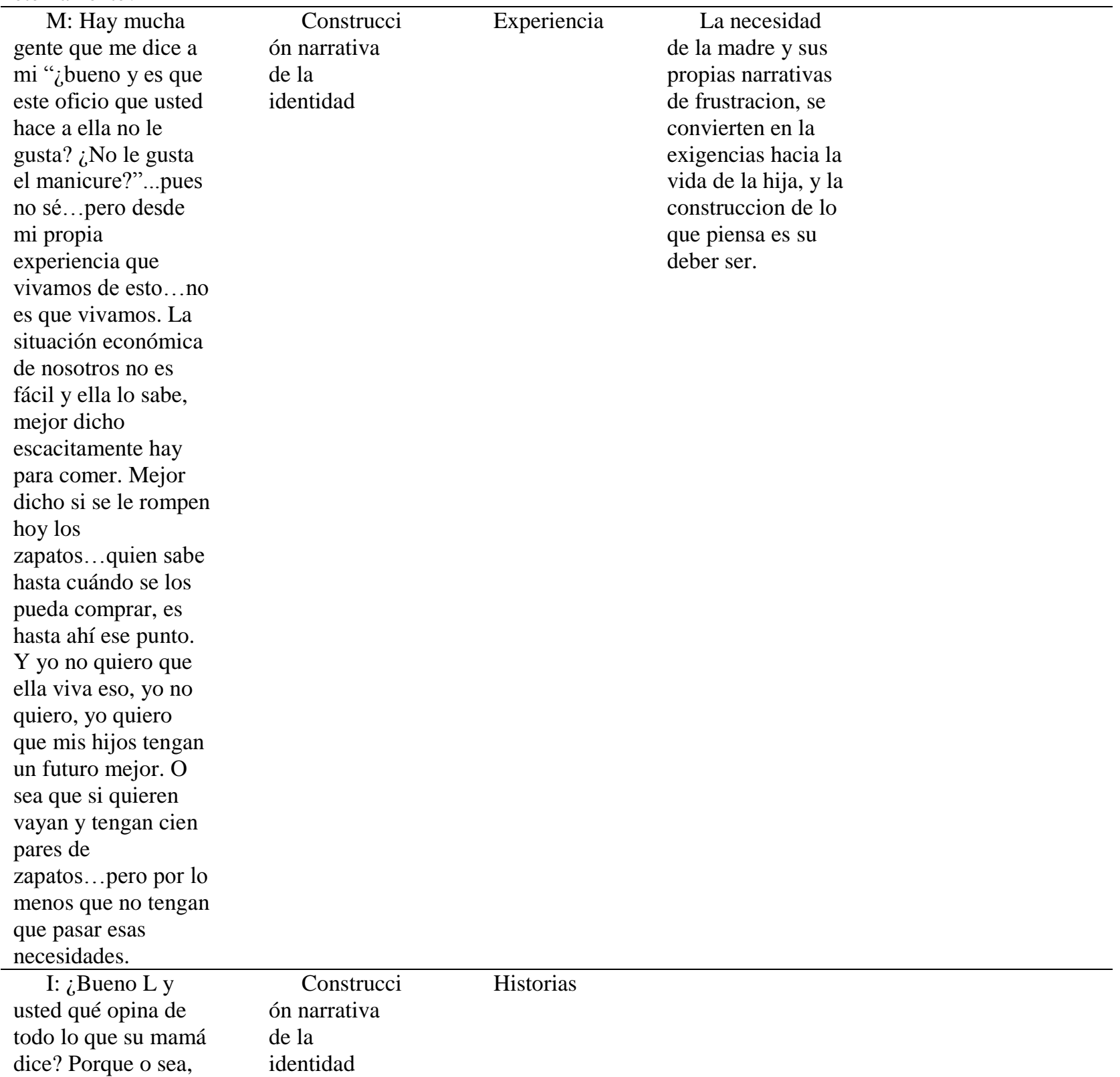




\section{LA DESERCIÓN ESCOLAR COMO PRETEXTO PARA CONVERSAR SOBRE IDENTIDAD, FAMILIA Y ESCUELA

ella tiene tan claro lo que tú debes hacer y ¿eso es lo que tú quieres hacer?

\begin{tabular}{|c|c|c|c|}
\hline $\begin{array}{c}\text { A: (silencio) } \\
\text { Pues...todavía no sé. }\end{array}$ & $\begin{array}{l}\quad \text { Construcci } \\
\text { ón narrativa } \\
\text { de la } \\
\text { identidad }\end{array}$ & Historias & \begin{tabular}{l}
\multicolumn{1}{c}{ La hija aun no } \\
es capaz de \\
construir en si \\
misma las \\
percepciones de su \\
misma identidad, y \\
se refugia en si \\
misma para evitar \\
enfrentar su propio \\
proyecto.
\end{tabular} \\
\hline $\begin{array}{c}\text { I: ¿Qué te falta } \\
\text { para poder saberlo? }\end{array}$ & $\begin{array}{l}\quad \text { Construcci } \\
\text { ón narrativa } \\
\text { de la } \\
\text { identidad }\end{array}$ & Historias & \\
\hline A: intentar. & $\begin{array}{l}\quad \text { Construcci } \\
\text { ón narrativa } \\
\text { de la } \\
\text { identidad }\end{array}$ & $\begin{array}{l}\text { Relatos } \\
\text { alternos }\end{array}$ & \\
\hline $\begin{array}{l}\text { I: ¿Cómo } \\
\text { intentarías? }\end{array}$ & $\begin{array}{l}\quad \text { Intervenci } \\
\text { ones } \\
\text { narrativas en } \\
\text { situaciones de } \\
\text { deserción } \\
\text { escolar } \\
\end{array}$ & $\begin{array}{l}\text { Relatos } \\
\text { alternos }\end{array}$ & \\
\hline $\begin{array}{l}\text { A: Mmm, pues a } \\
\text { mí en el colegio } \\
\text { siempre iba bien más } \\
\text { que todo en } \\
\text { educación física y } \\
\text { artística. }\end{array}$ & $\begin{array}{l}\text { Construcci } \\
\text { ón narrativa } \\
\text { de la } \\
\text { identidad }\end{array}$ & $\begin{array}{l}\text { Relatos } \\
\text { alternos }\end{array}$ & $\begin{array}{l}\quad \text { La consultante } \\
\text { busca a traves de } \\
\text { sus experiencia } \\
\text { configurar una } \\
\text { alternativa frente a } \\
\text { la exigencias } \\
\text { impuestas por su } \\
\text { entorno escolar y } \\
\text { familiar, } \\
\text { retomando sus } \\
\text { memorias y } \\
\text { reconstruyendo sus } \\
\text { experiencias } \\
\text { positivas. }\end{array}$ \\
\hline $\begin{array}{l}\text { I: Sí, o sea que } \\
\text { eres hábil con las } \\
\text { manitas. Con las } \\
\text { manualidades y eso. }\end{array}$ & $\begin{array}{l}\quad \text { Construcci } \\
\text { ón narrativa } \\
\text { de la } \\
\text { identidad }\end{array}$ & $\begin{array}{l}\text { Relatos } \\
\text { alternos }\end{array}$ & \\
\hline $\begin{array}{l}\text { A: mmm, sí...un } \\
\text { poco sí. }\end{array}$ & $\begin{array}{l}\quad \text { Construcci } \\
\text { ón narrativa } \\
\text { de la } \\
\text { identidad }\end{array}$ & $\begin{array}{l}\text { Relatos } \\
\text { alternos }\end{array}$ & \\
\hline
\end{tabular}




\section{LA DESERCIÓN ESCOLAR COMO PRETEXTO PARA CONVERSAR SOBRE IDENTIDAD, FAMILIA Y ESCUELA

\begin{tabular}{clc}
$\begin{array}{c}\text { I: Ok. Y entonces } \\
\text { ¿qué solución }\end{array}$ & \multicolumn{1}{c}{ Intervenci } & Historias \\
plantearía? & ones & \\
& $\begin{array}{l}\text { narrativas en } \\
\text { situaciones de } \\
\text { deserción }\end{array}$ & \\
& escolar & \\
\hline A: Mmm... & \multicolumn{1}{c}{ Intervenci } & Historias \\
(Silencio) & ones & \\
& narrativas en \\
& situaciones de & \\
& deserción & \\
& escolar &
\end{tabular}

\begin{tabular}{|c|c|c|c|}
\hline \begin{tabular}{l}
\multicolumn{1}{c}{ I: A ver. Siento } \\
que a tus quince \\
años aun no has \\
logrado como cortar \\
ese cordón umbilical \\
que tiene con D, o \\
¿es que me parece? \\
Porque yo a los \\
quince años ya tomo \\
mis propias \\
decisiones y me \\
puedo equivocar \\
claro, pero del \\
error...eh lo \\
convierto ese error \\
en positivo y lo \\
pongo a funcionar y \\
nuevamente emerjo. \\
Porque es lo único \\
D, porque yo no creo \\
que tú tampoco \\
hayas pasado así \\
siempre en línea \\
recta, uno tiene que \\
equivocarse y eso es \\
lo que hace la vida. \\
Pero y ¿entonces L?
\end{tabular} & \begin{tabular}{l}
\multicolumn{1}{c}{ Intervenci } \\
ones \\
narrativas en \\
situaciones de \\
deserción \\
escolar
\end{tabular} & $\begin{array}{l}\text { Relatos } \\
\text { alternos }\end{array}$ & \\
\hline $\begin{array}{l}\quad \text { M: Entonces que } \\
\text { no se vaya a dar } \\
\text { cuenta demasiado } \\
\text { tarde como me pasó } \\
\text { a mí. Yo vi la } \\
\text { oportunidad de } \\
\text { estudiar y se dieron } \\
\text { las cosas, o sea, un } \\
\text { día por casualidad } \\
\text { entré a internet y vi } \\
\text { que estaban las } \\
\text { convocatorias, me } \\
\text { inscribí y pasé y en } \\
\text { esas estoy. Sufriendo } \\
\text { (risa), vuelta nada }\end{array}$ & $\begin{array}{l}\quad \text { Construcci } \\
\text { ón narrativa } \\
\text { de la } \\
\text { identidad }\end{array}$ & Experiencia & $\begin{array}{l}\quad \text { La madre } \\
\text { retoma de su } \\
\text { propia experiencia } \\
\text { para intentar } \\
\text { reconfigurarse en } \\
\text { la realidad de su } \\
\text { hija. }\end{array}$ \\
\hline
\end{tabular}

En esa
construccion, aun
falta conectar esas
experiencias frente
a la realidad
percibida en el
presente.




\section{LA DESERCIÓN ESCOLAR COMO PRETEXTO PARA CONVERSAR SOBRE IDENTIDAD, FAMILIA Y ESCUELA

pero estoy haciendo

algo que siempre

quise hacer.

\begin{tabular}{|c|c|c|c|}
\hline $\begin{array}{l}\text { A: Ya casi } \\
\text { muerta }\end{array}$ & $\begin{array}{l}\quad \text { Construcci } \\
\text { ón narrativa } \\
\text { de la } \\
\text { identidad }\end{array}$ & Historias & \begin{tabular}{l}
\multicolumn{1}{c}{ La hija } \\
responde de \\
manera fuerte, y \\
muestra en parte \\
algo de reconr \\
frente a los \\
consejos que le \\
presenta su mama.
\end{tabular} \\
\hline $\begin{array}{l}\quad \text { M: Pero en este } \\
\text { momento yo por } \\
\text { ejemplo digo, qué } \\
\text { día me sentaba y dije } \\
\text { ¿será que si vale la } \\
\text { pena todo este } \\
\text { esfuerzo? Yo ya casi } \\
\text { con } 42 \text { años ¿quién } \\
\text { me va a dar } \\
\text { trabajo?” }\end{array}$ & $\begin{array}{l}\quad \text { Construcci } \\
\text { ón narrativa } \\
\text { de la } \\
\text { identidad }\end{array}$ & Experiencia & $\begin{array}{l}\quad \text { La } \\
\text { construccion de } \\
\text { vida se cuestiona y } \\
\text { se narran algunos } \\
\text { apartes de su } \\
\text { debilidad. }\end{array}$ \\
\hline A: $¿ 42 ?$ & $\begin{array}{l}\quad \text { Construcci } \\
\text { ón narrativa } \\
\text { de la } \\
\text { identidad }\end{array}$ & Historias & \begin{tabular}{l}
\multicolumn{1}{c}{ La } \\
incredulidad de la \\
hija muestra en \\
parte, un cambio \\
frente al esfuerzo \\
de su madre y \\
como vivio su \\
vida.
\end{tabular} \\
\hline $\begin{array}{l}\text { M: Cuando } \\
\text { termine, de aquí a } \\
\text { que termine ya voy a } \\
\text { tener } 42 \text { años. }\end{array}$ & $\begin{array}{l}\quad \text { Construcci } \\
\text { ón narrativa } \\
\text { de la } \\
\text { identidad }\end{array}$ & $\begin{array}{l}\text { Acontecimi } \\
\text { entos }\end{array}$ & \\
\hline \begin{tabular}{l}
\multicolumn{1}{c}{ I:Bueno, y A } \\
entonces ¿hasta \\
cuándo va a esperar \\
para tomar esas \\
riendas de su vida y \\
decir "esto es lo que \\
yo quiero y lo puedo \\
hacer porque tengo \\
las habilidades, pero \\
necesito que crean \\
en mí, yo tener esa \\
red de apoyo para \\
poder salir"? o \\
¿hasta cuando vas a \\
seguir ahí pegada a \\
ese cordón
\end{tabular} & $\begin{array}{l}\quad \text { Intervenci } \\
\text { ones } \\
\text { narrativas en } \\
\text { situaciones de } \\
\text { deserción } \\
\text { escolar }\end{array}$ & $\begin{array}{l}\text { Relatos } \\
\text { alternos }\end{array}$ & \\
\hline
\end{tabular}




\section{LA DESERCIÓN ESCOLAR COMO PRETEXTO PARA CONVERSAR SOBRE IDENTIDAD, FAMILIA Y ESCUELA

umbilical? Y creces

y entonces de 20

años “¿mamá puedo

ir a la esquina?"

dónde está esa

independencia,

donde está esa

autonomía, donde

está tu proyecto, el

ser L; no el ser la

sombra de D.

\begin{tabular}{|c|c|c|c|}
\hline $\begin{array}{l}\text { A: Pues hasta } \\
\text { ahora, me he } \\
\text { concentrado } \\
\text { más...en lo que más } \\
\text { he pensado es en lo } \\
\text { de la música. }\end{array}$ & \begin{tabular}{l}
\multicolumn{1}{c}{ Construcci } \\
ón narrativa \\
de la \\
identidad
\end{tabular} & $\begin{array}{l}\text { Relatos } \\
\text { alternos }\end{array}$ & $\begin{array}{l}\quad \text { La } \\
\text { construccion que } \\
\text { retoma la } \\
\text { consultante, se } \\
\text { configura algunas } \\
\text { veces en un relato } \\
\text { que permite } \\
\text { vislumbrar algo } \\
\text { mas alla, sin } \\
\text { embargo, } \\
\text { sepercibeaun no } \\
\text { verbalizada la } \\
\text { realidad mas } \\
\text { profunda. }\end{array}$ \\
\hline
\end{tabular}

\begin{tabular}{|c|c|c|c|}
\hline $\begin{array}{l}\quad \text { I: Lo de la } \\
\text { música... ¿cómo has } \\
\text { pensado llevarlo a } \\
\text { cabo? ¿Qué has } \\
\text { pensado para poder } \\
\text { llegar hasta allá? } \\
\text { ¿Has hablado eso } \\
\text { con D? }\end{array}$ & $\begin{array}{l}\quad \text { Construcci } \\
\text { ón narrativa } \\
\text { de la } \\
\text { identidad }\end{array}$ & $\begin{array}{l}\text { Relatos } \\
\text { alternos }\end{array}$ & \\
\hline A: ehhh no. & $\begin{array}{l}\quad \text { Construcci } \\
\text { ón narrativa } \\
\text { de la } \\
\text { identidad }\end{array}$ & Historias & \begin{tabular}{l}
\multicolumn{1}{c}{ La respuesta } \\
genera una \\
percepcion de alta \\
desconfianza con \\
su madre, y de la \\
falta de \\
integracion con \\
alguien que le \\
permita darle una \\
percepcion de \\
apoyo para \\
moverse y \\
construirse en sus \\
proyectos.
\end{tabular} \\
\hline
\end{tabular}




\section{LA DESERCIÓN ESCOLAR COMO PRETEXTO PARA CONVERSAR SOBRE IDENTIDAD, FAMILIA Y ESCUELA

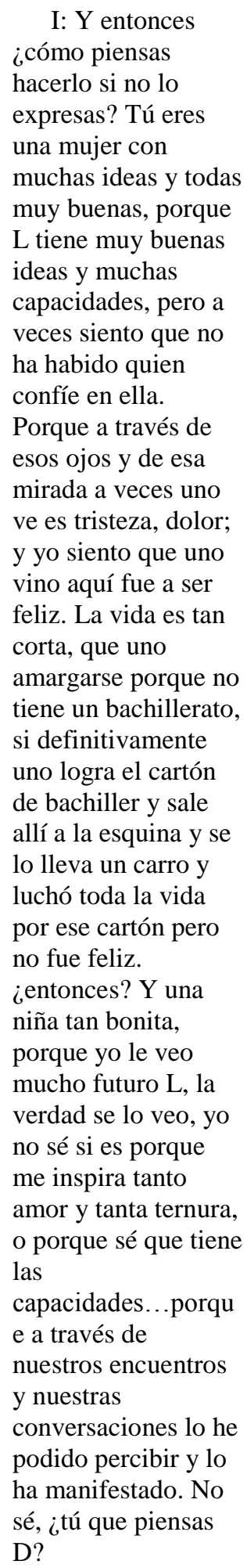

\author{
Relatos
}

alternos

ones
narrativas en
situaciones de
deserción
escolar




\section{LA DESERCIÓN ESCOLAR COMO PRETEXTO PARA CONVERSAR SOBRE IDENTIDAD, FAMILIA Y ESCUELA

\begin{abstract}
M: Pues en estos momentos, pues sí, pues uno dice, pues el camino o la ruta sería... como dicen el camino tradicional o el camino obvio...
\end{abstract}

\begin{tabular}{|c|c|c|c|}
\hline I: ¿Sería ese? & \begin{tabular}{l}
\multicolumn{1}{c}{ Intervenci } \\
ones \\
narrativas en \\
situaciones de \\
deserción \\
escolar \\
\end{tabular} & Historias & \\
\hline M: es ese & $\begin{array}{l}\quad \text { Intervenci } \\
\text { ones } \\
\text { narrativas en } \\
\text { situaciones de } \\
\text { deserción } \\
\text { escolar }\end{array}$ & Historias & \\
\hline $\begin{array}{l}\quad \text { I: Pero ¿y si no? } \\
\text { Por ejemplo } \\
\text { miramos aquí, a } \\
\text { todos estos } \\
\text { campesinos y esta } \\
\text { gente tan prospera } \\
\text { como son los } \\
\text { boyacenses y uno va } \\
\text { a ver la cantidad de } \\
\text { tierras, la cantidad } \\
\text { de dinero que tienen } \\
\text { en especies, en } \\
\text { vacas, en cultivos. } \\
\text { La mayoría de ellos } \\
\text { no saben siquiera } \\
\text { leer, entonces ahí } \\
\text { uno se hace } \\
\text { muchísimas } \\
\text { preguntas, pues yo } \\
\text { me las hago cuando } \\
\text { pienso en L. } \\
\text { ¿Ustedes no se las } \\
\text { han llegado a hacer? }\end{array}$ & $\begin{array}{l}\quad \text { Intervenci } \\
\text { ones } \\
\text { narrativas en } \\
\text { situaciones de } \\
\text { deserción } \\
\text { escolar }\end{array}$ & $\begin{array}{l}\text { Relatos } \\
\text { alternos }\end{array}$ & \\
\hline $\begin{array}{l}\quad \text { M: Pues yo la } \\
\text { verdad yo la miro y } \\
\text { yo no sé ni qué } \\
\text { ponerla a hacer } \\
\text { (risa). O sea, es que } \\
\text { esa es la otra... }\end{array}$ & $\begin{array}{l}\quad \text { Intervenci } \\
\text { ones } \\
\text { narrativas en } \\
\text { situaciones de } \\
\text { deserción } \\
\text { escolar }\end{array}$ & Historias & \begin{tabular}{l}
\multicolumn{1}{c}{ La madre no } \\
desarrolla aun \\
narrativa \\
constructivas \\
frente al futuro de \\
vida de su hija. \\
\end{tabular} \\
\hline \begin{tabular}{l}
\multicolumn{1}{c}{ I: ¿Será que tú } \\
tienes que ponerla a \\
hacer? O ¿será que \\
es que hay que darle \\
independencia para \\
que ella haga? Y \\
dejar de pensar en lo
\end{tabular} & $\begin{array}{l}\quad \text { Intervenci } \\
\text { ones } \\
\text { narrativas en } \\
\text { situaciones de } \\
\text { deserción } \\
\text { escolar }\end{array}$ & Historias & \\
\hline
\end{tabular}

\begin{tabular}{lr}
\multicolumn{1}{c}{ Intervenci } & Relatos \\
ones & alternos \\
narrativas en & \\
situaciones de & \\
deserción & \\
escolar &
\end{tabular}

Relatos

narrativas en

deserción

escolar narrativas en

situaciones de

deserción

Intervenci

ones Relatos

Por ejemplo

miramos aquí, a

campesinos y esta

gente tan prospera

deserción

como son los

tierras, la cantidad

de dinero que tienen

en especies, en

vacas, en cultivos.

La mayoría de ellos

no saben siquiera

leer, entonces ah

preguntas, pues yo

me las hago cuando

pienso en L.

han llegado a hacer?

verdad yo la miro

yo no sé ni qué

ponerla a hacer

(risa). O sea, es que

deserción

I: ¿Será que tú

tienes que ponerla a

ones

narrativas en

situaciones de

deserción

dejar de pensar en lo 


\section{LA DESERCIÓN ESCOLAR COMO PRETEXTO PARA CONVERSAR SOBRE IDENTIDAD, FAMILIA Y ESCUELA

que ella tiene que

hacer y que tú la

ordenes, sino que

ella tenga la

iniciativa y lo haga

por la misma

necesidad.

\begin{tabular}{|c|c|c|c|}
\hline $\begin{array}{l}\quad \text { M: yo no sé, yo } \\
\text { la veo tan } \\
\text { desorientada que yo } \\
\text { creo que ella no, o } \\
\text { sea yo lo percibo así, } \\
\text { como que ella vive } \\
\text { el día a día y "tengo } \\
\text { mi comida y mi } \\
\text { techo, pa' qué busco } \\
\text { más" }\end{array}$ & $\begin{array}{l}\quad \text { Construcci } \\
\text { ón narrativa } \\
\text { de la } \\
\text { identidad }\end{array}$ & Historias & \begin{tabular}{l}
\multicolumn{1}{c}{ la madre al } \\
hablar de su hija \\
desarrolla su \\
narrativa a partir \\
de narrativas \\
saturadas que no \\
permiten relatos \\
posibilitadores.
\end{tabular} \\
\hline $\begin{array}{l}\text { I: ¿Y será que } \\
\text { eso la hace feliz? } \\
\text { ¿M, tú te has } \\
\text { preguntado si A, es } \\
\text { feliz con la vida que } \\
\text { lleva? }\end{array}$ & $\begin{array}{l}\quad \text { Intervenci } \\
\text { ones } \\
\text { narrativas en } \\
\text { situaciones de } \\
\text { deserción } \\
\text { escolar }\end{array}$ & Historias & \\
\hline $\begin{array}{l}\text { M: Pues no, yo } \\
\text { pienso que feliz no, } \\
\text { quién va a ser feliz } \\
\text { así. }\end{array}$ & $\begin{array}{l}\quad \text { Construcci } \\
\text { ón narrativa } \\
\text { de la } \\
\text { identidad }\end{array}$ & Historias & \begin{tabular}{l}
\multicolumn{1}{c}{ la madre } \\
legitima el sentir \\
de su hija sin \\
embaego de \\
manera paradogica \\
manifiesta su no \\
necesidad de \\
cambio.
\end{tabular} \\
\hline $\begin{array}{r}\text { I: } ¿ \text { Y no te } \\
\text { preocupa eso? }\end{array}$ & $\begin{array}{l}\quad \text { Intervenci } \\
\text { ones } \\
\text { narrativas en } \\
\text { situaciones de } \\
\text { deserción } \\
\text { escolar } \\
\end{array}$ & Historias & \\
\hline $\begin{array}{l}\text { M: Pues sí } \\
\text { porque va directo al } \\
\text { fracaso. }\end{array}$ & $\begin{array}{l}\text { Construcci } \\
\text { ón narrativa } \\
\text { de la } \\
\text { identidad }\end{array}$ & Historias & $\begin{array}{l}\quad \text { Nuevamente la } \\
\text { madre manifiesta } \\
\text { una narrativa } \\
\text { saturada en la cual } \\
\text { da a conocer su } \\
\text { comprensión } \\
\text { rigida de lo que } \\
\text { puede llegar a } \\
\text { pasar con su hija, } \\
\text { sin tener en cuenta } \\
\text { nuevas } \\
\text { construcciones. }\end{array}$ \\
\hline $\begin{array}{c}\text { I: ¿Pero por qué } \\
\text { hablas de fracaso D? }\end{array}$ & $\begin{array}{l}\quad \text { Intervenci } \\
\text { ones } \\
\text { narrativas en } \\
\text { situaciones de } \\
\text { deserción } \\
\text { escolar }\end{array}$ & Historias & \\
\hline
\end{tabular}




\section{LA DESERCIÓN ESCOLAR COMO PRETEXTO PARA CONVERSAR SOBRE IDENTIDAD, FAMILIA Y ESCUELA

\author{
M: Porque una \\ persona que no \\ quiere hacer nada, \\ porque es que una \\ cosa es querer...si \\ ella me dice "es que \\ yo quiero hacer \\ esto" pero no ve que \\ no.
}

$\quad$ Construcci
ón narrativa
de la
identidad

\author{
La madre \\ manifiesta que su \\ hija no quiere \\ hacer algunas \\ cosas sin embargo \\ tambien propone \\ que le gustarian \\ hacer otros, sin \\ embargo es \\ paradogico ver \\ como a la hora de \\ hablar de lo \\ sibilitador se le \\ resta importancia.
}

\begin{tabular}{|c|c|c|c|}
\hline $\begin{array}{l}\text { I: ¿Entonces a } \\
\text { qué horas hablan, en } \\
\text { qué momento es ese } \\
\text { momento de ustedes, } \\
\text { para que se } \\
\text { encuentren como } \\
\text { madre y como hija y } \\
\text { decir "mamá yo } \\
\text { quiero, a mí me } \\
\text { gustaría intentarlo”? } \\
\text { oír sus propias } \\
\text { palabras, no sé, o } \\
\text { que tú le generaras } \\
\text { ese espacio para que } \\
\text { L tal vez se acerque } \\
\text { y diga "mamá mi } \\
\text { sueño es...” no sé. } \\
\text { Cuantas veces se } \\
\text { abrazan me } \\
\text { pregunto, son tan } \\
\text { parecidas } \\
\text { físicamente y al } \\
\text { mismo tiempo las } \\
\text { veo tan distantes, es } \\
\text { como si un abismo } \\
\text { las separara, ¿o es } \\
\text { solamente mi } \\
\text { percepción? }\end{array}$ & $\begin{array}{l}\quad \text { Construcci } \\
\text { ón narrativa } \\
\text { de la } \\
\text { identidad }\end{array}$ & Historias & \\
\hline $\begin{array}{l}\text { M: No, sí. } \\
\text { Debido a tantas } \\
\text { cosas y esto ya...sí, } \\
\text { yo con ella...o sea } \\
\text { de hecho yo no soy } \\
\text { de las que } \\
\text { quichiqueo, a D (el } \\
\text { hijo) porque es el } \\
\text { bebé y yo le he } \\
\text { dicho a ella que } \\
\text { "cuando usted era } \\
\text { chiquita era igual" a } \\
\text { ella la cogía la }\end{array}$ & $\begin{array}{l}\quad \text { Construcci } \\
\text { ón narrativa } \\
\text { de la } \\
\text { identidad }\end{array}$ & Memorias & \begin{tabular}{l}
\multicolumn{1}{c}{ la madre } \\
nuevamente \\
deslegitimiza el \\
sentir de su hija, la \\
emociones y \\
necesidades que \\
puede tener, \\
teniendo en cuenta \\
sus propias \\
consideraciones.
\end{tabular} \\
\hline
\end{tabular}




\section{LA DESERCIÓN ESCOLAR COMO PRETEXTO PARA CONVERSAR SOBRE IDENTIDAD, FAMILIA Y ESCUELA

besaba, la alzaba, la

subía, la baja...hasta

cierta edad, después

ya no. Igual con mi

hija

mayor...empezando

que no sé, no me

gusta que me

abracen, yo por

ejemplo ya dormir

con ellas no.

I: ¿No te gusta

que te abracen? ¿No

recibiste muchos

abrazos?
Construcci Historias

ón narrativa

de la

identidad

Construcci Historias

ón narrativa

de la

identidad
D da a conocer

la poca cercania

emocional que

tuvieron con ella.

\begin{tabular}{|c|c|c|c|}
\hline $\begin{array}{l}\text { I: ¿Y por lo } \\
\text { mismo tal vez hay } \\
\text { que castigar a quien } \\
\text { quiere un abrazo? }\end{array}$ & $\begin{array}{l}\quad \text { Construcci } \\
\text { ón narrativa } \\
\text { de la } \\
\text { identidad }\end{array}$ & Historias & \\
\hline $\begin{array}{l}\text { M: (risa } \\
\text { nerviosa) Si, no sé. } \\
\text { Yo creo que la vida } \\
\text { me enseñó a ser dura } \\
\text { y aprendí a ser fuerte } \\
\text { porque me } \\
\text { pisotearon mucho }\end{array}$ & $\begin{array}{l}\text { Construcci } \\
\text { ón narrativa } \\
\text { de la } \\
\text { identidad }\end{array}$ & Experiencia & $\begin{array}{l}\quad \text { La madre da a } \\
\text { conocer sus } \\
\text { consideraciones } \\
\text { frente al expresar } \\
\text { emociones y el por } \\
\text { qué mantiene } \\
\text { dificultades al } \\
\text { respecto. }\end{array}$ \\
\hline $\begin{array}{l}\text { I: Pero por lo } \\
\text { mismo ¿tus hijos } \\
\text { tienen que pagar } \\
\text { eso? }\end{array}$ & $\begin{array}{l}\quad \text { Construcci } \\
\text { ón narrativa } \\
\text { de la } \\
\text { identidad }\end{array}$ & Historias & \\
\hline \begin{tabular}{l}
\multicolumn{1}{c}{ M: entonces } \\
aprende a que si uno \\
da...(silencio)
\end{tabular} & $\begin{array}{l}\text { Construcci } \\
\text { ón narrativa } \\
\text { de la } \\
\text { identidad }\end{array}$ & Memorias & $\begin{array}{l}\quad \text { Sin embargo la } \\
\text { mamá no continua } \\
\text { con las preguntas } \\
\text { que se le hacen, } \\
\text { continuando con } \\
\text { su relato. }\end{array}$ \\
\hline $\begin{array}{l}\text { I: ¿Qué pasa si } \\
\text { uno da? }\end{array}$ & $\begin{array}{l}\quad \text { Construcci } \\
\text { ón narrativa } \\
\text { de la } \\
\text { identidad }\end{array}$ & Historias & \\
\hline C1: pierde (risa) & $\begin{array}{l}\quad \text { Construcci } \\
\text { ón narrativa } \\
\text { de la } \\
\text { identidad }\end{array}$ & Historias & $\begin{array}{l}\quad \text { Y nuevamente } \\
\text { la madre da paso a } \\
\text { lo que considera, } \\
\text { sería interesante en } \\
\text { alguna sesión } \\
\text { posterior indagar } \\
\text { un poco mas sobre } \\
\text { este sentir. }\end{array}$ \\
\hline
\end{tabular}




\section{LA DESERCIÓN ESCOLAR COMO PRETEXTO PARA CONVERSAR SOBRE IDENTIDAD, FAMILIA Y ESCUELA

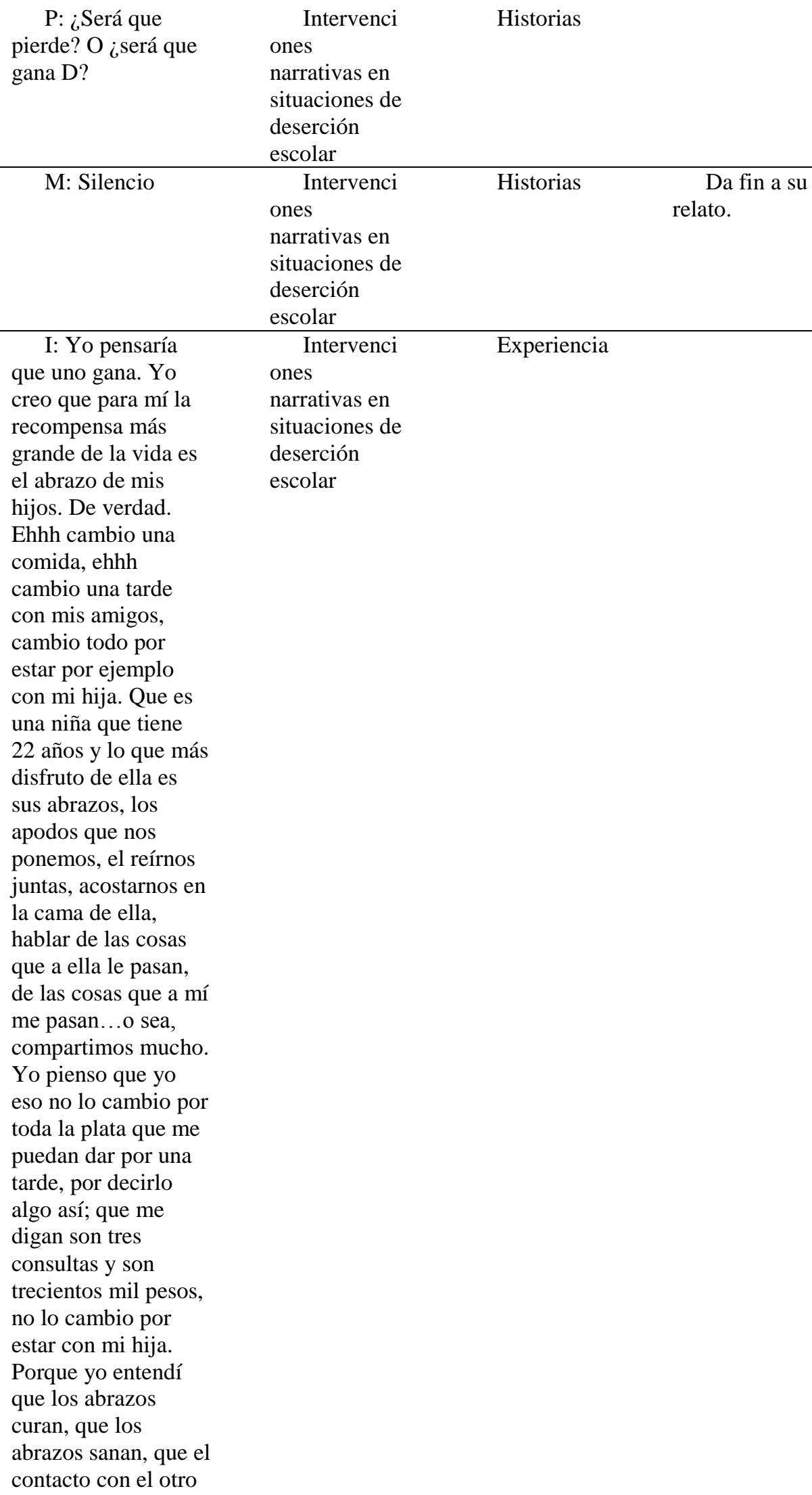




\section{LA DESERCIÓN ESCOLAR COMO PRETEXTO PARA CONVERSAR SOBRE IDENTIDAD, FAMILIA Y ESCUELA

me hace más

humana...y puedo

comprender al otro

en toda su esencia,

cuando lo siento

tibio, cuando lo

siento frío, tal vez

cuando lo abrazo y

siento el latir de su

corazón a mi lado y

puedo comprender

que estamos

conectados el uno

con el otro. Entonces

yo nunca diría que

pierdo, yo diría que

gano y yo a veces

siento que eso es lo

que les hace falta a

ustedes dos, ese

fundirse en un solo

abrazo y saber que

está la una para la

otra, pero no tal vez

con el miedo y el

temor que yo le veo

a L en los ojitos

cuando la mira a

usted. Porque es que

ella no tiene la culpa

de lo duro que le

haya tocado D.

M: No, yo se eso. Pero llegó un punto

en que sentí que

sufrí tanto por la

situación con ella

que un vacío sí se

formó y ella me

abraza y yo no siento

nada. Entonces es

como si ella me

abrazara pero no

sinceramente,

entonces no lo

siento. Porque sí

obviamente, de

pronto mi hija mayor

me abraza y es muy

diferente a lo que

siento con L. Mi hijo

menor pues

obviamente es

diferente por ser

chiquito...

\begin{tabular}{|c|c|c|}
\hline $\begin{array}{l}\text { Construcci } \\
\text { ón narrativa } \\
\text { de la } \\
\text { identidad }\end{array}$ & Experiencia & \begin{tabular}{l}
\multicolumn{1}{c}{ la madre } \\
propone un \\
paralelo entre su \\
hija L y su hija \\
mayor \\
manifestando la \\
poca cercania \\
emocional que \\
logra tener con L, \\
deslegitimizando \\
el sentir de su hija.
\end{tabular} \\
\hline
\end{tabular}




\section{LA DESERCIÓN ESCOLAR COMO PRETEXTO PARA CONVERSAR SOBRE IDENTIDAD, FAMILIA Y ESCUELA

I: Por ser el bebé.

Pero es que yo te siento aún herida, es como si le quisieras pasar una cuenta de cobro a L por algo y yo siento que $\mathrm{L}$ ha sido víctima, no sé de qué situación.

Pero abrieron una brecha terrible entre ustedes dos, es como si estuvieran midiendo fuerzas y me duele mucho ver así a L, de verdad D. $\mathrm{Y}$ usted sabe que yo la estimo mucho a usted, porque fue mi aprendiz, por toda esa situación...pero también pienso en $\mathrm{L}$ y no me parece justo. No sé, siento que ella sufre, la veo sufrir, la veo llorar, la veo como con desesperanza, como el no saber qué hacer, pero tú eres el timón de la vida de ella... y ¿entonces...qué hacemos?

\begin{tabular}{|c|c|c|}
\hline $\begin{array}{l}\text { M: Jum no sé, yo } \\
\text { con ella no sé qué } \\
\text { hacer. Un día le dije } \\
\text { "haga lo que quiera" }\end{array}$ & $\begin{array}{l}\quad \text { Intervenci } \\
\text { ones } \\
\text { narrativas en } \\
\text { situaciones de } \\
\text { deserción } \\
\text { escolar }\end{array}$ & Memorias \\
\hline \begin{tabular}{l}
\multicolumn{1}{c}{ I: Yo creería que } \\
si tú buscas en tu \\
corazón como mamá \\
vas a saber qué hacer \\
con tu hija. Tal vez \\
si tú le permitieras \\
que ella se acerque y \\
que ustedes abran \\
ese espacio para \\
sanar, para \\
conversar, para
\end{tabular} & $\begin{array}{l}\quad \text { Intervenci } \\
\text { ones } \\
\text { narrativas en } \\
\text { situaciones de } \\
\text { deserción } \\
\text { escolar }\end{array}$ & Historias \\
\hline
\end{tabular}

Intervenci Historias

ones

en

situaciones de

deserción

escolar

\author{
la madre se \\ desliga de la \\ solución y la \\ responsabilidad \\ que seria asumir la \\ dificultad, \\ manifestando \\ imposibilidad a la \\ hora de generar \\ soluciones.
}




\section{LA DESERCIÓN ESCOLAR COMO PRETEXTO PARA CONVERSAR SOBRE IDENTIDAD, FAMILIA Y ESCUELA

llegar a acuerdos,

para...

\begin{tabular}{|c|c|c|c|}
\hline $\begin{array}{l}\text { M: No sé, yo ya } \\
\text { estoy tan prevenida } \\
\text { y tan decepcionada } \\
\text { de ella que... siento } \\
\text { que cuando le doy } \\
\text { una oportunidad o } \\
\text { algo me decepciona }\end{array}$ & $\begin{array}{l}\text { Construcci } \\
\text { ón narrativa } \\
\text { de la } \\
\text { identidad }\end{array}$ & Historias & $\begin{array}{l}\quad \text { La madre } \\
\text { asume la realidad } \\
\text { como algo } \\
\text { preconstruido, no } \\
\text { perminitiendo } \\
\text { ningun tipo de } \\
\text { autonomia, de } \\
\text { igual manera no } \\
\text { genera relatos } \\
\text { alternos } \\
\text { encaminados a la } \\
\text { construcción de } \\
\text { relatos } \\
\text { emergentes. }\end{array}$ \\
\hline
\end{tabular}

\begin{tabular}{lll}
\hline \multicolumn{1}{c}{ I: Pero bueno, es } & \multicolumn{1}{c}{ Intervenci } & Historias \\
que está chiquita y & ones & \\
está aprendiendo... & $\begin{array}{l}\text { narrativas en } \\
\text { situaciones de } \\
\text { ¿eserción } \\
\text { ¿no crees? }\end{array}$ & \\
& \multicolumn{1}{c}{ Construcci } & Historias \\
\hline M: No, chiquita & ón narrativa & \\
$\begin{array}{l}\text { ya no es. No chiquita } \\
\text { ya no la veo chiquita } \\
\text { (risa) }\end{array}$ & $\begin{array}{l}\text { de la } \\
\text { identidad }\end{array}$ &
\end{tabular}

\begin{tabular}{ll} 
& \\
& \\
& \\
& \multicolumn{1}{c}{ Intervenci } \\
I: Pero es que & Historias \\
solo son quince & ones \\
años, quince años & narrativas en \\
que aún no ha & situaciones de \\
cumplido y que ella & deserción \\
no ha tenido la & escolar \\
autonomía para & \\
vivirlos. ¿o sí? & \\
Porque uno cuando & \\
habla con L, con sus & \\
palabras no se atreve & \\
a decir cosas, pero & \\
ella es todo como & \\
"bueno, pero es que & \\
me tocó... (Silencio) & \\
pues sí" y lo piensa &
\end{tabular}




\section{LA DESERCIÓN ESCOLAR COMO PRETEXTO PARA CONVERSAR SOBRE IDENTIDAD, FAMILIA Y ESCUELA

mucho. Es como si

siempre tuviera

miedo de expresar,

¿es eso L?

\begin{tabular}{|c|c|c|c|}
\hline A: Si. & $\begin{array}{l}\quad \text { Construcci } \\
\text { ón narrativa } \\
\text { de la } \\
\text { identidad }\end{array}$ & Historias & \begin{tabular}{l}
\multicolumn{1}{c}{ Como } \\
conclucion de la \\
sesión propone \\
una comprensión \\
no relacionada con \\
la dificultad, de \\
narrativas \\
saturadas, sin \\
propuestas que \\
generen soluciones \\
a la dificultad.
\end{tabular} \\
\hline $\begin{array}{l}\text { I: Miedo a } \\
\text { expresarle a D } \\
\text { cosas... ¿cómo } \\
\text { cuáles? }\end{array}$ & $\begin{array}{l}\quad \text { Intervenci } \\
\text { ones } \\
\text { narrativas en } \\
\text { situaciones de } \\
\text { deserción } \\
\text { escolar }\end{array}$ & Historias & \\
\hline $\begin{array}{l}\text { A: (silencio) } \\
\text { Pues...con la única } \\
\text { persona con la que } \\
\text { me expreso bien es } \\
\text { con mi prima que a } \\
\text { veces...que de vez } \\
\text { en cuando nos } \\
\text { vemos. Pero con ella } \\
\text { es con la que hablo. }\end{array}$ & $\begin{array}{l}\quad \text { relación } \\
\text { joven, familia } \\
\text { e institución } \\
\text { educativa en } \\
\text { torno a la } \\
\text { deserción } \\
\text { escolar. }\end{array}$ & Experiencia & $\begin{array}{l}\quad \text { La menor } \\
\text { manifiesta la } \\
\text { relación cercana } \\
\text { que tiene con su } \\
\text { prima, lo cual } \\
\text { podria ser utíl a la } \\
\text { hora de encontrar } \\
\text { posibles } \\
\text { soluciones futuras } \\
\text { a la dificultad. }\end{array}$ \\
\hline $\begin{array}{l}\text { I: ¿Es con la } \\
\text { única persona con la } \\
\text { que puedes hablar? }\end{array}$ & \begin{tabular}{l}
\multicolumn{1}{c}{ Intervenci } \\
ones \\
narrativas en \\
situaciones de \\
deserción \\
escolar
\end{tabular} & Historias & \\
\hline A: (Silencio) & $\begin{array}{l}\quad \text { Intervenci } \\
\text { ones } \\
\text { narrativas en } \\
\text { situaciones de } \\
\text { deserción } \\
\text { escolar }\end{array}$ & Experiencia & $\begin{array}{l}\quad \text { L guarda } \\
\text { silencio frente a la } \\
\text { pregunta que se le } \\
\text { hace, sería } \\
\text { interesante abordar } \\
\text { comprensiones } \\
\text { relacionadas con el } \\
\text { silencio. }\end{array}$ \\
\hline $\begin{array}{l}\text { I: ¿Tú que } \\
\text { piensas D? }\end{array}$ & $\begin{array}{l}\quad \text { Intervenci } \\
\text { ones } \\
\text { narrativas en } \\
\text { situaciones de } \\
\text { deserción }\end{array}$ & HIstorias & \\
\hline
\end{tabular}




\section{LA DESERCIÓN ESCOLAR COMO PRETEXTO PARA CONVERSAR SOBRE IDENTIDAD, FAMILIA Y ESCUELA

escolar

\begin{tabular}{|c|c|c|c|}
\hline M: (Silencio) & $\begin{array}{l}\quad \text { Intervenci } \\
\text { ones } \\
\text { narrativas en } \\
\text { situaciones de } \\
\text { deserción } \\
\text { escolar }\end{array}$ & Experiencia & $\begin{array}{l}\quad \text { Nuevamente la } \\
\text { madre guarda } \\
\text { silencio, teniendo } \\
\text { en cuenta la } \\
\text { importancia de } \\
\text { profundizar frente } \\
\text { a este tema. }\end{array}$ \\
\hline $\begin{array}{l}\text { I: ¿No será que } \\
\text { tú estás siendo muy } \\
\text { dura? }\end{array}$ & $\begin{array}{l}\quad \text { Intervenci } \\
\text { ones } \\
\text { narrativas en } \\
\text { situaciones de } \\
\text { deserción } \\
\text { escolar }\end{array}$ & Experiencia & \\
\hline \begin{tabular}{l}
\multicolumn{1}{c}{ M: De pronto } \\
si...lo que le digo yo \\
estoy muy prevenida \\
con ella porque me \\
ha mentido en tantas \\
cosas que ya esas \\
lágrimas y eso, ya \\
para mí son lágrimas \\
de cocodrilo. Porque \\
la he visto mentir \\
una y otra vez, una y \\
otra vez, y es tan \\
convincente, que una \\
persona que no la \\
conoce dice "pero es \\
que está diciendo la \\
verdad", pero yo sí \\
ya la conozco, por \\
eso es que no le \\
creo. Para mí las \\
palabras de ella ya \\
no tienen valor, o \\
sea a mí ya no me \\
hable, ya no me diga \\
"voy a hacer esto" \\
ya no me diga, \\
hágalo.
\end{tabular} & $\begin{array}{l}\quad \text { Construcci } \\
\text { ón narrativa } \\
\text { de la } \\
\text { identidad }\end{array}$ & Historias & $\begin{array}{l}\quad \text { La madre no } \\
\text { legitimiza la } \\
\text { emocion de su } \\
\text { hija, manifestando } \\
\text { nuevamente un } \\
\text { relato saturado } \\
\text { frente a una nueva } \\
\text { comprension de la } \\
\text { dificultad. }\end{array}$ \\
\hline $\begin{array}{l}\text { I: Bueno y iqué } \\
\text { herramientas le has } \\
\text { dado para que ella } \\
\text { haga lo que... }\end{array}$ & $\begin{array}{l}\quad \text { Construcci } \\
\text { ón narrativa } \\
\text { de la } \\
\text { identidad }\end{array}$ & Memorias & \\
\hline
\end{tabular}




\section{LA DESERCIÓN ESCOLAR COMO PRETEXTO PARA CONVERSAR SOBRE IDENTIDAD, FAMILIA Y ESCUELA

M: Porque no sé qué es lo que quiere, entonces un día le dije "haga lo que quiera" "haga lo que quiera". (silencio)
Construcci

ón narrativa

de la

identidad
HIstorias

Por un lado la madre manifiesta su frustración con respecto a lo entendido como problema, y por otro lado, no propone soluciones y acciones encaminadas a una nueva comprensión, manifestando en repetidas ocaciones, una narrativa saturada similar.

\begin{tabular}{|c|c|c|c|}
\hline $\begin{array}{l}\text { I: Qué pensarías } \\
\text { tu D, si de repente L } \\
\text { tomara la decisión } \\
\text { de irse de casa. }\end{array}$ & \begin{tabular}{l}
\multicolumn{1}{c}{ Intervenci } \\
ones \\
narrativas en \\
situaciones de \\
deserción \\
escolar \\
\end{tabular} & Experiencia & \\
\hline $\begin{array}{l}\text { M: Ya lo hizo } \\
\text { una vez }\end{array}$ & $\begin{array}{l}\quad \text { Construcci } \\
\text { ón narrativa } \\
\text { de la } \\
\text { identidad }\end{array}$ & Experiencia & \begin{tabular}{l}
\multicolumn{1}{c}{ Confieza un } \\
hecho ya \\
desarrollado con \\
anterioridad por \\
parte de la hija, sin \\
mayor \\
emocionalidad.
\end{tabular} \\
\hline $\begin{array}{l}\text { I: ¿Cuántos años } \\
\text { tenía? }\end{array}$ & $\begin{array}{l}\quad \text { Construcci } \\
\text { ón narrativa } \\
\text { de la } \\
\text { identidad }\end{array}$ & Memorias & \\
\hline M: 12 & $\begin{array}{l}\text { Construcci } \\
\text { ón narrativa } \\
\text { de la } \\
\text { identidad }\end{array}$ & Memorias & $\begin{array}{l}\text { Manifiesta la } \\
\text { edad }\end{array}$ \\
\hline $\begin{array}{l}\text { I: Bueno pero } \\
\text { con doce uno no va } \\
\text { muy lejos. ¿Pero } \\
\text { ahora? }\end{array}$ & $\begin{array}{l}\text { Construcci } \\
\text { ón narrativa } \\
\text { de la } \\
\text { identidad }\end{array}$ & Memorias & \\
\hline
\end{tabular}




\section{LA DESERCIÓN ESCOLAR COMO PRETEXTO PARA CONVERSAR SOBRE IDENTIDAD, FAMILIA Y ESCUELA

\begin{tabular}{ll}
\multicolumn{1}{c}{ M: Pues por ley, } & \multicolumn{1}{c}{ Construcci } \\
por cosas legales, & ón narrativa \\
pues inmediatamente & de la \\
toca que la policía la & identidad \\
busque y la & \\
encuentre...y yo se & \\
lo he dicho a ella, si \\
tiene ganas de \\
decir...tómelo \\
porque yo ya no \\
puedo.
\end{tabular}

Memorias

Por un lado la madre manifiesta como solución a una dificultad, el respaldo legal, sin embargo por otro lado da a conoceer su desinteres en caso de que su hija considere el avandono como una solución, de igual menra deslegitimiza la emocion de la joven.

\begin{tabular}{clc}
\hline \multicolumn{1}{c}{ I: ¿Será que una } & \multicolumn{1}{c}{ Construcci } & Historias \\
$\begin{array}{l}\text { mamá se vence así } \\
\text { de rápido? }\end{array}$ & $\begin{array}{l}\text { ón narrativa } \\
\text { de la } \\
\text { identidad }\end{array}$ & \\
\hline \multicolumn{2}{c}{ M: Yo siento que } & \multicolumn{1}{c}{ Construcci } \\
sí. & $\begin{array}{l}\text { ón narrativa } \\
\text { de la } \\
\text { identidad }\end{array}$ & Historias \\
&
\end{tabular}

I: Pero yo
sentiría que el papel
de nosotras...nunca
termina.
M: O sea, es que
como una ésta de
"vaya, viva y dese
cuenta por usted
misma de que lo que
yo le estoy diciendo
es lo que va a pasar".

Construcci

Experiencia ón narrativa de la identidad

Construcci
ón narrativa
de la
identidad

$\quad$ la madre cierra
nuevamente
caminos
posibilitadores a la
hora de nuevas
construcciones,
mostrando su
frustración

constante. .

\begin{tabular}{lll}
\hline I: ¿Y si no fuese & \multicolumn{1}{c}{ Intervenci } & Experiencia \\
así? & ones & \\
& narrativas en & \\
& situaciones de \\
& deserción \\
& escolar
\end{tabular}

$\quad$ La madre
asume la realidad
como algo
preconstruido, no
perminitiendo
ningun tipo de
autonomia a la
menor a partir de
la coherción.




\section{LA DESERCIÓN ESCOLAR COMO PRETEXTO PARA CONVERSAR SOBRE IDENTIDAD, FAMILIA Y ESCUELA

\begin{tabular}{|c|c|c|c|}
\hline $\begin{array}{l}\quad \text { M: Bueno, me } \\
\text { gustaría que me } \\
\text { callara la boca de esa } \\
\text { forma y yo he } \\
\text { pensado que es de } \\
\text { esa forma en que } \\
\text { uno calla la gente así } \\
\text { sea la mamá, estar } \\
\text { uno diciéndole "vea } \\
\text { que sí pudo". Igual } \\
\text { yo ya les he dicho a } \\
\text { ellas "yo de mis } \\
\text { hijos no espero } \\
\text { nada" y yo les he } \\
\text { dicho "yo no quiero } \\
\text { que ustedes sean } \\
\text { profesionales y que } \\
\text { tengan una economía } \\
\text { buena para que me } \\
\text { den a mí, a mí no me } \\
\text { den nada. Pero si yo } \\
\text { los veo a ustedes } \\
\text { bien yo voy a estar } \\
\text { feliz" }\end{array}$ & $\begin{array}{l}\quad \text { Construcci } \\
\text { ón narrativa } \\
\text { de la } \\
\text { identidad }\end{array}$ & Historias & $\begin{array}{l}\quad \text { la madre } \\
\text { manifiesta una } \\
\text { narrativa saturada } \\
\text { con respecto a la } \\
\text { confianza que } \\
\text { pone en sus hijos, } \\
\text { de igual manera da } \\
\text { a conocer el } \\
\text { desinteres aparente } \\
\text { que tiene en } \\
\text { esperar algo de } \\
\text { ellos, por otro lado } \\
\text { da a conocer } \\
\text { cercania } \\
\text { emocional con sus } \\
\text { aciertos. }\end{array}$ \\
\hline $\begin{array}{l}\text { I: ¿Qué es lo que } \\
\text { más le afecta de que } \\
\text { L no estudie? De que } \\
\text { no termine su } \\
\text { bachillerato. }\end{array}$ & $\begin{array}{l}\quad \text { Construcci } \\
\text { ón narrativa } \\
\text { de la } \\
\text { identidad }\end{array}$ & Historias & \\
\hline $\begin{array}{l}\quad \text { M: Pues que si } \\
\text { no termina el } \\
\text { bachillerato no va a } \\
\text { poder acceder a la } \\
\text { educación superior. }\end{array}$ & $\begin{array}{l}\quad \text { Construcci } \\
\text { ón narrativa } \\
\text { de la } \\
\text { identidad }\end{array}$ & HIstorias & $\begin{array}{l}\quad \text { La madre } \\
\text { manifiesta una } \\
\text { narrativa saturada } \\
\text { relacionada con la } \\
\text { finalizacion de la } \\
\text { edución media y } \\
\text { superior. }\end{array}$ \\
\hline I: Bueno... & \begin{tabular}{l}
\multicolumn{1}{c}{ Intervenci } \\
ones \\
narrativas en \\
situaciones de \\
deserción \\
escolar \\
\end{tabular} & Historias & \\
\hline $\begin{array}{l}\quad \text { C1: Y si no } \\
\text { accede a la } \\
\text { educación superior } \\
\text { pues a qué se va a } \\
\text { dedicar... }\end{array}$ & $\begin{array}{l}\text { Construcci } \\
\text { ón narrativa } \\
\text { de la } \\
\text { identidad }\end{array}$ & Historias & \begin{tabular}{l}
\multicolumn{1}{c}{ se identifica la } \\
imposibilidad de la \\
madre de \\
comprender una \\
alternativa \\
diferente a la \\
escolarización.
\end{tabular} \\
\hline $\begin{array}{l}\text { P: ¿para ella no } \\
\text { hay otras } \\
\text { alternativas? }\end{array}$ & $\begin{array}{l}\quad \text { Intervenci } \\
\text { ones } \\
\text { narrativas en } \\
\text { situaciones de } \\
\text { deserción } \\
\text { escolar }\end{array}$ & Historias & \\
\hline
\end{tabular}




\section{LA DESERCIÓN ESCOLAR COMO PRETEXTO PARA CONVERSAR SOBRE IDENTIDAD, FAMILIA Y ESCUELA

\author{
M: Y si no se \\ dedica a algo que le \\ de plata pa' vivir, \\ porque \\ desafortunadamente \\ la plata no lo es todo \\ pero si no la hay, \\ con qué se va a \\ mantener, con qué \\ va a comprarse su \\ comida...al menos \\ su comida. O sea, \\ eso es una realidad \\ porque algo tiene \\ que hacer.
}

$\quad$ Construcci
ón narrativa
de la
identidad

\author{
La madre \\ manifiesta \\ nuevamente su \\ interes economico, \\ y el desarrollo que \\ pueda llegar a \\ tener su hija en un \\ futuro, sin \\ embargo es \\ paradojíco su \\ accionar con \\ respecto a esto, \\ pese a su interes a \\ que su hija "se \\ defienda sola", sin \\ embaego no \\ proporciona armas \\ para este fin.
}

\begin{tabular}{|c|c|c|c|}
\hline $\begin{array}{l}\quad \text { I: Pero bueno, ¿y } \\
\text { si no es el } \\
\text { bachillerato habrán } \\
\text { otras alternativas, } \\
\text { otras posibilidades? } \\
\text { Porque yo veo que } \\
\text { eso es lo que ha } \\
\text { generado todo el } \\
\text { conflicto. }\end{array}$ & \begin{tabular}{l}
\multicolumn{1}{c}{ Intervenci } \\
ones \\
narrativas en \\
situaciones de \\
deserción \\
escolar
\end{tabular} & Historias & \\
\hline $\begin{array}{l}\text { M: Sí claro, el } \\
\text { hecho de que ella } \\
\text { esté desescolarizada } \\
\text { sí. }\end{array}$ & $\begin{array}{l}\text { Construcci } \\
\text { ón narrativa } \\
\text { de la } \\
\text { identidad }\end{array}$ & HIstorias & \begin{tabular}{l}
\multicolumn{1}{c}{ La madre } \\
manifiesta la \\
importancia de la \\
escolarización para \\
cualquier solución.
\end{tabular} \\
\hline $\begin{array}{l}\text { I: Y entonces } \\
\text { todo... }\end{array}$ & $\begin{array}{l}\text { Construcci } \\
\text { ón narrativa } \\
\text { de la } \\
\text { identidad }\end{array}$ & Memorias & \\
\hline $\begin{array}{l}\text { M: } \\
\text {...Empezando } \\
\text { porque todos como } \\
\text { que me dicen a mí } \\
\text { "pero a usted qué le } \\
\text { pasa por qué no la } \\
\text { tiene estudiando" }\end{array}$ & $\begin{array}{l}\quad \text { Intervenci } \\
\text { ones } \\
\text { narrativas en } \\
\text { situaciones de } \\
\text { deserción } \\
\text { escolar }\end{array}$ & Memorias & \begin{tabular}{l}
\multicolumn{1}{c}{ La madre } \\
propone la \\
cuestión de la \\
desescolarización \\
como construcción \\
de su sistema \\
externo, lo cual \\
podria ser de \\
ayuda a la hora de \\
proponer futuras \\
alternativas al \\
problema.
\end{tabular} \\
\hline
\end{tabular}

I: ¿Y L cómo se percibe ahí? ones narrativas en situaciones de deserción escolar

\author{
La madre \\ propone la \\ cuestión de la \\ esescolarización \\ podria ser de \\ ayuda a la hora de
}

Experiencia 


\section{LA DESERCIÓN ESCOLAR COMO PRETEXTO PARA CONVERSAR SOBRE IDENTIDAD, FAMILIA Y ESCUELA

\begin{tabular}{ll}
\multicolumn{1}{l}{ A: (silencio) No } & \multicolumn{1}{c}{ Intervenci } \\
sé. & ones \\
& narrativas en \\
& situaciones de \\
& deserción \\
& escolar
\end{tabular}

Experiencia

L

aparentemente se

encuntra

confundida con

respecto a su

acciónar, lo que

quiere, y lo

mandado por su

madre

\begin{tabular}{|c|c|c|c|}
\hline $\begin{array}{l}\text { I: No, yo sé que } \\
\text { usted sí ha pensado } \\
\text { en eso. }\end{array}$ & $\begin{array}{l}\quad \text { Intervenci } \\
\text { ones } \\
\text { narrativas en } \\
\text { situaciones de } \\
\text { deserción } \\
\text { escolar }\end{array}$ & Experiencia & \\
\hline $\begin{array}{l}\text { A: (silencio) } \\
\text { Pues todo el mundo } \\
\text { me dice que sin un } \\
\text { bachiller... }\end{array}$ & $\begin{array}{l}\quad \text { Intervenci } \\
\text { ones } \\
\text { narrativas en } \\
\text { situaciones de } \\
\text { deserción } \\
\text { escolar }\end{array}$ & Relatos & \begin{tabular}{l}
\multicolumn{1}{c}{ la menor no } \\
considera \\
soluciones difentes \\
a lo dicho por su \\
madre
\end{tabular} \\
\hline $\begin{array}{l}\text { I: ¿Y usted qué } \\
\text { cree? }\end{array}$ & $\begin{array}{l}\quad \text { Intervenci } \\
\text { ones } \\
\text { narrativas en } \\
\text { situaciones de } \\
\text { deserción } \\
\text { escolar }\end{array}$ & Experiencia & \\
\hline $\begin{array}{l}\text { A: Pues según lo } \\
\text { que me dice la gente } \\
\text { creo que sí es cierto. }\end{array}$ & $\begin{array}{l}\quad \text { Intervenci } \\
\text { ones } \\
\text { narrativas en } \\
\text { situaciones de } \\
\text { deserción } \\
\text { escolar }\end{array}$ & Experiencia & $\begin{array}{l}\quad \text { la madre reitera } \\
\text { nuevamente la } \\
\text { importancia de la } \\
\text { finalizacion de la } \\
\text { formacion } \\
\text { secundaria, } \\
\text { identificancose } \\
\text { una narrativa } \\
\text { saturada. }\end{array}$ \\
\hline $\begin{array}{l}\quad \text { I: Bueno, ¿y si la } \\
\text { gente estuviese } \\
\text { equivocada? Y usted } \\
\text { tuviera habilidades } \\
\text { para otras cosas, si } \\
\text { las explorara, ¿cree } \\
\text { que podría vivir sin } \\
\text { un bachillerato? }\end{array}$ & $\begin{array}{l}\quad \text { Intervenci } \\
\text { ones } \\
\text { narrativas en } \\
\text { situaciones de } \\
\text { deserción } \\
\text { escolar }\end{array}$ & Historias & \\
\hline $\begin{array}{l}\text { A: No sé. } \\
\text { (silencio) }\end{array}$ & $\begin{array}{l}\quad \text { Intervenci } \\
\text { ones } \\
\text { narrativas en } \\
\text { situaciones de } \\
\text { deserción } \\
\text { escolar }\end{array}$ & Experiencia & $\begin{array}{l}\quad \text { la madre no } \\
\text { identifica otra } \\
\text { manera de } \\
\text { comprender la } \\
\text { dificultad. }\end{array}$ \\
\hline
\end{tabular}




\section{LA DESERCIÓN ESCOLAR COMO PRETEXTO PARA CONVERSAR SOBRE IDENTIDAD, FAMILIA Y ESCUELA

\begin{tabular}{l}
\multicolumn{1}{c}{ I: Como familia, } \\
no como D, sino \\
como familia ¿qué \\
han intentado para \\
poder apoyar a L? \\
No solamente D; que \\
D sea la que ordena, \\
que D sea la que \\
hace... sino como \\
familia, con su \\
nuevo compañero, \\
con su hija de \\
pronto, incluso hasta \\
con el bebé, con tu \\
mamá ¿sí? ¿Qué han \\
pensado? ¿Cómo \\
han intentado \\
organizarse para \\
poder apoyar a L?
\end{tabular}

M: No, que

alguien me diga a mi

"mire hagamos esto"

no. Yo con la

situación de ella

siempre he estado

como sola en ese

sentido, o sea, está

mi mamá mi esposo

y sí se enteran de lo

que pasa y eso pero

pues de ahí a

decir...a plantear

una solución o

apoyar, ayudarla, no.

I: ¿Por qué?

¿Usted qué cree que

ha faltado? ¿Porque

usted sola se ha

echado el problema

encima? ¿Porque no

lo ha comentado con

los otros?

M: Sí claro ellos

saben, le digo "es

que pasa esto" "es

que L hizo

esto"...pero sí o sea,

de pronto decir

"haga esto" "intente

esto" o "yo le ayudo

con esto" no. Y

bueno también

mucha gente se ha

cansado de hablarle

(risa)...

$\quad$ Intervenci Historias
ones
narrativas en
situaciones de
deserción
escolar

\begin{tabular}{lll}
\multicolumn{1}{c}{ Intervenci } & Relatos & \multicolumn{1}{c}{ La madre de } \\
ones & & igual manera da a \\
narrativas en & & conocer su \\
situaciones de & & frustración \\
deserción & & constante frente a \\
escolar & & la dificultad.
\end{tabular}

Intervenci Historias

ones

narrativas en

situaciones de

deserción

escolar

\begin{tabular}{lll}
\multicolumn{1}{c}{ Intervenci } & Memorias & \multicolumn{1}{c}{ nuevamente la } \\
ones & & madre no \\
narrativas en & construye relatos \\
situaciones de & alternos que \\
deserción & posibiliten una \\
escolar & mirada diferente al \\
& problema y a la \\
& forma de \\
& sobrellevarlo.
\end{tabular}




\section{LA DESERCIÓN ESCOLAR COMO PRETEXTO PARA CONVERSAR SOBRE IDENTIDAD, FAMILIA Y ESCUELA

\begin{tabular}{|c|c|c|}
\hline $\begin{array}{l}\quad \text { I: ¿Bueno y en } \\
\text { algún momento la } \\
\text { familia le ha } \\
\text { reconocido lo que } \\
\text { ella es? ¿Le han } \\
\text { visto todas las cosas } \\
\text { positivas que L } \\
\text { tiene? }\end{array}$ & $\begin{array}{l}\quad \text { Intervenci } \\
\text { ones } \\
\text { narrativas en } \\
\text { situaciones de } \\
\text { deserción } \\
\text { escolar }\end{array}$ & Memorias \\
\hline $\begin{array}{l}\text { M: Claro, todos } \\
\text { le decimos, que ella } \\
\text { tiene muchas } \\
\text { habilidades. }\end{array}$ & $\begin{array}{l}\quad \text { Intervenci } \\
\text { ones } \\
\text { narrativas en } \\
\text { situaciones de } \\
\text { deserción } \\
\text { escolar }\end{array}$ & Memorias \\
\hline
\end{tabular}

$\begin{array}{ll} & \text { de otras } \\ & \text { habilidades fuera } \\ & \text { de la } \\ \text { escolarización }\end{array}$

\begin{tabular}{lll}
\hline \multicolumn{1}{c}{ I: Pero no se han } & \multicolumn{1}{c}{ Intervenci } & HIstorias \\
movilizado para & ones & \\
sacarle esas & narrativas en \\
habilidades adelante, & situaciones de \\
porque todos están & deserción \\
centrados en un & escolar &
\end{tabular}

bachillerato.

\begin{tabular}{|c|c|c|c|}
\hline $\begin{array}{l}\quad \text { M: Si, pero por } \\
\text { ejemplo ella es } \\
\text { buena con los } \\
\text { computadores pero } \\
\text { ¿en dónde carajos le } \\
\text { dan un curso sin } \\
\text { bachillerato? }\end{array}$ & $\begin{array}{l}\quad \text { Intervenci } \\
\text { ones } \\
\text { narrativas en } \\
\text { situaciones de } \\
\text { deserción } \\
\text { escolar }\end{array}$ & Historias & $\begin{array}{l}\quad \text { Se comprende } \\
\text { por parte de la } \\
\text { madre la } \\
\text { posibilidad de } \\
\text { desarrollar un } \\
\text { relato alterno, sin } \\
\text { embargo continua } \\
\text { con la narrativa } \\
\text { saturada } \\
\text { relacionada con el } \\
\text { desarrollo } \\
\text { adacemico. }\end{array}$ \\
\hline
\end{tabular}

\begin{tabular}{|c|c|c|c|}
\hline $\begin{array}{l}\text { I: Bueno y } \\
\text { empíricamente, por } \\
\text { internet...ehhh en } \\
\text { fin. }\end{array}$ & $\begin{array}{l}\quad \text { Intervenci } \\
\text { ones } \\
\text { narrativas en } \\
\text { situaciones de } \\
\text { deserción } \\
\text { escolar } \\
\end{array}$ & Memorias & \\
\hline $\begin{array}{l}\text { M: Yo le he } \\
\text { dicho a ella que } \\
\text { busque arto por } \\
\text { internet y no, coge } \\
\text { es a mirar otras } \\
\text { cosas. Entonces es } \\
\text { que yo no le veo el } \\
\text { interés por ninguna } \\
\text { parte. Sumerced cree } \\
\text { que es que yo no le } \\
\text { digo... qué no le he } \\
\text { dicho, eso busque }\end{array}$ & \begin{tabular}{l}
\multicolumn{1}{c}{ Intervenci } \\
ones \\
narrativas en \\
situaciones de \\
deserción \\
escolar
\end{tabular} & HIstorias & \begin{tabular}{l}
\multicolumn{1}{c}{ La madre } \\
nuevamente \\
genera alternativas \\
de solucion a la \\
dificultad, sin \\
embargo \\
imposibilita la \\
solucion y pone su \\
comportamiento \\
como ejemplo de \\
lo deberia ser \\
concevido como
\end{tabular} \\
\hline
\end{tabular}




\section{LA DESERCIÓN ESCOLAR COMO PRETEXTO PARA CONVERSAR SOBRE IDENTIDAD, FAMILIA Y ESCUELA \\ por internet, uno \\ positivo.}

busca ahí tutoriales,

ella me ha visto

estudiando a punta

de tutoriales. Y yo le

he dicho...

\begin{tabular}{|c|c|c|c|}
\hline $\begin{array}{l}\text { I: Y ¿cuándo se } \\
\text { han sentado ustedes } \\
\text { dos a hacer ese } \\
\text { ejercicio? }\end{array}$ & $\begin{array}{l}\quad \text { Intervenci } \\
\text { ones } \\
\text { narrativas en } \\
\text { situaciones de } \\
\text { deserción } \\
\text { escolar } \\
\end{array}$ & Memorias & \\
\hline M: No & \begin{tabular}{l}
\multicolumn{1}{c}{ Intervenci } \\
ones \\
narrativas en \\
situaciones de \\
deserción \\
escolar
\end{tabular} & Memorias & $\begin{array}{l}\text { La madre } \\
\text { reconoce su } \\
\text { carencia al actuar, } \\
\text { frente a la ficultad }\end{array}$ \\
\hline $\begin{array}{l}\text { I: ¿Por qué? ¿Es } \\
\text { por falta de qué? }\end{array}$ & \begin{tabular}{l}
\multicolumn{1}{c}{ Intervenci } \\
ones \\
narrativas en \\
situaciones de \\
deserción \\
escolar \\
\end{tabular} & HIstorias & \\
\hline $\begin{array}{l}\quad \text { M: No, de } \\
\text { pronto...sí es por } \\
\text { muchos factores. O } \\
\text { sea, como el tiempo, } \\
\text { como...por ejemplo } \\
\text { en este momento me } \\
\text { tiene absorbida el } \\
\text { SENA y en este } \\
\text { momento tengo } \\
\text { hasta conflictos con } \\
\text { mi pareja por eso. }\end{array}$ & \begin{tabular}{l}
\multicolumn{1}{c}{ Intervenci } \\
ones \\
narrativas en \\
situaciones de \\
deserción \\
escolar
\end{tabular} & Historias & \begin{tabular}{l}
\multicolumn{1}{c}{ Nuevamente } \\
manifiesta su \\
imposibilidad de \\
cnstruir camino en \\
soluciones \\
posibilitadoras, \\
hablando de su \\
historia.
\end{tabular} \\
\hline $\begin{array}{l}\quad \text { I: Sí, es } \\
\text { exigente... Pero } \\
\text { recuerdo que en la } \\
\text { entrevista pasada, en } \\
\text { el encuentro pasado } \\
\text { decíamos que "cómo } \\
\text { ha cambiado la } \\
\text { situación de L la } \\
\text { vida de la familia". } \\
\text { ¿No ha avanzado } \\
\text { nada, sino se ha } \\
\text { quedado ahí } \\
\text { estancado? O sea, } \\
\text { ¿el problema se } \\
\text { generó y ahí está y }\end{array}$ & $\begin{array}{l}\quad \text { Intervenci } \\
\text { ones } \\
\text { narrativas en } \\
\text { situaciones de } \\
\text { deserción } \\
\text { escolar }\end{array}$ & Memorias & \\
\hline
\end{tabular}




\section{LA DESERCIÓN ESCOLAR COMO PRETEXTO PARA CONVERSAR SOBRE IDENTIDAD, FAMILIA Y ESCUELA

no se ha movilizado?

$\mathrm{O}$ ¿sí ha tomado algún otro rumbo $\mathrm{D}$ ? o ¿Qué ha pasado ahí?

\begin{tabular}{|c|c|c|c|}
\hline $\begin{array}{l}\quad \text { M: Pues en este } \\
\text { momento tanto como } \\
\text { el bachillerato no, } \\
\text { porque en este } \\
\text { momento... asumimo } \\
\text { s que el otro año ya } \\
\text { si va a estudiar. Esa } \\
\text { es la idea que } \\
\text { nosotros tenemos de } \\
\text { lo que ella ha dicho, } \\
\text { ya el problema se ha } \\
\text { ido es como a otras } \\
\text { situaciones, a otras } \\
\text { actitudes de ella. }\end{array}$ & $\begin{array}{l}\quad \text { Intervenci } \\
\text { ones } \\
\text { narrativas en } \\
\text { situaciones de } \\
\text { deserción } \\
\text { escolar }\end{array}$ & Historias & $\begin{array}{l}\quad \text { De nuevo la } \\
\text { madre propone } \\
\text { que el bachillerao } \\
\text { y la culminación } \\
\text { de este es la unica } \\
\text { forma posible de } \\
\text { solución. }\end{array}$ \\
\hline $\begin{array}{l}\text { I: El problema se } \\
\text { ha ido agrandando... } \\
\text { ¿y han pensado en } \\
\text { que L viva en otro } \\
\text { sitio? ¿Que no sea } \\
\text { contigo D? }\end{array}$ & $\begin{array}{l}\quad \text { Intervenci } \\
\text { ones } \\
\text { narrativas en } \\
\text { situaciones de } \\
\text { deserción } \\
\text { escolar } \\
\end{array}$ & Historias & \\
\hline $\begin{array}{l}\text { M: No, es que no } \\
\text { hay donde más viva. } \\
\text { A parte del papá ella } \\
\text { no tiene familia, o } \\
\text { sea la tiene pero jum } \\
\text { no se en donde...y } \\
\text { por parte de mi } \\
\text { familia pues quién se } \\
\text { va a hacer cargo de } \\
\text { alguien que no es de } \\
\text { uno. }\end{array}$ & $\begin{array}{l}\text { Construcci } \\
\text { ón narrativa } \\
\text { de la } \\
\text { identidad }\end{array}$ & Memorias & $\begin{array}{l}\quad \text { la madre cierra } \\
\text { nuevamente } \\
\text { caminos } \\
\text { posibilitadores a la } \\
\text { hora de nuevas } \\
\text { construcciones que } \\
\text { movilicen una } \\
\text { mirada diferente al } \\
\text { problema }\end{array}$ \\
\hline $\begin{array}{l}\text { I: O sea...nos } \\
\text { tocó vivir con L. }\end{array}$ & $\begin{array}{l}\quad \text { Intervenci } \\
\text { ones } \\
\text { narrativas en } \\
\text { situaciones de } \\
\text { deserción } \\
\text { escolar }\end{array}$ & Historias & \\
\hline
\end{tabular}




\section{LA DESERCIÓN ESCOLAR COMO PRETEXTO PARA CONVERSAR SOBRE IDENTIDAD, FAMILIA Y ESCUELA

M: Sí

\begin{tabular}{lll} 
M: Sí & \multicolumn{1}{c}{ Intervenci } & Memorias \\
& ones & \\
& narrativas en \\
& situaciones de \\
& deserción \\
& escolar
\end{tabular}

\begin{tabular}{lll}
\multicolumn{1}{c}{ I: Es básicamente } & \multicolumn{1}{c}{ Intervenci } & Memorias \\
lo que me estás & ones & \\
diciendo. & narrativas en & \\
& situaciones de & \\
& deserción & \\
& escolar &
\end{tabular}

\begin{tabular}{|c|c|c|c|}
\hline $\begin{array}{l}\quad \text { M: Si o sea, yo } \\
\text { decir "la mando para } \\
\text { algún lado" no. O } \\
\text { sea yo no le puedo } \\
\text { dar un problema a } \\
\text { otra persona que no } \\
\text { tiene por qué } \\
\text { asumirlo. }\end{array}$ & $\begin{array}{l}\quad \text { Construcci } \\
\text { ón narrativa } \\
\text { de la } \\
\text { identidad }\end{array}$ & Relatos & \begin{tabular}{l}
\multicolumn{1}{c}{ la madre o } \\
propone ningun \\
tipo de \\
comprension \\
diferente al \\
problema, \\
manifestando \\
como problema \\
especifico su hija, \\
nuevamente se \\
identifica una \\
narrativa saturada
\end{tabular} \\
\hline
\end{tabular}

A la ho
sugerir el

problema como

obligacion, la

madre lo acepta

como tal, sin tener

en cuenta nuevas

comprensiones a la

dificultad, de igual

manera no parece

asumir a

importancia que

implica que su hija

se encuentre

presente.

\begin{tabular}{|c|c|c|c|}
\hline $\begin{array}{l}\quad \text { I: Y dentro de las } \\
\text { soluciones que tú } \\
\text { has pensado, ¿qué } \\
\text { has visto? Es decir, } \\
\text { si ella no logra } \\
\text { ingresar el otro año a } \\
\text { validar ¿cómo va a } \\
\text { continuar la vida de } \\
\text { ella? }\end{array}$ & $\begin{array}{l}\quad \text { Intervenci } \\
\text { ones } \\
\text { narrativas en } \\
\text { situaciones de } \\
\text { deserción } \\
\text { escolar }\end{array}$ & Historias & \\
\hline $\begin{array}{l}\quad \text { M: Jum, pues si } \\
\text { ella no quiere } \\
\text { estudiar ¿qué la } \\
\text { pongo a hacer? No la } \\
\text { puedo poner a } \\
\text { trabajar, trabajar ahí } \\
\text { en el negocio que ya } \\
\text { me lo tiene casi en } \\
\text { quiebra, ¿en qué más } \\
\text { va a trabajar? }\end{array}$ & \begin{tabular}{l}
\multicolumn{1}{c}{ Construcci } \\
ón narrativa \\
de la \\
identidad
\end{tabular} & Historias & $\begin{array}{l}\text { Nuevamente se } \\
\text { permite ver por } \\
\text { parte de la madre } \\
\text { una narrativa } \\
\text { saturada. }\end{array}$ \\
\hline
\end{tabular}




\section{LA DESERCIÓN ESCOLAR COMO PRETEXTO PARA CONVERSAR SOBRE IDENTIDAD, FAMILIA Y ESCUELA

\author{
I: Pero tengo \\ entendido que ella \\ trabaja ahí y le \\ colabora en el \\ negocio.
}

$\begin{array}{cll} & \text { Construcci } & \text { Historias } \\ \text { Aparentemente } & \text { ón narrativa } & \\ & \text { de la } & \\ & \text { identidad } & \end{array}$

\author{
La madre \\ manifiesta la \\ imposibilidad de \\ accionar de su \\ hija, de igual \\ manera minimiza \\ los esfuerzos \\ desarrollados por \\ parte de la manor.
}

L.

I: ¿Cómo es eso?

A: Pues es que
casi no hay plata... y
casi no hay
estudiantes, casi no
quieren entrar. Ya
solo son pocos
estudiantes los que
quedan en el barrio
que van a sacar
fotocopias,
impresiones. Ya lo
que preguntan más
es lo de peluquería.

I: $¿$ Y usted maneja el negocio es en la parte de fotocopias, minutos, impresiones?

(silencio). ¿L y entonces qué harías con tu vida?

A: (silencio)
Mmm, no sé. ón narrativa de la identidad

$\quad$ Intervenci
ones
narrativas en
situaciones de
deserción
escolar

$$
\text { escolar }
$$

Experiencia

Experiencia 


\section{LA DESERCIÓN ESCOLAR COMO PRETEXTO PARA CONVERSAR SOBRE IDENTIDAD, FAMILIA Y ESCUELA

\begin{tabular}{rlr} 
A: (Silencio) & \multicolumn{1}{c}{ Construcci } & Relatos \\
Mmm, bachiller. & ón narrativa & \\
& de la & \\
& identidad &
\end{tabular}

\begin{tabular}{|c|c|c|c|}
\hline $\begin{array}{c}\mathrm{I}: \\
\text { ¿Definitivamente? }\end{array}$ & $\begin{array}{l}\quad \text { Construcci } \\
\text { ón narrativa } \\
\text { de la } \\
\text { identidad }\end{array}$ & Historias & \\
\hline $\begin{array}{l}\text { A: Pues sí. } \\
\text { (Silencio) }\end{array}$ & $\begin{array}{l}\quad \text { Construcci } \\
\text { ón narrativa } \\
\text { de la } \\
\text { identidad }\end{array}$ & Historias & $\begin{array}{l}\quad \text { La madre no } \\
\text { proporciona ni } \\
\text { construye otro } \\
\text { camino diferente } \\
\text { encaminado a la } \\
\text { solcion de la } \\
\text { dificultad, } \\
\text { manifestando } \\
\text { nuevamente } \\
\text { narrativas } \\
\text { saturadas. }\end{array}$ \\
\hline
\end{tabular}

\section{I: Bueno, $\mathrm{y}$} entonces hoy ¿qué se llevan? ¿Qué puede sacar cada una de conclusiones, de reflexión de este encuentro?

\section{M: Pues que sí} que la enana se ha ido creciendo y entre más pasa el tiempo, o sea entre más crece digo hay unas cosas que me desesperan a mí más.

$\quad$ Intervenci
ones
narrativas en
situaciones de
deserción
escolar

Intervenci
ones narrativas en situaciones de deserción escolar
Memorias

saturadas.
Y nuevamente
aparece la
narrativa saturada
relacionada con la
finalizacion de los
estudios
secundarios.

\begin{tabular}{|c|c|c|c|}
\hline & & & $\begin{array}{l}\text { propuestas que } \\
\text { generen soluciones } \\
\text { a la dificultad. }\end{array}$ \\
\hline $\begin{array}{l}\text { I: ¿Eso es lo que } \\
\text { te llevas del día de } \\
\text { hoy? }\end{array}$ & $\begin{array}{l}\quad \text { Intervenci } \\
\text { ones } \\
\text { narrativas en } \\
\text { situaciones de } \\
\text { deserción } \\
\text { escolar }\end{array}$ & Historias & \\
\hline $\begin{array}{l}\quad \text { M: Mmm } \\
\text { no...pues (risa) que } \\
\text { ella se siente } \\
\text { aburrida obviamente } \\
\text { y que quiere que su } \\
\text { vida cambie, pero no } \\
\text { hace nada para que } \\
\text { cambie. }\end{array}$ & $\begin{array}{l}\quad \text { Intervenci } \\
\text { ones } \\
\text { narrativas en } \\
\text { situaciones de } \\
\text { deserción } \\
\text { escolar }\end{array}$ & Historias & \begin{tabular}{l}
\multicolumn{1}{c}{ De nuevo la } \\
madre manifiesta \\
un relato satura en \\
el cual no se \\
comprende una \\
relación con la \\
dificultad ni su \\
solución.
\end{tabular} \\
\hline
\end{tabular}




\section{LA DESERCIÓN ESCOLAR COMO PRETEXTO PARA CONVERSAR SOBRE IDENTIDAD, FAMILIA Y ESCUELA

I: ¿Pero será que la vida de ella solo depende del cambio de ella? O ¿será del cambio de la familia?

M: Pues yo le he dicho a ella, cuando uno quiere que las cosas cambien empieza por cambiar uno. Pero si no cambia y no cede.

$\begin{array}{ll}\quad \text { Intervenci } & \text { HIstorias } \\ \text { ones } & \\ \text { narrativas en } & \\ \text { situaciones de } & \\ \text { deserción } & \\ \text { escolar } & \end{array}$

Construcci

ón narrativa

de la

identidad

HIstorias

$\quad$ la madre
manifiesta
nuevamente su
imposibilidad
frente a la
proposición de
soluciones,
negando su
responsabilidad
tanto en la
solucion como en
la construcción de
nuevos caminos.

$\begin{array}{ll}\quad \text { Intervenci } & \text { Memorias } \\ \text { ones } & \\ \text { narrativas en } & \\ \text { situaciones de } & \\ \text { deserción } & \\ \text { escolar } & \end{array}$

Construcci Historias
ón narrativa de la identidad
La madre

interrumoe la voz

de su hija para

manifestar una

solución interntada mas, encaminada a la construcción de nuevas comprensiones, sin embargo subvalora acciónar y la voz de su hija. 


\section{LA DESERCIÓN ESCOLAR COMO PRETEXTO PARA CONVERSAR SOBRE IDENTIDAD, FAMILIA Y ESCUELA

hay" y ahí sentada

en el computador, mirando una película y si llegan a hacer una impresión "no, no hay" porque no le interrumpan la película. Cosas como yo estando ahí, le dice a la gente que no estoy, hoy otra señora me dijo.

Entonces son cosas que uno dice...o sea yo lo siento como si ella dijera "yo no quiero atender esto acá acabémoslo". Así lo percibo yo.

\begin{tabular}{lll}
\multicolumn{1}{c}{ I: ¿M y usted no } & \multicolumn{1}{c}{ Intervenci } & Historias \\
se ha preguntado si & ones & \\
es que a ella no le & narrativas en \\
gusta hacer ese & situaciones de \\
trabajo...y de & deserción \\
repente lo hace pues & escolar
\end{tabular}

porque no le gusta?

M: Jum...¿pero
entonces qué? Un zángano ahí en la casa, ¿sin producir nada? No es justo. Porque sí, listo si ella no colabora en la casa entonces ¿de dónde le voy a dar yo? Si ese negocio fracasa en este momento, es nuestra única

entrada...entonces no hay ni pa' darle comida a ella misma. Entonces mantener a una persona, tenerla ahí todo el día como un zángano pegada a un televisor porque es lo que ella quiere hacer, porque ella es así. Ese es el televisor y ella está así y la gente le está hablando "niña una fotocopia" ella jum.

\begin{tabular}{|c|c|c|}
\hline $\begin{array}{l}\text { Construcci } \\
\text { ón narrativa } \\
\text { de la } \\
\text { identidad }\end{array}$ & Memorias & \begin{tabular}{l}
\multicolumn{1}{c}{ La madre } \\
manifiesta la \\
importancia de que \\
su hija ayude en \\
casa, sin embargo \\
desarrolla su idea a \\
partir de lenguaje \\
poco posibilitador, \\
de igual manera \\
manifiesta \\
nuevamente una \\
narrativa saturada.
\end{tabular} \\
\hline
\end{tabular}




\section{LA DESERCIÓN ESCOLAR COMO PRETEXTO PARA CONVERSAR SOBRE IDENTIDAD, FAMILIA Y ESCUELA

I: A ¿Qué te llevas del encuentro de hoy?
Intervenci

ones

narrativas en

situaciones de deserción

escolar

A: Mmm...

(Silencio). Pues no sé la verdad.

Intervenci

ones

narrativas en

situaciones de

deserción

escolar
I: Ok. Bueno, pues en este orden de ideas, solo me resta decirles que les agradezco realmente el tiempo que me han dado para poder compartir con ustedes. Pero yo si tengo una reflexión y no me puedo quedar con ella porque siento que la debo manifestar. Siento que ustedes se han lastimado muchísimo, muchísimo, muchísimo y yo no estoy aquí como para culpar a nadie ¿sí? Porque cada uno trae una historia de vida, pero hay cosas que no comparto y por ejemplo, se hieren tanto que no puedo comprender cómo puede pasar eso. Yo pienso que lo mismo que las distancia, es lo mismo parecidas que son y tal vez por lo mismo no encuentran cómo comunicarse, pero yo creo que ustedes como mamá y como hija necesitan encontrar un espacio para poder hablar de ustedes; y tal vez
Historias

Historias

La madre

manifiesta

nuevamente una

narrativa satura

frente al problema

$\mathrm{y}$ al proceso.

ones

narrativas en

situaciones de deserción

escolar

Historias 


\section{LA DESERCIÓN ESCOLAR COMO PRETEXTO PARA CONVERSAR SOBRE IDENTIDAD, FAMILIA Y ESCUELA

cuando eso suceda

las cosas empiezan a cambiar, porque yo siento que uno no se puede cansar de un hijo D...porque es mi responsabilidad hasta el final. Y a veces entiendo que el silencio de $\mathrm{L}$ dice más cosas de las que ella nos puede expresar con sus palabras; su lenguaje no verbal, su actitud, su conformismo con su misma vida, habla de su no proyección hacia futuro, o sea de...está estancada, la veo estancada y yo que voy a seguir llevando el caso de $\mathrm{L}$, yo les pediría que busquen un espacio, pero que vayan dispuestas a escucharse mutuamente, no juzgando sino hablando, poder hablar de lo que ha pasado. Ir reconociendo, pero ir construyendo a partir de lo que el otro dice, porque tal vez ahí está la clave de toda la situación...en ir construyendo a través de lo que el otro me cuenta, de lo que el otro me expresa y también no estar como tan a la defensiva, sino poder escuchar para poder transformar, porque fíjate $\mathrm{D}$ que tú misma lo dices cuando dices "yo no le puedo dejar el problema a otro, no le puedo trasladar el 


\section{LA DESERCIÓN ESCOLAR COMO PRETEXTO PARA CONVERSAR SOBRE IDENTIDAD, FAMILIA Y ESCUELA

problema al otro

porque es mío" ¿sí?

Y nadie se va a

hacer cargo de ese

supuesto problema, pero yo no lo vería como un problema, yo lo vería como una posibilidad para que ustedes se acerquen, como esa posibilidad. Eso es lo que me llevo de la sesión de hoy y las invitaría a que se quiten tantos prejuicios tal vez de lo que el otro ha dicho, de lo que éste dice, como de todos esos rótulos que le han puesto a $\mathrm{L} y$ vernos tal vez al desnudo, con lo que es $\mathrm{L}$, con sus quince años, que aunque parezcan muchos no son tantos en relación con los que usted tiene y la experiencia de vida que usted tiene. ¿sí? Para nuestro ejercicio nos queda un escenario, pero para el proceso que vamos a seguir nos quedan varios encuentros. Entonces yo les pediría que piensen un poco en lo que sucedió hoy aquí, en este espacio y que reflexionemos, todos tenemos que reflexionar un poco acerca de la conversación que hoy tuvimos y poder ver qué podemos rescatar de todo eso, para poder ir transformando porque definitivamente, la 


\section{LA DESERCIÓN ESCOLAR COMO PRETEXTO PARA CONVERSAR SOBRE IDENTIDAD, FAMILIA Y ESCUELA

situación no se va a

transformar sola. La

situación

DEBEMOS

transformarla y

ustedes son quienes

van a empezar a

transformar a partir

de estos encuentros

¿sí? Entonces lo

pensamos y nos

vemos en el próximo

encuentro. Me dicen

que L se va una

semana, entonces yo

la estoy contactando

para hacer la última

parte del ejercicio y

continuar en forma

con la terapia.

\begin{tabular}{|c|c|c|c|}
\hline $\begin{array}{l}\text { M: Bueno } \\
\text { doctora, muchas } \\
\text { gracias. }\end{array}$ & $\begin{array}{l}\quad \text { Intervenci } \\
\text { ones } \\
\text { narrativas en } \\
\text { situaciones de } \\
\text { deserción } \\
\text { escolar }\end{array}$ & Historias & $\begin{array}{l}\quad \text { se finaliza la } \\
\text { sesión con las } \\
\text { gracias de la } \\
\text { madre, sin } \\
\text { embaego se } \\
\text { imposibilita el } \\
\text { desarrollo de una } \\
\text { idea que implique } \\
\text { solción. }\end{array}$ \\
\hline
\end{tabular}

Escenario 3.

ESCENARIO 3 intervencione historias participantes y abreviaturas

s narrativas en

situación de

deserción escolar

lugar: construcción

narrativa de la

memorias

madre: abreviatura ( $\mathrm{m}$ )

fecha: $27 / 09 / 2015$

identidad

hija:( a)

duracion

\begin{tabular}{ll}
\hline \multicolumn{1}{c}{ relación } & relatos \\
\cline { 2 - 2 } joven, & acontecimi \\
familia e & ento \\
\cline { 2 - 2 } institución & relatos \\
educativa en & emergentes \\
torno a la & \\
deserción & \\
escolar. &
\end{tabular}


LA DESERCIÓN ESCOLAR COMO
IDENTIDAD, FAMILIA Y ESCUELA

textualidad

categor

macroproyecto

autorref

ias

erencia

heteroref
erencia

categ

orias

emergent

es 


\section{LA DESERCIÓN ESCOLAR COMO PRETEXTO PARA CONVERSAR SOBRE IDENTIDAD, FAMILIA Y ESCUELA

otros dos

encuentros. Ehhh a

partir de todo eso

que hemos venido

hablando, en donde

el segundo

escenario fue tan

fuerte para ustedes

dos por la forma

como confrontamos

las situaciones, en

donde usted me

decía "es que estoy

cansada, no sé qué

hacer con ella

porque no me

habla..." y L pues

también había

optado como por

ese silencio ¿no?

que finalmente

logramos que nos

dijera algo y era

cuando

retomábamos la

SITUACIÓNn de

D (el hijo menor)

que ella decía

"pues para mí fue

muy duro cuando

llegó $\mathrm{D}$, dejé de ser

el centro de

atención...” ¿sí?

Eso fue interesante

porque creo que

usted como que no

lo sabía $\mathrm{D}$, digamos

como directamente,

pero que logramos

que L nos

comentara esa

parte. Entonces hoy

vamos a mirar ya lo

que es el futuro de

ella y cómo han

logrado como

visualizarlo.

Entonces a partir de ahí yo les pregunto ¿cómo comprenden la SITUACIÓNn

de L? La

SITUACIÓNn a

nivel escolar,

¿cómo la 
LA DESERCIÓN ESCOLAR COMO PRETEXTO PARA CONVERSAR SOBRE IDENTIDAD, FAMILIA Y ESCUELA

comprende usted

$\mathrm{D}$ ? 


\section{LA DESERCIÓN ESCOLAR COMO PRETEXTO PARA CONVERSAR SOBRE IDENTIDAD, FAMILIA Y ESCUELA

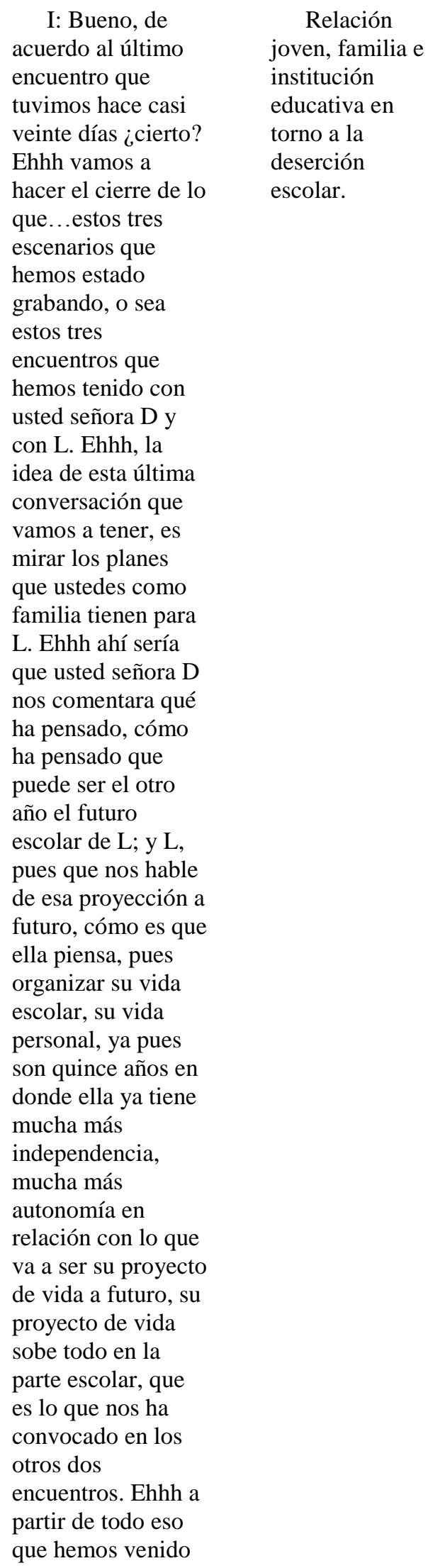

I: Bueno, de acuerdo al último encuentro que tuvimos hace casi veinte días ¿cierto? Ehhh vamos a hacer el cierre de lo que...estos tres escenarios que hemos estado grabando, o sea estos tres encuentros que hemos tenido con usted señora D y con L. Ehhh, la idea de esta última conversación que vamos a tener, es mirar los planes que ustedes como familia tienen para L. Ehhh ahí sería que usted señora D nos comentara qué ha pensado, cómo ha pensado que puede ser el otro año el futuro escolar de L; y L, pues que nos hable de esa proyección a futuro, cómo es que ella piensa, pues organizar su vida escolar, su vida personal, ya pues son quince años en donde ella ya tiene mucha más independencia, mucha más autonomía en relación con lo que va a ser su proyecto de vida a futuro, su proyecto de vida sobe todo en la parte escolar, que es lo que nos ha convocado en los otros dos encuentros. Ehhh a partir de todo eso que hemos venido

\section{Relación}

joven, familia e

institución

educativa en

torno a la

deserción

escolar.

Historias

Se

indentifican

por parte de

la madre

relatos

alternos al

problema

inicial,

proponiendo

un nuevo

camino con

respecto a la

dificultad 


\section{LA DESERCIÓN ESCOLAR COMO PRETEXTO PARA CONVERSAR SOBRE IDENTIDAD, FAMILIA Y ESCUELA

hablando, en donde

el segundo

escenario fue tan

fuerte para ustedes

dos por la forma

como confrontamos

las situaciones, en

donde usted me

decía "es que estoy

cansada, no sé qué

hacer con ella

porque no me

habla..." y L pues

también había

optado como por

ese silencio ¿no?

que finalmente

logramos que nos

dijera algo y era

cuando

retomábamos la

situación de D (el

hijo menor) que

ella decía "pues

para mí fue muy

duro cuando llegó

$\mathrm{D}$, dejé de ser el

centro de

atención..." ¿sí?

Eso fue interesante

porque creo que

usted como que no

lo sabía $\mathrm{D}$, digamos

como directamente, pero que logramos

que $\mathrm{L}$ nos

comentara esa

parte. Entonces hoy

vamos a mirar ya lo

que es el futuro de

ella y cómo han

logrado como

visualizarlo.

Entonces a partir de

ahí yo les pregunto

¿cómo comprenden

la situación de L?

La situación a nivel

escolar, ¿cómo la

comprende usted

$\mathrm{D}$ ?

\begin{tabular}{cll} 
I: Pero ya & \multicolumn{1}{c}{ Intervencione } & Historias \\
stamos mirando & s narrativas en & \\
tras alternativas & situación de & \\
deserción escolar &
\end{tabular}




\section{LA DESERCIÓN ESCOLAR COMO PRETEXTO PARA CONVERSAR SOBRE IDENTIDAD, FAMILIA Y ESCUELA

M: Pues sí, porque yo dije "qué saco yo con ir a gastar un poco de plata otra vez en matrículas, en cosas en gastos, pa' que en un mes me lo bote" entonces no, yo quiero que ella misma tome la decisión y me diga "yo quiero esto" pero que lo cumpla.

\section{Relación}

joven, familia e

institución

educativa en

torno a la

deserción

escolar.
Historias

$\mathrm{Se}$

identifica en

la madre

interés por

acercarse a la

dificultad de

su hija, a

partir de las

emociones de

esta,

proponiendo

nuevos

recursos que

den lugar a la

solución de la

dificultad

\section{I: Ahhh ok. \\ ¿Usted qué nos \\ tiene que \\ mencionar al \\ respecto? ¿Qué ha \\ pensado en relación \\ con su futuro?}

Intervencione

Relatos $s$ narrativas en

situación de

deserción escolar

\begin{tabular}{clc}
\hline A: (Silencio) & \multicolumn{1}{c}{$\begin{array}{c}\text { Intervencione } \\
\text { s narrativas en } \\
\text { situación de } \\
\text { deserción escolar }\end{array}$} & Relatos \\
& & \\
\hline M: ¿Qué has & $\begin{array}{l}\text { Intervencione } \\
\text { s narrativas en } \\
\text { situación de } \\
\text { pensado hacer el } \\
\text { otro año L? }\end{array}$ & Experiencia \\
&
\end{tabular}

\section{La menor}

guarda

silencio

frente a la

pregunta de

la psicologa

La madre

anima a la

hija a dar una

respuesta,

frente a su

futuro.

$\quad$ A: (Silencio)
Pues que... pues
los cursos. Pues
serían de
informática que es
en lo que mejor me
va...(silencio)

Construcción
narrativa de la

identidad

Historias

L propone

como

solución

abordar un

futuro en

relación a sus

intereses,

identificando

un relato

alterno

encaminado

al abordaje

de la

dificultad.

\begin{tabular}{lll}
\multicolumn{1}{c}{ I: O sea, debo } & \multicolumn{1}{c}{ Intervencione } & Historias \\
de entender con ese & s narrativas en & \\
silencio que no has & situación de & \\
pensado en volver a & deserción escolar & \\
un colegio & \\
tradicional, o ¿qué &
\end{tabular}




\section{LA DESERCIÓN ESCOLAR COMO PRETEXTO PARA CONVERSAR SOBRE IDENTIDAD, FAMILIA Y ESCUELA

has pensado en

relación con tu

bachillerato o

piensas que

solamente con los

cursos de

informática son

suficiente...cómo

te visualizas ahí?

¿Qué quieres? ¿qué

piensas hacer? ¿O

continúas con la

rutina que ya has

venido llevando

durante tres años?

$$
\text { A: } \mathrm{Mmm} . .
$$

(Silencio) ehhh...

pues no, no me he

Intervencione

$s$ narrativas en

situación de

visualizado (risa) la

verdad.

I: ¿Para usted es cómodo estar en la

casa y seguir la

rutina que va

llevando hace dos

años ya? ¿Usted

quiere seguir con

eso?

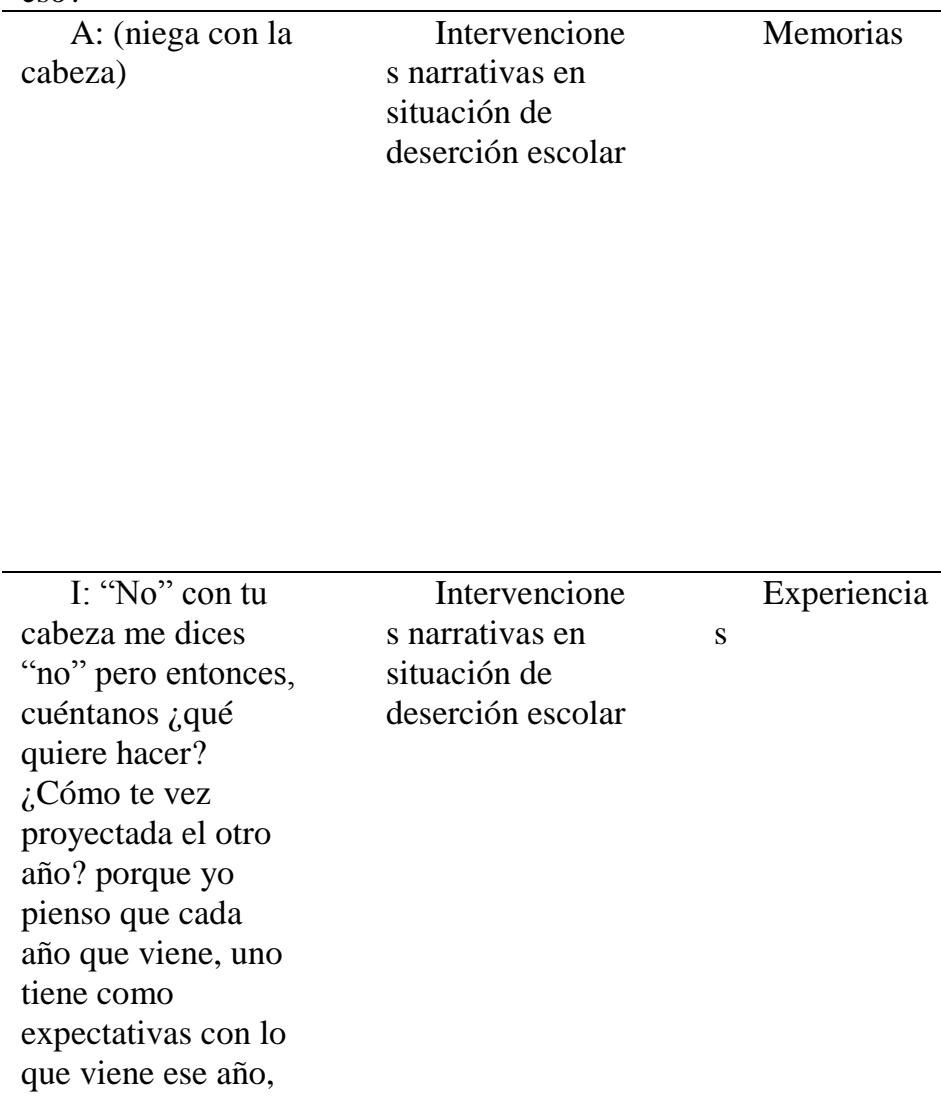

Intervencione Memorias

$s$ narrativas en

situación de

deserción escolar

\begin{tabular}{|c|c|}
\hline Historias & $\begin{array}{l}\text { L niega } \\
\text { haber } \\
\text { visualizado } \\
\text { su futuro }\end{array}$ \\
\hline
\end{tabular}

La menor

nuevamente

niega con la

cabeza, frente

a las

preguntas de

la

interventora

relacionadas

con el hecho

de continuar

actuando

como lo

hacia antes 


\section{LA DESERCIÓN ESCOLAR COMO PRETEXTO PARA CONVERSAR SOBRE IDENTIDAD, FAMILIA Y ESCUELA

con lo que trae, uno

se atreve a pensar,

a soñar, imaginar, a

crear, ¿usted qué ha pensado?

\begin{tabular}{|c|c|c|c|}
\hline $\begin{array}{c}\mathrm{A}: \mathrm{mmm} . . . \\
\text { (Silencio) } \mathrm{mmm} . . .\end{array}$ & $\begin{array}{l}\quad \text { Intervencione } \\
\text { s narrativas en } \\
\text { situación de } \\
\text { deserción escolar }\end{array}$ & Historias & $\begin{array}{l}\text { L guarda } \\
\text { silencio } \\
\text { nuevamente }\end{array}$ \\
\hline $\begin{array}{l}\quad \text { M: Uno planea } \\
\text { las cosas según lo } \\
\text { que va a dar L, yo } \\
\text { por ejemplo ya } \\
\text { ahorita ya termino } \\
\text { mi etapa electiva y } \\
\text { yo ya tengo } \\
\text { proyectado que el } \\
\text { otro año voy a } \\
\text { hacer mi } \\
\text { práctica...y yo ya } \\
\text { tengo claro cómo } \\
\text { van a ser las cosas } \\
\text { porque yo ya no } \\
\text { voy a estar ahí en } \\
\text { todo el día y he } \\
\text { programado las } \\
\text { cosas asumiendo } \\
\text { que usted al menos } \\
\text { medio día va a estar } \\
\text { en una actividad. } \\
\text { Pero queremos } \\
\text { saber en qué } \\
\text { actividad va a estar. }\end{array}$ & $\begin{array}{l}\text { Intervencione } \\
\text { s narrativas en } \\
\text { situación de } \\
\text { deserción escolar }\end{array}$ & Historias & $\begin{array}{l}\quad \text { La madre } \\
\text { propone } \\
\text { nuevas } \\
\text { alternativas } \\
\text { teniendo en } \\
\text { cuenta su } \\
\text { experiencia } \\
\text { de vida, } \\
\text { identificando } \\
\text { relatos } \\
\text { alternos }\end{array}$ \\
\hline $\begin{array}{l}\quad \text { A: Hmmm, } \\
\text { pues } \\
\text { qué...ehhh...yo...t } \\
\text { e había dicho lo de } \\
\text { la capoeira. } \\
\text { Mmm...lo de los } \\
\text { cursos de } \\
\text { informática } \\
\text { también...mmm... } \\
\text { (Silencio). }\end{array}$ & $\begin{array}{l}\text { Construcción } \\
\text { narrativa de la } \\
\text { identidad }\end{array}$ & Relatos & $\begin{array}{l}\quad \text { La menor } \\
\text { identifica } \\
\text { intereses, } \\
\text { comunicando } \\
\text { le a su madre } \\
\text { nuevas } \\
\text { alternativas } \\
\text { utiles frente a } \\
\text { la } \\
\text { comprensión } \\
\text { del problema. }\end{array}$ \\
\hline
\end{tabular}




\section{LA DESERCIÓN ESCOLAR COMO PRETEXTO PARA CONVERSAR SOBRE IDENTIDAD, FAMILIA Y ESCUELA

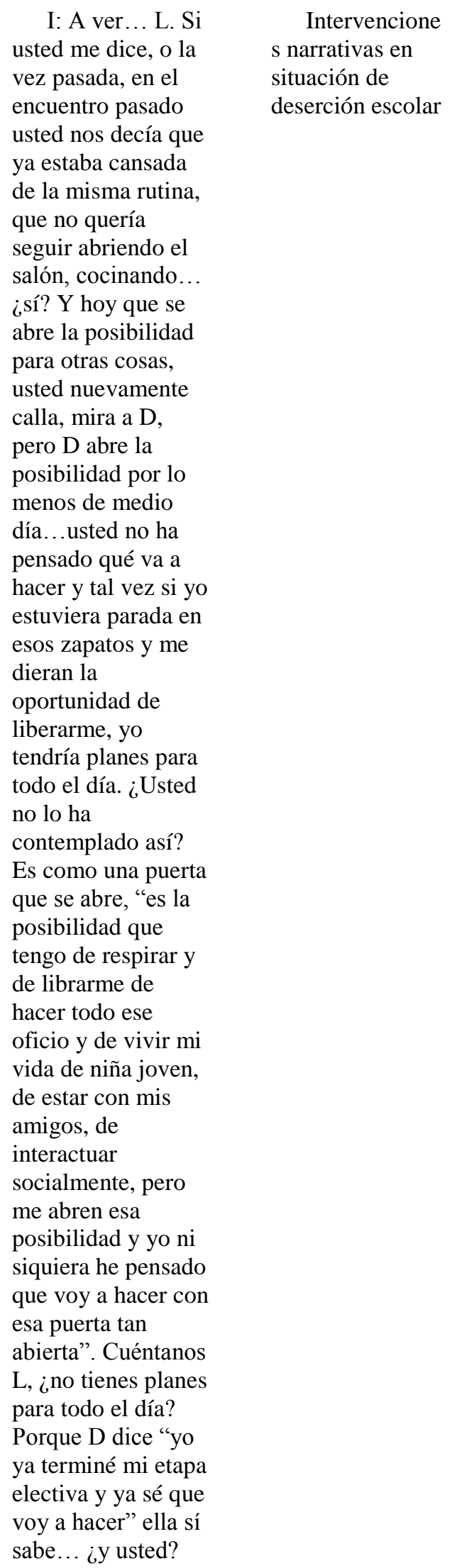

I: A ver... L. Si usted me dice, o la vez pasada, en el encuentro pasado usted nos decía que ya estaba cansada de la misma rutina, que no quería seguir abriendo el salón, cocinando... ¿sí? Y hoy que se abre la posibilidad para otras cosas, usted nuevamente calla, mira a D, pero D abre la posibilidad por lo menos de medio día...usted no ha pensado qué va a hacer y tal vez si yo estuviera parada en esos zapatos y me dieran la oportunidad de liberarme, yo tendría planes para todo el día. ¿Usted no lo ha contemplado así? Es como una puerta que se abre, "es la posibilidad que tengo de respirar y de librarme de hacer todo ese oficio y de vivir mi vida de niña joven, de estar con mis amigos, de interactuar socialmente, pero me abren esa posibilidad y yo ni siquiera he pensado que voy a hacer con esa puerta tan abierta". Cuéntanos L, ¿no tienes planes para todo el día? Porque D dice "yo ya terminé mi etapa electiva y ya sé que voy a hacer" ella sí sabe... ¿y usted?

\author{
Intervencione \\ $s$ narrativas en \\ situación de \\ deserción escolar
}

Memorias 


\section{LA DESERCIÓN ESCOLAR COMO PRETEXTO PARA CONVERSAR SOBRE IDENTIDAD, FAMILIA Y ESCUELA

\begin{tabular}{ll}
\multicolumn{1}{c}{ A: Mmm... } & \multicolumn{1}{c}{ Intervencione } \\
(Silencio) & s narrativas en \\
ehhh...en el & situación de \\
colegio. & deserción escolar
\end{tabular}

Memorias

$\mathrm{L}$

comunica la

idea de pasar

su tiempo en

el colegio, se

podria

considerar

como una

relato alterno

el hecho de

que el

colegio sea

entendido

como un

lugar para

pasar el

tiempo, en el

cual se

planea un

futuro.

\begin{tabular}{|c|c|c|}
\hline $\begin{array}{l}\text { I: ¿en qué } \\
\text { colegio? ¿haciendo } \\
\text { qué? ¿validando? ¿h } \\
\text { aciendo el } \\
\text { bachillerato } \\
\text { tradicional? A ver, } \\
\text { cuéntanos cómo va } \\
\text { a ser esos planes } \\
\text { tuyos. }\end{array}$ & $\begin{array}{l}\quad \text { Relación } \\
\text { joven, familia e } \\
\text { institución } \\
\text { educativa en } \\
\text { torno a la } \\
\text { deserción } \\
\text { escolar. }\end{array}$ & Relatos \\
\hline $\begin{array}{l}\text { A: Pues... } \\
\text { ¿validar? }\end{array}$ & $\begin{array}{l}\quad \text { Relación } \\
\text { joven, familia e } \\
\text { institución } \\
\text { educativa en } \\
\text { torno a la } \\
\text { deserción } \\
\text { escolar. }\end{array}$ & Relatos \\
\hline \begin{tabular}{l}
\multicolumn{1}{c}{ I: ¿En qué } \\
horario validarías? \\
¿A dónde irías a \\
validar? ¿Ya \\
hablaste eso con tu \\
mamá? ¿Cómo \\
piensas hacer? ¿En \\
dónde está lo que tú \\
quieres? ¿En dónde \\
está lo que tú \\
piensas? Díselo a \\
D, mírala y dile. \\
Claro, eso es lo que
\end{tabular} & $\begin{array}{l}\quad \text { Relación } \\
\text { joven, familia e } \\
\text { institución } \\
\text { educativa en } \\
\text { torno a la } \\
\text { deserción } \\
\text { escolar. }\end{array}$ & Experiencia \\
\hline
\end{tabular}
La menor
propone el
validar su
bachillerato
como un plan
de su futuro
cercano,
dando lugar a
nuevas
alternativas y
comprension
es de la
dificultad




\section{LA DESERCIÓN ESCOLAR COMO PRETEXTO PARA CONVERSAR SOBRE IDENTIDAD, FAMILIA Y ESCUELA

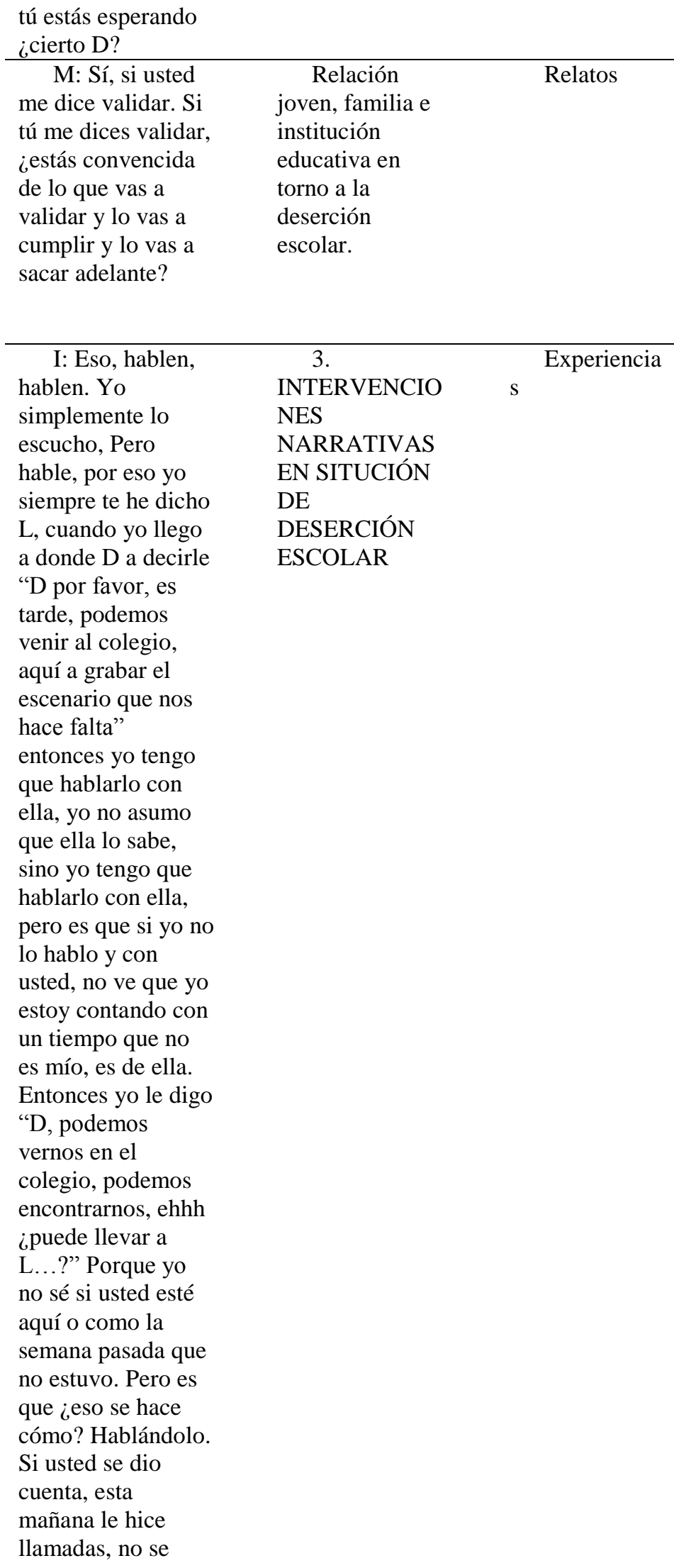

\begin{tabular}{lll}
\hline \multicolumn{1}{c}{ I: Eso, hablen, } & \multicolumn{1}{c}{3.} & Experiencia \\
hablen. Yo & INTERVENCIO & s \\
simplemente lo & NES & \\
escucho, Pero & NARRATIVAS & \\
hable, por eso yo & EN SITUCIÓN & \\
siempre te he dicho & DE & \\
L, cuando yo llego & DESERCIÓN \\
a donde D a decirle & ESCOLAR \\
"D por favor, es & \\
tarde, podemos & \\
venir al colegio, & \\
aquí a grabar el & \\
escenario que nos & \\
hace falta" & \\
entonces yo tengo & \\
que hablarlo con & \\
ella, yo no asumo & \\
que ella lo sabe, & \\
sino yo tengo que & \\
hablarlo con ella, & \\
pero es que si yo no & \\
lo hablo y con & \\
usted, no ve que yo & \\
estoy contando con & \\
un tiempo que no & \\
es mío, es de ella. & \\
Entonces yo le digo & \\
"D, podemos & \\
vernos en el & \\
colegio, podemos & \\
encontrarnos, ehhh & \\
¿puede llevar a & \\
L...?" Porque yo & \\
no sé si usted esté & \\
aquí o como la & \\
semana pasada que & \\
no estuvo. Pero es & \\
que ¿eso se hace & \\
cómo? Hablándolo. & \\
Si usted se dio \\
cuenta, esta & \\
mañana le hice & \\
llamadas, no se &
\end{tabular}




\section{LA DESERCIÓN ESCOLAR COMO PRETEXTO PARA CONVERSAR SOBRE IDENTIDAD, FAMILIA Y ESCUELA

pudo, hasta que nos

conectamos, nos

hablamos y nos

pusimos de acuerdo

y ahora estamos

aquí en el colegio

grabando. Pero

hablándolo, porque

yo no puedo asumir

o me puedo parar

aquí en la puerta

del colegio

esperando a que D

llegue si yo nunca

lo hablé con

ella...eso es lo

mismo que yo te

digo, háblalo con tu

mamá, háblalo,

mira ahí está D. Y

$\mathrm{D}$ en estos

encuentros, ella me

ha demostrado que

es una persona...o

nos ha demostrado

a usted y a mí...que

es una persona que

se deja hablar, que

está dispuesta para

hablar, pero si yo

no le digo nada,

pues ella

simplemente se

queda callada

porque...entonces

eso es lo que ha

pasado con ustedes, háblenlo. Dile, dile que es lo que quieres, dile cuáles son tus planes para el otro año, cómo lo piensas hacer, si puedes contar con ella, cómo ella la va a apoyar...eso es lo que quiero que hablen. Ese es el futuro de usted, el que se está poniendo en juego ahí. Cuéntale a D. ya hablaste de los cursos

informáticos, me 


\section{LA DESERCIÓN ESCOLAR COMO PRETEXTO PARA CONVERSAR SOBRE IDENTIDAD, FAMILIA Y ESCUELA

parecen geniales,

¿A qué hora los

piensas hacer? ¿En

dónde los piensas

hacer? Eso es

planear para el

futuro. Ya no

piensas volver al

colegio tradicional,

ya nos dijiste que

no...que ahora

piensas validar $¿$ en

dónde? Cuéntanos.

Pero todo eso se

hace mirándola, yo

no me puedo meter

debajo de la mesa,

de ésta mesa, a

peguntarle a D si

me puede dar un

espacio para que

hablemos

\begin{tabular}{|c|c|c|c|}
\hline A: (Silencio) & $\begin{array}{l}\quad \text { Intervencione } \\
\text { s narrativas en } \\
\text { situación de } \\
\text { deserción escolar }\end{array}$ & Memorias & $\begin{array}{l}\quad \text { La menor } \\
\text { guarda } \\
\text { silencio } \\
\text { frente a la } \\
\text { intervención } \\
\text { de la } \\
\text { interventora }\end{array}$ \\
\hline $\begin{array}{l}\text { I: Mira a tu } \\
\text { mamá y dile. }\end{array}$ & $\begin{array}{l}\quad \text { Intervencione } \\
\text { s narrativas en } \\
\text { situación de } \\
\text { deserción escolar }\end{array}$ & Historias & \\
\hline $\begin{array}{l}\text { A: Ehhh, pues } \\
\text { validar yo pensé } \\
\text { que era entre } \\
\text { semana (risa)... }\end{array}$ & \begin{tabular}{l}
\multicolumn{1}{c}{ Relación } \\
joven, familia e \\
institución \\
educativa en \\
torno a la \\
deserción \\
escolar.
\end{tabular} & Historias & $\begin{array}{l}\quad \text { Nuevame } \\
\text { nte L } \\
\text { comunica a } \\
\text { su madre otra } \\
\text { claridad } \\
\text { frente a sus } \\
\text { planes, lo } \\
\text { cual permite }\end{array}$ \\
\hline
\end{tabular}




\section{LA DESERCIÓN ESCOLAR COMO PRETEXTO PARA CONVERSAR SOBRE IDENTIDAD, FAMILIA Y ESCUELA

reconocer su capacidad a la hora de comprender su vida y su futuro.

\begin{tabular}{|c|c|c|c|}
\hline $\begin{array}{l}\quad \text { M: Pero es que, } \\
\text { o sea eso hay } \\
\text { diferentes opciones } \\
\text { L. hay } \\
\text { diferentes...o sea } \\
\text { eso depende de } \\
\text { cada instituto, o } \\
\text { hay un instituto que } \\
\text { tiene varios } \\
\text { horarios, o sea, hay } \\
\text { de lunes a viernes o } \\
\text { hay solo los } \\
\text { sábados o sábados } \\
\text { y domingos, o sea } \\
\text { eso hay diferentes. }\end{array}$ & $\begin{array}{l}\quad \text { Relación } \\
\text { joven, familia e } \\
\text { institución } \\
\text { educativa en } \\
\text { torno a la } \\
\text { deserción } \\
\text { escolar. }\end{array}$ & $\begin{array}{l}\text { Experiencia } \\
\mathrm{S}\end{array}$ & $\begin{array}{l}\quad \text { La madre } \\
\text { inicia una } \\
\text { narrativa } \\
\text { posibilitadora } \\
\text { con su hija, } \\
\text { dando lugar a } \\
\text { una } \\
\text { construcción } \\
\text { conjunta de } \\
\text { relatos } \\
\text { emergentes } \\
\text { frente a la } \\
\text { dificultad. }\end{array}$ \\
\hline $\begin{array}{l}\quad \text { I: A usted, } \\
\text { ¿cómo le gustaría } \\
\text { validar? En qué } \\
\text { horario, de acuerdo } \\
\text { a lo que D nos está } \\
\text { comentando, } \\
\text { porque si ella nos } \\
\text { está comentando } \\
\text { fue porque ella } \\
\text { averiguó. ¿En qué } \\
\text { horario le gustaría a } \\
\text { usted ir a validar? }\end{array}$ & $\begin{array}{l}\quad \text { Relación } \\
\text { joven, familia e } \\
\text { institución } \\
\text { educativa en } \\
\text { torno a la } \\
\text { deserción } \\
\text { escolar. }\end{array}$ & $\begin{array}{ll} & \text { Experiencia } \\
\mathrm{S} & \end{array}$ & \\
\hline $\begin{array}{l}\text { A: Mmm, pues } \\
\text { si, de ¿lunes a } \\
\text { viernes? }\end{array}$ & $\begin{array}{l}\quad \text { Relación } \\
\text { joven, familia e } \\
\text { institución } \\
\text { educativa en } \\
\text { torno a la } \\
\text { deserción } \\
\text { escolar. }\end{array}$ & $\begin{array}{ll} & \text { Experiencia } \\
\mathrm{S} & \end{array}$ & \begin{tabular}{l}
\multicolumn{1}{c}{ La hija } \\
continua la \\
construcción \\
que se ha \\
empezado \\
con la madre, \\
manifestando \\
mas intereses \\
y claridades \\
con respecto \\
a su futuro.
\end{tabular} \\
\hline $\begin{array}{l}\quad \mathrm{I}: \mathrm{Mmm} \text {, } \\
\text { interesante, muy } \\
\text { interesante. De } \\
\text { lunes a viernes, ¿en } \\
\text { dónde? }\end{array}$ & $\begin{array}{l}\quad \text { Relación } \\
\text { joven, familia e } \\
\text { institución } \\
\text { educativa en } \\
\text { torno a la } \\
\text { deserción } \\
\text { escolar. }\end{array}$ & $\begin{array}{ll} & \text { Experiencia } \\
\mathrm{s} & \end{array}$ & \\
\hline
\end{tabular}




\section{LA DESERCIÓN ESCOLAR COMO PRETEXTO PARA CONVERSAR SOBRE IDENTIDAD, FAMILIA Y ESCUELA

\begin{tabular}{clc} 
A: (Risa) No sé, & \multicolumn{1}{c}{ Relación } & Experiencia \\
porque no... & joven, familia e & \\
institución & educativa en \\
torno a la & \\
deserción & \\
escolar. &
\end{tabular}

\begin{tabular}{clc}
$\begin{array}{c}\text { I: Ahhh, usted } \\
\text { no ha ido con D a } \\
\text { averiguar. }\end{array}$ & \multicolumn{1}{c}{$\begin{array}{c}\text { Relación } \\
\text { joven, familia e } \\
\text { institución } \\
\text { educativa en } \\
\text { torno a la } \\
\text { deserción } \\
\text { escolar. }\end{array}$} & \\
& \multicolumn{1}{c}{ Relación } & \\
& joven, familia e & \\
institución & Memorias \\
educativa en & \\
torno a la & \\
deserción & \\
escolar. & \\
&
\end{tabular}




\section{LA DESERCIÓN ESCOLAR COMO PRETEXTO PARA CONVERSAR SOBRE IDENTIDAD, FAMILIA Y ESCUELA

colegio de lunes a

viernes a validar y

¿A qué instituto? A

donde, a ver

cuénteme D.

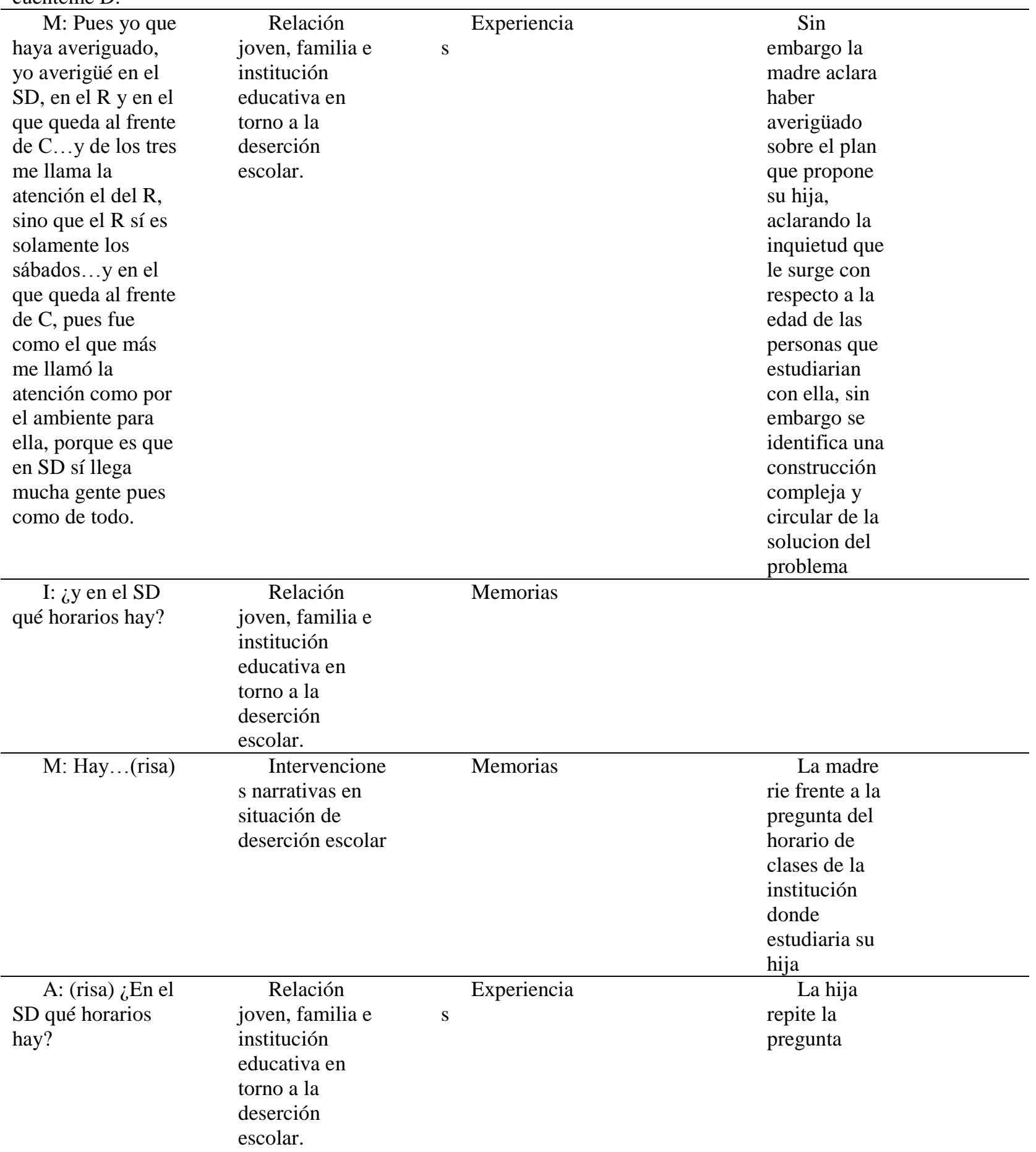




\section{LA DESERCIÓN ESCOLAR COMO PRETEXTO PARA CONVERSAR SOBRE IDENTIDAD, FAMILIA Y ESCUELA

M: Ahí hay de los tres horarios.

Hay los fines de semana, de noche, en el día, en la tarde. Allá sí que hay de todos. En el que es de lunes a viernes al frente de $\mathrm{C}$ es de 8 a 12 , de lunes a viernes. $Y$ en el R, pues ese hay de...solo los sábados porque entre semana estudian las niñas que estudian de día. Entonces en el R sí es solamente los sábados.

\begin{tabular}{|c|c|c|}
\hline $\begin{array}{l}\text { A: Mmm...pues } \\
\text { sería mirar en el } \\
\text { que queda al frente } \\
\text { del C. }\end{array}$ & $\begin{array}{l}\quad \text { Relación } \\
\text { joven, familia e } \\
\text { institución } \\
\text { educativa en } \\
\text { torno a la } \\
\text { deserción } \\
\text { escolar. }\end{array}$ & $\begin{array}{ll} & \text { Experiencia } \\
\mathrm{s} & \end{array}$ \\
\hline
\end{tabular}

Experiencia joven, familia e S institución educativa en torno a la deserción escolar.

La madre responde con gran conocimiento de los horarios y demas detalles de la institución, reconociendo un gran interes de la madre por los los planes, el futuro y los intereses de su hija.

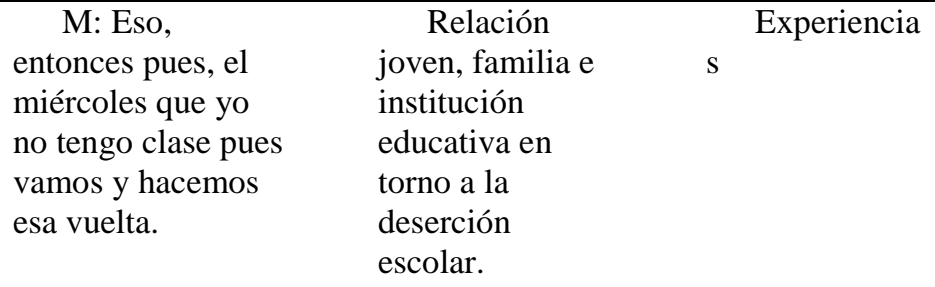




\section{LA DESERCIÓN ESCOLAR COMO PRETEXTO PARA CONVERSAR SOBRE IDENTIDAD, FAMILIA Y ESCUELA

\begin{tabular}{|c|c|c|}
\hline $\begin{array}{l}\text { I: Van a ir las } \\
\text { dos... }\end{array}$ & $\begin{array}{l}\quad \text { Relación } \\
\text { joven, familia e } \\
\text { institución } \\
\text { educativa en } \\
\text { torno a la } \\
\text { deserción } \\
\text { escolar. }\end{array}$ & Experiencia \\
\hline
\end{tabular}

\begin{tabular}{|c|c|c|c|}
\hline \begin{tabular}{l}
\multicolumn{1}{c}{ M: Vamos y } \\
averiguamos y mira \\
las instalaciones, \\
hablas con la gente. \\
Porque si, todo eso \\
toca mirar porque \\
de todas maneras, \\
pues tampoco \\
puedo ir a meter, o \\
yo por lo menos no \\
puedo ir a dejarla \\
que meta la cabeza \\
en el primer lugar \\
que haya...porque \\
pues tampoco...hay \\
gente demasiado \\
mayor, gente que \\
ya no es para ti, \\
gente que de pronto \\
ya con más \\
experiencia de \\
muchas cosas, \\
entonces pues no es \\
bueno. O sea, lo \\
ideal sería en ese \\
sitio que he visto \\
que hay como más \\
o menos \\
muchachos...
\end{tabular} & \begin{tabular}{l}
\multicolumn{1}{c}{ Relación } \\
joven, familia e \\
institución \\
educativa en \\
torno a la \\
deserción \\
escolar.
\end{tabular} & Historias & $\begin{array}{l}\quad \text { La madre } \\
\text { ademas narra } \\
\text { sus } \\
\text { coprensiones } \\
\text { frente al } \\
\text { hecho de } \\
\text { asistir juntas } \\
\text { al colegio, las } \\
\text { personas, la } \\
\text { planeación } \\
\text { del día, sus } \\
\text { intereses sin } \\
\text { dejar de tener } \\
\text { en cuenta los } \\
\text { intereses de } \\
\text { su hija, } \\
\text { identificando } \\
\text { se una } \\
\text { construcción } \\
\text { compleja y } \\
\text { circular de la } \\
\text { solución de la } \\
\text { dificultad. }\end{array}$ \\
\hline $\begin{array}{l}\text { I: ¿De la edad } \\
\text { de ella? }\end{array}$ & \begin{tabular}{l}
\multicolumn{1}{c}{ Intervencione } \\
s narrativas en \\
situación de \\
deserción escolar
\end{tabular} & Experiencia & \\
\hline $\begin{array}{l}\text { M: De la edad } \\
\text { de ella sí. }\end{array}$ & $\begin{array}{l}\quad \text { Intervencione } \\
\text { s narrativas en } \\
\text { situación de } \\
\text { deserción escolar }\end{array}$ & $\begin{array}{l}\text { Experiencia } \\
\mathrm{s}\end{array}$ & $\begin{array}{l}\quad \text { La madre } \\
\text { de igual } \\
\text { forma da a } \\
\text { conocer su } \\
\text { preocupación } \\
\text { con respecto } \\
\text { a las edades } \\
\text { de las } \\
\text { personas que } \\
\text { estudiaran } \\
\text { con su hija. }\end{array}$ \\
\hline
\end{tabular}




\section{LA DESERCIÓN ESCOLAR COMO PRETEXTO PARA CONVERSAR SOBRE IDENTIDAD, FAMILIA Y ESCUELA

I: ¿sí L, te llama la atención ir el miércoles con tu mami a mirar el sitio donde estarías?
Intervencione s narrativas en situación de deserción escolar

Historias

\begin{tabular}{|c|c|c|c|}
\hline A: $\mathrm{Si}$. & $\begin{array}{l}\quad \text { Intervencione } \\
\text { s narrativas en } \\
\text { situación de } \\
\text { deserción escolar }\end{array}$ & Historias & $\begin{array}{l}\quad \text { La madre } \\
\text { muestra } \\
\text { interes en la } \\
\text { pregunta que } \\
\text { porpone la } \\
\text { interventora, } \\
\text { afirmando. }\end{array}$ \\
\hline $\begin{array}{l}\quad \text { I: Bueno L... y } \\
\text { ya, estamos allá, ya } \\
\text { es } 2016 \text {. Eso fue } \\
\text { rápido que } \\
\text { llegamos allá...tu } \\
\text { compromiso, ¿qué } \\
\text { esperas encontrar } \\
\text { allí? ¿Cómo te ves } \\
\text { allí? ¿Te llama la } \\
\text { atención? ¿Te pone } \\
\text { feliz? }\end{array}$ & $\begin{array}{l}\text { Intervencione } \\
\text { s narrativas en } \\
\text { situación de } \\
\text { deserción escolar }\end{array}$ & Experiencia & \\
\hline $\begin{array}{l}\text { A: Nerviosa } \\
\text { (risa) }\end{array}$ & \begin{tabular}{l}
\multicolumn{1}{c}{ Intervencione } \\
s narrativas en \\
situación de \\
deserción escolar
\end{tabular} & $\begin{array}{l}\text { Relatos } \\
\text { Alternos }\end{array}$ & $\begin{array}{l}\quad \text { La menor } \\
\text { narra estar } \\
\text { nerviosa } \\
\text { frente al } \\
\text { nuevo hecho } \\
\text { de asistir } \\
\text { nuevamente a } \\
\text { clase. }\end{array}$ \\
\hline $\begin{array}{l}\text { I: ¿Nerviosa? } \\
\text { ¿Por qué a ver? }\end{array}$ & $\begin{array}{l}\quad \text { Intervencione } \\
\text { s narrativas en } \\
\text { situación de } \\
\text { deserción escolar } \\
\end{array}$ & $\begin{array}{l}\text { Relatos } \\
\text { Alternos }\end{array}$ & \\
\hline A: Emmm & $\begin{array}{l}\quad \text { Intervencione } \\
\text { s narrativas en } \\
\text { situación de } \\
\text { deserción escolar }\end{array}$ & Experiencia & \begin{tabular}{l}
\multicolumn{1}{c}{ Cuando } \\
se le pregunta \\
el por que se \\
siente \\
nerviosa, \\
piensa sin \\
demostrar \\
mayor \\
claridad de lo \\
que quiere \\
decir \\
\end{tabular} \\
\hline $\begin{array}{l}\text { I: Es un reto } \\
\text { nuevamente para ti, } \\
\text { ¿cómo asumes ese } \\
\text { reto? }\end{array}$ & \begin{tabular}{l}
\multicolumn{1}{c}{ Intervencione } \\
s narrativas en \\
situación de \\
deserción escolar \\
\end{tabular} & $\begin{array}{l}\text { Experiencia } \\
\mathrm{s}\end{array}$ & \\
\hline A: ¿intentando? & \begin{tabular}{l}
\multicolumn{1}{c}{ Intervencione } \\
s narrativas en \\
situación de
\end{tabular} & Memorias & $\begin{array}{l}\quad \mathrm{Se} \\
\text { mantiene una } \\
\text { actitud }\end{array}$ \\
\hline
\end{tabular}




\section{LA DESERCIÓN ESCOLAR COMO PRETEXTO PARA CONVERSAR SOBRE IDENTIDAD, FAMILIA Y ESCUELA \\ deserción escolar \\ basada en el miedo y en la \\ evasion}

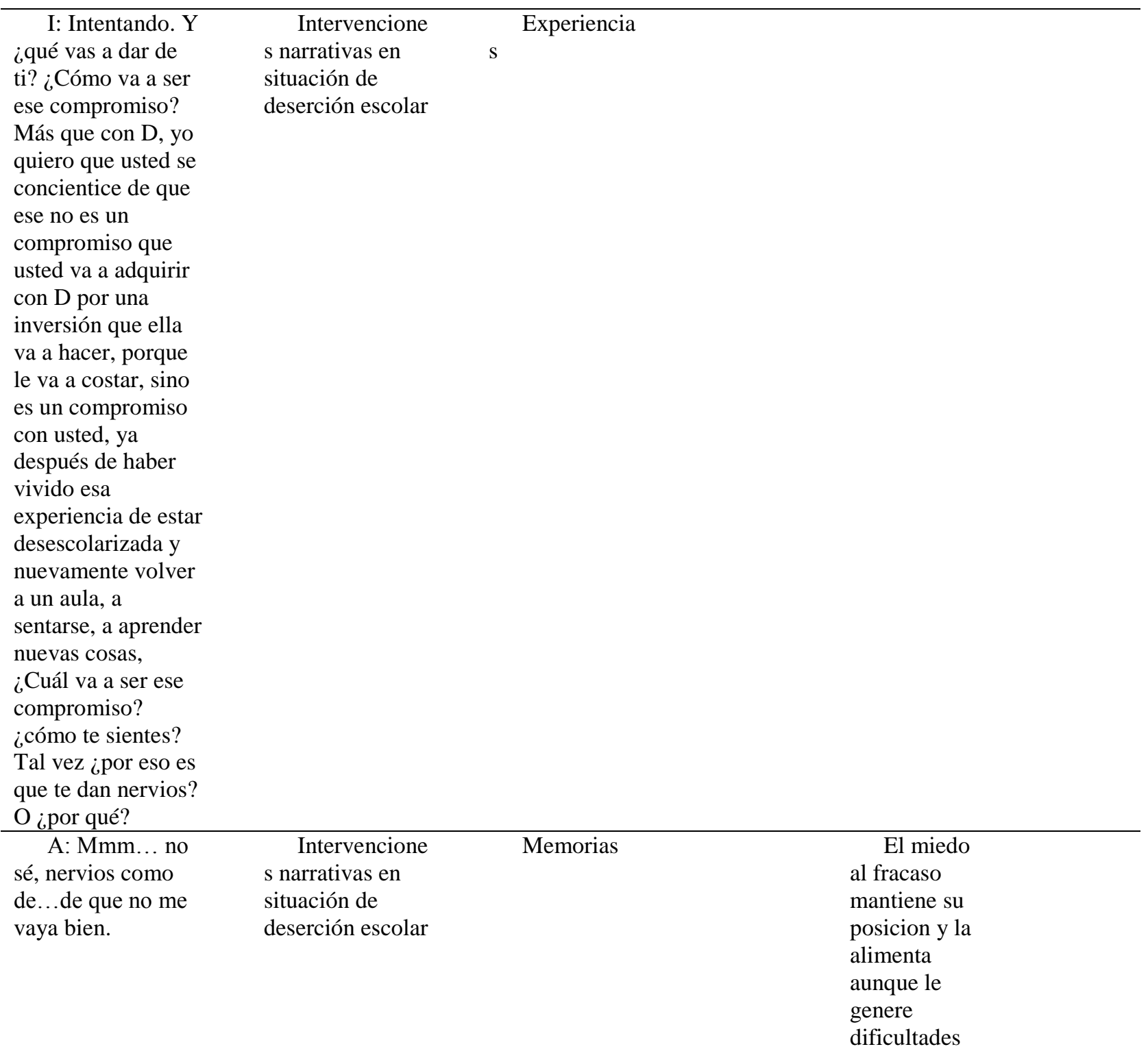




\section{LA DESERCIÓN ESCOLAR COMO PRETEXTO PARA CONVERSAR SOBRE IDENTIDAD, FAMILIA Y ESCUELA

I: ¿pero por qué? Si usted es una niña con todas las facultades para poder responder a ese reto. La experiencia que tu viviste de años anteriores, solamente tiene que servirte para no volver a repetir esos errores. Como por ejemplo cuando tu evadías las clases, usted sabe que esa fue una experiencia que no fue muy benéfica para usted, porque mire todo lo que nos desencadenó, el hecho de que usted hubiese dejado el colegio, que nuevamente.... ¿sí? Hubieras intentado en otro colegio y tampoco respondiste, que un mes sí, que un mes no, que no ibas, que te ibas con tus amigos...esa experiencia yo creo que para ti fue muy buena, porque te dejó una enseñanza ¿Cuál fue esa enseñanza?

A: Mmm...pues que no...no hay que salirse de clases. Porque no va a dejar nada bueno.
Intervencione
s narrativas en

situación de

deserción escolar

Historias 


\section{LA DESERCIÓN ESCOLAR COMO PRETEXTO PARA CONVERSAR SOBRE IDENTIDAD, FAMILIA Y ESCUELA

años?

\begin{tabular}{|c|c|c|c|}
\hline A: Dos. & $\begin{array}{l}\text { Intervencione } \\
\text { s narrativas en } \\
\text { situación de } \\
\text { deserción escolar }\end{array}$ & Experiencia & $\begin{array}{l}\text { Reconoce } \\
\text { su tiempo de } \\
\text { experiencia } \\
\text { de manera } \\
\text { especifica } \\
\end{array}$ \\
\hline $\begin{array}{l}\quad \mathrm{I}: \text { Dos. } \\
\text { ¿Haciendo qué? } \\
\text { (risas) }\end{array}$ & $\begin{array}{l}\text { Intervencione } \\
\text { s narrativas en } \\
\text { situación de } \\
\text { deserción escolar }\end{array}$ & Experiencia & \\
\hline A: (Risas) & $\begin{array}{l}\text { Intervencione } \\
\text { s narrativas en } \\
\text { situación de } \\
\text { deserción escolar }\end{array}$ & Experiencia & \begin{tabular}{l}
\multicolumn{1}{c}{ Con su } \\
risa reconoce \\
su situacion \\
dentron de su \\
contexto y \\
que implica \\
eso para los \\
otros.
\end{tabular} \\
\hline $\begin{array}{l}\text { I: A ver, a veces } \\
\text { uno tiene que } \\
\text { repetirse a sí } \\
\text { mismo para } \\
\text { poderse } \\
\text { convencer... }\end{array}$ & $\begin{array}{l}\text { Intervencione } \\
\text { s narrativas en } \\
\text { situación de } \\
\text { deserción escolar }\end{array}$ & Experiencia & \\
\hline $\begin{array}{l}\quad \text { M: "Cuando mi } \\
\text { mamá me pescó } \\
\text { que me escapaba } \\
\text { del colegio y me } \\
\text { metió a la cocina" } \\
\text { (risa) }\end{array}$ & \begin{tabular}{l}
\multicolumn{1}{c}{ Relación } \\
joven, familia e \\
institución \\
educativa en \\
torno a la \\
deserción \\
escolar.
\end{tabular} & HIstorias & $\begin{array}{l}\text { Se repitio } \\
\text { la idea de un } \\
\text { sistema } \\
\text { represivo de } \\
\text { modo } \\
\text { constructivo }\end{array}$ \\
\hline $\begin{array}{l}\text { I: (risa) Eso, } \\
\text { mira como D lo } \\
\text { cuenta así como tan } \\
\text { folclóricamente...y } \\
\text { lo que eso para ti } \\
\text { implicó. Dejaste de } \\
\text { compartir con } \\
\text { personas de tu } \\
\text { edad, de vivir tu } \\
\text { mundo de niña, de } \\
\text { tu juventud, mira } \\
\text { fueron dos años } \\
\text { que tu perdiste allá } \\
\text { en la cocina ¿o no? }\end{array}$ & $\begin{array}{l}\text { Intervencione } \\
\text { s narrativas en } \\
\text { situación de } \\
\text { deserción escolar }\end{array}$ & HIstorias & \\
\hline $\begin{array}{l}\text { M: Aprendió a } \\
\text { cocinar porque } \\
\text { cocina muy rico. } \\
\text { (risa) }\end{array}$ & $\begin{array}{l}\text { Construcción } \\
\text { narrativa de la } \\
\text { identidad }\end{array}$ & Relatos & $\begin{array}{l}\text { Se genera } \\
\text { un relato } \\
\text { positivo } \\
\text { frente a sus } \\
\text { castigos }\end{array}$ \\
\hline
\end{tabular}




\section{LA DESERCIÓN ESCOLAR COMO PRETEXTO PARA CONVERSAR SOBRE IDENTIDAD, FAMILIA Y ESCUELA

\begin{tabular}{|c|c|c|c|}
\hline A: Ash (risa) & $\begin{array}{l}\text { Construcción } \\
\text { narrativa de la } \\
\text { identidad }\end{array}$ & HIstorias & \\
\hline $\begin{array}{l}\text { I: ¿Sí? ¿Cocina } \\
\text { delicioso? }\end{array}$ & $\begin{array}{l}\text { Construcción } \\
\text { narrativa de la } \\
\text { identidad }\end{array}$ & HIstorias & \\
\hline M: Sí & $\begin{array}{l}\text { Construcción } \\
\text { narrativa de la } \\
\text { identidad }\end{array}$ & HIstorias & \begin{tabular}{l}
\multicolumn{1}{c}{ La madre } \\
afirma que su \\
hija cocina de \\
manera \\
adecuada, \\
reconociendo \\
y \\
permitiendo \\
que su hija \\
construya \\
con ella un \\
relato alterno, \\
encaminado a \\
una narrativa \\
emergente
\end{tabular} \\
\hline $\begin{array}{l}\text { I: Y para D } \\
\text { ¿esos dos años } \\
\text { cómo fueron? }\end{array}$ & $\begin{array}{l}\text { Intervencione } \\
\text { s narrativas en } \\
\text { situación de } \\
\text { deserción escolar }\end{array}$ & HIstorias & \\
\hline $\begin{array}{l}\text { M: No pues, } \\
\text { amargos, de } \\
\text { angustia, de estar } \\
\text { ahí como en un... } \\
\text { "qué va a pasar con } \\
\text { ella", }\end{array}$ & $\begin{array}{l}\text { Intervencione } \\
\text { s narrativas en } \\
\text { situación de } \\
\text { deserción escolar }\end{array}$ & HIstorias & \begin{tabular}{l}
\multicolumn{1}{c}{ La madre } \\
identifica la \\
problematica \\
inicial como \\
un suceso del \\
pasado, \\
reconociendo \\
se un relato \\
emergente \\
frente a la \\
dificultad
\end{tabular} \\
\hline $\begin{array}{l}\text { I: Pero yo creo } \\
\text { que también fue } \\
\text { como un beneficio } \\
\text { para ti } D \text {, de cierta } \\
\text { forma. }\end{array}$ & $\begin{array}{l}\text { Intervencione } \\
\text { s narrativas en } \\
\text { situación de } \\
\text { deserción escolar }\end{array}$ & $\begin{array}{r}\text { Relatos } \\
\text { emergentes }\end{array}$ & \\
\hline \begin{tabular}{l}
\multicolumn{1}{c}{ M: Pues sí } \\
porque pienso que \\
eso la ayudó a \\
madurar y pienso \\
que eso la ayuda a \\
que, ya ahorita que \\
si de verdad va a \\
retomar su vida \\
escolar, se \\
concientice de que \\
es importante y de \\
que ya hacer esas \\
cosas no la lleva a \\
nada bueno.
\end{tabular} & $\begin{array}{l}\text { Intervencione } \\
\text { s narrativas en } \\
\text { situación de } \\
\text { deserción escolar }\end{array}$ & $\begin{array}{r}\text { Relatos } \\
\text { emergentes }\end{array}$ & $\begin{array}{l}\quad \text { La madre } \\
\text { en un } \\
\text { principio } \\
\text { narra el } \\
\text { interes que } \\
\text { tiene en el } \\
\text { cambio que } \\
\text { ha tenido su } \\
\text { hija, sin } \\
\text { embargo } \\
\text { nuevamente } \\
\text { vuelve a la } \\
\text { narativa } \\
\text { saturada }\end{array}$ \\
\hline
\end{tabular}




\section{LA DESERCIÓN ESCOLAR COMO PRETEXTO PARA CONVERSAR SOBRE IDENTIDAD, FAMILIA Y ESCUELA \\ anterior en la cual propone el hecho de que su hija vuelva a estar como se encontraba antes.}

\begin{tabular}{|c|c|c|c|}
\hline \begin{tabular}{l}
\multicolumn{1}{c}{ I: Pero no, yo } \\
pienso que no \\
solamente no fue el \\
beneficio de la \\
maduración para L. \\
porque claro L sí \\
hoy ya ve la \\
sItuación y tiene la \\
capacidad de \\
reflexionar y decir \\
"sí, la embarre...sí, \\
me equivoqué" \\
pero también para \\
ti yo creo que fue \\
un beneficio en el \\
sentido de que te \\
colaboró.
\end{tabular} & $\begin{array}{l}\text { Intervencione } \\
\text { s narrativas en } \\
\text { situación de } \\
\text { deserción escolar }\end{array}$ & $\begin{array}{r}\text { Relatos } \\
\text { emergentes }\end{array}$ & \\
\hline $\begin{array}{l}\text { M: A sí, eso sí. } \\
\text { Pues sobre todo } \\
\text { cuando empecé a } \\
\text { estudiar. }\end{array}$ & $\begin{array}{l}\quad \text { Relación } \\
\text { joven, familia e } \\
\text { institución } \\
\text { educativa en } \\
\text { torno a la } \\
\text { deserción } \\
\text { escolar. }\end{array}$ & Relatos & \begin{tabular}{l}
\multicolumn{1}{c}{ La madre } \\
reconoce \\
nuevamente \\
los valores de \\
su hija, \\
comprendien \\
do el \\
problema \\
como algo \\
del pasado, \\
entiendo \\
además la \\
nueva \\
realidad \\
como \\
venefiiciosa.
\end{tabular} \\
\hline $\begin{array}{l}\quad \text { I: Ese fue un } \\
\text { beneficio muy } \\
\text { grande para ti. } \\
\text { Donde las dos... o } \\
\text { sea L a través de su } \\
\text { experiencia poco } \\
\text { grata para ella, } \\
\text { estuvo ahí } \\
\text { colaborándote... }\end{array}$ & $\begin{array}{l}\text { Intervencione } \\
\text { s narrativas en } \\
\text { situación de } \\
\text { deserción escolar }\end{array}$ & Relatos & \\
\hline
\end{tabular}




\section{LA DESERCIÓN ESCOLAR COMO PRETEXTO PARA CONVERSAR SOBRE IDENTIDAD, FAMILIA Y ESCUELA

Sí, bastante porque hay semanas en que el SENA me absorbe totalmente y no tengo tiempo absolutamente para nada y pues la que está ahí al frente es ella. s narrativas en

situación de

deserción escolar reconoce la

madurez y

ayuda que proporciona su hija en el hogar, dando a conocer a su hija de manera clara y verbal lo positiva y servicial que es su rol en casa, entendiendos e relatos alternos y posibles narrativas emergentes frente al problema.

\begin{tabular}{|c|c|c|c|}
\hline $\begin{array}{l}\quad \text { I: Ehhh, D y si } \\
\text { L ¿no se le hubiera } \\
\text { presentado esa } \\
\text { situación de tener } \\
\text { que abandonar el } \\
\text { colegio por todo lo } \\
\text { que se presentó, } \\
\text { cómo hubiese sido } \\
\text { tu vida? }\end{array}$ & $\begin{array}{l}\text { Construcción } \\
\text { narrativa de la } \\
\text { identidad }\end{array}$ & Experiencia & \\
\hline $\begin{array}{l}\text { M: No hubiera } \\
\text { ingresado a } \\
\text { estudiar. }\end{array}$ & $\begin{array}{l}\text { Construcción } \\
\text { narrativa de la } \\
\text { identidad }\end{array}$ & Experiencia & $\begin{array}{l}\quad \text { La madre } \\
\text { nuevamente } \\
\text { reconoce la } \\
\text { importancia } \\
\text { que ha tenido } \\
\text { su hija en } \\
\text { casa, } \\
\text { concluyendo } \\
\text { la } \\
\text { imposibilidad } \\
\text { que hubiera } \\
\text { tenido al } \\
\text { entrar a } \\
\text { estudiar si } \\
\text { ella no } \\
\text { estuviera } \\
\text { desescolariza } \\
\text { da, del } \\
\text { mismo modo, } \\
\text { se reconoce } \\
\text { una posible } \\
\text { funcionalidad } \\
\text { de la } \\
\text { desescolariza }\end{array}$ \\
\hline
\end{tabular}




\section{LA DESERCIÓN ESCOLAR COMO PRETEXTO PARA CONVERSAR SOBRE IDENTIDAD, FAMILIA Y ESCUELA

ción.

\begin{tabular}{|c|c|c|c|}
\hline $\begin{array}{r}\text { I: ¿No hubieras } \\
\text { podido estudiar D? }\end{array}$ & \begin{tabular}{l}
\multicolumn{1}{c}{ Relación } \\
joven, familia e \\
institución \\
educativa en \\
torno a la \\
deserción \\
escolar.
\end{tabular} & Experiencia & \\
\hline $\begin{array}{l}\text { M: No. No } \\
\text { porque no tenía a } \\
\text { quien dejar ahí. }\end{array}$ & $\begin{array}{l}\quad \text { Relación } \\
\text { joven, familia e } \\
\text { institución } \\
\text { educativa en } \\
\text { torno a la } \\
\text { deserción } \\
\text { escolar. }\end{array}$ & Experiencia & $\begin{array}{l}\quad \text { Nuevame } \\
\text { nte la madre } \\
\text { menciona la } \\
\text { importancia } \\
\text { de que su hija } \\
\text { no estuviera } \\
\text { escolarizada } \\
\text { en el pasado. }\end{array}$ \\
\hline $\begin{array}{l}\text { A: Más que } \\
\text { todo en las } \\
\text { mañanas. }\end{array}$ & $\begin{array}{l}\quad \text { Relación } \\
\text { joven, familia e } \\
\text { institución } \\
\text { educativa en } \\
\text { torno a la } \\
\text { deserción } \\
\text { escolar. }\end{array}$ & Experiencia & $\begin{array}{l}\quad \text { La menor } \\
\text { de igual } \\
\text { manera } \\
\text { afirma y } \\
\text { reconoce la } \\
\text { importancia } \\
\text { que tenia su } \\
\text { función en un } \\
\text { momento } \\
\text { específico, } \\
\text { existiendo un } \\
\text { relato alterno } \\
\text { entre madre e } \\
\text { hija de la } \\
\text { importancia y } \\
\text { la capacidad } \\
\text { de la hija. }\end{array}$ \\
\hline \begin{tabular}{l}
\multicolumn{1}{c}{ M: Porque mi } \\
hija mayor, pues \\
ella estudia...ella \\
estudiaba, en ese \\
momento estudiaba \\
en la universidad, \\
entonces...
\end{tabular} & $\begin{array}{l}\quad \text { Relación } \\
\text { joven, familia e } \\
\text { institución } \\
\text { educativa en } \\
\text { torno a la } \\
\text { deserción } \\
\text { escolar. }\end{array}$ & Experiencia & \begin{tabular}{l}
\multicolumn{1}{c}{ La madre } \\
afirma \\
nuevamente \\
que esta \\
función solo \\
la podia \\
desarrollar L, \\
ya que su hija \\
mayor se \\
encontraba \\
ocupada
\end{tabular} \\
\hline
\end{tabular}




\section{LA DESERCIÓN ESCOLAR COMO PRETEXTO PARA CONVERSAR SOBRE IDENTIDAD, FAMILIA Y ESCUELA

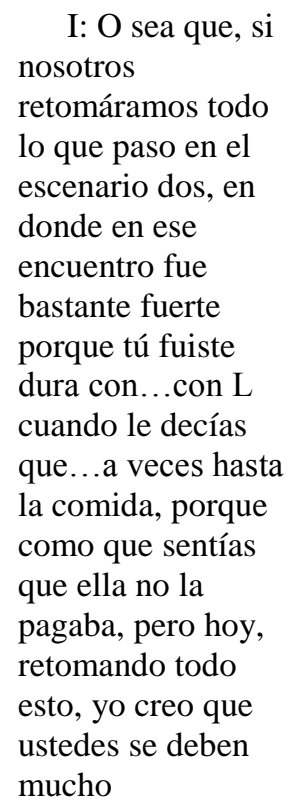

I: O sea que, si nosotros retomáramos todo lo que paso en el escenario dos, en donde en ese encuentro fue bastante fuerte porque tú fuiste dura con...con L cuando le decías que... a veces hasta la comida, porque como que sentías que ella no la pagaba, pero hoy, retomando todo esto, yo creo que ustedes se deben mucho mutuamente.

\begin{tabular}{|c|c|c|c|}
\hline M: Sí claro. & \begin{tabular}{l}
\multicolumn{1}{c}{ Intervencione } \\
s narrativas en \\
situación de \\
deserción escolar
\end{tabular} & Relato & $\begin{array}{l}\quad \text { La madre } \\
\text { afirma el } \\
\text { hecho de que } \\
\text { le debe } \\
\text { mucho a su } \\
\text { hija, } \\
\text { construyendo } \\
\text { se una } \\
\text { narrativa } \\
\text { emergente. }\end{array}$ \\
\hline $\begin{array}{l}\text { I: Y ¿tú le has } \\
\text { expresado a A eso } \\
\text { alguna vez? }\end{array}$ & $\begin{array}{l}\quad \text { Intervencione } \\
\text { s narrativas en } \\
\text { situación de } \\
\text { deserción escolar } \\
\end{array}$ & Memorias & \\
\hline M: No & \begin{tabular}{l}
\multicolumn{1}{c}{ Intervencione } \\
s narrativas en \\
situación de \\
deserción escolar
\end{tabular} & Memorias & \begin{tabular}{l}
\multicolumn{1}{c}{ De igual } \\
manera niega \\
la posibilidad \\
de haber \\
reconocido la \\
importancia \\
de la hija en \\
el hogar, \\
posibilitando \\
nuevas \\
construccione \\
s
\end{tabular} \\
\hline
\end{tabular}

I: Y ¿tú, qué le quisieras decir hoy a L?
Intervencione s narrativas en situación de deserción escolar
Relato

hecho de que hija, se una narrativa emergente. la posibilidad e haber importancia de la hija en el hogar posibilitando construccione

$\quad$ Intervencione
s narrativas en
situación de
deserción escolar




\section{LA DESERCIÓN ESCOLAR COMO PRETEXTO PARA CONVERSAR SOBRE IDENTIDAD, FAMILIA Y ESCUELA

\footnotetext{
M: Pues, lastimosamente, pues de su tragedia me beneficié yo (risas). Digo lastimosamente porque ya mi tiempo de estudiar ya había pasado y era el tuyo. Pero lo que yo te dije el día que...pues se presentó esa oportunidad por cosas de Dios porque prácticamente me llegó ahí, sin estarla buscando y la cogí, decidí cogerla, y me ha costado porque...me ha costado mucho, pero si, gracias a ti he podido hacer mis cosas, tú me has colaborado mucho. Tú has tenido mucho que ver en mi proceso y he querido, lo quise hacer y te lo dije el día que empecé a estudiar, tú no quisiste estudiar, no quisiste aprovechar esa oportunidad la voy a aprovechar yo...y lo hice. Y me ha costado y ha sido difícil, pero dentro de todas las posibilidades que hay la única que no he contemplado es la de retirarme. Porque decidí asumirlo y dije tanto que esperé esta oportunidad para llegar y decir "ay no esto me quedó grande, chao" no.
}

Relatos

Por otro

lado la madre reconoce la importancia que ha tenido la

desescolariza cion y la ayuda que ha proporcionad o su hija en casa, para sus propios planes y vida, claramanete se identifica una narrativa emergente. 


\section{LA DESERCIÓN ESCOLAR COMO PRETEXTO PARA CONVERSAR SOBRE IDENTIDAD, FAMILIA Y ESCUELA

\section{I: Pero bueno}

$\mathrm{D}$, ya en vista de

que sí tú has sido

un ejemplo, un gran

ejemplo para... no

solamente para L

sino creo que para

todos tus hijos,

porque tú misma lo

dices en el sentido

de "me ha

costado..." tal vez

más de una vez

pensaste en

abandonarlo, pero

la misma fuerza de voluntad y la

misma...el mismo

objetivo claro que

tú tienes para

seguir adelante, la misma

proyección... ¿sí?

Los mismos planes, podríamos decirlo

que tienes a futuro, te han mantenido

ahí, firme,

perseverante

siempre, entonces

ehhh... ¿qué de

todo eso le dejas a

L? a partir de esa

enseñanza...de

toda esa

experiencia, ¿sí?

difícil que tú has

tenido, de todos

esos obstáculos que

tú has vivido en

estos dos años en el

SENA... ¿qué le

dejas a L, qué le

compartes de todo

eso? ¿cuál sería tu

reflexión para ella

sabiendo que ella

ha sido una pieza

muy importante,

sabiendo que ella

ha sido muy

generativa para ti

en ese sentido?

Porque también tú eres muy

\author{
Intervencione \\ $s$ narrativas en \\ situación de \\ deserción escolar
}

Relatos 


\title{
LA DESERCIÓN ESCOLAR COMO PRETEXTO PARA CONVERSAR SOBRE IDENTIDAD, FAMILIA Y ESCUELA

\author{
consciente y lo \\ manifiestas, "si L \\ no hubiera estado \\ ahí yo no lo hubiera \\ podido hacer" o \\ sea, ella ha jugado \\ un papel muy \\ importante en todo \\ ese proceso que tú \\ has adelantado y ha \\ sido fundamental \\ para ti en ese \\ proceso, ahora tú \\ ¿Qué le devolverías \\ a L?
}




\section{LA DESERCIÓN ESCOLAR COMO PRETEXTO PARA CONVERSAR SOBRE IDENTIDAD, FAMILIA Y ESCUELA

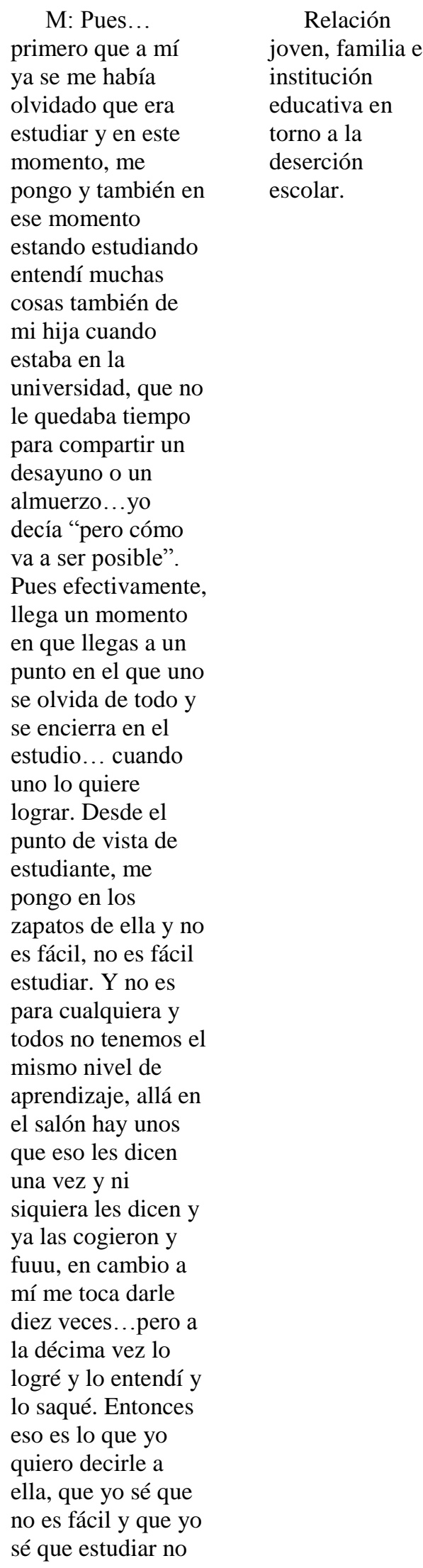

M: Pues...

primero que a mí

ya se me había

olvidado que era

estudiar y en este

momento, me

pongo y también en

ese momento

estando estudiando

entendí muchas

cosas también de

mi hija cuando

estaba en la

universidad, que no

le quedaba tiempo

para compartir un

desayuno o un

almuerzo...yo

decía "pero cómo

va a ser posible".

Pues efectivamente,

llega un momento

en que llegas a un

punto en el que uno

se olvida de todo y

se encierra en el

estudio... cuando

uno lo quiere

lograr. Desde el

punto de vista de

estudiante, me

pongo en los

zapatos de ella y no

es fácil, no es fácil

estudiar. Y no es

para cualquiera y

todos no tenemos el

mismo nivel de

aprendizaje, allá en

el salón hay unos

que eso les dicen

una vez y ni

siquiera les dicen y

ya las cogieron y

fuuu, en cambio a

mí me toca darle

diez veces...pero a

la décima vez lo

logré y lo entendí y

lo saqué. Entonces

eso es lo que yo

quiero decirle a

ella, que yo sé que

no es fácil y que yo

sé que estudiar no

\section{Relación}

joven, familia e

institución

educativa en

torno a la

deserción

escolar.

Relatos

emergentes
La madre

reconoce de

igual manera

la dificultad

que puede

implicar las

responsabilid

ades que

lleva a cabo

$\mathrm{L}$,

constuyendo

una nueva

narrativa

emergente al

respecto, a

partir del

reconocimine

to y la

legitimación

de la función

de la menor. 


\section{LA DESERCIÓN ESCOLAR COMO PRETEXTO PARA CONVERSAR SOBRE IDENTIDAD, FAMILIA Y ESCUELA

es para todo el mundo, pero si nos lo proponemos lo logramos, que de pronto a unos nos toca esforzarnos un poquito más para aprender lo que otro aprendió en una sola leída. A mí me toca leerla diez veces para cogerla, pero la termino cogiendo, pero si yo a la primera me venzo, pues no la cogí y no la voy a coger porque si no seguí insistiendo. Y que tiene todo mi apoyo para explicarle, para ayudarle a entender lo que se le dificulte, pues ella lo sabe. En primaria...y una de las críticas de mi hija mayor fue esa, yo a ella la ayudaba mucho y a la mayor pues a ella nunca lo hice porque yo nunca tuve la necesidad, ni ella me lo pidió, ni yo se lo ofrecí...pero

$\mathrm{L}$ fue diferente, con L yo estaba ahí pa' decirle "mire esto se hace así" "esto está bien, esto está mal" "corrija esto" y lo voy a seguir haciendo...entonce s académicamente si ella necesita ayuda... 


\section{LA DESERCIÓN ESCOLAR COMO PRETEXTO PARA CONVERSAR SOBRE IDENTIDAD, FAMILIA Y ESCUELA

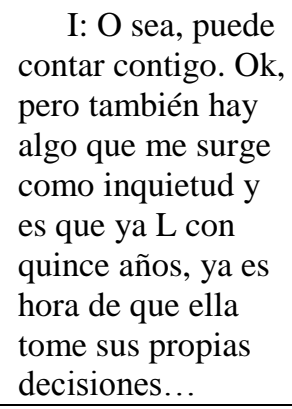

I: O sea, puede contar contigo. Ok, pero también hay algo que me surge como inquietud y es que ya $\mathrm{L}$ con quince años, ya es hora de que ella tome sus propias decisiones...

\begin{tabular}{|c|c|c|c|}
\hline M: ajá & $\begin{array}{l}\text { Construcción } \\
\text { narrativa de la } \\
\text { identidad }\end{array}$ & $\begin{array}{c}\text { Relatos } \\
\text { emergentes }\end{array}$ & \begin{tabular}{l}
\multicolumn{1}{r}{ La madre } \\
además de \\
legitimar la \\
función de su \\
hija, afirma \\
la \\
importancia \\
que tiene el \\
hecho de que \\
su hija tome \\
sus \\
desiciones, \\
delegando \\
responsabilid \\
ades a su \\
hija, \\
comprendien \\
dose una \\
narrativa \\
emergente.
\end{tabular} \\
\hline
\end{tabular}

Construcción narrativa de la identidad

Relatos emergentes

\footnotetext{
I: o ¿tú que

piensas M? y

¿Usted qué piensa

A?

C1: pues que

ella...pues sí, hay

cosas que ya está

en capacidad de

decidir ¿sí? Y pues

yo como...pues

mamá y ella por ser

todavía menor de

edad pues

obviamente yo

tengo que avalar

esas decisiones si le

convienen o no ¿sí?

y aconsejarla. Pues

pienso que en este

momento no va a

tomar una decisión

de decir "me voy a

ir con un hippie por
}

Construcción

Relatos

narrativa de la

emergentes

identidad

Construcción

Relatos

narrativa de la

emergentes

identidad

emergente. ahí"... 


\section{LA DESERCIÓN ESCOLAR COMO PRETEXTO PARA CONVERSAR SOBRE IDENTIDAD, FAMILIA Y ESCUELA

\begin{tabular}{|c|c|c|c|}
\hline A: (Risa) & $\begin{array}{l}\text { Construcción } \\
\text { narrativa de la } \\
\text { identidad }\end{array}$ & Memorias & $\begin{array}{l}\quad \text { Su hija } \\
\text { rie, } \\
\text { escuchando } \\
\text { las } \\
\text { exageracione } \\
\text { s que } \\
\text { implican la } \\
\text { narrativa de } \\
\text { su madre }\end{array}$ \\
\hline I: (Risa) & \begin{tabular}{l}
\multicolumn{1}{c}{ Intervencione } \\
s narrativas en \\
situación de \\
deserción escolar
\end{tabular} & Memorias & \\
\hline $\begin{array}{l}\quad \text { M: Pero sí se lo } \\
\text { digo, o sea, si } \\
\text { siente que este no } \\
\text { es el momento } \\
\text { todavía de retomar } \\
\text { su estudio, sino } \\
\text { quiere otra } \\
\text { cosa...pero sí me } \\
\text { preocupa ya verla } \\
\text { ahí, que con quince } \\
\text { años...y entre más } \\
\text { pase el tiempo más } \\
\text { se le dificulta a } \\
\text { uno. Porque yo } \\
\text { estoy sentada } \\
\text { estudiando con } \\
\text { muchachos que } \\
\text { acaban de cumplir } \\
\text { los dieciocho años } \\
\text { y yo ya con } \\
\text { cuarenta. Entonces } \\
\text { no es lo mismo, no } \\
\text { es lo mismo } \\
\text { estudiar cuando } \\
\text { uno está joven...es } \\
\text { más...hasta me ha } \\
\text { surgido y ni } \\
\text { siquiera 'por eso he } \\
\text { pensado en } \\
\text { retirarme...yo que } \\
\text { día dije yo “bueno, } \\
\text { pero yo que...será } \\
\text { que si vale la } \\
\text { pena...porque yo } \\
\text { ya termino, cuando } \\
\text { termine mi práctica } \\
\text { yo ya tengo } \\
\text { cuarenta y uno, a } \\
\text { puertas de los } \\
\text { cuarenta y dos... } \\
\text { tQuién me va a dar } \\
\text { trabajo a los }\end{array}$ & \begin{tabular}{l}
\multicolumn{1}{c}{ Relación } \\
joven, familia e \\
institución \\
educativa en \\
torno a la \\
deserción \\
escolar.
\end{tabular} & $\begin{array}{r}\text { Relatos } \\
\text { emergentes }\end{array}$ & $\begin{array}{l}\quad \text { La madre } \\
\text { muestra y da } \\
\text { a concoer la } \\
\text { preocupación } \\
\text { que siente } \\
\text { por su hija al } \\
\text { verla si } \\
\text { estudiar, } \\
\text { afrimando } \\
\text { que la mejor } \\
\text { desición es } \\
\text { continuar } \\
\text { escolarizada, } \\
\text { se identifican } \\
\text { narrativas } \\
\text { saturadas que } \\
\text { se construyen } \\
\text { como } \\
\text { narrativas } \\
\text { alternas. }\end{array}$ \\
\hline
\end{tabular}




\section{LA DESERCIÓN ESCOLAR COMO PRETEXTO PARA CONVERSAR SOBRE IDENTIDAD, FAMILIA Y ESCUELA

cuarenta y dos

años? Si en las

bolsas de empleo,

todas las

convocatorias son

de veinte cinco a

treinta y cinco"

pero aun así, no lo

dejo. Al igual, con

esos interrogantes

porque yo no sé

qué va a pasar, que

tal que de aquí a

mañana me digan

"ay si usted tuviera este tecnólogo le

daría trabajo" y yo

decir "medio bruta

yo no haber

terminado por

pensar en que ya

estoy vieja y quién

me va a dar

trabajo". ¿ves?

Entonces eso es lo

que yo quiero, que

aproveches la

oportunidad que

tienes de que eres

joven, de que tienes

mi apoyo, porque

hay muchos

muchachos, uno los

escucha

allá....mejor dicho

están estudiando

con las uñas.

Entonces yo quiero

que la decisión que

tu tomes sea de

corazón y que tu

digas "listo sí, voy

$a$ ir a hacer es un

curso de uñas" que

sea como dijo

Diomedes "que si

quiere ser zapatero,

que sea el mejor"

pero que sea algo

que usted tome la

decisión y que

usted saque

adelante, así se le

presenten

dificultades, 


\section{LA DESERCIÓN ESCOLAR COMO PRETEXTO PARA CONVERSAR SOBRE IDENTIDAD, FAMILIA Y ESCUELA

obstáculos, lo va a

sacar adelante. No

se va a echar para

atrás, no va a

desfallecer.

\begin{tabular}{|c|c|c|c|}
\hline $\begin{array}{l}\text { I: Y usted ¿qué } \\
\text { nos cuenta al } \\
\text { respecto? A ver, } \\
\text { retomando lo que } \\
\text { dice tu mamá. }\end{array}$ & $\begin{array}{l}\text { Construcción } \\
\text { narrativa de la } \\
\text { identidad }\end{array}$ & Experiencia & \\
\hline $\begin{array}{l}\text { A: Pues que sí, } \\
\text { tiene razón (risa). }\end{array}$ & $\begin{array}{l}\text { Construcción } \\
\text { narrativa de la } \\
\text { identidad }\end{array}$ & $\begin{array}{ll} & \text { Experiencia } \\
\mathrm{s} & \end{array}$ & $\begin{array}{l}\quad \text { La menor } \\
\text { concuerda } \\
\text { con las } \\
\text { comprension } \\
\text { es de su } \\
\text { madre. }\end{array}$ \\
\hline
\end{tabular}




\section{LA DESERCIÓN ESCOLAR COMO PRETEXTO PARA CONVERSAR SOBRE IDENTIDAD, FAMILIA Y ESCUELA

\begin{abstract}
I: Pero ¿cómo
lo vas a hacer?

¿qué más nos vas a contar? Yo sé que

el discurso de $\mathrm{D}$ es interesante. Ha

dicho cosas muy interesantes, todas en beneficio de usted...pero y usted ¿cómo va a hacer eso?
\end{abstract}

M: Vuelva y díganos ¿qué va a hacer el otro año?

\section{Construcción} narrativa de la identidad
Relatos emergentes

Construcción
narrativa de la
identidad

La madre

pregunta a su

hija a cerca

de sus planes

futuros

nuevamente.

\begin{tabular}{|c|c|c|c|}
\hline A: (risa) & $\begin{array}{l}\text { Construcción } \\
\text { narrativa de la } \\
\text { identidad }\end{array}$ & Relatos & $\begin{array}{l}\text { La hija } \\
\text { rie. }\end{array}$ \\
\hline \begin{tabular}{l}
\multicolumn{1}{c}{ M: Pero que } \\
esté convencida, no \\
que porque yo dije \\
que el otro año va a \\
validar y va a dar \\
en este \\
instituto...no. si \\
piensa que quiere \\
validar que lo va a \\
hacer, listo. Pero sí \\
¿está convencida de \\
que quiere hacer \\
esto?
\end{tabular} & $\begin{array}{l}\quad \text { Construcción } \\
\text { narrativa de la } \\
\text { identidad }\end{array}$ & Relatos & \begin{tabular}{l}
\multicolumn{1}{c}{ La madre } \\
nuevamente \\
pregunta a su \\
hija si esta \\
convencia de \\
la decisión \\
que ha \\
tomado.
\end{tabular} \\
\hline $\begin{array}{l}\text { A: Sí. (Silencio) } \\
\text { Pues sí, a validar. }\end{array}$ & \begin{tabular}{l}
\multicolumn{1}{c}{ Relación } \\
joven, familia e \\
institución \\
educativa en \\
torno a la \\
deserción \\
escolar.
\end{tabular} & Relatos & $\begin{array}{l}\quad \text { La hija } \\
\text { afirma su } \\
\text { desición }\end{array}$ \\
\hline $\begin{array}{l}\text { I: Y ¿eso te } \\
\text { produce emoción? } \\
\text { ¿Sí? }\end{array}$ & \begin{tabular}{l}
\multicolumn{1}{c}{ Relación } \\
joven, familia e \\
institución \\
educativa en \\
torno a la \\
deserción \\
escolar.
\end{tabular} & Relatos & \\
\hline $\begin{array}{l}\text { A: Sí... (Risa) } \\
\text { los nervios. }\end{array}$ & \begin{tabular}{l}
\multicolumn{1}{c}{ Relación } \\
joven, familia e \\
institución \\
educativa en \\
torno a la \\
deserción \\
escolar.
\end{tabular} & Relatos & $\begin{array}{l}\text { la menor } \\
\text { afirma estar } \\
\text { nerviosa } \\
\text { frente al } \\
\text { nuevo } \\
\text { cambio }\end{array}$ \\
\hline
\end{tabular}




\section{LA DESERCIÓN ESCOLAR COMO PRETEXTO PARA CONVERSAR SOBRE IDENTIDAD, FAMILIA Y ESCUELA

\begin{tabular}{|c|c|c|c|}
\hline $\begin{array}{l}\quad \text { I: no, pero } \\
\text { emoción de que vas } \\
\text { a conocer gente } \\
\text { nueva, de que tu } \\
\text { vida va a } \\
\text { cambiar... de una u } \\
\text { otra forma va a } \\
\text { cambiar, ya no es } \\
\text { levantase a abrir el } \\
\text { salón o a hacer el } \\
\text { almuerzo... }\end{array}$ & $\begin{array}{l}\quad \text { Relación } \\
\text { joven, familia e } \\
\text { institución } \\
\text { educativa en } \\
\text { torno a la } \\
\text { deserción } \\
\text { escolar. }\end{array}$ & Historias & \\
\hline $\begin{array}{l}\text { M: Y los } \\
\text { temores son lo más } \\
\text { normal... usted cree } \\
\text { que yo el primer } \\
\text { día que yo pisé el } \\
\text { SENA a mí me } \\
\text { temblaba hasta el } \\
\text { pelo, yo decía "no, } \\
\text { yo voy a hacer el } \\
\text { ridículo aquí, yo ya } \\
\text { con treinta y nueve } \\
\text { años al lado de } \\
\text { todos estos chinitos } \\
\text { de diecisiete" } \\
\text { porque habían } \\
\text { chinos que todavía } \\
\text { tenían diecisiete, } \\
\text { yo temblaba y yo } \\
\text { decía "estos chinos } \\
\text { me van a hacer } \\
\text { bullying” yo decía } \\
\text { "eso se van a burlar } \\
\text { y todo lo } \\
\text { contrario... }\end{array}$ & $\begin{array}{l}\quad \text { Relación } \\
\text { joven, familia e } \\
\text { institución } \\
\text { educativa en } \\
\text { torno a la } \\
\text { deserción } \\
\text { escolar. }\end{array}$ & Historias & $\begin{array}{l}\quad \text { La madre } \\
\text { permite una } \\
\text { construcción } \\
\text { alterna al } \\
\text { miedo que } \\
\text { propone la } \\
\text { menor, dando } \\
\text { a conocer a } \\
\text { su hija la } \\
\text { narrativa de } \\
\text { su hstoria } \\
\text { academica } \\
\text { inicial, } \\
\text { generando } \\
\text { una } \\
\text { construccion } \\
\text { de confianza } \\
\text { y empatia. }\end{array}$ \\
\hline $\begin{array}{l}\text { A: Ja...antes le } \\
\text { tienen un respeto. }\end{array}$ & \begin{tabular}{l}
\multicolumn{1}{c}{ Relación } \\
joven, familia e \\
institución \\
educativa en \\
torno a la \\
deserción \\
escolar.
\end{tabular} & Historias & $\begin{array}{l}\text { La menor } \\
\text { da a conocer } \\
\text { el valor que } \\
\text { representa su } \\
\text { madre para } \\
\text { ella y para } \\
\text { los } \\
\text { compañeros } \\
\text { de } \\
\text { universidad. }\end{array}$ \\
\hline $\begin{array}{l}\quad \mathrm{I} \text { : Por eso L...y } \\
\text { para ti ¿cómo } \\
\text { piensas que va a ser } \\
\text { esa experiencia? }\end{array}$ & $\begin{array}{l}\quad \text { Relación } \\
\text { joven, familia e } \\
\text { institución } \\
\text { educativa en } \\
\text { torno a la } \\
\text { deserción } \\
\text { escolar. }\end{array}$ & Historias & \\
\hline
\end{tabular}




\section{LA DESERCIÓN ESCOLAR COMO PRETEXTO PARA CONVERSAR SOBRE IDENTIDAD, FAMILIA Y ESCUELA

A: Pues buena.

Relación

joven, familia e

institución

educativa en

torno a la

deserción

escolar.
Historias

La menor

narra la

confianza

que tiene con

respeco a sus

planes

futuros,

construyendo

una narrativa

positiva.

\begin{tabular}{|c|c|c|c|}
\hline $\begin{array}{l}\quad \text { I: Interesante } \\
\text { ¿cierto? Nuevas } \\
\text { cosas, nuevos } \\
\text { amigos, otra vez } \\
\text { otra vida social, } \\
\text { rico volver a entrar } \\
\text { en ese rol de } \\
\text { estudiante. Y } \\
\text { posiblemente ya no } \\
\text { con tu uniforme, } \\
\text { uno para validar no } \\
\text { necesita un } \\
\text { uniforme ¿cierto? }\end{array}$ & $\begin{array}{l}\quad \text { Relación } \\
\text { joven, familia e } \\
\text { institución } \\
\text { educativa en } \\
\text { torno a la } \\
\text { deserción } \\
\text { escolar. }\end{array}$ & Historias & \\
\hline $\begin{array}{l}\text { M: No, ella va } \\
\text { es de particular. }\end{array}$ & \begin{tabular}{l}
\multicolumn{1}{c}{ Relación } \\
joven, familia e \\
institución \\
educativa en \\
torno a la \\
deserción \\
escolar.
\end{tabular} & Historias & $\begin{array}{l}\quad \text { La madre } \\
\text { aclara una } \\
\text { especificació } \\
\text { n del } \\
\text { uniforme }\end{array}$ \\
\hline I: De particular & \begin{tabular}{l}
\multicolumn{1}{c}{ Relación } \\
joven, familia e \\
institución \\
educativa en \\
torno a la \\
deserción \\
escolar.
\end{tabular} & Memorias & \\
\hline
\end{tabular}




\section{LA DESERCIÓN ESCOLAR COMO PRETEXTO PARA CONVERSAR SOBRE IDENTIDAD, FAMILIA Y ESCUELA

\begin{tabular}{|c|c|c|c|}
\hline $\begin{array}{l}\quad \text { M: Y allá ya no } \\
\text { va a haber } \\
\text { educación física, ni } \\
\text { artes, no. solo las } \\
\text { materias que va a } \\
\text { necesitar para una } \\
\text { universidad...inglé } \\
\text { s, matemáticas...yo } \\
\text { por ejemplo yo le } \\
\text { digo a ella "L coja } \\
\text { sus cuadernos, } \\
\text { usted todavía los } \\
\text { tiene por ahí..." } \\
\text { porque yo no los he } \\
\text { botado, ahí están } \\
\text { "al menos repace } \\
\text { sobre esos } \\
\text { cuadernos los } \\
\text { temas que..." } \\
\text { porque en ese } \\
\text { instituto de...el que } \\
\text { es de lunes a } \\
\text { viernes, le hacen un } \\
\text { examen y si ella } \\
\text { pasa ese examen de } \\
\text { sexto, no la hacen } \\
\text { hacer sexto, la } \\
\text { promueven a } \\
\text { séptimo. }\end{array}$ & $\begin{array}{l}\quad \text { Relación } \\
\text { joven, familia e } \\
\text { institución } \\
\text { educativa en } \\
\text { torno a la } \\
\text { deserción } \\
\text { escolar. }\end{array}$ & Memorias & $\begin{array}{l}\quad \text { La madre } \\
\text { aconseja a } \\
\text { cerca del } \\
\text { abordaje de } \\
\text { los planes } \\
\text { futuros de la } \\
\text { menor, } \\
\text { teniendo en } \\
\text { cuenta } \\
\text { narrativas } \\
\text { posibilitadora } \\
\text { s con el } \\
\text { futuro }\end{array}$ \\
\hline $\begin{array}{l}\text { I: Uy que bien } \\
\text { L, ¿eso te llama la } \\
\text { atención? }\end{array}$ & \begin{tabular}{l}
\multicolumn{1}{c}{ Relación } \\
joven, familia e \\
institución \\
educativa en \\
torno a la \\
deserción \\
escolar. \\
\end{tabular} & $\begin{array}{c}\text { Relatos } \\
\text { emergentes }\end{array}$ & \\
\hline $\begin{array}{l}\text { A: Ehhh...pues } \\
\text { sí. }\end{array}$ & \begin{tabular}{l}
\multicolumn{1}{c}{ Relación } \\
joven, familia e \\
institución \\
educativa en \\
torno a la \\
deserción \\
escolar.
\end{tabular} & $\begin{array}{c}\text { Relatos } \\
\text { emergentes }\end{array}$ & $\begin{array}{l}\quad \text { La menor } \\
\text { se muestra de } \\
\text { acuerdo con } \\
\text { lo que dice su } \\
\text { madre. }\end{array}$ \\
\hline $\begin{array}{l}\quad \text { I: ¿Sí? Ok, } \\
\text { bueno ¿cómo creen } \\
\text { que todos estos } \\
\text { encuentros y este } \\
\text { proceso que hemos } \\
\text { llevado las ha } \\
\text { podido ayudar para } \\
\text { que lleguen a esta } \\
\text { decisión? }\end{array}$ & $\begin{array}{l}\quad \text { Intervencione } \\
\text { s narrativas en } \\
\text { situación de } \\
\text { deserción escolar }\end{array}$ & $\begin{array}{c}\text { Relatos } \\
\text { emergentes }\end{array}$ & \\
\hline
\end{tabular}




\section{LA DESERCIÓN ESCOLAR COMO PRETEXTO PARA CONVERSAR SOBRE IDENTIDAD, FAMILIA Y ESCUELA

M: Pues que lográramos que ella exprese algo....algo de que de pronto...
Intervencione s narrativas en situación de deserción escolar
Relatos emergentes
La madre nuevamente entrega la responsabilid ad del problema a su hija, comunicando que la solución principalment e se produjo por el cambio de su hija, volviendo la narrativa suturada.

\begin{tabular}{|c|c|c|c|}
\hline $\begin{array}{l}\text { I: Pero ¿sí les } \\
\text { ha servido o...? }\end{array}$ & $\begin{array}{l}\text { Construcción } \\
\text { narrativa de la } \\
\text { identidad }\end{array}$ & $\begin{array}{r}\text { Relatos } \\
\text { emergentes }\end{array}$ & \\
\hline $\begin{array}{l}\text { M: Bastante sí. } \\
\text { Bastante, porque yo } \\
\text { por lo menos en } \\
\text { este momento me } \\
\text { siento más relajada } \\
\text { con ella. }\end{array}$ & $\begin{array}{l}\text { Construcción } \\
\text { narrativa de la } \\
\text { identidad }\end{array}$ & $\begin{array}{r}\text { Relatos } \\
\text { emergentes }\end{array}$ & $\begin{array}{l}\quad \text { sin } \\
\text { embargo } \\
\text { nuevamente } \\
\text { la madre } \\
\text { construye un } \\
\text { relato alterno } \\
\text { con respecto } \\
\text { a su hija }\end{array}$ \\
\hline $\begin{array}{l}\text { I: Siente que los } \\
\text { canales se abrieron, } \\
\text { que hay como más } \\
\text { interacción... }\end{array}$ & $\begin{array}{l}\text { Construcción } \\
\text { narrativa de la } \\
\text { identidad }\end{array}$ & $\begin{array}{r}\text { Relatos } \\
\text { emergentes }\end{array}$ & \\
\hline \begin{tabular}{l}
\multicolumn{1}{c}{ M: Sí, me ha } \\
ayudado a ver las \\
cosas de otra \\
manera diferente, \\
me ha ayudado \\
a...como a \\
tranquilizarme más \\
y a aprender a \\
esperar y a ser \\
paciente...y a no \\
acelerarme, o sea, a \\
no enfrascarme en \\
que una cosa tiene \\
que ser así y a \\
entender...a \\
entender mejor, a \\
entenderla a ella \\
mejor.
\end{tabular} & $\begin{array}{l}\text { Construcción } \\
\text { narrativa de la } \\
\text { identidad }\end{array}$ & $\begin{array}{r}\text { Relatos } \\
\text { emergentes }\end{array}$ & \begin{tabular}{l}
\multicolumn{1}{c}{ se } \\
identifica una \\
narrativa \\
emergente \\
clara frente al \\
problema \\
inicial, donde \\
la madre \\
reconoce la \\
importancia \\
que ha tenido \\
el proceso en \\
el \\
entendimient \\
o de su hija.
\end{tabular} \\
\hline
\end{tabular}
identidad

\begin{tabular}{llr} 
I: Mmm...que & \multicolumn{1}{c}{ Construcción } & \multicolumn{1}{c}{ Relatos } \\
bien D. Como me & narrativa de la & emergentes \\
alegro que & identidad &
\end{tabular}

realmente este

proceso haya sido 


\section{LA DESERCIÓN ESCOLAR COMO PRETEXTO PARA CONVERSAR SOBRE IDENTIDAD, FAMILIA Y ESCUELA

\begin{tabular}{l} 
así... \\
\multicolumn{1}{c}{ M: De hecho de } \\
todos los años que \\
llevo con ella en \\
terapias, es la \\
primer vez que veo \\
una luz (risa) en el \\
camino, porque \\
antes no, o sea, lo \\
que ella dice...o \\
sea, llegó un \\
momento en el que \\
nos aburrimos \\
porque o sea como \\
que llegamos ahí \\
pero "qué hacemos \\
aquí" "qué sacamos \\
de esto" "pa' donde \\
vamos"
\end{tabular}

así...

\begin{tabular}{lll}
\multicolumn{1}{c}{ Construcción } & Relatos \\
narrativa de la & Alternos & id \\
identidad & & re
\end{tabular}

identific

relatos

alternos

frente al

problema ya

que la madre

menciona

que ha sido

complejo el

hecho de

abordar la

problematica,

sin embargo

logra ver una

luz de

solución, lo

cual implica

una postura

generativa

frente al

problema.

$\begin{array}{lll}\text { A: “¿para qué? } & \begin{array}{l}\text { Construcción } \\ \text { narrativa de la } \\ \text { identidad }\end{array} & \text { Historias } \\ & \end{array}$

La hija

indaga un

poco sobre la postura de posible

solucion de la

madre. 


\section{LA DESERCIÓN ESCOLAR COMO PRETEXTO PARA CONVERSAR SOBRE IDENTIDAD, FAMILIA Y ESCUELA

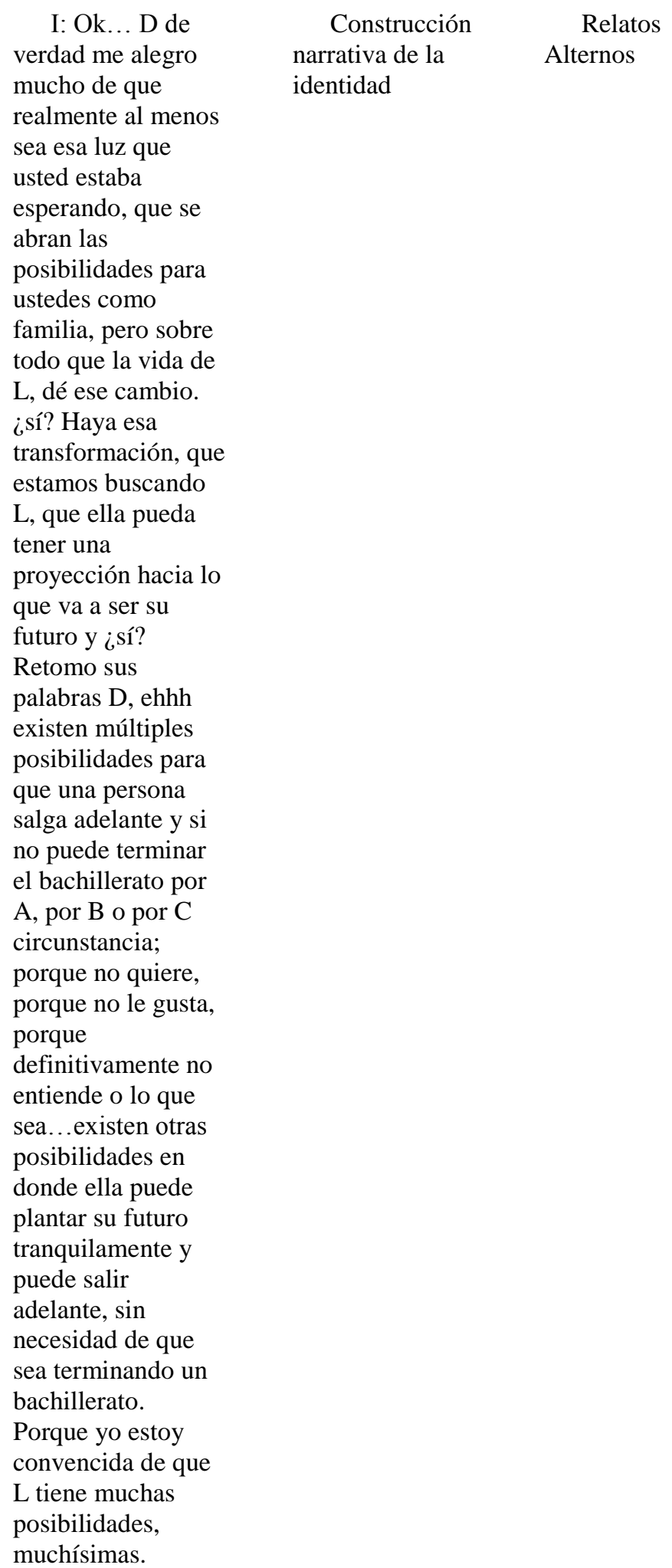

\author{
Construcción
}

narrativa de la

identidad

\section{Relatos}

Alternos 


\section{LA DESERCIÓN ESCOLAR COMO PRETEXTO PARA CONVERSAR SOBRE IDENTIDAD, FAMILIA Y ESCUELA

\author{
M: Sí, yo te \\ todo esto le dije \\ que...lo que \\ sumerced dice es \\ cierto o sea \\ desde...desde...si \\ me lo vendieron a \\ mí, imagínese a \\ ella, que era \\ pues...una niña. De \\ que "no podía" y \\ que "no podía"
}

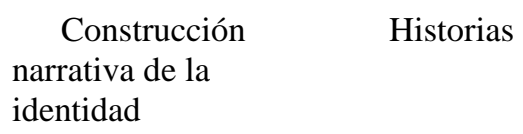

Construcción narrativa de la identidad

Historias

La madre identifica además la narrativa saturada en la cual se encontraba el sistema con respecto a la menor debido a que ha sido narrada de manera negativa.

\begin{tabular}{|c|c|c|c|}
\hline $\begin{array}{l}\text { I: No, yo estoy } \\
\text { convencida... }\end{array}$ & $\begin{array}{l}\text { Construcción } \\
\text { narrativa de la } \\
\text { identidad }\end{array}$ & Relatos & \\
\hline $\begin{array}{l}\quad \text { M: Y ya en este } \\
\text { momento, o sea yo } \\
\text { digo.....no en este } \\
\text { momento, ya...yo } \\
\text { ya me había dado } \\
\text { cuenta } \\
\text { que...viéndola } \\
\text { hacer otras cosas } \\
\text { que son más } \\
\text { difíciles que el } \\
\text { colegio... }\end{array}$ & \begin{tabular}{l}
\multicolumn{1}{c}{ Construcción } \\
narrativa de la \\
identidad
\end{tabular} & $\begin{array}{l}\text { Relatos } \\
\text { alternos }\end{array}$ & $\begin{array}{l}\quad \text { Nuevame } \\
\text { nte la madre } \\
\text { afirma la } \\
\text { capacidad de } \\
\text { la menor, } \\
\text { construyendo } \\
\text { una narrativa } \\
\text { emergente } \\
\text { con respecto } \\
\text { al problema. }\end{array}$ \\
\hline I: ajá & \begin{tabular}{l}
\multicolumn{1}{c}{ Construcción } \\
narrativa de la \\
identidad
\end{tabular} & $\begin{array}{l}\text { Relatos } \\
\text { alternos }\end{array}$ & \\
\hline $\begin{array}{l}\text { M: Yo dije, "L } \\
\text { lo que sufre es de } \\
\text { una pereza } \\
\text { espantosa" }\end{array}$ & $\begin{array}{l}\text { Construcción } \\
\text { narrativa de la } \\
\text { identidad }\end{array}$ & Historias & \begin{tabular}{l}
\multicolumn{1}{c}{ Sin } \\
embargo la \\
madre en \\
momentos \\
regresa a las \\
narraciones \\
saturadas del \\
pasado para \\
probar la \\
capacidad de \\
su hija \\
\end{tabular} \\
\hline $\begin{array}{c}\text { I: Y una } \\
\text { desmotivación... }\end{array}$ & $\begin{array}{l}\text { Construcción } \\
\text { narrativa de la } \\
\text { identidad }\end{array}$ & Memorias & \\
\hline $\begin{array}{l}\text { M: Sí, ella la } \\
\text { detienen...es eso. } \\
\text { Porque ella se pone } \\
\text { a hacer algo y lo } \\
\text { entiende rápido. }\end{array}$ & $\begin{array}{l}\text { Construcción } \\
\text { narrativa de la } \\
\text { identidad }\end{array}$ & Historias & $\begin{array}{l}\quad \text { Nuevame } \\
\text { nte la madre } \\
\text { propone una } \\
\text { narrativa } \\
\text { saturada para } \\
\text { continuar con } \\
\text { la relevancia } \\
\text { de la } \\
\text { capacidad de } \\
\text { su hija. }\end{array}$ \\
\hline
\end{tabular}




\section{LA DESERCIÓN ESCOLAR COMO PRETEXTO PARA CONVERSAR SOBRE IDENTIDAD, FAMILIA Y ESCUELA

$\quad \mathrm{I}$ : Mmm...la
rotularon...la
rotularon
definitivamente y
tal vez ustedes
como familia
cayeron en esa...

M: Sí.

\section{Construcción}

narrativa de la

identidad
Relatos

alternos

\begin{tabular}{|c|c|c|c|}
\hline M: Sí. & $\begin{array}{l}\text { Construcción } \\
\text { narrativa de la } \\
\text { identidad }\end{array}$ & $\begin{array}{l}\text { Relatos } \\
\text { alternos }\end{array}$ & \begin{tabular}{l}
\multicolumn{1}{c}{ la madre } \\
se muestra de \\
acuerdo ccon \\
el hecho de \\
que su hija ha \\
sido rotulada \\
de manera \\
negativa, se \\
ha construido \\
una narrativa \\
dominante.
\end{tabular} \\
\hline \begin{tabular}{l}
\multicolumn{1}{c}{ I: En ese... en } \\
esa postura que \\
colocaron los \\
colegios cuando \\
decían "es que ella \\
tiene un problema" \\
"es que ella tiene \\
un problema de \\
aprendizaje", pero \\
tampoco se avanzó \\
mucho para \\
solucionar ese \\
problema y claro, \\
ella se quedó \\
convencida de que \\
definitivamente \\
tenía un problema \\
para aprender. Pero \\
nos hemos dado \\
cuenta de que...
\end{tabular} & $\begin{array}{l}\text { Construcción } \\
\text { narrativa de la } \\
\text { identidad }\end{array}$ & Experiencia & \\
\hline M: No es así. & \begin{tabular}{l}
\multicolumn{1}{c}{ Construcción } \\
narrativa de la \\
identidad
\end{tabular} & $\begin{array}{l}\text { Relatos } \\
\text { alternos }\end{array}$ & $\begin{array}{l}\quad \text { La madre } \\
\text { continua con } \\
\text { el termino de } \\
\text { la frace de la } \\
\text { interventora, } \\
\text { afirmando la } \\
\text { capacidad de } \\
\text { su hija, } \\
\text { existiendo } \\
\text { una narrativa } \\
\text { emergente } \\
\text { clara. }\end{array}$ \\
\hline $\begin{array}{l}\text { I: No es así. L } \\
\text { tiene igual, o tal } \\
\text { vez diría yo, más } \\
\text { capacidades que } \\
\text { cualquiera de los }\end{array}$ & \begin{tabular}{l}
\multicolumn{1}{c}{ Construcción } \\
narrativa de la \\
identidad
\end{tabular} & $\begin{array}{l}\text { Relatos } \\
\text { alternos }\end{array}$ & \\
\hline
\end{tabular}




\section{LA DESERCIÓN ESCOLAR COMO PRETEXTO PARA CONVERSAR SOBRE IDENTIDAD, FAMILIA Y ESCUELA

chicos de su edad, porque es que ella

maneja un discurso

muy elaborado,

muy coherente...y

lo que sí veo muy

coartado en ella es

un poco la parte

social, o sea, no

expresa mucho

pero creo que sí

hemos avanzado.

\begin{tabular}{|c|c|c|c|}
\hline M: Sí. & $\begin{array}{l}\quad \text { Construcción } \\
\text { narrativa de la } \\
\text { identidad }\end{array}$ & $\begin{array}{l}\text { Relatos } \\
\text { alternos }\end{array}$ & $\begin{array}{l}\text { La madre } \\
\text { se encuentra } \\
\text { de acuerdo } \\
\text { con lo dicho } \\
\text { por la } \\
\text { interventora }\end{array}$ \\
\hline $\begin{array}{l}\quad \text { I: Para ya llegar } \\
\text { a mirar a D y } \\
\text { decirle "quiero } \\
\text { validar y estoy } \\
\text { cansada de..." } \\
\text { hemos avanzado. } \\
\text { Cuando ella llegó } \\
\text { aquí... }\end{array}$ & $\begin{array}{l}\quad \text { Intervencione } \\
\text { s narrativas en } \\
\text { situación de } \\
\text { deserción escolar }\end{array}$ & $\begin{array}{l}\text { Relatos } \\
\text { alternos }\end{array}$ & \\
\hline $\begin{array}{l}\text { M: No hablaba } \\
\text { nada. }\end{array}$ & $\begin{array}{l}\text { Construcción } \\
\text { narrativa de la } \\
\text { identidad }\end{array}$ & Memorias & $\begin{array}{l}\quad \text { La madre } \\
\text { reconoce el } \\
\text { camio que ha } \\
\text { tenido su } \\
\text { hija, } \\
\text { identificando } \\
\text { relatos } \\
\text { alternos. }\end{array}$ \\
\hline $\begin{array}{l}\text { I: No hablaba } \\
\text { nada. Y usted ¿Qué } \\
\text { se lleva de todo } \\
\text { esto? }\end{array}$ & \begin{tabular}{l}
\multicolumn{1}{c}{ Intervencione } \\
s narrativas en \\
situación de \\
deserción escolar
\end{tabular} & Memorias & \\
\hline \begin{tabular}{l}
\multicolumn{1}{c}{ A: Qué me } \\
llevo...Mmm... \\
ehhh...decir (risa), \\
hablar (risa), ehhh \\
abrir un espacio \\
entre mi mami y \\
yo...y nuevas \\
oportunidades.
\end{tabular} & $\begin{array}{l}\text { Construcción } \\
\text { narrativa de la } \\
\text { identidad }\end{array}$ & $\begin{array}{l}\text { Acontecimi } \\
\text { entos }\end{array}$ & \begin{tabular}{l}
\multicolumn{1}{c}{ Al } \\
preguntarle a \\
la menor que \\
se lleva hace \\
relevante la \\
cercania con \\
su madre, \\
anteriormente \\
comprendido \\
coo problema \\
debido a la \\
poca cercania \\
que existia, \\
comprendien \\
dose una \\
narrativa \\
emergente
\end{tabular} \\
\hline
\end{tabular}




\section{LA DESERCIÓN ESCOLAR COMO PRETEXTO PARA CONVERSAR SOBRE IDENTIDAD, FAMILIA Y ESCUELA

\section{I: Ok A. La} verdad es que, me alegra mucho haber podido, pues ser como esa parte o esa persona intermedia entre ustedes dos... y pues hay algo que todavía me queda como en sin sabor y es como la parte del...la parte afectiva. Yo sí les pediría, no sé, yo siento que eso nace de cada cual...pero aún siento que tienen como heridos esos corazones $i s i ́$ ? Y tal vez un abrazo $\mathrm{D}$, tal vez un "te quiero", diariamente les caería muy bien a ustedes dos. Porque hay amor, como madre puedo decirlo ¿no? o sea, el ser de uno son sus hijos y yo pienso que un abrazo, un "te quiero", un beso...es más benéfico que tal vez la plata que uno les pueda dar para las onces ¿no? si a uno...

\begin{tabular}{llc}
\hline A: (risa) & $\begin{array}{c}\text { Intervencione } \\
\text { s narrativas en } \\
\text { situación de } \\
\text { deserción escolar }\end{array}$ & $\begin{array}{c}\text { Acontecimi } \\
\text { entos }\end{array}$ \\
\hline $\begin{array}{c}\text { I: Sí de verdad, } \\
\text { si a uno no tienen }\end{array}$ & $\begin{array}{c}\text { Construcción } \\
\text { narrativa de la }\end{array}$ & $\begin{array}{c}\text { Acontecimi } \\
\text { entos }\end{array}$ \\
midentidad pesos de la & idente los dos & \\
lonchera, pero ese & \\
día me abrazan y & \\
me dicen "hija te & \\
amo"y "hoy no & \\
puedo darte porque & \\
las cosas han &
\end{tabular}

\author{
Intervencione \\ $s$ narrativas en \\ Acontecimi \\ entos
} situación de deserción escolar 


\section{LA DESERCIÓN ESCOLAR COMO PRETEXTO PARA CONVERSAR SOBRE IDENTIDAD, FAMILIA Y ESCUELA

estado difíciles" yo

creo que ese día yo

no voy a sentir la

misma

hambre...porque

ese abrazo y ese "te

quiero" me van a

alimentar tal vez

más que el jugo que

le pueda echar a mi

estómago y la

galleta...no sé, es

mi sentir. No sé

ustedes cómo lo

vean.

$$
\text { M: Sí claro. }
$$

Construcción

narrativa de la

identidad

\begin{tabular}{l} 
I: Sí, yo pienso \\
que a veces hay que \\
romper esa pauta \\
de ser tan estrictos \\
D y...abrazar más, \\
consentir más. \\
\hline \multicolumn{1}{c}{ M: Sí, es que de } \\
pronto llegó un \\
momento en que... \\
en que de pronto yo \\
decía "es que la \\
acabo de "basear" y \\
me voy a despedir \\
y voy a ir a decirle \\
te quiero mucho" \\
entonces (risa)...
\end{tabular}

A: (risa)
Intervencione

$s$ narrativas en

situación de

deserción escolar

Acontecimi
entos

entos

Relatos

alternos

La madre
rie de lo
richo por la
interventora

interventora

\begin{tabular}{|c|c|c|c|}
\hline A: (risa) & $\begin{array}{l}\text { Construcción } \\
\text { narrativa de la } \\
\text { identidad }\end{array}$ & Relatos & $\begin{array}{l}\text { La menor } \\
\text { rie de lo } \\
\text { dicho por su } \\
\text { madre. }\end{array}$ \\
\hline $\begin{array}{l}\quad \text { M: ...Como que } \\
\text { no } \\
\text { concuerda...como } \\
\text { que no combina } \\
\text { (risa) }\end{array}$ & $\begin{array}{l}\text { Construcción } \\
\text { narrativa de la } \\
\text { identidad }\end{array}$ & Historias & $\begin{array}{l}\quad \text { nuevamen } \\
\text { te la madre } \\
\text { afirma la } \\
\text { inutilidad de } \\
\text { la } \\
\text { demostración } \\
\text { afectiva. }\end{array}$ \\
\hline A: (risa) $\mathrm{Si}$ & $\begin{array}{l}\text { Construcción } \\
\text { narrativa de la } \\
\text { identidad }\end{array}$ & Historias & $\begin{array}{l}\text { La menor } \\
\text { rie } \\
\text { nuevamente. }\end{array}$ \\
\hline
\end{tabular}




\section{LA DESERCIÓN ESCOLAR COMO PRETEXTO PARA CONVERSAR SOBRE IDENTIDAD, FAMILIA Y ESCUELA

\author{
M: Entonces se \\ convirtió en eso, en \\ que desde que me \\ levantaba era \\ peleando con \\ ella...entonces ya \\ cuando me iba "ta' \\ luego" (risa).
}

Construcción narrativa de la identidad
Relatos

la madre afirma que en el pasado la relación emocional con la hija se basaba en pautas violentas y narrativas saturadas

\begin{tabular}{|c|c|c|c|}
\hline $\begin{array}{l}\text { I: Estaban } \\
\text { castigándose. }\end{array}$ & $\begin{array}{l}\text { Construcción } \\
\text { narrativa de la } \\
\text { identidad }\end{array}$ & $\begin{array}{l}\text { Acontecimi } \\
\text { entos }\end{array}$ & 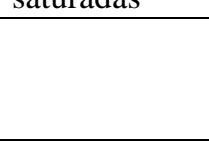 \\
\hline $\begin{array}{l}\text { M: Sí...si claro. } \\
\text { Pero sí obviamente } \\
\text { si yo se lo he dicho } \\
\text { a ella, si yo no la } \\
\text { quisiera "no, que } \\
\text { me importa, pues } \\
\text { yo mejor tenerla } \\
\text { ahí y quien me } \\
\text { cocine" yo antes le } \\
\text { diría "no no no, no } \\
\text { vaya } \\
\text { estudiar...quédese } \\
\text { ahí quieta"... }\end{array}$ & $\begin{array}{l}\text { Construcción } \\
\text { narrativa de la } \\
\text { identidad }\end{array}$ & Relatos & $\begin{array}{l}\quad \text { La madre } \\
\text { reconoce su } \\
\text { cambio, } \\
\text { haciendo una } \\
\text { comparación } \\
\text { con respcto a } \\
\text { lo que pudo } \\
\text { haber hecho } \\
\text { antes con su } \\
\text { hija. }\end{array}$ \\
\hline A: (risa) & $\begin{array}{l}\text { Construcción } \\
\text { narrativa de la } \\
\text { identidad }\end{array}$ & Relatos & $\begin{array}{l}\text { La menor } \\
\text { rie de lo } \\
\text { dicho por su } \\
\text { madre }\end{array}$ \\
\hline M: ...pero no & $\begin{array}{l}\text { Construcción } \\
\text { narrativa de la } \\
\text { identidad }\end{array}$ & Experiencia & \begin{tabular}{l}
\multicolumn{1}{c}{ psoterior } \\
mente prueba \\
su punto \\
nuevamente.
\end{tabular} \\
\hline $\begin{array}{c}\text { I: Y usted } \\
\text { ¿cuántas veces } \\
\text { busca a D para } \\
\text { darle un abrazo...? }\end{array}$ & $\begin{array}{l}\text { Construcción } \\
\text { narrativa de la } \\
\text { identidad }\end{array}$ & $\begin{array}{l}\text { Acontecimi } \\
\text { entos }\end{array}$ & \\
\hline $\begin{array}{c}\text { M: Ahhh ellas } \\
\text { si son melcochudas }\end{array}$ & $\begin{array}{l}\text { Construcción } \\
\text { narrativa de la } \\
\text { identidad }\end{array}$ & $\begin{array}{l}\text { Acontecimi } \\
\text { entos }\end{array}$ & \begin{tabular}{l}
\multicolumn{1}{c}{ La madre } \\
afirma que su \\
hija es muy \\
cercana a ella \\
emocionalme \\
nte, buscando \\
constante \\
cercania, \\
mantiendo \\
una narrativa \\
saturada \\
frente al \\
contacto \\
emocional.
\end{tabular} \\
\hline
\end{tabular}


LA DESERCIÓN ESCOLAR COMO PRETEXTO PARA CONVERSAR SOBRE IDENTIDAD, FAMILIA Y ESCUELA

\begin{tabular}{|c|c|c|c|}
\hline & $\begin{array}{l}\text { narrativa de la } \\
\text { identidad }\end{array}$ & entos & $\begin{array}{l}\text { nuevamente } \\
\text { rie. }\end{array}$ \\
\hline I: ¿sí? & $\begin{array}{l}\text { Construcción } \\
\text { narrativa de la } \\
\text { identidad }\end{array}$ & $\begin{array}{l}\text { Acontecimi } \\
\text { entos }\end{array}$ & \\
\hline $\begin{array}{l}\text { A: Sí, ahí } \\
\text { pegada. }\end{array}$ & $\begin{array}{l}\text { Construcción } \\
\text { narrativa de la } \\
\text { identidad }\end{array}$ & $\begin{array}{l}\text { Acontecimi } \\
\text { entos }\end{array}$ & $\begin{array}{l}\quad \text { La madre } \\
\text { nuevamente } \\
\text { afirma que su } \\
\text { hija } \\
\text { constantemen } \\
\text { te se } \\
\text { encuentra } \\
\text { cerca a ella } \\
\text { de manera } \\
\text { negativa. }\end{array}$ \\
\hline M y A: (risas) & $\begin{array}{l}\text { Construcción } \\
\text { narrativa de la } \\
\text { identidad }\end{array}$ & $\begin{array}{l}\text { Acontecimi } \\
\text { entos }\end{array}$ & $\begin{array}{l}\quad \text { madre e } \\
\text { hija rien de lo } \\
\text { dicho por la } \\
\text { madre. }\end{array}$ \\
\hline $\begin{array}{l}\text { I: Eso es bueno. } \\
\text { Eso es bueno, a mí } \\
\text { me parece lo más } \\
\text { sano, que ella te } \\
\text { busque porque... }\end{array}$ & $\begin{array}{l}\quad \text { Intervencione } \\
\text { s narrativas en } \\
\text { situación de } \\
\text { deserción escolar }\end{array}$ & $\begin{array}{l}\text { Relatos } \\
\text { alternos }\end{array}$ & \\
\hline $\begin{array}{l}\text { M: Sí y es como } \\
\text { dice la doctora, eso } \\
\text { va en cada...pues } \\
\text { en cada ser ¿no? }\end{array}$ & \begin{tabular}{l}
\multicolumn{1}{c}{ Intervencione } \\
s narrativas en \\
situación de \\
deserción escolar
\end{tabular} & Historias & $\begin{array}{l}\quad \text { La madre } \\
\text { justifica el } \\
\text { hecho de no } \\
\text { tener interes } \\
\text { en tener } \\
\text { cercania } \\
\text { emocional, } \\
\text { continuando } \\
\text { un relato } \\
\text { dominndo } \\
\text { con respecto } \\
\text { a este hecho }\end{array}$ \\
\hline I: ajá & $\begin{array}{l}\text { Intervencione } \\
\text { s narrativas en } \\
\text { situación de } \\
\text { deserción escolar }\end{array}$ & $\begin{array}{l}\text { Acontecimi } \\
\text { entos }\end{array}$ & \\
\hline
\end{tabular}




\section{LA DESERCIÓN ESCOLAR COMO PRETEXTO PARA CONVERSAR SOBRE IDENTIDAD, FAMILIA Y ESCUELA

\begin{tabular}{|c|c|c|}
\hline $\begin{array}{l}\quad \text { M: Aunque sí } \\
\text { pues uno con sus } \\
\text { hijos pues } \\
\text { obviamente. Yo por } \\
\text { lo menos ya } \\
\text { crecen...ya cuando } \\
\text { son...por ejemplo a } \\
\text { mi hija mayor } \\
\text { ya...tampoco. Yo } \\
\text { la adoro y yo vivo } \\
\text { pendiente de ella y } \\
\text { eso, pero ya por } \\
\text { ejemplo que llegue } \\
\text { y yo la coja, la } \\
\text { abrace y la } \\
\text { apapache, pues no } \\
\text { porque ya la veo } \\
\text { grande y ya no es } \\
\text { para eso ¿sí? } \\
\text { (risa)... }\end{array}$ & $\begin{array}{l}\quad \text { Construcción } \\
\text { narrativa de la } \\
\text { identidad }\end{array}$ & $\begin{array}{l}\quad \text { La madre } \\
\text { afirma } \\
\text { nuevamente } \\
\text { su desinteres } \\
\text { de de mostrar } \\
\text { afecto de } \\
\text { manera fisica } \\
\text { propone la } \\
\text { cercania de } \\
\text { otras maneras } \\
\text { que no sean } \\
\text { fisicas, } \\
\text { continuando } \\
\text { con } \\
\text { narrativas } \\
\text { dominantes. }\end{array}$ \\
\hline I: ¿Seguro? & \begin{tabular}{lr}
\multicolumn{1}{c}{ Intervencione } & Relatos \\
s narrativas en & alternos \\
situación de & \\
deserción escolar & \\
\end{tabular} & \\
\hline A: (risa) & \begin{tabular}{l}
\multicolumn{1}{c}{ Intervencione } \\
s narrativas en \\
situación de \\
deserción escolar \\
\end{tabular} & $\begin{array}{l}\quad \text { La menor } \\
\text { rie de lo } \\
\text { dicho por la } \\
\text { interventora } \\
\end{array}$ \\
\hline $\begin{array}{l}\quad \text { M: ...Pero la } \\
\text { amo. De pronto es } \\
\text { mi modo de ser o } \\
\text { así me criaron } \\
\text { ¿no?...porque pues } \\
\text { mi mamá tampoco } \\
\text { fue así como con } \\
\text { nosotros, ni yo con } \\
\text { ella. Yo a mi mamá } \\
\text { tampoco... yo } \\
\text { “quiubo mami” el } \\
\text { saludo en la mejilla } \\
\text { y ya. Yo por } \\
\text { ejemplo me aterro, } \\
\text { mi hermana } \\
\text { menor... }\end{array}$ & $\begin{array}{l}\text { Construcción } \\
\text { narrativa de la } \\
\text { identidad }\end{array}$ & $\begin{array}{l}\quad \text { La madre } \\
\text { narra su } \\
\text { desinteres de } \\
\text { de mostrar } \\
\text { afecto de } \\
\text { manera fisica } \\
\text { nuevamente, } \\
\text { comenta la } \\
\text { poca cercania } \\
\text { que mantenia } \\
\text { con su } \\
\text { madre, } \\
\text { contuniando } \\
\text { con una } \\
\text { narrativa } \\
\text { dominante al } \\
\text { respecto. }\end{array}$ \\
\hline $\begin{array}{l}\text { A: Uy no eso sí } \\
\text { ya es pasado. }\end{array}$ & $\begin{array}{l}\text { Construcción } \\
\text { narrativa de la } \\
\text { identidad }\end{array}$ & \begin{tabular}{l}
\multicolumn{2}{c}{ La menor } \\
al escuchar el \\
ejemplo que \\
pone su \\
madre, \\
tambien \\
asume una \\
postura de \\
rechazo \\
frente a tanta
\end{tabular} \\
\hline
\end{tabular}




\section{LA DESERCIÓN ESCOLAR COMO PRETEXTO PARA CONVERSAR SOBRE IDENTIDAD, FAMILIA Y ESCUELA

cercania.

\begin{tabular}{|c|c|c|c|}
\hline M: Sí & $\begin{array}{l}\text { Construcción } \\
\text { narrativa de la } \\
\text { identidad }\end{array}$ & & $\begin{array}{l}\quad \text { La madre } \\
\text { afirma lo } \\
\text { dicho por su } \\
\text { hija, } \\
\text { construyendo } \\
\text { entre las dos } \\
\text { una realidad } \\
\text { que no } \\
\text { posibilita } \\
\text { mayor } \\
\text { cercania } \\
\text { emocional. }\end{array}$ \\
\hline M у A: (risas) & $\begin{array}{l}\text { Construcción } \\
\text { narrativa de la } \\
\text { identidad }\end{array}$ & $\begin{array}{l}\text { Acontecimi } \\
\text { entos }\end{array}$ & $\begin{array}{l}\quad \text { Nuevame } \\
\text { nte madre e } \\
\text { hija rien de lo } \\
\text { dicho por la } \\
\text { madre. }\end{array}$ \\
\hline $\begin{array}{l}\text { A: Ya eso es } \\
\text { exceso de amor sí } \\
\text { (risa) }\end{array}$ & $\begin{array}{l}\text { Construcción } \\
\text { narrativa de la } \\
\text { identidad }\end{array}$ & $\begin{array}{l}\text { Acontecimi } \\
\text { entos }\end{array}$ & \begin{tabular}{l}
\multicolumn{1}{c}{ Y } \\
nuevamente \\
la hija \\
rechaza el \\
afecto, \\
siguiendo la \\
narrativa de \\
su madre.
\end{tabular} \\
\hline $\begin{array}{l}\quad \text { M: Sí, ella } \\
\text { sí...y ella es de las } \\
\text { que "mi mamita" y } \\
\text { la abraza y le da } \\
\text { besos y la... ¿sí? } \\
\text { Yo no. pues qué le } \\
\text { vamos a hacer, no } \\
\text { me gusta... }\end{array}$ & $\begin{array}{l}\text { Construcción } \\
\text { narrativa de la } \\
\text { identidad }\end{array}$ & Experiencia & $\begin{array}{l}\text { La madre } \\
\text { nuevamente } \\
\text { demuestra su } \\
\text { negativa } \\
\text { frente a la } \\
\text { cercania } \\
\text { emocional. }\end{array}$ \\
\hline $\begin{array}{l}\text { I: Eres un poco } \\
\text { más fría... }\end{array}$ & $\begin{array}{l}\text { Construcción } \\
\text { narrativa de la } \\
\text { identidad }\end{array}$ & Relatos & \\
\hline \begin{tabular}{l}
\multicolumn{1}{c}{ M: Sí, ni me } \\
gusta que ellas \\
hagan eso conmigo \\
tampoco, o sea, que \\
me cojan ahí a \\
melcocharme, a \\
babosearme... no \\
me gusta.
\end{tabular} & $\begin{array}{l}\text { Construcción } \\
\text { narrativa de la } \\
\text { identidad }\end{array}$ & Relatos & $\begin{array}{l}\quad \text { Nuevame } \\
\text { nte la madre } \\
\text { afirma no } \\
\text { gustarle las } \\
\text { caricias. }\end{array}$ \\
\hline $\begin{array}{l}\text { I: (risa) Bueno, } \\
\text { pero el esposo sí. }\end{array}$ & $\begin{array}{l}\text { Construcción } \\
\text { narrativa de la } \\
\text { identidad }\end{array}$ & $\begin{array}{l}\text { Acontecimi } \\
\text { entos }\end{array}$ & \\
\hline
\end{tabular}




\section{LA DESERCIÓN ESCOLAR COMO PRETEXTO PARA CONVERSAR SOBRE IDENTIDAD, FAMILIA Y ESCUELA

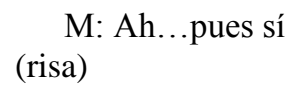

M: Ah...pues sí (risa)

Construcción narrativa de la identidad
Acontecimi entos
En el

momento en

el cual la

interventora pregunta si es agradable la cercania de su esposo, la madre responde que si, identificando se una posible ruta futura, si se quisiera abordar esta dificultad.

\begin{tabular}{|c|c|c|c|}
\hline $\begin{array}{l}\text { M, A y I: } \\
\text { (Risas) }\end{array}$ & $\begin{array}{l}\text { Construcción } \\
\text { narrativa de la } \\
\text { identidad }\end{array}$ & $\begin{array}{l}\text { Acontecimi } \\
\text { entos }\end{array}$ & \begin{tabular}{l}
\multicolumn{1}{c}{ Madre e } \\
hija rien \\
nuevamente.
\end{tabular} \\
\hline $\begin{array}{l}\text { M: Y por } \\
\text { ejemplo con mi } \\
\text { bebé. }\end{array}$ & $\begin{array}{l}\text { Construcción } \\
\text { narrativa de la } \\
\text { identidad }\end{array}$ & $\begin{array}{l}\text { Acontecimi } \\
\text { entos }\end{array}$ & $\begin{array}{l}\quad \text { La madre } \\
\text { afirma que } \\
\text { otra persona } \\
\text { con la cual } \\
\text { no es dificil } \\
\text { la cercania es } \\
\text { su hijo } \\
\text { menor, ya } \\
\text { que es } \\
\text { narrado como } \\
\text { su bebe. }\end{array}$ \\
\hline I: Claro & $\begin{array}{l}\text { Construcción } \\
\text { narrativa de la } \\
\text { identidad }\end{array}$ & $\begin{array}{l}\text { Acontecimi } \\
\text { entos }\end{array}$ & \\
\hline $\begin{array}{l}\quad \mathrm{M}: \text { Y yo le } \\
\text { explicaba eso a L, } \\
\text { con todos, eso sí, a } \\
\text { todos... }\end{array}$ & $\begin{array}{l}\text { Construcción } \\
\text { narrativa de la } \\
\text { identidad }\end{array}$ & Relatos & $\begin{array}{l}\quad \text { la madre } \\
\text { además } \\
\text { afrima ser } \\
\text { suy cercana } \\
\text { con su hijo } \\
\text { ya que es } \\
\text { pequeño } \\
\text { aclarandole, } \\
\text { que con todos } \\
\text { sus hijos ha } \\
\text { sido cercana, } \\
\text { mientras sean } \\
\text { menores. }\end{array}$ \\
\hline $\begin{array}{r}\text { A: ¿Hasta yo? } \\
\text { ¿Hasta yo mami? }\end{array}$ & $\begin{array}{l}\text { Construcción } \\
\text { narrativa de la } \\
\text { identidad }\end{array}$ & Relatos & $\begin{array}{l}\quad \text { la menor } \\
\text { pregunta si } \\
\text { con ella lo ha } \\
\text { sido, } \\
\text { manifestand } \\
\text { gran interes } \\
\text { con la }\end{array}$ \\
\hline
\end{tabular}




\section{LA DESERCIÓN ESCOLAR COMO PRETEXTO PARA CONVERSAR SOBRE IDENTIDAD, FAMILIA Y ESCUELA

\begin{tabular}{|c|c|c|c|}
\hline & & & $\begin{array}{l}\text { cercania } \\
\text { emocional } \\
\text { que su madre } \\
\text { pudo haber } \\
\text { tenido con } \\
\text { ella. }\end{array}$ \\
\hline $\begin{array}{l}\quad \text { M: ...A todos } \\
\text { los besaba, los } \\
\text { apretaba, los } \\
\text { mordía, los } \\
\text { apapachaba, } \\
\text { los...mejor dicho... }\end{array}$ & $\begin{array}{l}\text { Construcción } \\
\text { narrativa de la } \\
\text { identidad }\end{array}$ & $\begin{array}{l}\text { Acontecimi } \\
\text { entos }\end{array}$ & $\begin{array}{l}\quad \text { Nuevame } \\
\text { nte la madre } \\
\text { afirma haber } \\
\text { sido muy } \\
\text { cercana con } \\
\text { sus hijos } \\
\text { cuando eran } \\
\text { menores. }\end{array}$ \\
\hline $\begin{array}{l}\text { A: } \\
\text { Apapachaba... } \\
\text { ¿mor-di-a? }\end{array}$ & $\begin{array}{l}\text { Construcción } \\
\text { narrativa de la } \\
\text { identidad }\end{array}$ & $\begin{array}{l}\text { Acontecimi } \\
\text { entos }\end{array}$ & $\begin{array}{l}\text { La menor } \\
\text { busca aclarar } \\
\text { una palabra } \\
\text { no entendida. }\end{array}$ \\
\hline $\begin{array}{l}\quad \text { M: ...mi hija } \\
\text { era la que me } \\
\text { decía..."usted a } \\
\text { cada uno de los que } \\
\text { ha nacido algún } \\
\text { alias le pone" } \\
\text { porque a ella le } \\
\text { decía "mi ciela" y } \\
\text { "mi ciela" y era } \\
\text { "mi ciela". }\end{array}$ & $\begin{array}{l}\text { Construcción } \\
\text { narrativa de la } \\
\text { identidad }\end{array}$ & $\begin{array}{l}\text { Acontecimi } \\
\text { entos }\end{array}$ & $\begin{array}{l}\quad \text { La madre } \\
\text { afirma que } \\
\text { todos sus } \\
\text { hijos de } \\
\text { menores han } \\
\text { tenido } \\
\text { apodos, ya } \\
\text { que fue muy } \\
\text { cariñosa } \\
\text { cuando eran } \\
\text { pequeños. } \\
\end{array}$ \\
\hline $\begin{array}{l}\text { M, A y PI } \\
\text { (Risas) }\end{array}$ & $\begin{array}{l}\text { Construcción } \\
\text { narrativa de la } \\
\text { identidad }\end{array}$ & $\begin{array}{l}\text { Acontecimi } \\
\text { entos }\end{array}$ & \begin{tabular}{l}
\multicolumn{1}{c}{ Madre e } \\
hija rien \\
nuevamente.
\end{tabular} \\
\hline $\begin{array}{l}\quad \text { M: Y a C (la } \\
\text { hija mayor) era "mi } \\
\text { gordis", "mi } \\
\text { gordis" y " mi } \\
\text { gordis", }\end{array}$ & $\begin{array}{l}\text { Construcción } \\
\text { narrativa de la } \\
\text { identidad }\end{array}$ & $\begin{array}{l}\text { Acontecimi } \\
\text { entos }\end{array}$ & $\begin{array}{l}\quad \text { La madre } \\
\text { nuevamente } \\
\text { prueba su } \\
\text { punto de } \\
\text { haber } \\
\text { nombrado } \\
\text { con apodos a } \\
\text { sus hijos de } \\
\text { pequeños }\end{array}$ \\
\hline $\begin{array}{l}\text { A: Y todavía, } \\
\text { en el celular la } \\
\text { tiene como } \\
\text { "gordis" (risa) }\end{array}$ & $\begin{array}{l}\text { Construcción } \\
\text { narrativa de la } \\
\text { identidad }\end{array}$ & $\begin{array}{l}\text { Acontecimi } \\
\text { entos }\end{array}$ & $\begin{array}{l}\text { La menor } \\
\text { prueba el } \\
\text { punto. }\end{array}$ \\
\hline $\begin{array}{l}\text { M: Sí (risa), } \\
\text { pero ya pues llegó } \\
\text { un punto en que } \\
\text { crecieron y ya. }\end{array}$ & $\begin{array}{l}\text { Construcción } \\
\text { narrativa de la } \\
\text { identidad }\end{array}$ & $\begin{array}{l}\text { Acontecimi } \\
\text { entos }\end{array}$ & $\begin{array}{l}\quad \text { La madre } \\
\text { afirma que al } \\
\text { crecer todo } \\
\text { esto cambió, } \\
\text { manteniendos } \\
\text { e un relato } \\
\text { dominante. }\end{array}$ \\
\hline
\end{tabular}

\begin{tabular}{ccc}
\hline I: Pero aún uno & $\begin{array}{c}\text { Construcción } \\
\text { narrativa de la }\end{array}$ & Relatos \\
estando grande & nato
\end{tabular}




\section{LA DESERCIÓN ESCOLAR COMO PRETEXTO PARA CONVERSAR SOBRE IDENTIDAD, FAMILIA Y ESCUELA

necesita... identidad

\begin{tabular}{|c|c|c|c|}
\hline $\begin{array}{l}\text { M: Ya no...ya } \\
\text { no es para... }\end{array}$ & $\begin{array}{l}\text { Construcción } \\
\text { narrativa de la } \\
\text { identidad }\end{array}$ & Historias & $\begin{array}{l}\quad \text { La madre } \\
\text { niega la } \\
\text { necesidad } \\
\text { que pueden } \\
\text { llegar a sentir } \\
\text { sus hijos de } \\
\text { grandes } \\
\text { frente a la } \\
\text { cercania } \\
\text { afectiva, } \\
\text { manteniendos } \\
\text { e un relato } \\
\text { dominante. }\end{array}$ \\
\hline A: (risas) & $\begin{array}{l}\text { Construcción } \\
\text { narrativa de la } \\
\text { identidad }\end{array}$ & $\begin{array}{l}\text { Acontecimi } \\
\text { entos }\end{array}$ & \begin{tabular}{l}
\multicolumn{1}{c}{$\mathrm{La}$} \\
maenor rie de \\
lo dicho por \\
su madre. \\
\end{tabular} \\
\hline $\begin{array}{l}\text { I: O bueno, yo } \\
\text { no sé. }\end{array}$ & \begin{tabular}{l}
\multicolumn{1}{c}{ Intervencione } \\
s narrativas en \\
situación de \\
deserción escolar \\
\end{tabular} & $\begin{array}{l}\text { Acontecimi } \\
\text { entos }\end{array}$ & \\
\hline $\begin{array}{l}\text { A: (risa) A mí } \\
\text { ya no me dicen } \\
\text { fetico... me dicen } \\
\text { feto. (risa) }\end{array}$ & $\begin{array}{l}\text { Construcción } \\
\text { narrativa de la } \\
\text { identidad }\end{array}$ & Relatos & $\begin{array}{l}\text { La menor } \\
\text { comenta su } \\
\text { apodo. }\end{array}$ \\
\hline M, A y I: (risas) & $\begin{array}{l}\text { Construcción } \\
\text { narrativa de la } \\
\text { identidad }\end{array}$ & $\begin{array}{l}\text { Acontecimi } \\
\text { entos }\end{array}$ & \begin{tabular}{l}
\multicolumn{1}{c}{ Madre e } \\
hija rien de lo \\
dicho por la \\
madre. \\
\end{tabular} \\
\hline \begin{tabular}{l}
\multicolumn{1}{c}{ I: A mí será } \\
porque todavía si \\
soy muy....muy \\
querendona.
\end{tabular} & $\begin{array}{l}\text { Construcción } \\
\text { narrativa de la } \\
\text { identidad }\end{array}$ & Relatos & \\
\hline $\begin{array}{l}\text { M: Sí, eso va en } \\
\text { cada... }\end{array}$ & $\begin{array}{l}\text { Construcción } \\
\text { narrativa de la } \\
\text { identidad }\end{array}$ & Memorias & $\begin{array}{l}\quad \text { La madre } \\
\text { afirma que su } \\
\text { desición de } \\
\text { ser cercana, } \\
\text { depende } \\
\text { segun la } \\
\text { persona. }\end{array}$ \\
\hline I: Pienso que sí. & $\begin{array}{l}\text { Construcción } \\
\text { narrativa de la } \\
\text { identidad }\end{array}$ & $\begin{array}{l}\text { Acontecimi } \\
\text { entos }\end{array}$ & \\
\hline $\begin{array}{l}\text { M: ...en cada } \\
\text { persona }\end{array}$ & $\begin{array}{l}\text { Construcción } \\
\text { narrativa de la } \\
\text { identidad }\end{array}$ & Memorias & $\begin{array}{l}\text { Nuevame } \\
\text { nte prueba el } \\
\text { punto } \\
\text { anterior. } \\
\end{array}$ \\
\hline $\begin{array}{l}\text { I: Porque mi } \\
\text { hijo siendo tan } \\
\text { grande...tan grande } \\
\text { en años y tan } \\
\text { grande en }\end{array}$ & $\begin{array}{l}\text { Construcción } \\
\text { narrativa de la } \\
\text { identidad }\end{array}$ & $\begin{array}{l}\text { Acontecimi } \\
\text { entos }\end{array}$ & \\
\hline
\end{tabular}




\section{LA DESERCIÓN ESCOLAR COMO PRETEXTO PARA CONVERSAR SOBRE IDENTIDAD, FAMILIA Y ESCUELA

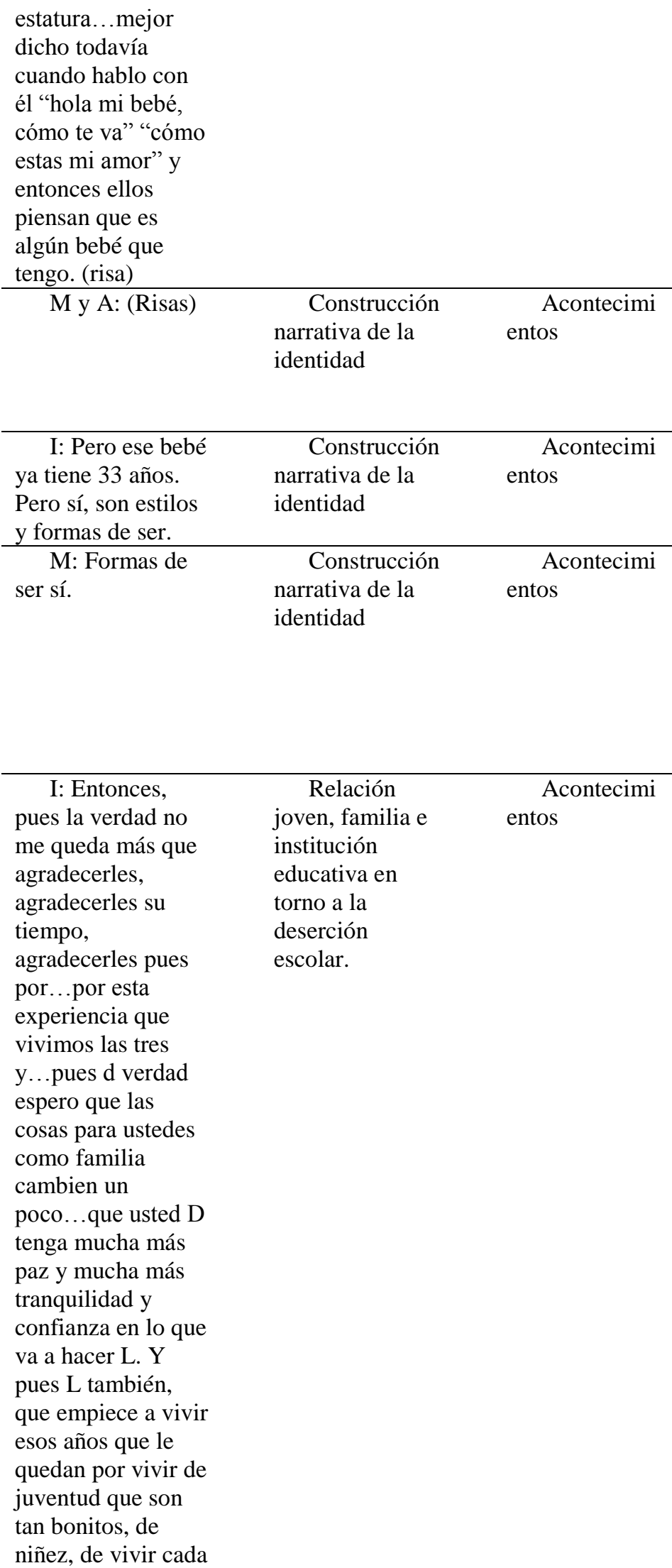

\begin{tabular}{cll}
$\begin{array}{c}\text { I: Entonces, } \\
\text { pues la verdad no }\end{array}$ & \multicolumn{1}{c}{ Relación } & \multicolumn{1}{c}{ Acontecimi } \\
me queda más que & joven, familia e & entos \\
institución & \\
agradecerles, & educativa en & \\
agradecerles su & torno a la & \\
tiempo, & deserción & \\
agradecerles pues & escolar. &
\end{tabular}

por...por esta

experiencia que

vivimos las tres

y...pues d verdad

espero que las

cosas para ustedes

como familia

cambien un

poco...que usted $\mathrm{D}$

tenga mucha más

paz y mucha más

tranquilidad y confianza en lo que va a hacer L. Y pues L también, que empiece a vivir esos años que le quedan por vivir de juventud que son tan bonitos, de niñez, de vivir cada

\begin{tabular}{|c|c|c|c|}
\hline $\begin{array}{l}\quad \text { I: Pero ese bebé } \\
\text { ya tiene } 33 \text { años. } \\
\text { Pero sí, son estilos } \\
\text { y formas de ser. }\end{array}$ & $\begin{array}{l}\text { Construcción } \\
\text { narrativa de la } \\
\text { identidad }\end{array}$ & $\begin{array}{l}\text { Acontecimi } \\
\text { entos }\end{array}$ & \\
\hline $\begin{array}{l}\text { M: Formas de } \\
\text { ser sí. }\end{array}$ & $\begin{array}{l}\text { Construcción } \\
\text { narrativa de la } \\
\text { identidad }\end{array}$ & $\begin{array}{l}\text { Acontecimi } \\
\text { entos }\end{array}$ & $\begin{array}{l}\quad \text { La madre } \\
\text { nuevamente } \\
\text { afirma que la } \\
\text { cercania } \\
\text { emocional } \\
\text { depende de la } \\
\text { cercania } \\
\text { emocional. }\end{array}$ \\
\hline
\end{tabular}




\section{LA DESERCIÓN ESCOLAR COMO PRETEXTO PARA CONVERSAR SOBRE IDENTIDAD, FAMILIA Y ESCUELA

momento...

\begin{tabular}{|c|c|c|c|}
\hline \begin{tabular}{l}
\multicolumn{1}{c}{ M: (no se } \\
entiende)...ella \\
cumple los quince \\
años y yo le decía \\
"con quién le voy a \\
hacer la fiesta de \\
quince si no tiene \\
amigos"
\end{tabular} & $\begin{array}{l}\quad \text { Relación } \\
\text { joven, familia e } \\
\text { institución } \\
\text { educativa en } \\
\text { torno a la } \\
\text { deserción } \\
\text { escolar. }\end{array}$ & Historias & $\begin{array}{l}\quad \text { La madre } \\
\text { cuestiona a } \\
\text { su hija con } \\
\text { respecto a su } \\
\text { presente } \\
\text { social, debido } \\
\text { a que la } \\
\text { menor no } \\
\text { tiene amigos. }\end{array}$ \\
\hline $\begin{array}{l}\text { A: A demás no } \\
\text { me gustan las } \\
\text { fiestas. }\end{array}$ & $\begin{array}{l}\text { Construcción } \\
\text { narrativa de la } \\
\text { identidad }\end{array}$ & $\begin{array}{l}\text { Acontecimi } \\
\text { entos }\end{array}$ & $\begin{array}{l}\text { La menor } \\
\text { afirma que no } \\
\text { le gustan las } \\
\text { fiestas. }\end{array}$ \\
\hline $\begin{array}{l}\text { I: Pero } \\
\text { no...pero pues rico. } \\
\text { Es una experiencia } \\
\text { L...es una } \\
\text { experiencia que hay } \\
\text { que vivirla... }\end{array}$ & $\begin{array}{l}\text { Intervencione } \\
\text { s narrativas en } \\
\text { situación de } \\
\text { deserción escolar }\end{array}$ & $\begin{array}{l}\text { Acontecimi } \\
\text { entos }\end{array}$ & \\
\hline \begin{tabular}{l}
\multicolumn{1}{c}{ M: Entonces } \\
van a ser unos \\
quince años \\
diferentes a todas \\
las niñas.
\end{tabular} & $\begin{array}{l}\text { Construcción } \\
\text { narrativa de la } \\
\text { identidad }\end{array}$ & $\begin{array}{l}\text { Acontecimi } \\
\text { entos }\end{array}$ & $\begin{array}{l}\quad \text { La madre } \\
\text { demuestra la } \\
\text { diferencia } \\
\text { que puede } \\
\text { llegar a tener } \\
\text { el } \\
\text { cumpleaños } \\
\text { de su hija con } \\
\text { respecto al } \\
\text { resto de las } \\
\text { niñas es } \\
\text { posible que } \\
\text { movilice a su } \\
\text { hija a tener } \\
\text { mayor } \\
\text { cercania } \\
\text { social. }\end{array}$ \\
\hline \begin{tabular}{l}
\multicolumn{1}{c}{ I: Entonces } \\
pues \\
si... agradecerles. \\
Bueno...yo si voy a \\
los quince.
\end{tabular} & $\begin{array}{l}\text { Intervencione } \\
\text { s narrativas en } \\
\text { situación de } \\
\text { deserción escolar }\end{array}$ & $\begin{array}{l}\text { Relatos } \\
\text { alternos }\end{array}$ & \\
\hline A: (risa) & $\begin{array}{l}\text { Construcción } \\
\text { narrativa de la } \\
\text { identidad }\end{array}$ & $\begin{array}{l}\text { Acontecimi } \\
\text { entos }\end{array}$ & $\begin{array}{l}\text { La menor } \\
\text { ríe de lo } \\
\text { dicho por la } \\
\text { interventora. }\end{array}$ \\
\hline \begin{tabular}{l}
\multicolumn{1}{c}{ I: (risa) } \\
Entonces de \\
verdad,
\end{tabular} & $\begin{array}{l}\text { Intervencione } \\
\text { s narrativas en } \\
\text { situación de }\end{array}$ & $\begin{array}{l}\text { Acontecimi } \\
\text { entos }\end{array}$ & \\
\hline
\end{tabular}




\section{LA DESERCIÓN ESCOLAR COMO PRETEXTO PARA CONVERSAR SOBRE IDENTIDAD, FAMILIA Y ESCUELA

agradecerles este deserción escolar espacio y...

\begin{tabular}{llr}
\hline \multicolumn{1}{c}{ M: De parte mía } & \multicolumn{1}{c}{$\begin{array}{c}\text { Intervencione } \\
\text { s narrativas en } \\
\text { situación de } \\
\text { gracias de todo }\end{array}$} & $\begin{array}{c}\text { Relatos } \\
\text { alternos }\end{array}$ \\
corazón, le doy las & $\begin{array}{l}\text { deserción escolar } \\
\text { gracias a Dios }\end{array}$ & \\
porque pienso que & \\
Él fue quien la puso & \\
en mi camino y & \\
porque desde el día & \\
en que sumerced & \\
me conoció allá en & \\
clase, fijó sus ojos & \\
en mi caso...en & \\
nuestro caso y ...
\end{tabular}

La madre finalmente concluye agradeciendo el proceso, los cambios y nuevas comprension es entendidas en tal espacio. 